\title{
WestVirginiaUniversity
}

THE RESEARCH REPOSITORY @ WVU

Graduate Theses, Dissertations, and Problem Reports

2009

\section{Home range characteristics of the male eastern wild turkey in West Virginia}

Steven E. Rauch

West Virginia University

Follow this and additional works at: https://researchrepository.wvu.edu/etd

\section{Recommended Citation}

Rauch, Steven E., "Home range characteristics of the male eastern wild turkey in West Virginia" (2009).

Graduate Theses, Dissertations, and Problem Reports. 2827.

https://researchrepository.wvu.edu/etd/2827

This Thesis is protected by copyright and/or related rights. It has been brought to you by the The Research Repository @ WVU with permission from the rights-holder(s). You are free to use this Thesis in any way that is permitted by the copyright and related rights legislation that applies to your use. For other uses you must obtain permission from the rights-holder(s) directly, unless additional rights are indicated by a Creative Commons license in the record and/ or on the work itself. This Thesis has been accepted for inclusion in WVU Graduate Theses, Dissertations, and Problem Reports collection by an authorized administrator of The Research Repository @ WVU. For more information, please contact researchrepository@mail.wvu.edu. 


\title{
Home Range Characteristics of the Male Eastern Wild Turkey in West Virginia
}

\author{
Steven E. Rauch \\ Thesis submitted to the \\ Davis College of Agriculture, Natural Resources and Design \\ at West Virginia University \\ in partial fulfillment of the requirements \\ for the degree of \\ Master of Science \\ in \\ Wildlife and Fisheries Resources
}

James T. Anderson, Ph.D., Major Advisor

John W. Edwards, Ph.D., Committee Member

A.B. Billings, M.S., Committee Member

Division of Forestry and Natural Resources

Morgantown, West Virginia

2009

Keywords: Eastern Wild Turkey, eccentricity, mast, Meleagris gallopavo silvestris, home range shape, home range size, kernel density, population estimates, West Virginia 


\section{ABSTRACT \\ Home Range Characteristics of the Male Eastern Wild Turkey in West Virginia}

\section{Steven E. Rauch}

Extensive research has been conducted on the eastern wild turkey (Meleagris gallopavo silvestris) in West Virginia, but research on male wild turkey home range characteristics is lacking. To address this, I proposed to quantify home range shape by the use of eccentricity (E: circle is $\mathrm{E}=1$ ) and to estimate the least-squares cross validation fixed-kernel $95 \%$ and $50 \%$ utilization distribution (UD) annual and 95\% UD seasonal home range as well as minimum convex polygon (MCP) home range estimate of male wild turkey on 2 study areas in West Virginia. I estimated the home range size of adult and juvenile male wild turkey during the April-May spring hunting season period of 2006 and 2007 in north-central West Virginia. Additionally, I compared the home range size of the 2-year and the 3-year+ age classes of adult male wild turkey. I tested a relation between home range size and shape and mast conditions, fate, and population estimates of male wild turkey.

I radio-equipped and monitored a total of 55 male wild turkey from September 2004 through August 2007. Statewide adult (831.5 ha, $\mathrm{SD}=646.5)$ and juvenile (868.3 ha, $\mathrm{SD}=$ 497.7) annual 95\% UD home range were similar $(P=0.38)$, with the smallest home ranges (311.2 ha, $\mathrm{SD}=79.2$ ) in the southern ecological region. Annual MCP home range averaged 963.2 ha $(\mathrm{SD}=678.2)$ for adults and 794.3 ha $(\mathrm{SD}=401.8)$ for juveniles. Juvenile annual $50 \%$ UD home range (156.2 ha, $\mathrm{SD}=121.9)$ was larger than adults $(106.1 \mathrm{ha}, \mathrm{SD}=98.1)(P=0.047)$. Adult and juvenile 95\% UD $(P=0.80)$ as well as the 50\% UD $(P=0.75)$ home ranges were similar between fall hunt and non-fall hunt counties. Adult seasonal 95\% UD home range were similar $(P>0.05)$ and averaged; spring - 475.7 ha $(S D=124.6)$, fall - 548.8 ha $(S D=209.6)$, winter -536.2 ha $(S D=403.2)$, spring-summer -510.2 ha $(S D=280.2)$, and fall-winter -608.8 ha (SD = 328.4). Adult seasonal MCP home range averaged; spring - 446.4 ha $(S D=200.7)$, fall - 453.3 ha (SD = 196.5), winter -444.5 ha $(S D=296.4)$, spring-summer -555.4 ha $(S D=297.4)$, and fall-winter -643.9 ha $(\mathrm{SD}=396.1)$. I found a relation between home range size and mast conditions $(P=0.003)$. I found a relation $(P=0.05)$ between the 2007 home range size and male wild turkey population size estimate, with a linear model $\left(\mathrm{R}^{2}=0.48\right)$. Legally harvested male wild turkeys had a smaller $(P \leq 0.03)$ home range $(404.1 \mathrm{ha}, \mathrm{SD}=193.6)$ than depredated $(892.3$ ha, $\mathrm{SD}=446.8$ ), died from other causes ( $867.3 \mathrm{ha}, \mathrm{SD}=499.3$ ), or those alive at end of study (822.2 ha, SD = 447.7). My results fell within the reported results of various other male eastern wild turkey studies. I compared my home range results with those of a regional female eastern wild turkey study.

Both adult and juvenile male wild turkeys had a non-circular home range shape $(P \leq$ 0.001). I estimated a difference $(P=0.02)$ between the home range shape of adult $(\bar{x}(E)=$ $2.421, \mathrm{SD}=1.516)$ and juvenile $(\bar{x}(\mathrm{E})=1.624, \mathrm{SD}=2.894)$ male wild turkeys when 6 juveniles that had dispersed approximately $5,400 \mathrm{~m}$ were removed from the comparison. I estimated a weak relation $(P=0.056)$ between juvenile male wild turkey fall-winter home range shape and 
hard mast conditions. No relation $(P>0.05)$ was detected between home range shape and ecological regions, population size estimates, or fate of radioed male wild turkeys. No significant difference $(P=0.14)$ in the home range shape of juveniles was estimated between the nontraditional fall hunting and traditional fall hunting counties, but adults have a more circular home range shape in the traditional counties. I estimated $(P=0.004)$ that juveniles had a more circular $(\bar{x}(\mathrm{E})=1.501, \mathrm{SD}=0.438)$ home range shape than do adults $(\bar{x}(\mathrm{E})=2.239, \mathrm{SD}=0.471)$ during the April-May period, whereas no significant difference $(P=0.22)$ was detected between the 2-year old and 3-year+ adult age classes during the same period. The use of eccentricity worked to quantify home range shape in male wild turkeys. I suggest the use of eccentricity in home range shape analysis.

During the April-May spring hunting season period, adult male $(n=7)$ wild turkey had a larger home range $(\bar{x}=410.5$ ha, $\mathrm{SD}=74.8)$ than did juvenile $(n=12, \bar{x}=163.5$ ha, $\mathrm{SD}=74.7)$ during the period $(P<0.001)$. I found no difference in the home range size of the 2-year age class and the 3 -year+ age class of adult male wild turkey $(P=0.46)$. I detected a relation $(P<$ 0.001) between population size and the April-May home range size of male wild turkey. I suspect that movement related to breeding behavior was a factor in adults having larger home ranges during the period. My results can benefit resource managers and spring turkey hunters by providing behavior information on the male wild turkey home range characteristics during the spring turkey hunting season. My results give resource managers knowledge on the home range dynamics of male wild turkey to facilitate the effective management of the resource with the development of management plans. 


\section{Acknowledgements}

I first must thank God and only through His will and the strength He gave was I able to complete this project and graduate school. To my loving wife, Shaunda, without her encouragement and support I would not have made it through the last five years. Her and our son, Shaun, put up with a lot of late nights of me studying or in front of a computer screen and I love them immensely. Thank You.

I am grateful to Dr. Jim Anderson for the support and direction he has given to me as my major advisor. I thank Dr. John Edwards for his input he has provided as one of my committee members. I thank A. B. Billings for being on my committee and for his statistical help and guidance with this thesis.

I thank my immediate supervisor, Gary Foster, in the Wildlife Resources Section of the West Virginia Division of Natural Resources. It has been a considerable challenge balancing graduate school over the last five years and completing my duties as the Assistant District Wildlife Biologist, but Gary has given me considerable latitude to return and complete school. Also, I thank Gary and Mike Peters for the extra time and effort they put into assisting my research by collecting additional data for me. I am grateful for the support and encouragement I have received from many of my Wildlife Resources Section colleagues, several of which have retired since I started graduate school. I am thankful to Paul Johansen, Assistant Chief of Game Management, and Curtis I. Taylor, Chief of the Wildlife Resources Section, for their support and approval for the agency to cover my tuition, without which I could not have completed this. 


\section{Table of Contents}

\section{Table of Contents}

Chapter 1 List of Tables ................................................................................................. vii

Chapter 2 List of Tables ............................................................................................. viii

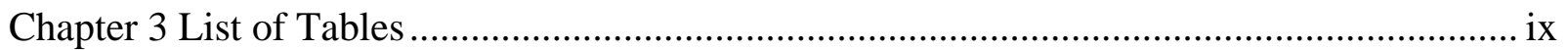

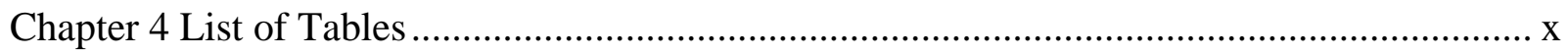

Chapter 1 List of Figures............................................................................................ xi

Chapter 2 List of Figures................................................................................................... xii

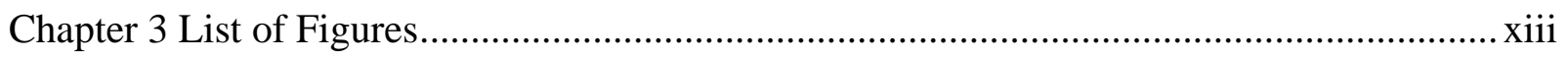

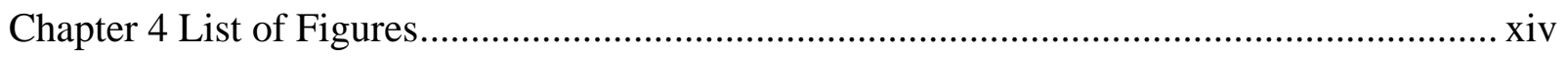

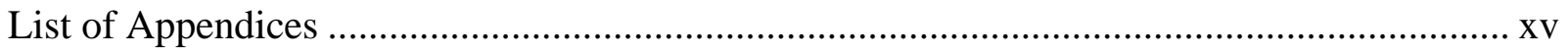

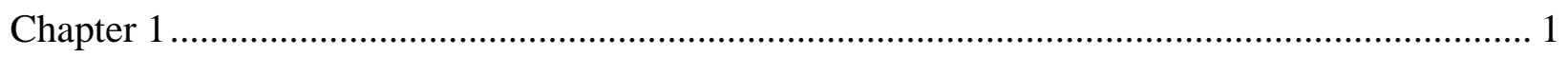

Introduction and Justification for a Male Wild Turkey Home Range Study in West Virginia ...... 1

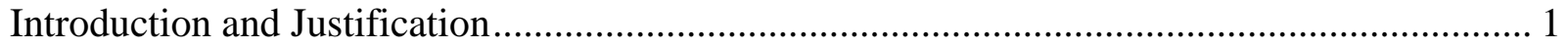

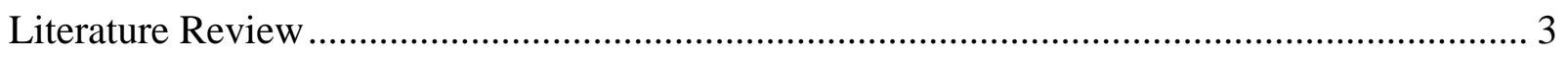

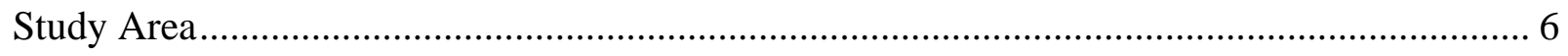

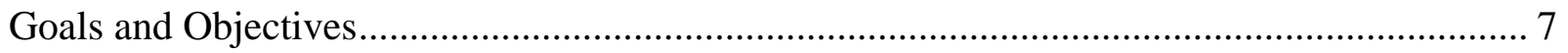

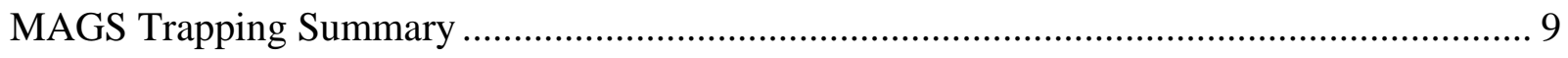

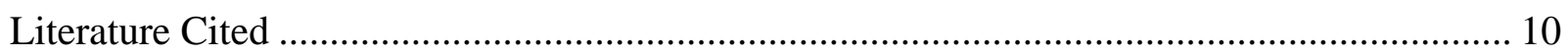

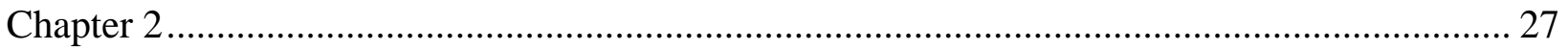

Home Range Estimates of the Male Eastern Wild Turkey in West Virginia ............................. 27

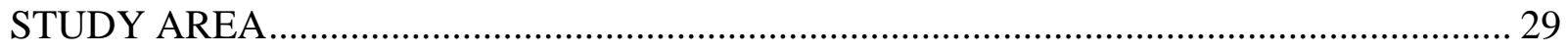

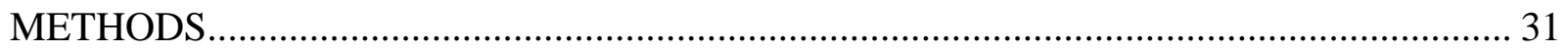

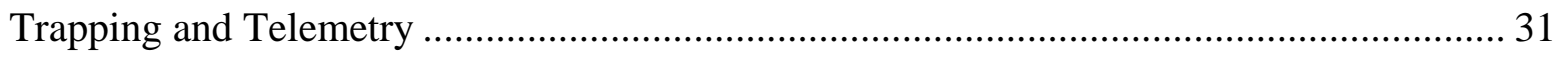

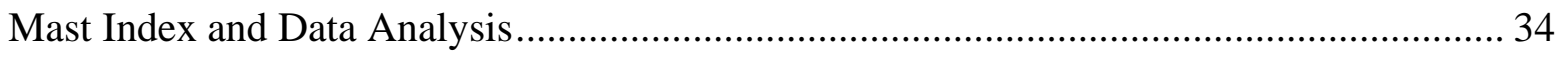

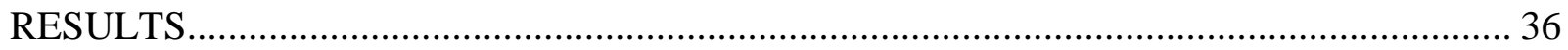

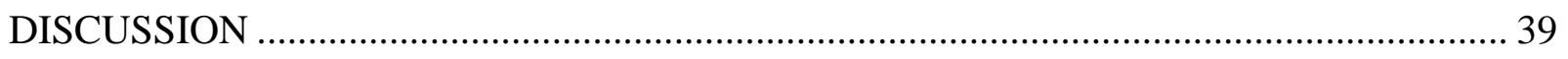

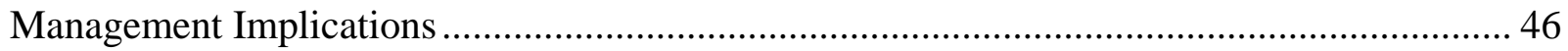

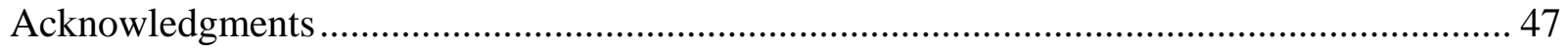




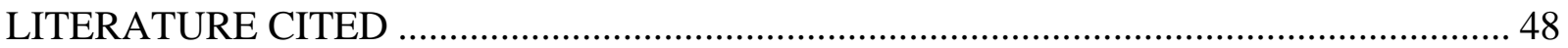

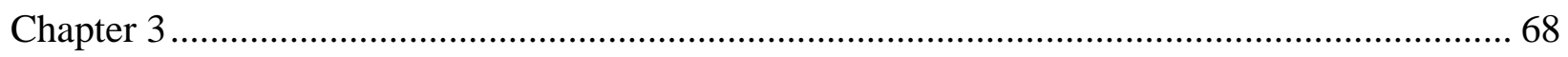

THE USE OF ECCENTRICITY TO DESCRIBE THE HOME RANGE SHAPE OF MALE

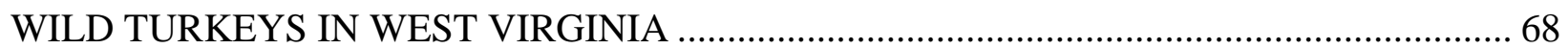

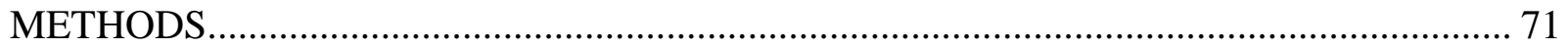

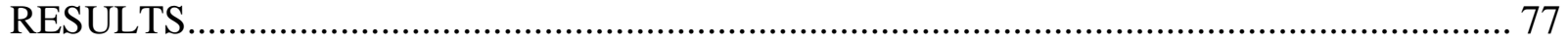

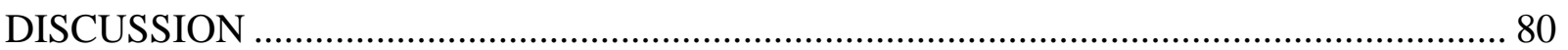

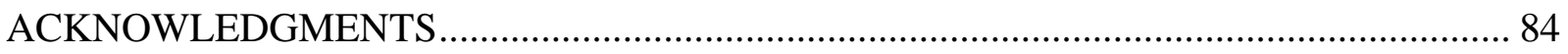

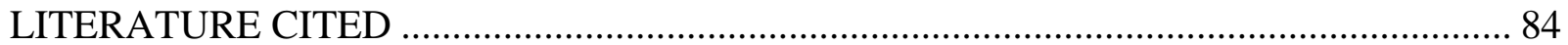

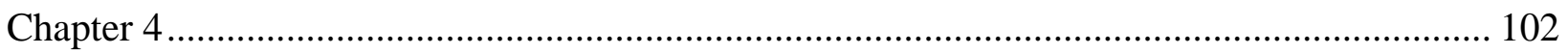

Spring Hunting Season Home Range Size of Male Wild Turkeys in

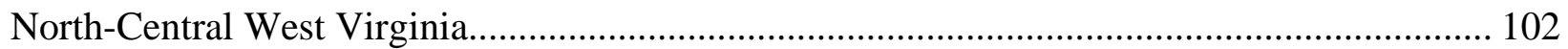

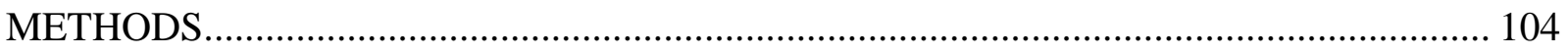

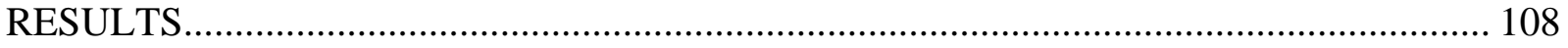

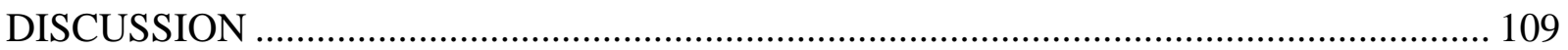

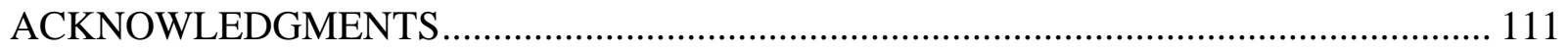

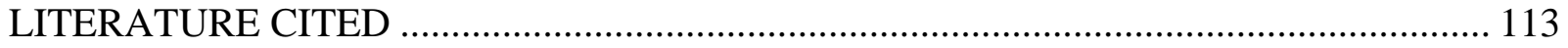




\section{Chapter 1 List of Tables}

Table 1. Review of wild turkey research in West Virginia..................................................... 19

Table 2. Summary of various male eastern wild turkey home range studies. ........................... 21 


\section{Chapter 2 List of Tables}

Table 1. Annual 95\% and 50\% utilization distributions (UDs), including ecological regions (EC), and seasonal 95\% UDs for the fixed-kernel home range and the minimum convex polygon (MCP) home range of male eastern wild turkeys from two study areas in West Virginia, 20042007.

Table 2. Results of stepwise regression analysis on the relation of mast conditions and the fallwinter 95\% utilization distribution fixed kernel home range of juvenile and adult male eastern wild turkey in West Virginia, 2004-2007.

Table 3. Mast indices for three of the six ecological regions of West Virginia, 2004-2006.

Table 4. Male eastern wild turkey population estimates, by age class, from Downing Population Reconstruction (Downing 1980) using harvest figures and spur lengths from the cooperators of the annual Spring Gobbler Survey in West Virginia, 2005-2007.

Table 5. Results of linear regression analysis on the relation of the fixed kernel 95\% utilization distribution annual home range of adult and juvenile male eastern wild turkeys and male eastern wild turkey Downing Population Reconstruction (Downing 1980) estimates in West Virginia, 2005-2007.

Table 6. Results of linear regression analysis on the relation of the home range size of adult and juvenile male eastern wild turkeys and the fate of radioed male eastern wild turkeys in West Virginia, 2004-2007. 


\section{Chapter 3 List of Tables}

Table 1. The eccentricity (E) of the home range shape of adult and juvenile male Eastern Wild Turkeys in West Virginia, 2004-2007.

Table 2. The Eccentricity (E) of the home range shape of three age classes of male Eastern Wild Turkeys in the District I Study Area (DISA) in north-central West Virginia during the April-May period, 2006-2007.

Table 3. Results of linear regression analysis on the relation of mast conditions and the eccentricity of the fall-winter home range shape of male Eastern Wild Turkeys in West Virginia, 2004-2007. 96

Table 4. Male Eastern Wild Turkey population estimates, by age class, from Downing Population Reconstruction (Downing 1980) using harvest figures and spur lengths from the cooperators of the annual Spring Gobbler Survey in West Virginia, 2005-2007.

Table 5. Results of linear regression analysis on the relation of the eccentricity (E) of the home range shape of adult and juvenile male Eastern Wild Turkeys and male Eastern Wild Turkey Downing Population Reconstruction (Downing 1980) estimates in West Virginia, 2005-2007.. 98

Table 6. Results of linear regression analysis on the relation of the eccentricity (E) of the home range shape of adult and juvenile male Eastern Wild Turkeys and the fate of radioed male Eastern Wild Turkeys in West Virginia, 2004-2007.

Table 7. Mast indices for three of the six ecological regions of West Virginia, 2004-2006...... 100 


\section{Chapter 4 List of Tables}

Table 1. Home range sizes (ha) for male Eastern Wild Turkeys by age class and year during the April-May period in north-central West Virginia, 2006-2007.

Table 2. Male Eastern Wild Turkey population estimates for Harrison, Marion, and Taylor counties in West Virginia, by age class and year, from Downing Population Reconstruction (Downing 1980) using harvest figures and spur lengths from the cooperators of the annual Spring Gobbler Survey in West Virginia, 2006-2007........................................................................... 122

Table 3. Results of linear regression analysis, after removing the two outliers, on the relation of the April-May home range size and the population estimate of male Eastern Wild Turkeys in Harrison, Marion, and Taylor counties, West Virginia, 2006-2007. 


\section{Chapter 1 List of Figures}

Figure 1. West Virginia Statewide Study Area and the District I Study Area............................ 24

Figure 2. Traditional and non-traditional fall wild turkey hunting counties in West Virginia..... 25

Figure 3. Ecological Regions of West Virginia .................................................................. 26 


\section{Chapter 2 List of Figures}

Figure 1. Study areas, including ecological regions and fall eastern wild turkey season formats

for West Virginia, 2004-2007.

Figure 2. Means (ha) and confidence intervals (95\%) for; a) the pooled adult and juvenile age classes 95\% UD fixed kernel home range size of male wild turkeys within five ecological regions; b) the adult male wild turkey 50\% UD fixed kernel home range size within four ecological regions and the juvenile male wild turkey 50\% UD fixed kernel home range size within two ecological regions of West Virginia, 2004-2007 


\section{Chapter 3 List of Figures}

Figure 1. Eastern Wild Turkey home range study sites, including the fall wild turkey hunting season format and Ecological Regions in West Virginia.................................................... 10 


\section{Chapter 4 List of Figures}

Figure 1. District I Study Area in north-central West Virginia, 2006-2007, including the Pruntytown State Farm Wildlife Management Area. .... 


\section{List of Appendices}

Appendix A. I $a$-CLXXXIVa: Adult and juvenile 50\% and 95\% probability contours of the annual fixed kernel home range utilization distribution (UD) and 95\% probability contours of the seasonal fixed kernel home range UD for 55 male wild turkeys, West Virginia, 2004-2007. Smoothing parameter (h) determined by least squares cross validation (100K topo map and 2003 SAMB imagery used for map backgrounds).

Appendix B. Annual and seasonal 95\% utilization distributions (UD’s) of the fixed kernel home range estimate (ha) of juvenile and adult male wild turkey in West Virginia, 20042007.

Appendix C. Descriptive statistics for the 95\% and 50\% utilization distributions (UD's) of the fixed kernel and the minimum convex polygon (MCP) annual home range size estimates (ha) of juvenile and adult male wild turkey in 2 study areas in West Virginia, 2004-2007.

Appendix D. Id - XXIIId: The April-May 95\% probability contour fixed kernel home range utilization distribution of male wild turkeys in north-central West Virginia, 20062007. Least squares cross validation was used to determine the smoothing parameter (h) (2003 SAMB imagery used for map background). 
Chapter 1

Introduction and Justification for a Male Wild Turkey Home Range Study in West Virginia

$\underline{\text { Introduction and Justification }}$

Eastern wild turkeys (Meleagris gallopavo silvestris), hereafter, wild turkey, are an important wildlife species to hunters and outdoor enthusiasts throughout its range. Historically, wild turkeys were abundant in West Virginia, but declined in numbers due to wide-scale logging, made possible by the steam engine and railroads, and by the fires that commonly followed the logging operations. During the peak of logging activities in West Virginia, between 1902 and 1925, the wild turkey was restricted to only the most inaccessible mountain regions of the state (West Virginia Department of Natural Resources 1985). Today, due in part to a turkey transplant program, the wild turkey is once again found throughout West Virginia, providing fall turkey hunting in certain counties and all 55 counties reporting a spring gobbler harvest annually (West Virginia Division of Natural Resources 2008).

To manage a wild turkey population effectively, it is important to understand the dynamics of that population. Wild turkey research in West Virginia has been extensive (Table 1), but research on the male segment of the wild turkey population is lacking, including home range estimates. To better understand the population dynamics of the male wild turkey, in September of 2004, the West Virginia Division of Natural Resources (Wildlife Resources Section) and the Virginia Department of Game and Inland Fisheries initiated the Mid-Atlantic Gobbler Study (MAGS) to determine survival of male wild turkeys and impacts of hunting seasons. Although designed primarily as a mortality study, MAGS presented an opportunity to research home range 
characteristics of male wild turkeys in West Virginia. From September 2004 through August 2007, we collected data to estimate home range size and shape of male wild turkeys in West Virginia. We originally proposed to include the Virginia data to estimate home range size and shape, but due to MAGS being designed as a mortality study, only the West Virginia data met the requirements of our home range study (i.e. azimuths collected within a 20 minute period, 2 intersecting azimuths separated by $\geq 60^{\circ}$ and $\leq 120^{\circ}$ ).

The home range of an animal is the area in which it normally lives (Smith 1974). Brown (1980) stated that an "animal does not wander through space at random, but repeatedly covers the same general area”. Knowledge of male wild turkey home range size is important in establishing habitat requirements and population dynamics. Additionally, turkey hunters frequently question state wildlife personnel about wild turkey habitat requirements, including home range size. Although the home range and movement of wild turkeys have been widely studied over many geographic regions, the variability in the results of home range studies makes it necessary to develop management plans from specific regional studies (Brown 1980) and thus it is important to understand the home range size and shape of male wild turkeys in West Virginia to assist in making proper management decisions.

To manage a wild turkey population, it is important to understand the influence of food (mast) availability, especially when fall turkey seasons are considered. Swanson et al. (1994) found that female wild turkeys moved over larger areas during periods of low food availability than during periods of high food availability in Wetzel County, West Virginia. In West Virginia, there is a positive correlation between mast failure and high fall wild turkey harvests; whereas a lower than expected harvest occurs during excellent mast production years (Ryan et al. 2004). Although, Kelley et al. (1988) found that male wild turkeys have a smaller home range during 
years with abundant mast conditions in central Mississippi, limited research is available on the influence of mast conditions on male wild turkey home ranges in West Virginia.

Home range shape is commonly included in home range studies for many species of wildlife, but is rarely quantified in the research (Metzgar 1973, Bergstrom 1988, Spencer et al. 1990). Knowledge of male wild turkey home range shape could benefit state wildlife agencies and private land owners when developing habitat management plans for wild turkeys. Whether a home range is circular or elongated may determine where to implement habitat improvement projects. To quantify the home range shape, we calculated the eccentricity of the home range. Eccentricity $(\mathrm{E})$ is the measure of the symmetry of a shape. A circle has an eccentricity of $\mathrm{E}=$ 1.0, whereas an E $>1.0$ represents an increasingly elongate shape (Spencer et al. 1990). Eccentricity was used by Bergstrom (1988) to quantify the home range shape of 3 species of chipmunks (Tamias spp.) and by Spencer et al. (1990) for hispid cotton rats (Sigmodon hispidus).

\section{Literature Review}

Numerous home range studies have been conducted on male wild turkeys across its range (Table 2), but unlike female wild turkey home range studies (Swanson 1993, Swanson et al. 1994, Taylor 1997, Fearer and Pack 2003), male home range studies in West Virginia are lacking. Moreover, a broad range of research goals were studied over the years. The early male home range research were movement studies using non-telemetry techniques including, visual observations of snow trails of the turkey flock from roost to roost (Lewis 1963) and visual observation of wing-tagged birds (Bailey 1959, Speake et al. 1969, Davis 1973).

The early radio-telemetry home range studies were limited by radio transmitter battery life and/or sample size. In Virginia, 4 turkeys (3 female/1 male, 78 to 84 day battery life) were 
estimated to have a mean fall home range size of 197.3 ha (Raybourne 1968). Four male wild turkeys (subadult $=3$, adult $=1$ ) in Georgia, with a maximum number of tracking days of 115, were estimated to have an average home range size of 419.6 ha for the subadults and 280 ha for the adults (Eichholz and Marchinton 1975). In Missouri, 4 male birds were estimated to have an average annual home of 445.3 ha (Ellis and Lewis 1967). The seasonal home range of 14 male birds was estimated range in Alabama (annual $=398.4$ ha, spring $=204.5$ ha, summer $=133.2$ ha, fall $=170.9$ ha, winter 270.4 ha), but transmitters were only operational from 1 to 148 days (Barwick and Speake 1973). In Arkansas, Wigley et al. (1986) estimated an annual home range of 1,422.7 ha and a fall-winter home range of 524.3 ha for 5 male birds ( 3 adult, 2 juvenile), whereas in Michigan, Kulowiec and Haufler (1985) estimated a winter home range of 6 birds (3 adult, 3 juvenile) to be 389 ha.

Some studies estimated male wild turkey home range in specific habitat types. Clark (1985) estimated the movement and home range (mean annual home range $=1,567$ ha) in farmland area of Ohio and Hurst et al. (1991) estimated mean home range size of male wild turkeys in loblolly pine (Pinus taeda) plantations in Mississippi by season: spring (655 ha), summer (701 ha), fall (897 ha), and winter (877 ha). Carroll (1982) estimated home range of translocated wild turkeys and Hopkins et al. (1982) studied the dispersal of restocked wild turkeys in east Texas. In Mississippi, Godwin et al. (1990) monitored the seasonal movements (did not estimate home ranges) of male wild turkeys $(n=122)$ in relation to the boundary of a wildlife management area over a 4 year period.

A study in Alabama and Kentucky that included $n=20$ male wild turkeys, estimated that 4 “young” birds had an average home range of 247 ha, while the remaining 16 birds had a minimum spring/summer home range of 476 ha in pine forests (Alabama) and 221 ha in 
hardwood forests (Kentucky) (Speake et al. 1975). Also in Alabama, Everett et al. (1979) estimated the annual and seasonal home ranges of 38 male birds as follows: annual home ranges (from 18 of the 38 birds) averaged 1,631 ha, 488 ha in spring, 687 ha in summer, and 944 ha in fall/winter. In general, it was estimated in the Arkansas Ozarks that adult male wild turkeys used a larger area during the summer and fall than during the winter and juvenile male wild turkeys used a larger area during the fall than during the summer (Badyaev et al. 1996).

In central Mississippi, Kelley et al. (1988) estimated annual home ranges for adult (1,418 ha) and juvenile (2,204 ha) male wild turkeys. Additionally, they estimated the 2-year average spring, summer, fall, and winter home ranges as 1,073 ha, 663 ha, 455 ha, and 451 ha for the adults and 1,270 ha, 877 ha, 437 ha, and 569 ha for the juveniles, respectively. Again in central Mississippi, Godwin et al. (1995) estimated male wild turkey $(n=10)$ annual home ranges varying from 798 to 3,131 ha (mean $=1,941$ ha) and seasonal home ranges for $n=53$ male wild turkeys as: 1,131 during the spring, 653 ha during the summer, and 1,134 ha during the fall/winter. Also in central Mississippi, Miller et al. (1997) estimated the mean spring, summer, and fall/winter male wild turkey (24 adults, 30 subadults) home ranges to be 710.5 ha, 611.8 ha, and 668.8 ha for adults and 607.1 ha, 689.8 ha, and 809.8 ha for subadults, respectively.

Brown (1980) summarized several studies to show the variability of male wild turkey home ranges. Annual home ranges varied from 244 ha in Alabama to 553 ha in Missouri, while seasonal home ranges varied from a spring home range of 95 ha in South Carolina to a winter home range of 683 ha in Michigan. A literature review demonstrates a broad range in the estimated size of male wild turkey annual and seasonal home ranges. Some of these differences can be attributed to the differing habitats that the wild turkey inhabits across its range from north to south. But, also the home range estimator used by each researcher will show differences in 
home range size estimates. A literature search showed several different home range estimator methods being used by researchers. Commonly used was the minimum area method (Lewis 1963, Fleming and Webb 1974, Eichholz and Marchinton 1975), as was the modified minimum area method (Raybourne 1968, Carroll 1982). Hopkins et al. (1982) used the minimum home range method. Other common methods have been the convex polygon method (Kelley et al. 1988, Miller et al. 1997) and the minimum convex polygon method (Clark 1985, Hurst et al. 1991, Godwin et al. 1995).

Relatively new home range estimators being used are fixed and adaptive kernel density estimators to estimate utilization distributions of an organism's home range (Worton 1989, Seaman and Powell 1996). When estimating home range with a kernel density estimator, it is important to select the proper smoothing parameter or bandwidth (h) (Worton 1995). By the use of simulated data, both Worton (1995) and Seaman and Powell (1996) concluded that the fixed kernel gives the least biased results and Seaman and Powell (1996) concluded that selecting $h$ by least squares cross-validation performed well. We estimated home range size of male wild turkeys with the fixed kernel method with least squares cross-validation for the smoothing parameter and also with the minimum convex polygon method, both with the Animal Movement Extension in ArcView 3.3.

\section{Study Area}

Two study areas were used in West Virginia (Fig. 1), 1) state-wide and 2) Harrison, Marion, and Taylor counties in north-central West Virginia - District I Study Area (DISA). West Virginia is mountainous, with elevations varying from $73-1,524 \mathrm{~m}$. West Virginia has a statewide spring gobbler season (bearded wild turkeys only) and a 4-week either-sex fall wild turkey season in the traditional fall hunting counties (Fig. 2). Preston County was not included in the 
study area because the fall wild turkey season is 2 weeks in length, the only county in West Virginia with that fall season format.

The forest vegetation of West Virginia has been classified into 3 physiographic provinces: Western Hill Section, Allegheny Mountain and Upland Section, and Eastern Ridge and Valley Section (Stausbaugh and Core 1978). The Western Hill Section is comprised of central hardwoods and ranges from Oak-Pine and Oak-Chestnut communities (xeric) through Cove Hardwood or Mixed Mesophytic Forests (mesic) to Flood Plain communities (hydric). The Allegheny Mountain and Upland Section is comprised of Northern Hardwoods. The dominant species are sugar maple (Acer sacchrarum), American beech (Fagus grandifolia), and yellow birch (Betula alleghaniensis). The Eastern Ridge and Valley Section is comprised of oakhickory-pine. Because of variable habitat factors that affect directly or indirectly the distribution of vegetation, as well as annual mast conditions and game harvests, the state has been divided into 6 ecological regions for game management purposes (Fig. 3) (Uhlig and Wilson 1952). The DISA is located in the Central Allegheny Plateau.

\section{Goals and Objectives}

The project goals were to estimate home range size and shape of male wild turkeys in West Virginia. The project objectives were as follows:

1. Estimate and compare mean home range size and shape of male wild turkeys by season, ecological region, and age class in West Virginia. $\mathrm{H}_{o}=$ there is no significant difference in mean home range size by season, ecological region, and age class. $\mathrm{H}_{a}$ = there is a significant difference in mean home range size of at least one variable. $\mathrm{H}_{o}=$ the mean home range shape of male wild turkeys 
is circular: Eccentricity $=1 . \mathrm{H}_{a}$ = the mean home range shape is elongated: Eccentricity $>1$.

2. Estimate if there are any significant differences in mean home range size and shape for male wild turkeys in traditional fall-hunt counties and nontraditional fall-hunt counties in West Virginia. $\mathrm{H}_{o}=$ male wild turkey mean home range size and shape in traditional fall-hunt counties is not significantly different from male wild turkey mean home range size and shape in nontraditional fall-hunt counties. $\mathrm{H}_{a}$ = male wild turkey mean home range size and shape in traditional fall-hunt counties is significantly different than male wild turkey mean home range size and shape in non-traditional fall-hunt counties.

3. Estimate relation between seasonal mast production and mean home range size and shape of male wild turkeys in West Virginia. $\mathrm{H}_{o}=$ male wild turkey mean home range size and shape is not significantly related to seasonal mast production. $\mathrm{H}_{a}$ = male wild turkey mean home range and shape is significantly related to seasonal mast production.

4. Estimate relation between annual male wild turkey population estimate and mean home range size and shape of male wild turkeys in West Virginia. $\mathrm{H}_{o}=$ male wild turkey mean home range size and shape is not significantly related to relative annual male wild turkey population. $\mathrm{H}_{a}$ = male wild turkey mean home range size and shape is significantly related to relative annual male wild turkey population. 
5. Estimate any relation between mean annual male wild turkey home range size and shape and fate of male wild turkey during the study. $\mathrm{H}_{0}=$ male wild turkey mean annual home range size and shape is not significantly related to the fate of male wild turkey during the study. $\mathrm{H}_{a}=$ male wild turkey mean annual home range size and shape is significantly related to the fate of male wild turkey during the study.

6. Compare the results of this study on male wild turkey home range size to the results of Fearer and Pack (2003) on female wild turkey home range size.

I had proposed to compare the results from West Virginia to those of Virginia to estimate any significant difference in male wild turkey home range size and shape by season and age class, but this was not possible because of the lack of appropriate data for Virginia. Additionally, a sufficient sample size was not available to compare home range size and shape of male wild turkeys that were being supplementally baited/fed to those that were not.

\section{MAGS Trapping Summary}

From September 2004 through March 2007, 197 (119 juvenile, 78 adult [aged when trapped]) male wild turkeys were trapped and radioed statewide in West Virginia, 32 (25 juvenile, 7 adult [aged when trapped]) of which were radioed in the DISA. A total of 55 male wild turkeys were used for estimating home range size and shape in this study, 22 of which were in the DISA. The remaining 142 radioed male wild turkeys were not included in analysis because of the following circumstances: 57 - did not survive long enough after capture, 43 - survived long enough but had insufficient data for home range analysis, and 34 - were captured in early 2007. All of the 10 radioed male wild turkeys not included in the DISA analysis did not survive long enough for home range analysis (survived 1-117 days, averaged - 40.5 days). 


\section{Literature Cited}

Alipizar-Jara, R., E. N. Brooks, K. H. Pollock, D. E. Steffen, J. C. Pack, and G. W. Norman. 2001. An eastern wild turkey population dynamics model for Virginia and West Virginia. Journal of Wildlife Management 65:415-424.

Badyaev, A. V., W. J. Etges, and T. E. Martin. 1996. Ecological and behavioral correlates of variation in seasonal home ranges of wild turkey. Journal of Wildlife Management 60:154-164.

Bailey, R. W. 1956. Sex determination of adult wild turkeys by means of dropping configuration. Journal of Wildlife Management 20:220.

. 1959. Preliminary report on wild turkey banding studies as applicable to management in West Virginia. Pages 146-158. Proceedings of the First National Wild Turkey Symposium. National Wild Turkey Federation, Edgefield, South Carolina, USA. , and K. T. Rinell. 1965. Wild turkey population trends, productivity and harvest. West Virginia Department of Natural Resources, Division of Fish and Game Bulletin 6, Charleston, West Virginia, USA.

. 1973. Restoring wild-trapped turkeys to non-primary range in West Virginia. Pages 181-185 in G. C. Sanderson and H. C. Shultz, editors. Wild turkey management: current problems and programs. Proceedings of the Second National Wild Turkey Symposium. Missouri Chapter of the Wildlife Society and University of Missouri Press, Columbia, Missouri, USA. 
Barwick, L. H., and D. W. Speake. 1973. Seasonal movements and activities of wild turkey gobblers in Alabama. Pages 125-133 in G. C. Sanderson and H. C. Shultz, editors. Wild turkey management: current problems and programs. Proceedings of the Second National Wild Turkey Symposium. Missouri Chapter of the Wildlife Society and University of Missouri Press, Columbia, Missouri, USA.

Bergstrom, B. J. 1988. Home range of three species of chipmunks (Tamias) as assessed by radiotelemetry and grid trapping. Journal of Mammalogy 69:190-193.

Brown, E. K. 1980. Home range and movements of wild turkeys - a review. Pages 251-261 in J. M. Sweeny, editor. Proceedings of the Forth National Wild Turkey Symposium. National Wild Turkey Federation, Edgefield, South Carolina, USA.

Carroll, J. P. 1982. Dispersal, home range and habitat use of translocated eastern wild turkeys (Meleagris gallopavo sylvestris) in Jackson County, Kentucky. Thesis, Eastern Kentucky University, Richmond, Kentucky, USA.

Clark, L. G. 1985. Adjustment by transplanted wild turkeys to an Ohio farmland area. Pages 3347 in J. Earl and M. C. Kennemer, editors. Proceedings of the Fifth National Wild Turkey Symposium. National Wild Turkey Federation, Edgefield, South Carolina, USA.

Davis, J. R. 1973. Movements of wild turkeys in southeastern Alabama. Pages 135-139 in G. C. Sanderson and H. C. Shultz, editors. Wild turkey management: current problems and programs. Proceedings of the Second National Wild Turkey Symposium. Missouri Chapter of the Wildlife Society and University of Missouri Press, Columbia, Missouri, USA. 
Eichholz, N. E., and R. L. Marchinton. 1975. Dispersal and adjustment to habitat of restocked wild turkeys in Georgia. Proceedings of the Annual Conference Southeastern Association of Game and Fish Commissioners 29:373-378.

Ellis, J. E., and J. B. Lewis. 1967. Mobility and annual range of wild turkeys in Missouri. Journal of Wildlife Management 31:568-581.

Everett, D. D., D. W. Speake, and W. K. Maddox. 1979. Wild turkey ranges in Alabama mountain habitat. Proceeding of the Annual Conference Southeastern Association of Fish and Wildlife Agencies 33:233-238.

Fearer, T. M., and J. C. Pack. 2003. Home range characteristics of female wild turkeys in West Virginia. West Virginia Division of Natural Resources PR Report. Charleston, West Virginia, USA.

Fleming, W. H., and L. G. Webb. 1974. Home range, dispersal and habitat utilization of eastern wild turkey gobblers during the breeding season. Proceeding of the Annual Conference Southeastern Association of Fish and Wildlife Agencies 28:623-632.

Gilpin, D. D. 1959. Recent results of wild turkey restocking efforts in West Virginia. Pages 8796 in Proceedings of the First National Wild Turkey Symposium. National Wild Turkey Federation, Edgefield, South Carolina, USA.

Glover, F. A. 1948. Winter activities of wild turkey in West Virginia. Journal of Wildlife Management 12:416-427. , and R. W. Bailey. 1949. Wild turkey foods in West Virginia. Journal of Wildlife Management 13:255-265. 
Godwin, K. D., W. E. Palmer, G. A. Hurst, and R. L. Kelly. 1990. Relationship of wild turkey gobbler movements and harvest rates to management area boundaries. Proceeding of the Annual Conference Southeastern Association of Fish and Wildlife Agencies 44:260-267.

, G. A. Hurst, and B. D. Leopold. 1995. Size and percent overlap of gobbler home range and core-use areas in central Mississippi. Pages 45-52 in J. G. Dickson, editor. Proceedings of the Seventh National Wild Turkey Symposium. National Wild Turkey Federation, Edgefield, South Carolina, and Stackpole Books, Mechanicsburg, Pennsylvania, USA.

Healy, W. M. 1977. Wild turkey winter habitat in West Virginia cherry-maple forests. Transactions of the Northeast Section of The Wildlife Society 34:7-12. , and E. S. Nenno. 1985. Effects of weather on wild turkey poult survival. Pages 91101 in W. H. Healy and E. S. Nenno, editors. Proceedings of the Fifth National Wild Turkey Symposium. National Wild Turkey Federation, Edgefield, South Carolina, USA.

Hopkins, C. R., J. J. Campo, W. G. Swank, and D. J. Martin. 1982. Dispersal of restocked eastern wild turkeys in east Texas. Proceeding of the Annual Conference Southeastern Association of Fish and Wildlife Agencies 36:578-585.

Hurst, G. A., D. R. Smith, J. D. Burk, and B. D. Leopold. 1991. Wild turkey gobbler habitat use and home range in loblolly pine plantations. Proceeding of the Annual Conference Southeastern Association of Fish and Wildlife Agencies 45:115-123. 
Kelley, R. L., G. A. Hurst, and D. E. Steffen. 1988. Home ranges of wild turkey gobblers in central Mississippi. Proceeding of the Annual Conference Southeastern Association of Fish and Wildlife Agencies 42:470-475.

Kulowiec, T. G., and J. B. Haufler. 1985. Winter and dispersal movements of wild turkeys in Michigan’s northern lower peninsula. Pages 145-153 in W. H. Healy and E. S. Nenno, editors. Proceedings of the Fifth National Wild Turkey Symposium. National Wild Turkey Federation, Edgefield, South Carolina, USA.

Lewis, J. C. 1963. Observations on the winter range of wild turkeys in Michigan. Journal of Wildlife Management 27:98-102.

Metzgar, l. H. 1973. Home range shape and activity in Peromyscus leucopus. Journal of Mammalogy 54:383-390.

Miller, D. A., B. D. Leopold, and G. A. Hurst. 1997. Seasonal home ranges of wild turkeys in central Mississippi. Proceeding of the Annual Conference Southeastern Association of Fish and Wildlife Agencies 51:414-425.

Norman, G. W., D. E. Steffen, C. I. Taylor, J. C. Pack, K. H. Pollock, and K. Tsai. 2000. Reproductive chronology, spring hunting, an illegal kill of female wild turkey. Pages 269-280 in W. F. Porter and K. K. Fleming, editors. Making tracks, wild turkey management for the new millennium. Proceedings of the Eighth National Wild Turkey Symposium. National Wild Turkey Federation, Edgefield, South Carolina, USA. 
, J. C. Pack, C. I. Taylor, D. E. Steffen, and K. H. Pollock. 2001. Reproduction of eastern wild turkeys in Virginia and West Virginia. Journal of Wildlife Management $65: 1-9$

D. E. Steffen, and C. I. Taylor. 2005. Fall illegal kill of female wild turkey in Virginia and West Virginia. Pages 67-73 in C. A. Stewart and V. R. Frawley, editors. Wild turkey management - accomplishments, strategies, and opportunities. Proceedings of the National Wild Turkey Symposium. National Wild Turkey Federation, Edgefield, South Carolina, USA.

Pack, J. C., R. P. Burkert, W. K. Igo, and D. J. Pybus. 1980. Habitat utilized by wild turkey broods within oak-hickory forests of West Virginia. Pages 213-224 in J. M. Sweeney, editor. Proceedings of the Fourth National Wild Turkey Symposium. National Wild Turkey Federation, Edgefield, South Carolina, USA.

, C. I. Taylor, D. A. Swanson, and S. A. Warner. 1996. Evaluation of wild turkey trapping techniques in West Virginia. Proceeding of the Annual Conference Southeastern Association of Fish and Wildlife Agencies 55:436-441.

, G. W. Norman, C. I. Taylor, D. E. Steffen, D. A. Swanson, K. H. Pollock, and R. Alpizar-Jara. 1999. Effects of fall hunting on wild turkey populations in Virginia and West Virginia. Journal of Wildlife Management 63:964-975.

Raybourne, J. W. 1968. Telemetry of turkey movements. Proceeding of the Annual Conference Southeastern Association of Fish and Wildlife Agencies 22:47-54. 
Ryan, C. W., J. C. Pack, W. K. Igo, J. C. Rieffenberger, A. B. Billings. 2004. Relationship of mast production to big-game harvests in West Virginia. Wildlife Society Bulletin 32:1-9.

Seaman, D. E., and R. A. Powell. 1996. An evaluation of the accuracy of kernel density estimators for home range analysis. Ecology 77:2075-2085.

Smith, R. L. 1974. Ecology of Field biology. Second Edition. Harper \& Row. New York, New York, USA.

Smith, W. P., E. P. Lambert, and R. D. Teitelbaum. 1988. Seasonal movement and home range differences among age and sex groups of eastern wild turkeys within southeastern Louisiana. Proceedings of the International Symposium on Biotelemetry 10:151-158.

Speake, D. W., L. H. Barwick, H. O. Hillestad, and W. Sickney. 1969. Some characteristics of an expanding turkey population. Proceeding of the Annual Conference Southeastern Association of Fish and Wildlife Agencies 23:46-58.

, T. E. Lynch, W. J. Fleming, G. A. Wright, and W. J. Harnick. 1975. Habitat use and seasonal movements of wild turkeys in the southeast. Pages 122-130 in L. K. Halls, editor. Proceedings of the Third National Wild Turkey Symposium. The Texas Chapter of the Wildlife Society.

Spencer, S. R., G. N. Cameron, and R. K. Swilhart. 1990. Operationally defining home range: temporal dependence exhibited by hispid cotton rats. Ecology 71:1817-1822.

Strausbaugh, P. D., and E. L. Core. 1978. Flora of West Virginia. Second Edition. Seneca Books. Morgantown, West Virginia, USA. 
Swanson, D. A. 1993. Population dynamics of wild turkey in West Virginia. Dissertation, West Virginia University, Morgantown, West Virginia, USA.

, J. C. Pack, C. I. Taylor, P. W. Brown, and D. E. Samuel. 1994. Habitat use of wild turkey hens in northwestern West Virginia. Proceeding of the Annual Conference Southeastern Association of Fish and Wildlife Agencies 48:123-133.

D. E. Samuel, and P. W. Brown. 1995. Selective timber

harvesting and wild turkey reproduction in West Virginia. Pages 81-88 in J. G. Dickson, editor. Proceedings of the Seventh National Wild Turkey Symposium. The National Wild Turkey Federation, Edgefield, SC. and Stackpole Books, Mechanicsburg, Pennsylvania, USA.

Taylor, C. I. 1997. Home range and movements of wild turkey hens in the New River Valley, Summers County, West Virginia. Pages 67-80 in Proceedings, New River Symposium, April 11-12, 1997, Glade Springs Resort, Daniels, West Virginia. Glen Jean, West Virginia: National Park Service, USA.

Uhlig, H. G., and H. L. Wilson. 1952. A method of evaluating an annual mast index. Journal of Wildlife Management 16:338-343.

West Virginia Department of Natural Resources. 1985. The wild turkey in West Virginia. Publication \#3. West Virginia Department of Natural Resources, Wildlife Resources Section, Charleston, West Virginia, USA.

West Virginia Division of Natural Resources. 2008. Pages 11-22. Big Game Bulletin. West Virginia Division of Natural Resources, Bulletin 09-1. Charleston, West Virginia, USA. 
Wigley, T. B., J. M. Sweeny, M. E. Garner, and M. A. Melechiors. 1986. Wild turkey home ranges in the Ouachita Mountains. Journal of Wildlife Management 50:540-544.

Worton, B. J. 1989. Kernel methods for estimating the utilization distribution in home-range studies. Ecology 70:164-168.

. 1995. Using Monte Carlo simulations to evaluate kernel-based home range estimators. Journal of Wildlife Management 59:794-800. 
Table 1. Review of wild turkey research in West Virginia.

\section{Description}

Source

\section{Home Range and Movement}

Winter activities and movement of wild turkeys

Glover (1948)

Effects of selective timber harvest on home range and habitat use

Swanson (1994)

in Wetzel County

Home range and movements of female wild turkeys in

Taylor (1997)

Summers County

Home range characteristics of female wild turkeys

Fearer and Pack (2003)

\section{Population Dynamics}

Population trends, productivity, and harvest

Bailey and Rinell (1965)

Statewide female wild turkey study

Swanson (1993)

Reproduction in selectively harvested timber habitat

Swanson et al. (1995)

Population dynamics model development

Alpizar-Jara et al. (2001)

Female wild turkey reproduction in VA and WV

Norman et al. (2001)

\section{Harvest Management}

Effects of fall wild turkey hunting on wild turkey population in

Pack et al. (1999)

VA and WV

Reproduction and illegal kill of female wild turkey

Norman et al. (2000)

Relationship of mast production and fall wild turkey harvest

Ryan et al. (2004)

Illegal kill of female wild turkeys during fall hunting seasons in

Norman et al. (2005) VA and WV 
Table 1. cont.

Description

Source

\section{Habitat Requirements}

Analysis of utilized foods

Glover and Bailey (1949)

Wild turkey brood use in oak-hickory forests

Pack et al. (1980)

Use of cherry-maple forests in winter

Healy (1977)

\section{Miscellaneous}

Sex determination by means of droppings

Bailey (1956)

Applicability of banding studies to management in WV

Bailey (1959)

Results of restocking efforts

Gilpin (1959)

Restoration of wild-trapped wild turkeys to non-primary range

Bailey (1973)

Effects of weather on poult survival

Healy and Nenno (1985)

Evaluation of trapping techniques

Pack et al. (1996) 
Table 2. Summary of various male eastern wild turkey home range studies.

\begin{tabular}{|c|c|c|c|c|c|c|c|c|}
\hline \multirow[b]{2}{*}{ Source } & \multirow[b]{2}{*}{$(n)$} & \multirow[b]{2}{*}{ Age } & \multicolumn{5}{|c|}{ Home Range (ha) } & \multirow[b]{2}{*}{ Comments $^{\mathrm{a}}$} \\
\hline & & & Annual & Spring & Summer & Fall & Winter & \\
\hline Lewis (1963) & 31 & $\mathrm{~A}$ & & & & & 276.5 & $\begin{array}{l}\text { MI, male wild } \\
\text { turkeys in } 8 \\
\text { separate flocks, } \\
\text { non-telemetry, } \\
\text { MAM }\end{array}$ \\
\hline $\begin{array}{l}\text { Ellis and } \\
\text { Lewis (1967) }\end{array}$ & 4 & A & 445.3 & & & & & $\begin{array}{l}\text { MO, included visual } \\
\text { and telemetry (14- } \\
30 \text { days), MAM }\end{array}$ \\
\hline $\begin{array}{l}\text { Raybourne } \\
\text { (1968) }\end{array}$ & 1 & $\mathrm{~J}$ & & & & 198 & & $\begin{array}{l}\text { VA, small sample } \\
\text { size, short study } \\
\text { period, MMAM }\end{array}$ \\
\hline Barwick and & 8 & $*$ & 398.4 & & & & & AL, 4.5 yr study, \\
\hline Speake (1973) & 6 & $*$ & & 204.5 & 133.2 & 170.9 & 270.4 & $\begin{array}{l}\text { visual and telemetry } \\
\text { (1-148 days), MAM }\end{array}$ \\
\hline $\begin{array}{l}\text { Fleming and } \\
\text { Webb (1974) }\end{array}$ & $\begin{array}{l}2 \\
5\end{array}$ & $\begin{array}{c}\mathrm{A} \\
\mathrm{J}\end{array}$ & & $\begin{array}{l}93.5^{1} \\
95.0^{1}\end{array}$ & & & & $\begin{array}{l}\text { SC, }{ }^{1} \text { Feb-Mar, one } \\
\text { year study, MAM }\end{array}$ \\
\hline $\begin{array}{l}\text { Eichholz and } \\
\text { Marchinton } \\
\text { (1975) }\end{array}$ & $\begin{array}{l}1 \\
3\end{array}$ & $\begin{array}{c}\text { A } \\
\mathrm{J}\end{array}$ & & & $\begin{array}{c}280 \\
419.6\end{array}$ & & & $\begin{array}{l}\text { GA, small sample } \\
\text { size, } 115 \text { maximum } \\
\text { tracking days, } \\
\text { MAM }\end{array}$ \\
\hline $\begin{array}{l}\text { Speake et al. } \\
\text { (1975) }\end{array}$ & $\begin{array}{c}16 \\
4\end{array}$ & $\begin{array}{c}\text { A } \\
\mathrm{J}\end{array}$ & & $348.5^{1}$ & & $247^{2}$ & & $\begin{array}{l}\text { AL and KY, } \\
{ }^{1} \text { spring-summer, } \\
{ }^{2} \text { fall-winter, } \\
\text { MHRM }\end{array}$ \\
\hline $\begin{array}{l}\text { Everett et al. } \\
\text { (1979) }\end{array}$ & $\begin{array}{l}18 \\
36 \\
33 \\
23\end{array}$ & $\begin{array}{l}* \\
* \\
* \\
*\end{array}$ & 1,661 & 503 & 665 & & 973 & AL, MAM \\
\hline
\end{tabular}


Table 2. cont.

\begin{tabular}{|c|c|c|c|c|c|c|c|c|}
\hline \multirow[b]{2}{*}{ Source } & \multirow[b]{2}{*}{$(n)$} & \multirow[b]{2}{*}{ Age } & \multicolumn{5}{|c|}{ Home Range (ha) } & \multirow[b]{2}{*}{ Comments } \\
\hline & & & Annual & Spring & Summer & Fall & Winter & \\
\hline Carroll (1982) & $\begin{array}{l}2 \\
3 \\
3 \\
1 \\
3\end{array}$ & $\begin{array}{l}* \\
* \\
* \\
\text { A } \\
*\end{array}$ & 476 & 239 & 46.8 & 197 & 413 & $\begin{array}{l}\text { KY, small sample } \\
\text { size, 8-188 tracking } \\
\text { days, MAM, } \\
\text { MMAM }\end{array}$ \\
\hline $\begin{array}{l}\text { Kulowiec and } \\
\text { Haufler } \\
\text { (1985) }\end{array}$ & 6 & $*$ & & & & & 389 & AL, MAM \\
\hline $\begin{array}{l}\text { Wigley et al. } \\
\text { (1986) }\end{array}$ & 5 & $*$ & $1,422.7$ & & & $524.3^{1}$ & & $\begin{array}{l}\text { AR, }{ }^{1} \text { fall-winter, } \\
\text { small sample size, } \\
\text { averaged } 10 \text { months } \\
\text { monitoring, MAM }\end{array}$ \\
\hline $\begin{array}{l}\text { Kelley et al. } \\
\text { (1988) }\end{array}$ & $\begin{array}{c}6 \\
3 \\
12 \\
17 \\
10 \\
12 \\
8 \\
7 \\
7 \\
6\end{array}$ & $\begin{array}{c}\text { A } \\
\text { J } \\
\text { A } \\
\text { J } \\
\text { A } \\
\text { J } \\
\text { A } \\
\text { J } \\
\text { A } \\
\text { J }\end{array}$ & $\begin{array}{l}1,418 \\
2,204\end{array}$ & $\begin{array}{l}1,073 \\
1,270\end{array}$ & $\begin{array}{l}663 \\
877\end{array}$ & $\begin{array}{l}455 \\
437\end{array}$ & $\begin{array}{l}451 \\
569\end{array}$ & $\begin{array}{l}\text { MS, 2-year study, } \\
\text { CPM }\end{array}$ \\
\hline $\begin{array}{l}\text { Smith et al. } \\
\text { (1988) }\end{array}$ & $\begin{array}{l}4 \\
3 \\
6 \\
3 \\
4 \\
4 \\
5 \\
3 \\
3\end{array}$ & $\begin{array}{c}\text { A } \\
\text { J } \\
\text { A } \\
\text { J } \\
\text { A } \\
\text { A } \\
\text { J } \\
\text { A } \\
\text { J }\end{array}$ & $\begin{array}{c}1,473.0 \\
360.2\end{array}$ & $\begin{array}{c}390.8 \\
29.7\end{array}$ & 688.1 & $\begin{array}{l}127.7 \\
124.7\end{array}$ & $\begin{array}{l}140.4 \\
176.2\end{array}$ & $\begin{array}{l}\text { LA, 2-year study, } \\
\text { MCP }\end{array}$ \\
\hline
\end{tabular}


Table 2. cont.

\begin{tabular}{|c|c|c|c|c|c|c|c|c|}
\hline \multirow[b]{2}{*}{ Source } & \multirow[b]{2}{*}{$(n)$} & \multirow[b]{2}{*}{ Age } & \multicolumn{5}{|c|}{ Home Range (ha) } & \multirow[b]{2}{*}{ Comments } \\
\hline & & & Annual & Spring & Summer & Fall & Winter & \\
\hline \multirow{3}{*}{$\begin{array}{l}\text { Godwin et al. } \\
\text { (1995) }\end{array}$} & $53^{1}$ & A & & $1,369.5$ & 832.5 & $1,134^{2}$ & & \multirow{3}{*}{$\begin{array}{l}\text { MS, }{ }^{1} 53 \text { total for } \\
\text { adults and juveniles, } \\
{ }^{2} \text { fall-winter, MCP }\end{array}$} \\
\hline & & $\mathrm{J}$ & & 1,178 & 473.5 & & & \\
\hline & 10 & A & 1,941 & & & & & \\
\hline \multirow{2}{*}{$\begin{array}{l}\text { Miller et al. } \\
\text { (1997) }\end{array}$} & 24 & A & & 710.5 & 611.8 & $668.8^{1}$ & & \multirow{2}{*}{$\begin{array}{l}\text { MS, }{ }^{1} \text { fall-winter, }{ }^{5-} \\
\text { year study, CPM }\end{array}$} \\
\hline & 30 & $\mathrm{~J}$ & & 607.1 & 689.8 & $809.8^{1}$ & & \\
\hline
\end{tabular}

${ }^{\text {a}}$ Home range estimation method: MAM - minimum area method, MMAM - modified minimum area method, CPM - convex polygon method, MCP - modified convex polygon.

*Age classes pooled. 


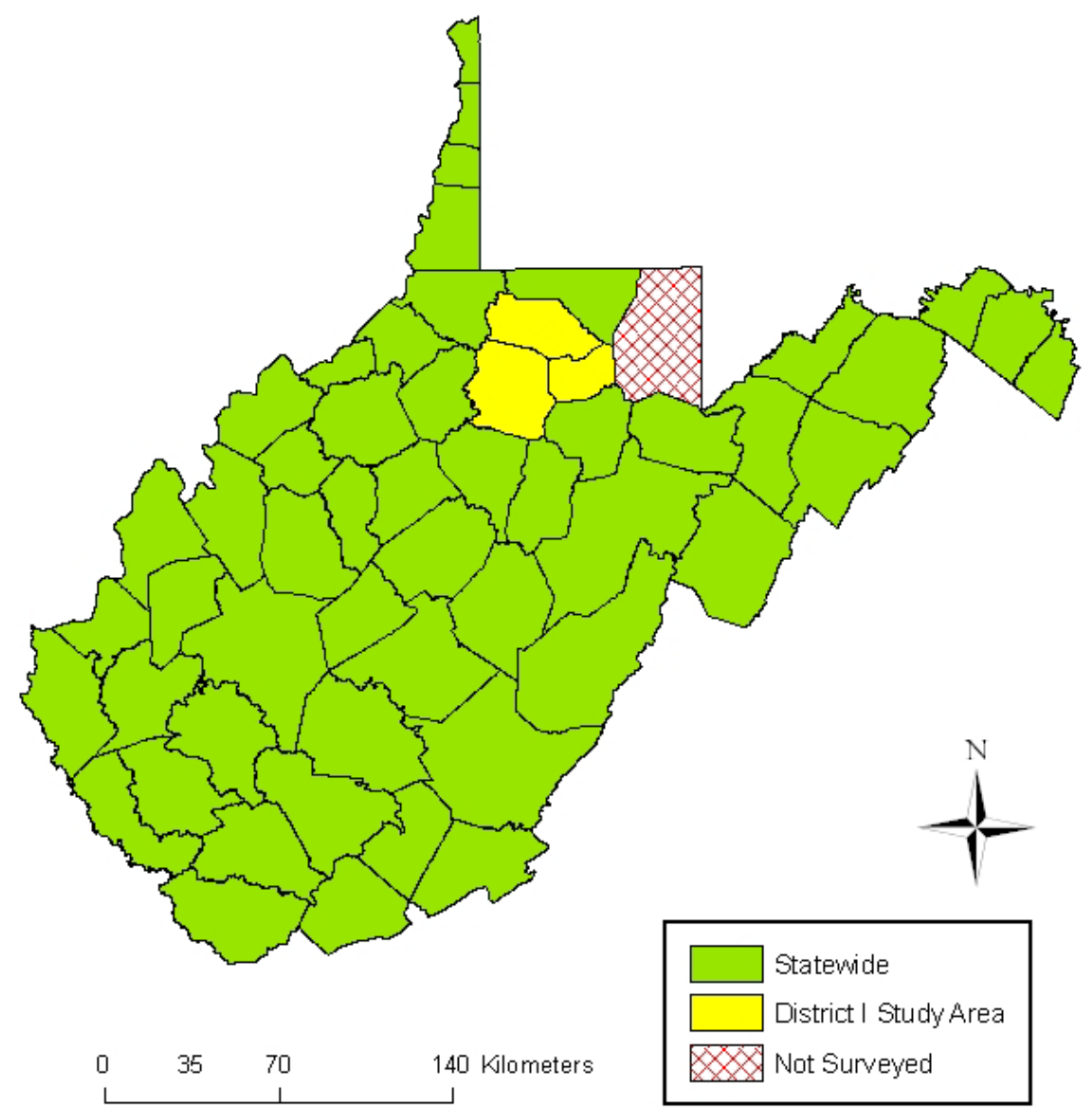

Figure 1. West Virginia Statewide Study Area and the District I Study Area. 


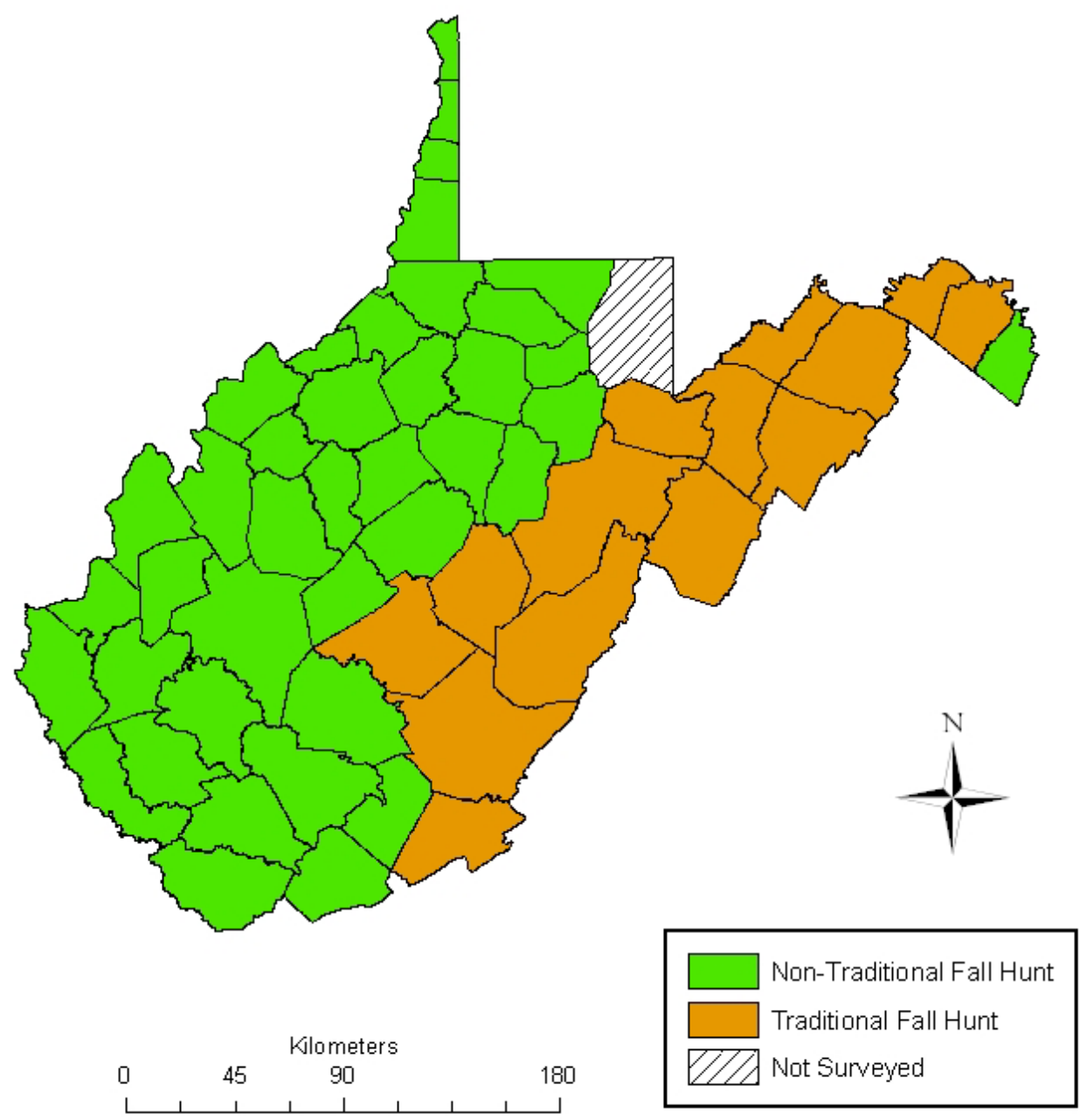

Figure 2. Traditional and non-traditional fall wild turkey hunting counties in West Virginia. 


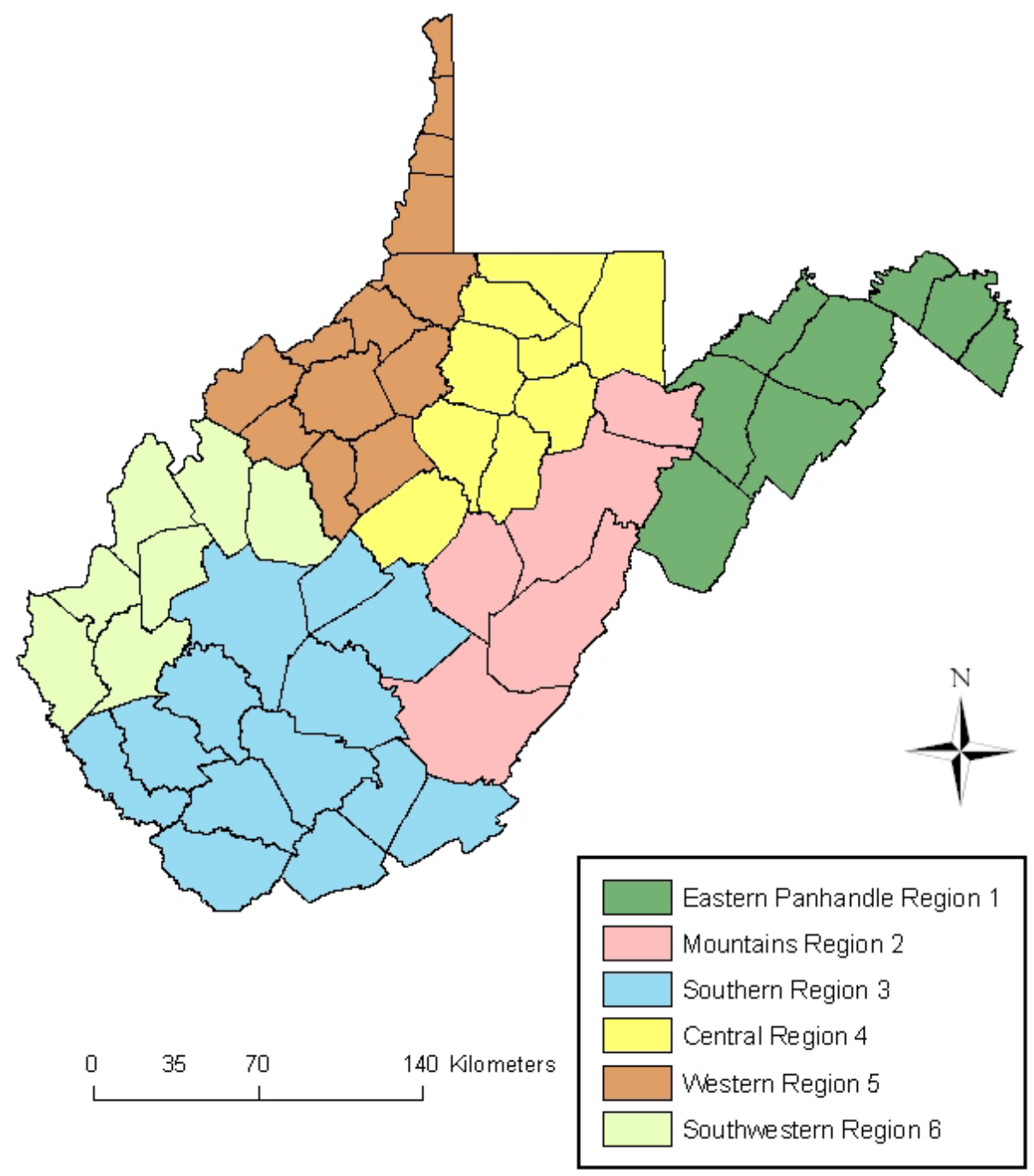

Figure 3. Ecological Regions of West Virginia 
Chapter $2^{\mathrm{a}}$

Date

Steven E. Rauch

West Virginia Division of Natural Resources

P.O. Box 99 Farmington, WV 26571

304/825-6787

steverauch@wvdnr.gov

RH: Rauch et al. • Male Turkey Home Range

Home Range Estimates of the Male Eastern Wild Turkey in West Virginia

STEVEN E. RAUCH ${ }^{1}$, West Virginia Division of Natural Resources, P.O. Box 99, Farmington, WV 26571, USA

JAMES T. ANDERSON, Division of Forestry and Natural Resources, West Virginia University, Morgantown, WV 26506, USA

A. B. BILLINGS, Department of Statistics, West Virginia University, Morgantown, WV 26506, USA

ABSTRACT: To address the lack of male wild turkey home range size estimates, 55 radioequipped male wild turkey were monitored from September 2004 through August 2007 in West Virginia. Least-squares cross validation fixed kernel 95\% and 50\% utilization distribution (UD) annual and 95\% UD seasonal home range as well as minimum convex polygon (MCP) home range was estimated. Statewide adult $(831.5 \mathrm{ha}, \mathrm{SD}=646.5)$ and juvenile $(868.3 \mathrm{ha}, \mathrm{SD}=497.7)$ annual 95\% UD home range were similar $(P=0.38)$, with the smallest home ranges (311.2 ha,

\footnotetext{
${ }^{\text {a }}$ This chapter written in the style of The Journal of Wildlife Management

${ }^{1}$ Email: steverauch@wvdnr.gov
} 
$\mathrm{SD}=79.2$ ) in the southern ecological region. Annual MCP home range averaging 963.2 ha (SD $=678.2)$ for adults and 794.3 ha $(\mathrm{SD}=401.8)$ for juveniles. Juvenile annual 50\% UD home range $(156.2$ ha, $\mathrm{SD}=121.9)$ was larger than adults $(106.1$ ha, $\mathrm{SD}=98.1)(P=0.047)$. Adult and juvenile 95\% UD $(P=0.80)$ as well as the 50\% UD $(P=0.75)$ home ranges were similar between fall hunt and non-fall hunt counties. Adult seasonal 95\% UD home range were similar $(P>0.05)$ and averaged: spring - 475.7 ha, $\mathrm{SD}=124.6$, fall -548.8 ha, $\mathrm{SD}=209.6$, winter 536.2 ha, $\mathrm{SD}=403.2$, spring-summer -510.2 ha, $\mathrm{SD}=280.2$, and fall-winter -608.8 ha, $\mathrm{SD}=$ 328.4. Adult seasonal MCP home range averaged; spring - 446.4 ha, $S D=200.7$, fall - 453.3 ha, $\mathrm{SD}=196.5$, winter -444.5 ha, $\mathrm{SD}=296.4$, spring-summer -555.4 ha, $\mathrm{SD}=297.4$, and fallwinter -643.9 ha, SD = 396.1. We found a relation between home range size and mast conditions $(P=0.003)$. We found a relation $(P=0.05)$ between the 2007 home range size and male wild turkey population size estimate, with a linear model $\left(R^{2}=0.48\right)$. Legally harvested male wild turkeys had a smaller $(P \leq 0.03)$ home range $(404.1$ ha, $\mathrm{SD}=193.6)$ than depredated (892.3 ha, $\mathrm{SD}=446.8$ ), died from other causes (867.3 ha, $\mathrm{SD}=499.3$ ), or those alive at end of study (822.2 ha, $\mathrm{SD}=447.7)$. Our results fell within the reported results of various other male eastern wild turkey studies. We compared our home range results with those of a regional female eastern wild turkey study.

KEY WORDS eastern wild turkey, fixed kernel density estimation, home range, mast condition, minimum convex polygon, Meleagris gallopavo silvestris, West Virginia

The Journal of Wildlife Management: 00(0): 000-000, 201X

Home range estimation of the male eastern wild turkey, hereafter, wild turkey (Meleagris gallopavo silvestris), has been widely studied across its range (Brown 1980), but is lacking in West Virginia. Brown (1980) concluded that, although the home range of male wild turkeys has 
been widely studied over many geographic regions, the variability in the results of home range studies makes it necessary to develop management plans from specific regional studies. Some of this variability can be attributed to the differing habitats that wild turkeys inhabit across their range, but compounding the variability of home range studies are the many methods of home range estimation used (Brown 1980, Godwin et al. 1995, Miller et al. 1997). Two commonly used home range estimators are the minimum convex polygon (MCP) and kernel density estimation (KDE) (Downs and Horner 2007). The MCP method was first used by Mohr (1947) and despite criticism (Worton 1987, 1989, 1995, Boulanger and White 1990) remains used because it is rather simple to construct (Downs and Horner 2007). First introduced by Worton (1989) the KDE is the most widely accepted method of home range estimation (Kernohan et al. 2001). The KDE corresponds to an animal's utilization distribution (UD; Worton 1987, Kernohan et al. 2001) by estimating a probability density function (Gitzen et al. 2006).

Because of the variability seen in wild turkey home range studies, it is important to understand the home range size of male wild turkeys in West Virginia to assist in making proper management decisions for the resource. Therefore, our objectives were to: 1 ) estimate the annual and seasonal home range size of adult and juvenile male wild turkey by both the fixed kernel density estimation with least-squares cross-validation for bandwidth selection and by the minimum convex polygon method; 2) examine a relation between male wild turkey home range size and mast conditions, male wild turkey population size and fate; and 3) compare our results with a recent female wild turkey home range study in West Virginia.

\section{STUDY AREA}

We conducted our research on 2 study sites in West Virginia: Statewide and District 1 (Fig. 1). West Virginia was classified into 3 physiographic provinces: Western Hill Section, Allegheny 
Mountain and Upland Section, and Eastern Ridge and Valley Section (Strausbaugh and Core 1978). The Western Hill Section, located from the Ohio River to the mountainous area, was comprised of the Central Hardwood Forest, in which the forest vegetation associations ranged from Oak-Pine (Quercus spp.-Pinus spp.) and Oak-Hickory (Carya spp.) communities (xeric) through Cove Hardwoods or Mixed Mesophytic Forests (mesic) to Flood Plain communities (hydric). The Allegheny Mountain and Upland Section contains the highest elevations of the state and was comprised of Northern Hardwood Forest, which was dominated by sugar maple (Acer saccharum), American beech (Fagus grandifolia), and yellow birch (Betula alleghaniensis), and in the highest elevations of this section by red spruce (Picea rubens). The Eastern Ridge and Valley Section in the Eastern Panhandle was characterized by oak-hickorypine forest vegetation. Elevations in West Virginia vary from 73 - 1,524 m (Strausbaugh and Core 1978). Because of West Virginia’s mountainous terrain, variable habitat factors affect directly or indirectly annual mast conditions and game harvest, as well as the distribution of vegetation. For these reasons, the state of West Virginia has been divided into 6 ecological regions (Uhlig and Wilson 1952) to facilitate effective management of wildlife species. An understanding of the effect on home range size estimates from the structure and composition of cover types in the landscape is important in making sound management decisions for the wild turkey resource in West Virginia.

The District I study area (DISA) was located in Harrison, Marion, and Taylor counties of north-central West Virginia. Topography of the DISA was described as having mountain ranges oriented in a northeast-southwest direction with steep to very steep hillsides and narrow valleys and floodplains (Beverage and Yoakum 1980, Wright et al. 1982). The 3-county area averaged $59.5 \%$ forested with $62.2 \%$ of the forestland comprised of oak/hickory (Griffith and Widmann 
2003). All 3 counties were located in the Central Allegheny Plateau and ecological region 4 (Central). Male wild turkeys in the DISA were also included in the statewide analysis of home range.

\section{METHODS}

Trapping and Telemetry

We trapped wild turkeys at 29 sites baited with cracked/whole corn during September-November and January-March of 2004-2007 by the use of rocket nets and/or rocket boxes (Kurzejeski and Vangilder 1992). We aged (adult or juvenile) and sexed each wild turkey by use of feather coloration as described by Pelham and Dickson (1992). Juvenile birds were aged and sexed as described by Healy and Nenno (1980), while yearling wild turkeys (12-16 months) caught in early September were aged by the tenth primary feather (Larson and Taber 1980). We weighed all wild turkeys with spring scales, recorded mass and fitted each wild turkey with a uniquely numbered aluminum leg band. We recorded physical condition for each wild turkey and only male wild turkeys with a mass $\geq 1.6 \mathrm{~kg}$ and having a physical condition of good (minor feather loss, minor scalping) or excellent (no feather loss, no injuries) were considered for radioing. We released captured wild turkeys at the trap site and trapping locations were recorded in Universal Transverse Mercator (UTM) coordinates.

We fitted male wild turkey with backpack style transmitters (Advanced Telemetry Systems Inc. (ATS) Isanti, MN) weighing about $80 \mathrm{~g}$, with a harness made from $4.8 \mathrm{~mm}$ nylon shock cord (Norman et al. 1997). Transmitter frequencies operated between 150 and $152 \mathrm{MHz}$ and each transmitter contained a motion-mortality sensor. We located radioed wild turkeys a minimum of once per week by triangulation (Cochran and Lord 1963) with at least 2 directional 
azimuths being used to obtain a location (Andelt and Gipson 1979, Nams and Boutin 1991, Wallingford and Lancia 1991, Zielinski et al. 2004). If only 2 intersecting directional azimuths were taken, we only used locations generated from azimuths separated by $\geq 60^{\circ}$ and $\leq 120^{\circ}$ (Kurzejeski and Lewis 1990, Sisson and Speake 1994, Miller et al. 2001). We only used locations generated by $\geq 2$ azimuths collected $\leq 20$ minutes apart for analysis. Moreover, we located radioed wild turkeys at least twice weekly during peak hunting pressure days, which included the first week of squirrel (Sciurus spp.), white-tailed deer (Odocoileus virginianus) (archery, buck-only firearms, antlerless, and muzzleloader), and spring and fall wild turkey hunting seasons. We estimated telemetry error by placing transmitters on $2.0 \mathrm{~L}$ bottles, filled with a saline solution, in forests at an average height of a male wild turkey $(46 \mathrm{~cm}$ : Townsend et al. 2007). We estimated a telemetry error of $6^{\circ}(\mathrm{SE}=0.84)$ with a mean distance from transmitter location to receiving location of $458.9 \mathrm{~m}(\mathrm{SE}=59.12)(\mathrm{N}=18$ : White and Garrott 1990). We used program LOCATE III (Pacer Computing, Truro, NS, Canada) to measure a 95\% confidence ellipse of 7.7 ha $(\mathrm{SD}=8.9)$ associated with the telemetry error (White and Garrott 1990, Saltz 1994). We only included male wild turkeys with a minimum of 30 locations (Seaman et al. 1999) in home range estimation. We used spatial autocorrelation, in ArcMap 9.2 (Environmental Systems Research Institute, Inc. (ESRI) Redlands, CA), on the mean centers of the UTM coordinates for each radioed male wild turkey to determine spatial distribution. Statewide, juvenile males were distributed randomly across the state (Morans I Index $=0.36, z$ score $=0.91 \mathrm{SD}$ ), while adults were clustered (significant at $\alpha=0.05$, Morans I Index $=0.65, z$ score $=2.34 \mathrm{SD}$ ). Conversely, in the DISA, juvenile males were clustered (significant at $\alpha=$ 0.01, Morans I Index $=1.17, \mathrm{z}$ score $=2.69 \mathrm{SD}$ ), while adult males were randomly located 
(Morans I Index $=0.27, z$ score $=1.18$ SD). Randomly located mean centers were considered to be uncorrelated, which strengthens statistical testing.

We classified male wild turkeys trapped during the fall or winter seasons as juveniles through the following August (Norman et al. 2004). Adults included male wild turkeys trapped as adults and individuals trapped as juveniles once they reached their second September. We analyzed male wild turkeys that entered the study as juveniles and survived to adults within their respective age classes. Telemetry data for each male wild turkey were pooled across years. A cause of death was determined from all recovered dead male wild turkeys and placed in the following categories of fate: legal harvest, illegal harvest, depredated, or other (disease, accidental). We classified all living radioed male wild turkey at the end of study and juvenile that survived to the adult age class as alive for home range size and fate relation analysis.

We estimated home ranges by age class (juvenile and adult) at the following temporal scales: total annual (all locations for a given bird), annual spring-summer (using locations from March - August for a given bird), annual fall - winter (using locations from September February for a given bird), and seasonal. We defined seasons as spring (March - May), fall (September - November), and winter (December - February) (Kelley et al. 1988, Fearer and Pack 2003). Only male wild turkeys with a $\geq 9$ month period of locations available were used in annual home range size estimation (Wigley et al. 1986). We used locations from September February (fall - winter) to estimate the effects of mast conditions on the home range size.

We computed 95\% and 50\% fixed-kernel (Worton 1989) utilization distributions (UD) for the adult and juvenile male wild turkey annual home range and 95\% fixed-kernel UD seasonal home range. The 50\% UD was computed to provide a nonstatistical size estimate of 
internal use of annual home range. We used the least square cross validation method, in the Animal Movement Extension (Hooge et al. 1999) in ArcView GIS 3.3 (Environmental Systems Research Institute, Inc (ESRI)), to calculate the bandwidth value - smoothing factor (h) (Seaman and Powell 1996, Seaman et al. 1999). Additionally, we used the MCP method to estimate annual and seasonal home range size. We used the Animal Movement Extension in ArcView GIS 3.3 to delineate the $95 \%$ and 50\% KDE contours and the MCP contour.

Mast Index and Data Analysis

Since 1970 in West Virginia, mast conditions have been monitored and indexed annually in August (Evans et al. 2008) by Division of Natural Resources personnel, Division of Forestry personnel, and volunteers. Each surveyor conducts a survey at the same high elevation site and low elevation site each year and records; county, date, elevation, aspect, and location. Each surveyor rates the available mast as abundant (above normal), common (normal), or scarce (below normal) (Uhlig and Wilson 1952, Ryan et al. 2004). A mast index for each species was calculated by adding the percentage of surveyors rating mast as abundant (value of 1) and the percentage rating mast as common (value of 0.5 ) by the following formula:

Mast Index $=$ [abundant observations/total observations $]+$

$$
\text { [common observations } \times 0.5 / \text { total observations] } \times 100 \text {, }
$$

while a rating of scarce was given a zero value (Uhlig and Wilson 1952, Ryan et al. 2004, Evans et al. 2008).

Hard-mast included the following species: American beech (Fagus grandifolia), red oak (Q. rubra), white oak (Q. alba), black oak (Q. velutina), chestnut oak (Q. prinus), scarlet oak ( $Q$. coccinea), and scrub oak (Q. ilicifolia), while soft-mast included: black cherry (Prunus serotina), 
grapes (Vitis spp.), hawthorn (Crataegus spp.), crabapple (Malus spp.), flowering dogwood (Cornus florida), greenbrier (Smilax spp.), blackberry (Rubus spp.), yellow poplar (Liriodendron tulipifera), and sassafras (Sassafras albidum). We calculated an annual mast index for soft mast species, hard-mast species and hard-mast + black cherry from 2004-2006 from data collected in the annual mast surveys for each of the 6 ecological regions. Additionally, we calculated a total mast index for each ecological region as well as a statewide total index.

Since 1983, the West Virginia Division of Natural Resources (Wildlife Resources Section) (WVDNR-WRS) has conducted an annual Spring Gobbler Survey in West Virginia (Evans et al. 2007). Cooperators for the survey record daily observations and biological data from harvested male wild turkeys. We used harvest figures and spur lengths for age of spring harvested male wild turkeys, from the Spring Gobbler Survey, as a sample of age classes to calculate a Downing Population Reconstruction (Downing 1980) estimate of male wild turkeys in West Virginia.

We used program LOCATE III to generate UTM coordinates (X and Y coordinates) of the locations from the telemetry data. The Shapiro-Wilk test of normality was performed on the fixed-kernel 95\% UD home range size results and we found the adult results were non-normal ( $\mathrm{w}$ $=0.786, P \leq 0.001)$, while the juvenile results were normal $(\mathrm{w}=0.957, P=0.28)$. Because normality assumptions were violated for the adult age class, we used the Wilcoxon signed rank test as a nonparametric equivalent to a $t$-test. The Kruskal-Wallis test was used as a nonparametric equivalent of ANOVA. We used linear regression to compare effects of mast conditions, fate, and male wild turkey densities on home range size. Independent variables for mast condition modeling included: year, region, age, hard-mast, soft-mast, hard-mast plus black cherry, total mast per region per year, and total mast statewide per year. We used the following 
independent variables to model fate: age, legally harvested, illegally killed, depredated, other (accident, disease), or alive at end of study. We classified juvenile male wild turkeys as alive for fate analysis if they survived through their second August. We performed the Shapiro-Wilk test of normality and graphical examination on the residuals in each linear regression model to test the normality assumption. We used Kruskal-Wallis test and multiple comparisons to test difference of home range size among seasons. We used the statistical package $\mathrm{R}$ (R Foundation for Statistical Computing, Vienna Austria, http://www.R-project.org) for all statistical analysis. Significance levels were set at $\alpha=0.05$ for all statistical tests.

\section{RESULTS}

In West Virginia from September 2004 through August 2007, a total of 197 male wild turkeys (32 in the DISA) were radioed (representing all 6 ecological regions). From these, we used 55 male wild turkeys (22 in the DISA) in the statewide analysis of home range size (Appendix A and Appendix B). These included 29 juveniles (11 of which were also included in the adult analysis) and 37 adults from ecological regions 1-4 and 6. We found no difference (KruskalWallis one-way ANOVA; $\chi^{2}{ }_{1,65}=0.78, P=0.38$ ) between age class for the statewide annual 95\% UD home range, but juveniles have a larger annual 50\% UD home range than adults $\left(\chi_{1,65}^{2}\right.$ = 3.93, $P=0.047$ ) (Table 1; also see Appendix C for descriptive statistics). We found no difference between the adult and juvenile $95 \%\left(\chi_{1,27}^{2}=0.27, P=0.61\right)$ or the $50 \%\left(\chi_{1,27}^{2}=0.14\right.$, $P=0.71)$ UD fixed-kernel annual home ranges in the DISA. No difference was detected between the adult $\left(\chi_{1,36}^{2}=0.03, P=0.87\right)$ and juvenile 95\% UD $\left(\chi_{1,28}^{2}=0.03, P=0.80\right)$ nor the adult $\left(\chi^{2}\right.$ $1,36=0.11, P=0.75)$ and juvenile $50 \% \operatorname{UD}\left(\chi_{1,28}^{2}=0.11, P=0.39\right)$ fixed-kernel home range and the fall hunt and non-fall hunt counties. Additionally, we found not difference between the age 
classes for the statewide $\left(\chi_{1,65}^{2}=0.39, P=0.53\right)$ nor the DISA $\left(\chi_{1,27}^{2}=2.56, P=0.11\right)$ annual MCP home ranges.

Because we detected no difference between adult and juvenile 95\% UD annual home range size, we pooled age classes to test for a difference in the 95\% UD annual home range size between ecological regions. We did not use ecological region 5 because of a lack of data. Male wild turkey 95\% UD annual home range size had a marginally significant difference among 5 ecological regions (regions $1-4$, and 6$)$ in West Virginia $\left(\chi_{4,65}^{2}=9.12, P=0.058\right)$. Male wild turkey in ecological region 3 (Southern) had a smaller mean home range (311.2 ha, SD = 79.2) than in the other regions (based on 95\% confidence intervals, Fig. 2a) (Table 1). Because of the difference in age classes for the 50\% UD annual home range, we did not pool age classes to test for a difference between ecological regions. We detected a difference in adult male wild turkey $50 \%$ UD home range size $\left(\chi_{3,34}^{2}=9.22, P=0.03\right)$ among 4 ecological regions in West Virginia. We omitted region 1 (Eastern Panhandle) from analysis due to insufficient sample size. Adult 50\% UD home range size was smaller in ecological region 3 (Southern) than in ecological region 4 (Central) (based on 95\% confidence intervals, Fig. 2b). For juvenile male wild turkey, we omitted ecological regions 1 (Eastern Panhandle), 3 (Southern), and 6 (Southwestern) due to small sample size and, although not significant $\left(\chi_{1,25}^{2}=1.48, P=0.22\right)$, based on $95 \%$ confidence intervals, juveniles in ecological region 2 (Mountains) had a smaller 50\% UD home range than juveniles in ecological region 4 (Central) (see Fig. 2b).

We found no difference (W $\geq 37, P \geq 0.26$ ) between adult statewide 95\% UD fixedkernel home range size among seasons (Table1). Adult seasonal home range size did not differ between seasons ( $\mathrm{W} \geq 8, P \geq 0.16$ ) in the DISA. Moreover, we found no difference $\left(\chi_{1,17}^{2}=\right.$ 1.50, $P=0.22$ ) between the DISA spring fixed-kernel home range size of adult and juvenile male 
wild turkey, but adults had a larger spring-summer home range $\left(\chi_{1,16}^{2}=7.47, P=0.006\right)$ than did juveniles in the DISA.

Because we found no difference between 95\% UD home range size, we pooled age classes to test for a relation to mast conditions. We used 39 (10 - juvenile, 29 - adult) male wild turkey from ecological regions 2, 4, and 6 to model for a relation between home range size and annual mast conditions. We removed the variables total mast by region, total mast statewide, and hard mast + cherry because of collinearity with the variable year. Our initial linear model did not meet the assumption of normality for the residuals, thus we removed 3 outliers (all adults) from the analysis to normalize the residuals $(\mathrm{W}=0.95, P=0.11)$. Our linear regression model was significant $\left(F_{6,29}=3.20, P=0.02\right)$ with no independent variables being significant after accounting for the effects of the other independent variables in the model. We used stepwise regression and detected a relation $\left(F_{3,32}=5.81, P=0.003\right)$ between home range and both hard mast and soft mast (Table 2). Home range size for the 2006-2007 fall/winter period was smaller (423.6 ha, SD = 179.9: marginally significant with 2005-2006 [W=111, $P=0.06]$ ) than the 2004-2005 (793.0 ha, SD = 536.8) and 2005-2006 (643.6 ha, SD = 349.8) periods and the 20062007 period had the highest mast index of all years (Table 3).

We pooled male wild turkey age classes and found a significant difference $\left(\chi_{2,59}^{2}=6.83\right.$, $P=0.03$ ) in mean annual home range size among years with the average 2007 home range (414.9, SD = 153.5) smaller than in 2005 (809.9 ha, SD = 458.8). Home range size in 2006 averaged 610.7 ha $(S D=423.3)$. To test for a relation between home range size and male wild turkey population estimates we used 55 (11 - juvenile, 44 - adult) wild turkey (Table 4). Our initial model did not meet the normality assumption for the residuals. We were able to meet this assumption $(\mathrm{W}=0.98, P=0.56)$ through 2 iterations of removing outliers ( 6 adults). We 
removed the age and region variables from the model because of no relation to population estimates and found a relation $\left(F_{3,45}=13.62, P<0.001\right)$ between year (2007: marginally significant, $P=0.05$ among years) and male wild turkey population estimate (Table 5). The population estimate accounted for about half $\left(\mathrm{R}^{2}=0.48\right)$ of the variability observed in annual home range size.

We used 66 (29 - juvenile, 37 - adult) male wild turkey (pooled age classes) to test for a relation between home range size and the fate of the bird. We were again required to remove the outliers $(1$ - juvenile, 2 - adult) to meet the normality assumption for residuals $(\mathrm{W}=0.97, P=$ 0.10). Linear regression results estimated a relation between home range and legally harvested male wild turkey $\left(F_{4,58}=2.79, P=0.03\right)$ (Table 6). Post hoc tests confirmed that legally harvested male wild turkey had a smaller mean home range (404.1 ha, SD = 193.6) than male wild turkey that were depredated (892.3 ha, SD = 446.8), died from other causes (867.3 ha, SD = 499.3), or were alive at the end of the study (822.2 ha, $\mathrm{SD}=447.7)(\mathrm{W} \leq 64, P \leq 0.03)$. Illegally killed male wild turkey had an average home range size of 470.3 ha $(\mathrm{SD}=102.8)$, but no comparisons could be made because of a small sample size $(n=2)$. The average monitoring period for each fate class was: harvested - 439.0 days, depredated -477.9 days, other causes 472.3 days, alive - 501.2 days, and illegal - 514.5 days.

\section{DISCUSSION}

Our results show the variation seen from 2 different home range estimation methods on both annual and seasonal home range of male wild turkey. We agree with Brown (1980) and Kelley et al. (1988) that high variation is seen in wild turkey home range studies and thus it is important to make management decisions based on regional home range estimates. These variations may be attributed to several factors, including study length, sample size, improved transmitters for 
longer monitoring (Kelley et al. 1988), as well as habitat quality (Everett et al. 1979). Moreover, home range estimation methods can add to the variations seen in home range sizes (Brown 1980, Laver and Kelly 2008).

Our home range estimates fell within the reported male wild turkey home range of various studies, but direct comparisons are difficult because several studies pooled the adult and juvenile male wild turkey and the varied home range estimation methods used. Our annual as well as seasonal home ranges were larger than those reported in Kentucky (annual - 476 ha, spring - 239 ha, fall - 197 ha, winter - 413 ha: minimum area method (MAM), Carroll 1982) and Alabama (annual - 398.4 ha, spring - 204.5 ha, fall - 170.9 ha, winter - 270.4 ha: (MAM) Barwick and Speake 1973) from pooled age classes. Everett et al. (1979) estimated an annual home range (pooled age classes, MAM) of 1,661 ha, which was twice the size of our statewide annual home range. Ellis and Lewis (1967) found 4 adult male wild turkeys had a mean annual home range (MAM) of 445.3, which was about half the size of our statewide results and near a third the size of the DISA adults. In Louisiana, Smith et al. (1988) reported adult MCP annual home ranges (1,473.0 ha) that were larger than our results, while they reported juvenile annual home ranges (360.2 ha) that were smaller than our results. We found that the winter home range of adult wild turkeys in our study was about twice the size of the 276.5 ha winter home range (MAM) reported in Michigan (Lewis 1963).

Some of the largest male wild turkey home ranges have been reported from Mississippi. Kelley et al. (1988) estimated adult annual home range (1,418 ha, convex polygon method [CPM]) larger than our results from both study areas and Godwin et al. (1995) reported annual adult home range (1,941 ha, MCP) that is more than 2 times our reported home range. Additionally, Kelley et al. (1988) reported an annual juvenile home range (2,204 ha) that was 
about 2.5 times larger than our results. Similarly, both authors reported spring home ranges sizes for adult and juvenile male wild turkey that were about 2.5 times larger than our results and Godwin et al. (1995) reported a fall-winter home range (1,134 ha) that was about twice the size we reported. Miller et al. (1997) reported adult and juvenile spring home ranges about 1.5 times larger and fall-winter home ranges similar to our results (CPM).

As has been reported in other research (Brown 1980, Kelley et al. 1988, Miller et al. 1997, Fearer and Pack 2003), our results show a wide variation in wild turkey home range size among individuals, which decreased power. Factors such as localized habitat quality differences (Exum et al. 1987, Godwin et al. 1995) and individual behavior (Miller et al. 1997) may contribute to the observed variation. Smaller male wild turkey home ranges have been reported from areas with a large portion being open/pasture lands (Barwick and Speake 1973, Fleming and Webb 1974, Smith et al. 1988, Hurst et al. 1991), while larger home ranges have been reported in areas dominated by forests with few fields (Wigley et al. 1986, Kelley et al. 1988, Hurst et al. 1991, Miller et al. 1997).

We observed differences in home range size among the ecological regions of West Virginia, although sample sizes were small or insufficient for analysis and thus probably weakened significance testing. We suspect that habitat differences were the most likely variable causing the observed variation in home range size among the ecological regions. The movement and home range size of an animal can be influenced by cover type structure within that landscape (Forman 1995) and the effects of landscape composition of cover types and structure on home range size has been documented in wild turkeys (Miller et al. 1999). Fearer and Pack (2003) observed differences among ecological regions in West Virginia and female wild turkey home range size with ecological region 3 (Southern) having the smallest home range size, which was 
similar to our results. Also, they found that females tended to have larger home ranges in ecological regions 1 (Eastern Panhandle) and 2 (Mountains), which our data showed similar trends. These regions of the state are more mountainous and characterized by more contiguous forest cover and thus differing cover types tend to be more scattered than other regions of the state. Additionally, Godwin et al. (1995) suspected low quality turkey habitat (contiguous forest) in their study area explained the observed larger home ranges of their results from other studies. We suspect the variation in 50\% UD home range size was a function of habitat variation also. The lack of uniform use of areas within a male wild turkeys home range has been suggested (Godwin et al. 1995). Habitat analysis is needed to further examine the relations with ecological region and home range size of male wild turkeys in West Virginia.

Mast abundance and distribution influence home range characteristics of wild turkey (Burhans et al. 2000). When mast is abundant, it is not necessary for wild turkey to move as much to find food and subsequently they have smaller home ranges (Kelley et al. 1988), but when mast is poor, wild turkey move more in search of food (Kurzejseki and Lewis 1990, Healy 1992), although Everett et al. (1979) found winter home ranges to be larger in mature hardwood forests in Alabama during years with abundant acorn crops. Correlations with wild turkey fall and/or winter home range size and mast conditions have been documented (Badyaev et al. 1996b, Steffen et al. 2002). Fearer and Pack (2003) found significant variation between years for fall-winter home range size for female wild turkey in West Virginia and suggested that mast production had an effect on the female home range size. Our results tend to support this also, although we believe that because of the lack of mast condition variability that can be seen from year to year, longer duration studies are warranted to examine the relation between mast conditions and home range size. For example, Ryan et al. (2004) found that hard mast + black 
cherry had the strongest negative correlation with wild turkey harvest in West Virginia and evidence suggests that greater wild turkey harvests occur during years of poor mast conditions (Menzel 1975, Pack 1994), because home ranges are larger under those mast conditions. We were unable to detect whether a relation exists or not because there was little variability in the hard mast + black cherry mast index variable during the 3 years of this study (Table 3). Additionally, we were only able to examine 3 of the 6 ecological regions (Mountains, Central, and Southwestern) of West Virginia because of insufficient sample sizes from the remainder of regions (Eastern Panhandle, Southern, and Western).

Our results detected a marginally significant relation between home range size and male wild turkey population size. Age status of male wild turkey has potential effects on dispersal and movement patterns, especially during the breeding period (Badyaev et al. 1996a). Their results showed that younger, especially the lighter body massed males, dispersed farther distances than did older adults. Smith et al. (1988) found that much of the observed difference in movement and home range size of male wild turkey age classes was related to dispersal of juveniles. In Alabama, Davis (1973) suspected that turkey population levels had a strong influence on spring dispersal. Because of social status, younger males are subordinate to older males (Healy 1992). Annual fluctuations in wild turkey nesting success create "pulses" in the cohorts across time. These "pulses" may lead to changes in home range size because of the influence in social status of male wild turkeys. In Mississippi, Godwin et al. (1995) did not detect a significant relation between estimated male wild turkey density and home range size, although they stated that their power of correlation analysis was limited by sample size (i.e., 4 study years). We suspect that our 3 study years also had an effect on the power of our correlation analysis. 
Our study did not include habitat analysis in relation to home range size, but the function of habitat diversity and male wild turkey population densities may be associated with home range size. Kelley et al. (1988) speculated that high turkey population densities and small home ranges may be associated with diverse habitats. A study area in Missouri contained about a 50/50 ratio of forest and open lands with a high turkey population and annual male wild turkey home range was 446 ha (Ellis and Lewis 1967). Large home ranges have been associated with low population densities in mostly forested areas (Wigley et al. 1986, Exum et al. 1987, Kelley et al. 1988). We did not adequately explain the relation between population size and home range on male wild turkey in West Virginia, because of various factors that have been shown to affect home range size, including habitat quality (Everett et al. 1979, Godwin et al. 1995), habitat diversity (Kelley et al. 1988), individual behavior (Miller et al. 1997), and female movement (Hurst et al. 1991).

Our results suggest that legally harvested male wild turkey have a smaller home range size than do birds that survived during the study period or were killed by depredation or other mortality factors. Male wild turkey having smaller home ranges may be easier for hunters to pattern making them more vulnerable to harvest. We did not incorporate hunting pressure into this study, but others have concluded that hunting pressure did not have a significant effect on wild turkey movement (Everett et al. 1978, Williams et al. 1978, Godwin et al. 1990).

Additionally, male wild turkey use of fields in the spring has been reported (Barwick and Speake 1973, Everett et al. 1985, Exum et al. 1987). Both rifles and shotguns are legal firearms during the spring wild turkey season in West Virginia. The vulnerability of male wild turkeys to being harvested may be increased by using fields during the spring hunting season, because of the increase visibility to hunters. 
From 1989 to 1994, the West Virginia Division of Natural Resources and the Virginia Department of Game and Inland Fisheries conducted a study estimating survival and recruitment rates of female wild turkeys (see Pack et al. 1999, Norman et al. 2001). Telemetry data from this study was used by Fearer and Pack (2003) to estimate annual and seasonal home range size of 315 female wild turkeys from West Virginia by the adaptive kernel method of home range estimation. Our annual statewide adult home range estimate for male wild turkey was less than half the size of the 1,823 ha $(n=189, \mathrm{SD}=2,356)$ mean annual adult female home range and juvenile females had a mean annual home range $(5,296$ ha, $n=126$, SD $=7,897) 6$ times larger than our juvenile male wild turkey results. Moreover, Fearer and Pack (2003) estimated adult female spring $(n=152)$ and winter $(n=114)$ mean home ranges (994 ha and 847 ha, respectively) to be approximately twice the size of our male wild turkey spring and winter estimates and a mean fall $(n=150)$ home range of 1,578 ha, which was about 3 times larger than our results.

Several studies have reported larger home ranges for male than female wild turkey (Lewis 1963, Ellis and Lewis 1967, Davis 1973, Porter 1977, Miller et al. 1997), which was opposite from our results compared to the female home range results of Fearer and Pack (2003). Fearer and Pack (2003) did caution that the small sample sizes, especially seasonal, may have artificially inflated the female home range sizes they observed, which was a similar situation we experienced. Moreover, temporal changes in habitat composition and structure between the study periods may have biased making home range size comparisons. Female wild turkeys were reported to have a larger spring-summer home range (425 ha) than did males (350 ha) in Alabama (Speake et al. 1975) and in southeastern Louisiana, Smith et al. (1988) found that the male fall and winter home range (126.0 ha and 158.3 ha, respectively) were smaller than female 
fall and winter home range (302.3 ha and 254.0 ha, respectively). They speculated that, except for breeding activities, male and female eastern wild turkeys remain separated to reduce possible competition or predation. In southwestern New York, Eaton et al. (1976) found female wild turkey moved farther than males, with spring movements accounting for the increased size.

\section{Management Implications}

The variability of male wild turkey home range estimates across its range makes it important to make management decisions based on regional studies (Brown 1980) and our results provide male wild turkey home range size estimates to help meet the needs in making sound resource management decisions. We observed differences in male wild turkey home range size across the ecologically different regions of West Virginia. Landscape scale habitat configuration affects wild turkey movements and home range size (Miller et al. 1999), and accordingly resource managers should shape habitat management projects to the structure and composition of the cover types in the landscape. Mast conditions influence wild turkey home range (Burhans et al. 2000) and male wild turkey home range size is smaller during high mast conditions in West Virginia. The development of wild turkey management plans should provide a diversity of food sources while considering the greater movements required by wild turkey during years with poor mast conditions.

Legally harvested male wild turkey had smaller home ranges than the other male wild turkey during this study. Male wild turkey legal spring harvest rates have varied from $15 \%$ to 51\% across their range (Vangilder 1992) and have been estimated to be $16.5 \%$ in West Virginia (West Virginia Division of Natural Resources 2009). With the increasing development of homes, roads, and other developed properties, habitat fragmentation has resulted, which tends to increase boundaries thus restricting movement of birds and impacting mobility throughout their habitat 
(Forman 1995). Resource managers should consider this in developing harvest management plans, especially in areas with increasing habitat fragmentation.

Knowledge of habitat use patterns is important in better understanding population dynamics of male wild turkey. Without this knowledge, home range size provides limited information (Miller et al. 1997). Understandings of the effects on home range size from a diverse habitat or a mostly forested habitat will provide information in implementing habitat management plans. Future research should include habitat quality and diversity analysis to help better understand the influences habitat has on male wild turkey home range estimates. Increasing the length of study periods will help better understand the relation between home range size and male wild turkey population estimates (Godwin et al. 1995) as well as effects from annual mast conditions. Additionally, we recommend that male wild turkey movement/dispersal patterns and core-use analysis be included in future research. Dispersal distance and movement patterns may be important variables to survival and reproduction (Badyaev et al. 1996b), as well as accessing basic requirements (Exum et al. 1987). Statistical analysis of internal home range structure (core-use areas) would provide details on preference to areas within a home range (Godwin et al. 1995).

\section{Acknowledgments}

Data for this study were collected in conjunction with the Mid-Atlantic Gobbler Study (MAGS), a joint effort between the West Virginia Division of Natural Resources (Wildlife Resources Section) (WVDNR-WRS), the Virginia Department of Game and Inland Fisheries, and the West Virginia State Chapter of the National Wild Turkey Federation. Funding for the MAGS, in part, was provided by the WVDNR-WRS and the Federal Aid in Wildlife Restoration Grant W-48-R. We thank the West Virginia Chapter of The National Wild Turkey Federation for the funding of 
the transmitters used in the MAGS. We are grateful to J. Edwards for reviewing this manuscript and J. Evans (retired) for providing the Downing Population Reconstruction estimates of male wild turkeys and for reviewing this manuscript. Special thanks go to G. Foster and M. Peters for the extra effort they put into tracking the wild turkeys from the DISA used in this analysis. This manuscript is scientific article number $\mathrm{xxxx}$ of the West Virginia University Agriculture and Forestry Experiment Station.

\section{LITERATURE CITED}

Andelt, W. F., and P. S. Gipson. 1979. Home range, activity, and daily movements of coyotes. Journal of Wildlife Management 43:944-951.

Badyaev, A. V., W. J. Etges, and T. E. Martin. 1996a. Age-biased spring dispersal in male wild turkeys. Auk 113:240-242. , and . 1996b. Ecological and behavioral correlates of variation in seasonal home ranges of wild turkey. Journal of Wildlife Management 60:154-164.

Barwick, L. H., and D. W. Speake. 1973. Seasonal movements and activities of wild turkey gobblers in Alabama. Pages 125-133 in G. C. Sanderson and H. C. Shultz, editors. Wild turkey management: current problems and programs. Proceedings of the Second National Wild Turkey Symposium. Missouri Chapter of the Wildlife Society and University of Missouri Press, Columbia, Missouri, USA.

Beverage, W. W., and T. D. Yoakum. 1980. Soil survey of Harrison and Taylor Counties, West Virginia. U.S. Department of Agriculture, Soil Conservation Service, Washington, D. C., USA. 
Boulanger, J. G., and G. C. White. 1990. A comparison of home-range estimators using Monte Carlo simulation. Journal of Wildlife Management 54:310-315.

Brown, E. K. 1980. Home range and movements of wild turkeys - a review. Pages 251-261 in J. M. Sweeny, editor. Proceedings of the Fourth National Wild Turkey Symposium. National Wild Turkey Federation, Edgefield, South Carolina, USA.

Burhans, B. J., D. Harmen, and G. W. Norman. 2000. Influence of landscape characteristics on the winter home range dynamics of wild turkeys in western Virginia. Proceedings of the Annual Northeast Fish and Wildlife Conference 56:3.

Carroll, J. P. 1982. Dispersal, home range and habitat use of translocated eastern wild turkeys (Meleagris gallopavo sylvestris) in Jackson County, Kentucky. Thesis, Eastern Kentucky University, Richmond, Kentucky, USA.

Cochran, W. W., and R. D. Lord. 1963. A radio-tracking system for wild animals. Journal of Wildlife Management 27:9-24.

Davis, J. R. 1973. Movements of wild turkeys in southwestern Alabama. Pages 135-140 in G. C. Sanderson and H. C. Shultz, editors. Wild turkey management: current problems and programs. Proceedings of the Second National Wild Turkey Symposium. Missouri Chapter of the Wildlife Society and University of Missouri Press, Columbia, Missouri, USA.

Downing, R. L. 1980. Vital statistics of animal populations. Pages 247-267 in S. D. Schemnitz, ed. Wildlife Techniques Manual. The Wildlife Society, Washington, D. C., USA. 
Downs, J. A., and M. W. Horner 2007. Effects of point pattern shape on home-range estimates. Journal of Wildlife Management 72:1813-1818.

Eaton, S. W., F. M. Evans, J. W. Glidden, and B. D. Penrod. 1976. Annual range of wild turkeys in southwestern New York. New York Fish and Game Journal 23:20-33.

Ellis, J. E., and J. B. Lewis. 1967. Mobility and annual range of wild turkeys in Missouri. Journal of Wildlife Management 31:568-581.

Evans, J. E., J. C. Pack, W. K. Igo, R. L. Tucker, G. H. Sharp, D. Vandevander, and C. P. Carpenter. 2007. 2007 Spring gobbler survey. West Virginia Division of Natural Resources, Wildlife Resources Section and West Virginia Chapter of the National Wild Turkey Federation, Wildlife Resources Section Bulletin 08-02, Charleston, West Virginia, USA.

, R. L. Tucker, E. Richmond, and W. K. Igo. 2008. West Virginia mast survey and hunting outlook. West Virginia Division of Natural Resources, Wildlife Resources Bulletin 08-5, Charleston, West Virginia, USA.

Everett, D. D., D. W. Speake, W. K. Maddox, D. R. Hillestad, and D. N. Nelson. 1978. Impact of managed public hunting on wild turkeys in Alabama. Proceeding of the Annual Conference Southeastern Association of Fish and Wildlife Agencies 32:116-125. and 1979. Wild turkey ranges in Alabama mountain

habitat. Proceeding of the Annual Conference Southeastern Association of Fish and Wildlife Agencies 33:233-238. 
and 1985. Habitat use by wild turkeys in northern

Alabama. Proceeding of the Annual Conference Southeastern Association of Fish and Wildlife Agencies 39:479-488.

Exum, J. H., J. A. McGlincy, D. W. Speake, J. L. Buckner, and F. M. Stanley. 1987. Ecology of the eastern wild turkey in an intensively manage pine forest in southern Alabama. Tall Timbers Research Station Bulletin 23. Tallahassee, Florida, USA.

Fearer, T. M., and J. C. Pack. 2003. Home range characteristics of female wild turkeys in West Virginia. West Virginia Division of Natural Resources PR Report. Charleston, West Virginia, USA.

Fleming, W. H., and L. G. Webb. 1974. Home range, dispersal and habitat utilization of eastern wild turkey gobblers during the breeding season. Proceeding of the Annual Conference Southeastern Association of Fish and Wildlife Agencies 28:623-632.

Forman, R. T. T. 1995. Land mosaics: the ecology of landscapes and regions. Cambridge University Press, Cambridge, UK.

Gitzen, R. A., J. J. Millspaugh, and B. J. Kernohan. 2006. Bandwidth selection for fixed-kernel analysis of animal utilization distributions. Journal of Wildlife Management 70:11341344.

Godwin, K. D., W. E. Palmer, G. A. Hurst, and R. L. Kelly. 1990. Relationship of wild turkey gobbler movements and harvest rates to management area boundaries. Proceeding of the Annual Conference Southeastern Association of Fish and Wildlife Agencies 44:260-267. 
, G. A. Hurst, and B. D. Leopold. 1995. Size and percent overlap of gobbler home range and core-use areas in central Mississippi. Pages 45-52 in J. G. Dickson, editor. Proceedings of the Seventh National Wild Turkey Symposium. National Wild Turkey Federation, Edgefield, South Carolina, and Stackpole Books, Mechanicsburg, Pennsylvania, USA.

Griffith, D. M., and R. H. Widmann. 2003. Forest statistics for West Virginia: 1989 and 2000. Resource Bulletin NE-157. Newton Square, Pennsylvania: U.S. Department of Agriculture, Forest Service. Northeastern Research Station, Newton Square, Pennsylvania, USA.

Healy, W. M., and E. S. Nenno. 1980. Growth parameters and age and sex criteria for juvenile eastern wild turkeys. Pages 168-185 in J. M. Sweeney, editor. Proceedings of the Fourth National Wild Turkey Symposium. National Wild Turkey Federation, Edgefield, South Carolina, USA.

. 1992. Behavior. Pages 46-65 in J. G. Dickson, editor. The wild turkey: biology and management. Stackpole Books, Harrisburg, Pennsylvania, USA.

Hooge, P. N., W. Eichenlaub, and E. Solomon. 1999. The animal movement program. USGS, Alaska Biological Science Center, Anchorage, Alaska, USA.

Hurst, G. A., D. R. Smith, J. D. Burk, and B. D. Leopold. 1991. Wild turkey gobbler habitat use and home range in loblolly pine plantations. Proceeding of the Annual Conference Southeastern Association of Fish and Wildlife Agencies 45:115-123. 
Kelley, R. L., G. A. Hurst, and D. E. Steffen. 1988. Home ranges of wild turkey gobblers in central Mississippi. Proceeding of the Annual Conference Southeastern Association of Fish and Wildlife Agencies 42:470-475.

Kernohan, B. J., R. A. Gitzen, and J. J. Millspaugh. 2001. Analysis of animal space use and movements. Pages 125-167 in J. J. Millspaugh and J. M. Marzluff, editors. Radio tracking and animal populations. Academic Press, San Diego, California, USA.

Kurzejeski, E. W., and J. B. Lewis. 1990. Home range, movements, and habitat use of wild turkey hens in northern Missouri. Pages 67-71 in W. M. Healy and G. B. Healy, editors. Proceedings of the Sixth National Wild Turkey Symposium. National Wild Turkey Federation, Edgefield, South Carolina, USA. , and L. D. Vangilder. 1992. Population management. Pages 165-184 in J. G. Dickson, editor. The wild turkey: biology and management. Stackpole Books, Harrisburg, Pennsylvania, USA.

Larson, J. D., and R. D. Taber. 1980. Criteria of sex and age. Pages 143-202 in S. D. Schemnitz. editor. Wildlife Management Techniques Manual, Forth Edition. The Wildlife Society, Washington, D. C., USA.

Laver, P. N., and M. J. Kelly. 2008. A critical review of home range studies. Journal of Wildlife Management 72:290-298.

Lewis, J. C. 1963. Observations on the winter range of wild turkeys in Michigan. Journal of Wildlife Management 27:98-102. 
Menzel, K. E. 1975. Population and harvest data for Merriam’s turkeys in Nebraska. Proceedings of the National Wild Turkey Symposium 3:184-188.

Miller, D. A., B. D. Leopold, and G. A. Hurst. 1997. Seasonal home ranges of wild turkeys in central Mississippi. Proceeding of the Annual Conference Southeastern Association of Fish and Wildlife Agencies 51:414-425.

, G. A. Hurst, and B. D. Leopold. 1999. Habitat use of eastern wild turkeys in central Mississippi. Journal of Wildlife Management 63:210-222.

, L. M. Conner, B. D. Leopold, and G. A. Hurst. 2001. Spatial fidelity of wild turkeys between seasons in central Mississippi. Proceedings of the Annual Conference Southeastern Association of the Fish and Wildlife Agencies 55:475-487.

Mohr, C. O. 1947. Table of equivalent populations of North American small mammals. American Midland Naturalist 37:223-249.

Nams, V. O., and S. Boutin. 1991. What is wrong with error polygons? Journal of Wildlife Management 55:172-176.

Norman, G. W., J. C. Pack, and G. A. Hurst. 1997. Transmitter selection and attachment technique for wild turkey research. National Wild Turkey Federation Research Bulletin Number 4.

, J. C. Pack, C. I. Taylor, D. E. Steffen, and K. H. Pollock. 2001. Reproduction of eastern wild turkeys in Virginia and West Virginia. Journal of Wildlife Management 65:1-9. 
M. M. Conner, J. C. Pack, and G. C. White. 2004. Effects of fall hunting on survival of male wild turkeys in Virginia and West Virginia. Journal of Wildlife Management 68:393-404.

Pack, J. C. 1994. Analysis of the proposal to open squirrel and turkey season on the same date. West Virginia Division of Natural Resources, Wildlife Resources Section. Charleston, West Virginia, USA.

, G. W. Norman, C. I. Taylor, D. E. Swanson, K. H. Pollock, and R. Alpizar-Jara. 1999. Effects of fall hunting on wild turkey populations in Virginia and West Virginia. Journal of Wildlife Management 63:964-975.

Pelham, P. M., and J. G. Dickson. 1992. Physical characteristics. Pages 32-45 in J. G. Dickson, editor. The wild turkey: biology and management. Stackpole Books, Harrisburg, Pennsylvania, USA.

Porter, W. F. 1977. Home range dynamics of wild turkeys in southeastern Minnesota. Journal of Wildlife Management 41:434-437.

Ryan, C. W., J. C. Pack, W. K. Igo, J. C. Rieffenberger, and A. B. Billings. 2004. Relationship of mast production to big-game harvests in West Virginia. Wildlife Society Bulletin 32:786794.

Saltz, D. 1994. Reporting error measures in radio location by triangulation: a review. Journal of Wildlife Management 58:181-184.

Seaman, D. E., and R. A. Powell.1996. An evaluation of the accuracy of kernel density estimators for home range analysis. Ecology 77:2075-2085. 
, J. J. Millspaugh, B. J. Kernoham, G. C. Brundige, K. L. Raedeke, and R. A.

Gitzen. 1999. Effects of sample size on kernel home range estimates. Journal of Wildlife Management 63:739-747.

Sisson, D. C., and D. W. Speake. 1994. Spring burning for wild turkey brood habitat: an evaluation. Proceedings of the Annual Conference Southeastern Association of the Fish and Wildlife Agencies 48:134-139.

Smith, W. P., E. P. Lambert, and R. D. Teitelbaum. 1988. Seasonal movement and home range differences among age and sex groups of eastern wild turkeys within southeastern Louisiana. Proceedings of the International Symposium on Biotelemetry 10:151-158.

Speake, D. W., T. E. Lynch, W. J. Fleming, G. A. Wright, and W. J. Harnick. 1975. Habitat use and seasonal movements of wild turkeys in the southeast. Pages 122-130 in L. K. Halls, editor. Proceedings of the Third National Wild Turkey Symposium. The Texas Chapter of the Wildlife Society.

Steffen, D. E., N. L. Lafon, and G. W. Norman. 2002. Turkeys, acorns, and oaks. Pages 241-255 in W. J. McShea and W. M. Healy, editors. Oak forest ecosystems: ecology and management for wildlife. Johns Hopkins University Press, Baltimore, Maryland, USA.

Strausbaugh, P. D., and E. L. Core. 1978. Flora of West Virginia, Second Edition. Seneca Books, Morgantown, West Virginia, USA.

Townsend, D. E. II., S. S. Ditchkoff, and S. D. Fuhlendorf. 2007. Transmitter height influences error of ground-based radio-telemetry. Wildlife Biology 13:98-101. 
Uhlig, H. G., and H. L. Wilson. 1952. A method of evaluating an annual mast index. Journal of Wildlife Management 16:338-343.

Vangilder, L. D. 1992. Population dynamics. Pages 144-164 in J. G. Dickson, editor. The wild turkey: biology and management. Stackpole Books, Harrisburg, Pennsylvania, USA.

Wallingford, B. D., and R. A. Lancia. 1991. Telemetry accuracy and a model for predicting telemetry error. Proceedings of the Annual Conference Southeastern Association of the Fish and Wildlife Agencies 45:178-188.

West Virginia Division of Natural Resources. 2009. Pages 11-22 in 2008 Big Game Bulletin. West Virginia Division of Natural Resources Bulletin 09-1. Charleston, West Virginia, USA.

White, G. C., and R. A. Garrott. 1990. Analysis of wildlife radio-tracking data. Academic Press, Inc., London, UK.

Wigley, T. B., J. M. Sweeny, M. E. Garner, and M. A. Melechiors. 1986. Wild turkey home ranges in the Ouachita Mountains. Journal of Wildlife Management 50:540-544.

Williams, L. E., D. A. Austin, and T. E. Peoples. 1978. Turkey harvest patterns on a heavily hunted area. Proceeding of the Annual Conference Southeastern Association of Fish and Wildlife Agencies 32:303-308.

Worton, B. J. 1987. A review of models of home range for animal movement. Ecological Modelling 38:277-298.

. 1989. Kernel methods for estimating the utilization distribution in home-range studies. Ecology 70:164-168. 
. 1995. A convex hull-based estimator of home-range size. Biometrics 51:1206-

1215.

Wright, E. L., C. H. Delp, K. Sponaugle, C. Cole, J. T. Ammons, J. Gorman, and F. D. Childs. 1982. Soil survey of Marion and Monongalia Counties, West Virginia. U. S. Department of Agriculture, Soil Conservation Service. USA.

Zielinski, W. J., R. L. Truex, G. A. Schmidt, F. V. Schilexer, K. N. Schmidt, and R. H. Barrett. 2004. Home range characteristics of fishers in California. Journal of Mammalogy 85:649657. 
Table 1. Annual 95\% and 50\% utilization distributions (UDs), including ecological regions (EC), and seasonal 95\% UDs for the fixed-kernel home range and the minimum convex polygon (MCP) home range of male eastern wild turkeys from 2 study areas in West Virginia, 2004-2007.

\begin{tabular}{|c|c|c|c|c|c|c|c|c|c|c|}
\hline \multirow[b]{3}{*}{ Study Area } & \multirow[b]{3}{*}{ Age } & \multirow[b]{3}{*}{ Season } & \multirow[b]{3}{*}{ EC } & \multirow[b]{3}{*}{$n$} & \multicolumn{6}{|c|}{ Home Range (ha) } \\
\hline & & & & & \multicolumn{2}{|c|}{$95 \%$ UD } & \multicolumn{2}{|c|}{$50 \%$ UD } & \multicolumn{2}{|c|}{ MCP } \\
\hline & & & & & $\bar{x} \pm \mathrm{SD}$ & Min-Max & $\bar{x} \pm \mathrm{SD}$ & Min-Max & $\bar{x} \pm \mathrm{SD}$ & Min-Max \\
\hline \multirow[t]{11}{*}{ Statewide } & Ad & Annual & & 37 & $831.5 \pm 646.5$ & $175.8-2,895.2$ & $106.1 \pm 98.1$ & $18.1-407.1$ & $963.2 \pm 678.2$ & $137.2-3,719.0$ \\
\hline & & & 1 & 2 & $1,184.1 \pm 6.2$ & $1,179.7-1,188.5$ & $180.9 \pm 91.9$ & $115.9 \pm 245.9$ & & \\
\hline & & & 2 & 10 & $697.6 \pm 408.0$ & $329.1-1,490.7$ & $86.9 \pm 71.9$ & $19.7-270.5$ & & \\
\hline & & & 3 & 5 & $311.2 \pm 79.2$ & $175.8-377.7$ & $33.2 \pm 10.0$ & $24.4-45.8$ & & \\
\hline & & & 4 & 15 & $1,099.8 \pm 862.5$ & $205.0-2,895.2$ & $145.7 \pm 122.6$ & $18.1-407.1$ & & \\
\hline & & & 6 & 5 & $673.6 \pm 174.2$ & $460.0-909.0$ & $69.2 \pm 46.1$ & $26.8-144.9$ & & \\
\hline & & Spring & & 9 & $475.7 \pm 124.6$ & $326.7-679.6$ & & & $446.4 \pm 200.7$ & $226.4-797.5$ \\
\hline & & Fall & & 9 & $548.8 \pm 209.6$ & $241.1-774.5$ & & & $453.3 \pm 196.5$ & $221.8-706.9$ \\
\hline & & Winter & & 8 & $536.2 \pm 403.2$ & $167.6-1,173.0$ & & & $444.5 \pm 296.4$ & $206.3-1.006 .3$ \\
\hline & & $\begin{array}{l}\text { Spring- } \\
\text { Summer }\end{array}$ & & 17 & $510.2 \pm 280.2$ & $181.6-1,232.3$ & & & $555.4 \pm 297.4$ & $251.4-1,139.3$ \\
\hline & & $\begin{array}{l}\text { Fall- } \\
\text { Winter }\end{array}$ & & 17 & $608.8 \pm 328.4$ & $249.6-1,495.9$ & & & $643.9 \pm 396.1$ & $189.1-1,726.1$ \\
\hline
\end{tabular}


Table 1. cont.

\begin{tabular}{|c|c|c|c|c|c|c|c|c|c|c|}
\hline \multirow[b]{3}{*}{ Study Area } & \multirow[b]{3}{*}{ Age } & \multirow[b]{3}{*}{ Season } & \multirow[b]{3}{*}{ EC } & \multirow[b]{3}{*}{$n$} & \multicolumn{6}{|c|}{ Home Range (ha) } \\
\hline & & & & & \multicolumn{2}{|c|}{$95 \%$ UD } & \multicolumn{2}{|c|}{$50 \%$ UD } & \multicolumn{2}{|c|}{ MCP } \\
\hline & & & & & $\bar{x} \pm \mathrm{SD}$ & Min-Max & $\bar{x} \pm \mathrm{SD}$ & Min-Max & $\bar{x} \pm \mathrm{SD}$ & Min-Max \\
\hline \multirow[t]{5}{*}{ Statewide } & Juv & Annual & & 29 & $868.3 \pm 497.7$ & $620.2-1,904.8$ & $156.2 \pm 121.9$ & $11.0-511.3$ & $794.3 \pm 401.8$ & $167.2-1,593.2$ \\
\hline & & & 1 & 1 & $1,490.8$ & --- & 224.4 & --- & & \\
\hline & & & 2 & 6 & $703.9 \pm 193.1$ & $485.1-921.2$ & $91.9 \pm 9.8$ & $82.3-104.3$ & & \\
\hline & & & 4 & 20 & $859.1 \pm 506.9$ & $62.0-1,736.9$ & $160.1 \pm 113.9$ & $11.0-397.0$ & & \\
\hline & & & 6 & 1 & 378.1 & ---- & 39.4 & ---- & & \\
\hline \multirow[t]{9}{*}{ DISA } & Ad & Annual & & 9 & $1,110.7 \pm 973.1$ & $289.9-2,895.2$ & $143.5 \pm 128.1$ & $26.2-407.1$ & $1,187.4 \pm 638.0$ & $472.0-2,041.3$ \\
\hline & & Spring & & 7 & $490.4 \pm 128.0$ & $338.7-679.6$ & & & $485.9 \pm 211.4$ & $226.4-797.5$ \\
\hline & & Fall & & 5 & $512.6 \pm 247.2$ & $241.1-741.7$ & & & $378.1 \pm 179.9$ & $221.8-661.2$ \\
\hline & & Winter & & 4 & $569.1 \pm 420.3$ & $167.6-977.1$ & & & $452.0 \pm 244.8$ & $222.3-704.9$ \\
\hline & & $\begin{array}{l}\text { Spring- } \\
\text { Summer }\end{array}$ & & 7 & $465.6 \pm 139.4$ & $262.7-673.7$ & & & $591.2 \pm 310.5$ & $251.4-1,131.3$ \\
\hline & & $\begin{array}{c}\text { Fall- } \\
\text { Winter }\end{array}$ & & 7 & $666.1 \pm 280.3$ & $348.8-1,190.1$ & & & $714.1 \pm 458.9$ & $393.0-1,726.1$ \\
\hline & Juv & Annual & & 19 & $812.9 \pm 475.6$ & $620.2-1,416.7$ & $161.2 \pm 116.8$ & $11.0-397.0$ & $746.8 \pm 402.9$ & $167.2-1,318.6$ \\
\hline & & Spring & & 11 & $377.2 \pm 120.1$ & $205.7-479.2$ & & & $494.5 \pm 283.1$ & $151.0-757.9$ \\
\hline & & $\begin{array}{l}\text { Spring- } \\
\text { Summer }\end{array}$ & & 10 & $260.6 \pm 216.3$ & $62.0-317.3$ & & & $451.4 \pm 271.6$ & $151.9-757.9$ \\
\hline
\end{tabular}


Table 2. Results of stepwise regression analysis on the relation of mast conditions and the fallwinter 95\% utilization distribution fixed kernel home range of juvenile and adult male eastern wild turkey in West Virginia, 2004-2007.

\begin{tabular}{cccccc}
\hline Coefficients & Estimate $(\beta)$ & SE & $t$-Value & $P$ & $R^{2}$ \\
\hline Hard Mast & -113.6 & 50.4 & -2.257 & 0.03 & 0.35 \\
Soft Mast & -107.8 & 42.3 & -2.550 & 0.02 \\
\hline
\end{tabular}


Table 3. Mast indices for 3 of the 6 ecological regions of West Virginia, 2004-2006.

\begin{tabular}{|c|c|c|c|c|c|c|}
\hline \multirow[b]{2}{*}{ Year } & \multirow[b]{2}{*}{ Region } & \multicolumn{5}{|c|}{ Mast Indices $^{\mathrm{a}}$} \\
\hline & & Hard mast $^{\mathrm{b}}$ & $\begin{array}{l}\text { Hard mast } \\
+ \text { cherry }\end{array}$ & Soft mast ${ }^{\mathrm{c}}$ & $\begin{array}{l}\text { Total mast } \\
\text { for region }\end{array}$ & $\begin{array}{l}\text { Total mast } \\
\text { statewide }\end{array}$ \\
\hline \multirow{3}{*}{2004} & 2 & 32 & 31 & 40 & 37 & 36 \\
\hline & 4 & 29 & 31 & 40 & 36 & 36 \\
\hline & 6 & 26 & 32 & 51 & 41 & 36 \\
\hline \multirow{3}{*}{2005} & 2 & 31 & 33 & 39 & 35 & 45 \\
\hline & 4 & 23 & 29 & 49 & 38 & 45 \\
\hline & 6 & 43 & 43 & 60 & 53 & 45 \\
\hline \multirow{3}{*}{2006} & 2 & 30 & 29 & 42 & 38 & 45 \\
\hline & 4 & 29 & 27 & 44 & 38 & 45 \\
\hline & 6 & 49 & 51 & 64 & 58 & 45 \\
\hline
\end{tabular}

${ }^{\mathrm{a}}$ Mast Index $=$ [abundant observations/total observations $]+[$ common observations $\times$ 0.5/total observations] $\times 100$

${ }^{\text {b}}$ Hard mast species - white oak, red oak, black oak, scarlet oak, chestnut oak, scrub oak, and American beech.

'Soft mast species - black cherry, grapes, hawthorn, crabapple, flowering dogwood, greenbrier, blackberry, sassafras, and yellow poplar. 
Table 4. Male eastern wild turkey population estimates for West Virginia, by age class, from Downing Population Reconstruction (Downing 1980) using harvest figures and spur lengths from the cooperators of the annual Spring Gobbler Survey in West Virginia, 2005-2007.

\begin{tabular}{cccc}
\hline & & Year & \\
\cline { 2 - 4 } Age & 2005 & 2006 & 2007 \\
\hline Juveniles & 15,935 & 5,198 & 10,609 \\
2 yr-old adults & 11,495 & 13,393 & 3,555 \\
$3+$ yr-old adults & 23,243 & & 29,624 \\
Total population est. & $\mathbf{5 0 , 6 7 3}$ & $\mathbf{4 4 , 9 1 4}$ & $\mathbf{4 3 , 7 8 8}$ \\
\hline
\end{tabular}


Table 5. Results of linear regression analysis on the relation of the fixed kernel $95 \%$ utilization distribution annual home range of adult and juvenile male eastern wild turkeys and male eastern wild turkey Downing Population Reconstruction (Downing 1980) estimates in West Virginia, 2005-2007.

\begin{tabular}{cccccc}
\hline Coefficients & Estimate $(\beta)$ & SE & $t$-Value & $P$ & $R^{2}$ \\
\hline 2006 & 118.0 & 121.1 & 0.98 & 0.34 & 0.48 \\
2007 & -236.5 & 117.9 & -2.01 & 0.05 \\
$\begin{array}{c}\text { Population } \\
\text { Estimate }\end{array}$ & -247.6 & 46.12 & -5.37 & $<0.001$ \\
\hline
\end{tabular}


Table 6. Results of linear regression analysis on the relation of the home range size of adult and juvenile (pooled) male eastern wild turkeys and the fate of radioed male eastern wild turkeys in West Virginia, 2004-2007.

\begin{tabular}{lccccc}
\hline \multicolumn{1}{c}{ Variables } & Estimate $(\beta)$ & SE & $t$-Value & $P$ & $R^{2}$ \\
\hline Legal Harvest & -446.7 & 150.8 & -2.96 & 0.004 & 0.16 \\
Illegal Kill & -380.5 & 314.5 & -1.21 & 0.23 \\
Other & 16.5 & 162.8 & 0.10 & 0.92 \\
Predation & 41.5 & 162.8 & 0.26 & 0.80 \\
\hline
\end{tabular}




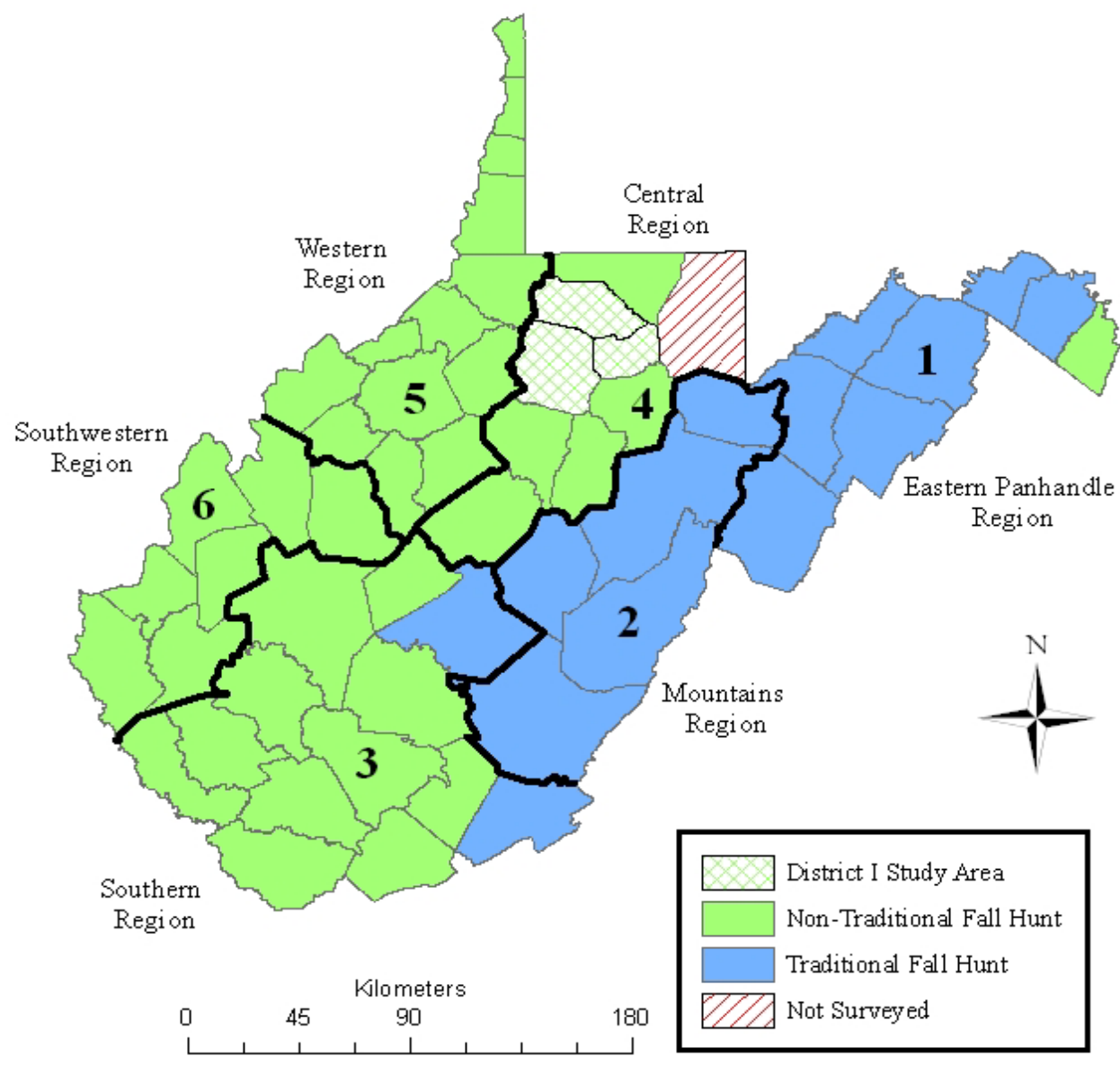

Figure 1. Study areas, including ecological regions and fall eastern wild turkey season formats for West Virginia, 2004-2007. 

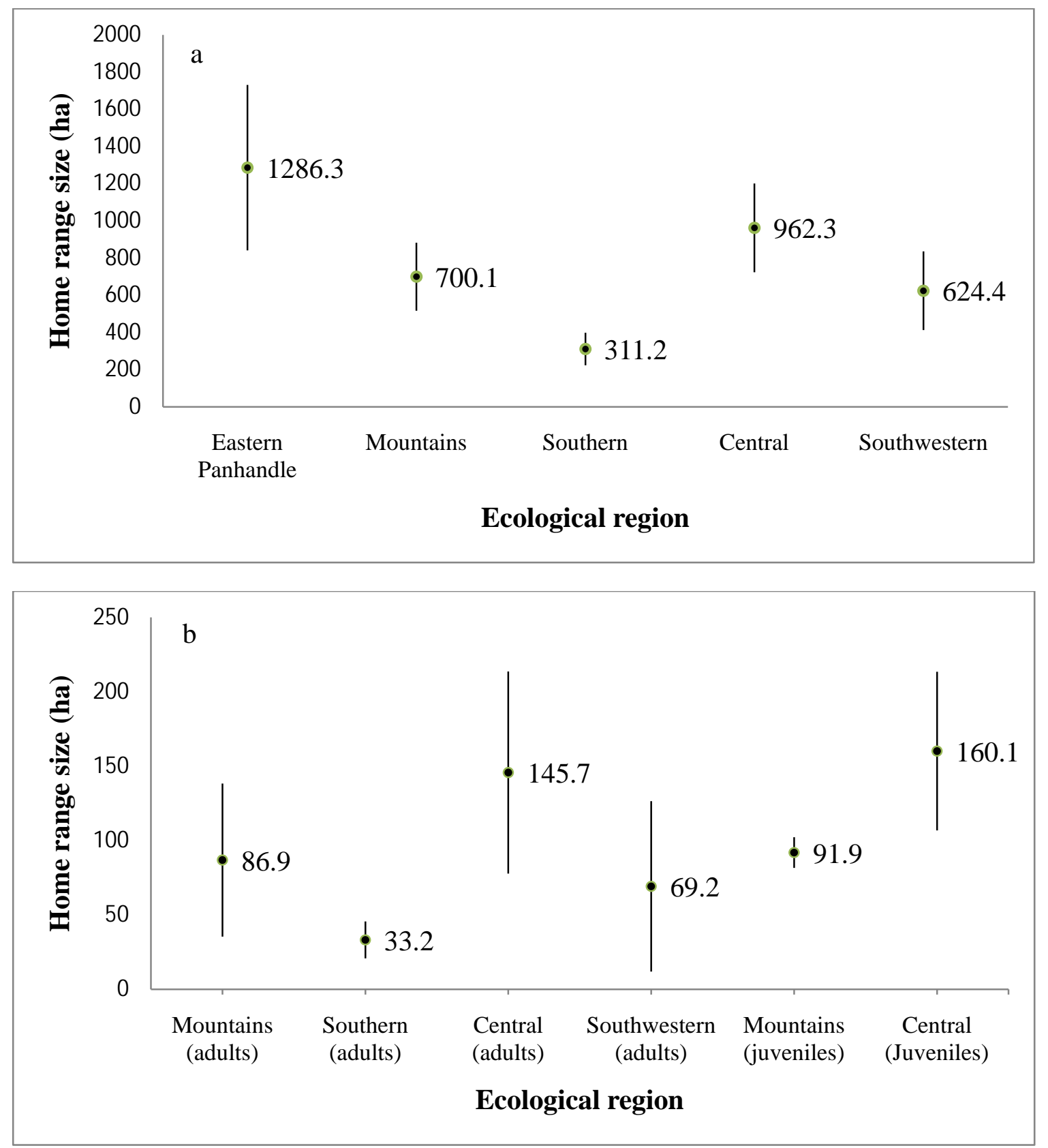

Figure 2. Means (ha) and confidence intervals (95\%) for; a) the pooled adult and juvenile age classes 95\% UD fixed kernel home range size of male wild turkeys within 5 ecological regions; b) the adult male wild turkey 50\% UD fixed kernel home range size within 4 ecological regions and the juvenile male wild turkey 50\% UD fixed kernel home range size within 2 ecological regions of West Virginia, 2004-2007. 
Chapter $3^{\mathrm{b}}$

\title{
THE USE OF ECCENTRICITY TO DESCRIBE THE HOME RANGE SHAPE OF MALE WILD TURKEYS IN WEST VIRGINIA
}

\author{
Steven E. Rauch ${ }^{1,4}$, James T. Anderson ${ }^{2}$, and A. B. Billings ${ }^{3}$ \\ ${ }^{1}$ West Virginia Division of Natural Resources, P.O. Box 99, Farmington, West Virginia 26571, \\ USA; \\ ${ }^{2}$ Division of Forestry and Natural Resources, West Virginia University, Morgantown, West \\ Virginia 26506, USA; \\ ${ }^{3}$ Department of Statistics, West Virginia University, Morgantown, West Virginia 26506, USA.
}

ABSTRACT.- Although male Eastern Wild Turkey (Meleagris gallopavo silvestris) home range size has been widely studied across the wild turkey range, quantitative home range shape studies have not been conducted in West Virginia or elsewhere. We used eccentricity (E), where a circle is $E=1$ and $E>1$ represents an increasingly elongated shape, to quantify the home range shape of 55 male Eastern Wild Turkeys (hereafter, male wild turkey) statewide in West Virginia from 2004 to 2007. The home range shape of the male wild turkey also was estimated in north-central West Virginia during the April-May period by age class. We examined the relation between home range shape and the ecological regions of West Virginia, annual mast conditions, male wild turkey population size estimates, fall/non-fall turkey hunting season counties, and fate.

\footnotetext{
${ }^{\mathrm{b}}$ This chapter written in the style of The Auk

${ }^{4}$ E-mail: steverauch@wvdnr.gov
} 
Both adult and juvenile male wild turkeys had a non-circular home range shape $(P \leq 0.001)$. A significant difference was estimated between the home range shape of adult $(\bar{x}(\mathrm{E})=2.421$, SD $=1.516)$ and juvenile $(\bar{x}(E)=1.624, \mathrm{SD}=2.894)$ male wild turkeys when six juveniles that had dispersed approximately 5,400 m were removed from the comparison $(P=0.02)$. We estimated a weak relation $(P=0.056)$ between juvenile male wild turkey fall-winter home range shape and hard mast conditions, 2004-2007. No relation $(P>0.05)$ was detected between home range shape and ecological regions, population size estimates, or fate of radioed male wild turkeys. No significant difference $(P=0.14)$ in the home range shape of juvenile male wild turkeys was estimated between the non-traditional fall hunting and traditional fall hunting counties, but adults have a more circular home range shape in the traditional counties. We estimated $(P=0.004)$ that juvenile male wild turkey have a more circular $(\bar{x}(E)=1.501, \mathrm{SD}=0.438)$ home range shape than do adults $(\bar{x}(\mathrm{E})=2.239, \mathrm{SD}=0.471)$ during the April-May period, whereas no significant difference ( $P=0.22$ ) was detected between the 2-year old and 3-year+ adult age classes during the same period. The use of eccentricity worked to quantify home range shape in male wild turkeys. We suggest the use of eccentricity in non-linear home range shape analysis.

Key words: eccentricity, Eastern Wild Turkey, home range shape, mast conditions, Meleagris gallopavo silvestris, West Virginia,

Knowledge of the shape of a wildlife species’ home range is important for developing management plans, habitat improvement projects, and, if a game species, harvest management among others. Numerous studies have been conducted on the home range of male Eastern Wild Turkeys (Meleagris gallopavo silvestris), hereafter, male wild turkey, (Lewis 1963, Kelley et al. 1988, Godwin et al. 1995, Miller et al. 1997). Likewise, studies have incorporated movement characteristics of male wild turkeys (Speake et al. 1975, Godwin et al. 1990, Wright and 
Vangilder 2005), but home range shape is rarely quantified in the research. Ellis and Lewis (1967) listed from early literature (e.g., Clark 1947, Davis 1949, Wheeler 1948) that the wild turkeys' daily movement is generally in a rather circular pattern, although their research did not quantitatively evaluate shape. The authors are not aware of any research quantifying the shape of male wild turkey home ranges in West Virginia or elsewhere. We propose to quantify the shape of male wild turkey home ranges in West Virginia by the use of eccentricity. Ford (1983) described eccentricity as "a probability density function that can be expressed as the ratio of the standard deviation along the major axis of the distribution to the standard deviation along the minor axis”. Eccentricity has been used to describe the canopy structure of prairie grass (Jurik and Kliebenstein 2000), characterize ant mounds (Vogt 2007), and evaluate home range shape of three species of chipmunks (Tamias spp.) (Bergstrom 1988) and hispid cotton rats (Sigmodon hispidus) (Spencer et al. 1990). Because of the mountainous characteristic of West Virginia, we expect to find that male wild turkeys have a non-circular home range shape.

The relation between mast conditions and wild turkey harvest rates in West Virginia (Ryan et al. 2004) and home range size of wild turkey hens in West Virginia (Fearer and Pack 2003) has been evaluated, but a relation, if any, between mast conditions and home range shape is unknown. A state-wide annual mast survey is conducted in West Virginia and from this data sets, we studied the relation of mast condition from 2004-2006 with the home range shape of male wild turkeys.

It is important to understand all possible factors that could contribute to the susceptibility of male wild turkey during the hunting season. Although studies have examined the relation of home range size and male wild turkey’s fate during the hunting season (Kelley et al. 1988) and with seasonal movements and harvest rates related to a wildlife management area boundary 
(Godwin et al. 1990), little is known about the relation between male wild turkey home range shape and fall hunting/non-fall hunting season formats. Fall turkey hunting seasons were established in the early 1900s in the mountainous regions of eastern West Virginia (Pack et al.1999). Our objectives were to determine differences in home range shape of male wild turkeys in these "traditional" fall either-sex hunting counties and the rest of the state (non-traditional fall hunt counties). Moreover, we studied the relation between male wild turkey population size and home range shape and the relation between home range shape and fate of the male wild turkey during the study period.

\section{METHODS}

Study sites. - We conducted our research on two study sites in West Virginia: Statewide and District 1 (Fig. 1). West Virginia is classified into three physiographic provinces: Western Hill Section, Allegheny Mountain and Upland Section, and Eastern Ridge and Valley Section (Strausbaugh and Core 1978). The Western Hill Section, located from the Ohio River to the mountainous area, is comprised by the Central Hardwood Forest. Central Hardwood Forest vegetation associations range from Oak-Pine (Quercus spp.-Pinus spp.) and Oak-Hickory (Carya spp.) communities (xeric) through Cove Hardwoods or Mixed Mesophytic Forests (mesic) to Flood Plain communities (hydric). The Allegheny Mountain and Upland Section contains the highest elevations of the state and is comprised of Northern Hardwood Forest, which is dominated by sugar maple (Acer saccharum), American beech (Fagus grandifolia), and yellow birch (Betula alleghaniensis), and in the highest elevations of this section by red spruce (Picea rubens). The Eastern Ridge and Valley Section in the Eastern Panhandle is characterized by oakhickory-pine forest vegetation. Elevations in West Virginia vary from 73 - 1,524 m (Strausbaugh and Core 1978). Because of the mountainous terrain of West Virginia, variable habitat factors 
affect directly or indirectly annual mast conditions and game harvest, as well as the distribution of vegetation. For these reasons, the state of West Virginia has been divided into six ecological regions (Uhlig and Wilson 1952) to facilitate effective management of wildlife species.

The District I study area (DISA) was located in Harrison, Marion, and Taylor counties of north-central West Virginia. Topography of Marion County was described as having mountain ranges oriented in a northeast-southwest direction with steep hillsides and narrow valleys (Wright et al. 1982), while Harrison and Taylor Counties have mostly steep to very steep hillsides with narrow floodplains (Beverage and Yoakum 1980). The three-county area averaged 59.5\% forested with $62.2 \%$ of the forestland comprised of oak-hickory (Griffith and Widmann 2003). All three counties were located in the Central Allegheny Plateau and Ecological Region 4. Male wild turkeys in the DISA were also included in the statewide analysis of home range shape.

Trapping and Telemetry. - We trapped wild turkeys at 29 sites baited with cracked/whole corn during September-November and January-March of 2004-2007. Wild turkeys were trapped by the use of rocket nets and/or rocket boxes (Kurzejeski and Vangilder 1992). We aged (adult or juvenile) and sexed each wild turkey by use of feather coloration as described by Pelham and Dickson (1992). Juvenile birds were aged and sexed as described by Healy and Nenno (1980), while yearling wild turkeys (12-16 months) caught in early September were aged by the tenth primary feather (Larson and Taber 1980). We fitted all captured wild turkeys with a uniquely numbered aluminum leg band. All wild turkeys were weighed with spring scales and mass was recorded. Each wild turkey’s physical condition was also recorded. Only male wild turkeys weighing $\geq 1.6 \mathrm{~kg}$ and having a physical condition of good (minor feather loss, minor scalping) or excellent (no feather loss, no injuries) were considered for radioing. All wild turkeys were 
released at the capture site. Trapping locations were recorded in Universal Transverse Mercator (UTM) coordinates.

Male wild turkeys were fitted with backpack style transmitters (Advanced Telemetry Systems Inc. (ATS) Isanti, MN) weighing about $80 \mathrm{~g}$, which were affixed to the wild turkey with a harness made from $4.8 \mathrm{~mm}$ nylon shock cord (Norman et al. 1997). Transmitter frequencies operated between 150 and $152 \mathrm{MHz}$ and each transmitter contained a motion-mortality sensor. We located radioed wild turkeys a minimum of once per week by triangulation (Cochran and Lord 1963) with at least two directional azimuths being used to obtain a location (Andelt and Gipson 1979, Nams and Boutin 1991, Wallingford and Lancia 1991, Zielinski et al. 2004). If only two intersecting directional azimuths were taken, we only used locations generated from azimuths separated by $\geq 60^{\circ}$ and $\leq 120^{\circ}$ (Kurzejeski and Lewis 1990, Sisson and Speake 1994, Miller et al. 2001). Only locations generated by $\geq 2$ azimuths collected $\leq 20$ minutes apart were used for analysis. We estimated telemetry error by attaching transmitters to $2.0 \mathrm{~L}$ bottles filled with a saline solution and placing in forested habitat at an average height of a male wild turkey (46 cm: Townsend et al. 2007). We estimated telemetry error to be $6^{\circ}(\mathrm{SE}=0.84)$ with a mean distance from transmitter location to receiving location of $458.9 \mathrm{~m}(\mathrm{SE}=59.12)(\mathrm{N}=18$ : White and Garrott 1990). ). We used program LOCATE III (Pacer Computing, Truro, NS, Canada) to measure a 95\% confidence ellipse of 7.7 ha $(\mathrm{SD}=8.9)$ associated with the telemetry error (White and Garrott 1990, Saltz 1994). Moreover, we located radioed wild turkeys at least twice weekly during peak hunting pressure days, which included the first week of squirrel (Sciurus spp.), white-tailed deer (Odocoileus virginianus) (archery, buck-only firearms, antlerless, and muzzleloader), and spring and fall wild turkey hunting seasons. In 2006 and 2007, the radioed male wild turkeys in the DISA were located a minimum of three times per week each month in 
April and May. Only male wild turkeys with a minimum of 30 locations (Seaman et al. 1999) and $\mathrm{a} \geq 9$ month of period of locations were included in home range shape estimation. We used spatial autocorrelation in ArcMap 9.2 (Environmental Systems Research Institute, Inc. (ESRI) Redlands, CA) on the mean centers of the UTM coordinates for each radioed male wild turkey to determine spatial distribution. Statewide, juvenile males were distributed randomly across the state $($ Morans I Index $=0.36, z$ score $=0.91 \mathrm{SD})$, while adults were clustered (significant at $\alpha=$ 0.05, Morans I Index $=0.65, z$ score $=2.34$ SD). Conversely, in the DISA, adult males were randomly located (Morans I Index $=0.27, z$ score $=1.18$ SD), while juvenile males were clustered (significant at $\alpha=0.01$, Morans I Index $=1.17, z$ score $=2.69$ SD). Locations from September - February (fall - winter) were used to estimate the effects of mast conditions on home range shape. A cause of death was determined from all recovered dead male wild turkeys and placed in the following categories of fate: legal harvest, illegal harvest, depredated, or other (disease, accidental). A radioed male wild turkey was considered alive for the home range shape and fate relation analysis if living at the end of study or for juveniles, a juvenile that survived to the adult age class.

Male wild turkeys trapped during the fall or winter seasons as juveniles were considered juveniles through the following August (Norman et al. 2004). Adults included male wild turkeys trapped as adults and individuals trapped as juveniles once they reached their second September. The 3-year+ age class was defined as adults monitored $\geq 1$ year or juveniles monitored $\geq 2$ years as adults (Norman et al. 2001). Male wild turkeys that entered the study as juveniles and survived to adults were analyzed within their respective age classes. Telemetry data for each male wild turkey were pooled across years. 
Mast Index and Data Analysis. - Mast conditions have been monitored and indexed annually in August since 1970 in West Virginia (Evans et al. 2008). These annual mast surveys are conducted by Division of Natural Resources personnel, Division of Forestry personnel, and volunteers. Each surveyor conducts a survey at the same high elevation site and low elevation site each year and records: county, date, elevation, aspect, and location. Each surveyor rates the available mast as abundant (above normal), common (normal), or scarce (below normal) (Uhlig and Wilson 1952, Ryan et al. 2004). A species was listed as not present if not found in the survey area. A mast index for each species was calculated by adding the percentage of surveyors rating mast as abundant (value of 1 ) and the percentage rating mast as common (value of 0.5 ) by the following formula:

Mast Index $=$ [abundant observations/total observations $]+$

[common observations $\times 0.5 /$ total observations] $\times 100$,

while a rating of scarce was given a zero value (Uhlig and Wilson 1952, Ryan et al. 2004, Evans et al. 2008).

We calculated an annual mast index for hard-mast and soft-mast species from 2004-2006 from data collected in the annual mast surveys for each of the 6 ecological regions. Additionally, a total mast index was calculated for each ecological region as well as a statewide total index. Hard-mast included the following species: American beech, red oak (Q. rubra), white oak (Q. alba), black oak (Q. velutina), chestnut oak (Q. prinus), scarlet oak (Q. coccinea), and scrub oak (Q. ilicifolia), while soft-mast included: black cherry (Prunus serotina), grapes (Vitis spp.), hawthorn (Crataegus spp.), crabapple (Malus spp.), flowering dogwood (Cornus florida), 
greenbrier (Smilax spp.), blackberry (Rubus spp.), yellow poplar (Liriodendron tulipifera), and sassafras (Sassafras albidum).

The West Virginia Division of Natural Resources (Wildlife Resources Section) (WVDNR-WRS) has conducted an annual Spring Gobbler Survey since 1983 in West Virginia (Evans et al. 2007). Cooperators for the survey record daily observations and biological data from harvested male wild turkeys. Harvest figures and spur lengths of spring harvested male wild turkeys, from the Spring Gobbler Survey, were used as a sample of age classes to calculate a Downing Population Reconstruction (Downing 1980) estimate of male wild turkeys in West Virginia.

Program LOCATE III was used to generate UTM coordinates (X and Y coordinates) of the locations from the telemetry data. The eccentricity $(E)$ of the home range shape was calculated as:

$$
E=\sqrt{\lambda 1 / \lambda 2}
$$

where $\lambda_{1}$ and $\lambda_{2}$ are the eigenvalues of the variance-covariance matrix of the $\mathrm{X}$ and $\mathrm{Y}$ coordinates, where a circle is $\mathrm{E}=1$ (Bergstrom 1988) and $\mathrm{E}>1$ represents an increasingly elongated shape (Spencer et al. 1990). The Shapiro-Wilk test of normality was performed on the eccentricity results and we found the adult eccentricity ( $w=0.603, P \leq 0.001)$ and juvenile eccentricity ( $\mathrm{w}=0.674, P \leq 0.001)$ results were non-normal. Because normality assumptions were violated, the Wilcoxon signed rank test and Kruskal-Wallis test were used as nonparametric equivalents of $t$-test and ANOVA, respectively. Linear regression was used to compare effects of mast conditions, fate, and male wild turkey densities on home range shape. Independent variables for mast condition modeling included: year, region, age, hard-mast, soft-mast, hard- 
mast plus black cherry, total mast per region per year, and total mast statewide per year. We used the following independent variables to model fate: legally harvested, illegally killed, depredated, other (accident, disease, lost contact), or alive at end of study. Juvenile male wild turkeys were classified as alive if they survived through their second August. The Shapiro-Wilk test of normality and graphical examination were performed on the residuals in each linear regression model to test the normality assumption. The statistical package R (R Foundation for Statistical Computing, Vienna Austria, http://www.R-project.org) was used for all statistical analysis. Significance levels were set at $\alpha=0.05$ for all statistical tests.

\section{RESULTS}

From September 2004 through August 2007, a total of 197 male wild turkey was radioed statewide (32 in the DISA) in West Virginia (representing all 6 ecological regions), of which 55 wild turkeys (22 in the DISA) were used in the statewide analysis of home range shape. This included 26 juveniles (11 of which also were included in analysis of adults) from ecological regions 2, 4, and 6 and 40 adults from ecological regions $1-4$ and 6 . The shape of the home range was estimated to be non-circular for both adults (Wilcoxon: $\mathrm{V}=820, P \leq 0.001$ ) and

juvenile $(\mathrm{V}=351, P \leq 0.001)$ male wild turkey, with adults $(\bar{x}(\mathrm{E})=2.421, \mathrm{SD}=1.516)$ having a more circular home range shape than juveniles $(\bar{x}(\mathrm{E})=3.162$, SD $=2.894)$. The eccentricity of the home range for 22 male wild turkeys, 19 juvenile $(\bar{x}(\mathrm{E})=3.755$, median $=1.949$, SD $=$ 3.222) and 9 adult $(\bar{x}(\mathrm{E})=3.083$, median $=2.478, \mathrm{SD}=1.891)$, was estimated in the DISA over the three-year study period (Table 1). Six of the 9 adult wild turkeys also were analyzed as juveniles in the DISA. Six juvenile male wild turkeys in Marion County moved about 5,400 m during spring (2007) dispersal and with the eccentricity of these birds removed from the statistical analysis, the juvenile male wild turkeys $(\bar{x}(\mathrm{E})=1.624$, median $=1.684, \mathrm{SD}=0.444)$ 
have a more circular shape than the adults statewide and in the DISA $(\bar{x}(\mathrm{E})=1.663$, median $=$ 1.686, SD = 0.432). Eccentricity of the home range shape was not different between adults and juveniles (Kruskal-Wallis one-way ANOVA, $\chi_{1,65}^{2}=1.49, P=0.22$ ) statewide nor in the DISA $\left(\chi_{1,27}^{2}=0.14, P=0.71\right)$, but there was an observed difference between juvenile and adult home range shape with the 6 dispersing juveniles removed from analysis, both statewide $\left(\chi_{1,59}^{2}=\right.$ $10.54, P=0.001)$ and in the DISA $\left(\chi_{1,21}^{2}=5.31, P=0.02\right)$.

There was no difference in the shape of the adult home ranges $\left(\chi_{4,39}^{2}=8.03, P=0.09\right)$ and juvenile home ranges $\left(\chi_{2,25}^{2}=2.15, P=0.34\right)$ in relation to the ecological regions. Adults had a more circular home range shape $\left(\chi_{1,39}^{2}=4.52, P=0.03\right)$ in the "traditional" fall hunt counties $(n=14, \bar{x}(\mathrm{E})=1.842$, median $=1.913, \mathrm{SD}=0.371)$ than in the remainder of the state $(n=26, \bar{x}(\mathrm{E})=2.732$, median $=2.334, \mathrm{SD}=1.796)$, but we found no difference $\left(\chi_{1,25}^{2}=2.14, P\right.$ $=0.14)$ in juvenile home range shape between the "traditional" fall hunt counties $(n=5, \bar{x}(\mathrm{E})=$ 1.561 , median $=1.175, \mathrm{SD}=0.57)$ and the “non-traditional” $(n=21, \bar{x}(\mathrm{E})=3.526$, median $=$ $1.801, \mathrm{SD}=3.10)$

In 2006 and 2007, the home range eccentricity was estimated for 21 (12 juvenile and 9 adult) male wild turkeys (Table 2) during the April-May period. Our results showed that juveniles had a more circular home range shape than adult $\left(\chi_{1,20}^{2}=8.51, P=0.004\right)$ male wild turkeys during the April-May period. Conversely, we saw no significant difference in home range shape between the 2-year old and the 3-year or more adult age classes of male wild turkey $\left(\chi_{1,8}^{2}=1.5, P=0.22\right)$.

A sample size of 40 male wild turkeys (10 juveniles, 30 adults) was used to test for effects of mast conditions on home range shape. We removed from our linear model the total 
mast statewide variable because of collinearity with year and subsequently removed year, region, soft-mast, and hard-mast with cherry because of no effect on eccentricity $(P>0.05)$. The final model $\left(F_{2,56}=5.61, P=0.006\right)$ estimated a weak relation $(P=0.056)$ between the eccentricity of the home shape of juvenile male wild turkeys and hard-mast conditions (Table 3) during the 2004-2006 period. Model $\mathrm{R}^{2}$ was low at 0.17 . We accepted the assumption of normal distribution of the model residuals on the basis of a high $\mathrm{W}(\mathrm{W}=0.95)$ and from the plotting of residuals for graphical examination, although $P=0.01$.

To test for a relation between home range shape and population size estimates of male wild turkeys, we estimated the eccentricity of the home range shape of wild turkeys for the annual period beginning June and running through May for 8 juveniles and 31 adults over the three-year period. Initially, we modeled the home range shape against the total population size of male wild turkeys per year during 2005-2007 from the Downing Population Reconstruction output, but total population size and year were collinear. Subsequently, we used population estimates by age class (Table 4) to model effects on home range shape. Our linear model was significant $\left(F_{7,47}=3.20, P=0.007\right)$ because of age, region and year effects on the overall model, but we did not detect a linear relation between the eccentricity of home range shape and population size estimates $(P=0.12$ ) of male wild turkey during the 2005-2007 period (Table 5). Linear model residuals were normally distributed $(\mathrm{W}=0.96, P=0.06)$.

We used a sample size of 66 male wild turkeys (26 juveniles, 40 adults) to test for effects of home range shape and the bird's fate during the study. No significant effect $\left(F_{5,60}=1.02, P=\right.$ 0.41) was detected from the fate of the male wild turkey on home range shape within the threeyear period (Table 6), but the model residuals were not normal ( $\mathrm{W}=0.77, P \leq 0.001$ ). 


\section{DISCUSSION}

The use of eccentricity worked to quantify the home range shape of male wild turkeys in West Virginia. As hypothesized, male wild turkeys had a non-circular home range, with adult males having a more circular home range than juveniles after dispersing juveniles were removed from the analysis. In the DISA we found similar results of no significant difference in home range shape between juveniles and adults except that the home range shape of juveniles was more circular than adults when the six dispersing juveniles were removed from comparison. Although our objectives were not to determine dispersal distances, we did see the influence of dispersal on home range shape and past research on wild turkey movement has shown that juvenile male wild turkeys disperse greater distances than adults. Porter (1977) found that juvenile males dispersed approximately three times the distance that adult males did. Moreover, Ellis and Lewis (1967), Davis (1973), and Wright and Vangilder (2005) found juvenile males dispersed farther than adults, while Kulowiec and Haufler (1985) found the opposite to be true. Our results show that non-circularity in home range shape increases as dispersal distance increases. To compare the home range shape of adult and juvenile male wild turkeys, it is necessary to treat the dispersing juveniles as having two separate home ranges to eliminate the bias from the dispersal distance, thus more accurately describing the juvenile male wild turkey home range shape.

During the April-May period, juvenile male wild turkey had a more circular home range than did the adults and the 3-year+ age class adults had a slightly more circular home range shape than the 2-year age class in the DISA. Davis (1973) found that spring movement of male wild turkeys was related to breeding behavior and suspected that they may follow hens into spring ranges. Moreover, several researchers have reported the use of fields during the spring by 
male wild turkeys (Barwick and Speake 1973, Everett et al. 1985, Exum et al. 1987, Godwin et al. 1990), with Exum et al. (1987) suggesting that the use of fields was probably related to breeding activities. Habitat analysis was not included in this research so it is not known how the distributions of fields may affect home range shape. Badyaev et al. (1996a) found that adult male wild turkeys occupied smaller display grounds (1 April through 15 June) than did juvenile male wild turkeys in northern Arkansas. They speculated that by moving among adult display ranges, juveniles may experience reduced aggression from the adult male wild turkeys. This could explain why the home range shape of juvenile male wild turkeys is more circular in shape.

There was no difference in home range shape between the ecological regions in West Virginia, although we expected the variation in geographic features across the ecological regions of West Virginia to influence home range shape. Diverse habitats have been known to influence the home range size of male wild turkeys (Ellis and Lewis 1967, Everett et al. 1979, Badyaev et al. 1996b) and similarly may influence home range shape. It is possible that the small sample sizes we had in some ecological regions, the lack of the juvenile age class in three of the six regions, and the lack of an adult age class in region 5, contributed to not detecting variations, if any, in home range shape.

We found that adult male wild turkeys have a more circular home range shape in the traditional fall turkey hunting counties than adults in the non-traditional counties. Conversely, we estimated no significant difference in the home range shape between juveniles in the traditional fall hunt counties and those in the non-traditional counties. The traditional fall hunt counties are located primarily in the eastern mountains of the state, which are heavily forested and are higher in elevation. Badyaev et al. (1996b) found that male wild turkeys occupied larger home ranges in areas of "patchy distribution of habitat types” than in areas of “even distribution of habitat types” 
in the fall, and the overlap of adult male wild turkey seasonal home ranges was higher than the seasonal overlap of juveniles.

Mast conditions, especially oak-mast, affect the home range size of wild turkeys (Kelley et al. 1988, Healy 1992) and harvest rates (Norman and Steffen 2003, Ryan et al. 2004) of wild turkeys. Our results indicated a weak influence from hard mast on juvenile male wild turkey home range shape over the three year period. Conversely, we saw no influence from soft mast species over the same period. This is not unexpected given the importance of oak mast for wild turkeys, especially during the fall-winter period. It is interesting to note that we did not see a significant effect from hard mast + black cherry on home range shape, although Ryan et al. (2004) found that hard mast + black cherry combination had the strongest negative correlation with wild turkey harvest in West Virginia over a 30-year period. Because of the variability, or lack thereof, in mast conditions from year to year, it can be difficult to detect the influence of mast conditions on home range shape over a short period of time. We suspect that during the 2004 - 2006 period, mast indices from West Virginia (Table 7) did not vary enough to accurately examine all relations between mast conditions and home range shape. Mast indices from the WVDNR annual mast survey showed (averaged, from 1970 to 2006): an “average” mast year for oaks and black cherry in 2004, “slightly above average” oak mast and “above average” black cherry mast in 2005, and “above average” oak and "below average” black cherry production in 2006 (Evans et al. 2006).

Over the three year period, we detected no relation between male wild turkey population estimates and home range shape, although research has shown a potential association between wild turkey population densities and male wild turkey home range size. Exum et al. (1987) found that male wild turkeys tend to have larger home range sizes and lower population size estimates 
in heavily forested habitat, whereas male wild turkeys in diverse habitats have higher population size estimates with smaller home range size (Ellis and Lewis 1967). Also, we found no relation between the fate of male wild turkeys and home range shape, but we caution against making conclusions from these results because of the assumption of normality violation. Our results may imply that the birds were able to find and use adequate habitat without excessive movements or dispersal (Miller and Leopold 1992), thus making them less vulnerable to predation, harvest, and other forms of mortality. Kelley et al. (1988) estimated that the hunting season home range size of non-harvested male wild turkeys was different over a two year period in Mississippi; they found no significant difference between the home range size of harvested and non-harvested male wild turkeys or between adult and juvenile male wild turkey home ranges within years.

Management implications and research needs - We demonstrated that home range shape of male wild turkeys is quantifiable by the use of eccentricity using telemetry locations (X and Y coordinates) and is easily calculated with computer programs. The use of eccentricity may not be appropriate in describing the shape of all home ranges, i.e. an organism with a home range affected by a physical barrier (river, large lake, etc.). Moreover, eccentricity would not work with wildlife species’ having a linear home range. For planning and implementation, a better understanding of male wild turkey home range shape can assist with the spatial distributions of habitat management practices/improvements by wildlife agencies and private landowners. We suggest the use of eccentricity to quantify home range shape of wild turkey and other wildlife species with non-linear home ranges. Additional research needs include dispersal distances of male wild turkeys, (e.g., age class dispersal characteristics and seasonal dispersal patterns, cruising radius, site fidelity, and spatial patterns of habitat use). 


\section{ACKNOWLEDGMENTS}

Data used in this study were collected in conjunction with the Mid-Atlantic Gobbler Study (MAGS), a joint study between the West Virginia Division of Natural Resources (Wildlife Resources Section) (WVDNR-WRS), the Virginia Department of Game and Inland Fisheries, and the West Virginia State Chapter of the National Wild Turkey Federation. All data used in this study were from male wild turkeys in West Virginia. Funding for the Mid-Atlantic Gobbler Study (MAGS), in part, was provided by the WVDNR-WRS and the Federal Aid in Wildlife Restoration Grant W-48-R. We thank the dedicated personnel of the WVDNR-WRS that worked on MAGS and special thanks goes to G. Foster and M. Peters for the extra effort they put into data collection for this study and to J. Evans (retired) for providing the Downing Population Reconstruction estimates of male wild turkeys and for reviewing this manuscript, as well as Dr. J. Edwards for reviewing this manuscript. Thanks goes to the West Virginia Chapter of The National Wild Turkey Federation for the funding of the transmitters used in the MAGS. This manuscript is scientific article number xxxx of the West Virginia University Agriculture and Forestry Experiment Station.

\section{LITERATURE CITED}

Andelt, W. F., and P. S. Gipson. 1979. Home range, activity, and daily movements of coyotes. Journal of Wildlife Management 43:944-951.

Badyaev, A. V., W. J. Etges, and T. E. Martin. 1996a. Age-biased spring dispersal in male wild turkeys. Auk 113:240-242. 
and 1996b. Ecological and behavioral correlates of

variation in seasonal home ranges of wild turkeys. Journal of Wildlife Management 60:154-164.

Barwick, L H., and D. W. Speake. 1973. Seasonal movements and activities of wild turkey gobblers in Alabama. Pages 125-133 in Wild Turkey Management: Current Problems and Programs (C. C. Sanderson and H. C. Schultz, Eds.). University of Missouri Press, Columbia, Missouri.

Bergstrom, B. J. 1988. Home range of three species of chipmunks (Tamias) as assessed by radiotelemetry and grid trapping. Journal of Mammalogy 69:190-193.

Beverage, W. W., and T. D. Yoakum. 1980. Soil survey of Harrison and Taylor Counties, West Virginia. U. S. Department of Agriculture, Soil Conservation Service, Washington, D. C.

Clark, W. K., Jr. 1947. The status of hybrid wild turkeys in Missouri. M.A. Thesis. University of Missouri. Columbia, Missouri.

Cochran, W. W., and R. D. Lord. 1963. A radio-tracking system for wild animals. Journal of Wildlife Management 27:9-24.

Davis, H. E. 1949. The American wild turkey. Small-arms Technical Publishing Co. Georgetown, South Carolina.

Davis, J. R. 1973. Movements of wild turkeys in northwestern Alabama. Pages 61-88 in Wild Turkey Management: Current Problems and Programs (G. C. Sanderson and H. C. Schultz, Eds.). University of Missouri Press, Columbia, Missouri. 
Downing, R. L. 1980. Vital statistics of animal populations. Pages 247-267 in Wildlife Techniques Manual (S. D. Schemnitz, Ed.). The Wildlife Society, Washington, D. C.

Ellis, J. E., and J. B. Lewis. 1967. Mobility and annual range of wild turkeys in Missouri. Journal of Wildlife Management 31:568-581.

Evans, J. E., R. L. Tucker, W. K. Igo, and E. Richmond. 2006. 2006 West Virginia mast survey and hunting outlook. West Virginia Division of Natural Resources, Wildlife Resources Bulletin 06-04, Charleston, West Virginia.

, J. C. Pack, W. K. Igo, R. L. Tucker, G. H. Sharp, D. Vandevander, and C. P.

Carpenter. 2007. 2007 Spring gobbler survey. West Virginia Division of Natural Resources, Wildlife Resources Section and West Virginia Chapter of the National Wild Turkey Federation, Wildlife Resources Section Bulletin 08-02, Charleston, West Virginia.

, R. L. Tucker, E. Richmond, and W. K. Igo. 2008. West Virginia mast survey and hunting outlook. West Virginia Division of Natural Resources, Wildlife Resources Bulletin 08-5, Charleston, West Virginia.

Everett, D. D., D. W. Speake, and W. K. Maddox. 1979. Wild turkey ranges in Alabama mountain habitat. Proceedings of the Annual Conference Southeastern Association of Fish and Wildlife Agencies 33:233-238. and 1985. Habitat use by wild turkeys in northern Alabama. Proceedings of the Annual Conference Southeastern Association of Fish and Wildlife Agencies 39:260-267. 
Exum, J. H., J. A. McGlincy, D. W. Speake, J. L. Buckner, and F. M. Stanley. 1987. Ecology of the eastern wild turkey in an intensively manage pine forest in southern Alabama. Tall Timbers Research Station Bulletin 23. Tallahassee, Florida.

Fearer, T. M., and J. C. Pack. 2003. Home range characteristics of female wild turkeys in West Virginia. West Virginia Division of Natural Resources PR Report. Charleston, West Virginia.

Ford, R. G. 1983. Home range in a patchy environment: optimal foraging predictions. American Zoologist 23:315-326.

Godwin, K. D., W. E. Palmer, G. A. Hurst, and R. L. Kelly. 1990. Relationship of wild turkey gobbler movements and harvest rates to management area boundaries. Proceedings of the Annual Conference Southeastern Association of Fish and Wildlife Agencies 44:260-267.

, G. A. Hurst, and B. D. Leopold. 1995. Size and percent overlap of gobbler home range and core-use areas in central Mississippi. Pages 45-52 in Proceedings of the Seventh National Wild Turkey Symposium (J. G. Dickson, Ed.). National Wild Turkey Federation, Edgefield, South Carolina, and Stackpole Books, Mechanicsburg, Pennsylvania.

Griffith, D. M., and R. H. Widmann. 2003. Forest statistics for West Virginia: 1989 and 2000. Resources Bulletin NE-157. Newton Square, Pennsylvania: U.S. Department of Agriculture, Forest Service. Northeastern Research Station, Newton Square, Pennsylvania. 
Healy, W. M., and E. S. Nenno. 1980. Growth parameters and age and sex criteria for juvenile eastern wild turkeys. Pages 168-185 in Proceedings of the Fourth National Wild Turkey Symposium (J. M. Sweeney, Ed.). National Wild Turkey Federation, Edgefield, South Carolina.

. 1992. Behavior. Pages 46-65 in The wild turkey: biology and management (J. G.

Dickson, Ed.). Stackpole Books, Harrisburg, Pennsylvania.

Jurik, T. W., and H. Kliebenstein. 2000. Canopy architecture, light extinction and self-shading of a prairie grass, Andropogon gerardii. American Midland Naturalist 144:51-65.

Kelley, R. L., G. A. Hurst, and D. E. Steffen. 1988. Home ranges of wild turkey gobblers in central Mississippi. Proceedings of the Annual Conference Southeastern Association of Fish and Wildlife Agencies 42:470-475.

Kulowiec, T. G., and J. B. Huafler. 1985. Winter and dispersal movements of wild turkeys in Michigan’s northern Lower Peninsula. Pages 145-153 in Proceedings of the Fifth National Wild Turkey Symposium (J. Earl and M. C. Kennemer, Eds.). National Wild Turkey Federation, Edgefield, South Carolina.

Kurzejeski, E. W., and J. B. Lewis. 1990. Home range, movements, and habitat use of wild turkey hens in northern Missouri. Pages 67-71 in Proceedings of the Sixth National Wild Turkey Symposium (W. M. Healy and G. B. Healy, Eds.). National Wild turkey Federation, Edgefield, South Carolina. 
and L. D. Vangilder. 1992. Population management. Pages 165-184 in The wild turkey: biology and management (J. G. Dickson, Ed.). Stackpole Books, Harrisburg, Pennsylvania.

Larson, J. D., and R. D. Taber. 1980. Criteria of sex and age. Pages 143-202 in Wildlife Management Techniques Manual, Fourth Edition (S. D. Schemnitz. Ed.). The Wildlife Society, Washington, D. C.

Lewis, J. C. 1963. Observations on the winter range of wild turkeys in Michigan. Journal of Wildlife Management 27:98-102.

Miller, J. E., and B. D. Leopold. 1992. Population influences: predators. Pages 119-128 in The wild turkey: biology and management (J. G. Dickson, Ed.). Stackpole Books, Harrisburg, Pennsylvania.

Miller, D. A., B. D. Leopold, and G. A. Hurst. 1997. Seasonal home ranges of wild turkeys in central Mississippi. Proceedings of the Annual Conference Southeastern Association of Fish and Wildlife Agencies 51:414-425.

, L. M. Conner, B. D. Leopold, and G. A. Hurst. 2001. Spatial fidelity of wild turkeys between seasons in central Mississippi. Proceedings of the Annual Conference Southeastern Association of Fish and Wildlife Agencies 55:475-487.

Nams, V. O., and S. Boutin. 1991. What is wrong with error polygons? Journal of Wildlife Management 55:172-176. 
Norman, G. W., J. C. Pack, and G. A. Hurst. 1997. Transmitter selection and attachment technique for wild turkey research. National Wild Turkey Federation Research Bulletin Number 4.

, _ _ C. I. Taylor, D. E. Steffen, and K. H. Pollock. 2001. Reproduction of eastern wild turkeys in Virginia and West Virginia. Journal of Wildlife Management 65:1-9.

, and D. E. Steffen. 2003. Effects of recruitment, oak mast, and fall-season format on wild turkey harvest rates in Virginia. Wildlife Society Bulletin 31:553-559.

, M. M. Conner, J. C. Pack, and G. C. White. 2004. Effects of fall hunting on survival of male wild turkeys in Virginia and West Virginia. Journal of Wildlife Management 68:393-404.

Pack, J. C., G. W. Norman, C. I. Taylor, D. E. Steffen, D. A. Swanson, K. H. Pollock, and R. Alpizar-Jara. 1999. Effects of fall hunting on wild turkey populations in Virginia and West Virginia. Journal of Wildlife Management 63:964-975.

Pelham, P. M., and J. G. Dickson. 1992. Physical characteristics. Pages 32-45 in The wild turkey: biology and management (J. G. Dickson, Ed.). Stackpole Books, Harrisburg, Pennsylvania.

Porter, W. F. 1977. Home range dynamics of wild turkeys in southeastern Minnesota. Journal of Wildlife Management 41:434-437. 
Ryan, C. W., J. C. Pack, W. K. Igo, J. C. Rieffenberger, and A. B. Billings. 2004. Relationship of mast production to big-game harvests in West Virginia. Wildlife Society Bulletin 32:786794.

Saltz, D. 1994. Reporting error measures in radio location by triangulation: a review. Journal of Wildlife Management 58:181-184.

Seaman, D. E., J. J. Millspaugh, B. J. Kernoham, G. C. Brundige, K. L. Raedeke, and R. A. Gitzen. 1999. Effects of sample size on kernel home range estimates. Journal of Wildlife Management 63:739-747.

Sisson, D. C., and D. W. Speake. 1994. Spring burning for wild turkey brood habitat: and evaluation. Proceedings of the Annual Conference Southeastern Association of Fish and Wildlife Agencies 48:134-139.

Speake, D. W., T. E. Lynch, W. J. Fleming, G. A. Wright, and W. J. Harnrick. 1975. Habitat use and seasonal movements of wild turkeys in the southeast. Pages 122-130 in L. K. Halls, ed. Proceedings of the Third National Wild Turkey Symposium. The Texas Chapter of the Wildlife Society.

Spencer, S. R., G. N. Cameron, and R. K. Swihart. 1990. Operationally defining home range: temporal dependence exhibited by hispid cotton rats. Ecology 71:1817-1822.

Strausbaugh, P. D., and E. L. Core. 1978. Flora of West Virginia, Second Edition. Seneca Books. Morgantown, West Virginia.

Townsend, D. E. II., S. S. Ditchkoff, and S. D. Fuhlendorf. 2007. Transmitter height influences error of ground-based radio-telemetry. Wildlife Biology 13:98-101. 
Uhlig, H. G., and H. L. Wilson. 1952. A method of evaluating an annual mast index. Journal of Wildlife Management 16:338-343.

Vogt, J. T. 2007. Three-dimensional sampling method for characterizing ant mounds. Florida Entomologist 90:553-558.

Wallingford, B. D., and R. A. Lancia. 1991. Telemetry accuracy and a model for predicting telemetry error. Proceedings of the Annual Conference Southeastern Association of Fish and Wildlife Agencies 45:178-188.

Wheeler, R. J. Jr. 1948. The wild turkey in Alabama. Alabama Department Conservation Bulletin 12.

White, G. C., and R. A. Garrott. 1990. Analysis of wildlife radio-tracking data. Academic Press, Inc., London, UK.

Wright, E. L., C. H. Delp, K. Sponaugle, C. Cole, J. T. Ammonsm J. Gorman, and F. D. Childs. 1982. Soil Survey of Marion and Monongalia Counties, West Virginia. U.S. Department of Agriculture, Soil Conservation Service, Washington, D. C.

Wright, G. A., and L. D. Vangilder. 2005. Survival and dispersal of eastern wild turkey males in western Kentucky. Pages 367-373 in Wild turkey management: accomplishments, strategies, and opportunities (C. A. Stewart and V. R. Frawley, Eds.). Proceedings of the Ninth National Wild Turkey Symposium. Michigan Department of Natural Resources, Lansing, Michigan. 
Zielinski, W. J., R. L. Truex, G. A. Schmidt, F. V. Schilexer, K. N. Schmidt, and R. H. Barrett. 2004. Home range characteristics of fishers in California. Journal of Mammalogy 85:649657. 
TABLE 1. The eccentricity (E) of the home range shape of adult and juvenile male Eastern Wild Turkeys in West Virginia, 2004-2007.

\begin{tabular}{cccccccc}
\hline $\begin{array}{c}\text { Study } \\
\text { Area }\end{array}$ & Age & Median & $\bar{x}$ & SD & Skewness & Kurtosis & IQR $^{\mathrm{a}}$ \\
\hline Statewide & $\begin{array}{c}\text { Adults } \\
(n=40) \\
\text { Juvenile } \\
(n=26)\end{array}$ & 2.004 & 2.421 & 1.516 & 3.103 & 9.987 & 0.689 \\
DISA & $\begin{array}{c}\text { Adults } \\
(n=9) \\
\text { Juvenile } \\
(n=19)\end{array}$ & 2.47 & 3.083 & 1.891 & 1.222 & 0.365 & 2.224 \\
\hline
\end{tabular}

aQR - Interquartile Range 
TABLE 2. The Eccentricity (E) of the home range shape of three age classes of male Eastern Wild Turkeys in the District I Study Area (DISA) in north-central West Virginia during the April-May period, 2006-2007.

\begin{tabular}{|c|c|c|c|c|}
\hline Age & $n$ & Median & $\bar{x}$ & $\mathrm{SD}$ \\
\hline Juvenile & 12 & 1.501 & 1.645 & 0.438 \\
\hline Adults (all) & 9 & 2.239 & 2.236 & 0.471 \\
\hline 2 Yr Adults & 4 & 2.620 & 2.540 & 0.234 \\
\hline 3 Yr+ Adults & 5 & 1.749 & 1.994 & 0.487 \\
\hline
\end{tabular}


TABLE 3. Results of linear regression analysis on the relation of mast conditions and the eccentricity of the fall-winter home range shape of male Eastern Wild Turkeys in West Virginia, 2004-2007.

\begin{tabular}{cccccc}
\hline Variables & Estimate $(\beta)$ & SE & $t$-Value & $P$ & $R^{2}$ \\
\hline Juveniles & -0.667 & 0.227 & -2.94 & 0.005 & 0.17 \\
Hard Mast & -0.034 & 0.018 & -1.95 & 0.056 \\
\hline
\end{tabular}


TABLE 4. Male Eastern Wild Turkey population estimates, by age class, from Downing Population Reconstruction (Downing 1980) using harvest figures and spur lengths from the cooperators of the annual Spring Gobbler Survey in West Virginia, 2005-2007.

\begin{tabular}{cccc}
\hline & & Year & \\
\cline { 2 - 3 } Age & 2005 & 2006 & 2007 \\
\cline { 2 - 4 } Juveniles & 15,935 & 5,198 & 10,609 \\
2 yr-old adults & 11,495 & 13,393 & 3,555 \\
$3+$ yr-old adults & 23,243 & 26,324 & 29,624 \\
Total population est. & $\mathbf{5 0 , 6 7 3}$ & $\mathbf{4 4 , 9 1 4}$ & $\mathbf{4 3 , 7 8 8}$ \\
\hline
\end{tabular}


TABLE 5. Results of linear regression analysis on the relation of the eccentricity (E) of the home range shape of adult and juvenile male Eastern Wild Turkeys and male Eastern Wild Turkey Downing Population Reconstruction (Downing 1980) estimates in West Virginia, 2005-2007.

\begin{tabular}{|c|c|c|c|c|c|}
\hline Variables & Estimate $(\beta)$ & $\mathrm{SE}$ & $t$-Value & $P$ & $R^{2}$ \\
\hline 2006 & -0.180 & -0.304 & -0.594 & 0.56 & 0.32 \\
\hline 2007 & -0.784 & -0.359 & -2.186 & 0.03 & \\
\hline Region 1 & -0.562 & -0.602 & -0.934 & 0.36 & \\
\hline Region 4 & -0.007 & -0.226 & 0.031 & 0.98 & \\
\hline Region 6 & -0.694 & -0.339 & -2.045 & 0.047 & \\
\hline Age (juv.) & -2.787 & 1.099 & -2.536 & 0.02 & \\
\hline $\begin{array}{c}\text { Population } \\
\text { Estimate }\end{array}$ & -0.00007 & -0.00005 & -1.572 & 0.12 & \\
\hline
\end{tabular}


TABLE 6. Results of linear regression analysis on the relation of the eccentricity (E) of the home range shape of adult and juvenile male Eastern Wild Turkeys and the fate of radioed male Eastern Wild Turkeys in West Virginia, 2004-2007.

\begin{tabular}{cccccc}
\hline Variables & Estimate $(\beta)$ & SE & $t$-Value & $P$ & $R^{2}$ \\
\hline Age(juv) & 1.307 & 0.651 & 2.009 & 0.049 & 0.08 \\
Legal Harvest & 1.025 & 0.799 & 1.283 & 0.205 \\
Illegal Kill & 0.679 & 1.223 & 0.555 & 0.581 \\
Other & 0.498 & 0.915 & 0.544 & 0.589 \\
Predation & 1.473 & 0.886 & 1.663 & 0.102 \\
\hline
\end{tabular}


TABLE 7. Mast indices for three of the six ecological regions of West Virginia, 2004-2006.

\begin{tabular}{|c|c|c|c|c|c|c|}
\hline \multirow[b]{2}{*}{ Year } & \multirow[b]{2}{*}{ Region } & \multicolumn{5}{|c|}{ Mast Indices $^{\mathrm{a}}$} \\
\hline & & Hard mast ${ }^{b}$ & $\begin{array}{l}\text { Hard mast } \\
\text { + cherry }\end{array}$ & Soft mast ${ }^{\mathrm{c}}$ & $\begin{array}{l}\text { Total mast } \\
\text { for region }\end{array}$ & $\begin{array}{l}\text { Total mast } \\
\text { statewide }\end{array}$ \\
\hline \multirow{3}{*}{2004} & 2 & 32 & 31 & 40 & 37 & 36 \\
\hline & 4 & 29 & 31 & 40 & 36 & 36 \\
\hline & 6 & 26 & 32 & 51 & 41 & 36 \\
\hline \multirow{3}{*}{2005} & 2 & 31 & 33 & 39 & 35 & 45 \\
\hline & 4 & 23 & 29 & 49 & 38 & 45 \\
\hline & 6 & 43 & 43 & 60 & 53 & 45 \\
\hline \multirow{3}{*}{2006} & 2 & 30 & 29 & 42 & 38 & 45 \\
\hline & 4 & 29 & 27 & 44 & 38 & 45 \\
\hline & 6 & 49 & 51 & 64 & 58 & 45 \\
\hline
\end{tabular}

${ }^{\mathrm{a}}$ Mast Index $=[$ abundant observations/total observations $]+[$ common observations $\times 0.5 /$ total observations] $\times 100$

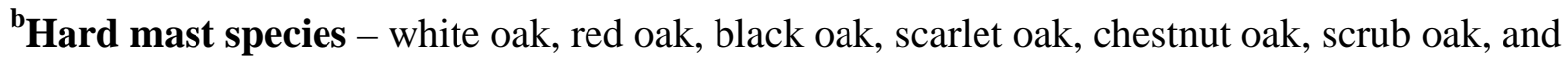
American beech.

'Soft mast species - black cherry, grapes, hawthorn, crabapple, flowering dogwood, greenbrier, blackberry, sassafras, and yellow poplar. 


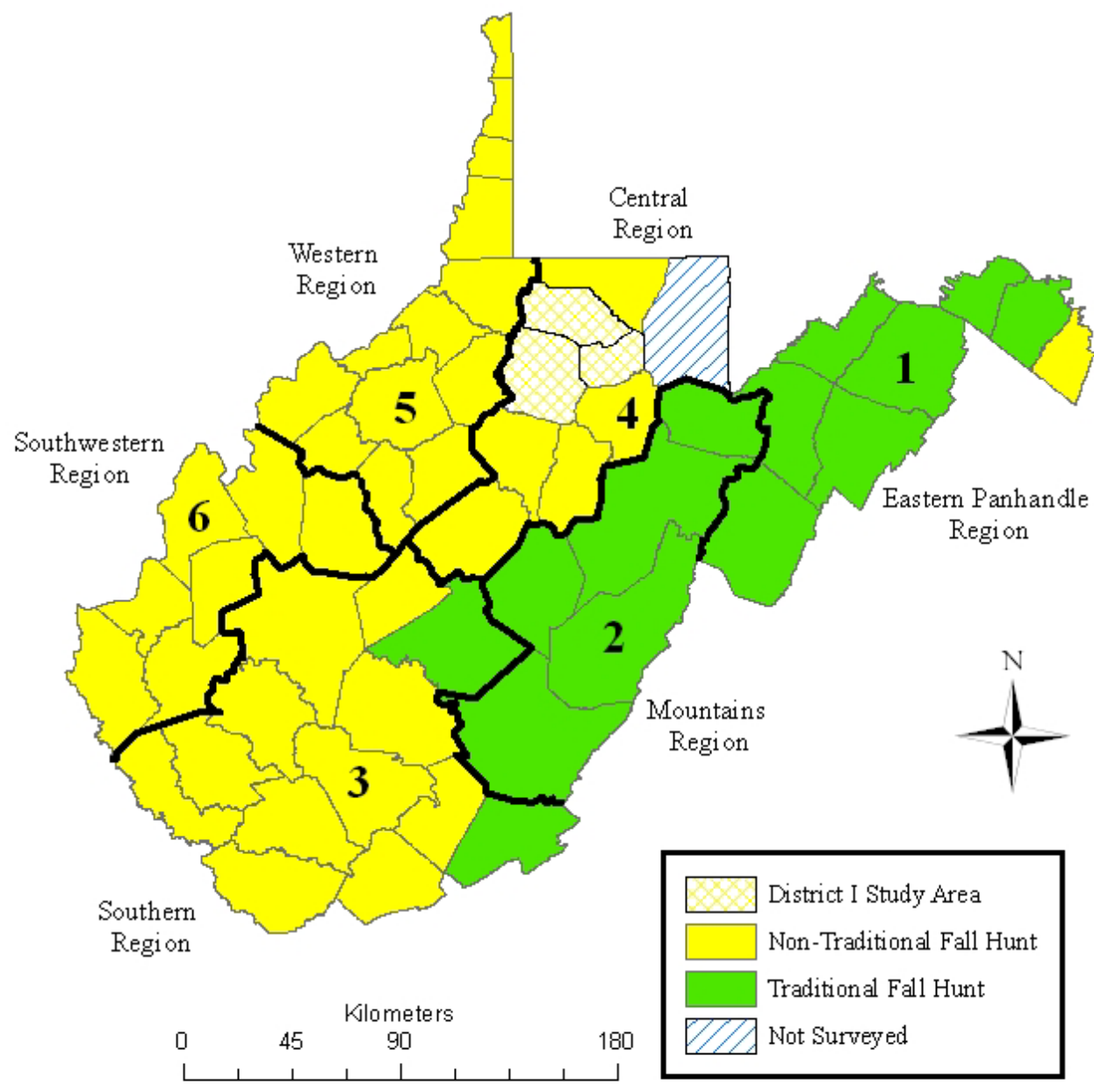

FIG. 1. Eastern Wild Turkey home range study sites, including the fall wild turkey hunting season format and Ecological Regions in West Virginia. 
Chapter $4^{\mathrm{c}}$

RRH: SHORT COMMUNICATIONS

\title{
Spring Hunting Season Home Range Size of Male Wild Turkeys in North-Central West Virginia
}

\author{
Steven E. Rauch ${ }^{1,4}$, James T. Anderson ${ }^{2}$, and A. B. Billings ${ }^{3}$
}

${ }^{1}$ West Virginia Division of Natural Resources, P.O. Box 99, Farmington, WV 26571, USA.

${ }^{2}$ Division of Forestry and Natural Resources, West Virginia University, Morgantown, WV 26506, USA.

${ }^{3}$ Department of Statistics, West Virginia University, Morgantown, WV 26506, USA.

${ }^{4}$ Corresponding author; e-mail: steverauch@wvdnr.gov

${ }^{\mathrm{C}}$ This chapter written in the style of The Wilson Journal of Ornithology 
ABSTRACT .---An understanding of the home range size of the male Eastern Wild Turkey (Meleagris gallopavo silvestris), hereafter, wild turkey, is important for effective management. We estimated the home range size of adult and juvenile male wild turkey during the April-May spring hunting season period of 2006 and 2007 in north-central West Virginia. Additionally, we compared the home range size of the 2-year and the 3year+ age classes of adult male wild turkey. We examined the relation between male wild turkey population size estimates and home range size during the April-May period. Adult male wild turkey had a larger home range $(\bar{x}=410.5 \mathrm{ha}, \mathrm{SD}=74.8)$ than did juvenile $(\bar{x}=163.5 \mathrm{ha}, \mathrm{SD}=74.7)$ during the period $(P<0.001)$. We found no difference in the home range size of the 2-year age class and the 3-year+ age class of adult male wild turkey $(P=0.46)$. We detected a relation $(P<0.001)$ between population size and the April-May home range size of male wild turkey. We suspect that movement related to breeding behavior was a factor in adults having larger home ranges during the period. Our results can benefit resource managers and spring turkey hunters by providing behavior information on the male wild turkey home range characteristics during the spring turkey hunting season. 
Numerous studies have reported male Eastern Wild Turkey (Meleagris gallopavo silvestris), hereafter, male wild turkey or gobbler, home range size (Ellis and Lewis 1967, Speake et al. 1975, Everett et al. 1979, Brown 1980, Kelley et al. 1988, Godwin et al. 1995, Miller et al. 1997), but few have estimated home range size associated with spring gobbler hunting season. Male wild turkey home range size estimates, during the spring gobbler season, are lacking in West Virginia.

It is important to understand the variables that may influence legal spring harvest rates of male wild turkeys to make effective management decisions. Home range size is fundamental knowledge for making these decisions. Legal spring harvest rates of male wild turkey have varied from $15 \%$ to $51 \%$ across their range (Vangilder 1992) and have been estimated to be $16.5 \%$ in West Virginia (West Virginia Division of Natural Resources 2009). Also, state wildlife personnel are frequently questioned by wild turkey hunters about behavior characteristics of male wild turkey during the spring turkey season. Our objective was to estimate the home range size of male wild turkey during April-May 2006 and 2007 in north-central West Virginia. We also studied the relation between the April-May home range size and male wild turkey population size estimates.

\section{METHODS}

Study Area. Our study area was located in Marion, Taylor, and northern Harrison counties of north-central West Virginia (Fig. 1). The topography of Harrison and Taylor counties was mostly steep to very steep hillsides with narrow floodplains (Beverage and Yoakum 1980), while Marion County was described as having mountain ranges oriented in a northeast-southwest direction with steep hillsides and narrow valleys (Wright et al. 1982). The three county area averages $59.5 \%$ forested with $62.2 \%$ of the forestland 
comprised of oak (Quercus spp.)-hickory (Carya spp.) (Griffith and Widmann 2003).

Elevations ranged from 260 to $625 \mathrm{~m}$ across the study area. All three counties were located in the Central Allegheny Plateau, which was part of the Central Hardwood Forest. Within central Taylor County was the 713.9-ha Pruntytown State Farm Wildlife Management Area (WMA). The WMA was characterized with gently rolling to moderately steep hills and level lowlands and elevations ranging from $335 \mathrm{~m}$ to $494 \mathrm{~m}$. About $62 \%$ of the WMA was openlands, with forestlands (35\%), wetlands (2\%), and developed areas (1\%) making up the remaining area (Rauch 2002).

Trapping and Telemetry. Trapping of wild turkey was conducted on private property and on the Pruntytown State Farm WMA, at eight sites baited with cracked/whole corn, in September-November and January-March of 2004-2007 by the use of rocket nets (Kurzejeski and Vangilder 1992). Each captured wild turkey was aged (adult or juvenile) and sexed by use of feather coloration as described by Pelham and Dickson (1992). Juvenile wild turkeys were aged and sexed as described by Healy and Nenno (1980), while we used Larson and Taber (1980) to age early September caught yearling wild turkeys (12-16 months) by the tenth primary. All wild turkeys were weighed with spring scales and mass was recorded. Moreover, we recorded each wild turkeys' physical condition at time of capture. All wild turkeys were fitted with a uniquely numbered aluminum leg band. All wild turkeys were released at the capture site and capture site coordinates were recorded in Universal Transverse Mercator (UTM).

We only considered male wild turkeys with a mass $\geq 1.6 \mathrm{~kg}$ and having a physical condition of good (minor feather loss, minor scalping) or excellent (no feather loss, no injuries) for transmitter placement. Selected male wild turkeys were fitted with backpack 
style transmitters (Advanced Telemetry Systems Inc. (ATS) Isanti, MN) weighing about $80 \mathrm{~g}$. Transmitters were affixed to the wild turkey with a harness made from $4.8 \mathrm{~mm}$ nylon shock cord (Norman et al. 1997). Each transmitter contained a motion-mortality sensor and the frequencies operated between 150 and $152 \mathrm{MHz}$.

We used triangulation (Cochran and Lord 1963) to locate each radioed male wild turkey a minimum of three times per week during the months of April and May of 2006 and 2007 with at least two directional azimuths being used to obtain a location (Andelt and Gipson 1979, Nams and Boutin 1991, Wallingford and Lancia 1991, Zielinski et al. 2004). If only two intersecting directional azimuths were taken, we only used a location generated from azimuths separated by $\geq 60^{\circ}$ and $\leq 120^{\circ}$ (Kurzejeski and Lewis 1990, Sisson and Speake 1994, Miller et al. 2001). We used only locations determined by azimuths taken $\leq 20$ minutes apart. We placed transmitters, attached to $2.0 \mathrm{~L}$ bottles filled with a saline solution, in forested areas at an average height of wild turkeys (46 $\mathrm{cm}$ : Townsend et al. 2007) to estimate telemetry error. Average telemetry error was $6^{\circ}$ $(\mathrm{SE}=0.84)$ with a mean distance between receiving location and transmitter of $458.9 \mathrm{~m}$ (SE = 59.12) ( $\mathrm{N}=18$ : White and Garrott 1990). We used program LOCATE III (Pacer Computing, Truro, NS, Canada) to measure a 95\% confidence ellipse of 7.7 ha (SD = 8.9) associated with the telemetry error (White and Garrott 1990, Saltz 1994). Only male wild turkeys with a minimum of 30 locations (Seaman et al. 1999) during the April-May periods of 2006 and 2007 were included in home range size estimation. All locations were recorded in UTMs.

We defined adults as wild turkeys trapped as adults and wild turkeys trapped as juveniles once they reached their second September; wild turkeys trapped as juveniles 
during the fall or winter seasons were considered juveniles through the following August (Norman et al. 2004). We further defined the 3-year+ age class as adults monitored $\geq 1$ year or juveniles monitored $\geq 2$ years as adults (Norman et al. 2001). Male wild turkeys that entered the study as juveniles and survived to adults were analyzed within their respective age classes. Only male wild turkeys that survived through the month of May, i.e. not harvested, were used for estimation of home range size, and thus this method may have been biased.

An annual Spring Gobbler Survey has been conducted in West Virginia since 1983 by the West Virginia Division of Natural Resources (Wildlife Resources Section) (WVDNR-WRS) (Evans et al. 2007). Survey cooperators record daily observations and biological data from harvested male wild turkeys. Spur lengths and harvest figures of spring harvested male wild turkeys, from the Spring Gobbler Survey, were used as a sample of age classes to calculate a Downing Population Reconstruction (Downing 1980) estimate of male wild turkeys in the three-county study area.

Data Analysis. Program LOCATE III was used to generate UTM coordinates ( $X$ and $Y$ coordinates) of the locations from the telemetry data. To determine the spatial distribution of the radioed male wild turkeys in the study area, we used spatial autocorrelation in ArcMap 9.2 (Environmental Systems Research Institute, Inc. (ESRI) Redlands, CA) on the mean centers of the UTM coordinates for each radioed male wild turkey. Adult males were randomly located (Morans I Index $=0.27, z$ score $=1.18$ SD), and juvenile males were clustered (significant at $\alpha=0.01$, Morans I Index $=1.17, z$ score $=2.69 \mathrm{SD}$ ). ArcView GIS 3.3 with the Animal Movement Extension (Hooge et al. 1999) was used to estimate the home range size by the fixed kernel method with least 
squares cross validation for the smoothing factor (Worton 1989). Shapiro-Wilk normality tests were performed and although the adult home range estimates were normally distributed $(\mathrm{W}=0.828, P=0.077)$, the juvenile home range estimates were not normally distributed $(\mathrm{W}=0.821, P=0.017)$. Because normality assumptions were violated, the Kruskal-Wallis test was used as the nonparametric equivalent of ANOVA. Linear regression was used to compare effects of male wild turkey densities on the April-May home range size. Independent variables included age, year, and population estimate. The Shapiro-Wilk test of normality and graphical examination were performed on the residuals in the linear regression model to test the normality assumption. Statistical package R (R Foundation for Statistical Computing, Vienna Austria, http://CRAN.Rproject.org) was used for data analysis. Significance levels were set at $\alpha=0.05$ for all statistical tests.

\section{RESULTS}

We estimated the home range size of 7 adult and 12 juvenile male wild turkeys during the April-May periods of 2006 and 2007 (Appendix D). Adult male wild turkey mean $( \pm \mathrm{SD})$ home range $(410.5 \mathrm{ha} \pm 74.8$; kurtosis $=-1.346$, skewness $=0.690$, Interquartile Range $=90.80)$ was larger than that of juvenile male wild turkey (163.5 ha \pm 74.7 ; kurtosis $=-0.676$, skewness $=0.905$, Interquartile Range $=67.44$ : KruskalWallis one-way ANOVA, $\chi^{2}{ }_{1,18}=12.644, P<0.001$ ) during the April-May period. We estimated no significant difference $\left(\chi^{2}{ }_{1,8}=0.54, P=0.46\right)$ in the home range size of the 2-year age class $(n=4)$ and the 3-year+ age class $(n=5)$ of adult male wild turkeys during the April-May period. The 2-year age class of male wild turkeys had an estimated mean home range size of 365.7 ha \pm 39.6 , while the 3-year+ age class had an 
estimated home range size of 455 ha \pm 150.9 (Table 1 ). There was no significant difference $\left(\chi_{1,9}^{2}=0.96, P=0.33\right)$ between years for adult male wild turkey home range size.

A Downing Population Reconstruction estimate by age class (Table 2) was used to test for a relation between male wild turkey population size and April-May home range size. Initial evaluation of the linear model residuals showed a lack of normality (W $=0.87, P=0.01$ ). We subsequently removed two outliers (adult-2007, juvenile-2006) from analysis to meet the normality assumption of the linear model $(\mathrm{W}=0.932, P=$ 0.17). We detected a significant relation $\left(F_{3,16}=43.12, P<0.001\right)$ between population size and the April-May home range size of male wild turkey (Table 3). Our linear model accounted for a high portion $\left(R^{2}=0.89\right)$ of the variability on April-May home range size and population size.

\section{DISCUSSION}

Adult male wild turkeys had larger home ranges than did juveniles during the April-May period. Our results did not completely agree with other estimates of home ranges, although comparisons to other studies are tentative at best because of various study variables, i.e. biological seasons, age classes. Kelley et al. (1988) found home range sizes of non-harvested adult and juvenile male wild turkeys during the Mississippi spring hunting season (22 Mar-1 May) over a two year period to be 578 ha and 680 ha, respectively. Also, Kelley et al. (1988) did not detect a significant difference within years between the adult and juvenile home ranges. In the Arkansas Ozarks, display range $\left(\mathrm{km}^{2}\right)$, defined as the home range occupied from $1 \mathrm{Apr}-15 \mathrm{Jun}$, was smaller for adult males (TY [third year after hatching] $4.9 \pm 1.4$; ATY [after third year since hatching] 0.9 
$\pm 0.05)$ than for juvenile $(10.7 \pm 2.8)$ (Badyaev et al. 1996a). Fleming and Webb (1974) found no difference in the breeding season (March - 15 Jun) mean home range size of adult (93.5 ha) and juvenile (95.0 ha) male wild turkeys in South Carolina.

Adult male wild turkey home range was probably dominated by movements related to courtship/mating behavior (Kelley et al. 1988). The adult males are the dominant breeders (Healy 1992), and there is evidence that they can suppress the physiological and behavioral development of juveniles (Lisano and Kennamer 1977). We agree with the conclusions of Kelley et al. (1988) that larger spring time home ranges may assist male wild turkey in finding female wild turkey during the breeding season. Badyaev et al. (1996b) found that early-nesting female wild turkey had higher nesting survival than did later nesting females and surmised that male wild turkey could increase their reproductive success by breeding with the early-nesting females. This may be a factor in our results in that adult male wild turkey potentially could encounter more of the early-nesting females by ranging over a larger area.

Our results showed an effect on the April-May home range size of male wild turkeys from population size estimates. Lower wild turkey population size may require male wild turkey, especially adults, to travel larger areas to find females for breeding purposes. Several studies have reported the largest male wild turkey home ranges occurred during the spring (Wigley et al. 1985, Exum et al. 1987, Kelley 1987, Godwin et al. 1995). Fearer and Pack (2003) found that the second smallest seasonal home range size (739 ha) of adult female wild turkeys occurred during the spring in West Virginia. Our results may show that male wild turkey, especially adults, are required to use larger home ranges during the April-May period to increase breeding potential 
during periods of lower turkey population densities. Godwin et al. (1995) found that male wild turkey spring home range overlap decreased and distance between activity centers increased and concluded that increased movements of male wild turkey searching for females created a "spacing" effect, although they detected no significant relation between relative male wild turkey abundance and spring home range size. They did state that sample size may have limited the power of their correlation analysis.

Additionally, Godwin et al. (1990) believed that breeding behavior caused a less dense spatial distribution of male wild turkey in Mississippi.

Our results can assist state wildlife agencies in providing behavioral information of the male wild turkey during the spring gobbler season to spring turkey hunters. Popular turkey hunting literature frequently states the premise of male wild turkeys having a specific roosting/strutting area. A recent survey showed that high gobbling activity was the primary factor contributing greatly to the enjoyment of $85 \%$ of spring turkey hunters in Ohio (Swanson et al. 2005) and turkey hunter success is to some extent dependent on gobbling rates from day to day during the turkey season, but our results show that male wild turkeys may not be restricted to specific areas, but rather have sizable home ranges during the hunting season. Thus a turkey hunter hunting the same specific area time after time will be affected by the movement of the male wild turkey. This insight into the home range size of male wild turkey can benefit the hunter in both pre-season scouting and recreational days afield.

\section{ACKNOWLEDGMENTS}

Data for this study were collected in conjunction with the Mid-Atlantic Gobbler Study (MAGS), a joint effort between the West Virginia Division of Natural Resources 
(Wildlife Resources Section), the Virginia Department of Game and Inland Fisheries, and the West Virginia State Chapter of the National Wild Turkey Federation. Funding for the MAGS, in part, was provided by the WVDNR-WRS and the Federal Aid in Wildlife Restoration Grant W-48-R. We are grateful to J. Edwards for reviewing this manuscript. We are grateful to J. Evans (retired) for providing the Downing Population Reconstruction estimates of male wild turkeys and for reviewing this manuscript. Special thanks go to G. Foster and M. Peters for the extra effort they put into tracking the wild turkeys used for this analysis. Thanks goes to the West Virginia Chapter of The National Wild Turkey Federation for the funding of the transmitters used in the MAGS. This manuscript is scientific article number xxxx of the West Virginia University Agriculture and Forestry Experiment Station. 


\section{LITERATURE CITED}

Andelt, W. F., and P. S. Gipson. 1979. Home range, activity, and daily movements of coyotes. Journal of Wildlife Management 43:944-951.

Badyaev, A. V., W. J. Etges, and T. E. Martin. 1996a. Age-biased spring dispersal in male wild turkeys. Auk 113:240-242.

and 1996b. Ecological and behavioral correlates of variation in seasonal home ranges of wild turkeys. Journal of Wildlife Management 60:154-164.

Beverage, W. W., and T. D. Yoakum. 1980. Soil survey of Harrison and Taylor Counties, West Virginia. U.S. Department of Agriculture, Soil Conservation Service, Washington, D.C., USA.

Brown, E. K. 1980. Home range and movement of wild turkeys - a review. Pages 251261 in Proceedings of the Fourth National Wild Turkey Symposium (J. M. Sweeny, Editor). National Wild Turkey Federation, Edgefield, South Carolina, USA.

Cochran, W. W., and R. D. Lord. 1963. A radio-tracking system for wild animals. Journal of Wildlife Management 27:9-24.

Downing, R. L. 1980. Vital statistics of animal populations. Pages 247-267 in Wildlife Techniques Manual (S. D. Schemnitz, Editor). The Wildlife Society, Washington, D.C., USA. 
Ellis, J. E., and J. B. Lewis. 1967. Mobility and annual range of wild turkeys in Missouri. Journal of Wildlife Management 31:568-581.

Exum, J. H., J. A. McGlincy, D. W. Speake, J. L. Buckner, and F. M. Stanley. 1987. Ecology of the eastern wild turkey in an intensively managed pine forest in southern Alabama. Tall Timbers Research Station Bulletin No. 23, Tallahassee, Florida, USA.

Evans, J. E., J. C. Pack, W. K. Igo, R. L. Tucker, G. H. Sharp, D. Vandevander, and C. P. Carpenter. 2007. 2007 Spring gobbler survey. West Virginia Division of Natural Resources, Wildlife Resources Section and West Virginia Chapter of the National Wild Turkey Federation, Wildlife Resources Section Bulletin 08-02, Charleston, West Virginia, USA.

Everett, D. D., D. W. Speake, and W. K. Maddox. 1979. Wild turkey ranges in Alabama mountain habitat. Proceedings of the Annual Conference Southeastern Association of Fish and Wildlife Agencies 33:233-238.

Fearer, T. M., and J. C. Pack. 2003. Home range characteristics of female wild turkeys in West Virginia. West Virginia Division of Natural Resources. PR Report. Charleston, West Virginia, USA.

Fleming, W. H., and L. G. Webb. 1974. Home range, dispersal and habitat utilization of eastern wild turkey gobblers during the breeding season. Proceedings of the Annual Conference Southeastern Association of Game and Fish Commissioners 28:623-632. 
Godwin, K. D., W. E. Palmer, G. A. Hurst, and R. L. Kelly. 1990. Relationship of wild turkey gobbler movements and harvest rates to management area boundaries. Proceedings of the Annual Conference Southeastern Association of Fish and Wildlife Agencies 44:260-267.

, G. A. Hurst, and B. D. Leopold. 1995. Size and percent overlap of gobbler home range and core-use areas in central Mississippi. Pages 45-52 in Proceedings of the Seventh National Wild Turkey Symposium (J. G. Dickson, Editor). National Wild Turkey Federation, Edgefield, South Carolina, and Stackpole Books, Mechanicsburg, Pennsylvania, USA.

Griffith, D. M., and R. H. Widmann. 2003. Forest statistics for West Virginia: 1989 and 2000. Resources Bulletin NE-157. Newton Square, PA: U.S. Department of Agriculture, Forest Service. Northeastern Research Station, Newtown, Pennsylvania, USA.

Healy, W. M., and E. S. Nenno. 1980. Growth parameters and age and sex criteria for juvenile eastern wild turkeys. Pages 168-185 in Proceedings of the Fourth National Wild Turkey Symposium (J. M. Sweeney, Editor). National Wild Turkey Federation, Edgefield, South Carolina, USA.

. 1992. Behavior. Pages 46-65 in The wild turkey: biology and management (J. G. Dickson, Editor). Stackpole Books, Harrisburg, Pennsylvania, USA. Hooge, P. N., W. Eichenlaub, and E. Solomon. 1999. The animal movement program. USGS, Alaska Biological Science Center, U. S. Geological Survey, Anchorage, Alaska, USA. 
Kelley, R. L. 1987. Temporary emigration, area of capture influence, and home range size for wild turkey gobblers on Tallahala Wildlife Management Area. M.S. thesis, Mississippi State University, Mississippi, USA.

., G. A. Hurst, and D. E. Steffen. 1988. Home ranges of wild turkey gobblers in central Mississippi. Proceedings of the Annual Conference Southeastern Association of Fish and Wildlife Agencies 42:470-475.

Kurzejeski, E. W., and J. B. Lewis. 1990. Home range, movements, and habitat use of wild turkey hens in northern Missouri. Pages 67-71 in Proceedings of the Sixth National Wild Turkey Symposium (W. M. Healy and G. B. Healy, Editors). National Wild Turkey Federation, Edgefield, South Carolina, USA. , and L. D. Vangilder. 1992. Population management. Pages 165-184 in The wild turkey: biology and management (J. G. Dickson, Editor). Stackpole Books, Harrisburg, Pennsylvania, USA.

Larson, J. D., and R. D. Taber. 1980. Criteria of sex and age. Pages 143-202 in Wildlife Techniques Manual (S. D. Schemnitz, Editor). The Wildlife Society, Washington, D.C., USA.

Lisano, M. E., and J. E. Kennamer. 1977. Seasonal variation in plasma testosterone level in male eastern wild turkeys. Journal of Wildlife Management 41:184-188.

Miller, D. A., B. D. Leopold, and G. A. Hurst. 1997. Seasonal home ranges of wild turkeys in central Mississippi. Proceedings of the Annual Conference Southeastern Association of Fish and Wildlife Agencies 51:414-425. 
, L. M. Conner, B. D. Leopold, and G. A. Hurst. 2001. Spatial fidelity of wild turkeys between seasons in central Mississippi. Proceedings of the Annual Conference Southeastern Association of Fish and Wildlife Agencies 55:475-487.

Nams, V. O., and S. Boutin. 1991. What is wrong with error polygons? Journal of Wildlife Management 55:172-176.

Norman, G. W., J. C. Pack, and G. A. Hurst. 1997. Transmitter selection and attachment technique for wild turkey research. National Wild Turkey Federation Research Bulletin Number 4, Edgefield, South Carolina, USA.

, C. I. Taylor, D. E. Steffen, and K. H. Pollock. 2001.

Reproduction of eastern wild turkeys in Virginia and West Virginia. Journal of Wildlife Management 65:1-9.

, M. M. Conner, J. C. Pack, and G. C. White. 2004. Effects of fall hunting on survival of male wild turkeys in Virginia and West Virginia. Journal of Wildlife Management 68:393-404.

Pelham, P. M., and J. G. Dickson. 1992. Physical characteristics. Pages 32-45 in The wild turkey: biology and management (J. G. Dickson, Editor). Stackpole Books, Harrisburg, Pennsylvania, USA.

Rauch, S. E. 2002. Wildlife management plan for the Pruntytown State Farm Wildlife Management Area. West Virginia Division of Natural Resources - District I. Farmington, West Virginia, USA. 
Saltz, D. 1994. Reporting error measures in radio location by triangulation: a review. Journal of Wildlife Management 58:181-184.

Seaman, D. E., J. J. Millspaugh, B. J. Kernohan, G. C. Brundige, K. L. Raedeke, and R. A. Gitzen. 1999. Effects of sample size on kernel home range estimates. Journal of Wildlife Management 63:739-747.

Sisson, D. C., and D. W. Speake. 1994. Spring burning for wild turkey brood habitat: an evaluation. Proceedings of the Annual Conference Southeastern Association of Fish and Wildlife Agencies 48:134-139.

Speake, D. W., L. H. Barwick, W. J. Fleming, G. A. Hillestad, and W. Stickney. 1975. Habitat use and seasonal movements of wild turkey in the southeast. Pages 122130 in Proceedings of the Third National Wild Turkey Symposium (L. K. Halls, Editor). The Texas Chapter of the Wildlife Society.

Swanson, D. A., R. J. Stoll, Jr., and W. L. Culbertson. 2005. Attitudes, preferences, and characteristics of Ohio's spring turkey hunters, 1985-2001. Pages 325-330 in Wild turkey management: accomplishments, strategies, and opportunities. Proceedings of the Ninth National Wild Turkey Symposium (C. A. Stewart and V. R. Frawley, Editors). Michigan Department of Natural Resources, Lansing, Michigan, USA.

Townsend, D. E. II., S. S. Ditchkoff, and S. D. Fuhlendorf. 2007. Transmitter height influences error of ground-based radio-telemetry. Wildlife Biology 13:98-101. 
Vangilder, L. D. 1992. Population dynamics. Pages 144-164 in The wild turkey: biology and management (J. G. Dickson, Editor). Stackpole Books, Harrisburg, Pennsylvania, USA.

Wallingford, B. D., and R. A. Lancia. 1991. Telemetry accuracy and a model for predicting telemetry error. Proceedings of the Annual Conference Southeastern Association of Fish and Wildlife Agencies 45:178-188.

West Virginia Division of Natural Resources. 2009. Pages 11-22 in 2008 Big Game Bulletin. West Virginia Division of Natural Resources Bulletin 09-1. Charleston, West Virginia, USA.

White, G. C, and R. A. Garrott. 1990. Analysis of wildlife radio-tracking data. Academic Press Inc., London, UK.

Wigley, T. B., J. M. Sweeney, M. E. Garner, and M. A. Melchiors. 1985. Forest habitat use by wild turkeys on the Ouachita Mountains. Pages 183-197 in Proceedings of the Fifth National Wild Turkey Symposium (J. Earl and M. C. Kennemer, Editors). National Wild Turkey Federation, Edgefield, South Carolina, USA.

Worton, B. J. 1989. Kernel methods for estimating the utilization distribution in homerange studies. Ecology 70:164-168.

Wright, E. L., C. H. Delp, K. Sponaugle, C. Cole, J. T. Ammons, J. Gorman, and F. D. Childs. 1982. Soil survey of Marion and Monongalia Counties, West Virginia. U.S. Department of Agriculture, Soil Conservation Service, Washington, D.C., USA. 
Zielinski, W. J., R. L. Truex, G. A. Schmidt, F. V. Schilexer, K. N. Schmidt, and R. H. Barrett. 2004. Home range characteristics of fishers in California. Journal of Mammalogy 85:649-657. 
TABLE 1. Home range sizes (ha) for male Eastern Wild Turkeys by age class and year during the April-May period in north-central West Virginia, 2006-2007.

\begin{tabular}{|c|c|c|c|c|c|c|c|c|}
\hline \multirow[b]{2}{*}{ Year } & \multicolumn{4}{|c|}{ Juvenile } & \multicolumn{4}{|c|}{ Adults } \\
\hline & $n$ & $\bar{x}$ & median & SD & $n$ & $\bar{x}$ & median & SD \\
\hline 2006 & 2 & 191.9 & 191.9 & 169.6 & 6 & 376.9 & 387.9 & 47.6 \\
\hline 2007 & 10 & 157.8 & 127.2 & 58.3 & 4 & 436.9 & 483.1 & 227.9 \\
\hline Overall & 12 & 163.5 & 127.2 & 74.7 & $7^{1}$ & 410.5 & 364.3 & 74.8 \\
\hline
\end{tabular}

${ }^{1}$ Total of different adult male wild turkeys for both years. 
TABLE 2. Male Eastern Wild Turkey population estimates for Harrison, Marion, and Taylor counties in West Virginia, by age class and year, from Downing Population Reconstruction (Downing 1980) using harvest figures and spur lengths from the cooperators of the annual Spring Gobbler Survey in West Virginia, 2006-2007.

\begin{tabular}{ccc}
\hline & \multicolumn{2}{c}{ Year } \\
\cline { 2 - 3 } Age Class & 2006 & 2007 \\
\hline Juveniles & 257 & 527 \\
2 yr-old adults & 666 & 181 \\
3+ yr-old adults & 1309 & 1506 \\
Total population estimate & $\mathbf{2 2 3 2}$ & $\mathbf{2 2 1 4}$ \\
\hline
\end{tabular}


TABLE 3. Results of linear regression analysis, after removing the two outliers, on the relation of the April-May home range size and the population estimate of male Eastern Wild Turkeys in Harrison, Marion, and Taylor counties, West Virginia, 2006-2007.

\begin{tabular}{cccccc}
\hline Variables & Estimate $(\beta)$ & SE & $t$-Value & $P$ & $R^{2}$ \\
Age & -278.93 & 42.62 & -6.544 & $<0.001$ & 0.89 \\
Year & 116.51 & 35.60 & 3.273 & 0.005 \\
Population & 1318.4 & 444.2 & 2.968 & 0.010 \\
Estimate & & & & \\
\hline
\end{tabular}




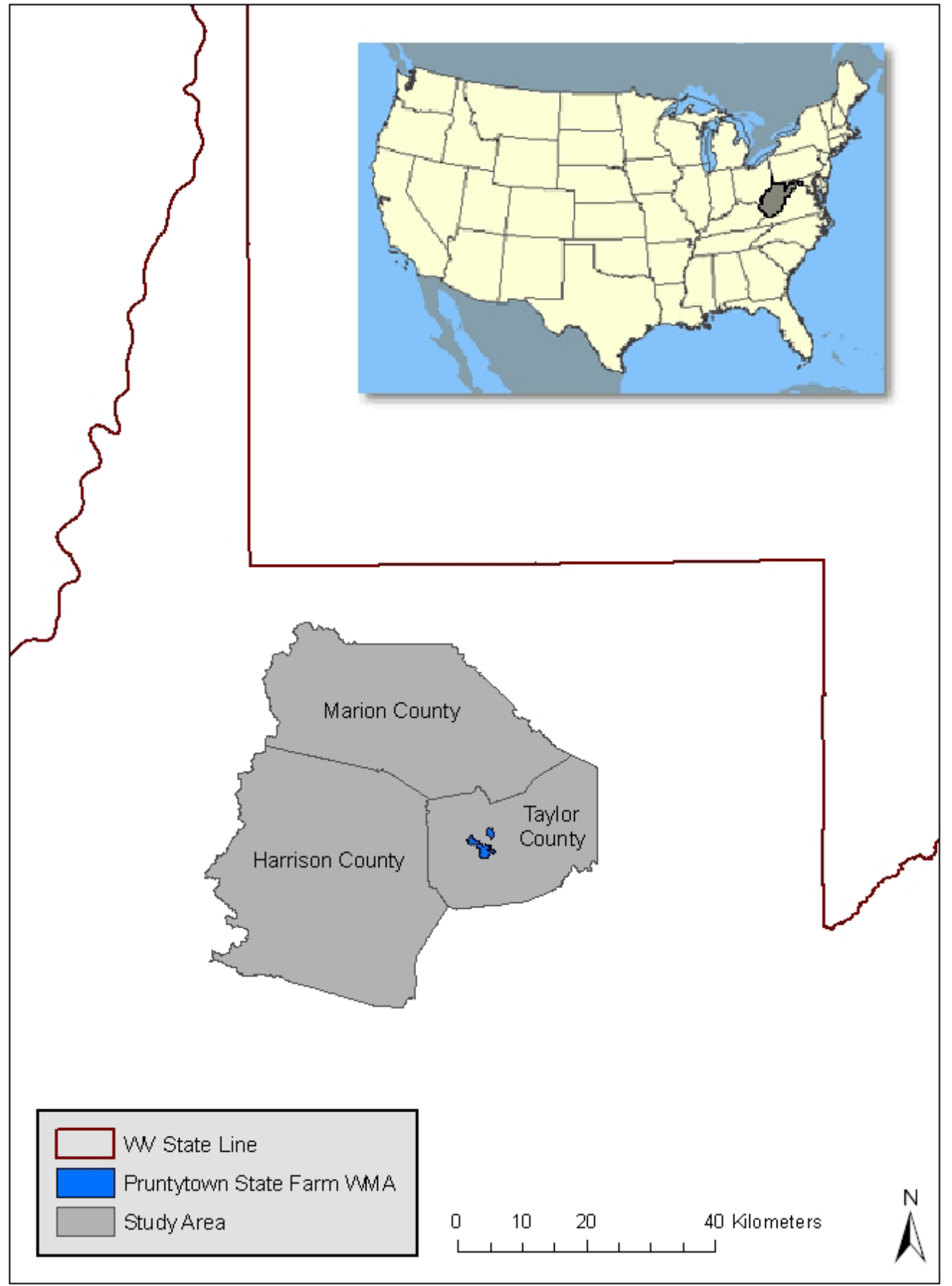

FIG. 1. District I Study Area in north-central West Virginia, 2006-2007, including the Pruntytown State Farm Wildlife Management Area (WMA). 
APPENDICES 
Appendix A. Ia-CLXXXIVa: Adult and juvenile 50\% and 95\% probability contours of the annual fixed kernel home range utilization distribution (UD) and 95\% probability contours of the seasonal fixed kernel home range UD for 55 male wild turkeys, West Virginia, 2004-2007.

Smoothing parameter (h) determined by least squares cross validation (100K topo map and 2003 SAMB imagery used for map backgrounds). 
Appendix Ia. RG5101 (juvenile) - 50\% and 95\% probability contours of the annual fixed kernel home range utilization distribution. Smoothing parameter (h) determined by least squares cross validation, Taylor County, West Virginia, 2004-2005 (100K topo map).

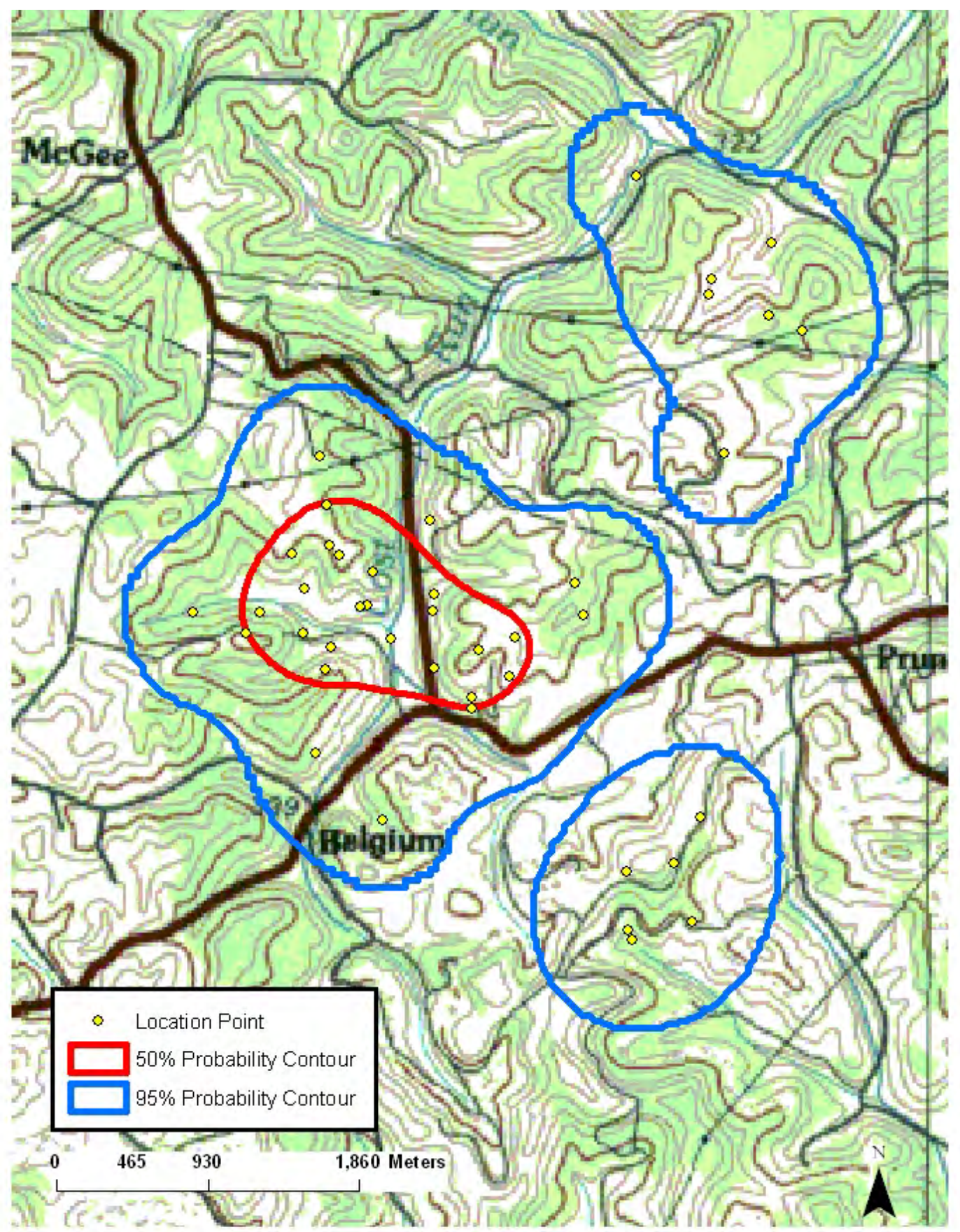


Appendix IIa. RG5101 (juvenile) - 50\% and 95\% probability contours of the annual fixed kernel home range utilization distribution. Smoothing parameter (h) determined by least squares cross validation, Taylor County, West Virginia, 2004-2005 (2003 SAMB imagery).

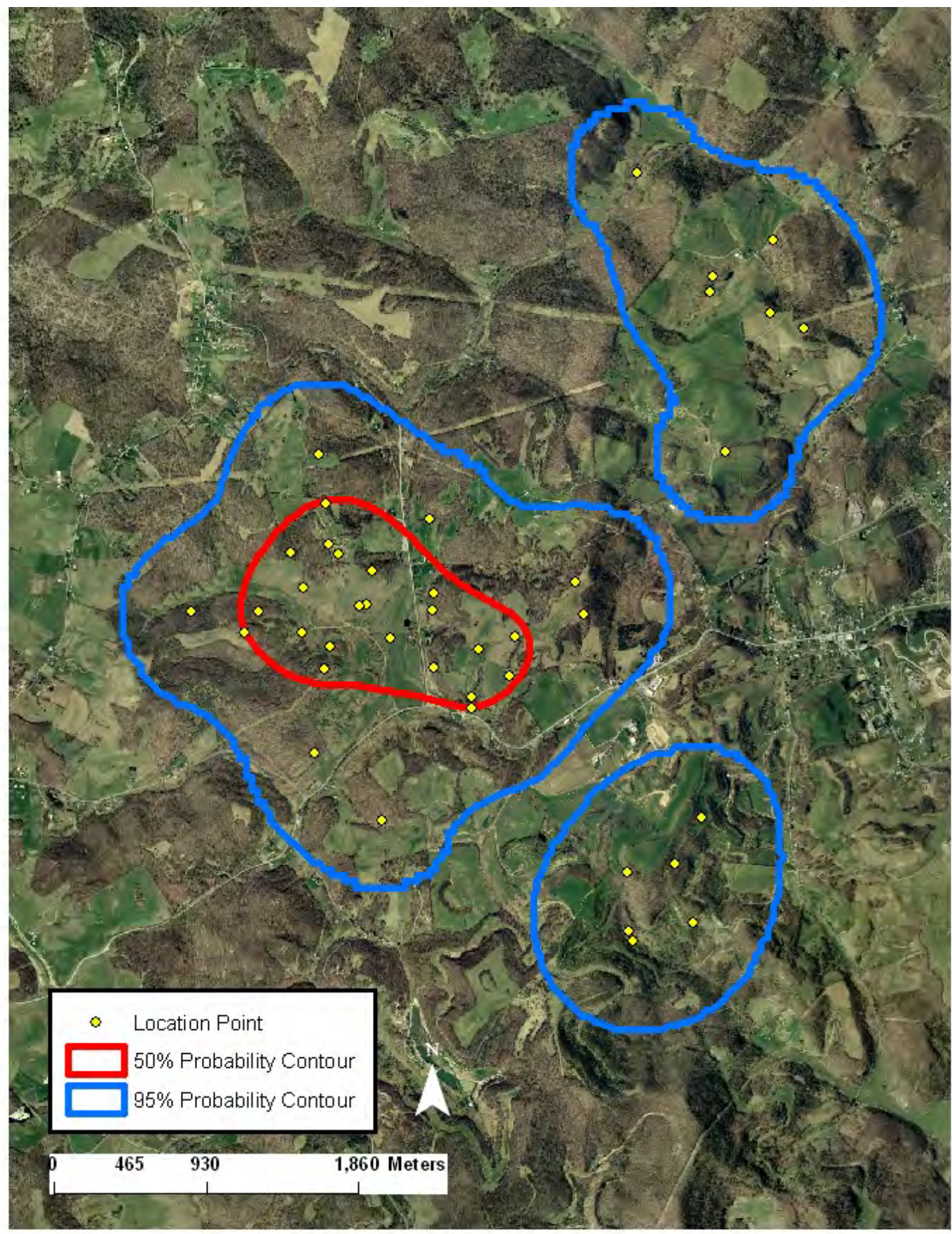


Appendix IIIa. RG5101 (adult) - 50\% and 95\% probability contours of the annual fixed kernel home range utilization distribution. Smoothing parameter (h) determined by least squares cross validation, Taylor County, West Virginia, 2005-2006 (100k topo map).

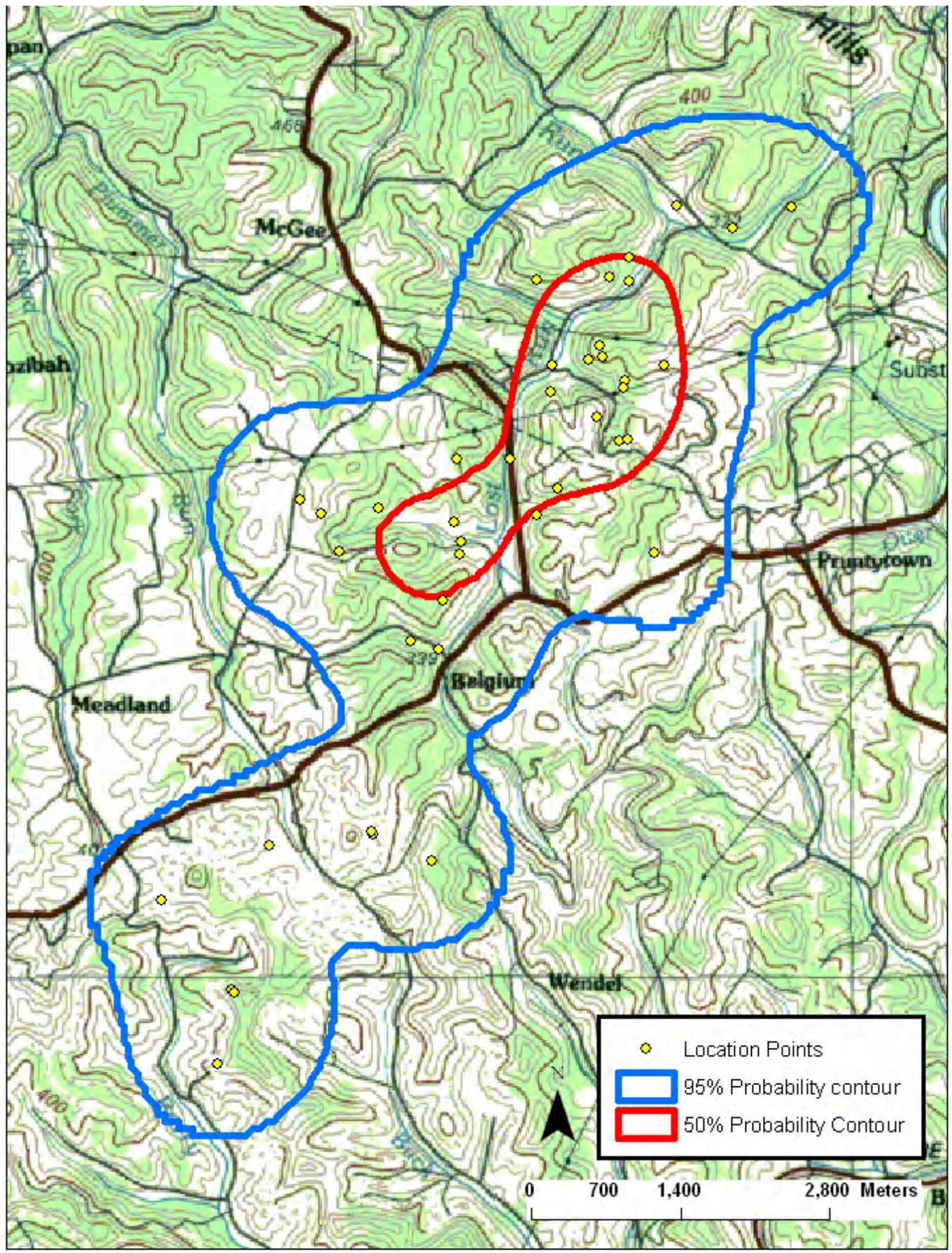


Appendix IVa. RG5101 (adult) - 50\% and 95\% probability contours of the annual fixed kernel home range utilization distribution. Smoothing parameter (h) determined by least squares cross validation, Taylor County, West Virginia, 2005-2006 (2003 SAMB imagery).

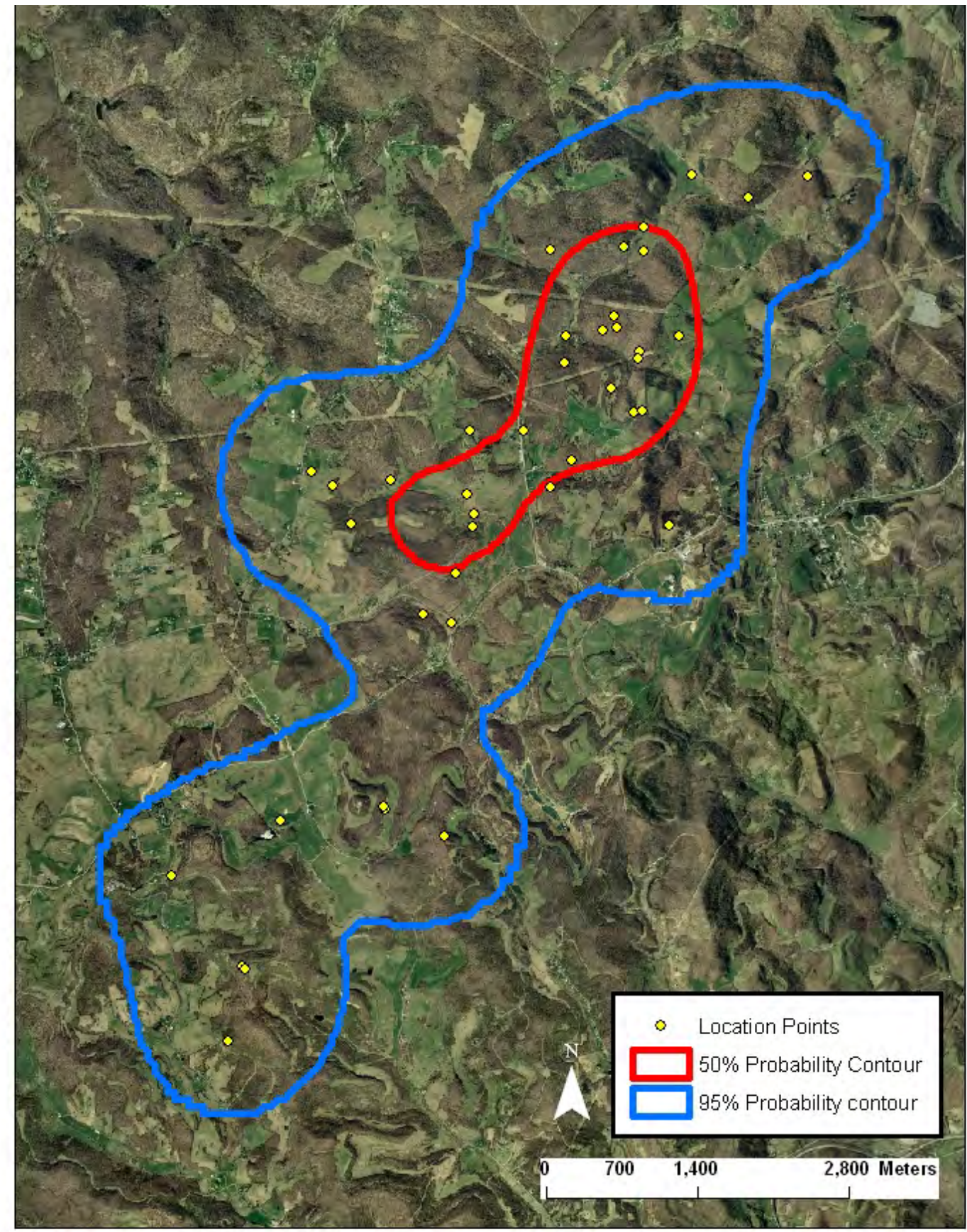


Appendix Va. RG5102 (juvenile) - 50\% and 95\% probability contours of the annual fixed kernel home range utilization distribution. Smoothing parameter (h) determined by least squares cross validation, Taylor County, West Virginia, 2004-2005 (100k topo map).

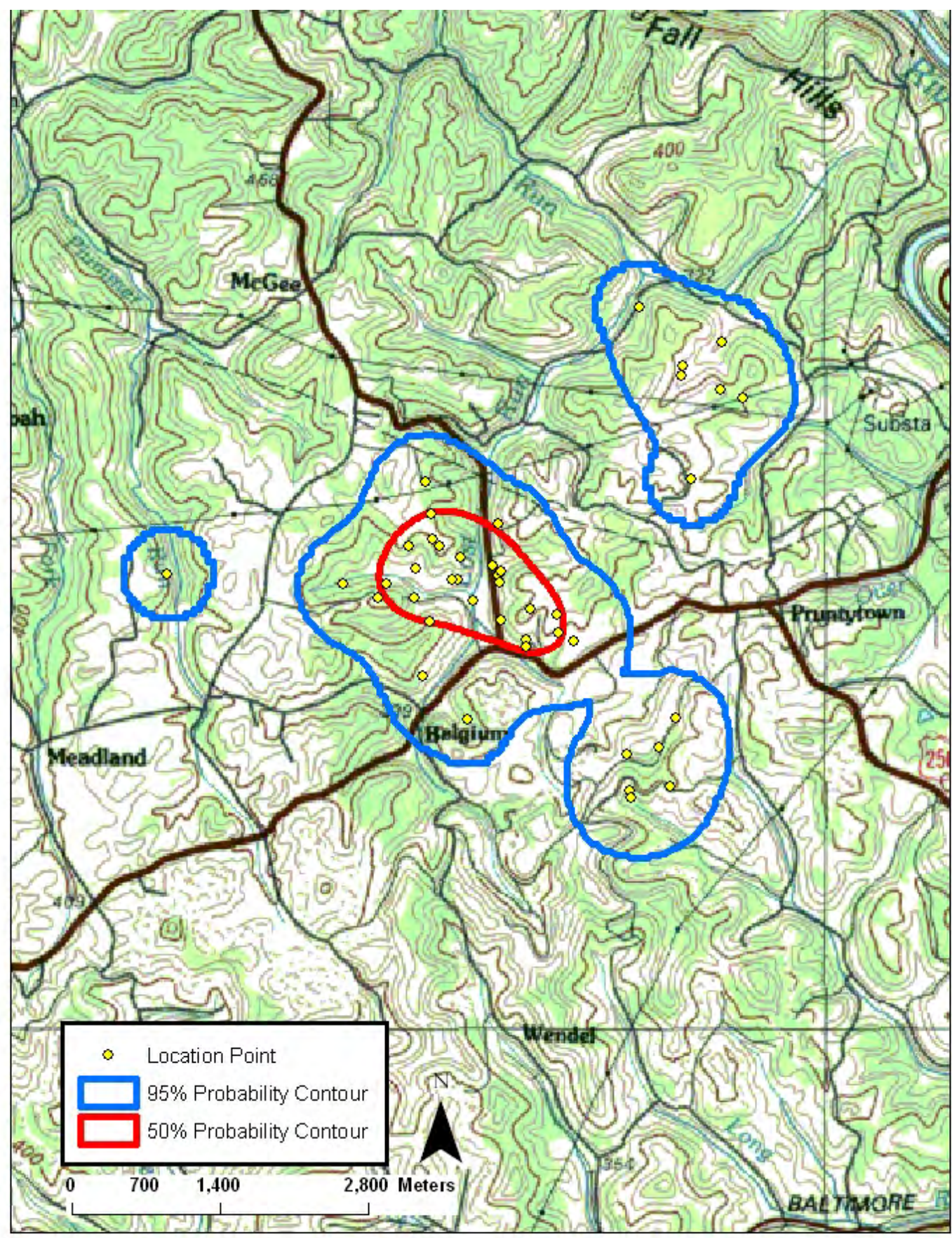


Appendix VIa. RG5102 (juvenile) - 50\% and 95\% probability contours of the annual fixed kernel home range utilization distribution. Smoothing parameter (h) determined by least squares cross validation, Taylor County, West Virginia, 2004-2005 (2003 SAMB imagery).

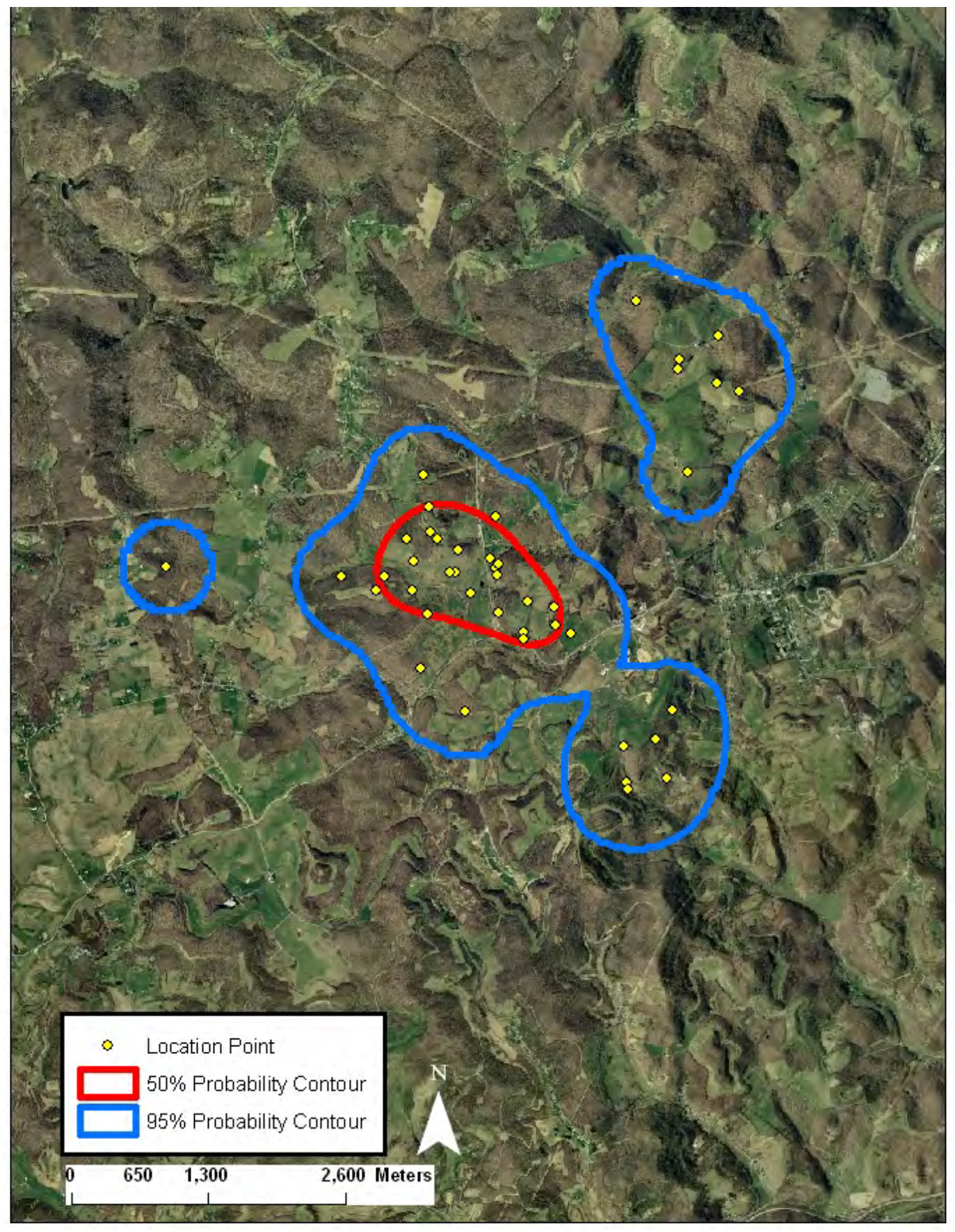


Appendix VIIa. RG5102 (adult) - 50\% and 95\% probability contours of the annual fixed kernel home range utilization distribution. Smoothing parameter (h) determined by least squares cross validation, Taylor County, West Virginia, 2005-2007 (100k topo map).

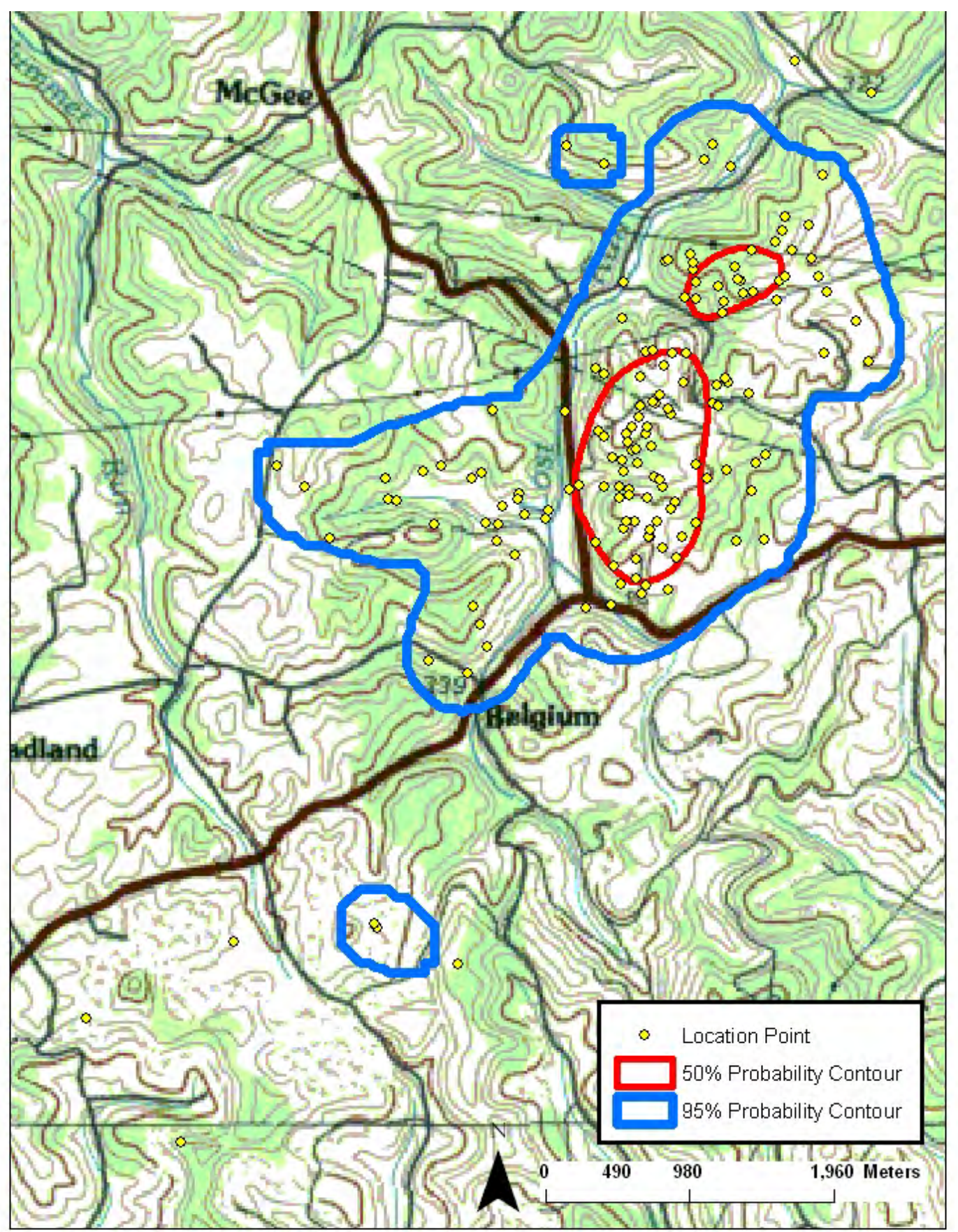


Appendix VIIIa. RG5102 (adult) - 50\% and 95\% probability contours of the annual fixed kernel home range utilization distribution. Smoothing parameter (h) determined by least squares cross validation, Taylor County, West Virginia, 2005-2007 (2003 SAMB imagery).

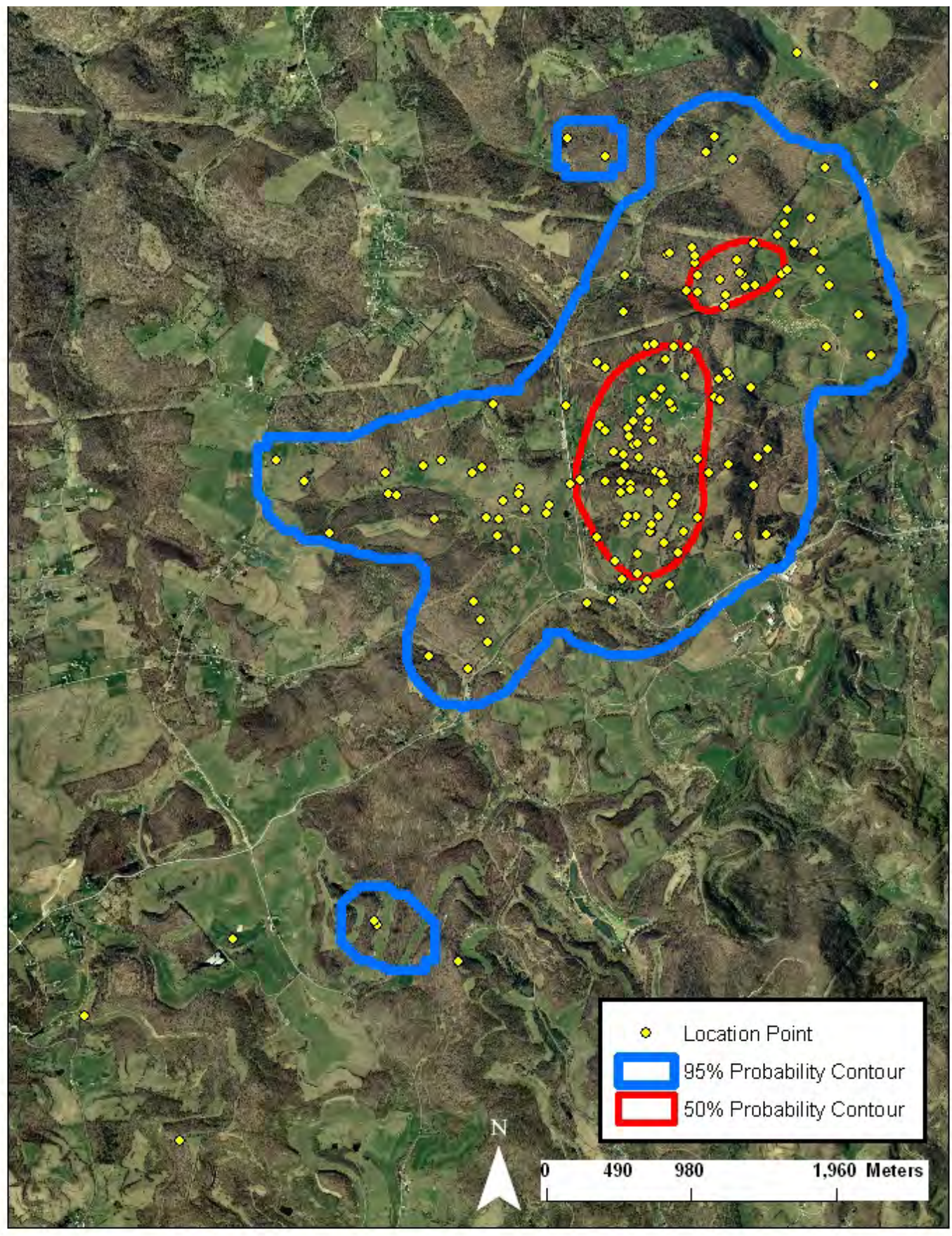


Appendix IXa. RG5102 (adult) - 95\% probability contours of the spring fixed kernel home range utilization distribution. Smoothing parameter (h) determined by least squares cross validation, Taylor County, West Virginia, 2005-2007 (2003 SAMB imagery).

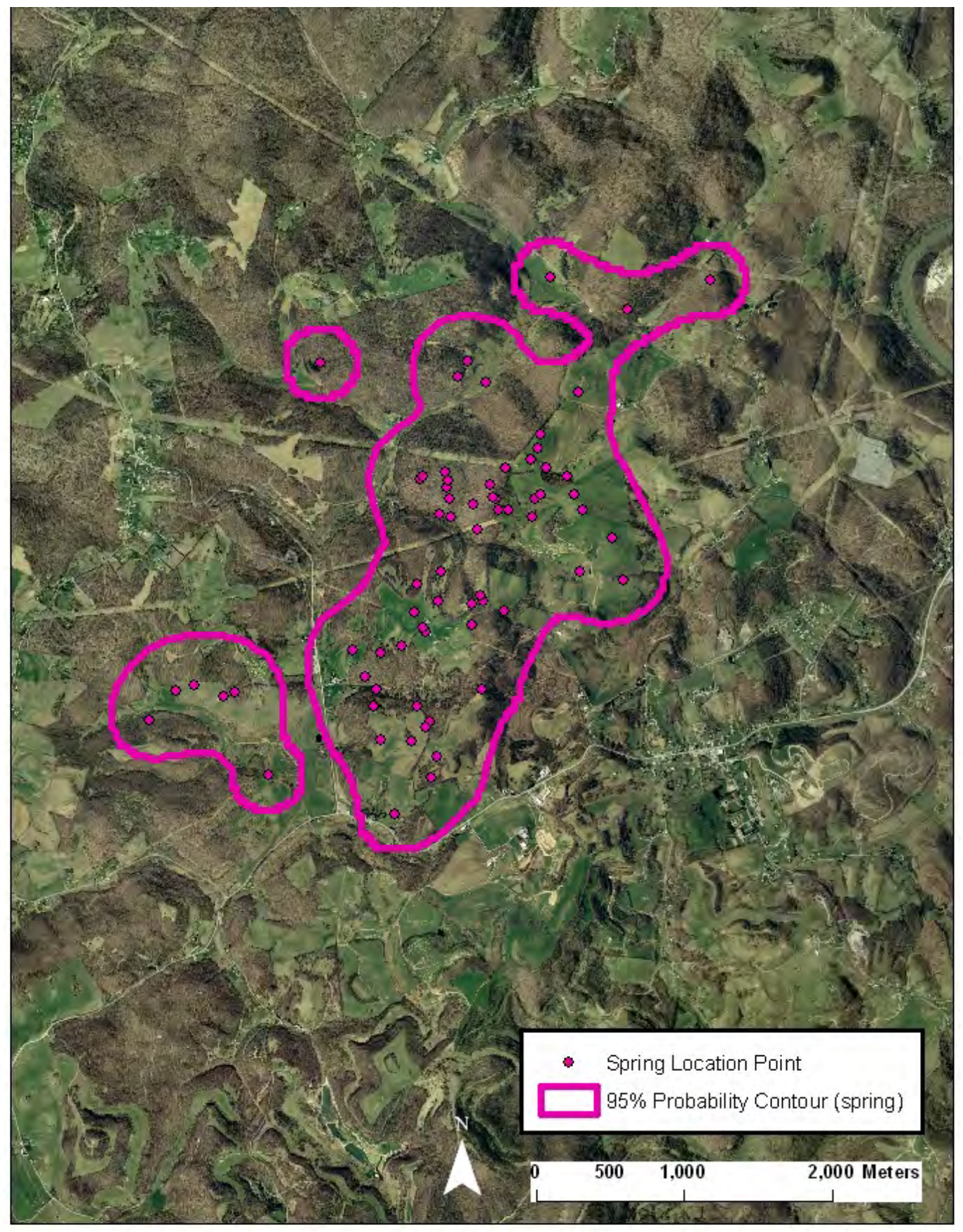


Appendix Xa. RG5102 (adult) - 95\% probability contours of the spring-summer and fallwinter fixed kernel home range utilization distributions. Smoothing parameter (h) determined by least squares cross validation, Taylor County, West Virginia, 2005-2007 (2003 SAMB imagery).

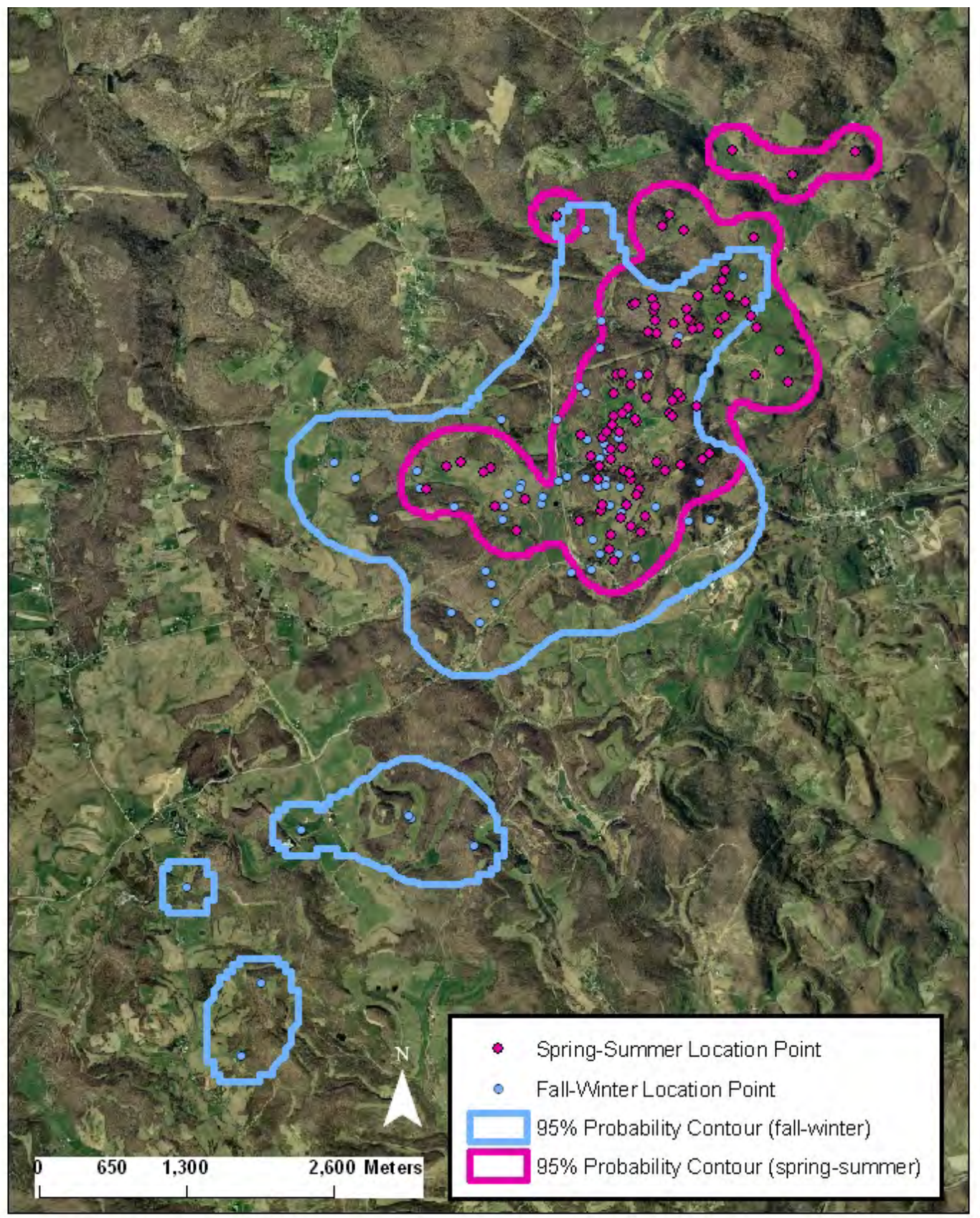


Appendix XIa. RG5103 (juvenile) - 50\% and 95\% probability contours of the annual fixed kernel home range utilization distribution. Smoothing parameter (h) determined by least squares cross validation, Taylor County, West Virginia, 2004-2005 (100k topo map).

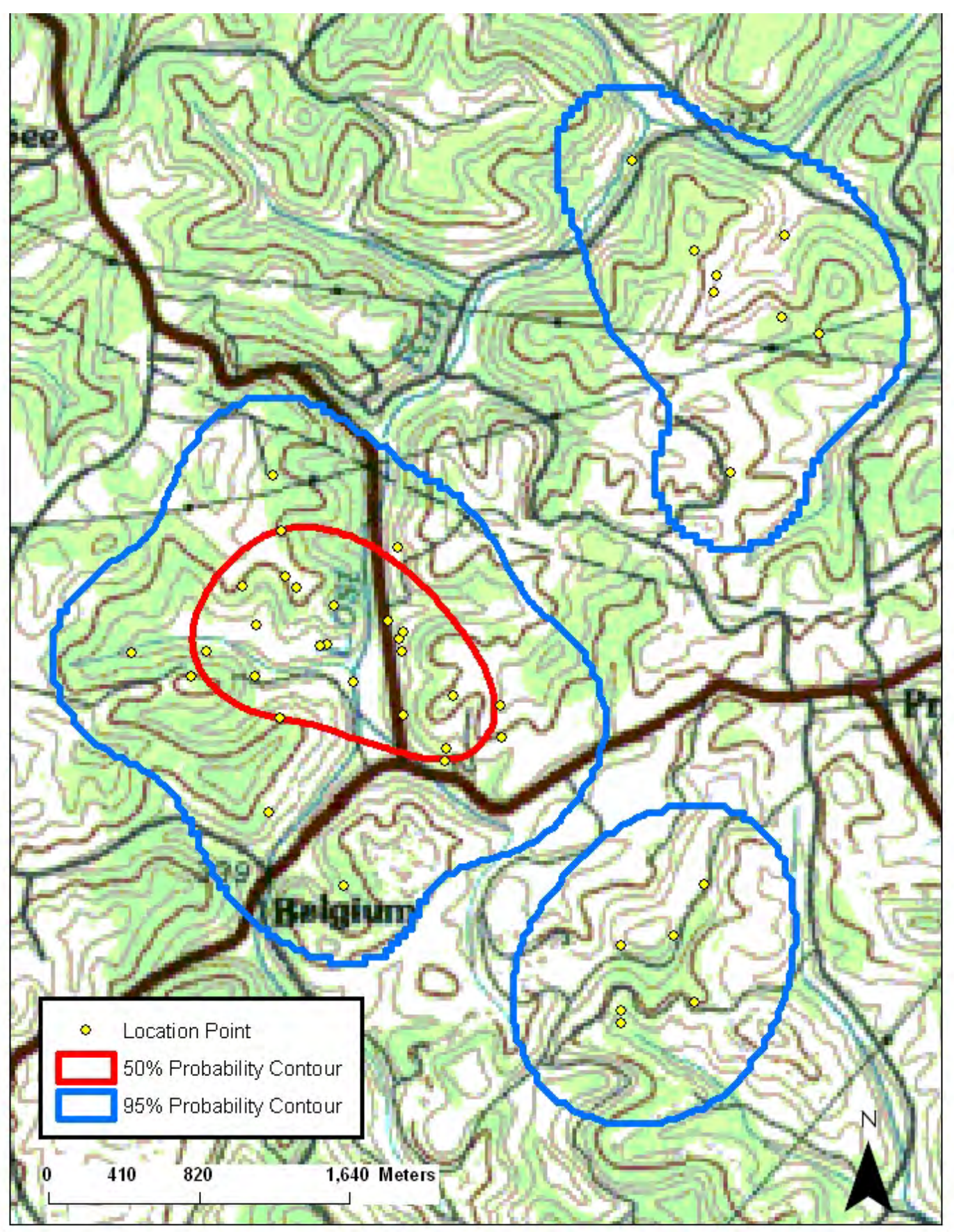


Appendix XIIa. RG5103 (juvenile) - 50\% and 95\% probability contours of the annual fixed kernel home range utilization distribution. Smoothing parameter (h) determined by least squares cross validation, Taylor County, West Virginia, 2004-2005 (2003 SAMB imagery).

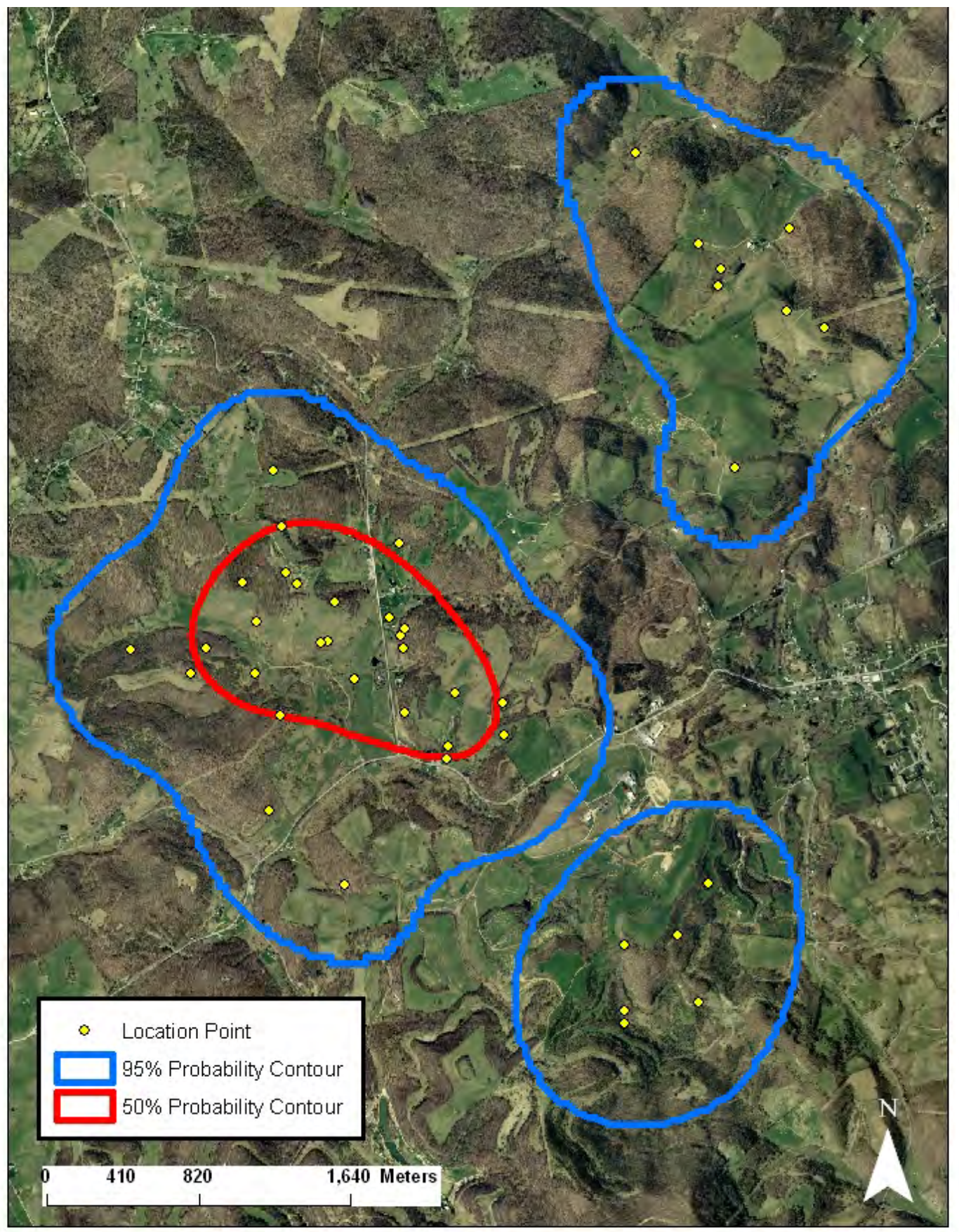


Appendix XIIIa. RG5103 (adult) - 50\% and 95\% probability contours of the annual fixed kernel home range utilization distribution. Smoothing parameter (h) determined by least squares cross validation, Taylor County, West Virginia, 2005-2006 (100k topo map).

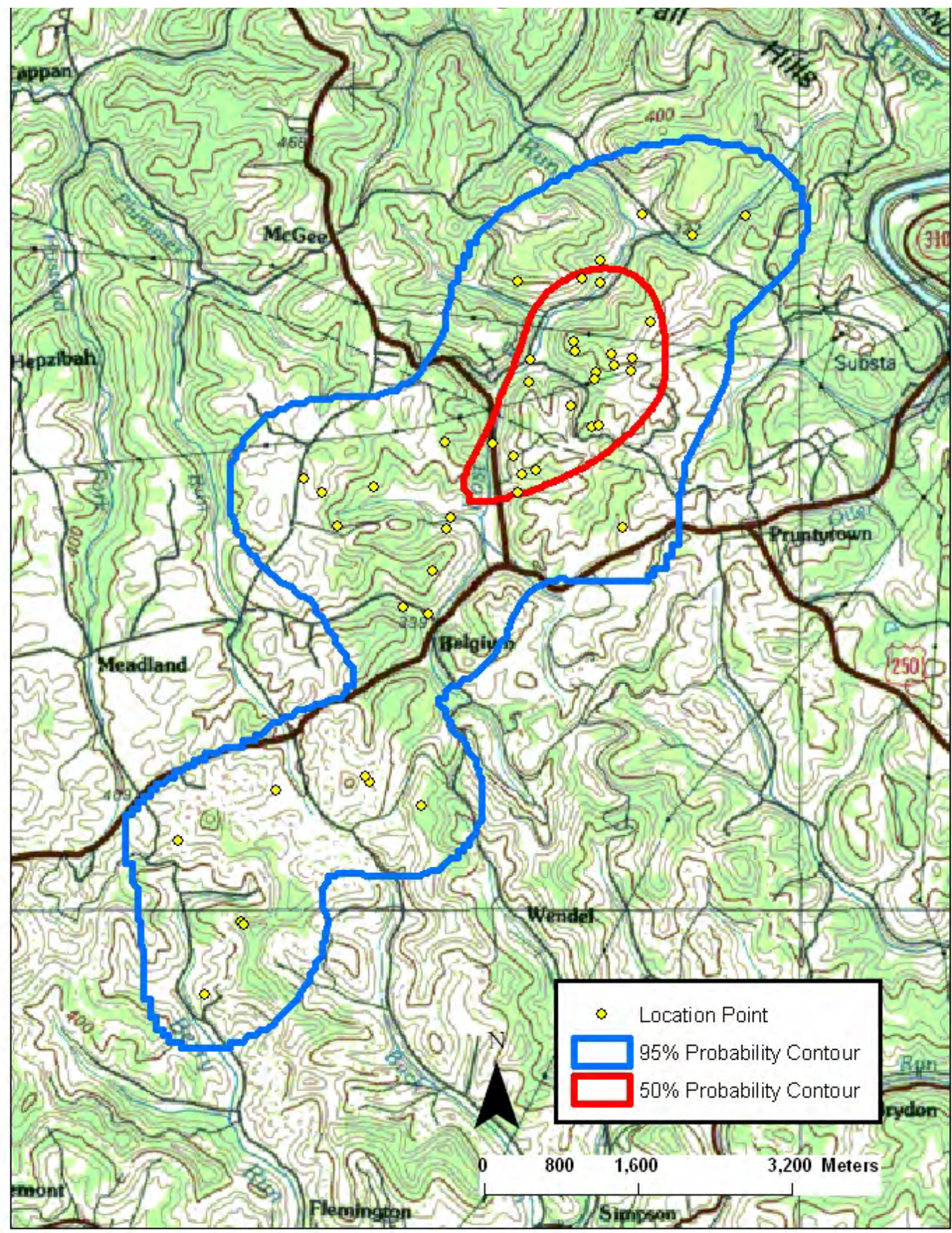


Appendix XIVa. RG5103 (adult) - 50\% and 95\% probability contours of the annual fixed kernel home range utilization distribution. Smoothing parameter (h) determined by least squares cross validation, Taylor County, West Virginia, 2005-2006 (2003 SAMB imagery).

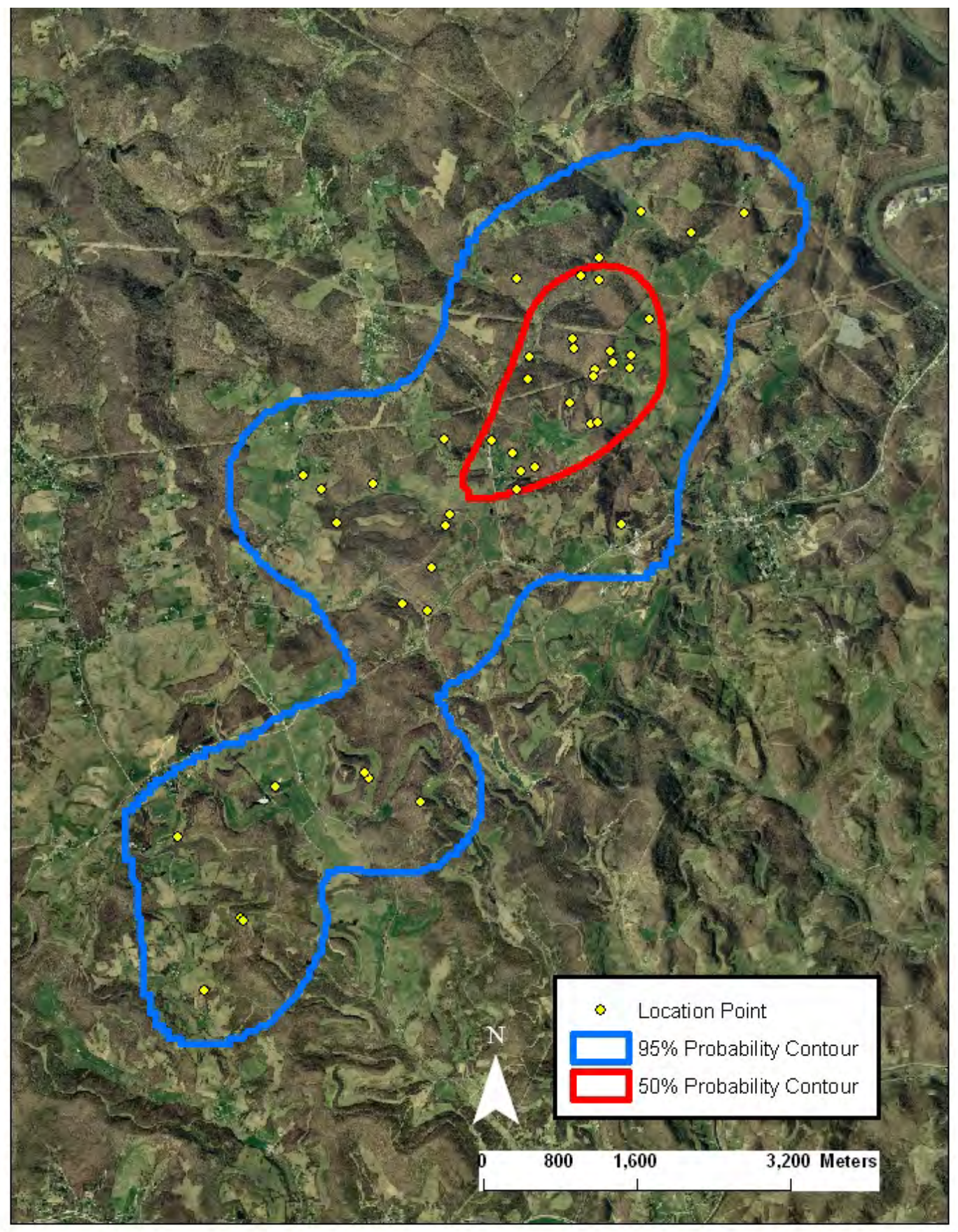


Appendix XVa. RG5104 (juvenile) - 50\% and 95\% probability contours of the annual fixed kernel home range utilization distribution. Smoothing parameter (h) determined by least squares cross validation, Taylor County, West Virginia, 2004-2005 (100k topo map).

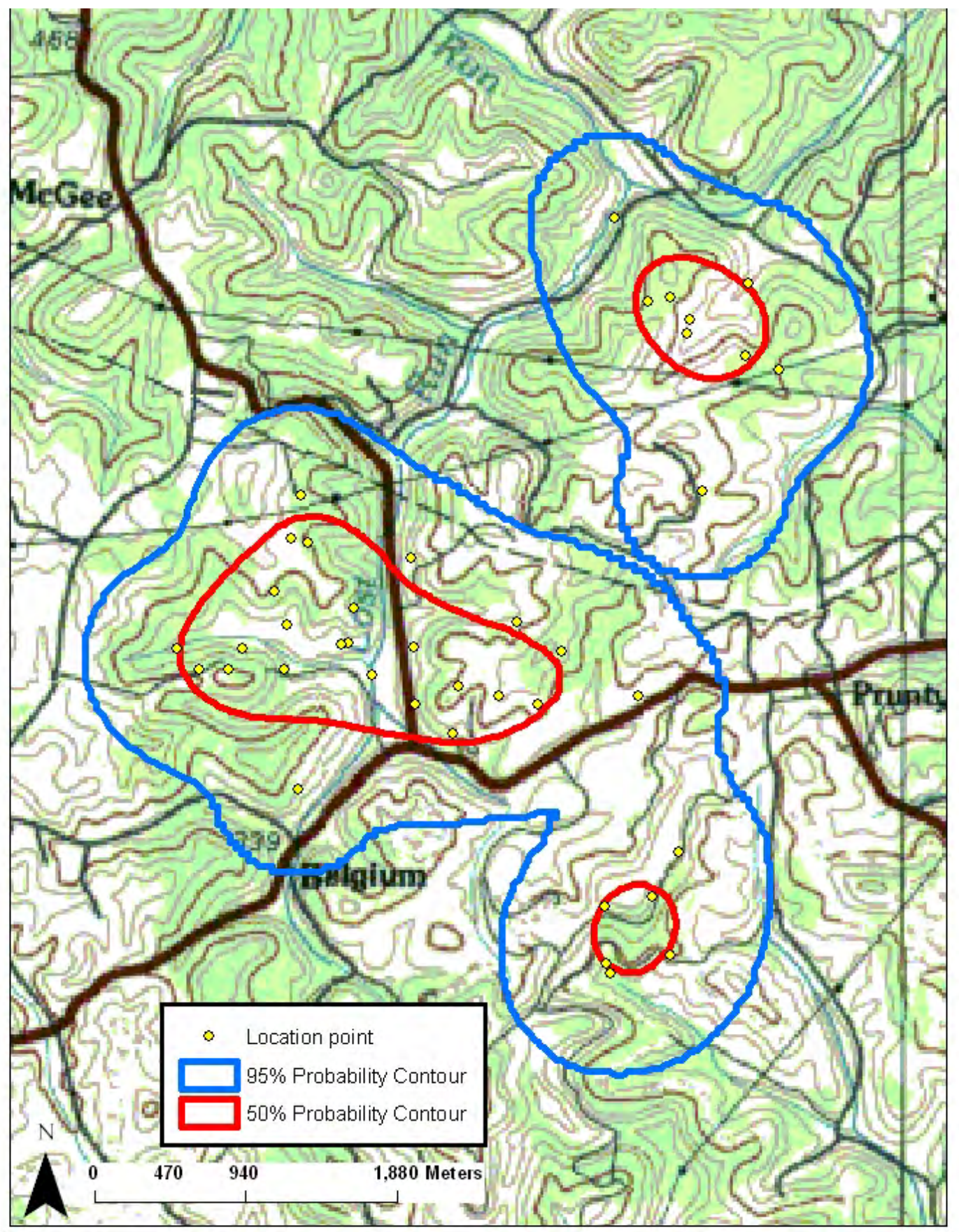


Appendix XVIa. RG5104 (juvenile) - 50\% and 95\% probability contours of the annual fixed kernel home range utilization distribution. Smoothing parameter (h) determined by least squares cross validation, Taylor County, West Virginia, 2004-2005 (2003 SAMB imagery).

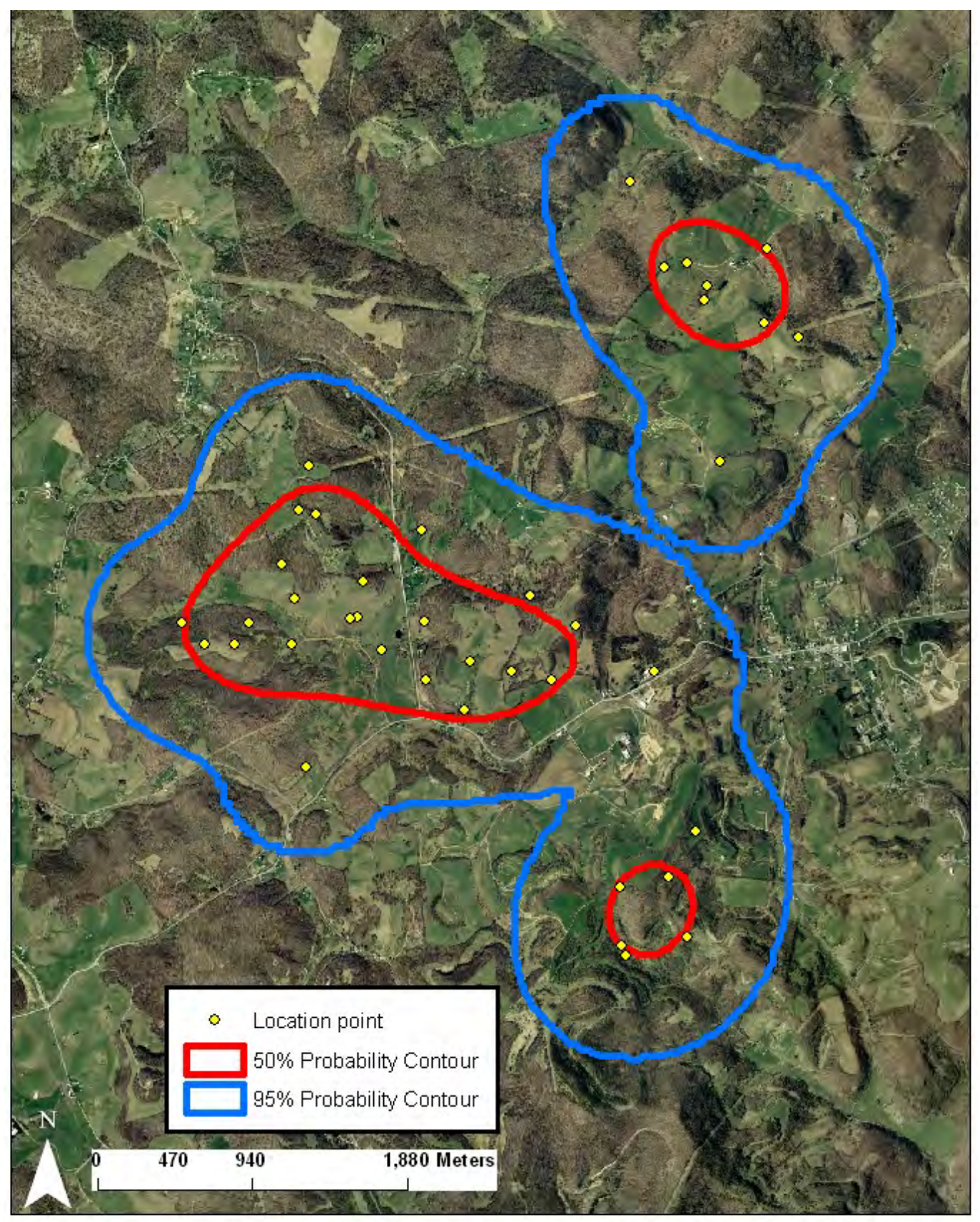


Appendix XVIIa. RG5106 (juvenile) - 50\% and 95\% probability contours of the annual fixed kernel home range utilization distribution. Smoothing parameter (h) determined by least squares cross validation, Marion County, West Virginia, 2004-2005 (100k topo map).

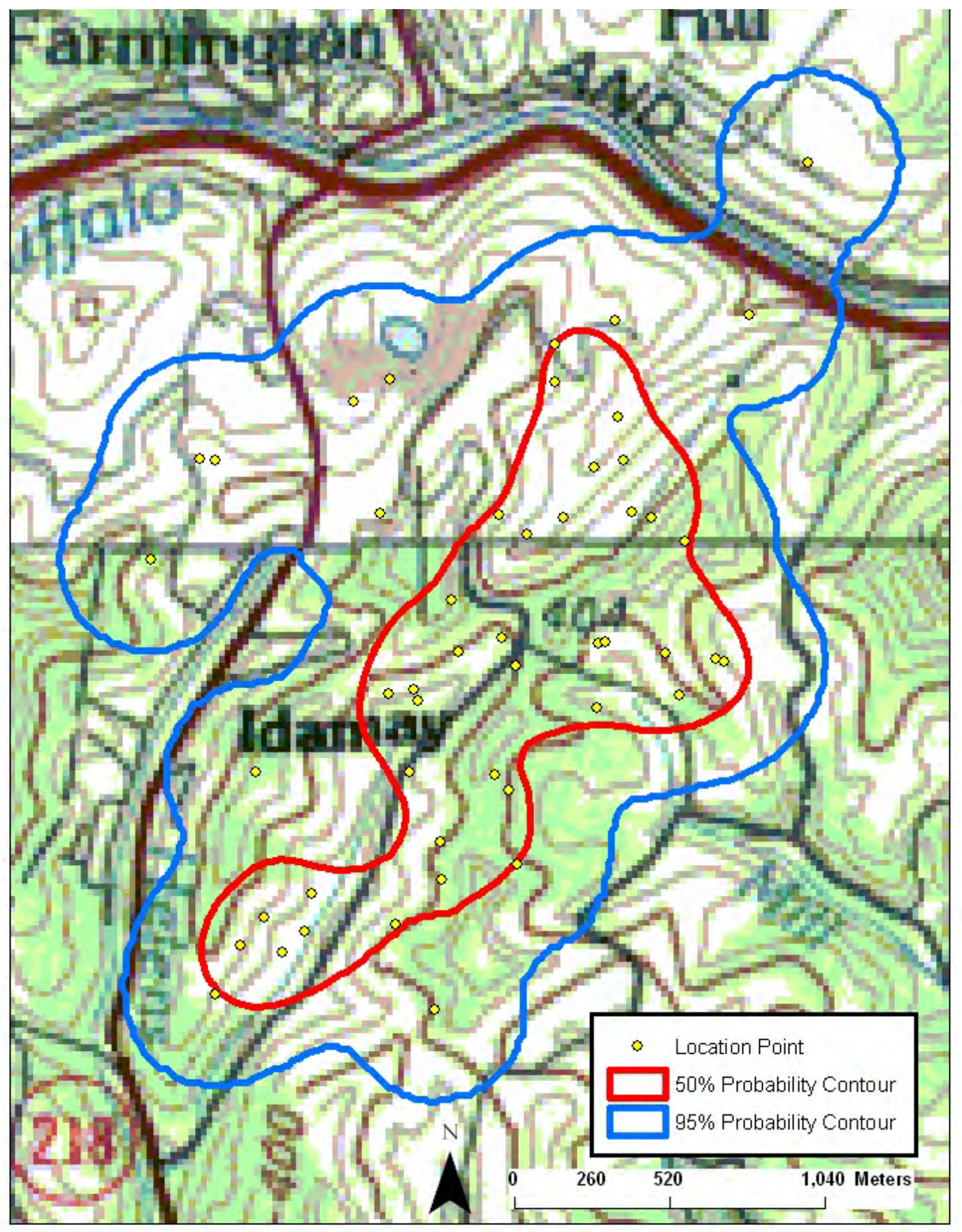


Appendix XVIII $a$. RG5106 (juvenile) - 50\% and 95\% probability contours of the annual fixed kernel home range utilization distribution. Smoothing parameter (h) determined by least squares cross validation, Marion County, West Virginia, 2004-2005 (2003 SAMB imagery).

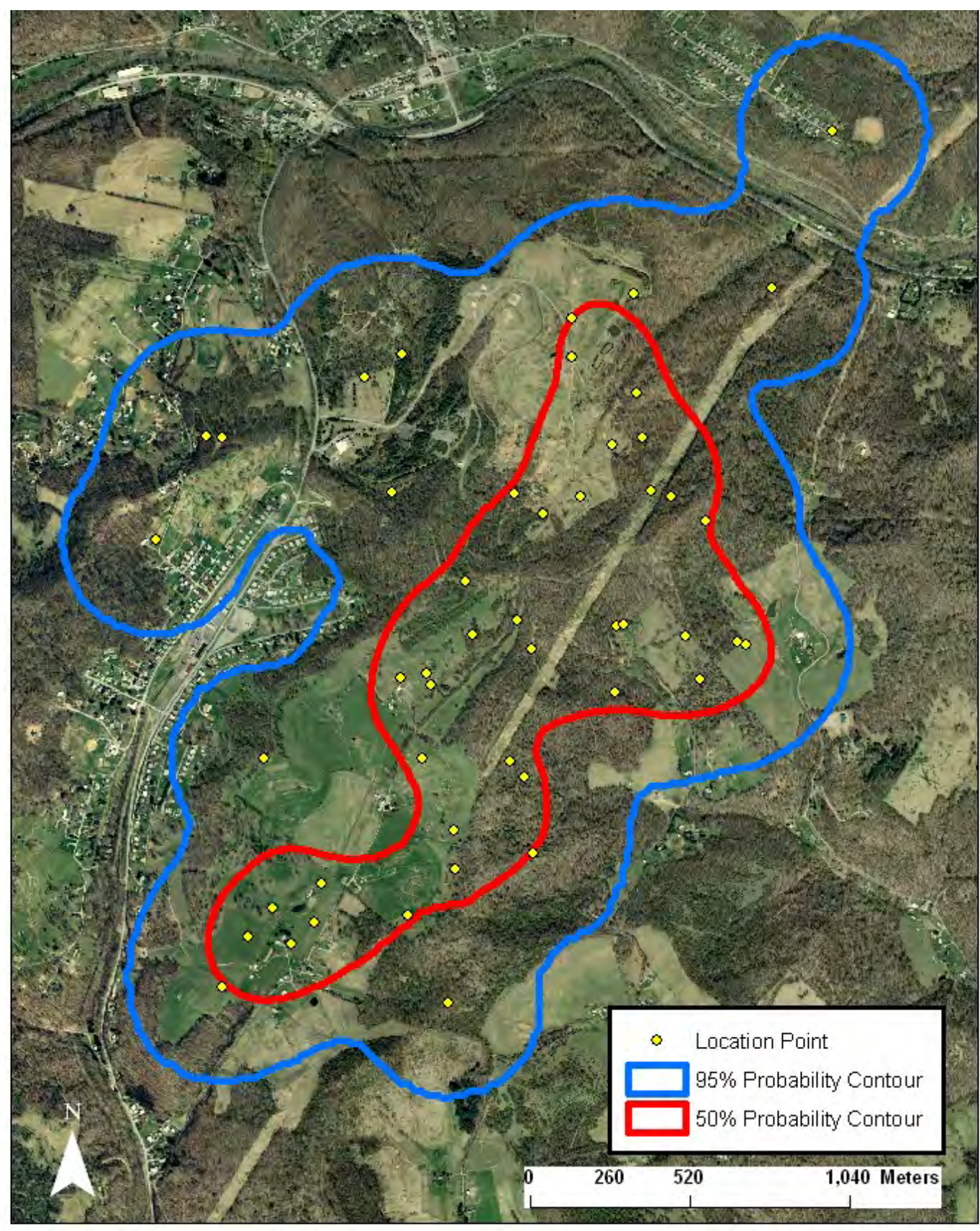


Appendix XIXa. RG5106 (adult) - 50\% and 95\% probability contours of the annual fixed kernel home range utilization distribution. Smoothing parameter (h) determined by least squares cross validation, Marion County, West Virginia, 2005-2006 (100k topo map).

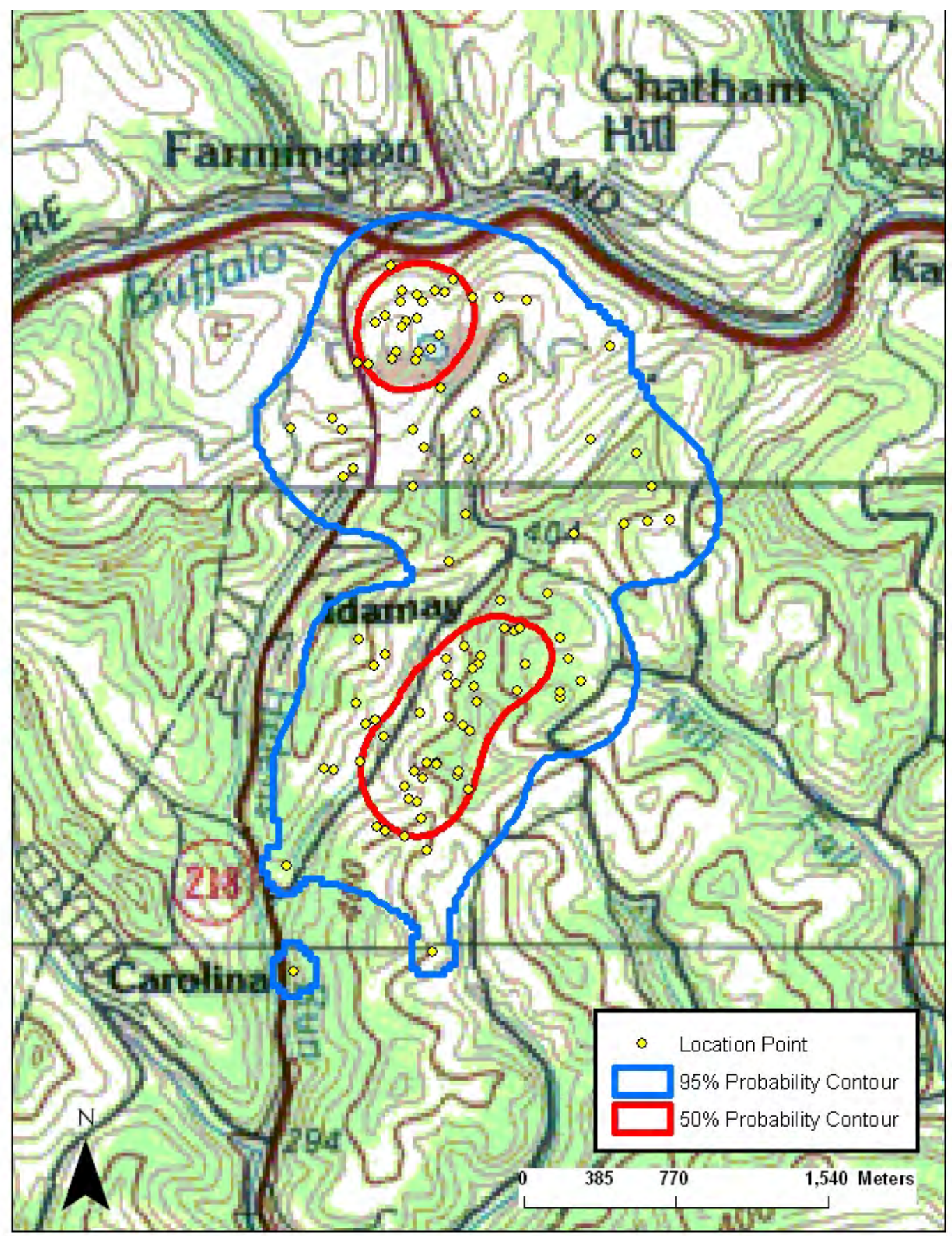


Appendix XXa. RG5106 (adult) - 50\% and 95\% probability contours of the annual fixed kernel home range utilization distribution. Smoothing parameter (h) determined by least squares cross validation, Marion County, West Virginia, 2005-2006 (2003 SAMB imagery).

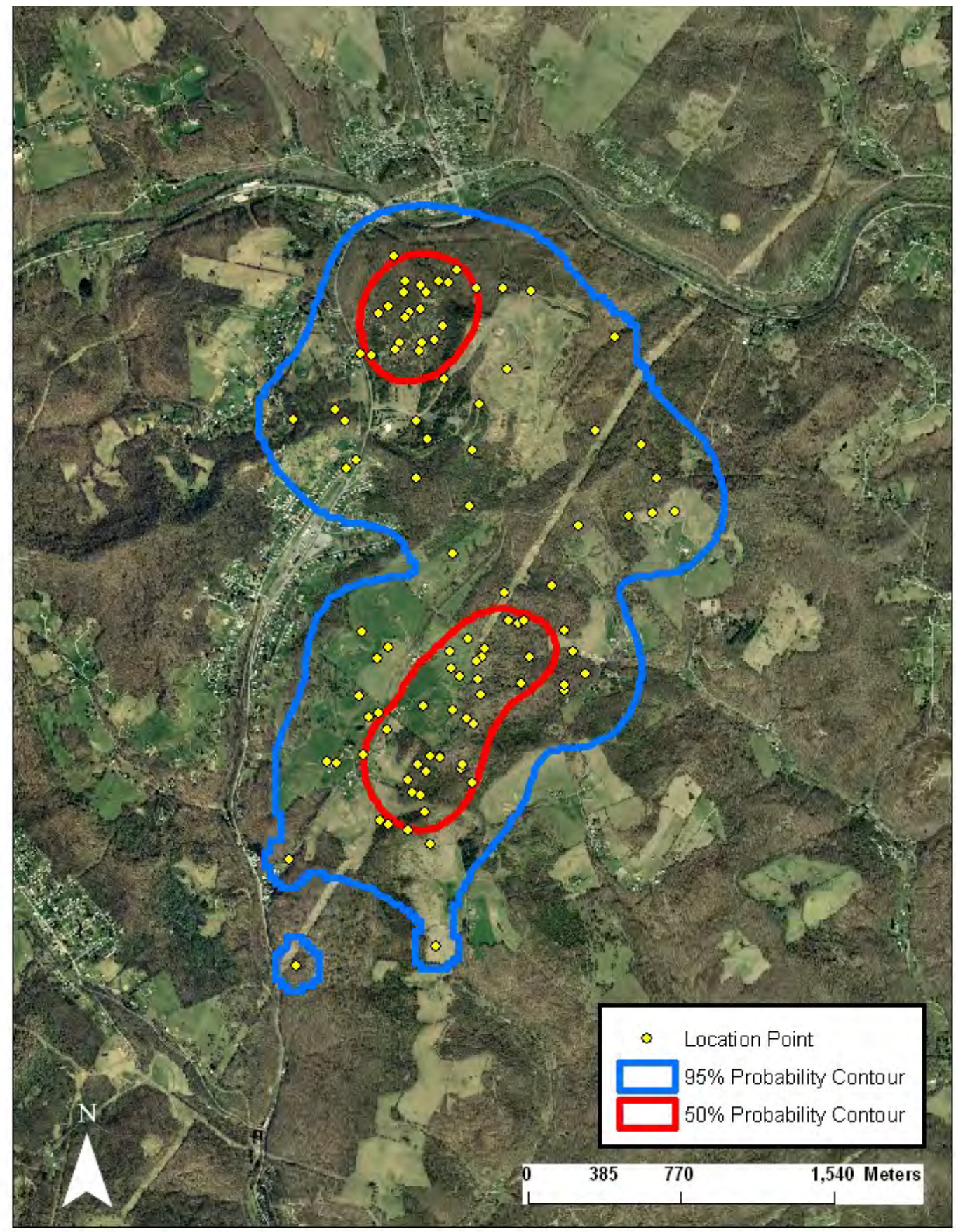


Appendix XXIa. RG5106 (adult) - 95\% probability contours of the spring and fall fixed kernel home range utilization distributions. Smoothing parameter (h) determined by least squares cross validation, Marion County, West Virginia, 2005-2006 (2003 SAMB imagery).

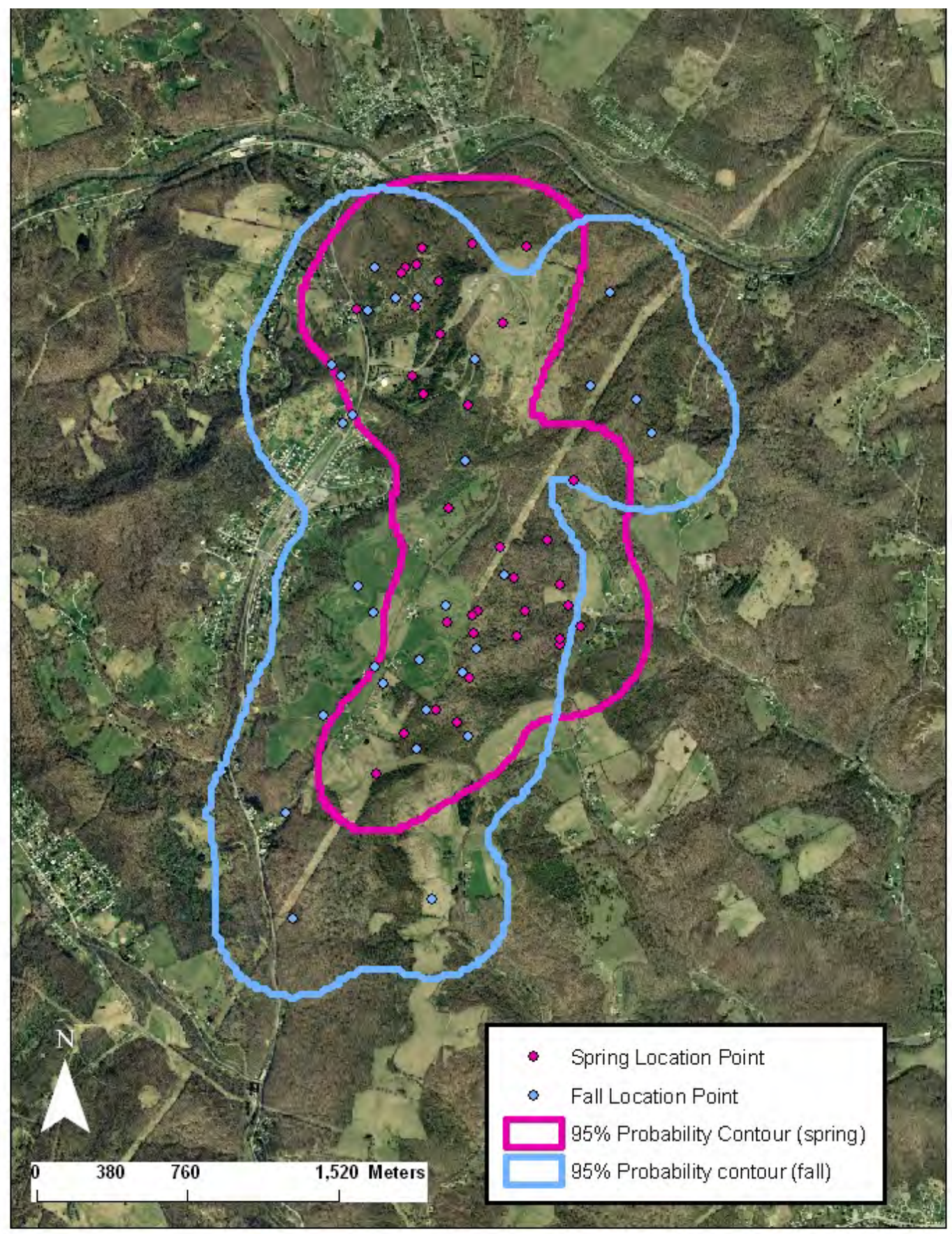


Appendix XXIIa. RG5106 (adult) - 95\% probability contours of the spring-summer and the fall-winter fixed kernel home range utilization distributions. Smoothing parameter (h) determined by least squares cross validation, Marion County, West Virginia, 2005-2006 (2003 SAMB imagery).

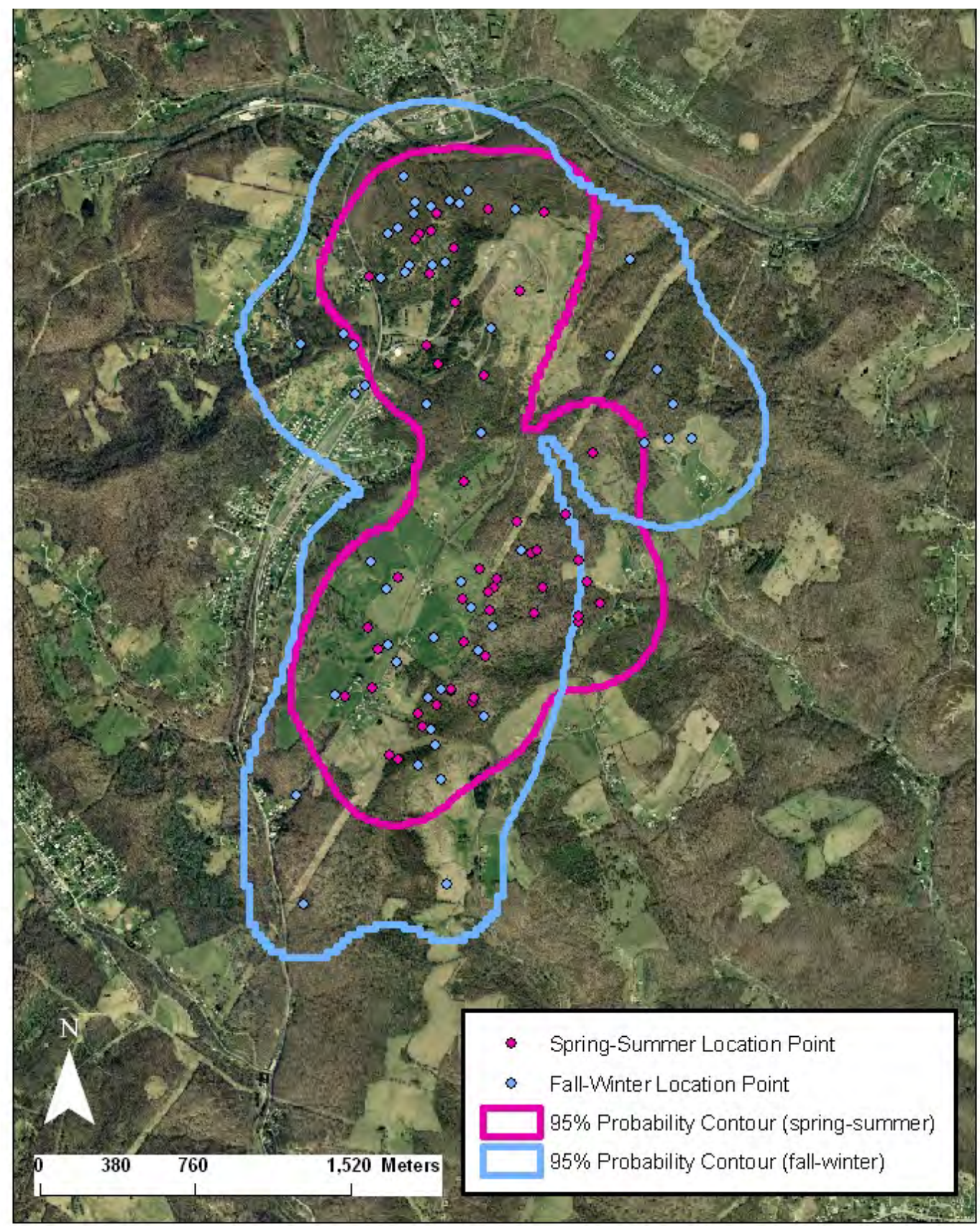


Appendix XXIII $a$. RG5109 (juvenile) - 50\% and 95\% probability contours of the annual fixed kernel home range utilization distribution. Smoothing parameter (h) determined by least squares cross validation, Marion County, West Virginia, 2004-2005 (100k topo map).

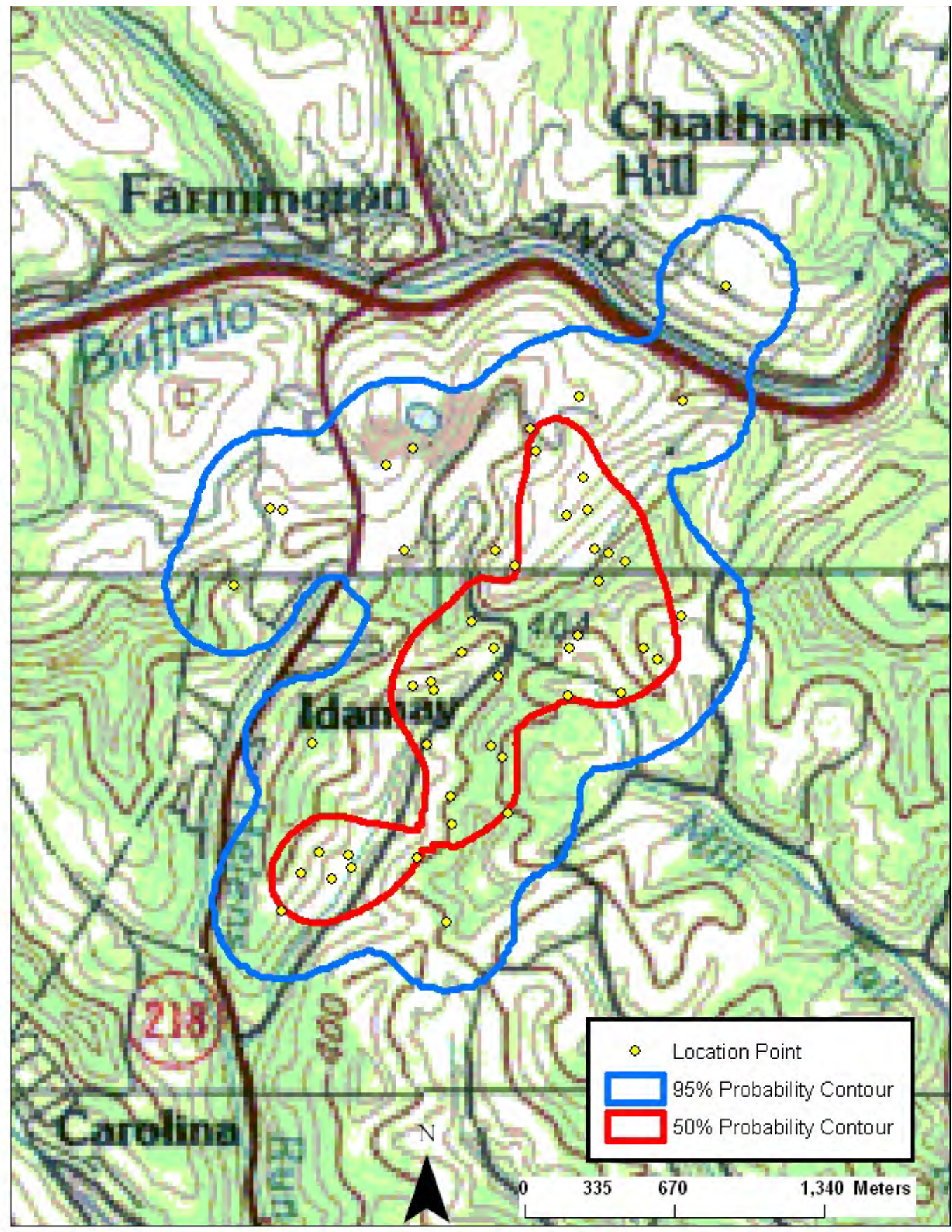


Appendix XXIVa. RG5109 (juvenile) - 50\% and 95\% probability contours of the annual fixed kernel home range utilization distribution. Smoothing parameter (h) determined by least squares cross validation, Marion County, West Virginia, 2004-2005 (2003 SAMB imagery).

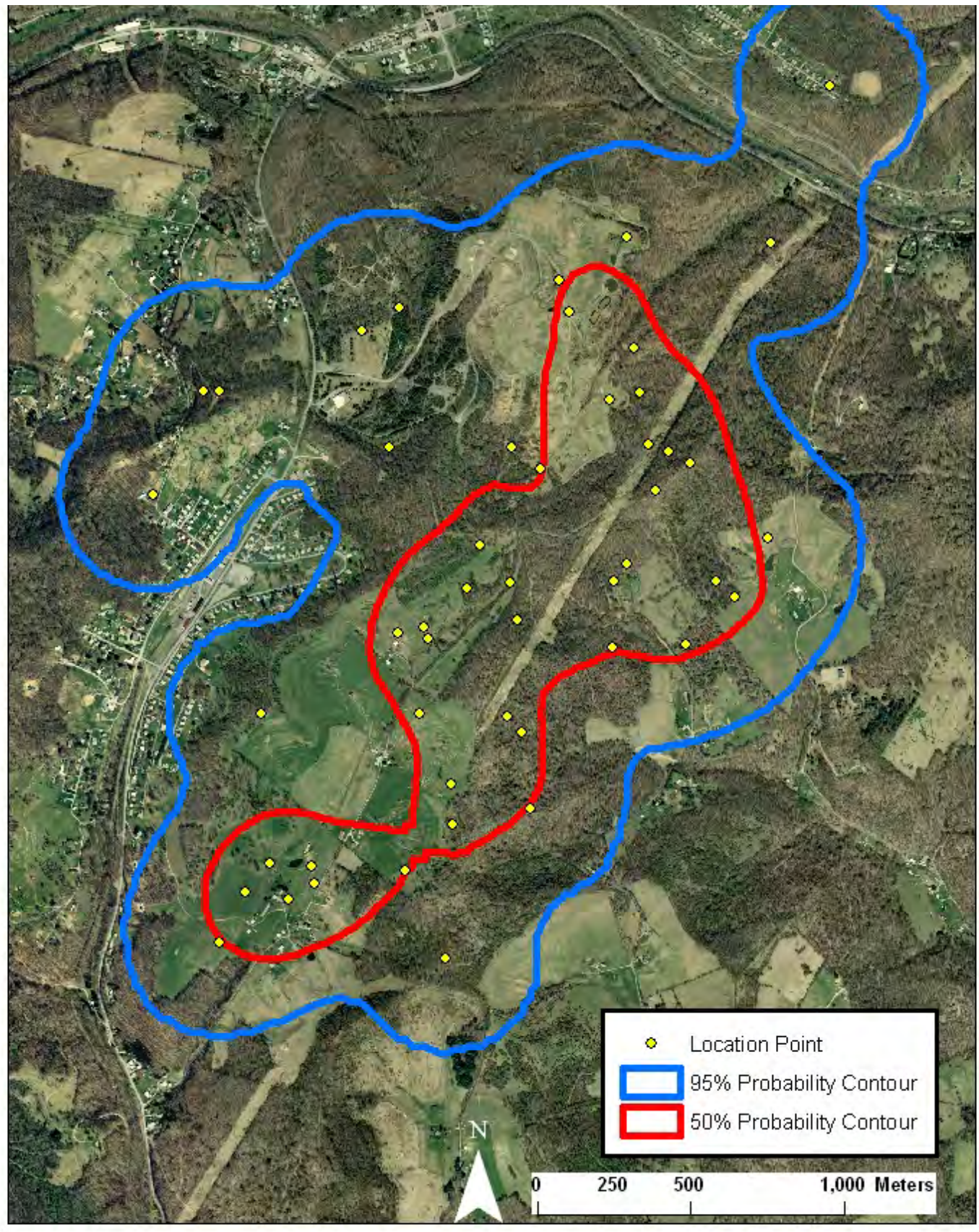


Appendix XXVa. RG5109 (adult) - 50\% and 95\% probability contours of the annual fixed kernel home range utilization distribution. Smoothing parameter (h) determined by least squares cross validation, Marion County, West Virginia, 2005-2007 (100k topo map).

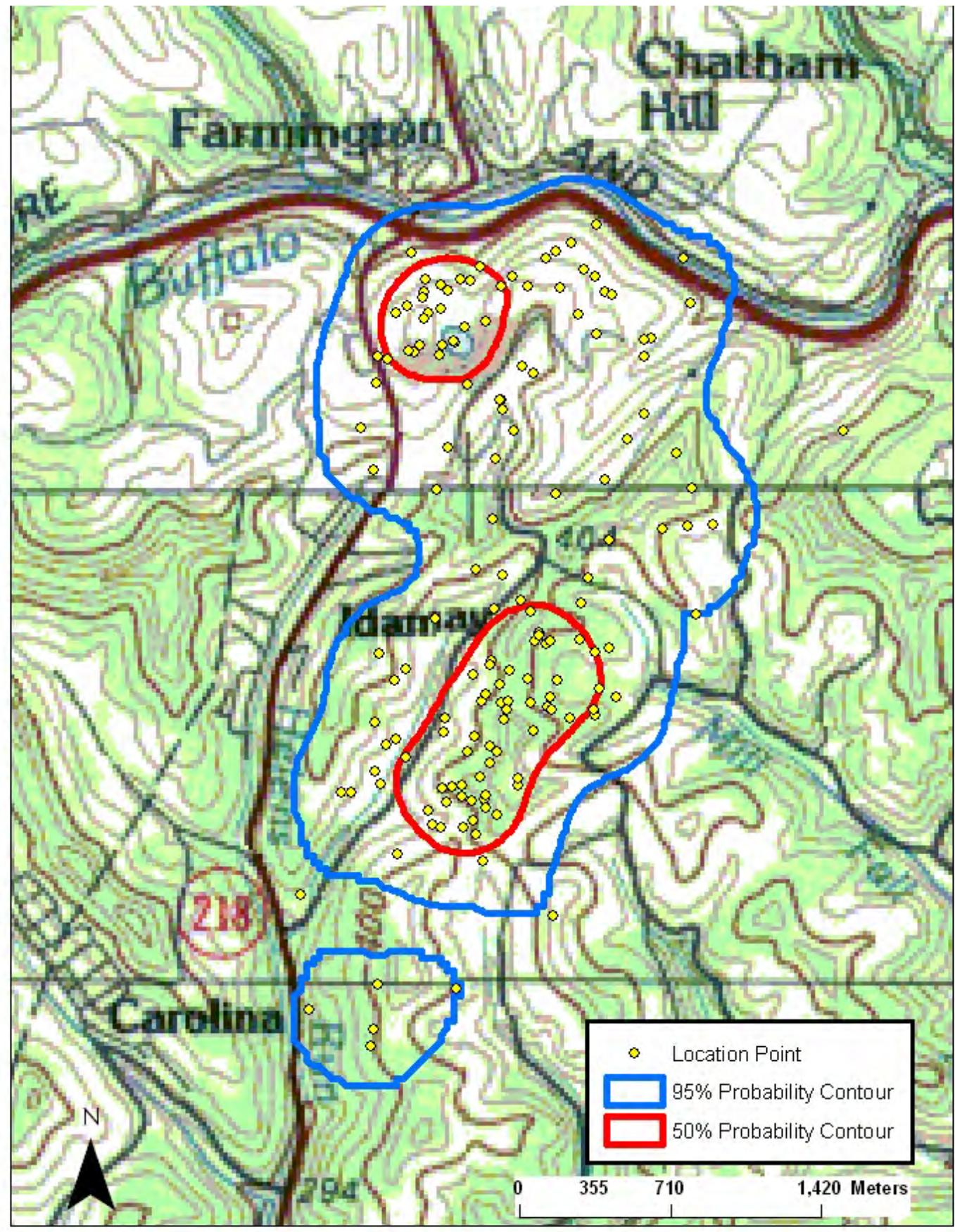


Appendix XXVIa. RG5109 (adult) - 50\% and 95\% probability contours of the annual fixed kernel home range utilization distribution. Smoothing parameter (h) determined by least squares cross validation, Marion County, West Virginia, 2005-2007 (2003 SAMB imagery).

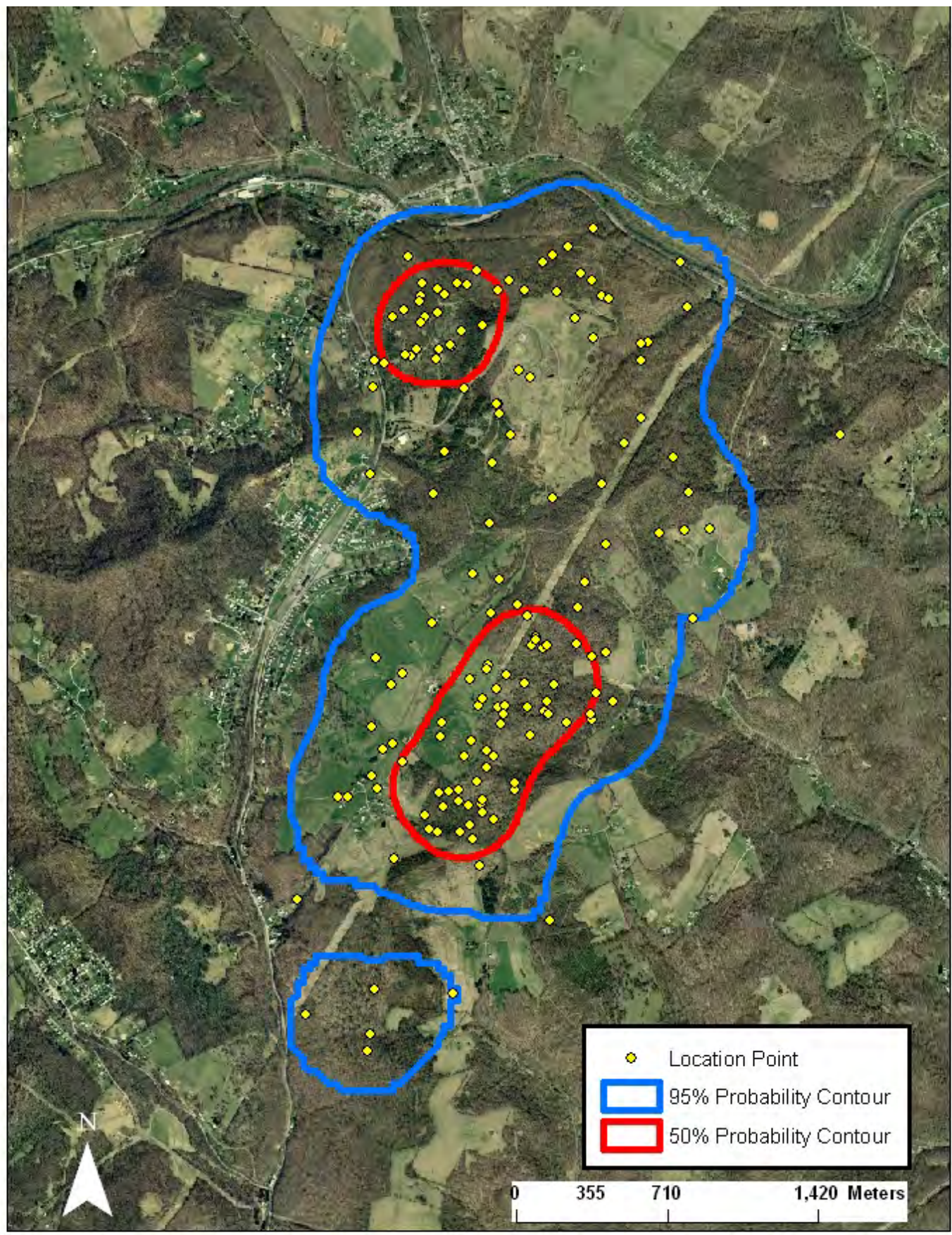


Appendix XXVIIa. RG5109 (adult) - 95\% probability contours of the spring, fall, and winter fixed kernel home range utilization distributions. Smoothing parameter (h) determined by least squares cross validation, Marion County, West Virginia, 2005-2007 (2003 SAMB imagery).

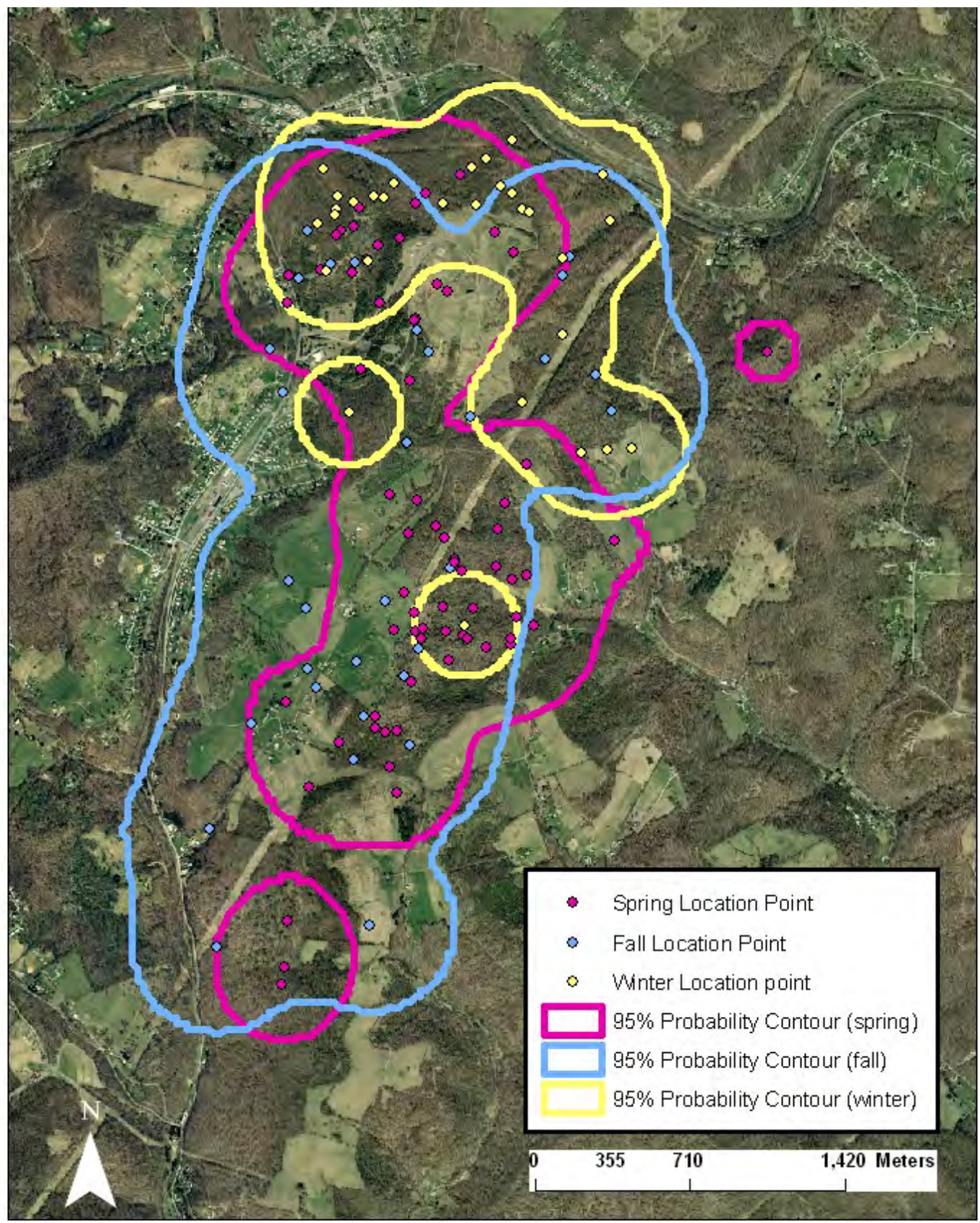


Appendix XXVIIIa. RG5109 (adult) - 95\% probability contours of the spring-summer and fall-winter fixed kernel home range utilization distributions. Smoothing parameter (h) determined by least squares cross validation, Marion County, West Virginia, 2005-2007 (2003 SAMB imagery).

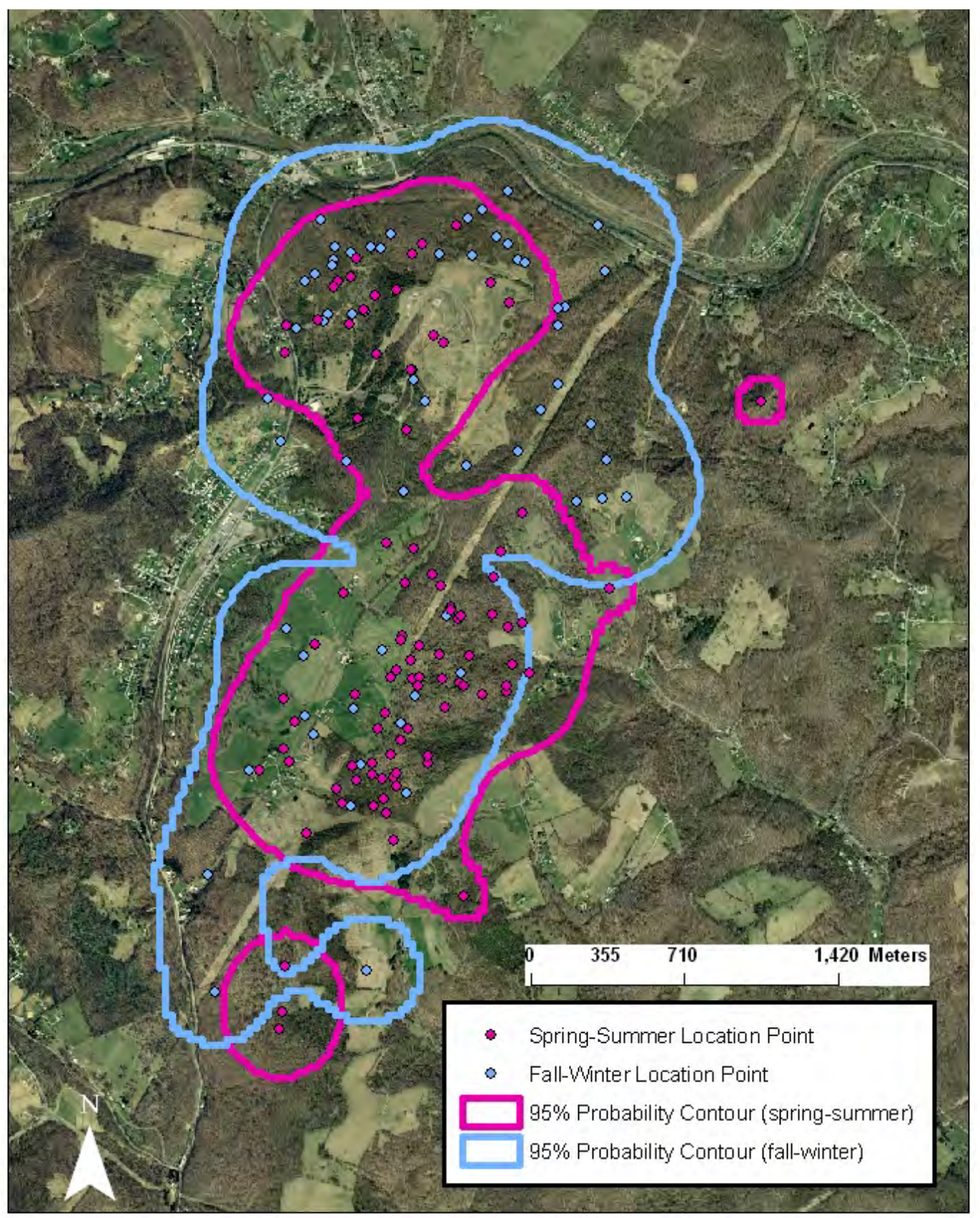


Appendix XXIXa. RG5110 (adult) - 50\% and 95\% probability contours of the annual fixed kernel home range utilization distribution. Smoothing parameter (h) determined by least squares cross validation, Marion County, West Virginia, 2004-2007 (100k topo map).

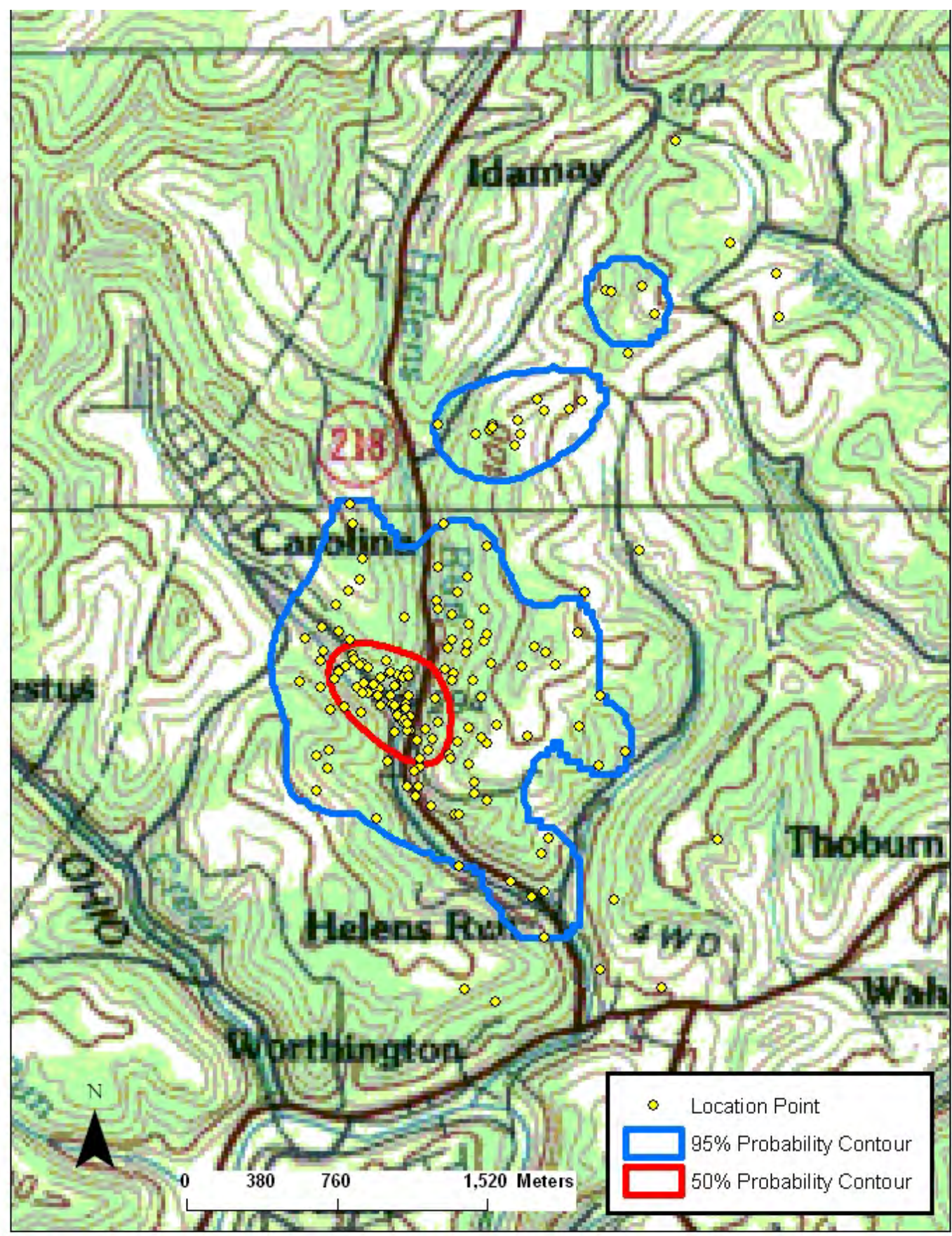


Appendix XXXa. RG5110 (adult) - 50\% and 95\% probability contours of the annual fixed kernel home range utilization distribution. Smoothing parameter (h) determined by least squares cross validation, Marion County, West Virginia, 2004-2007 (2003 SAMB imagery).

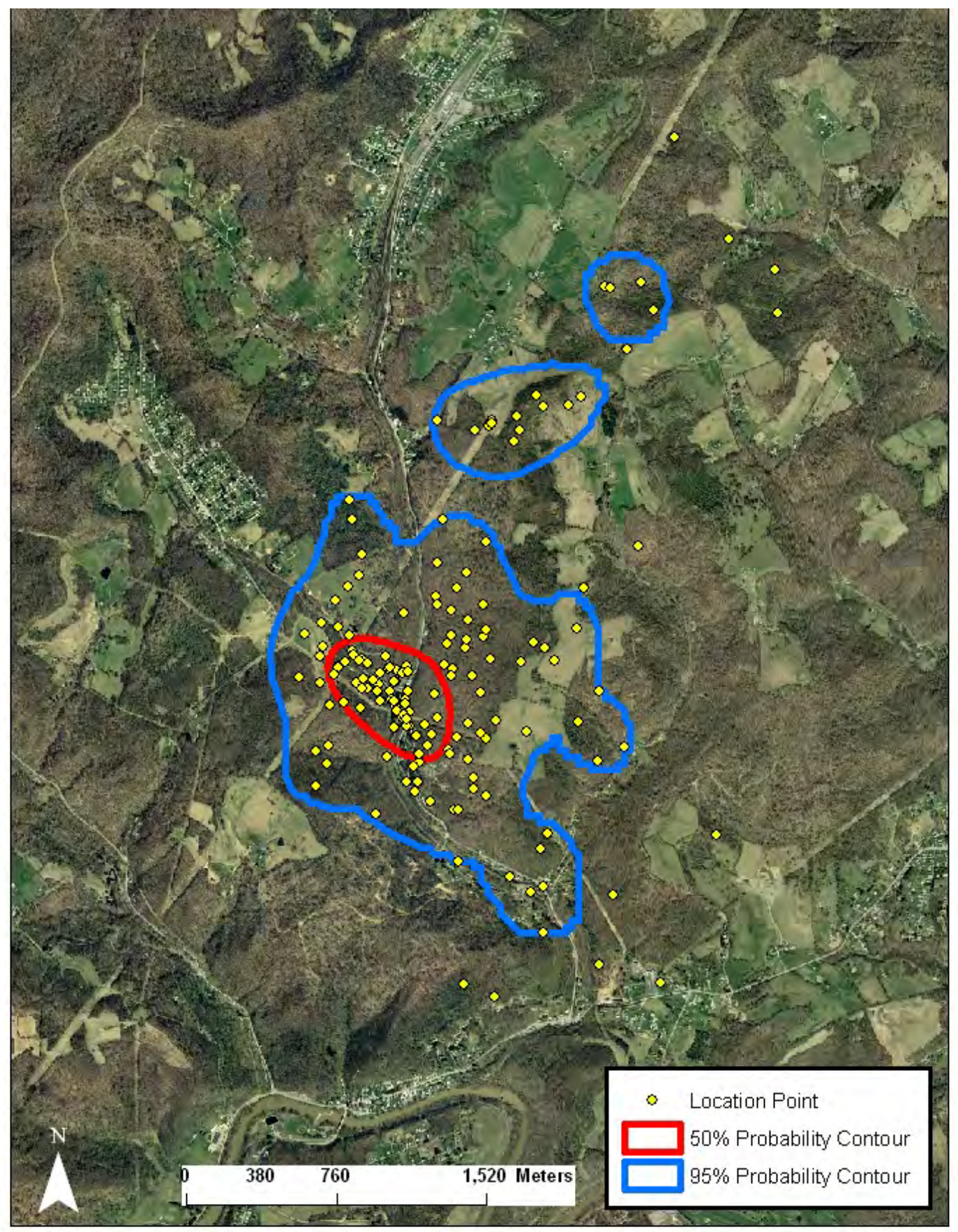


Appendix XXXIa. RG5110 (adult) - 95\% probability contours of the spring, fall, and winter fixed kernel home range utilization distributions. Smoothing parameter (h) determined by least squares cross validation, Marion County, West Virginia, 2004-2007 (2003 SAMB imagery).

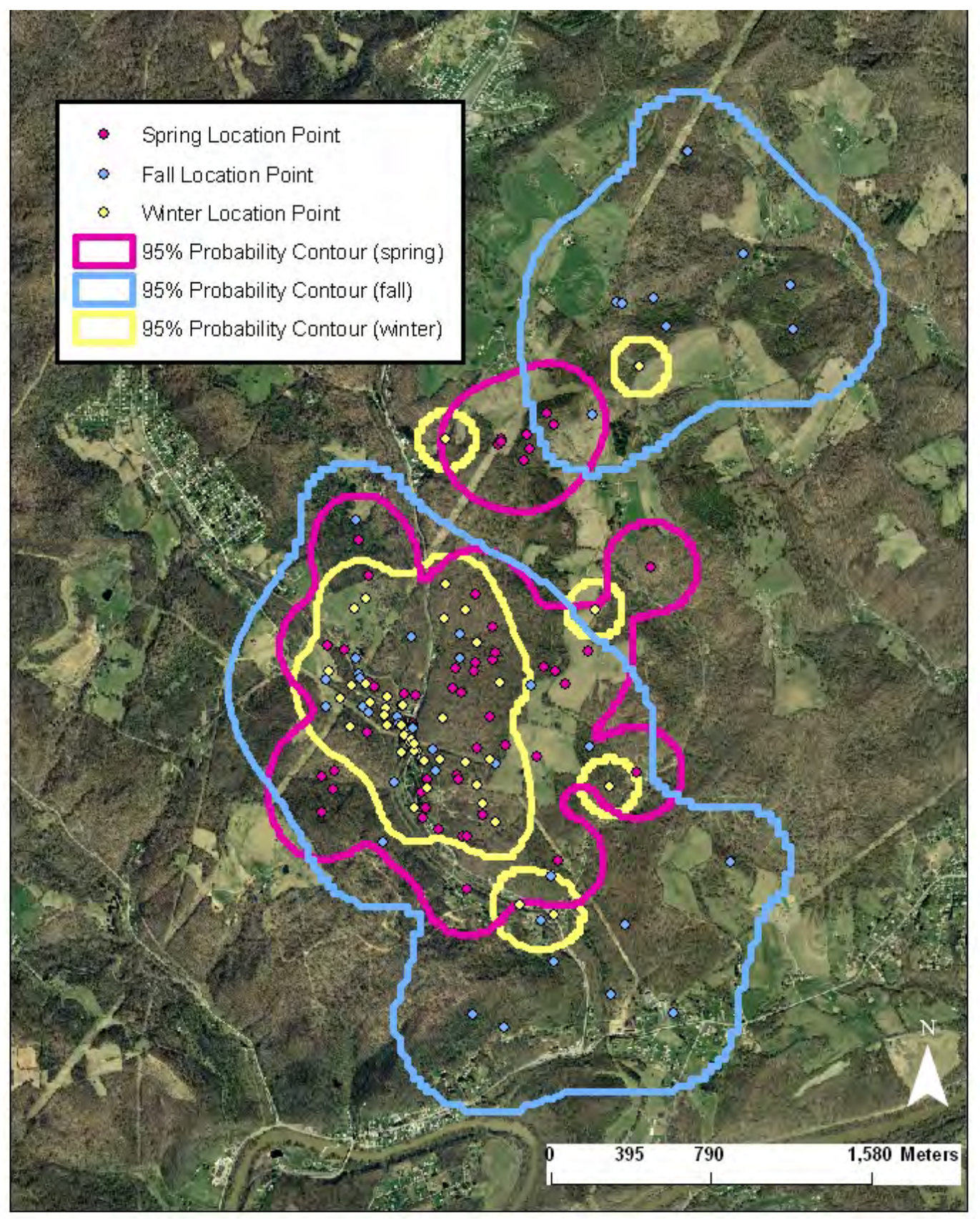


Appendix XXXIIa. RG5110 (adult) - 95\% probability contours of the spring-summer and fall-winter fixed kernel home range utilization distributions. Smoothing parameter (h) determined by least squares cross validation, Marion County, West Virginia, 2004-2007 (2003 SAMB imagery).

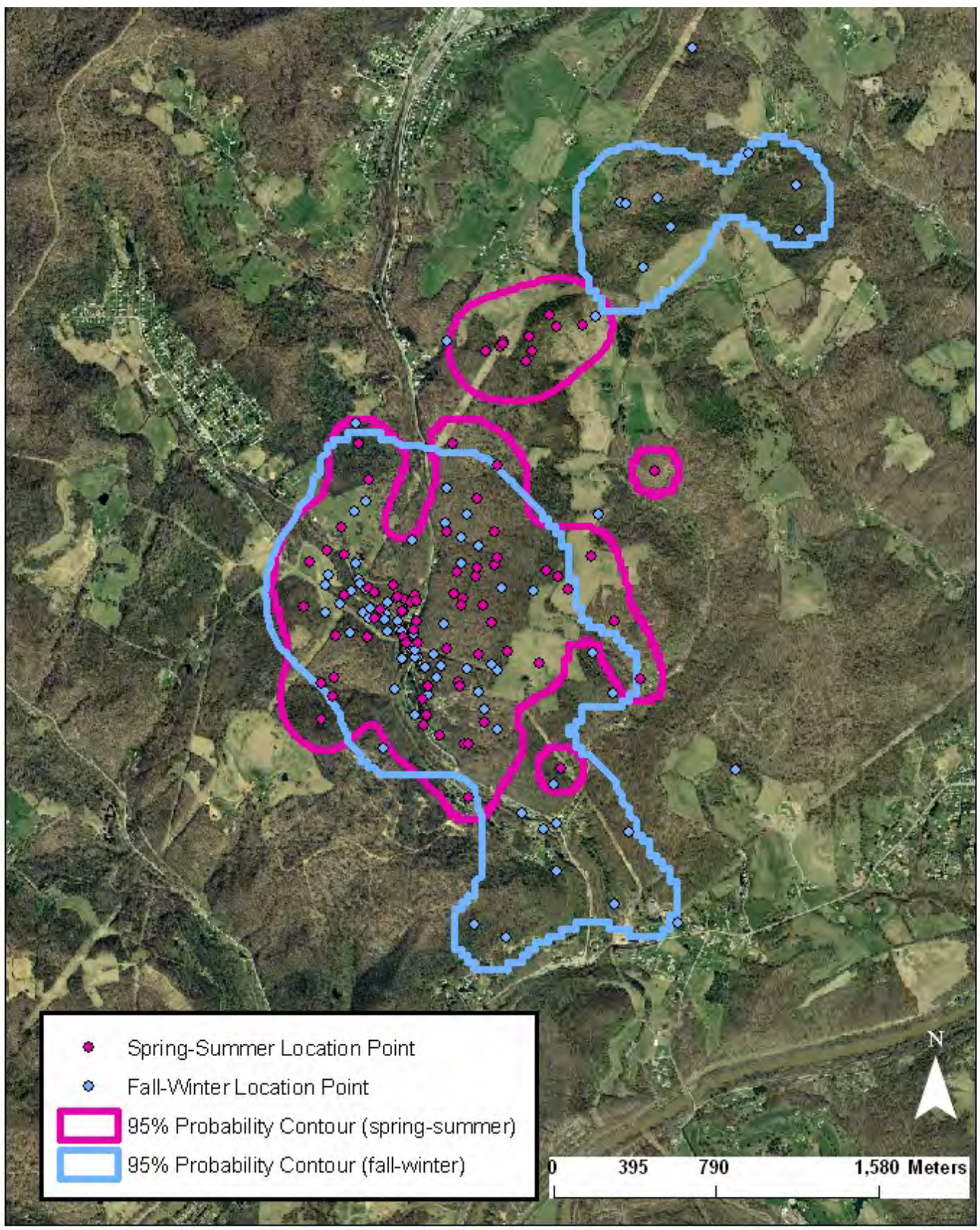


Appendix XXXIIIa. RG5111 (adult) - 50\% and 95\% probability contours of the annual fixed kernel home range utilization distribution. Smoothing parameter (h) determined by least squares cross validation, Taylor County, West Virginia, 2005-2007 (100k topo map).

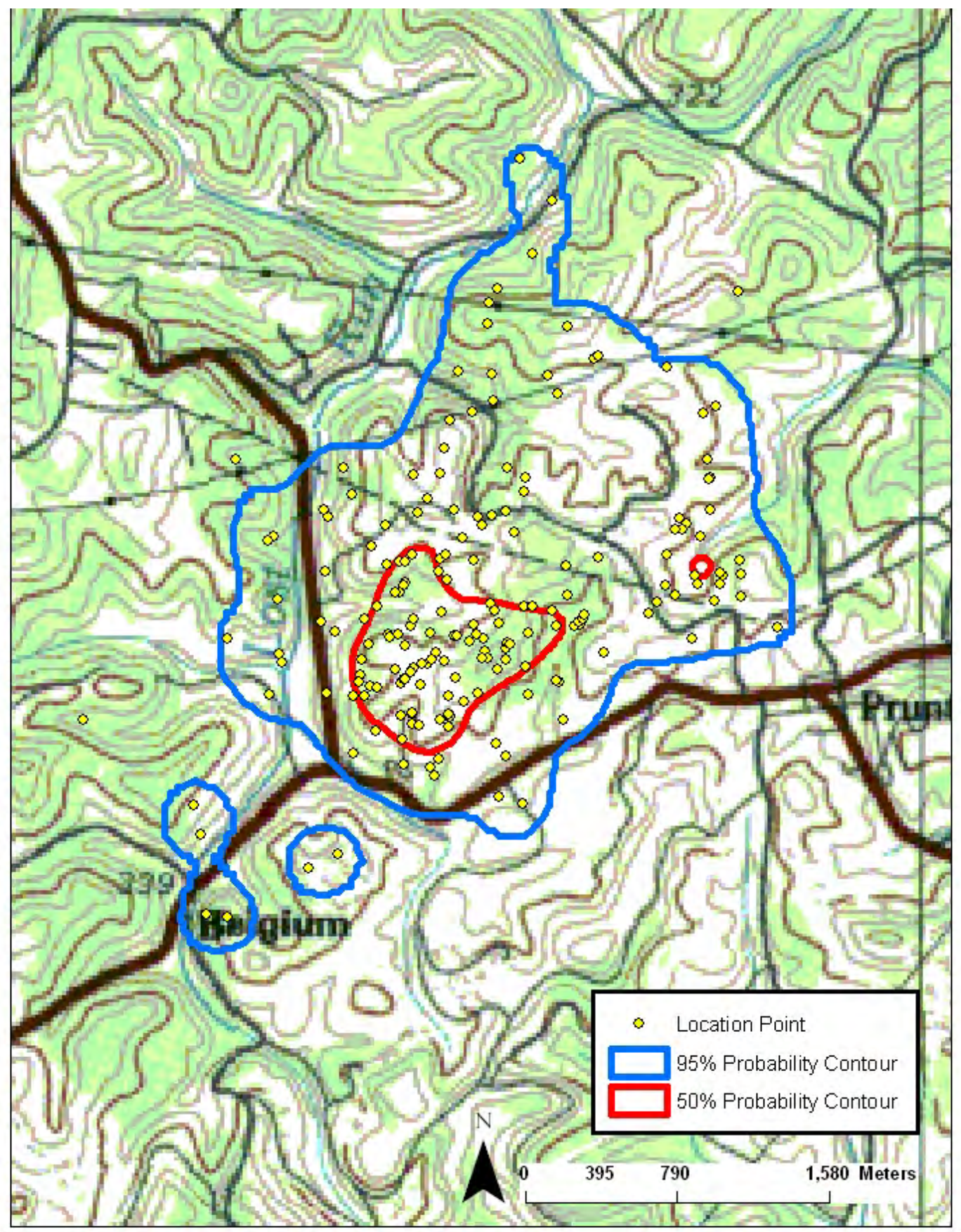


Appendix XXXIVa. RG5111 (adult) - 50\% and 95\% probability contours of the annual fixed kernel home range utilization distribution. Smoothing parameter (h) determined by least squares cross validation, Taylor County, West Virginia, 2005-2007 (2003 SAMB imagery).

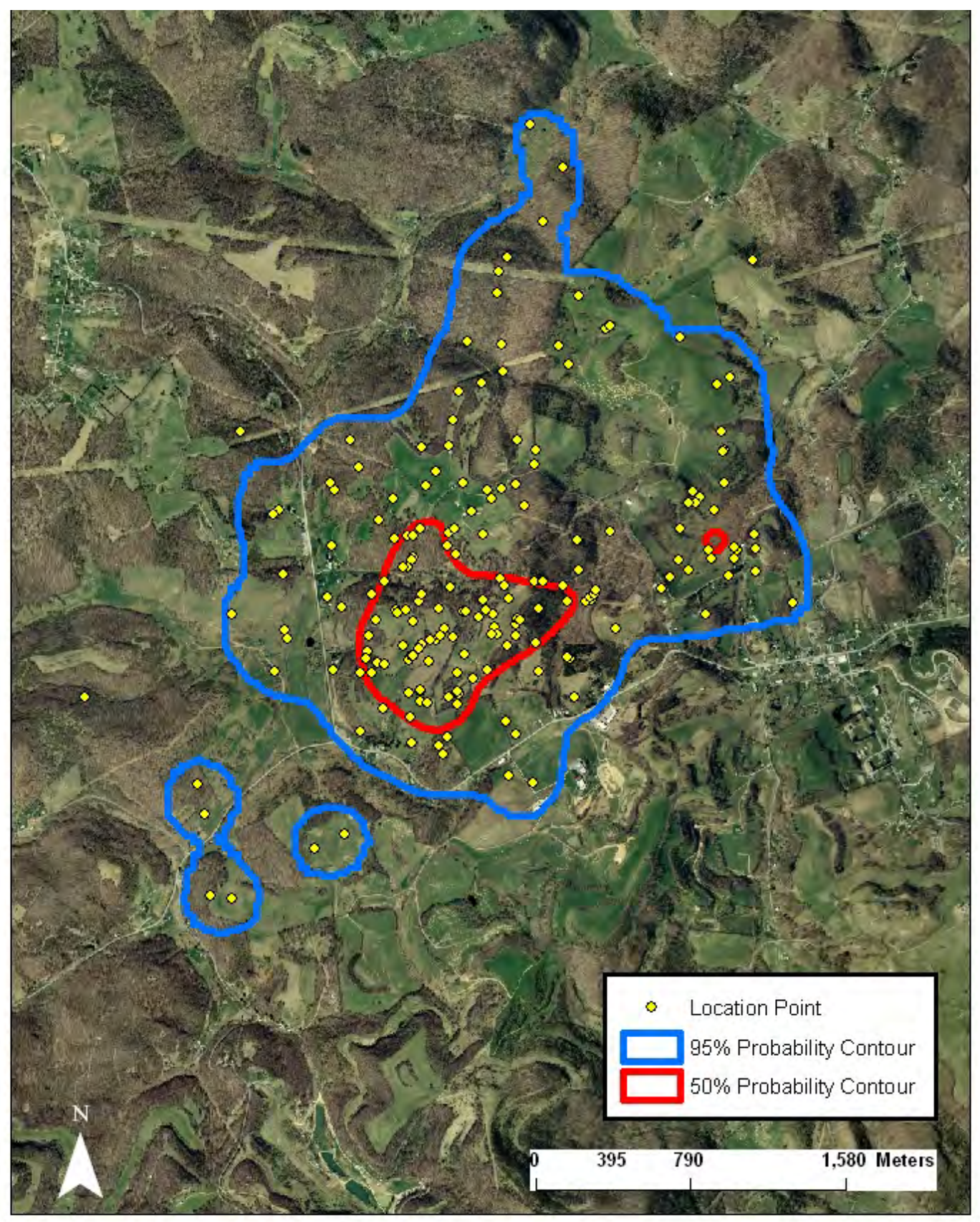


Appendix XXXVa. RG5111 (adult) - 95\% probability contours of the spring, fall, and winter fixed kernel home range utilization distributions. Smoothing parameter (h) determined by least squares cross validation, Taylor County, West Virginia, 2005-2007 (2003 SAMB imagery).

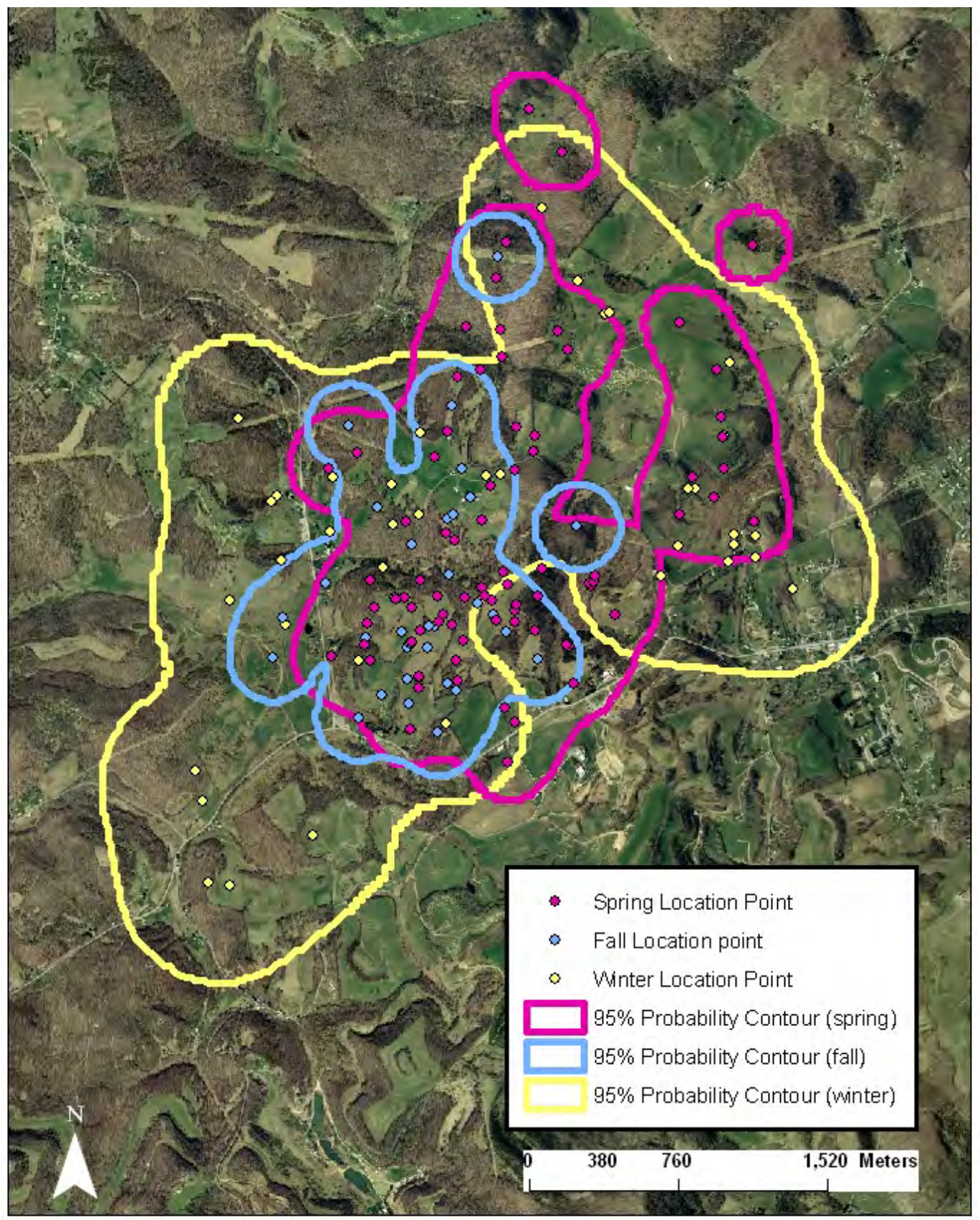


Appendix XXXVIa. RG5111 (adult) - 95\% probability contours of the spring-summer and fall-winter fixed kernel home range utilization distributions. Smoothing parameter (h) determined by least squares cross validation, Taylor County, West Virginia, 2005-2007 (2003 SAMB imagery).

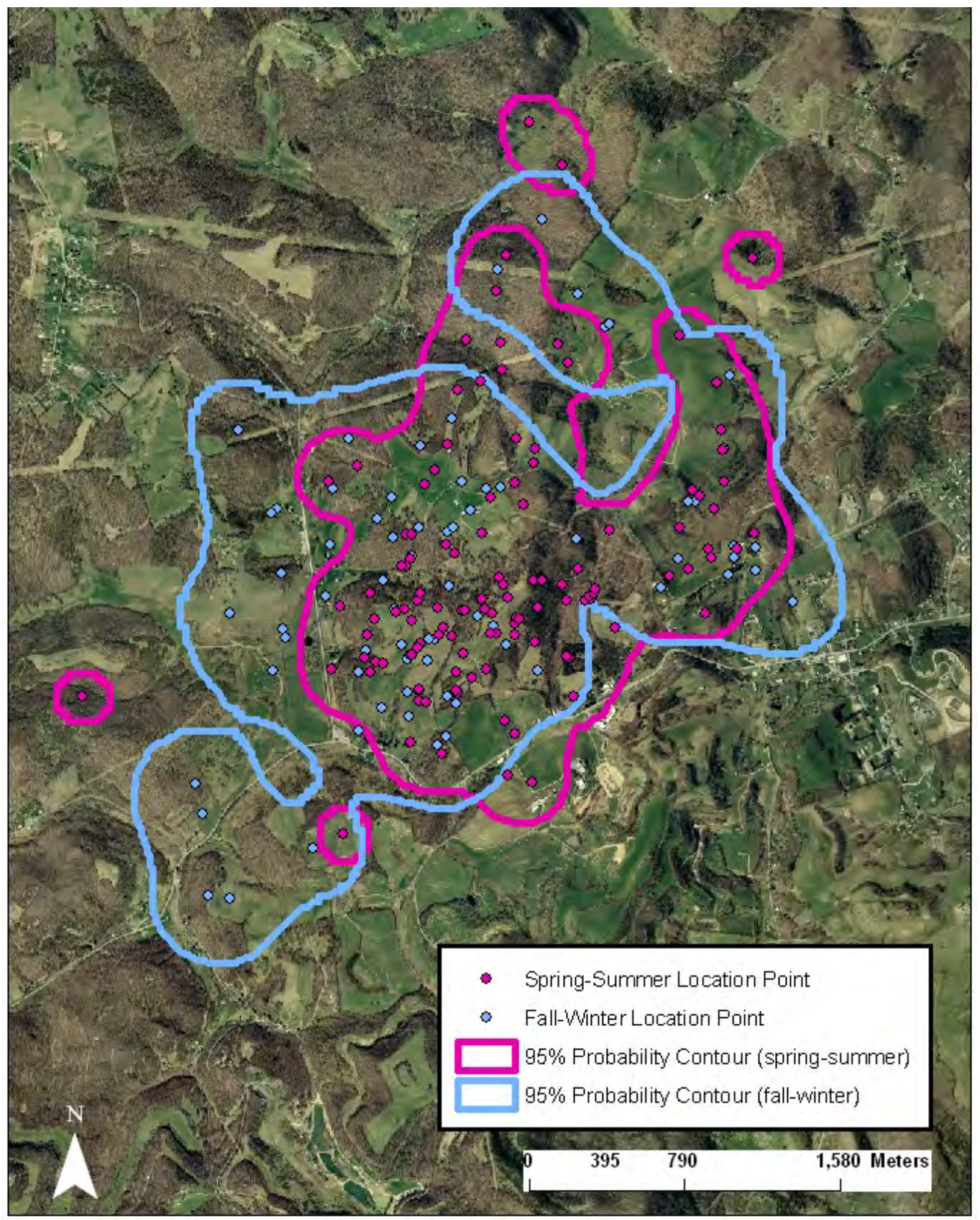


Appendix XXXVIIa. RG5114 (adult) - 50\% and 95\% probability contours of the annual fixed kernel home range utilization distribution. Smoothing parameter (h) determined by least squares cross validation, Taylor County, West Virginia, 2005-2007 (100k topo map).

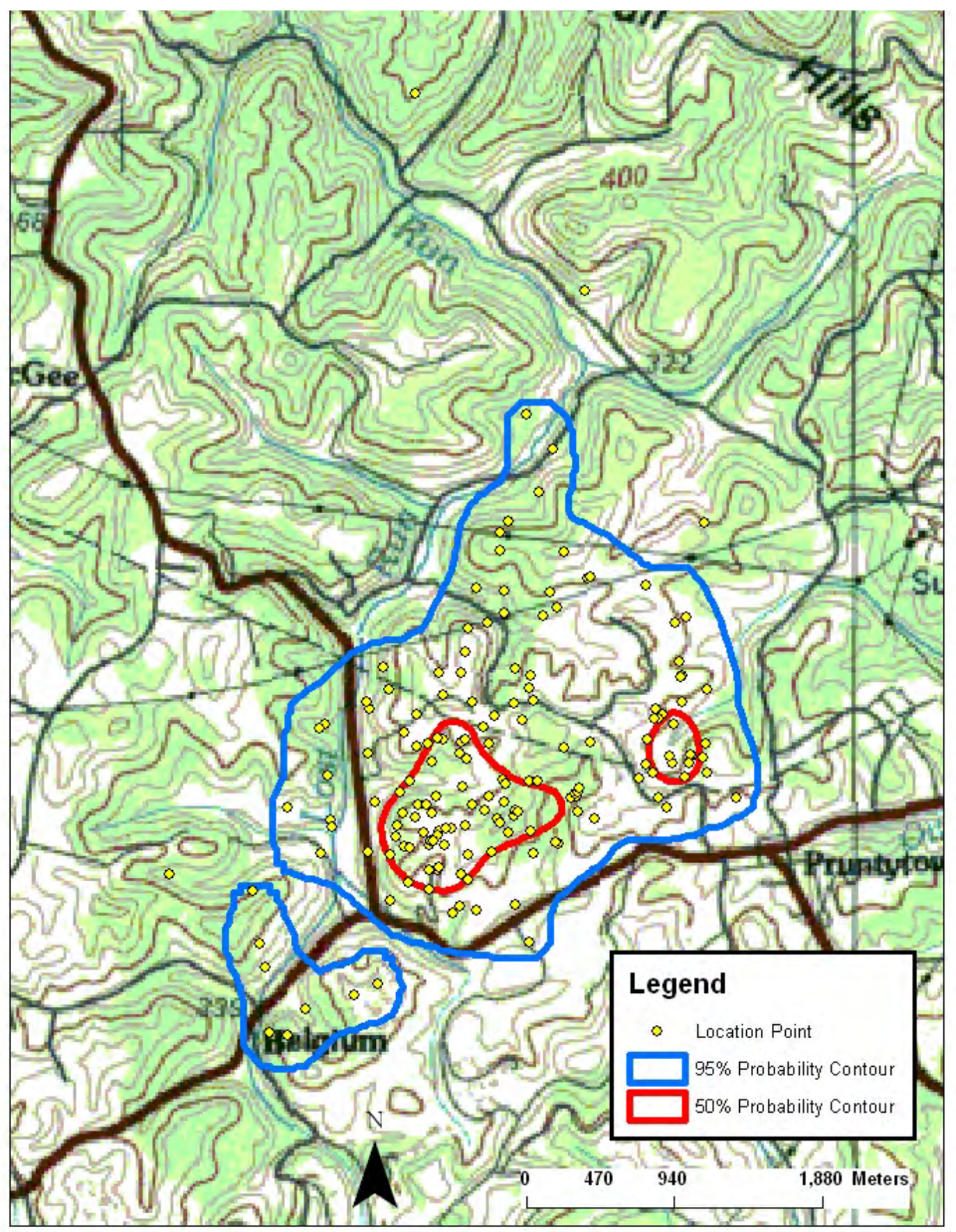


Appendix XXXVIIIa. RG5114 (adult) - 50\% and 95\% probability contours of the annual fixed kernel home range utilization distribution. Smoothing parameter (h) determined by least squares cross validation, Taylor County, West Virginia, 2005-2007 (2003 SAMB imagery).

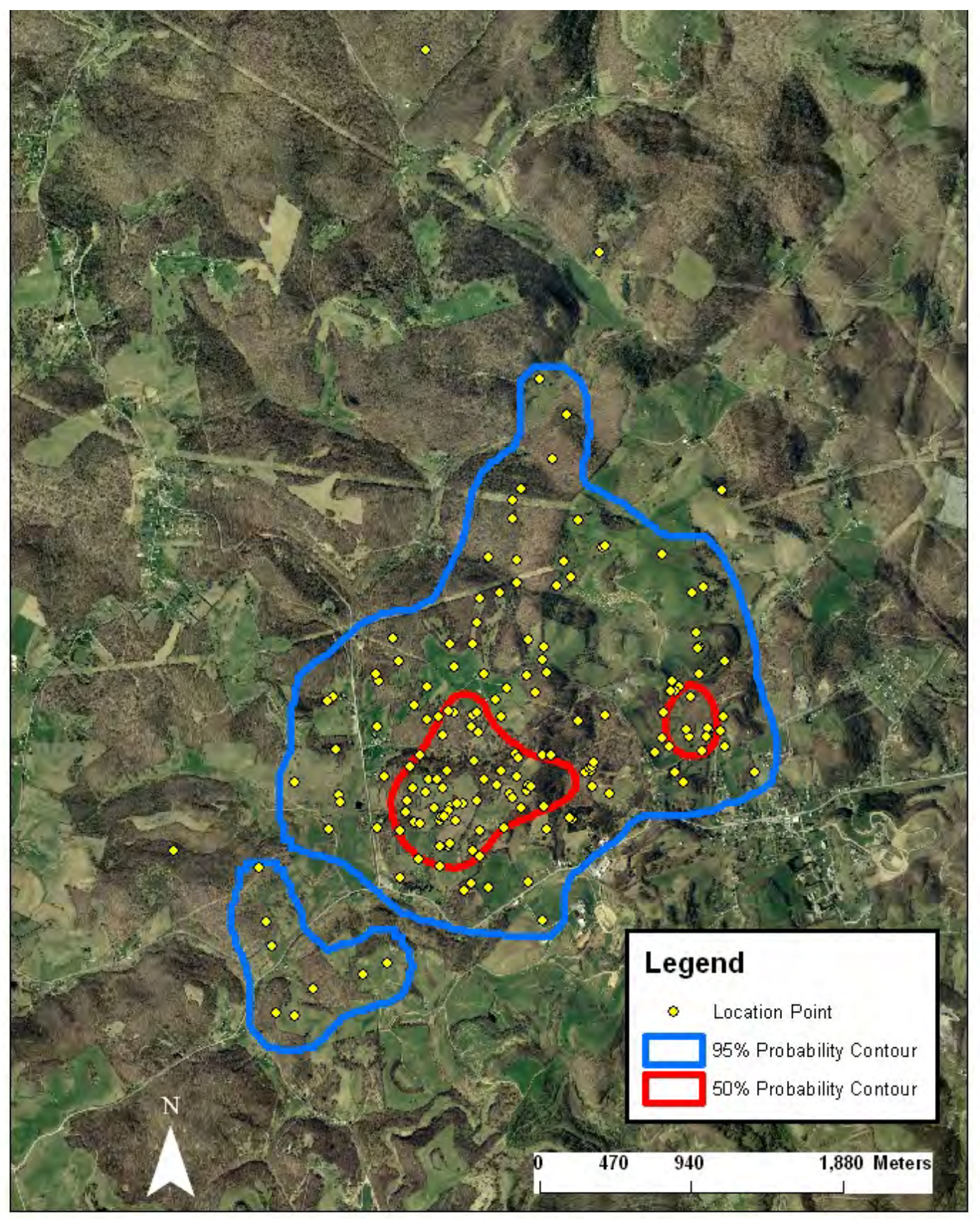


Appendix XXXIXa. RG5114 (adult) - 95\% probability contours of the spring, fall, and winter fixed kernel home range utilization distributions. Smoothing parameter (h) determined by least squares cross validation, Taylor County, West Virginia, 2005-2007 (2003 SAMB imagery).

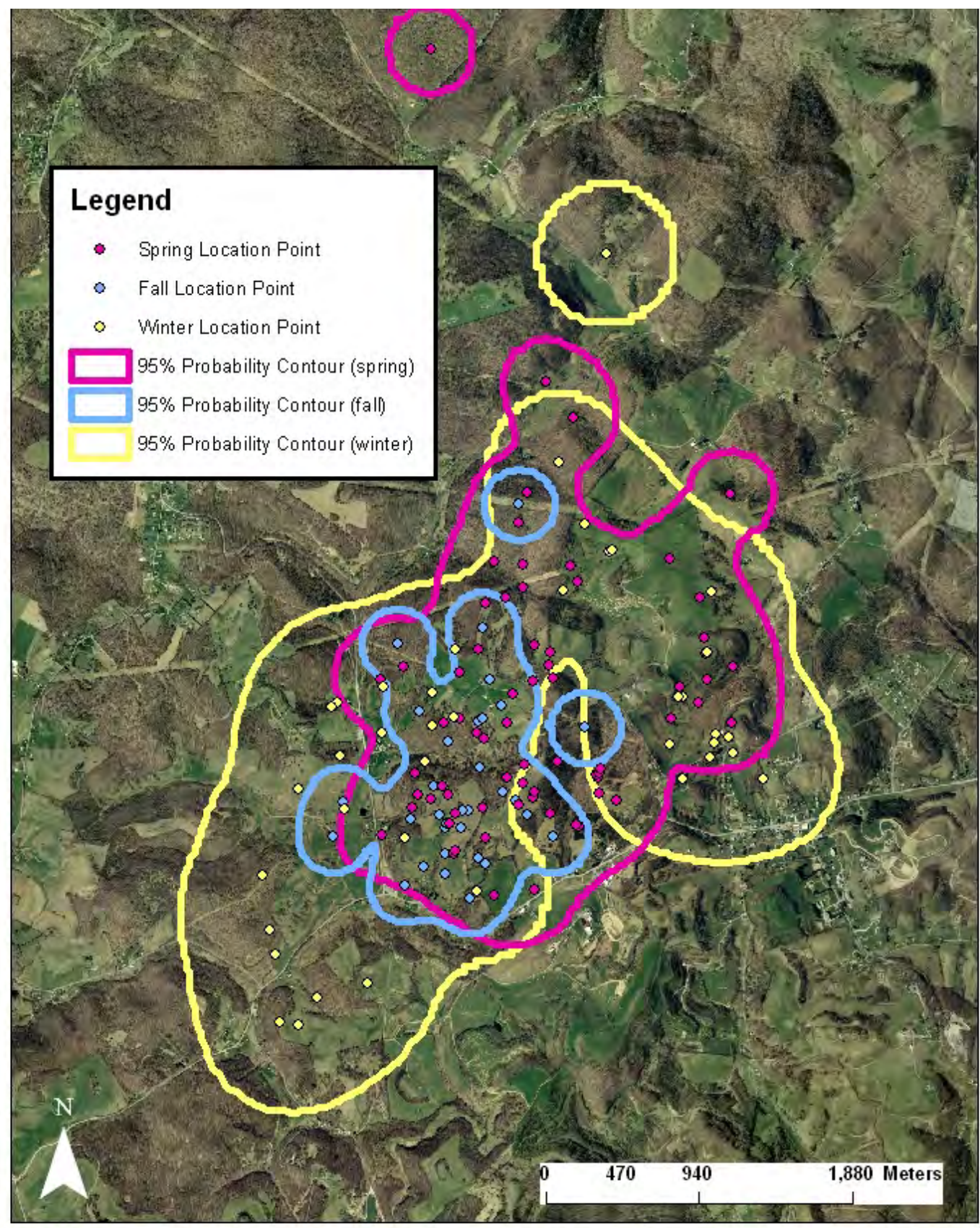


Appendix XLa. RG5114 (adult) - 95\% probability contours of the spring-summer and fallwinter fixed kernel home range utilization distributions. Smoothing parameter (h) determined by least squares cross validation, Taylor County, West Virginia, 2005-2007 (2003 SAMB imagery).

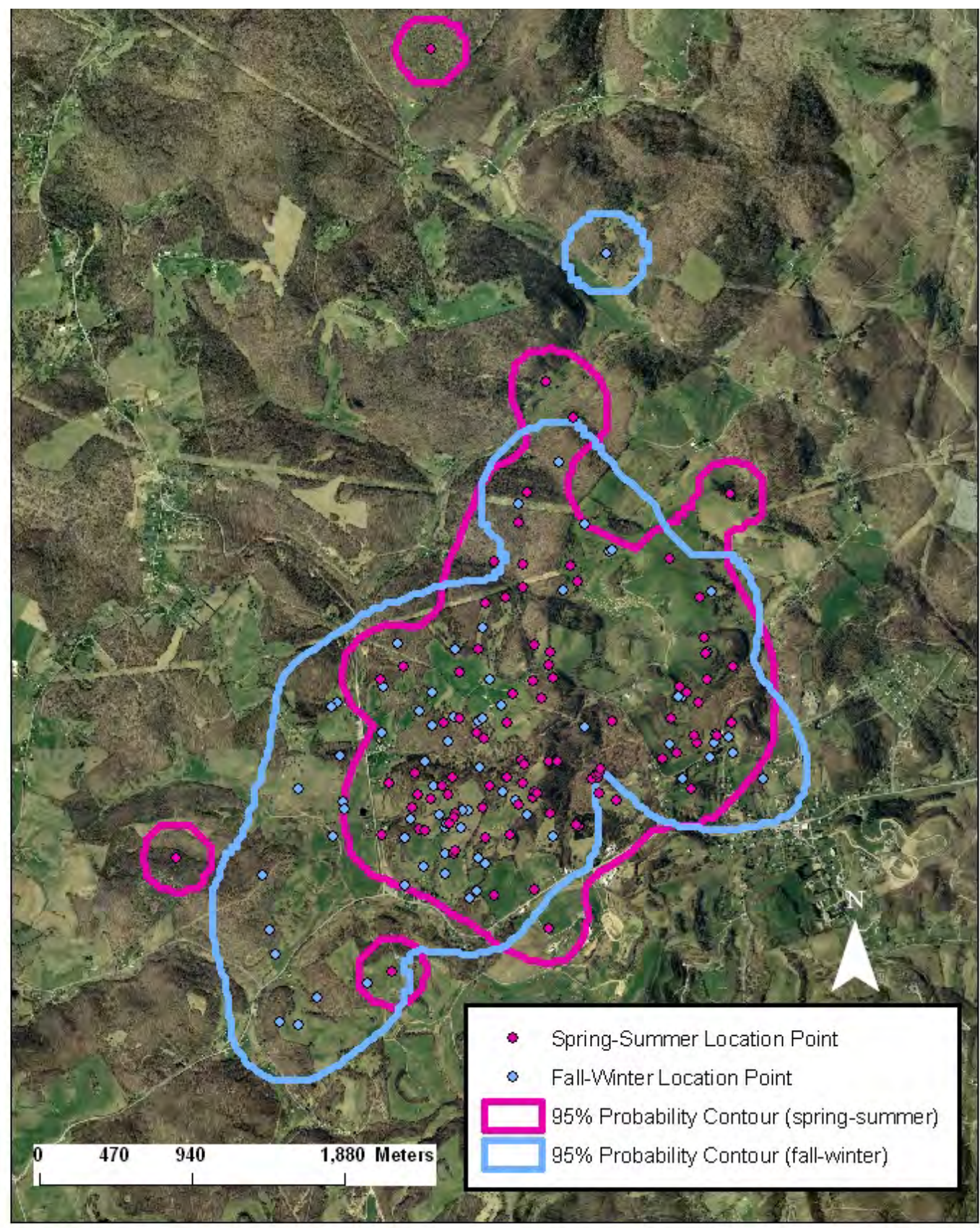


Appendix XLIa. RG5122 (juvenile) - 50\% and 95\% probability contours of the annual fixed kernel home range utilization distribution. Smoothing parameter (h) determined by least squares cross validation, Taylor County, West Virginia, 2005-2006 (100k topo map).

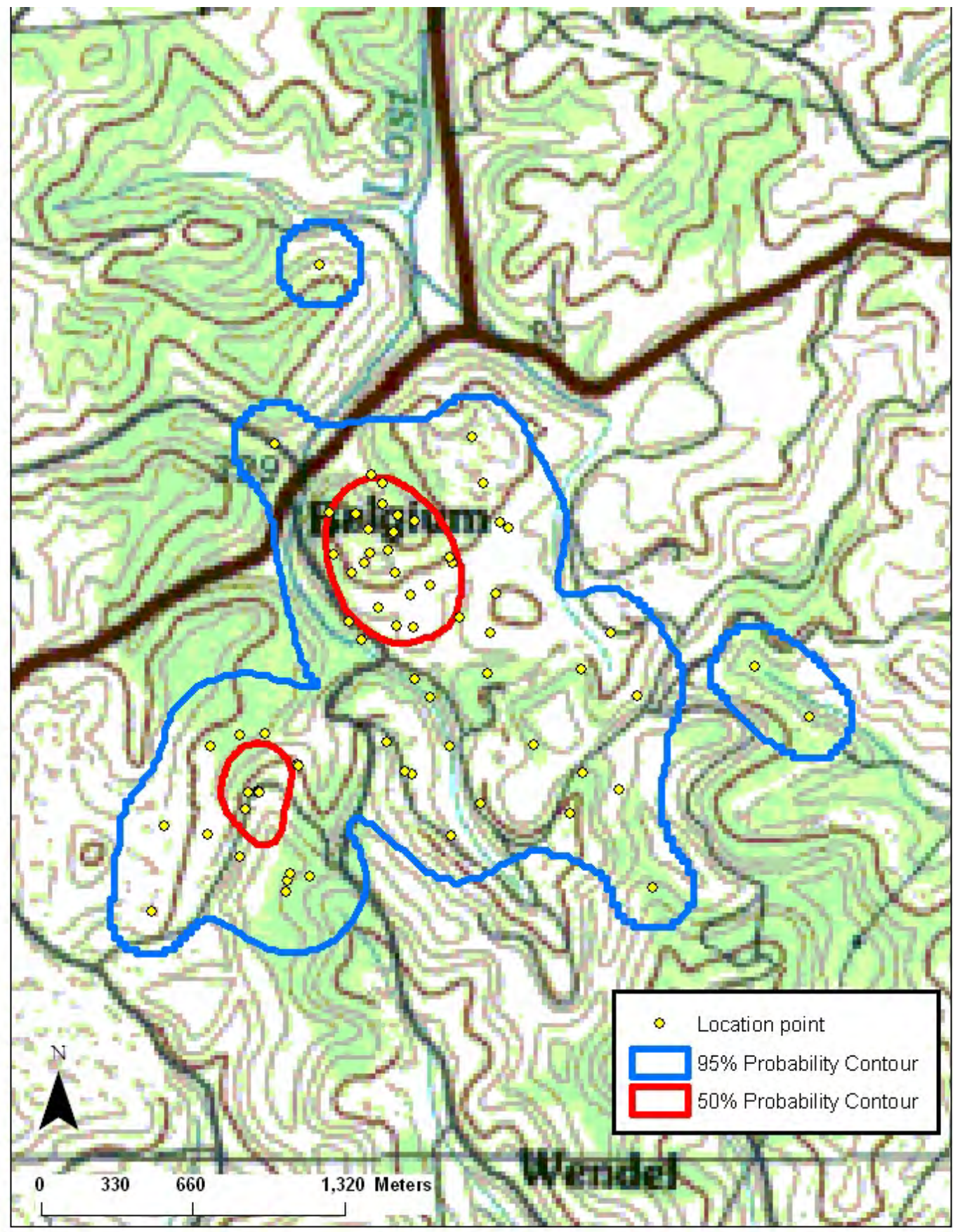


Appendix XLIIa. RG5122 (juvenile) - 50\% and 95\% probability contours of the annual fixed kernel home range utilization distribution. Smoothing parameter (h) determined by least squares cross validation, Taylor County, West Virginia, 2005-2006 (2003 SAMB imagery).

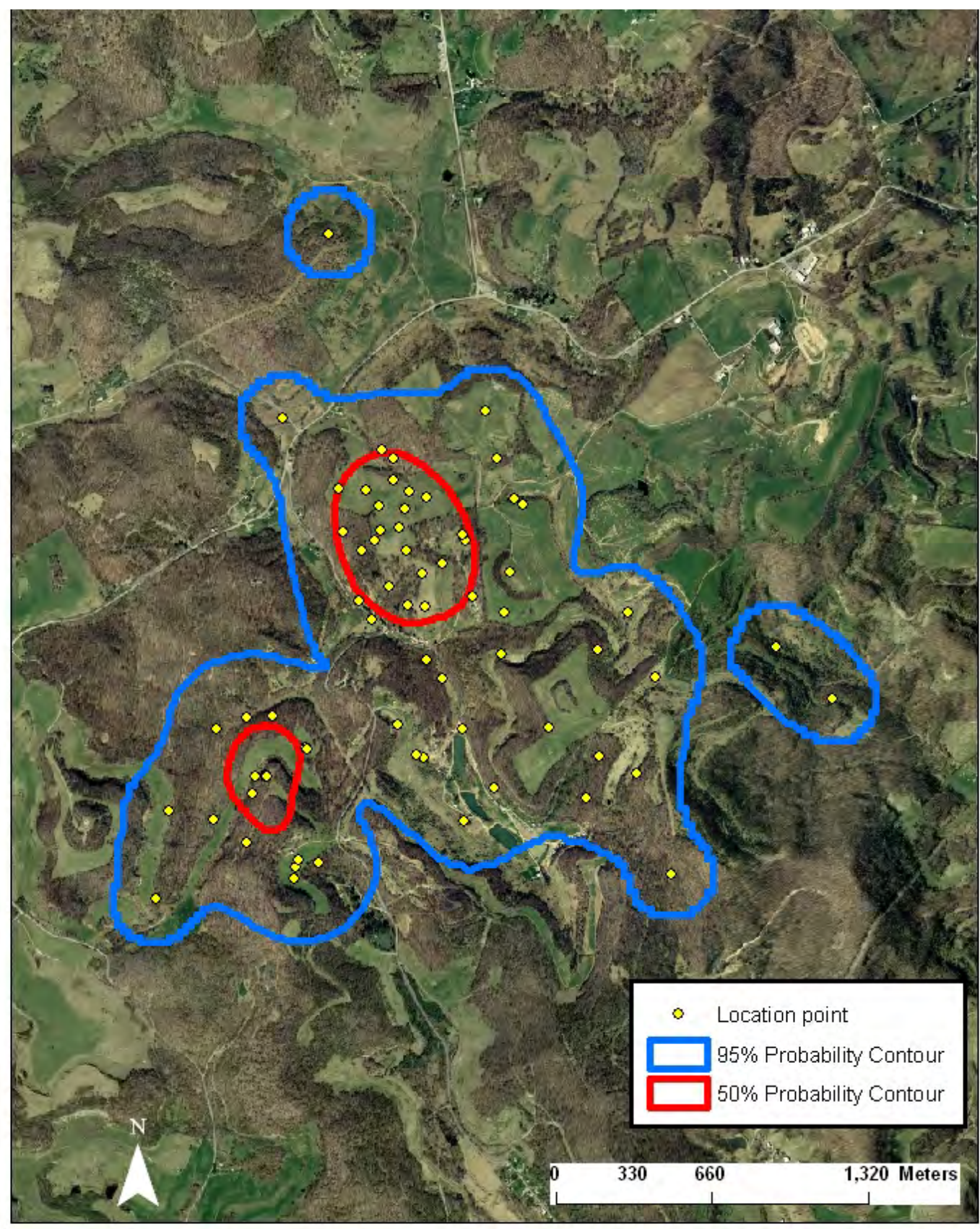


Appendix XLIIIa. RG5122 (juvenile) - 95\% probability contours of the spring fixed kernel home range utilization distribution. Smoothing parameter (h) determined by least squares cross validation, Taylor County, West Virginia, 2006 (2003 SAMB imagery).

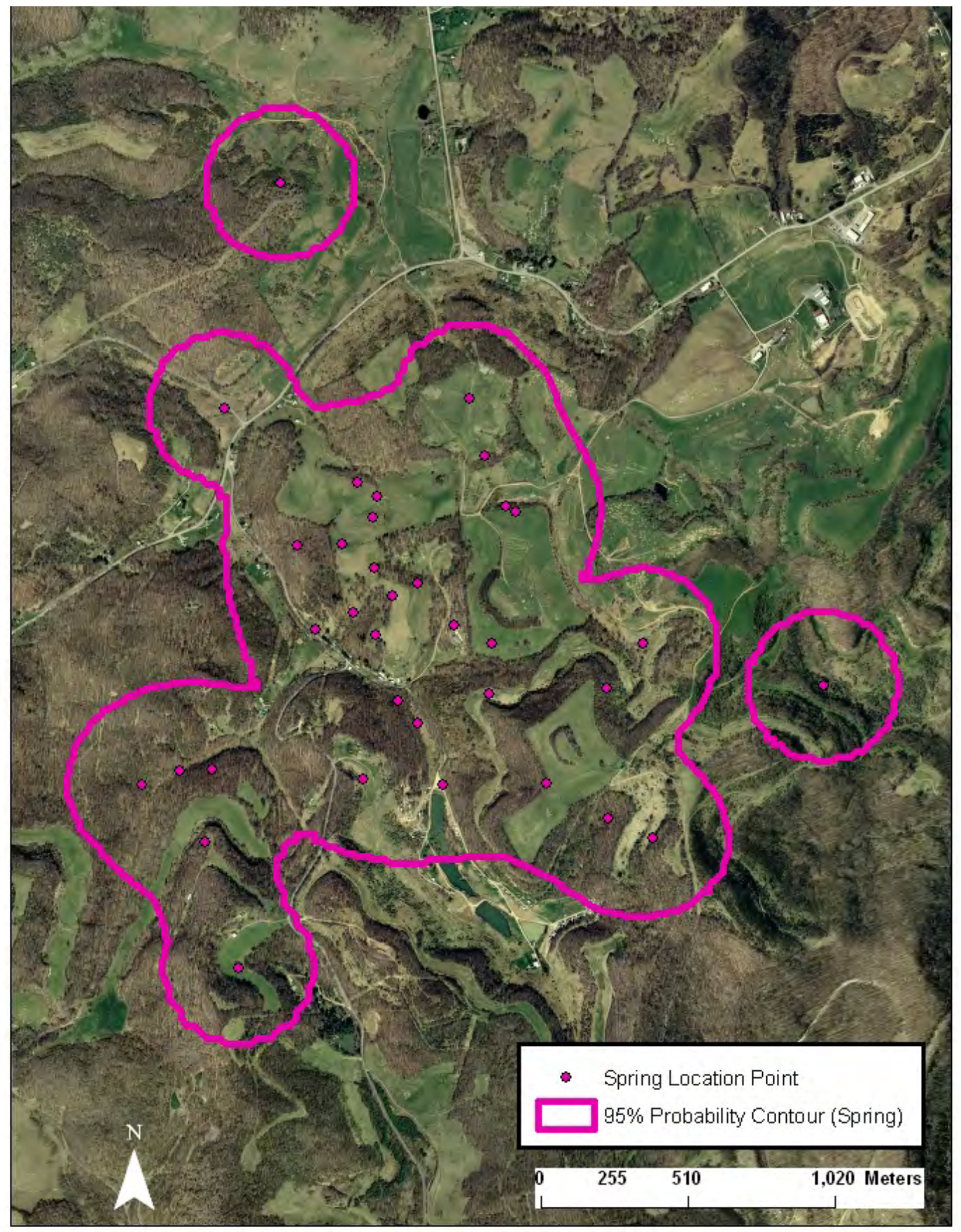


Appendix XLIVa. RG5122 (juvenile) - 95\% probability contours of the spring-summer fixed kernel home range utilization distribution. Smoothing parameter (h) determined by least squares cross validation, Taylor County, West Virginia, 2006 (2003 SAMB imagery).

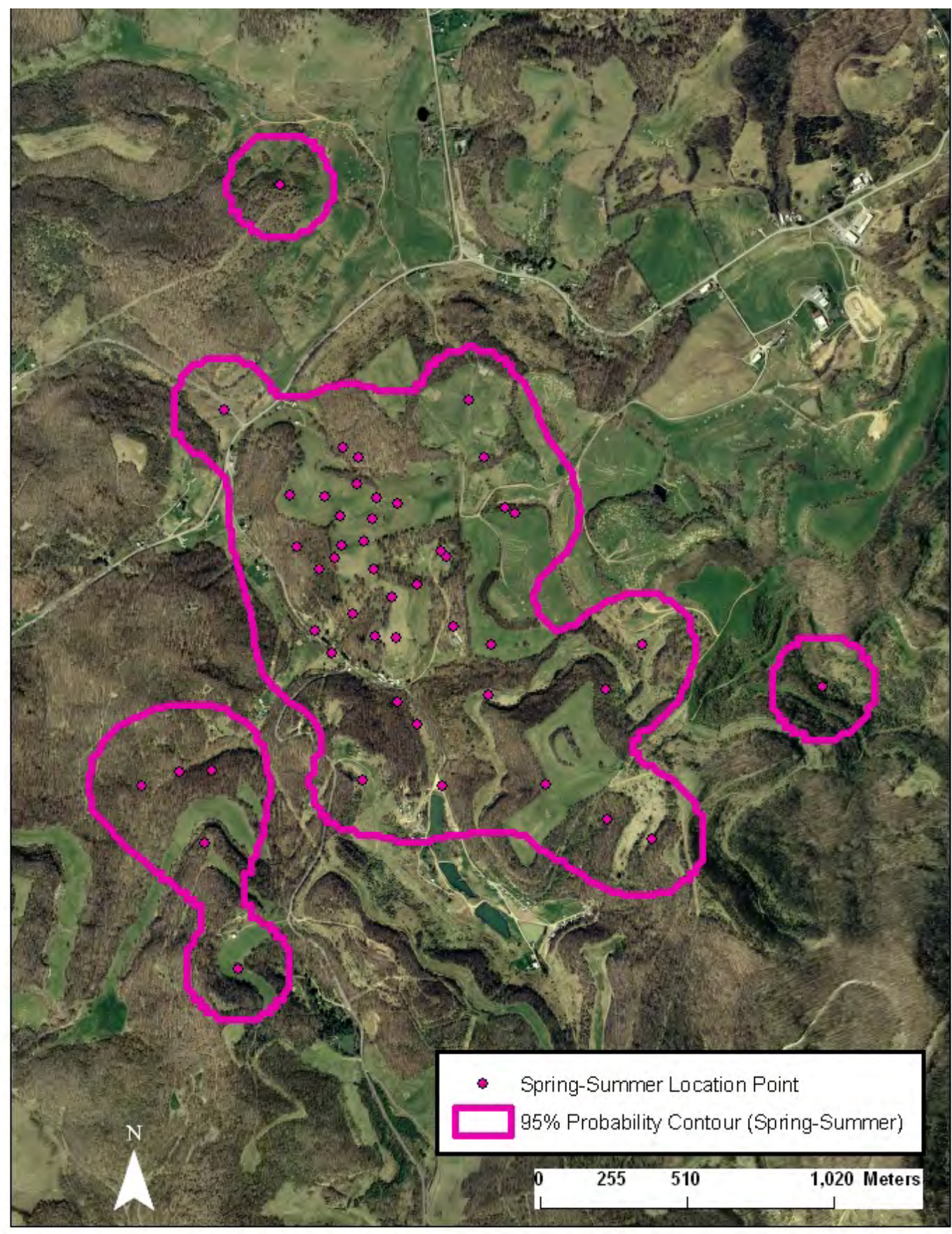


Appendix XLVa. RG5122 (adult) - 50\% and 95\% probability contours of the annual fixed kernel home range utilization distribution. Smoothing parameter (h) determined by least squares cross validation, Taylor County, West Virginia, 2006-2007 (100k topo map).

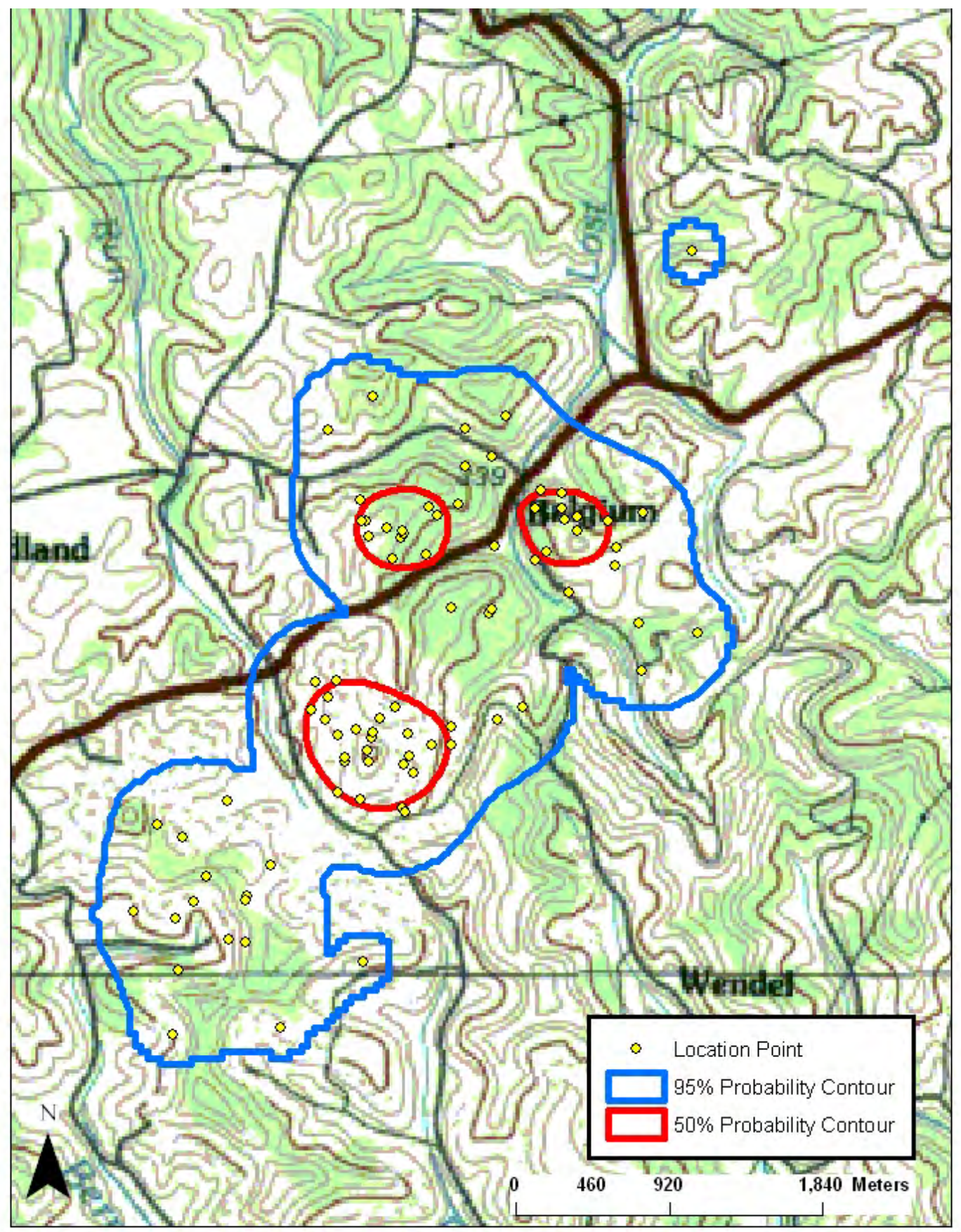


Appendix XLVIa. RG5122 (adult) - 50\% and 95\% probability contours of the annual fixed kernel home range utilization distribution. Smoothing parameter (h) determined by least squares cross validation, Taylor County, West Virginia, 2006-2007 (2003 SAMB imagery).

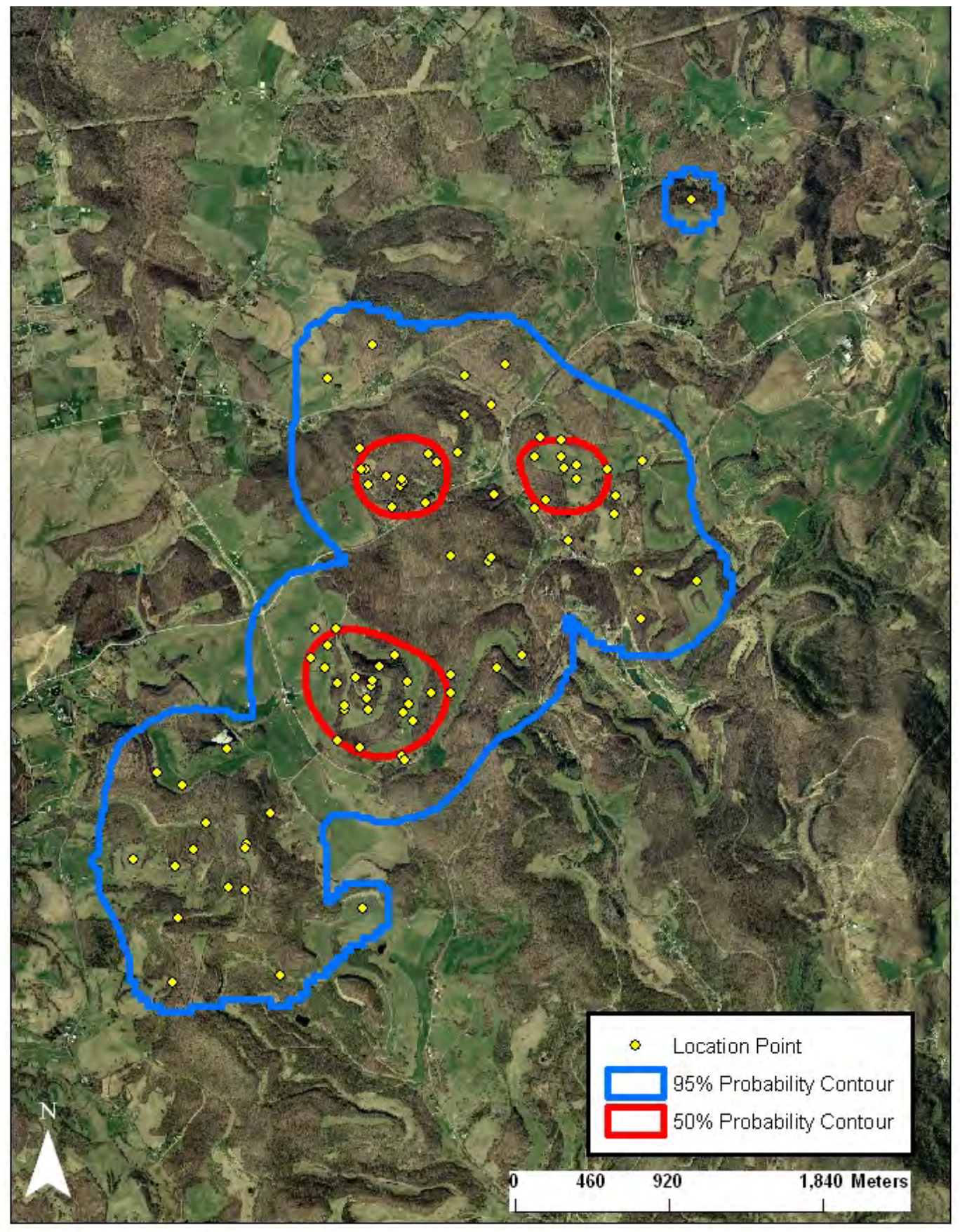


Appendix XLVIIa. RG5122 (adult) - 95\% probability contours of the spring fixed kernel home range utilization distribution. Smoothing parameter (h) determined by least squares cross validation, Taylor County, West Virginia, 2007 (2003 SAMB imagery).

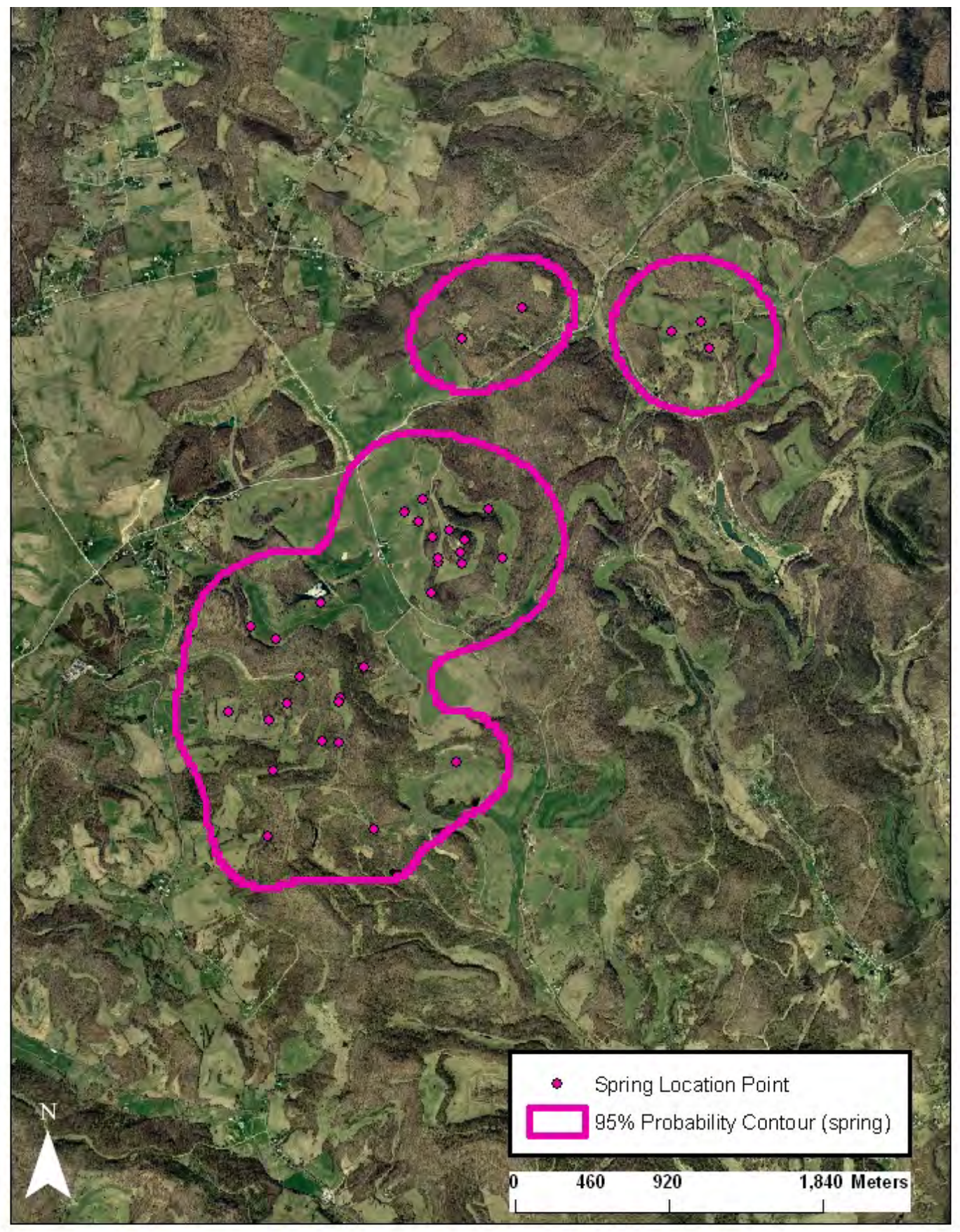


Appendix XLVIIIa. RG5122 (adult) - 95\% probability contours of the spring-summer and fall-winter fixed kernel home range utilization distributions. Smoothing parameter (h) determined by least squares cross validation, Taylor County, West Virginia, 2006-2007 (2003 SAMB imagery).

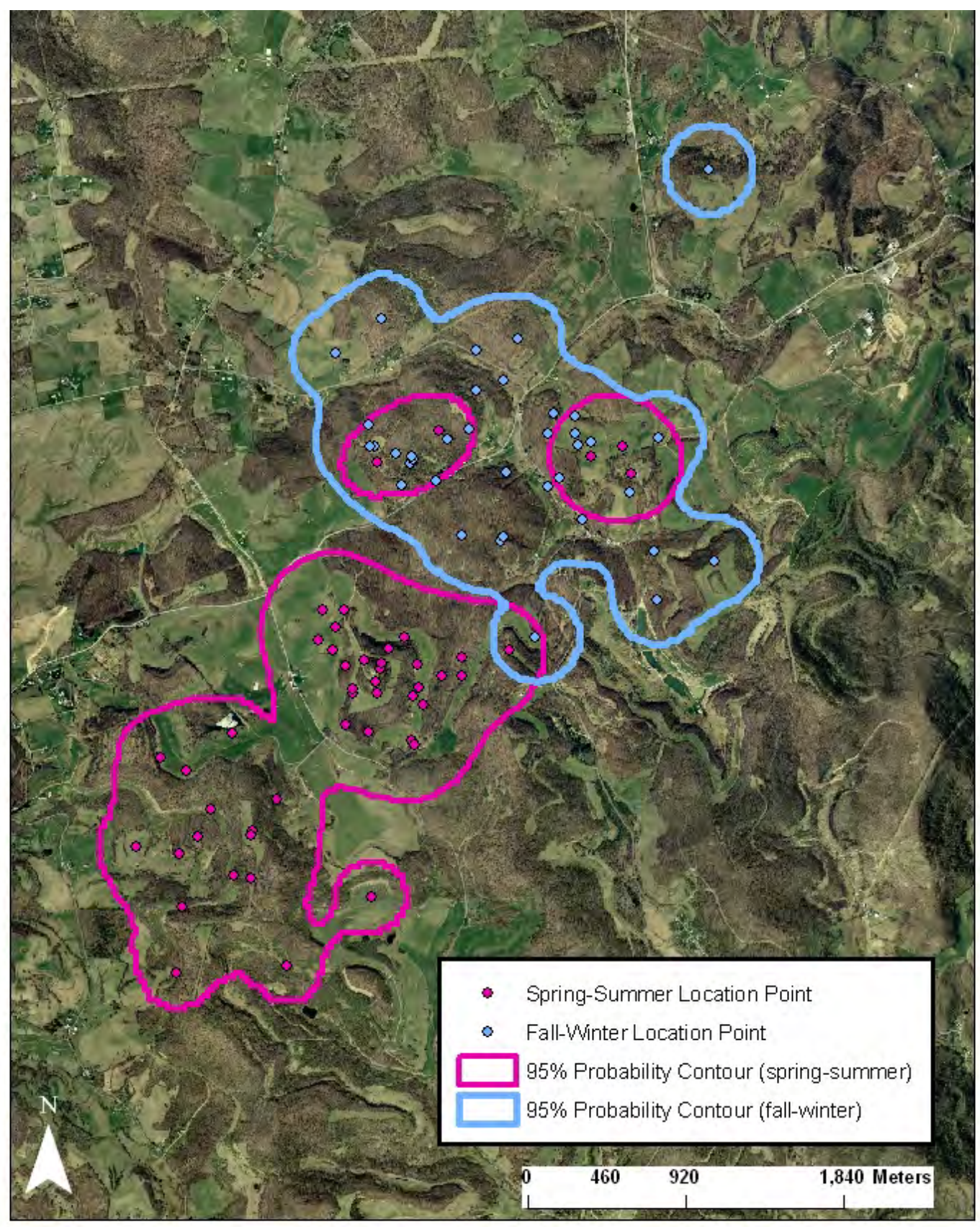


Appendix XLIXa. RG5126 (juvenile) - 50\% and 95\% probability contours of the annual fixed kernel home range utilization distribution. Smoothing parameter (h) determined by least squares cross validation, Marion County, West Virginia, 2006-2007 (100k topo map).

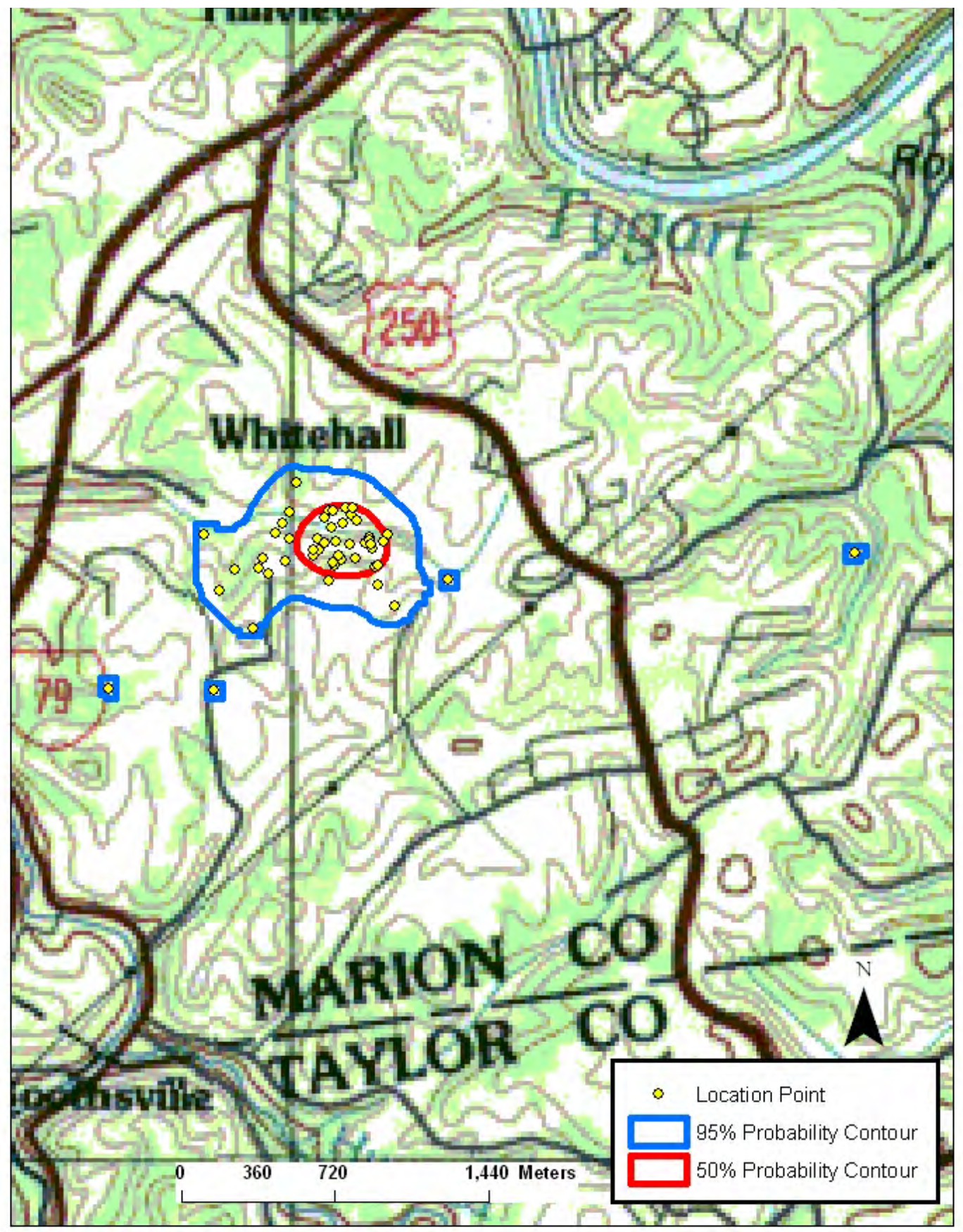


Appendix La. RG5126 (juvenile) - 50\% and 95\% probability contours of the annual fixed kernel home range utilization distribution. Smoothing parameter (h) determined by least squares cross validation, Marion County, West Virginia, 2006-2007 (2003 SAMB imagery).

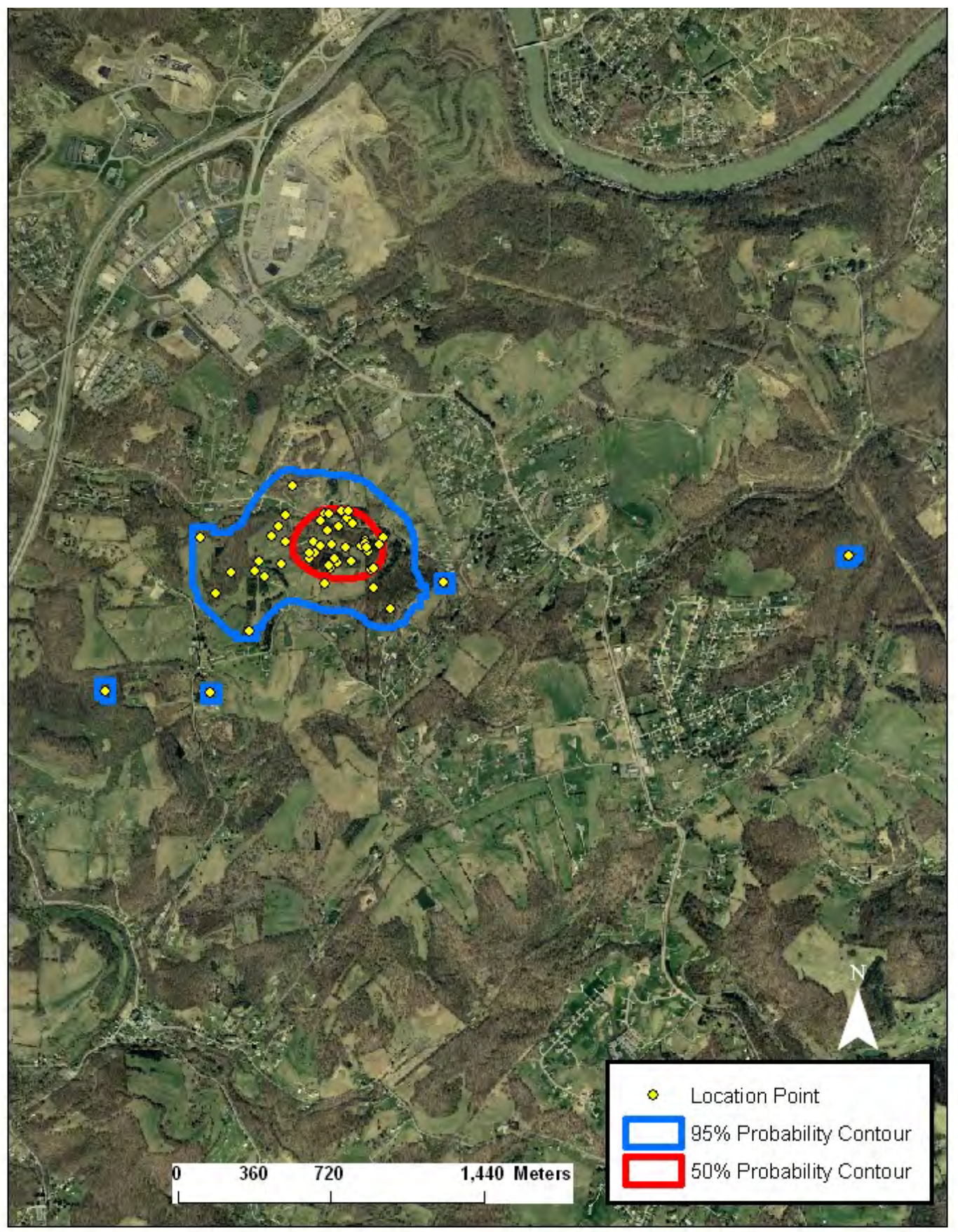


Appendix LIa. RG5126 (juvenile) - 95\% probability contour of the spring-summer fixed kernel home range utilization distribution. Smoothing parameter (h) determined by least squares cross validation, Marion County, West Virginia, 2006 (2003 SAMB imagery).

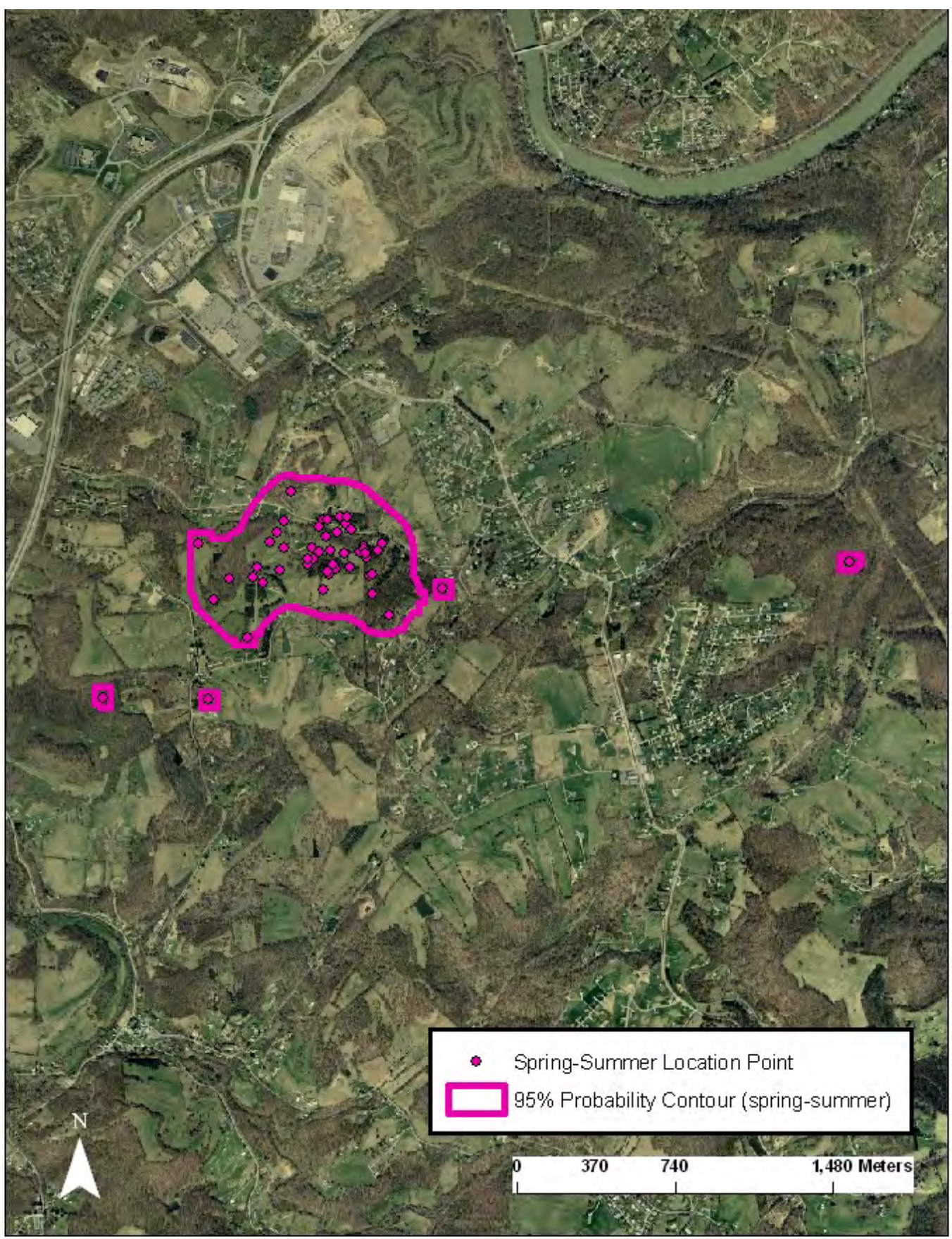


Appendix LIIa. RG5128 (juvenile) - 50\% and 95\% probability contours of the annual fixed kernel home range utilization distribution. Smoothing parameter (h) determined by least squares cross validation, Taylor County, West Virginia, 2006-2007 (100k topo map).

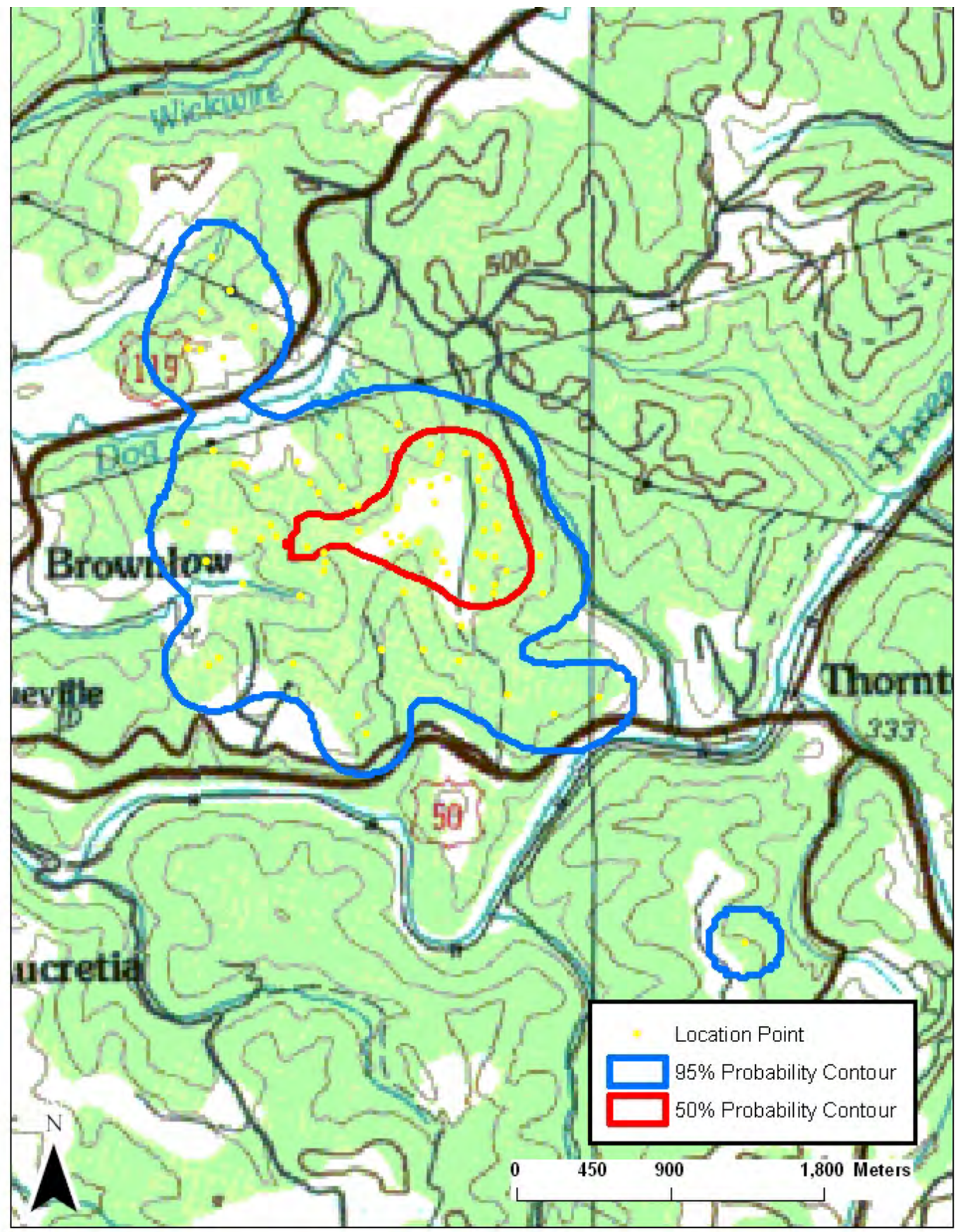


Appendix LIIIa. RG5128 (juvenile) - 50\% and 95\% probability contours of the annual fixed kernel home range utilization distribution. Smoothing parameter (h) determined by least squares cross validation, Taylor County, West Virginia, 2006-2007 (2003 SAMB imagery).

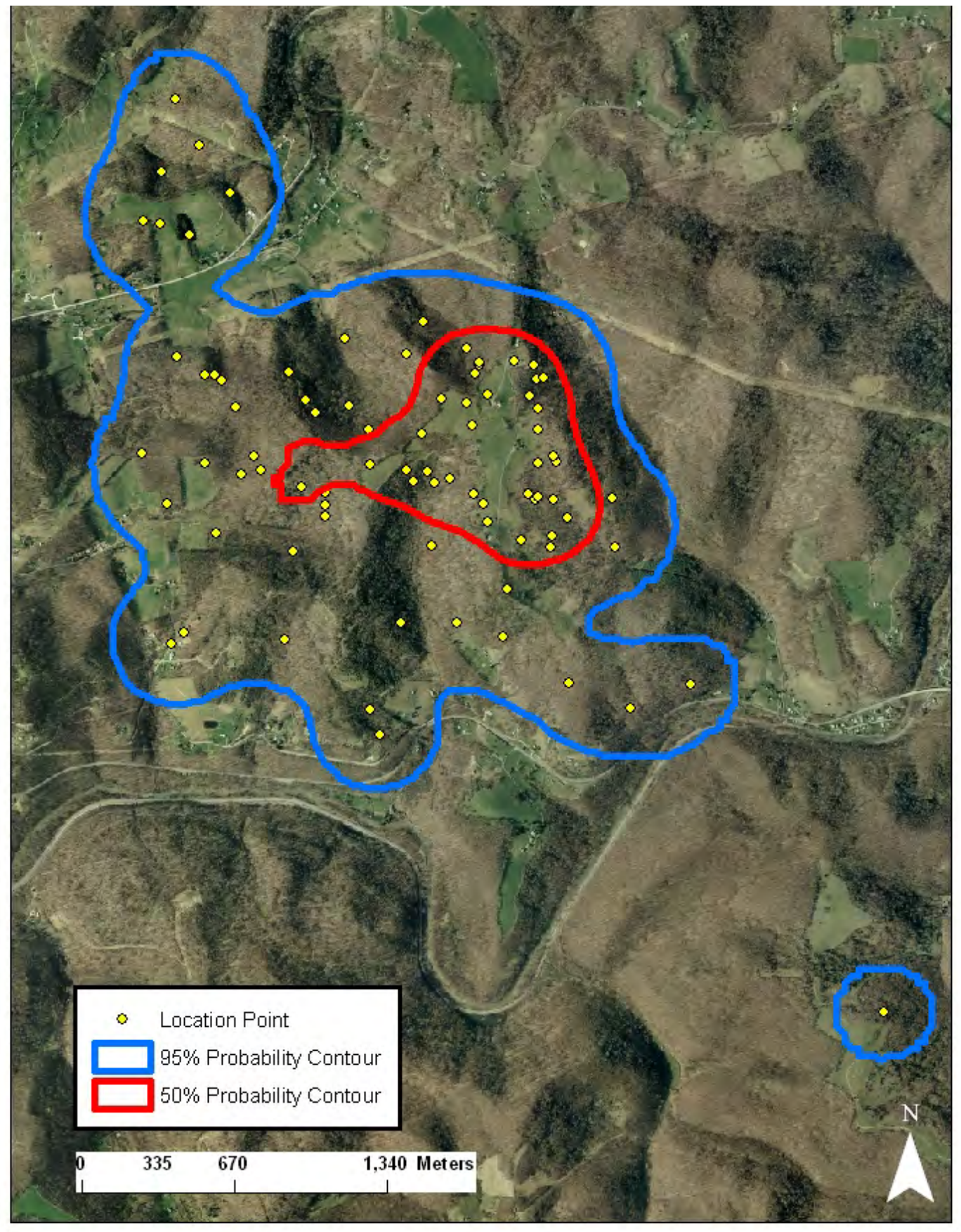


Appendix LIVa. RG5128 (juvenile) - 95\% probability contour of the spring fixed kernel home range utilization distribution. Smoothing parameter (h) determined by least squares cross validation, Taylor County, West Virginia, 2007 (2003 SAMB imagery).

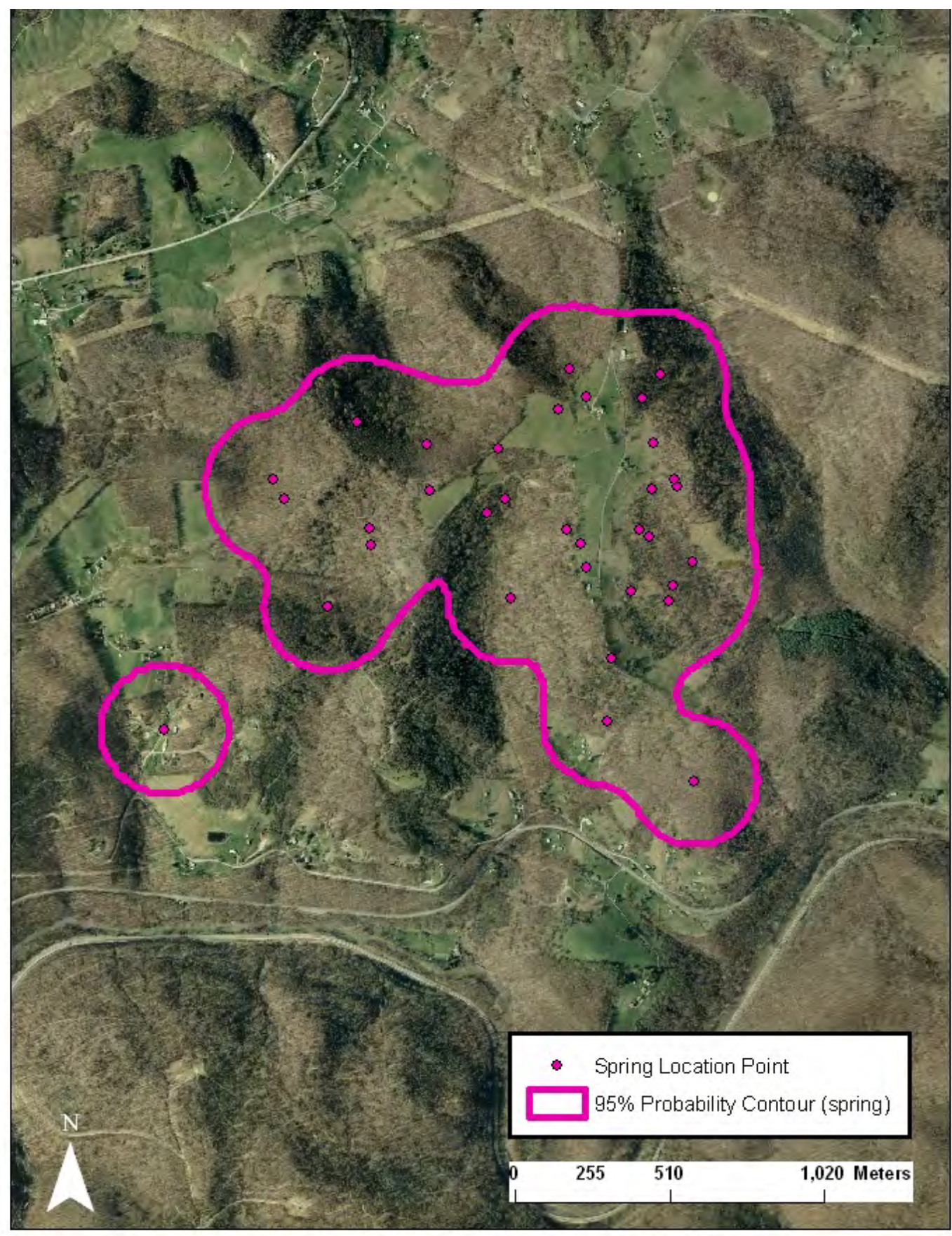


Appendix LVa. RG5128 (juvenile) - 95\% probability contour of the spring-summer fixed kernel home range utilization distribution. Smoothing parameter (h) determined by least squares cross validation, Taylor County, West Virginia, 2007 (2003 SAMB imagery).

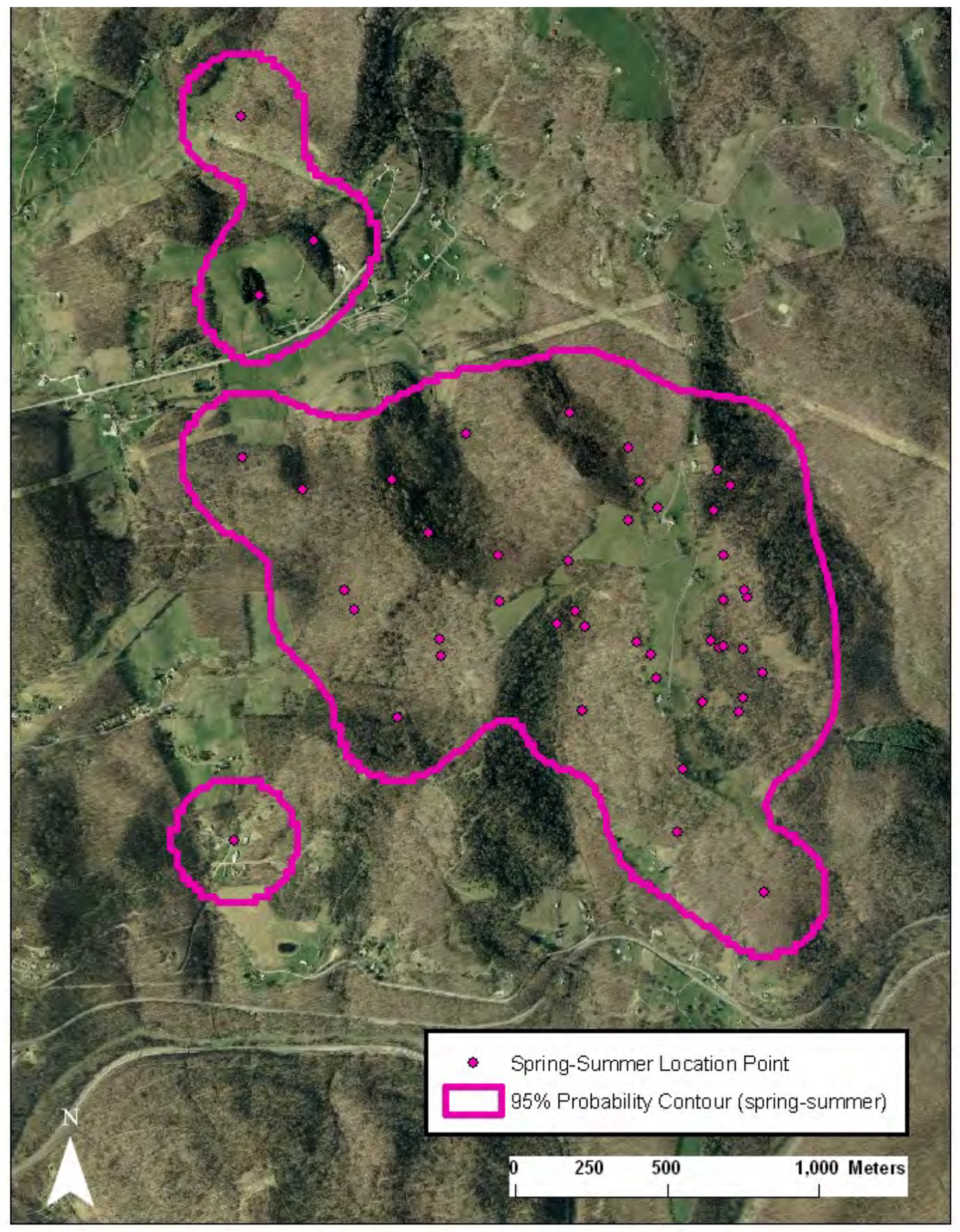


Appendix LVIa. RG5129 (juvenile) - 50\% and 95\% probability contours of the annual fixed kernel home range utilization distribution. Smoothing parameter (h) determined by least squares cross validation, Taylor County, West Virginia, 2006-2007 (100k topo map).

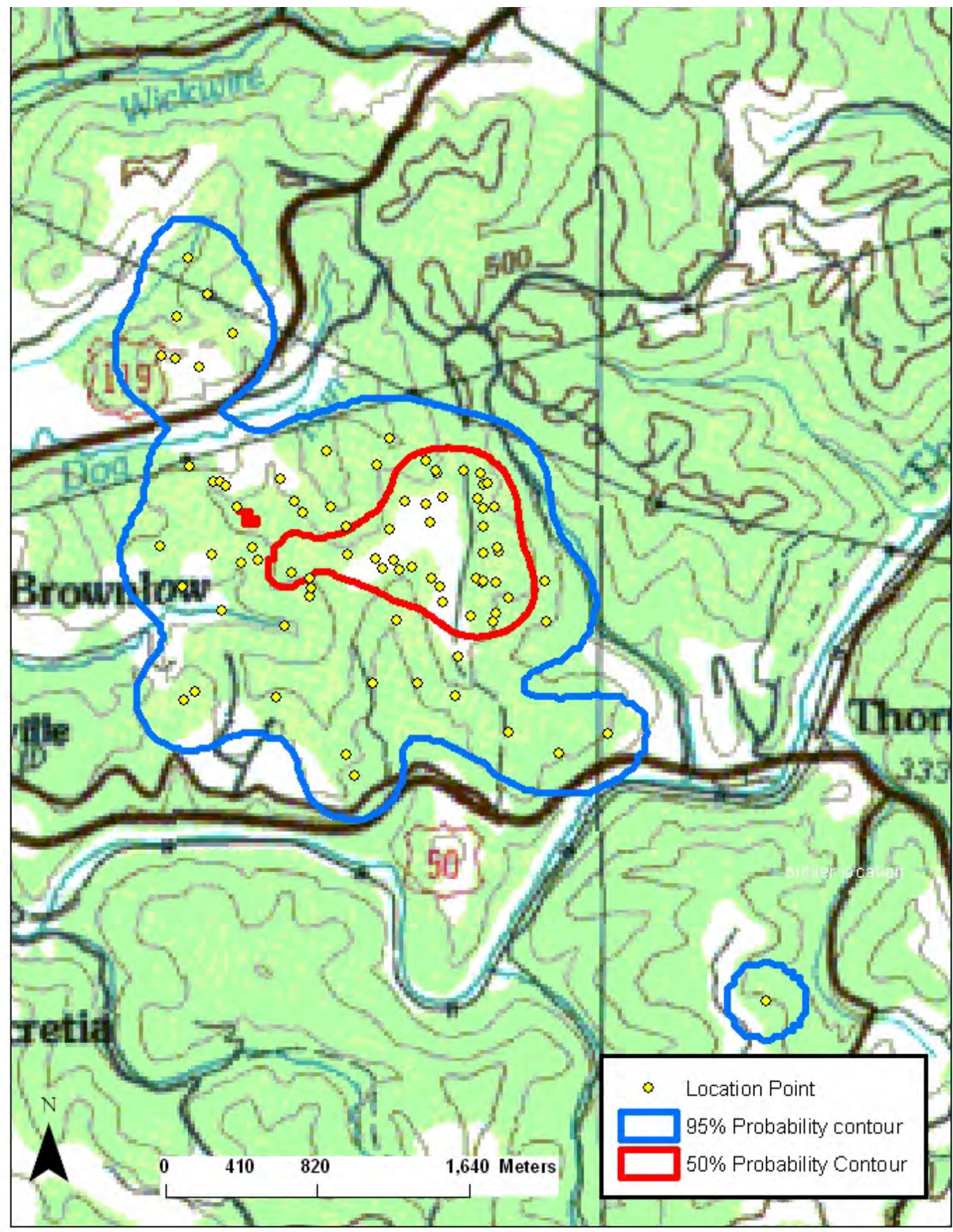


Appendix LVIIa. RG5129 (juvenile) - 50\% and 95\% probability contours of the annual fixed kernel home range utilization distribution. Smoothing parameter (h) determined by least squares cross validation, Taylor County, West Virginia, 2006-2007 (2003 SAMB imagery).

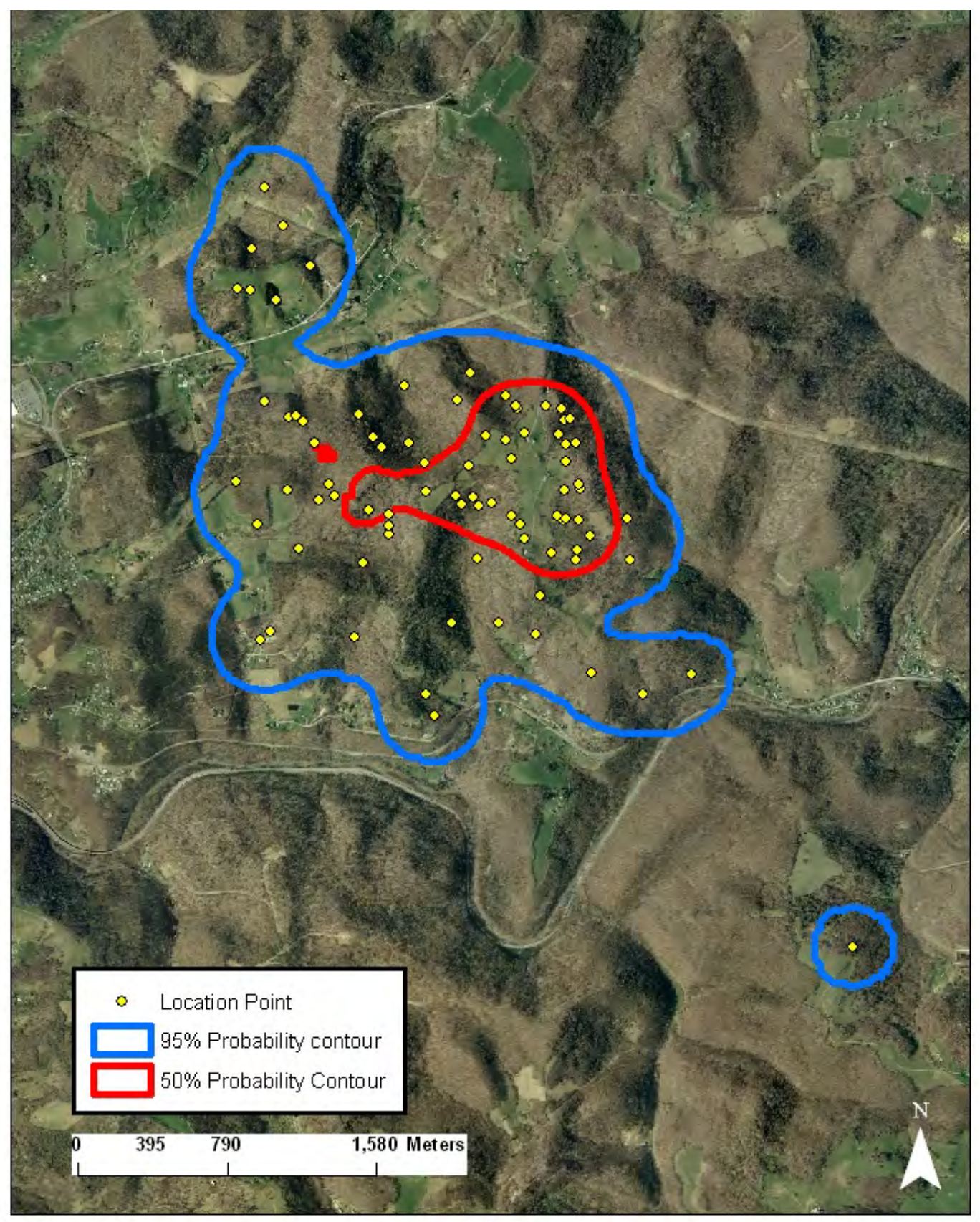


Appendix LVIIIa. RG5129 (juvenile) - 95\% probability contour of the spring fixed kernel home range utilization distribution. Smoothing parameter (h) determined by least squares cross validation, Taylor County, West Virginia, 2007 (2003 SAMB imagery).

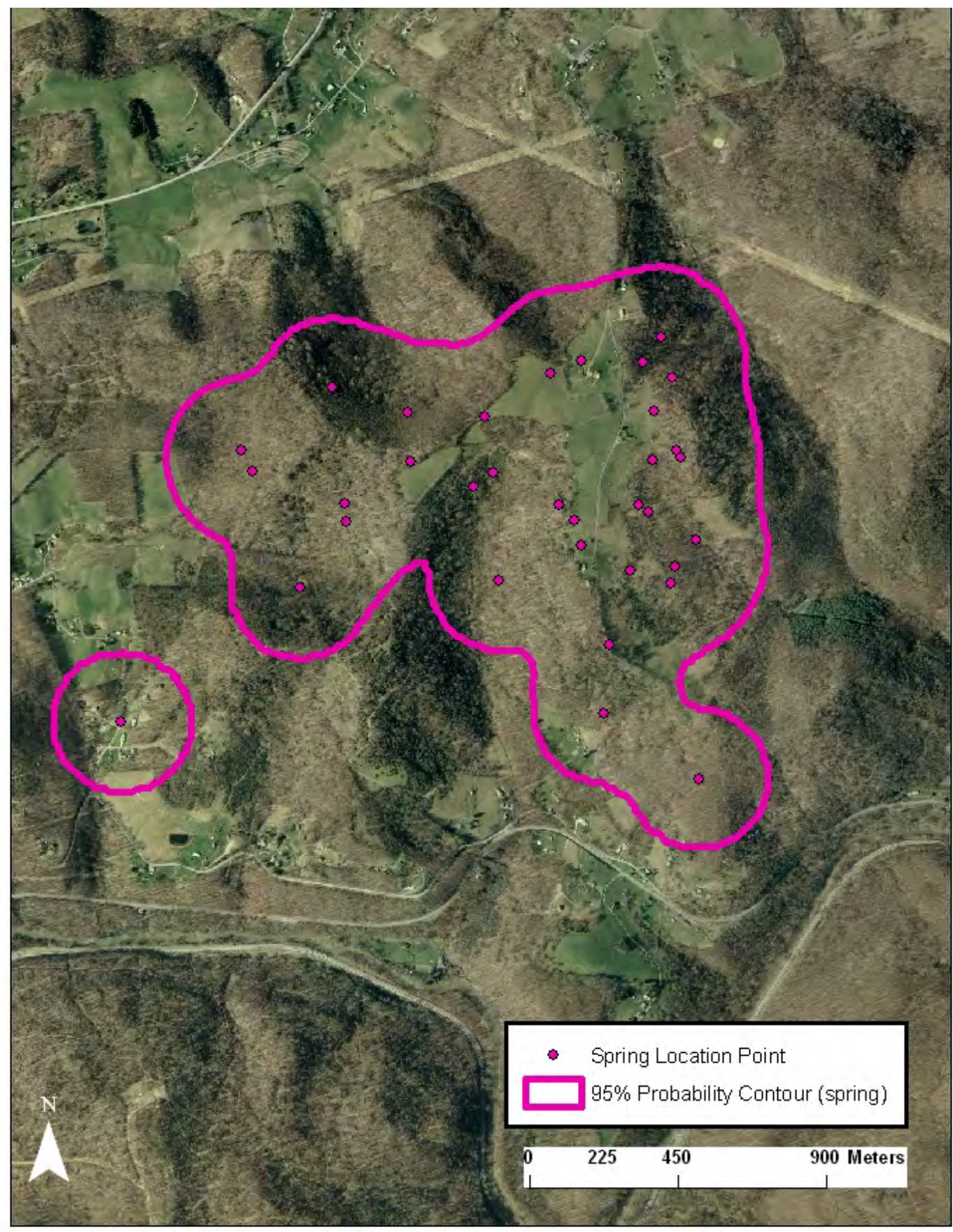


Appendix LIXa. RG5129 (juvenile) - 95\% probability contour of the spring-summer fixed kernel home range utilization distribution. Smoothing parameter (h) determined by least squares cross validation, Taylor County, West Virginia, 2007 (2003 SAMB imagery).

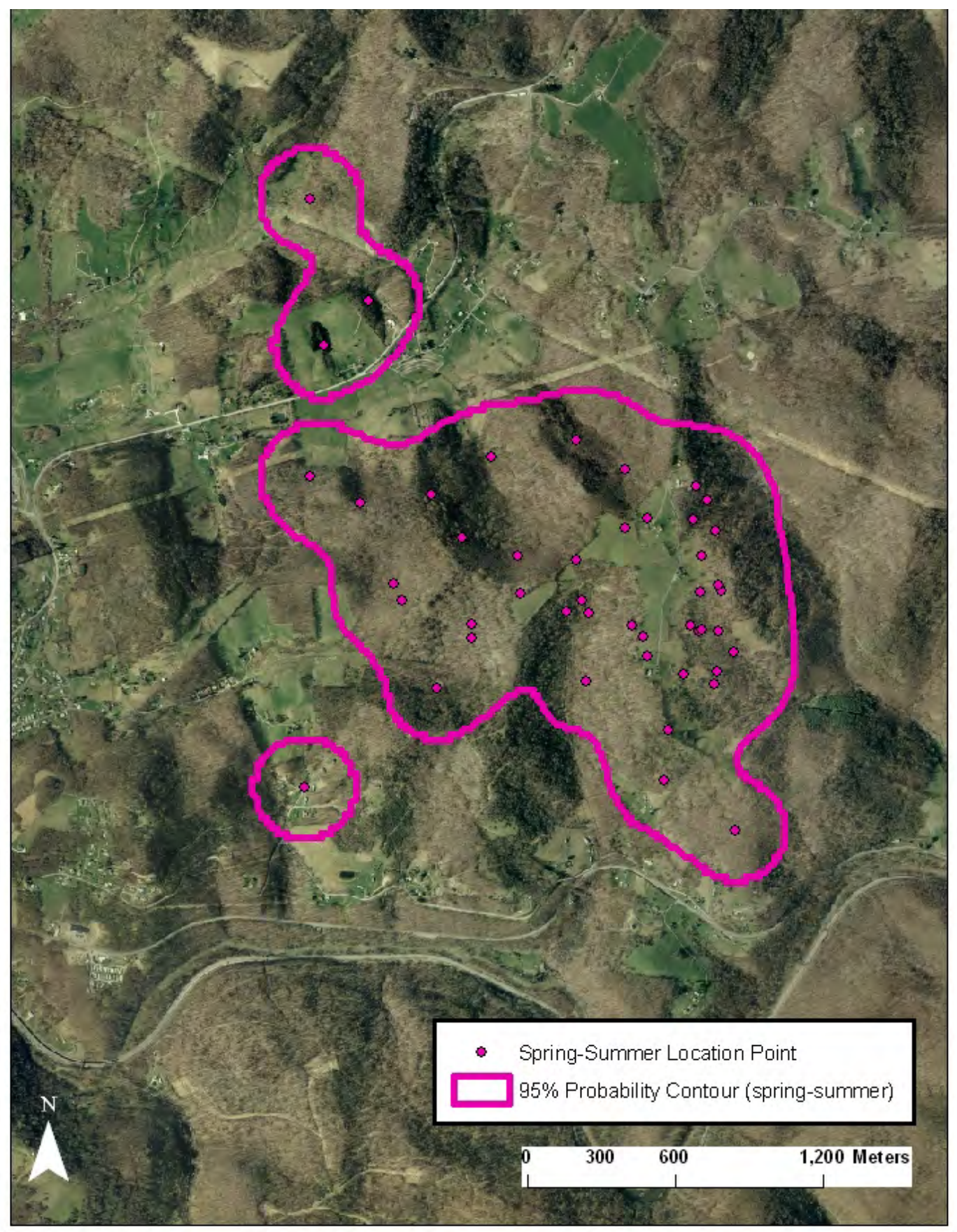


Appendix LXa. RG5130 (juvenile) - 50\% and 95\% probability contours of the annual fixed kernel home range utilization distribution. Smoothing parameter (h) determined by least squares cross validation, Marion/Taylor County, West Virginia, 2006-2007 (100k topo map).

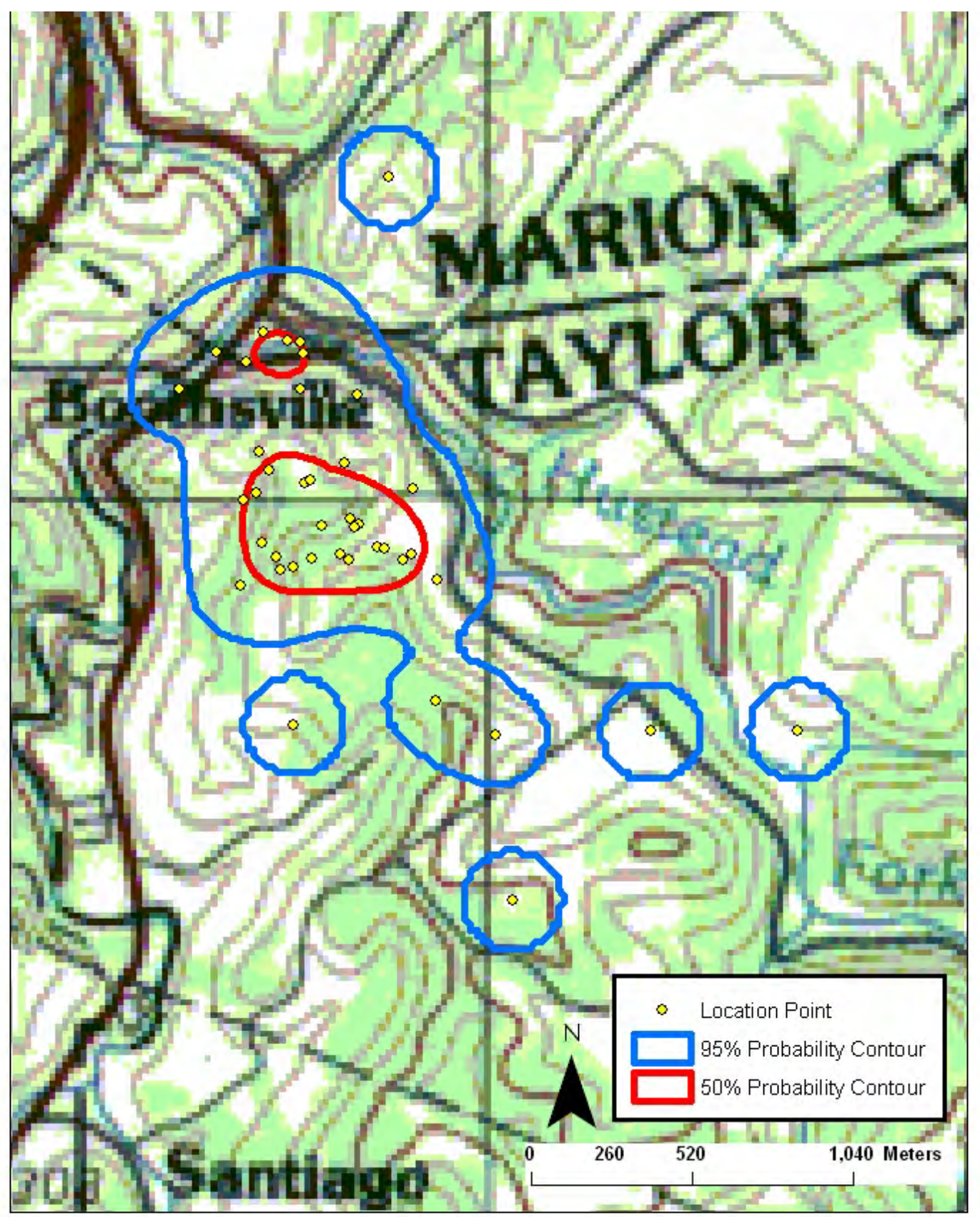


Appendix LXIa. RG5130 (juvenile) - 50\% and 95\% probability contours of the annual fixed kernel home range utilization distribution. Smoothing parameter (h) determined by least squares cross validation, Marion/Taylor County, West Virginia, 2006-2007 (2003

SAMB imagery).

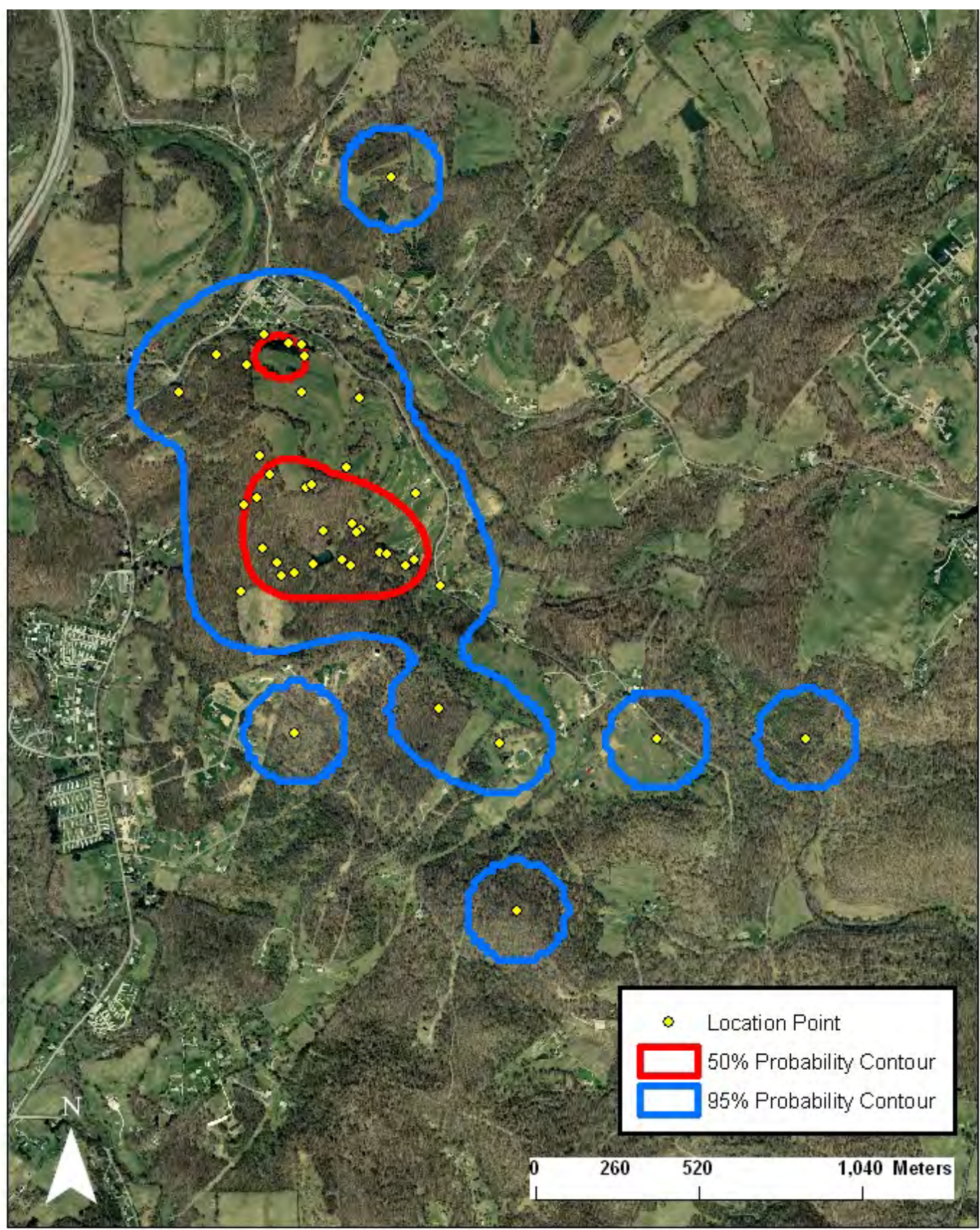


Appendix LXIIa. RG5131 (juvenile) - 50\% and 95\% probability contours of the annual fixed kernel home range utilization distribution. Smoothing parameter (h) determined by least squares cross validation, Harrison/Marion/Taylor County, West Virginia, 2006-2007 (100k topo map).

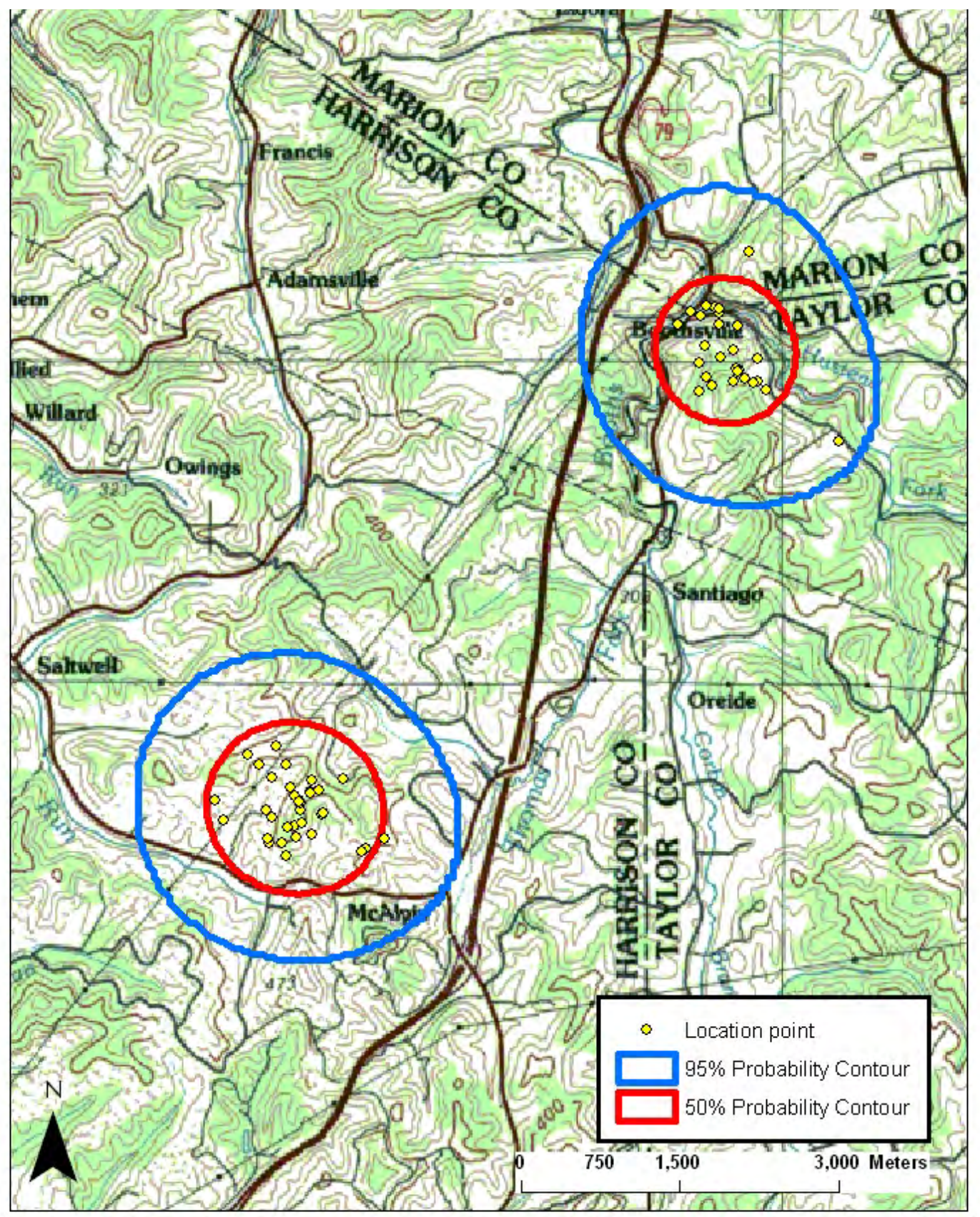


Appendix LXIIIa. RG5131 (juvenile) - 50\% and 95\% probability contours of the annual fixed kernel home range utilization distribution. Smoothing parameter (h) determined by least squares cross validation, Harrison/Marion/Taylor County, West Virginia, 2006-2007 (2003 SAMB imagery).

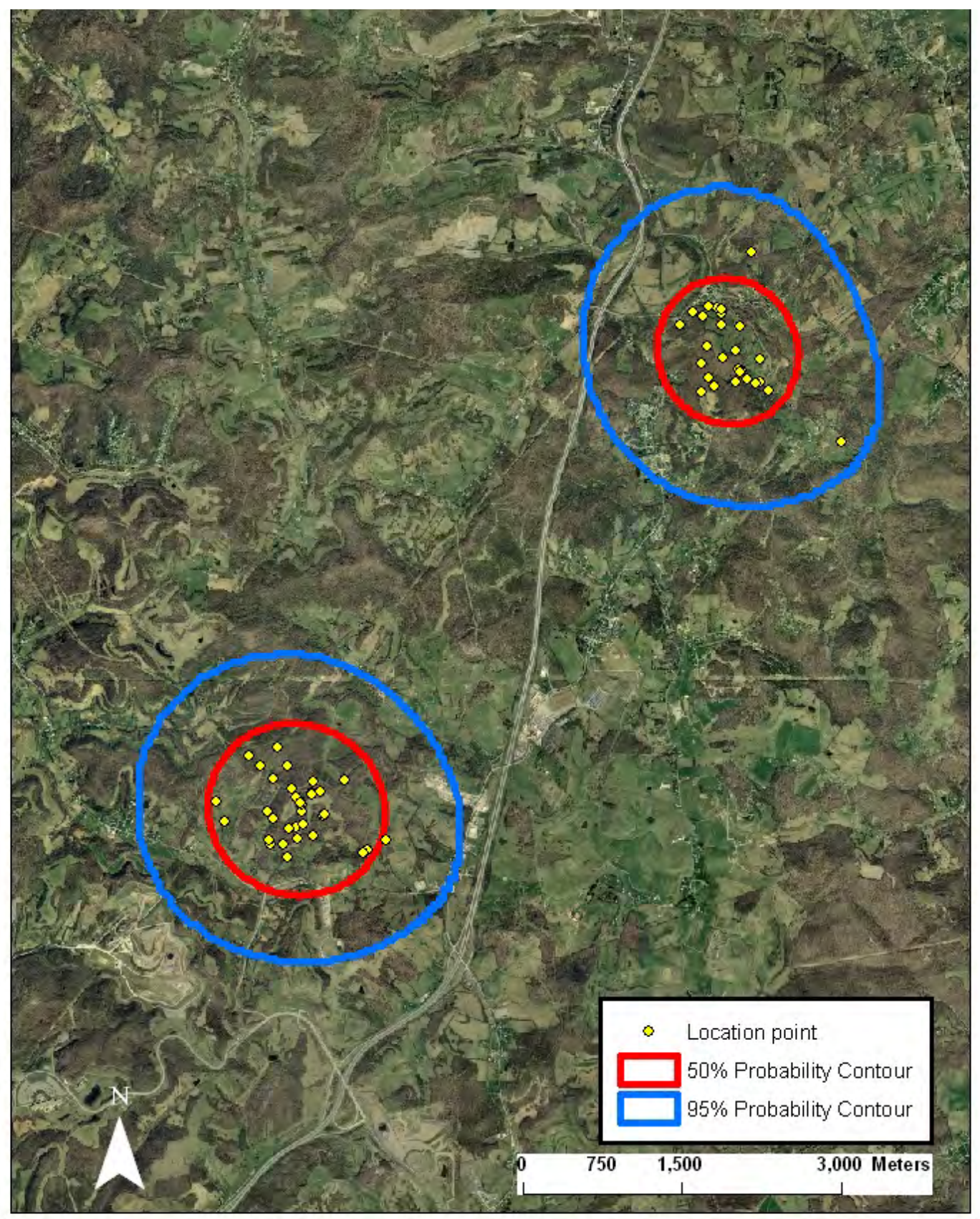


Appendix LXIVa. RG5131 (juvenile) - 95\% probability contour of the spring fixed kernel home range utilization distribution. Smoothing parameter (h) determined by least squares cross validation, Harrison/Marion/Taylor County, West Virginia, 2007 (2003 SAMB imagery).

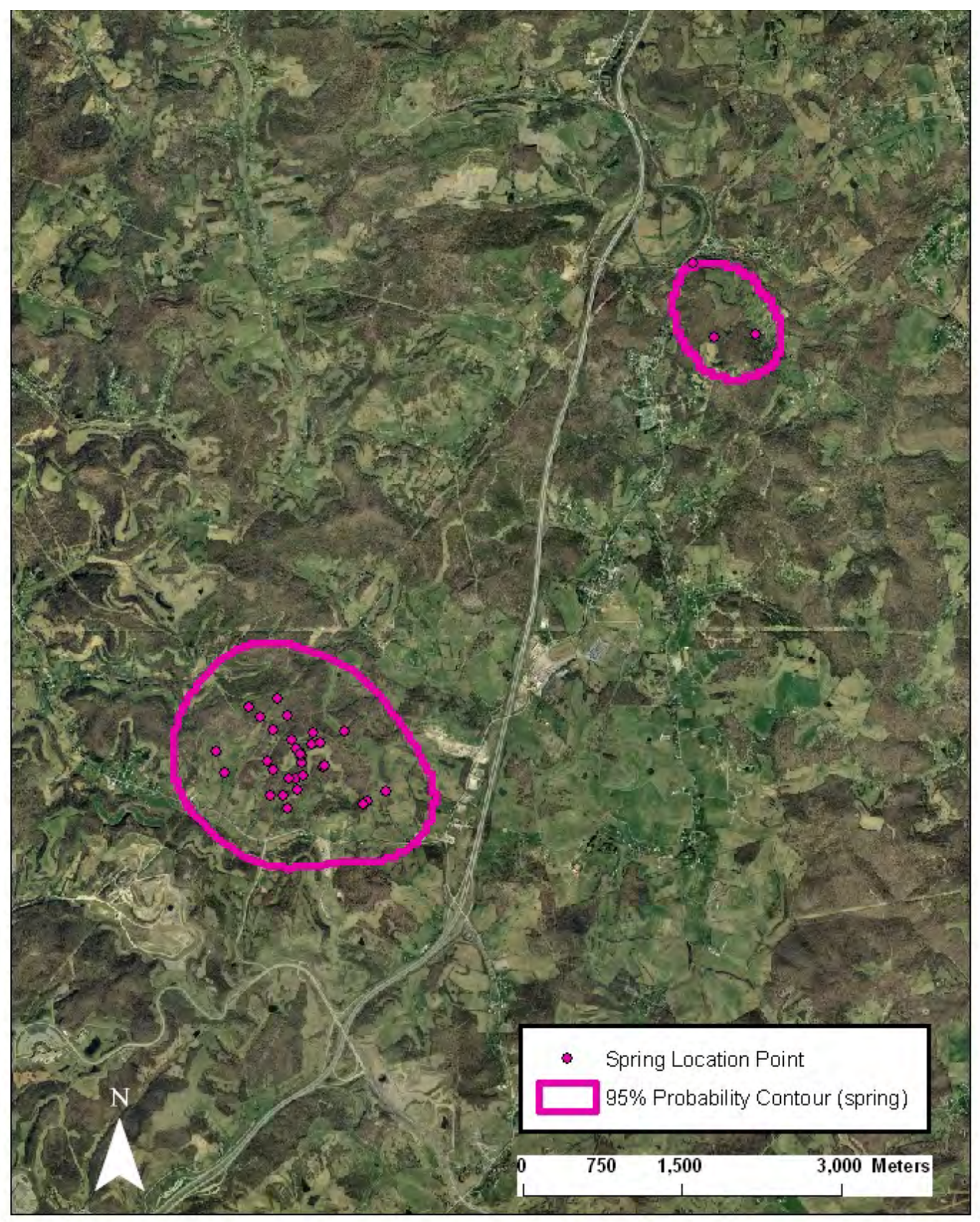


Appendix LXVa. RG5132 (juvenile) - 50\% and 95\% probability contours of the annual fixed kernel home range utilization distribution. Smoothing parameter (h) determined by least squares cross validation, Harrison/Marion/Taylor County, West Virginia, 2006-2007 (100k topo map).

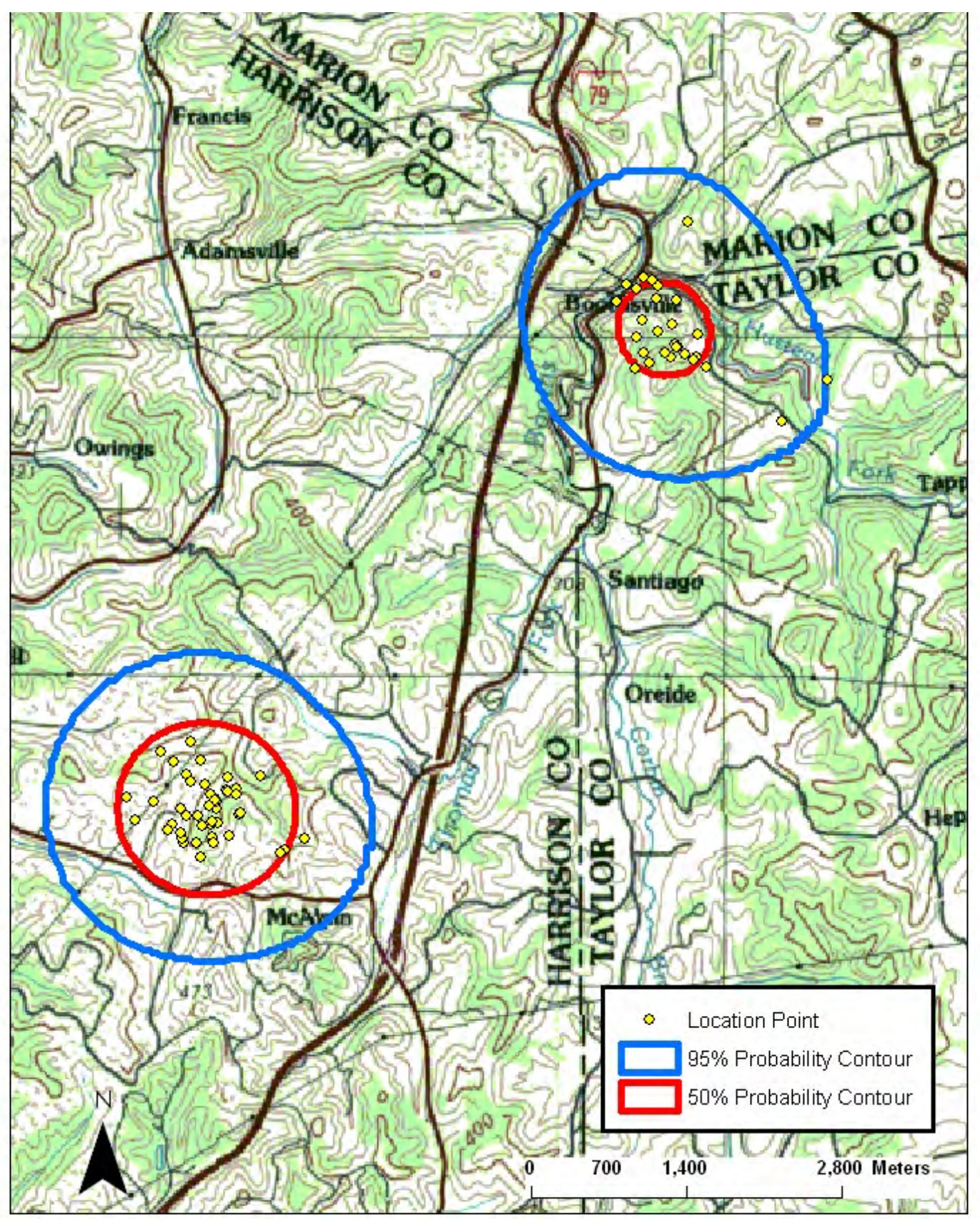


Appendix LXVIa. RG5132 (juvenile) - 50\% and 95\% probability contours of the annual fixed kernel home range utilization distribution. Smoothing parameter (h) determined by least squares cross validation, Harrison/Marion/Taylor County, West Virginia, 2006-2007 (2003 SAMB imagery).

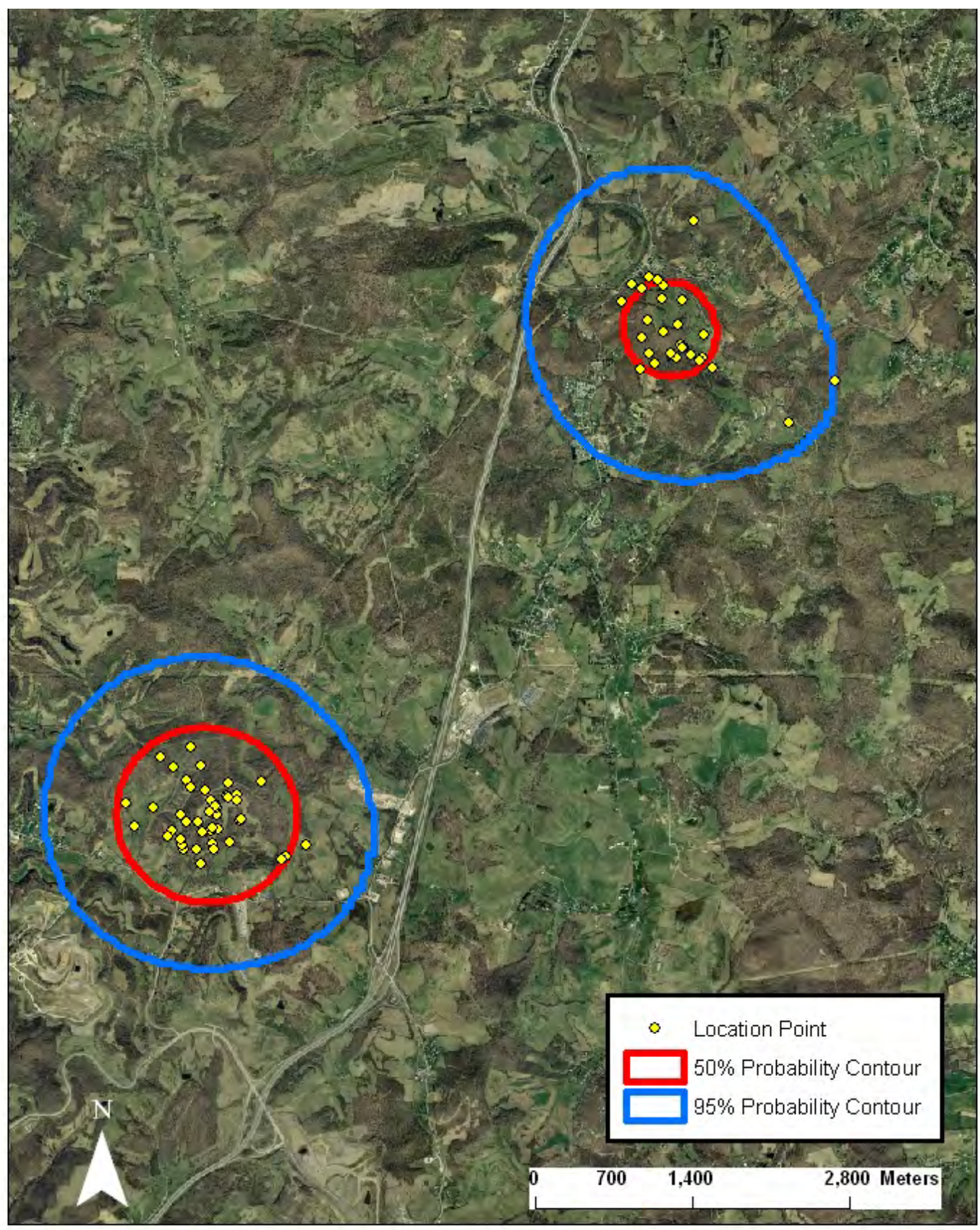


Appendix LXVIIa. RG5132 (juvenile) - 95\% probability contour of the spring fixed kernel home range utilization distribution. Smoothing parameter (h) determined by least squares cross validation, Harrison/Marion/Taylor County, West Virginia, 2007 (2003 SAMB imagery).

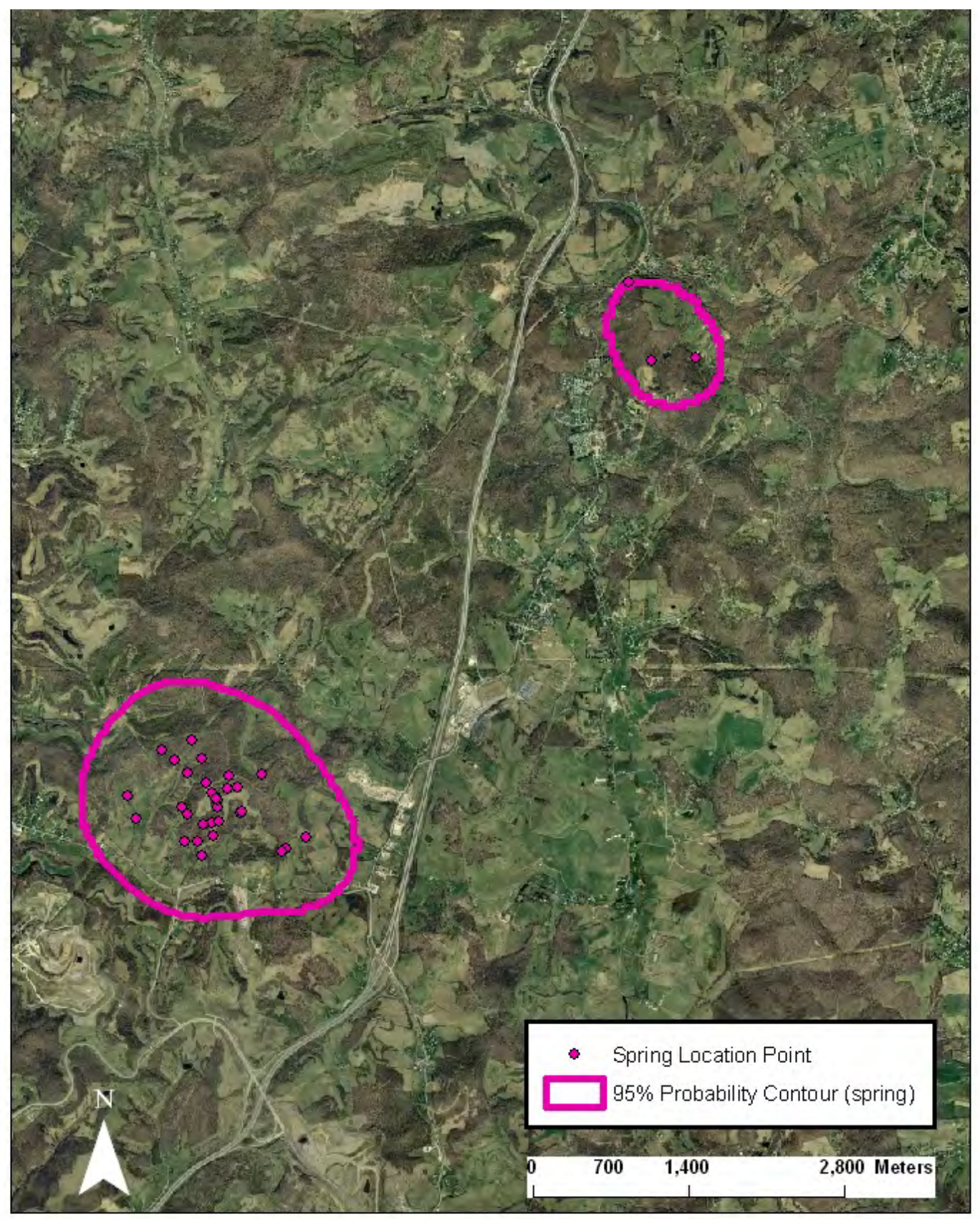


Appendix LXVIIIa. RG5132 (juvenile) - 95\% probability contour of the spring-summer fixed kernel home range utilization distribution. Smoothing parameter (h) determined by least squares cross validation, Harrison/Marion/Taylor County, West Virginia, 2007 (2003

SAMB imagery).

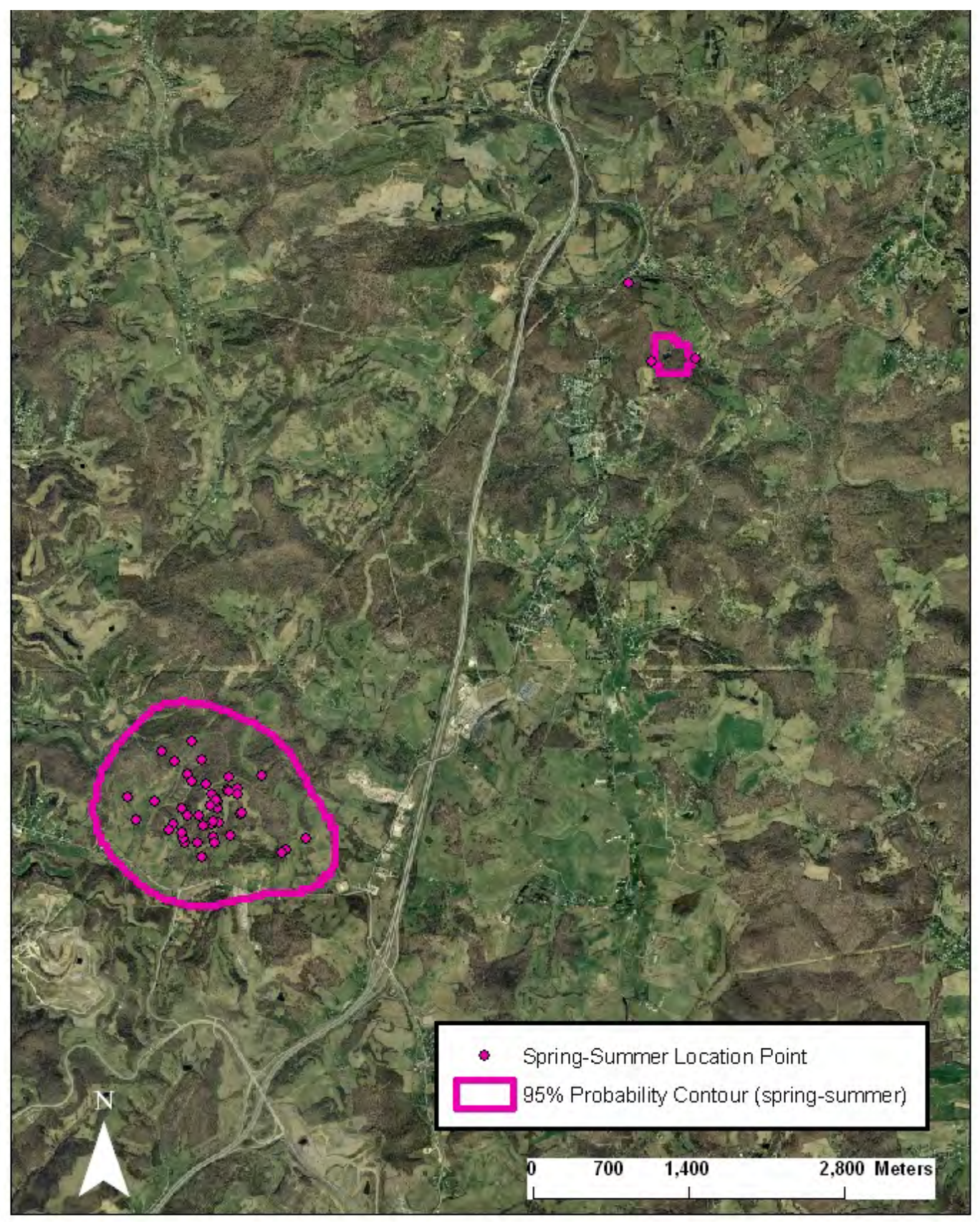


Appendix LXIXa. RG5133 (juvenile) - 50\% and 95\% probability contours of the annual fixed kernel home range utilization distribution. Smoothing parameter (h) determined by least squares cross validation, Marion/Taylor County, West Virginia, 2006-2007 (100k topo map).

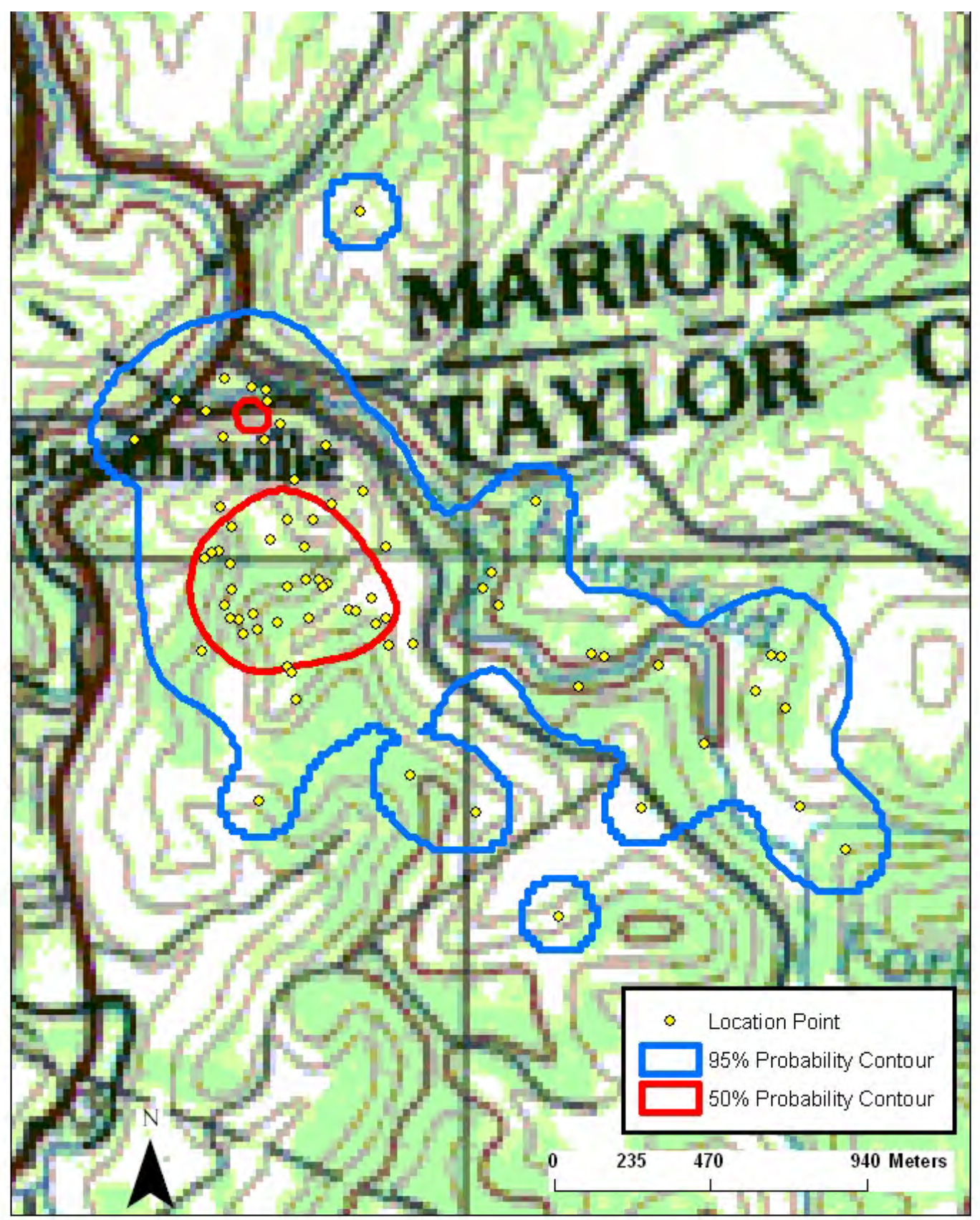


Appendix LXXa. RG5133 (juvenile) - 50\% and 95\% probability contours of the annual fixed kernel home range utilization distribution. Smoothing parameter (h) determined by least squares cross validation, Marion/Taylor County, West Virginia, 2006-2007 (2003

SAMB imagery).

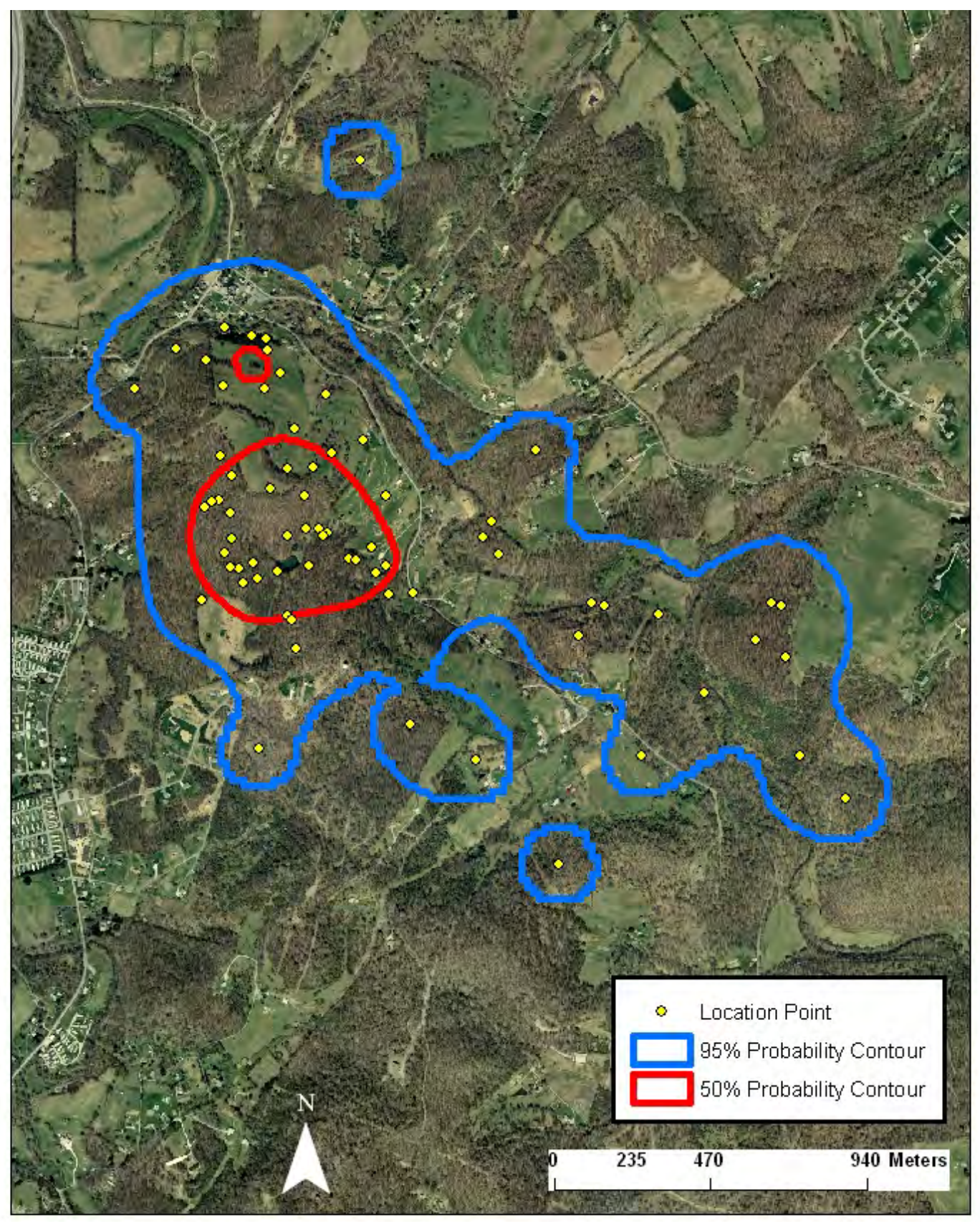


Appendix LXXIa. RG5133 (juvenile) - 95\% probability contour of the spring fixed kernel home range utilization distribution. Smoothing parameter (h) determined by least squares cross validation, Marion/Taylor County, West Virginia, 2007 (2003 SAMB imagery).

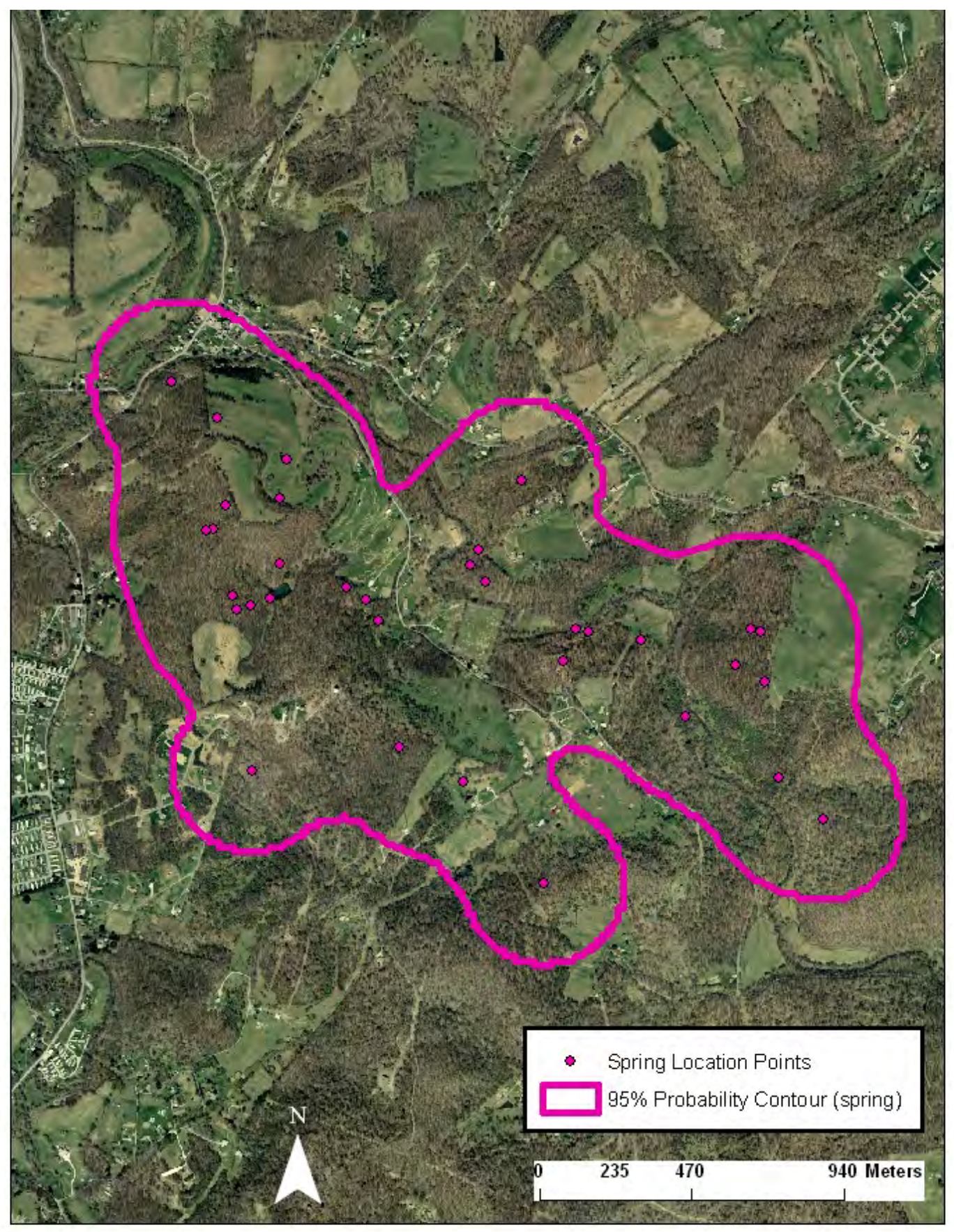


Appendix LXXIIa. RG5133 (juvenile) - 95\% probability contour of the spring-summer fixed kernel home range utilization distribution. Smoothing parameter (h) determined by least squares cross validation, Marion/Taylor County, West Virginia, 2007 (2003 SAMB imagery).

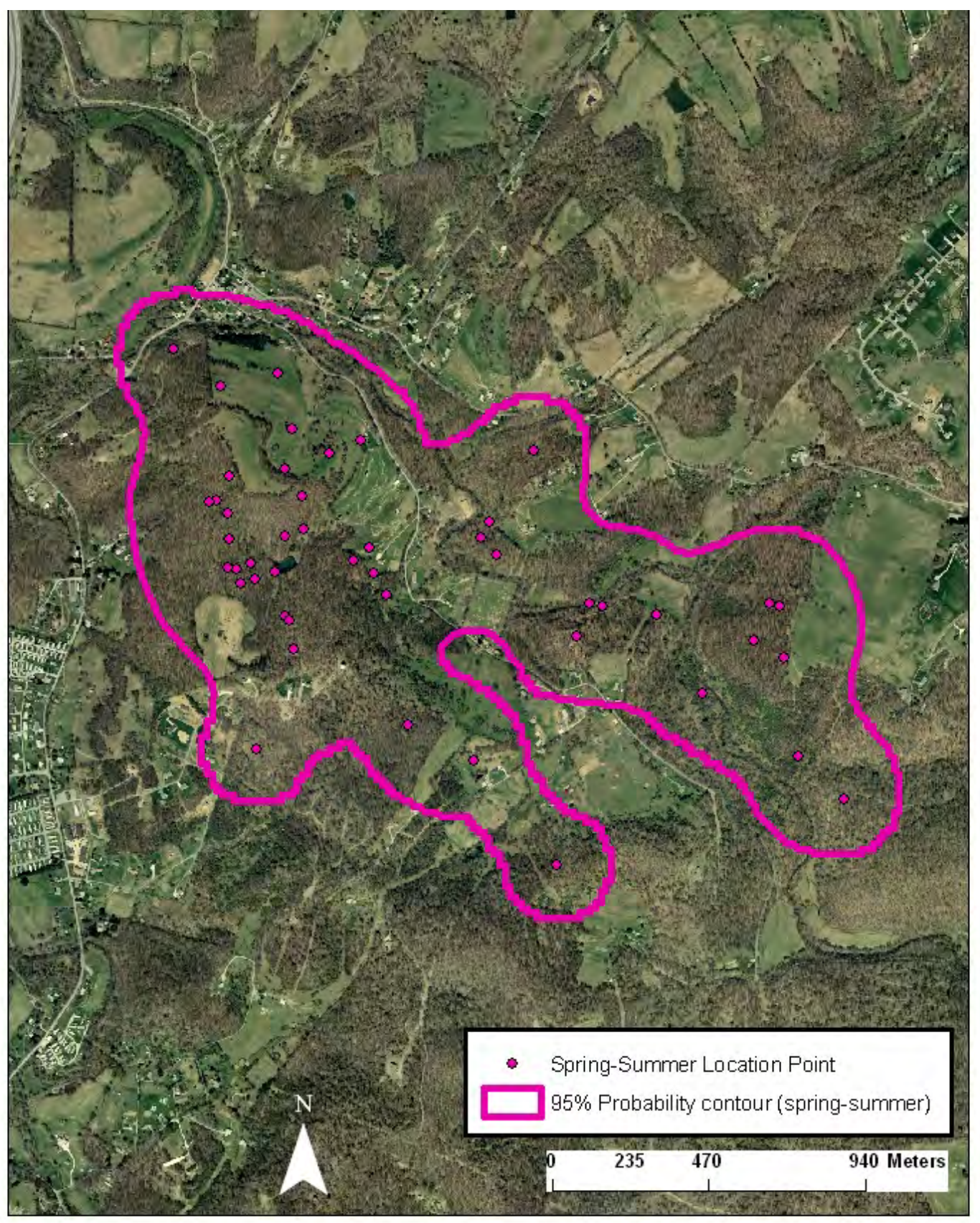


Appendix LXXIIIa. RG5135 (juvenile) - 50\% and 95\% probability contours of the annual fixed kernel home range utilization distribution. Smoothing parameter (h) determined by least squares cross validation, Harrison/Marion/Taylor County, West Virginia, 2006-2007 (100k topo map).

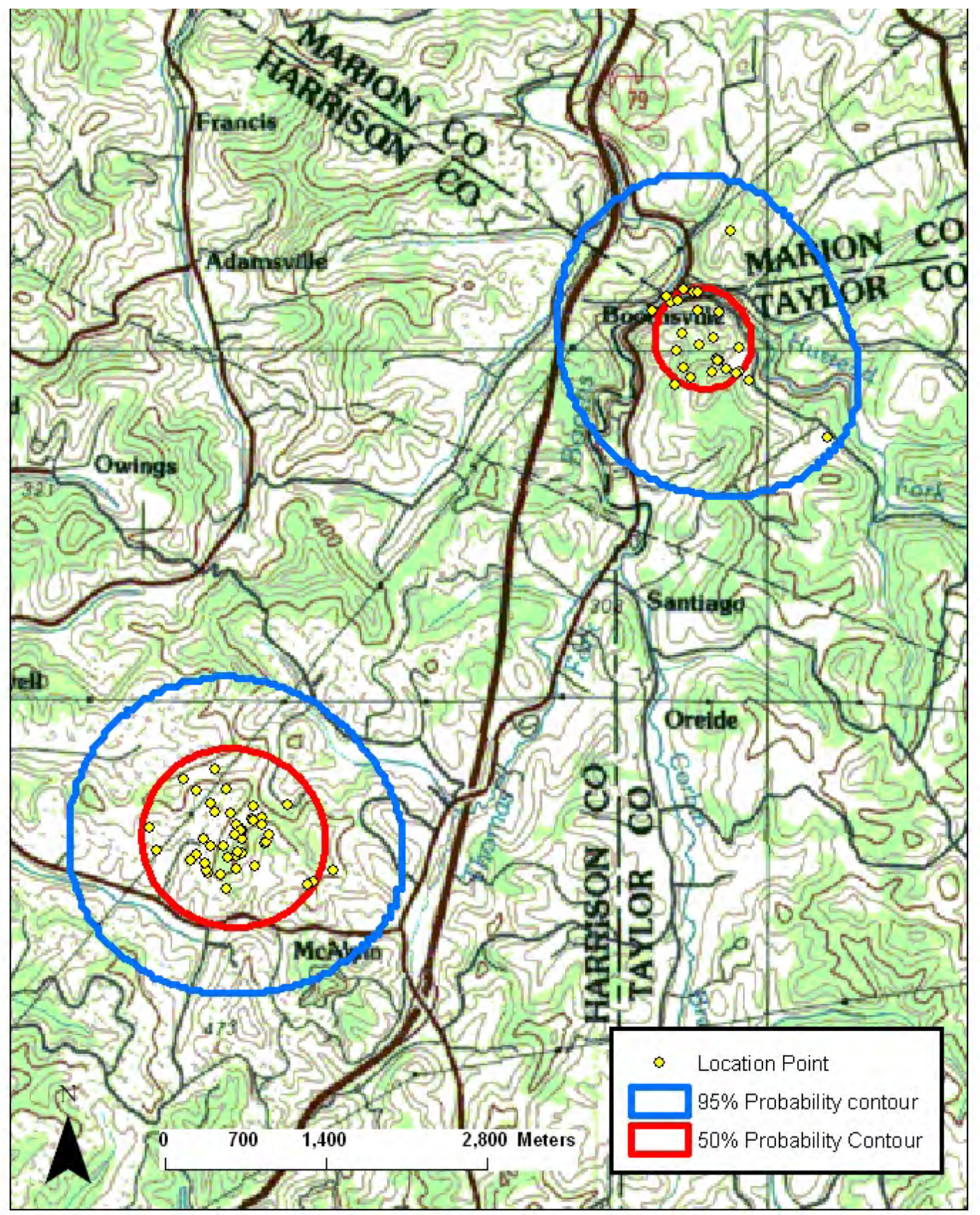


Appendix LXXIVa. RG5135 (juvenile) - 50\% and 95\% probability contours of the annual fixed kernel home range utilization distribution. Smoothing parameter (h) determined by least squares cross validation, Harrison/Marion/Taylor County, West Virginia, 2006-2007 (2003 SAMB imagery).

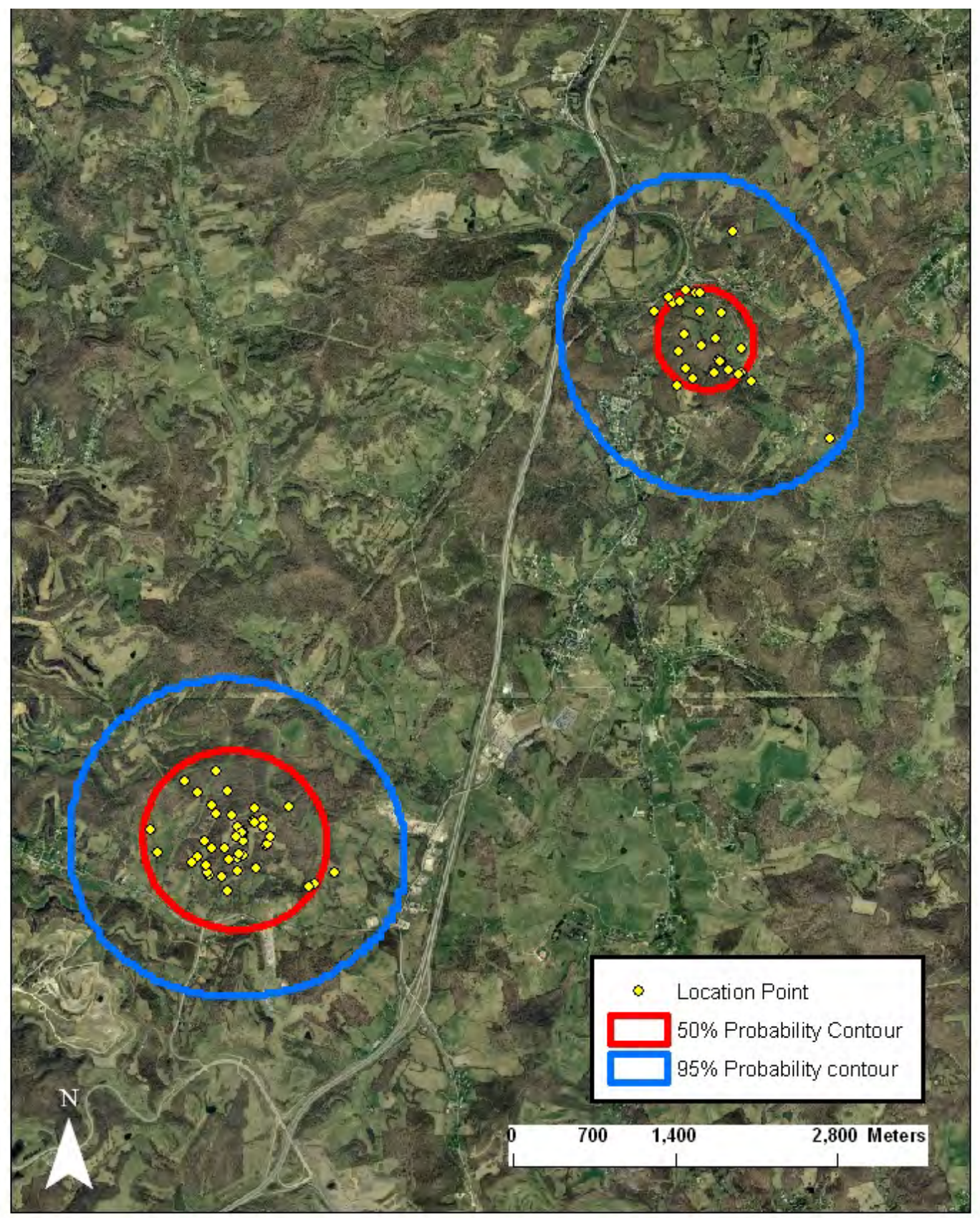


Appendix LXXVa. RG5135 (juvenile) - 95\% probability contour of the spring fixed kernel home range utilization distribution. Smoothing parameter (h) determined by least squares cross validation, Harrison/Marion/Taylor County, West Virginia, 2007 (2003 SAMB imagery).

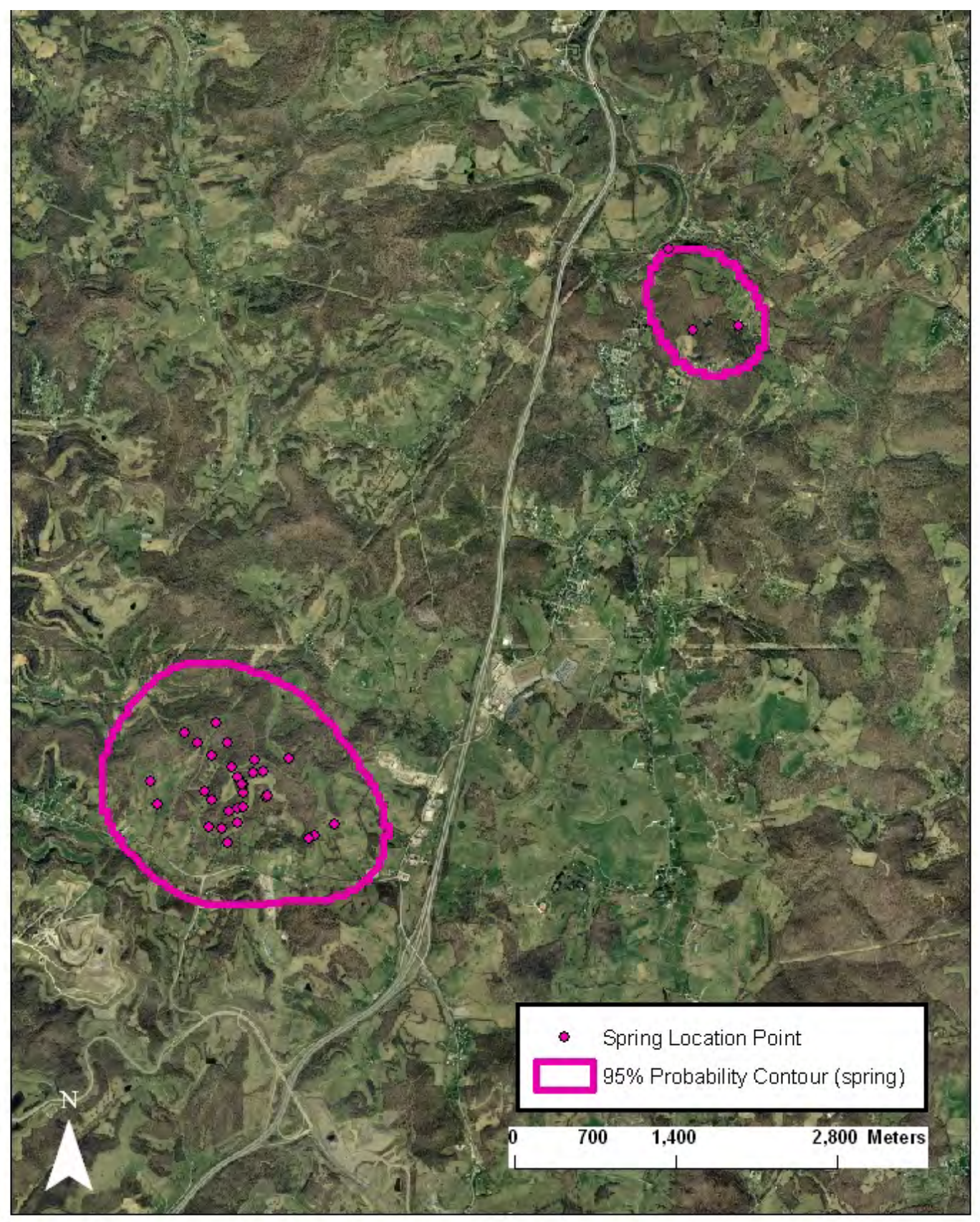


Appendix LXXVIa. RG5135 (juvenile) - 95\% probability contour of the spring-summer fixed kernel home range utilization distribution. Smoothing parameter (h) determined by least squares cross validation, Harrison/Marion/Taylor County, West Virginia, 2007 (2003

SAMB imagery).

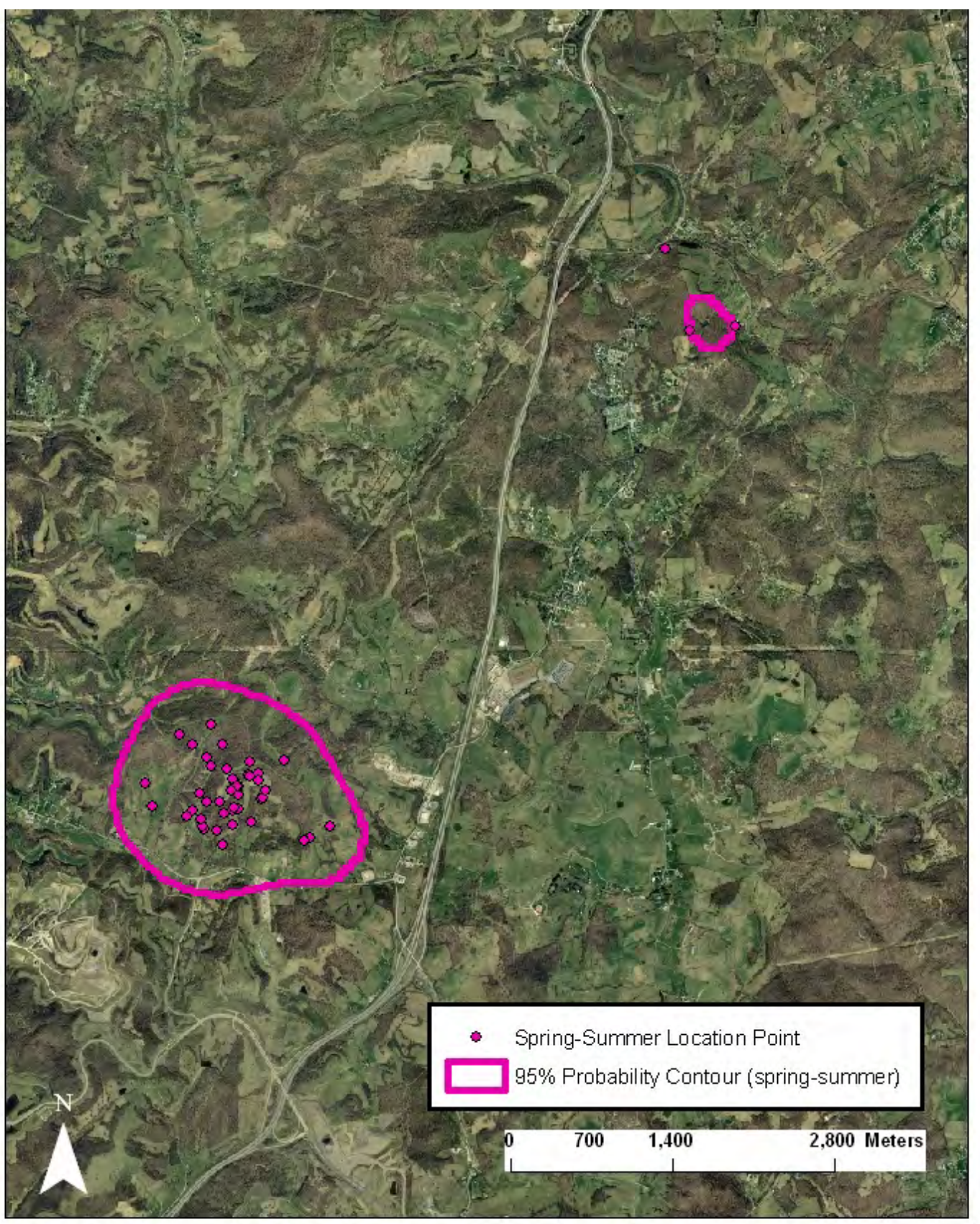


Appendix LXXVIIa. RG5136 (juvenile) - 50\% and 95\% probability contours of the annual fixed kernel home range utilization distribution. Smoothing parameter (h) determined by least squares cross validation, Harrison/Marion/Taylor County, West Virginia, 2006-2007 (100k topo map).

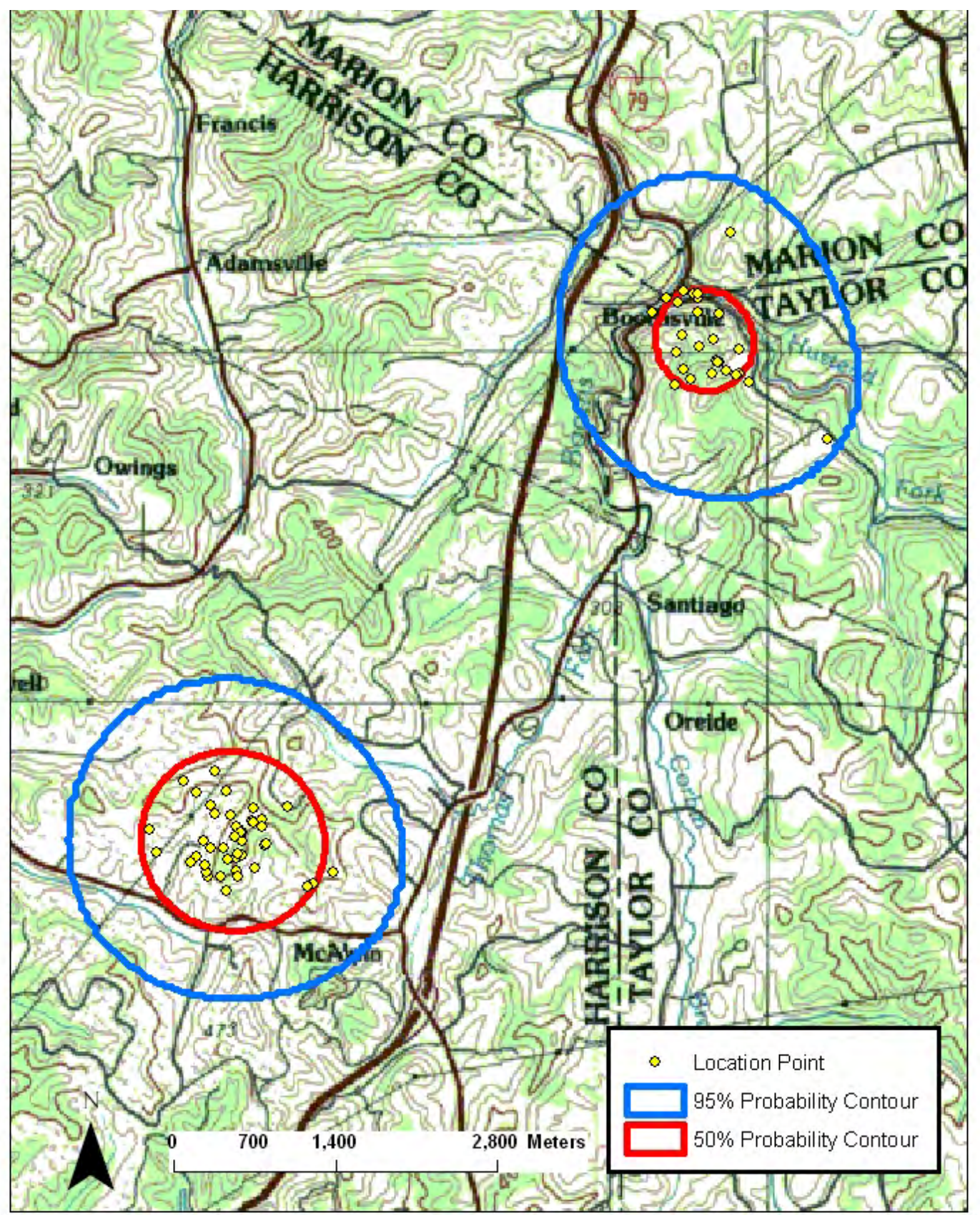


Appendix LXXVIIIa. RG5136 (juvenile) - 50\% and 95\% probability contours of the annual fixed kernel home range utilization distribution. Smoothing parameter (h) determined by least squares cross validation, Harrison/Marion/Taylor County, West Virginia, 2006-2007 (2003 SAMB imagery).

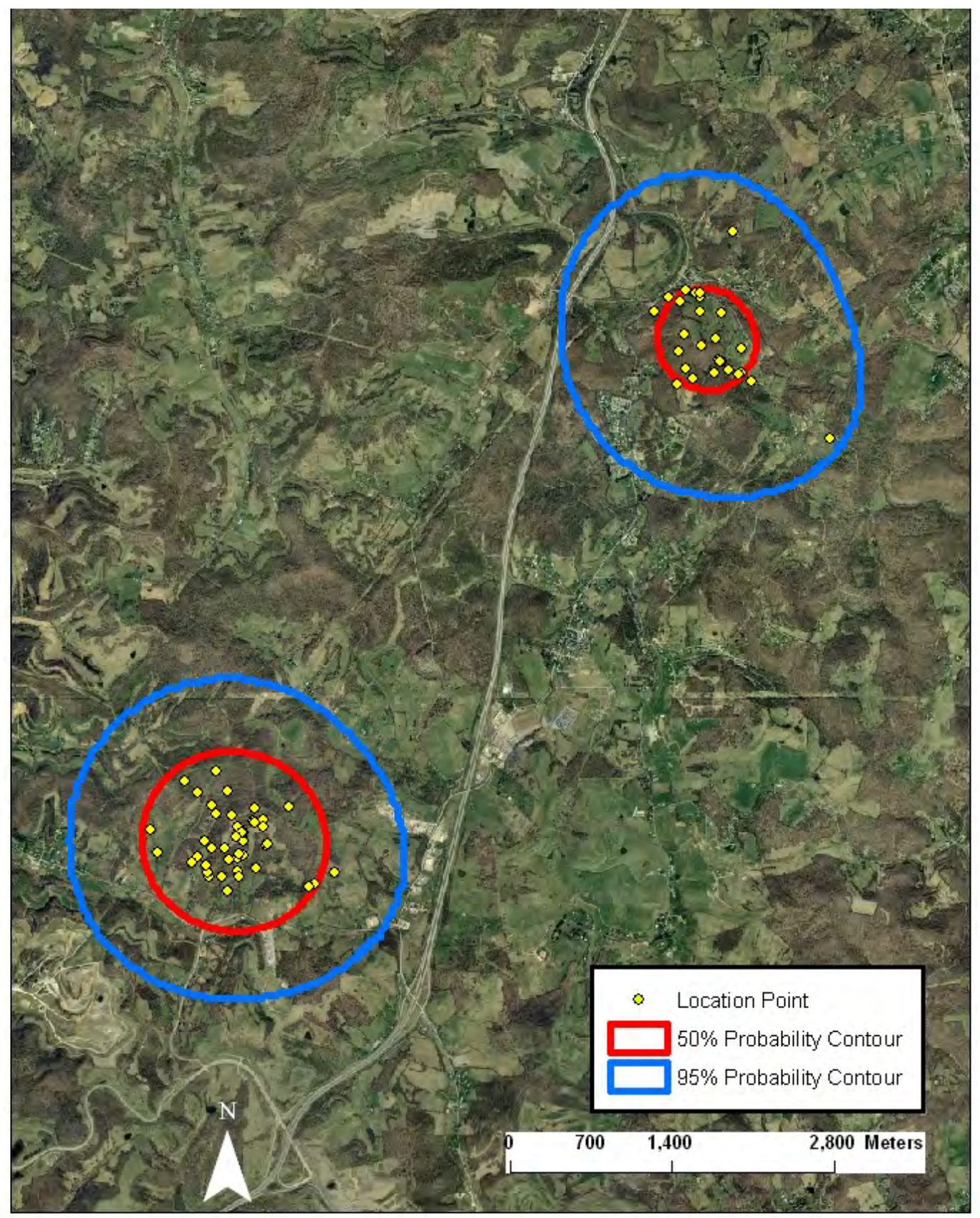


Appendix LXXIXa. RG5136 (juvenile) - 95\% probability contour of the spring fixed kernel home range utilization distribution. Smoothing parameter (h) determined by least squares cross validation, Harrison/Marion/Taylor County, West Virginia, 2007 (2003 SAMB imagery).

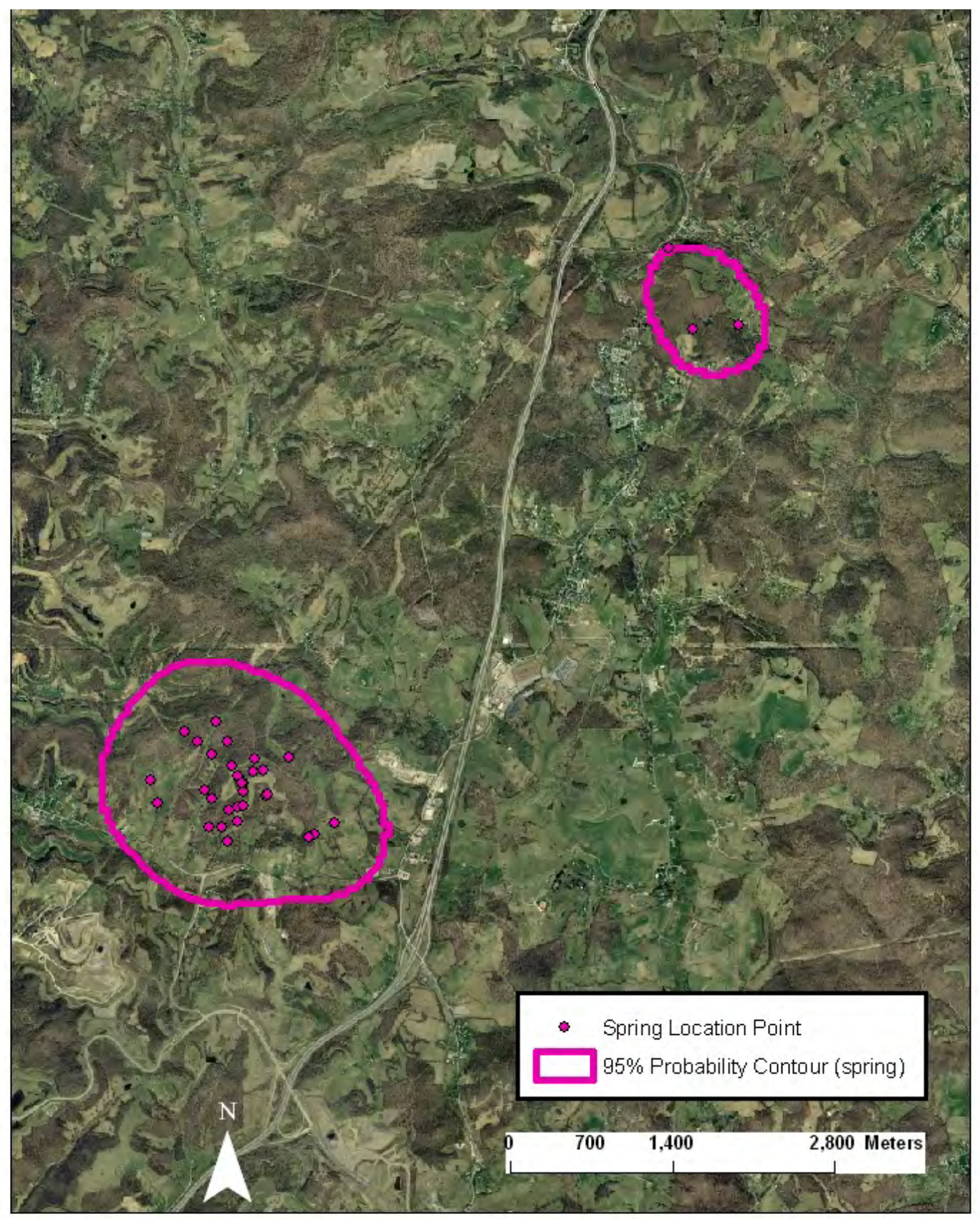


Appendix LXXXa. RG5136 (juvenile) - 95\% probability contour of the spring-summer fixed kernel home range utilization distribution. Smoothing parameter (h) determined by least squares cross validation, Harrison/Marion/Taylor County, West Virginia, 2007 (2003

SAMB imagery).

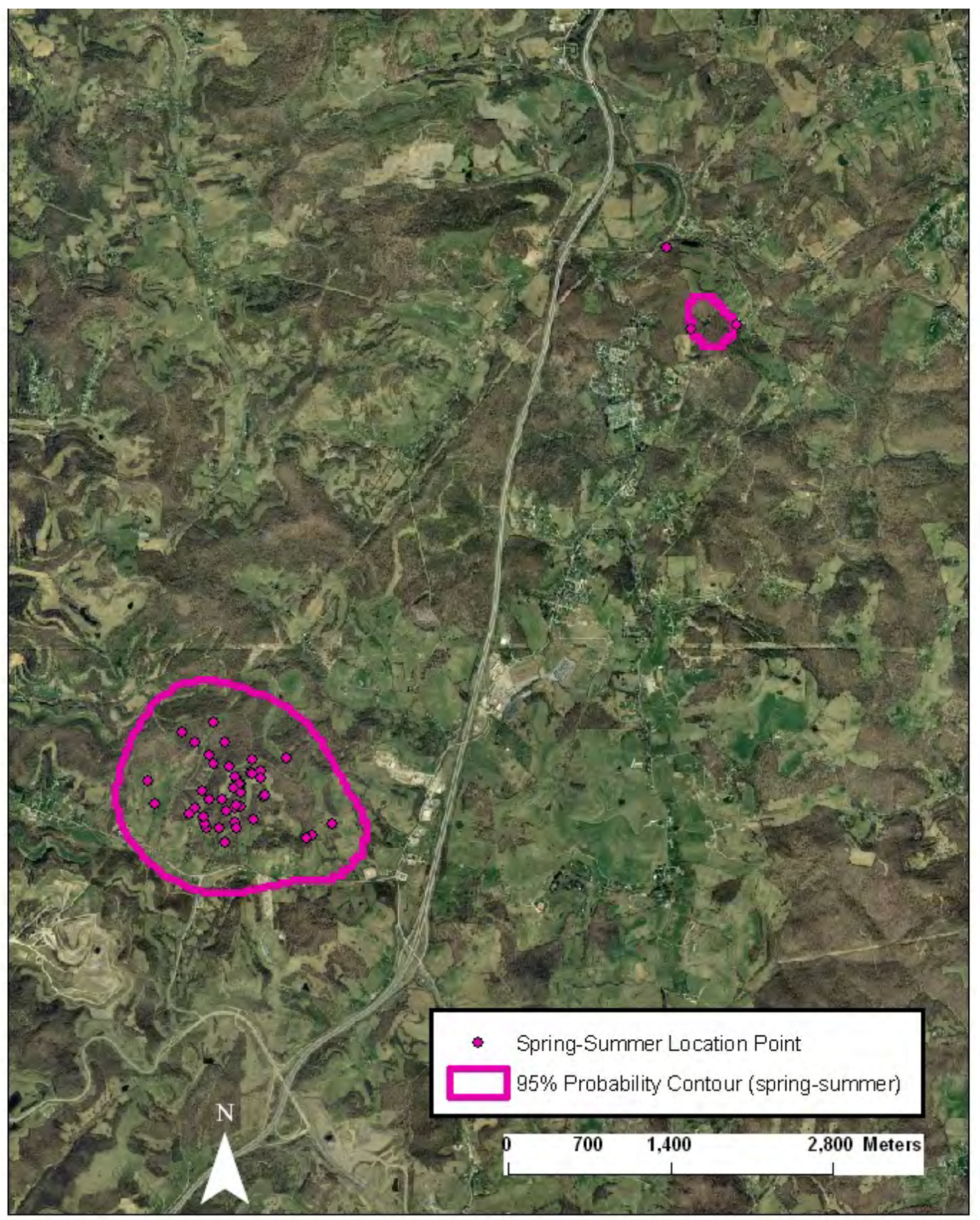


Appendix LXXXIa. RG5137 (juvenile) - 50\% and 95\% probability contours of the annual fixed kernel home range utilization distribution. Smoothing parameter (h) determined by least squares cross validation, Harrison/Marion/Taylor County, West Virginia, 2006-2007 (100k topo map).

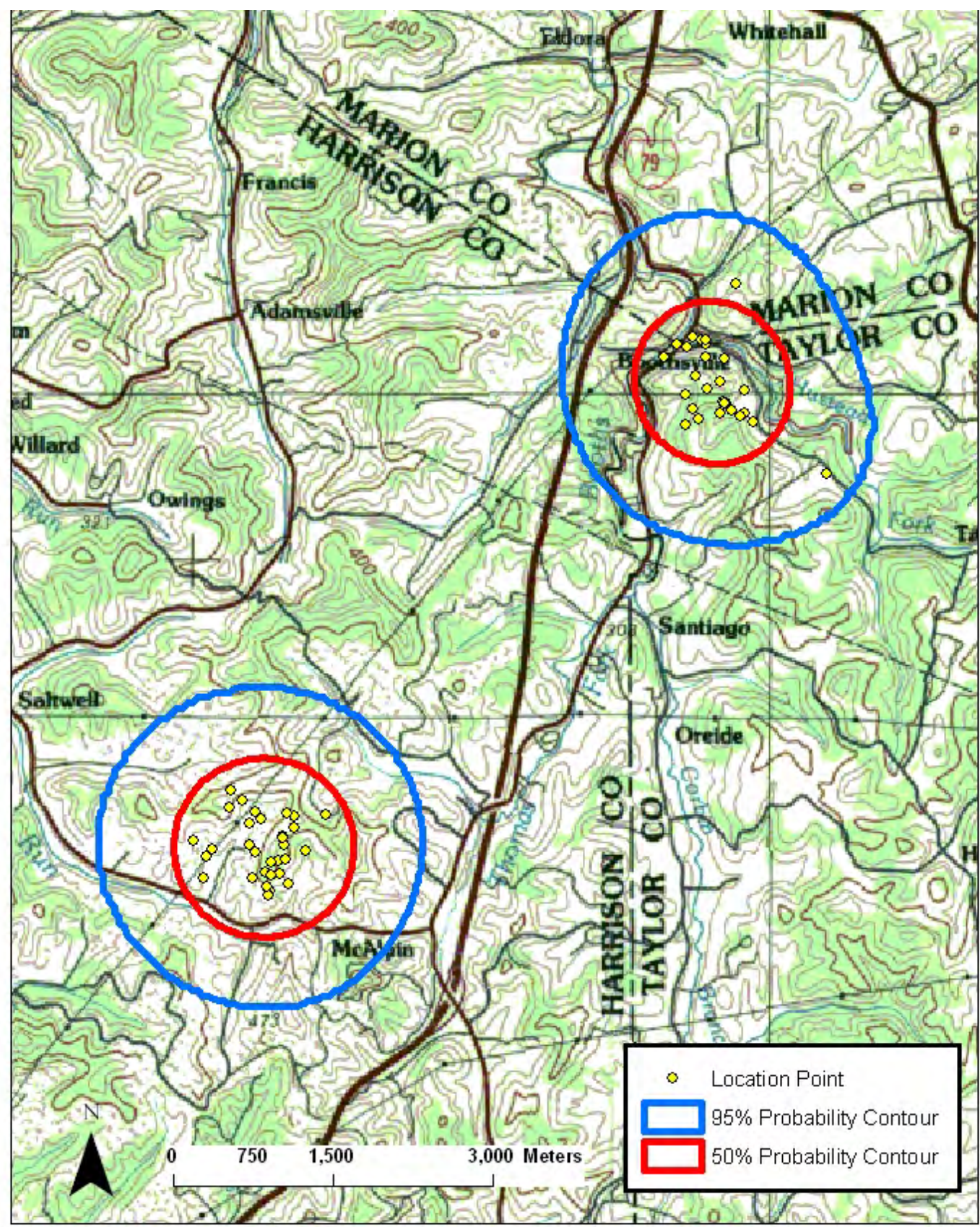


Appendix LXXXIIa. RG5137 (juvenile) - 50\% and 95\% probability contours of the annual fixed kernel home range utilization distribution. Smoothing parameter (h) determined by least squares cross validation, Harrison/Marion/Taylor County, West Virginia, 2006-2007 (2003 SAMB imagery).

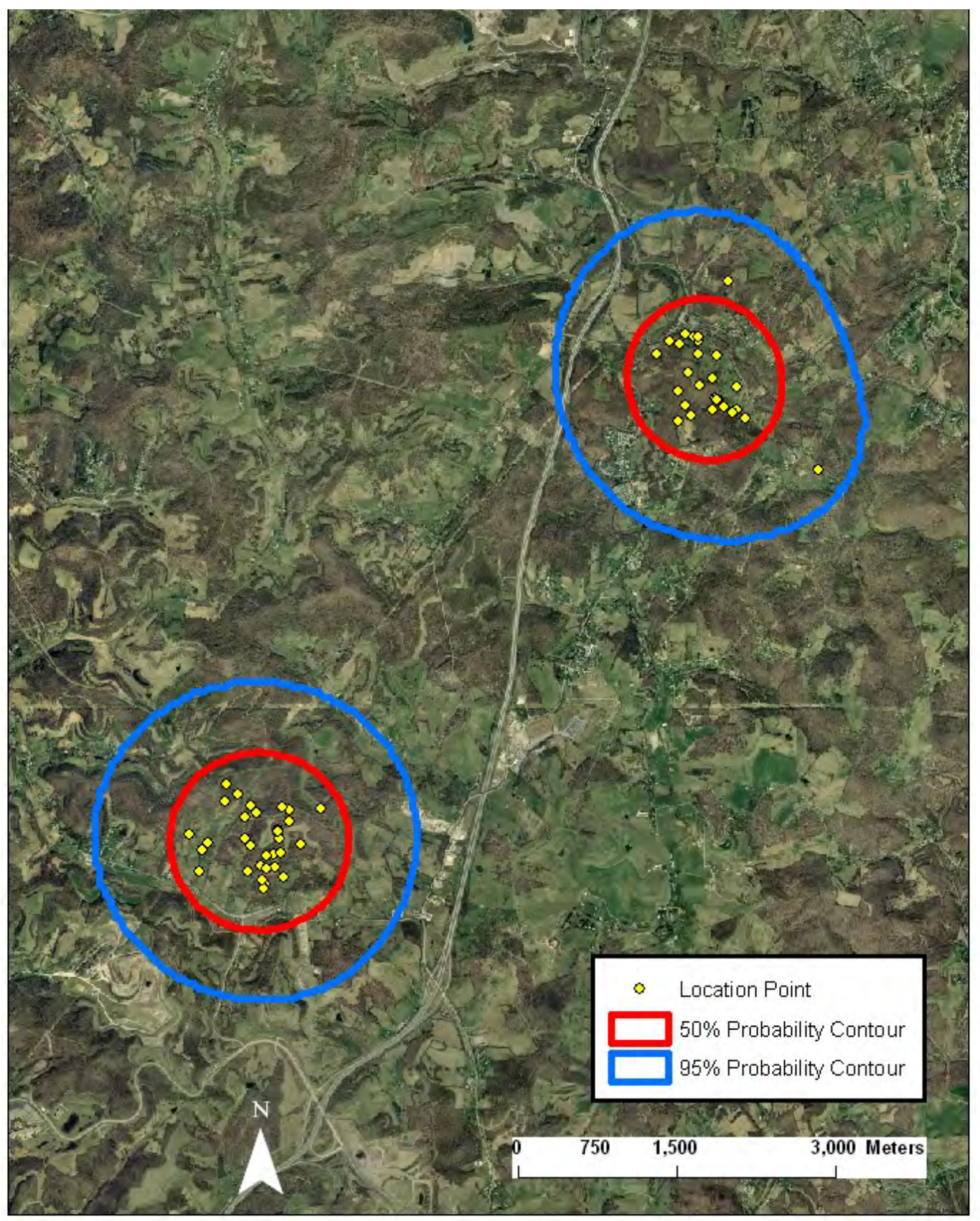


Appendix LXXXIIIa. RG5137 (juvenile) - 95\% probability contour of the spring fixed kernel home range utilization distribution. Smoothing parameter (h) determined by least squares cross validation, Harrison/Marion/Taylor County, West Virginia, 2007 (2003

SAMB imagery).

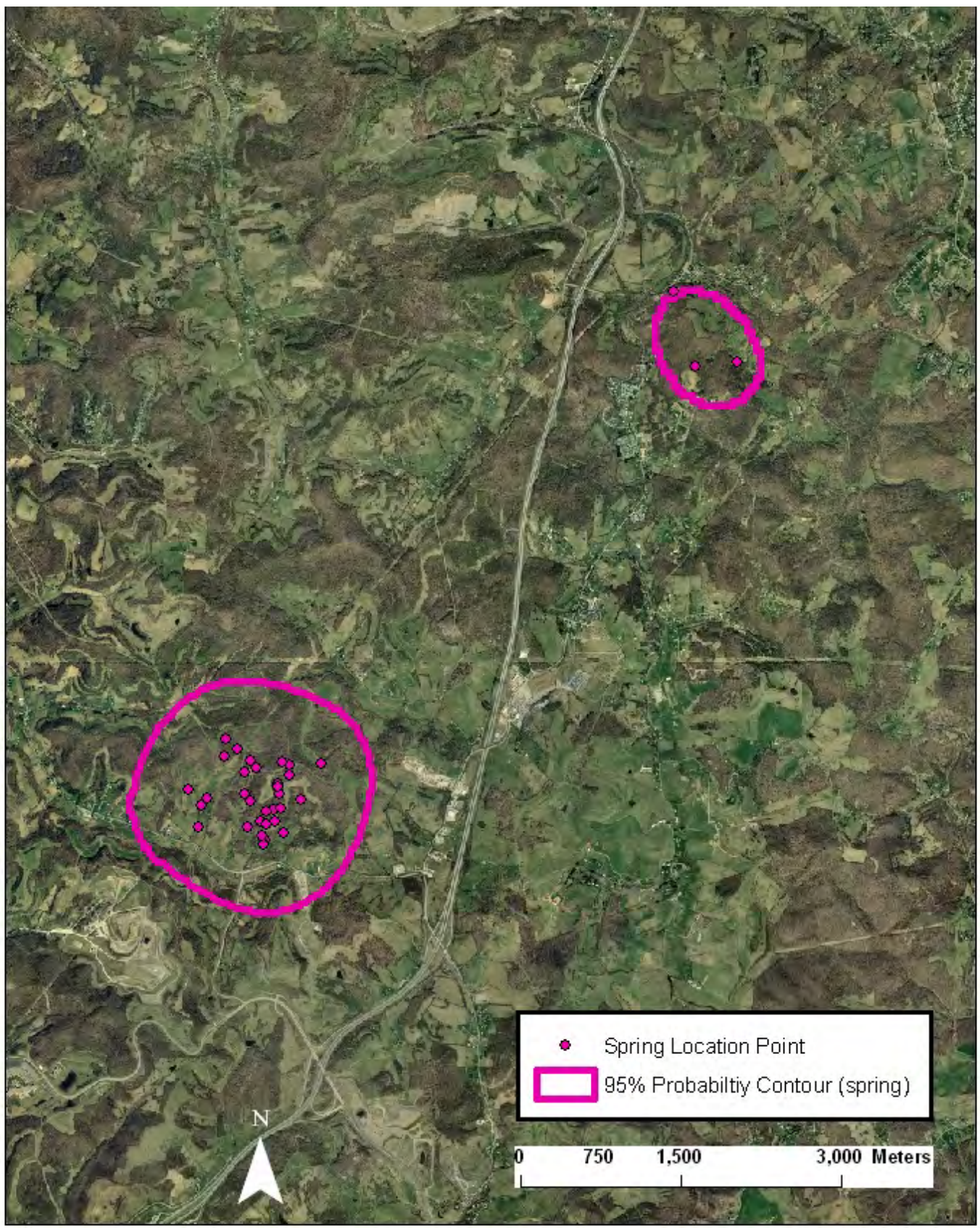


Appendix LXXXIVa. RG5138 (juvenile) - 50\% and 95\% probability contours of the annual fixed kernel home range utilization distribution. Smoothing parameter (h) determined by least squares cross validation, Harrison/Marion/Taylor County, West Virginia, 2006-2007 (100k topo map).

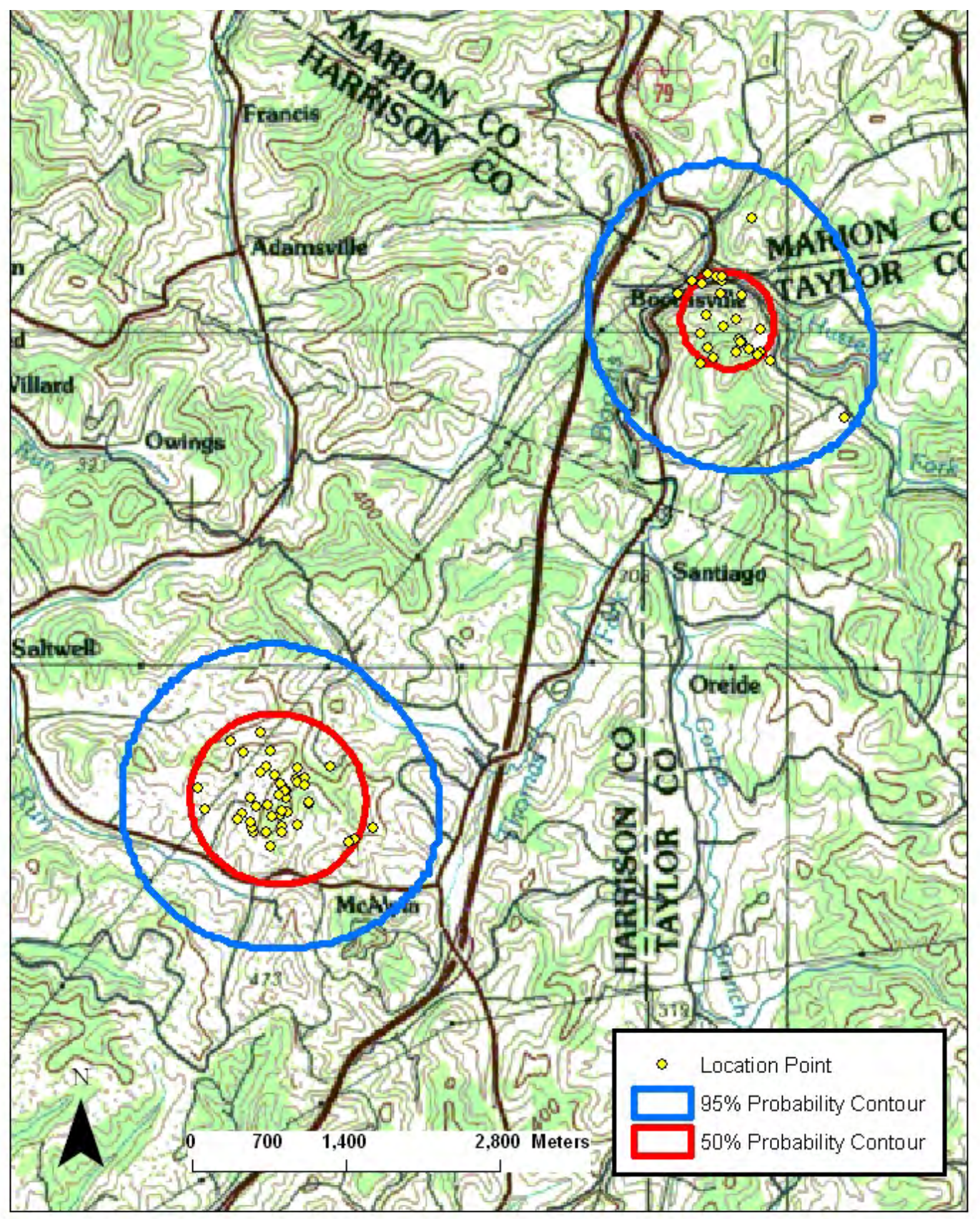


Appendix LXXXVa. RG5138 (juvenile) - 50\% and 95\% probability contours of the annual fixed kernel home range utilization distribution. Smoothing parameter (h) determined by least squares cross validation, Harrison/Marion/Taylor County, West Virginia, 2006-2007 (2003 SAMB imagery).

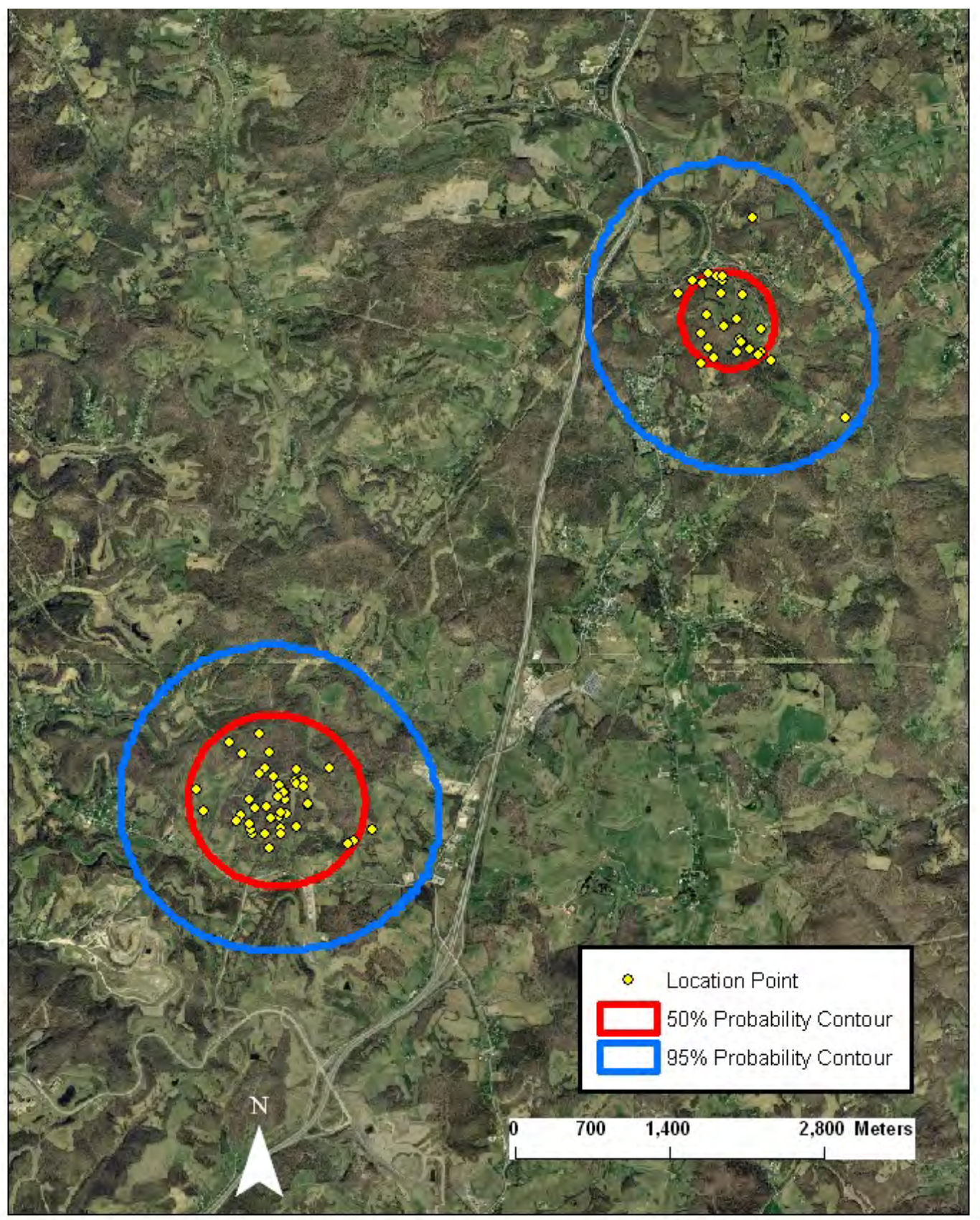


Appendix LXXXVIa. RG5138 (juvenile) - 95\% probability contour of the spring fixed kernel home range utilization distribution. Smoothing parameter (h) determined by least squares cross validation, Harrison/Marion/Taylor County, West Virginia, 2007 (2003

SAMB imagery).

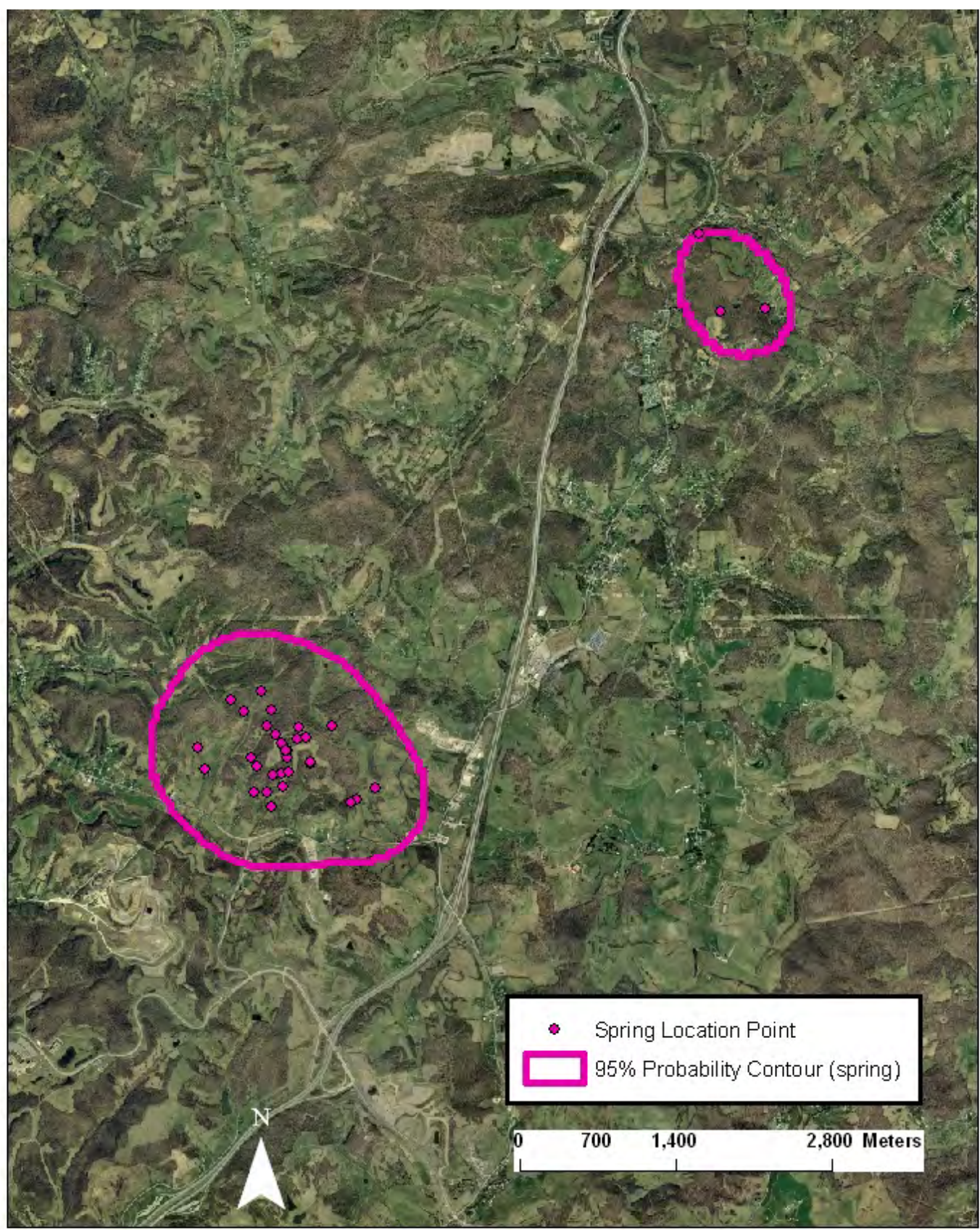


Appendix LXXXVIIa. RG5138 (juvenile) - 95\% probability contour of the spring-summer fixed kernel home range utilization distribution. Smoothing parameter (h) determined by least squares cross validation, Harrison/Marion/Taylor County, West Virginia, 2007 (2003

SAMB imagery).

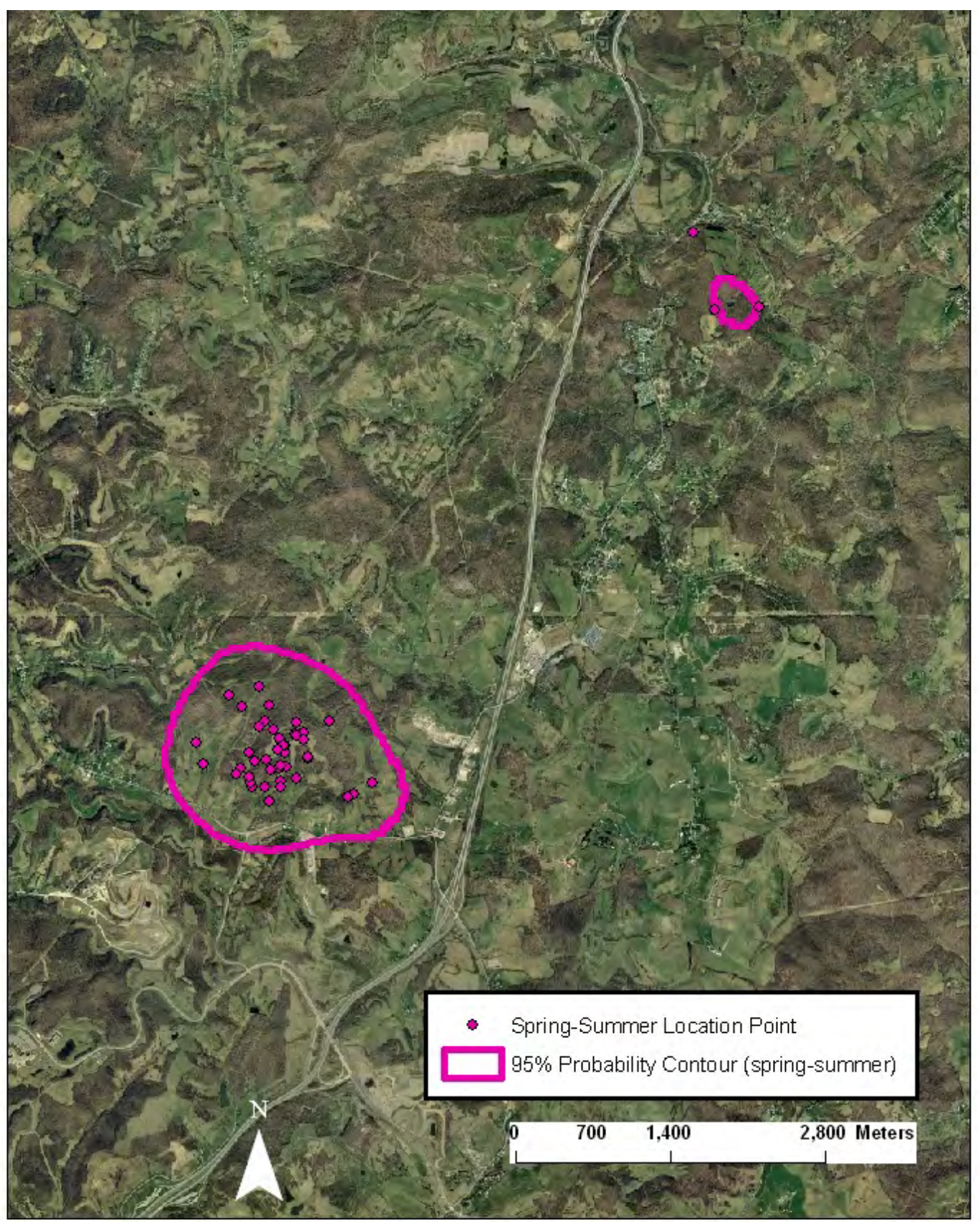


Appendix LXXXVIIIa. RG5139 (juvenile) - 50\% and 95\% probability contours of the annual fixed kernel home range utilization distribution. Smoothing parameter (h)

determined by least squares cross validation, Marion/Taylor County, West Virginia, 20062007 (100k topo map).

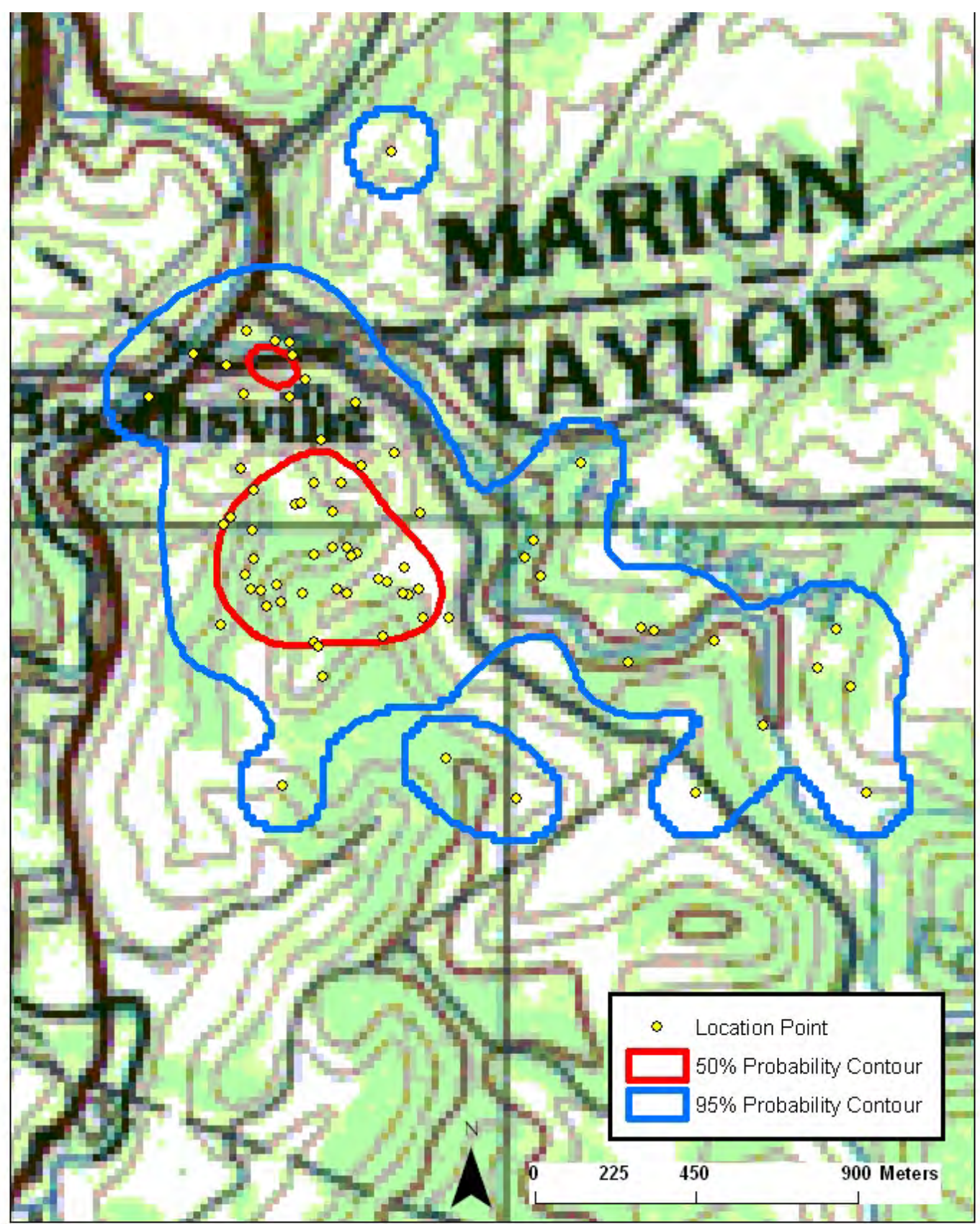


Appendix LXXXIXa. RG5139 (juvenile) - 50\% and 95\% probability contours of the annual fixed kernel home range utilization distribution. Smoothing parameter (h) determined by least squares cross validation, Marion/Taylor County, West Virginia, 2006-2007 (2003

SAMB imagery).

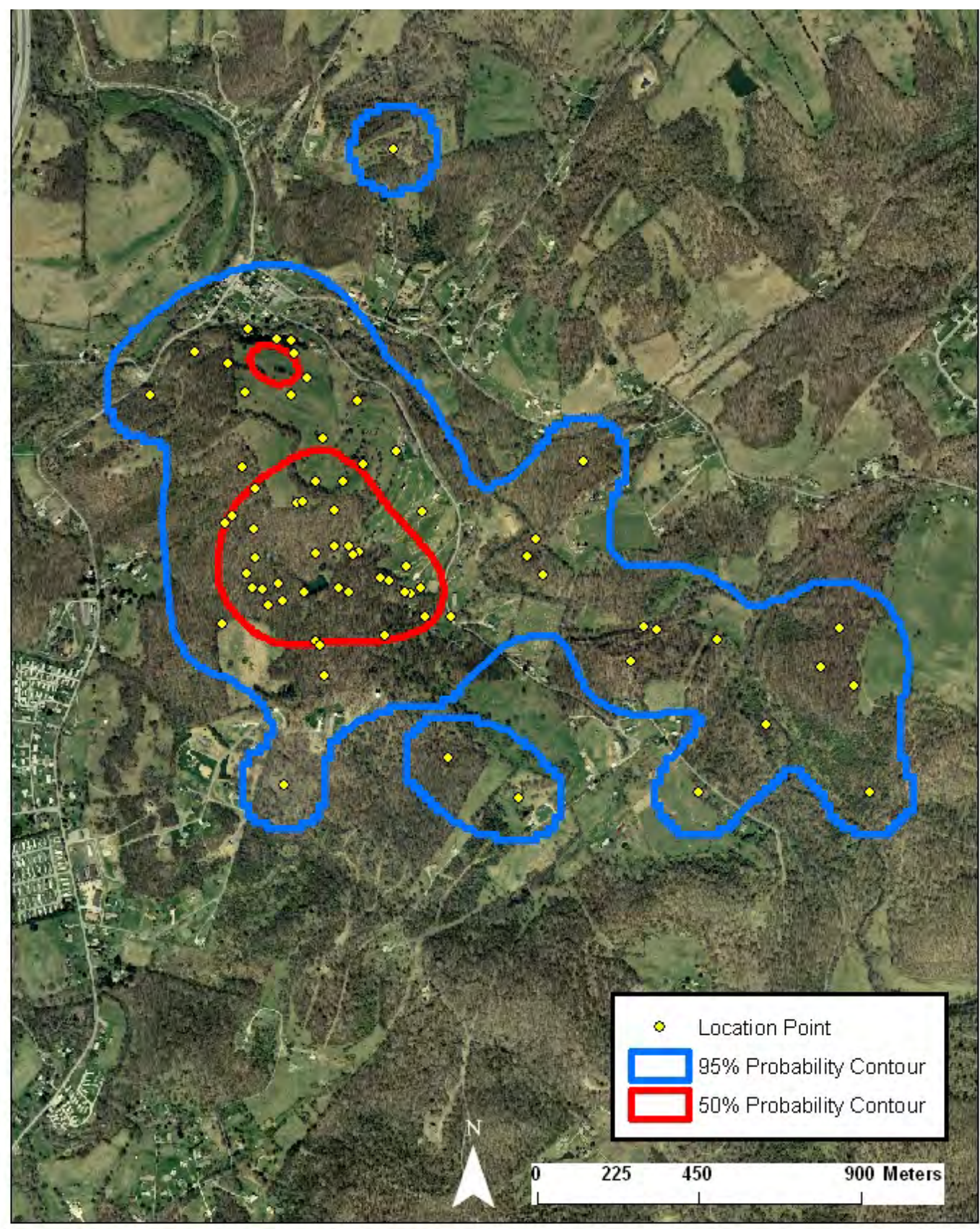


Appendix XCa. RG5139 (juvenile) - 95\% probability contour of the spring fixed kernel home range utilization distribution. Smoothing parameter (h) determined by least squares cross validation, Marion/Taylor County, West Virginia, 2007 (2003 SAMB imagery).

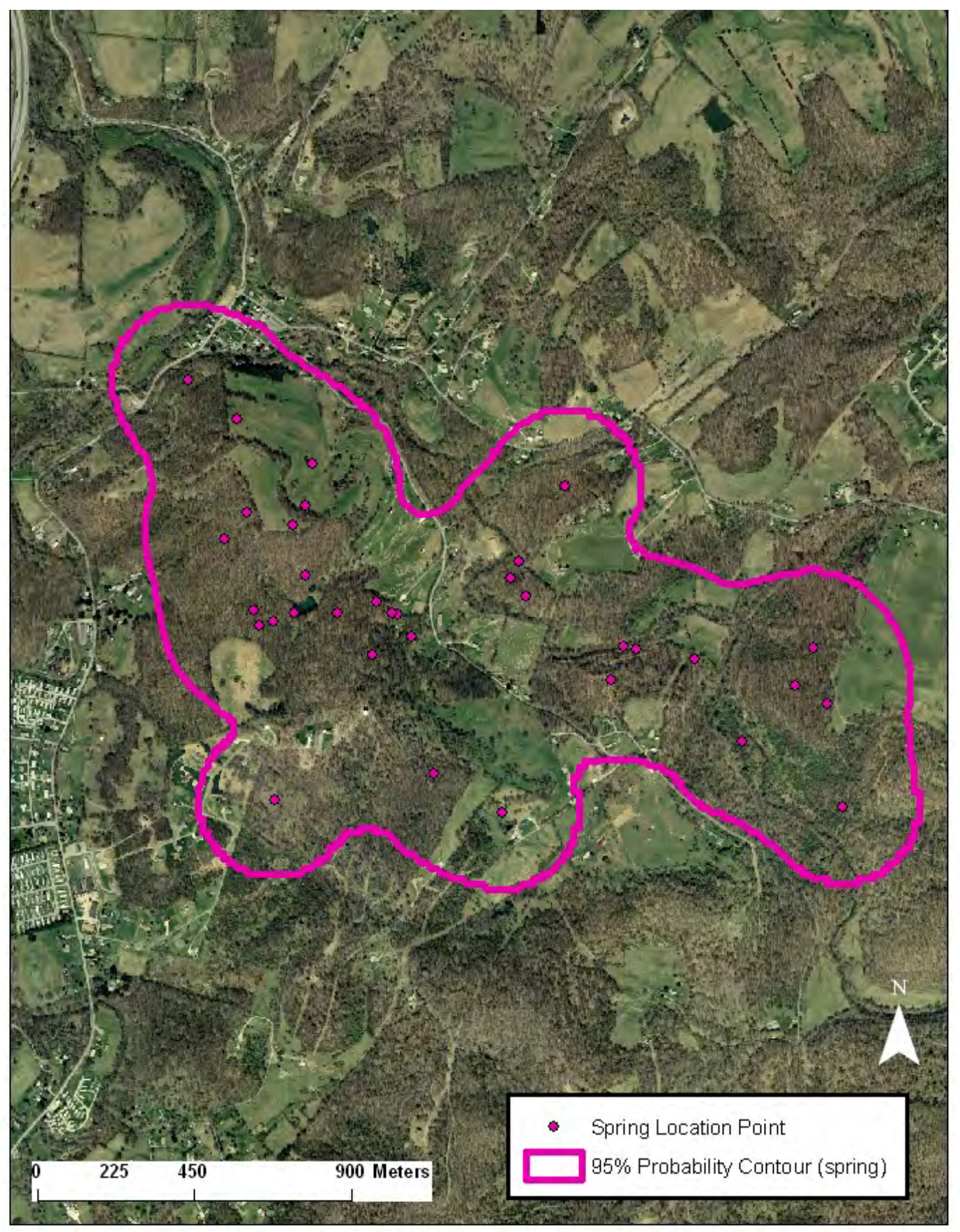


Appendix XCIa. RG5139 (juvenile) - 95\% probability contour of the spring-summer fixed kernel home range utilization distribution. Smoothing parameter (h) determined by least squares cross validation, Marion/Taylor County, West Virginia, 2007 (2003 SAMB imagery).

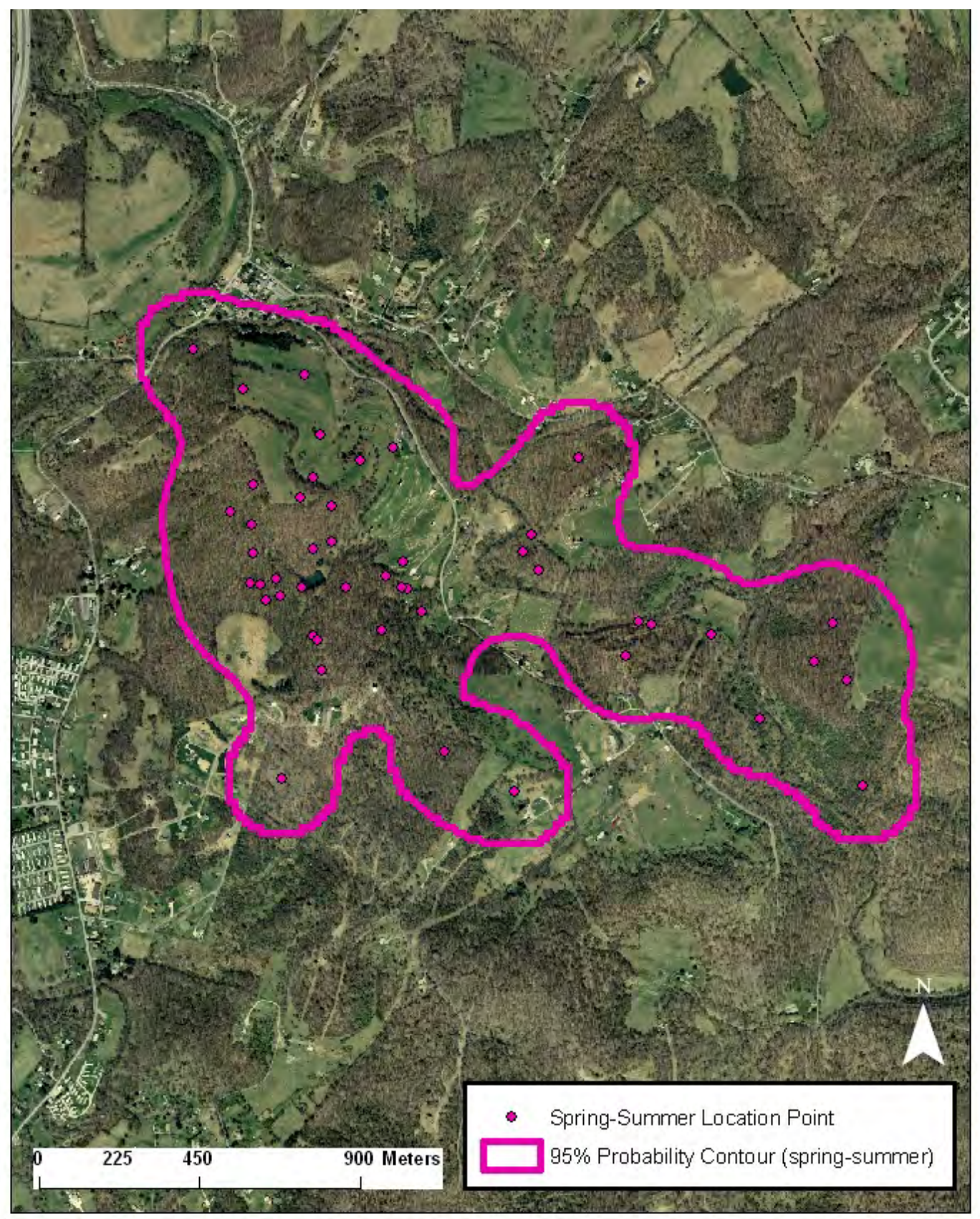


Appendix XCIIa. RG5207 (adult) - 50\% and 95\% probability contours of the annual fixed kernel home range utilization distribution. Smoothing parameter (h) determined by least squares cross validation, Pendleton County, West Virginia, 2005-2007 (100k topo map).

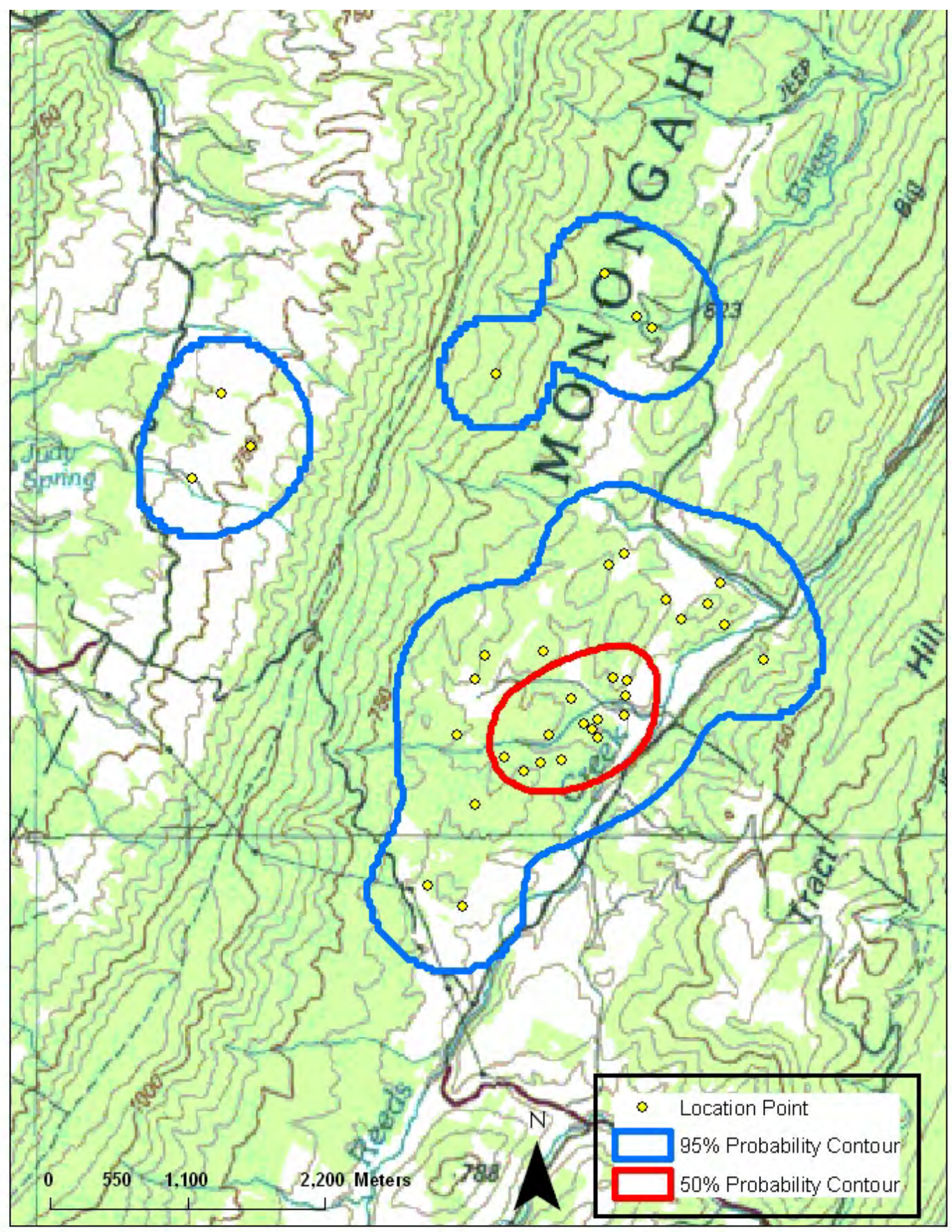


Appendix XCIIIa. RG5207 (adult) - 50\% and 95\% probability contours of the annual fixed kernel home range utilization distribution. Smoothing parameter (h) determined by least squares cross validation, Pendleton County, West Virginia, 2005-2007 (2003 SAMB imagery).

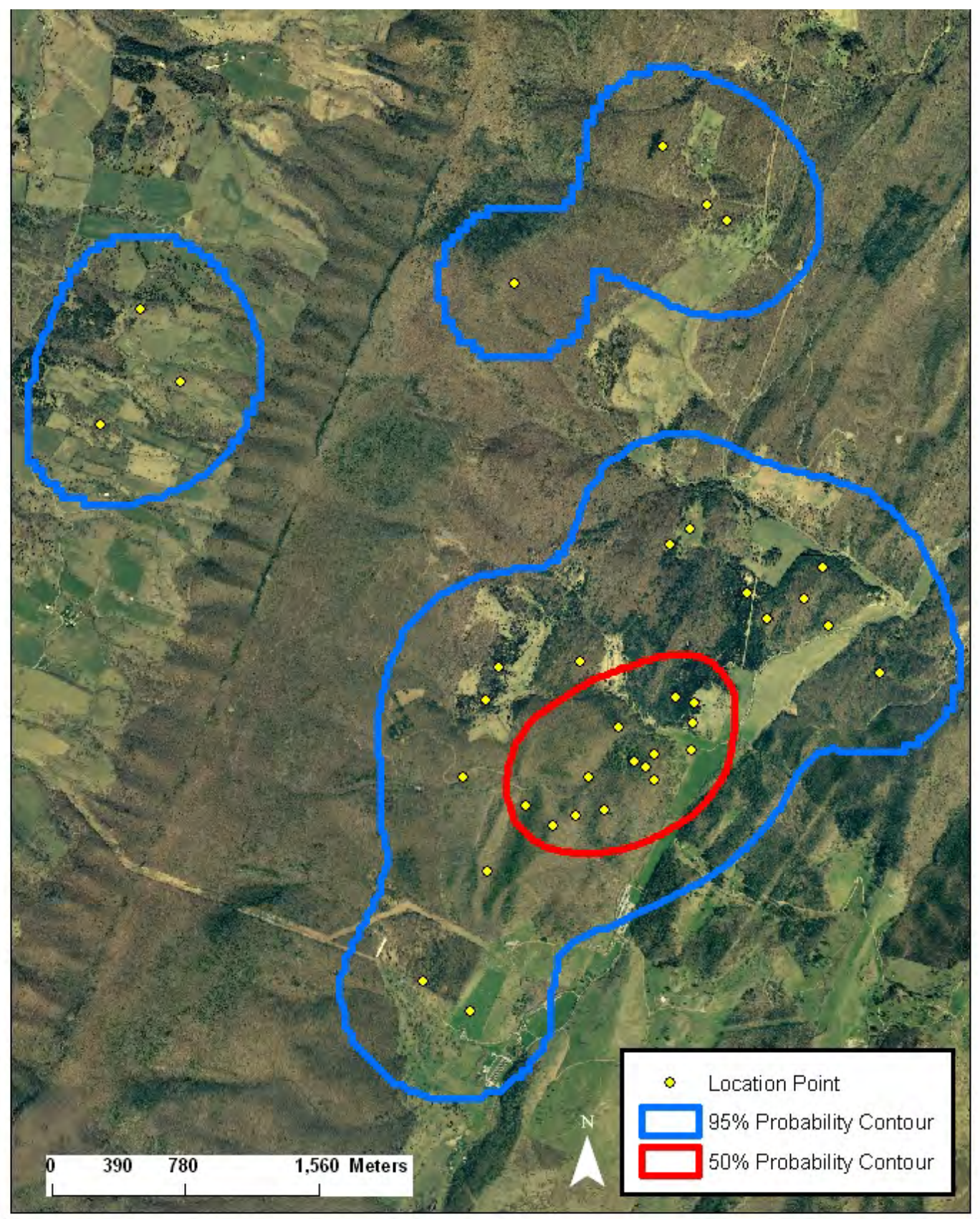


Appendix XCIVa. RG5212 (adult) - 50\% and 95\% probability contours of the annual fixed kernel home range utilization distribution. Smoothing parameter (h) determined by least squares cross validation, Hardy County, West Virginia, 2005-2007 (100k topo map).

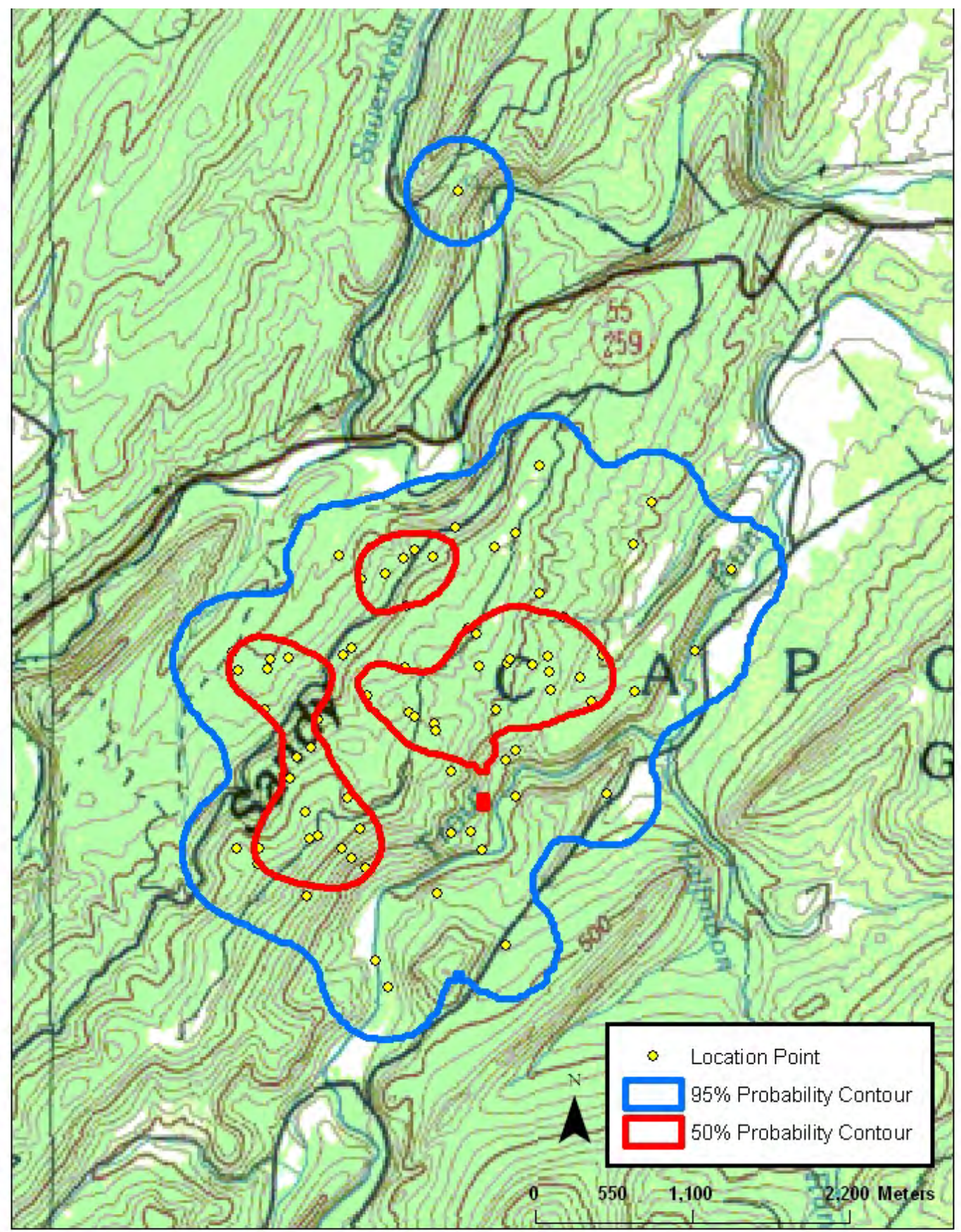


Appendix XCVa. RG5212 (adult) - 50\% and 95\% probability contours of the annual fixed kernel home range utilization distribution. Smoothing parameter (h) determined by least squares cross validation, Hardy County, West Virginia, 2005-2007 (2003 SAMB imagery).

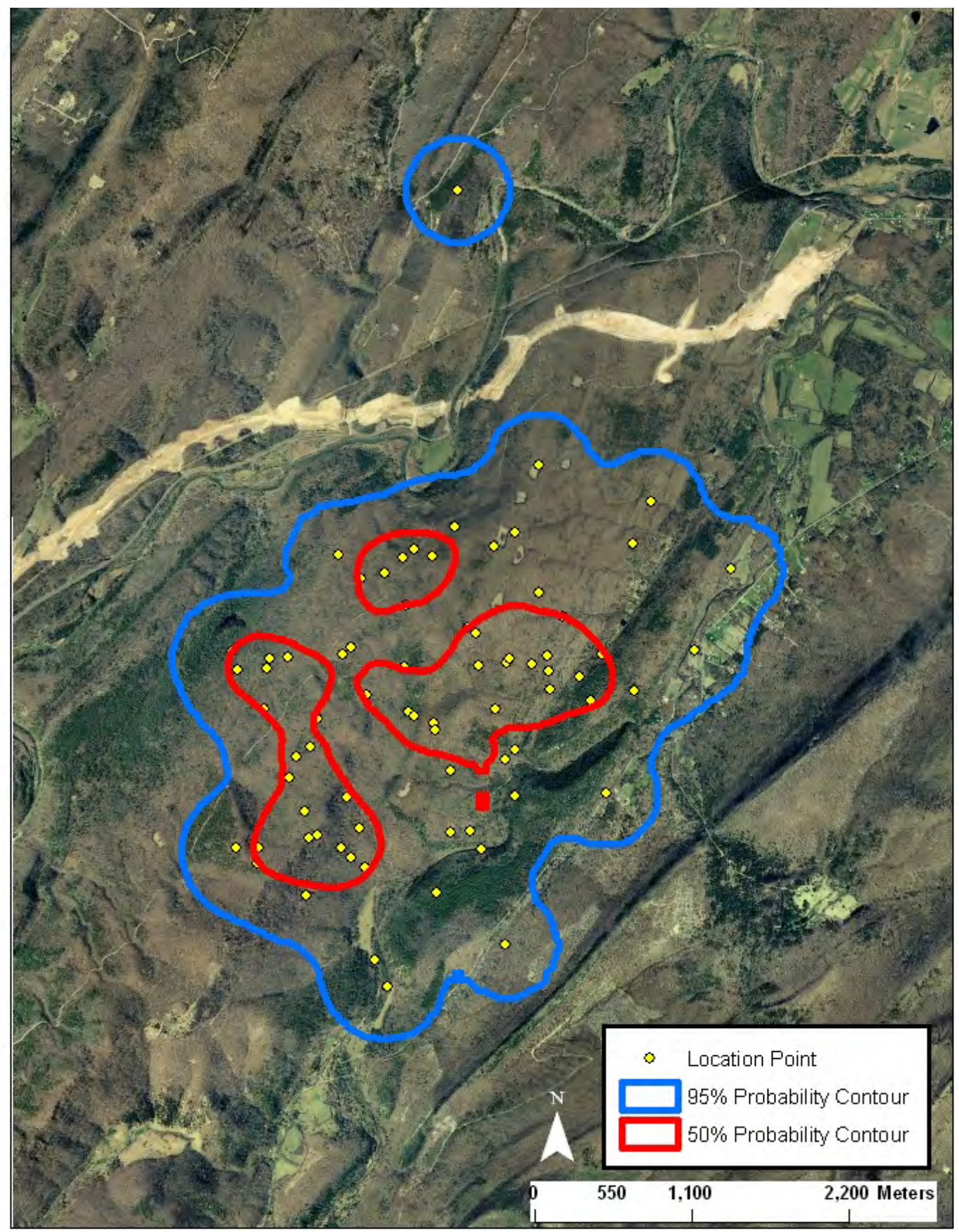


Appendix XCVIa. RG5212 (adult) - 95\% probability contour of the spring-summer fixed kernel home range utilization distribution. Smoothing parameter (h) determined by least squares cross validation, Hardy County, West Virginia, 2005-2007 (2003 SAMB imagery).

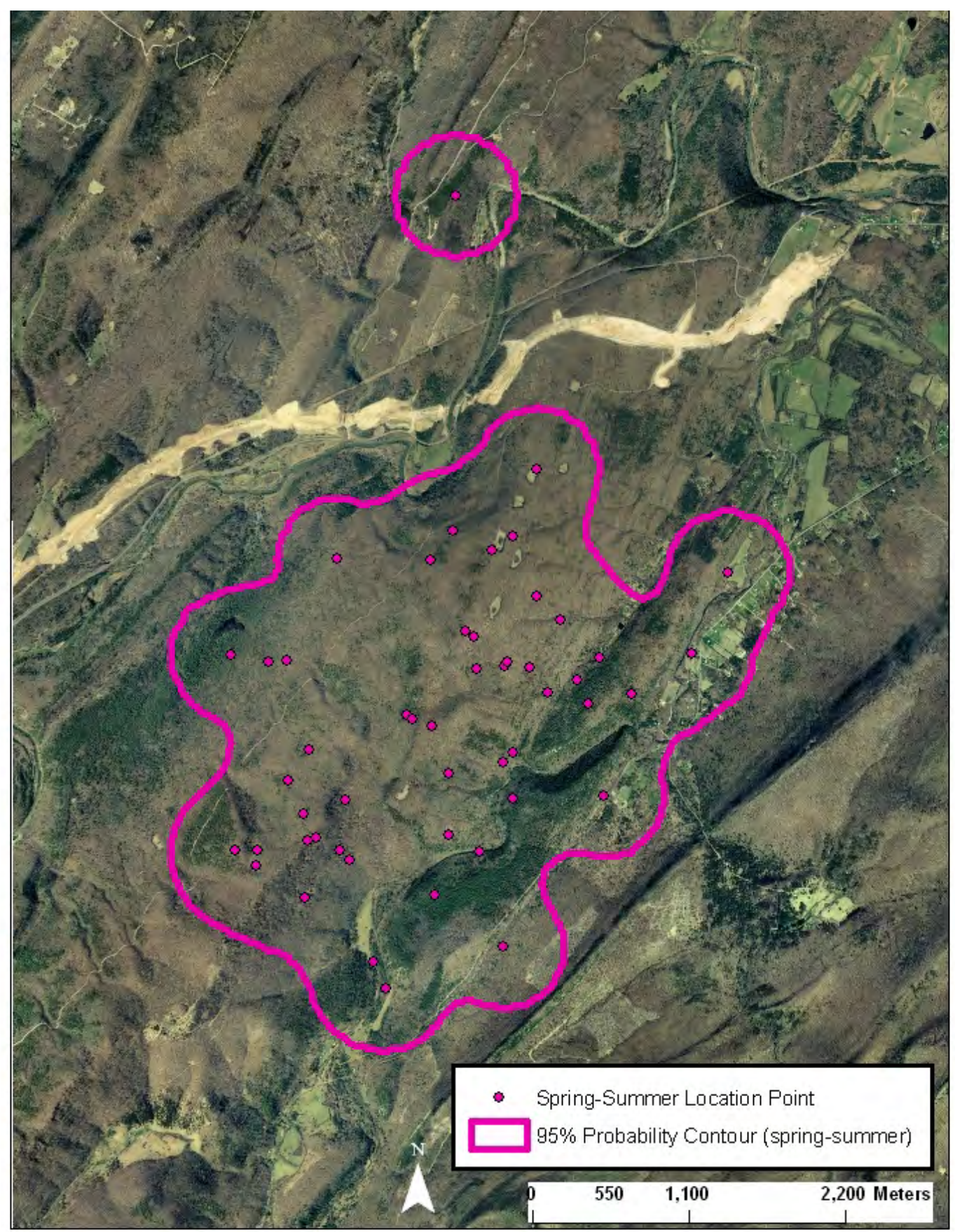


Appendix XCVIIa. RG5218 (adult) - 50\% and 95\% probability contours of the annual fixed kernel home range utilization distribution. Smoothing parameter (h) determined by least squares cross validation, Hardy County, West Virginia, 2005-2006 (100k topo map).

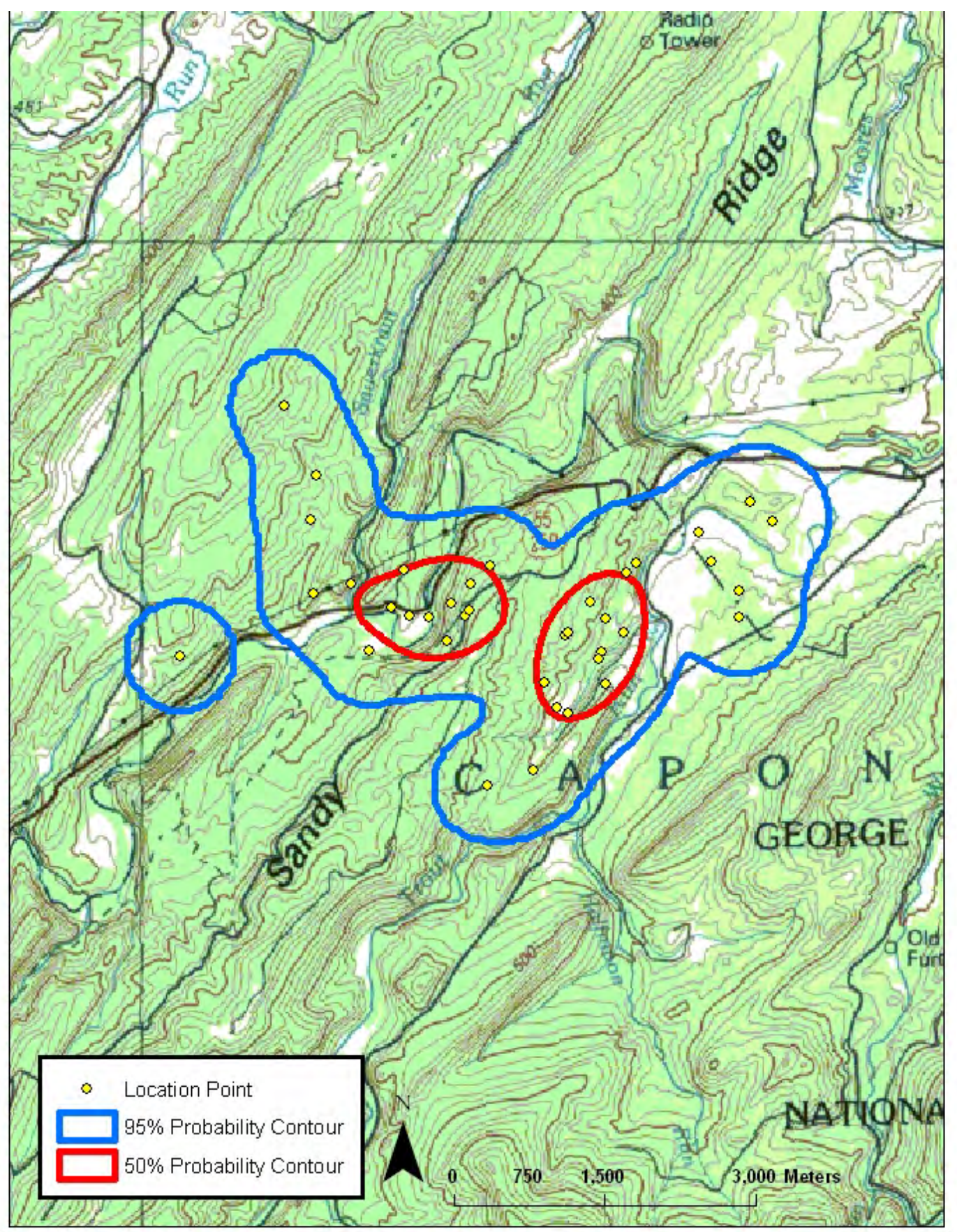


Appendix XCVIIIa. RG5218 (adult) - 50\% and 95\% probability contours of the annual fixed kernel home range utilization distribution. Smoothing parameter (h) determined by least squares cross validation, Hardy County, West Virginia, 2005-2006 (2003 SAMB imagery).

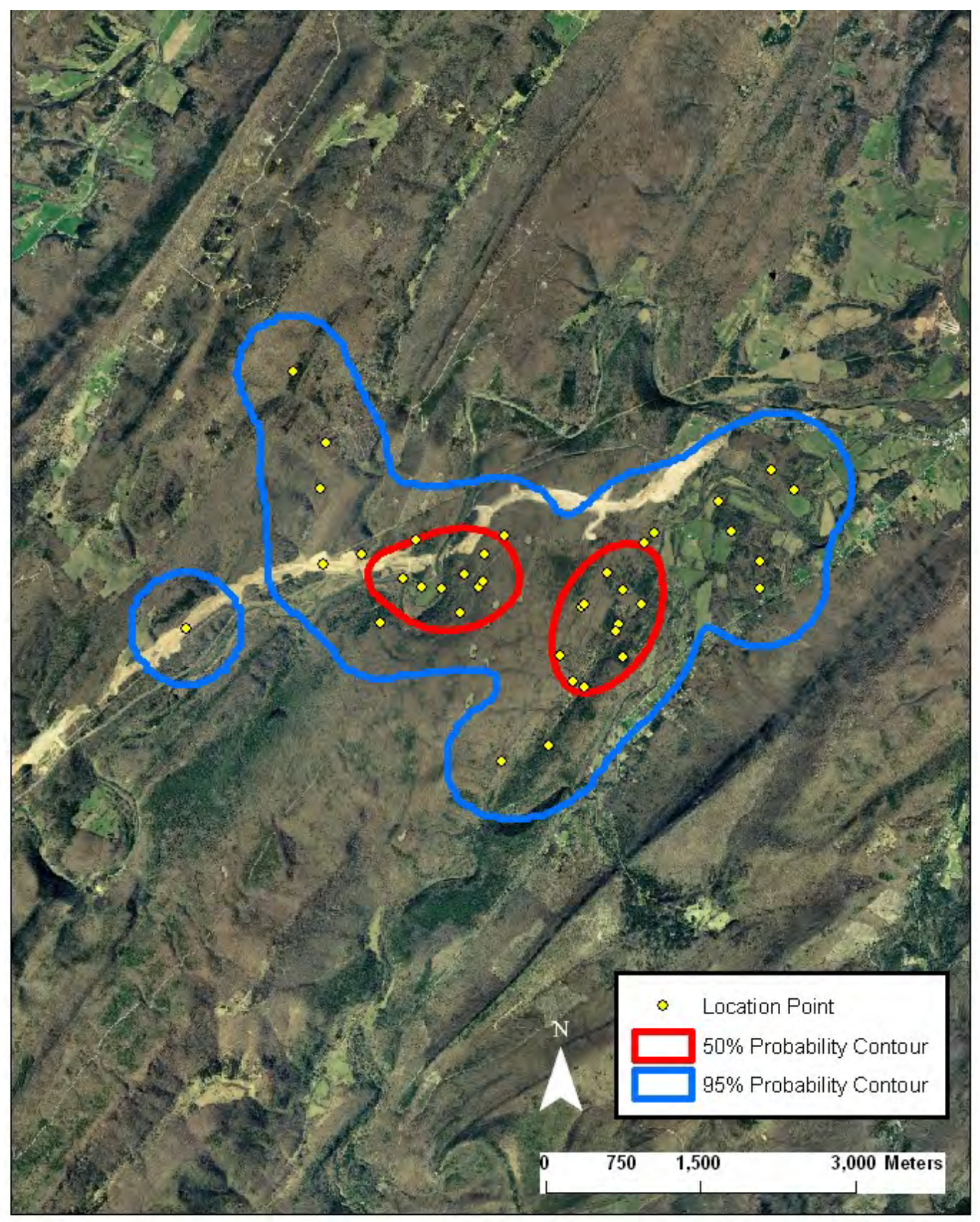


Appendix XCIXa. RG5303 (adult) - 50\% and 95\% probability contours of the annual fixed kernel home range utilization distribution. Smoothing parameter (h) determined by least squares cross validation, Lewis County, West Virginia, 2004-2006 (100k topo map).

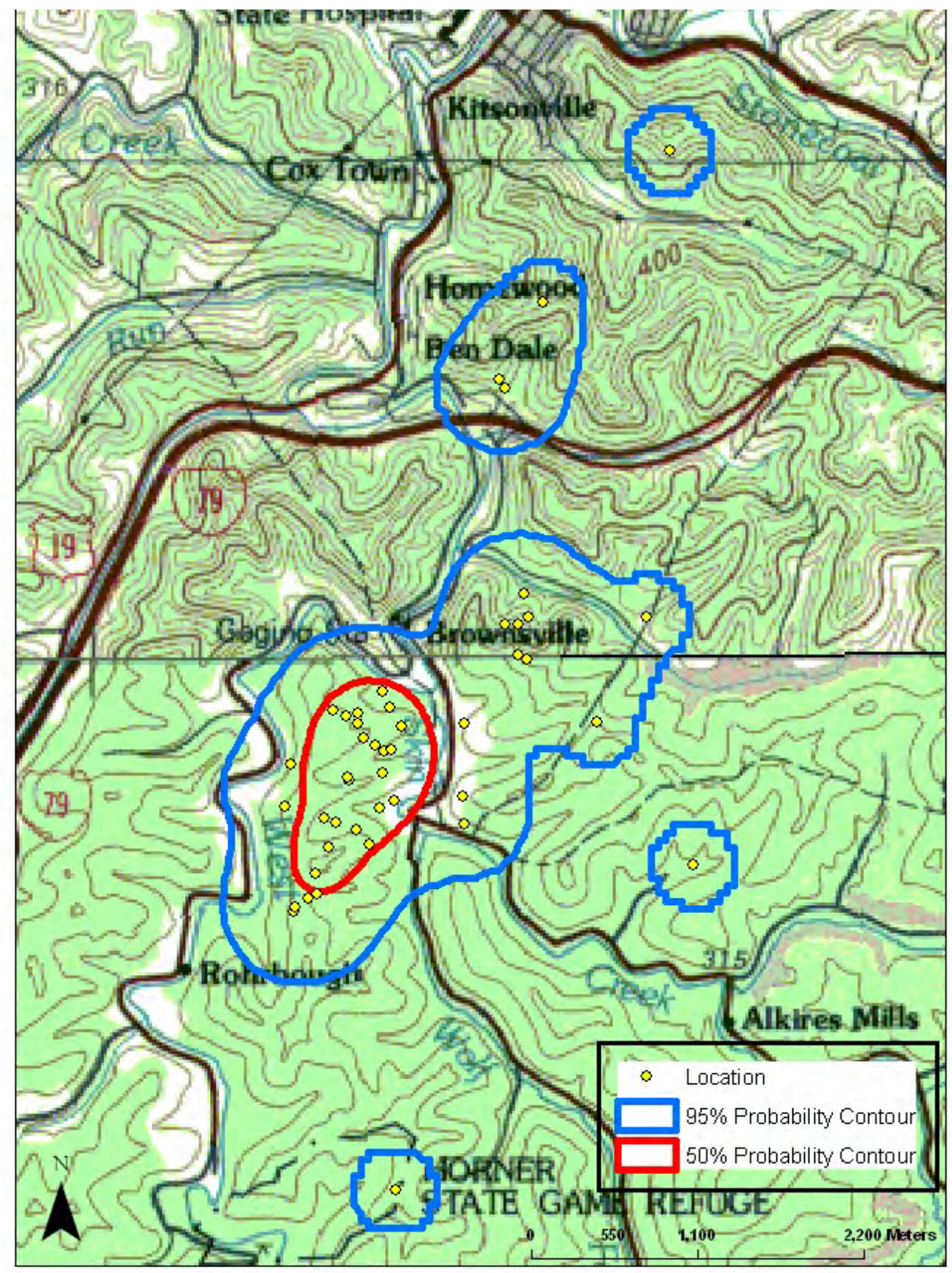


Appendix Ca. RG5303 (adult) - 50\% and 95\% probability contours of the annual fixed kernel home range utilization distribution. Smoothing parameter (h) determined by least squares cross validation, Lewis County, West Virginia, 2004-2006 (2003 SAMB imagery).

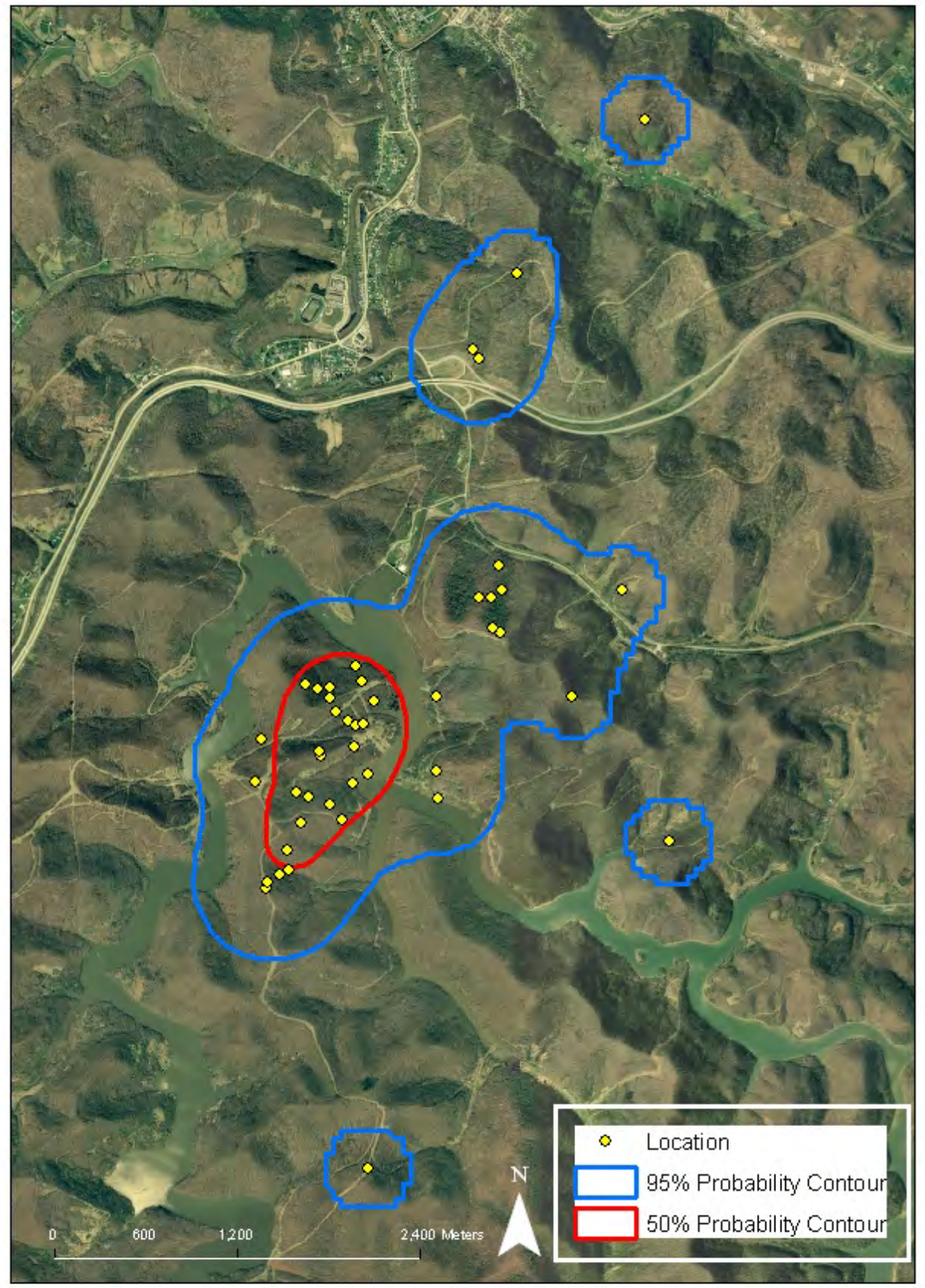


Appendix CIa. RG5304 (adult) - 50\% and 95\% probability contours of the annual fixed kernel home range utilization distribution. Smoothing parameter (h) determined by least squares cross validation, Lewis County, West Virginia, 2004-2006 (100k topo map).

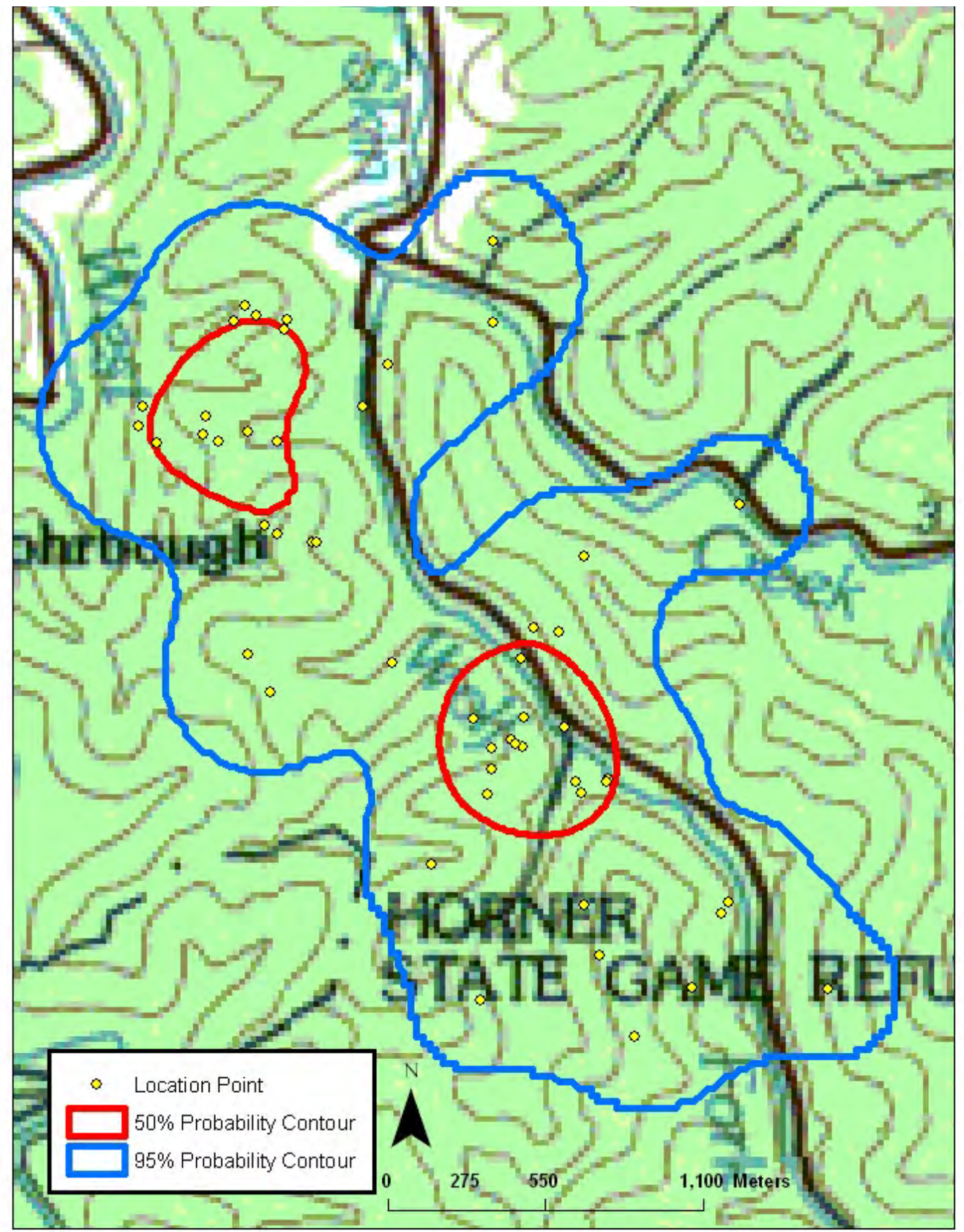


Appendix CIIa. RG5304 (adult) - 50\% and 95\% probability contours of the annual fixed kernel home range utilization distribution. Smoothing parameter (h) determined by least squares cross validation, Lewis County, West Virginia, 2004-2006 (2003 SAMB imagery).

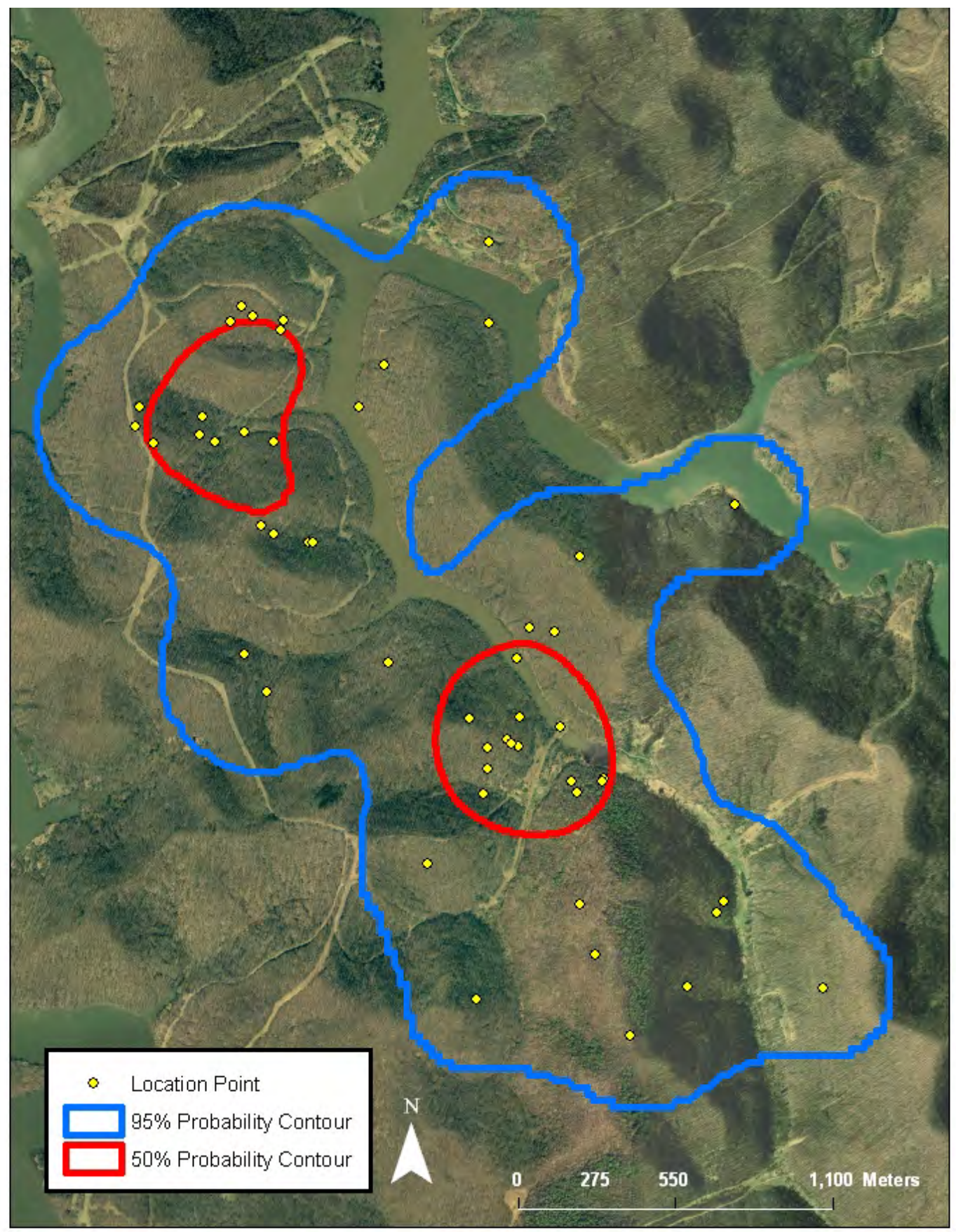


Appendix CIIIa. RG5305 (adult) - 50\% and 95\% probability contours of the annual fixed kernel home range utilization distribution. Smoothing parameter (h) determined by least squares cross validation, Lewis County, West Virginia, 2004-2005 (100k topo map).

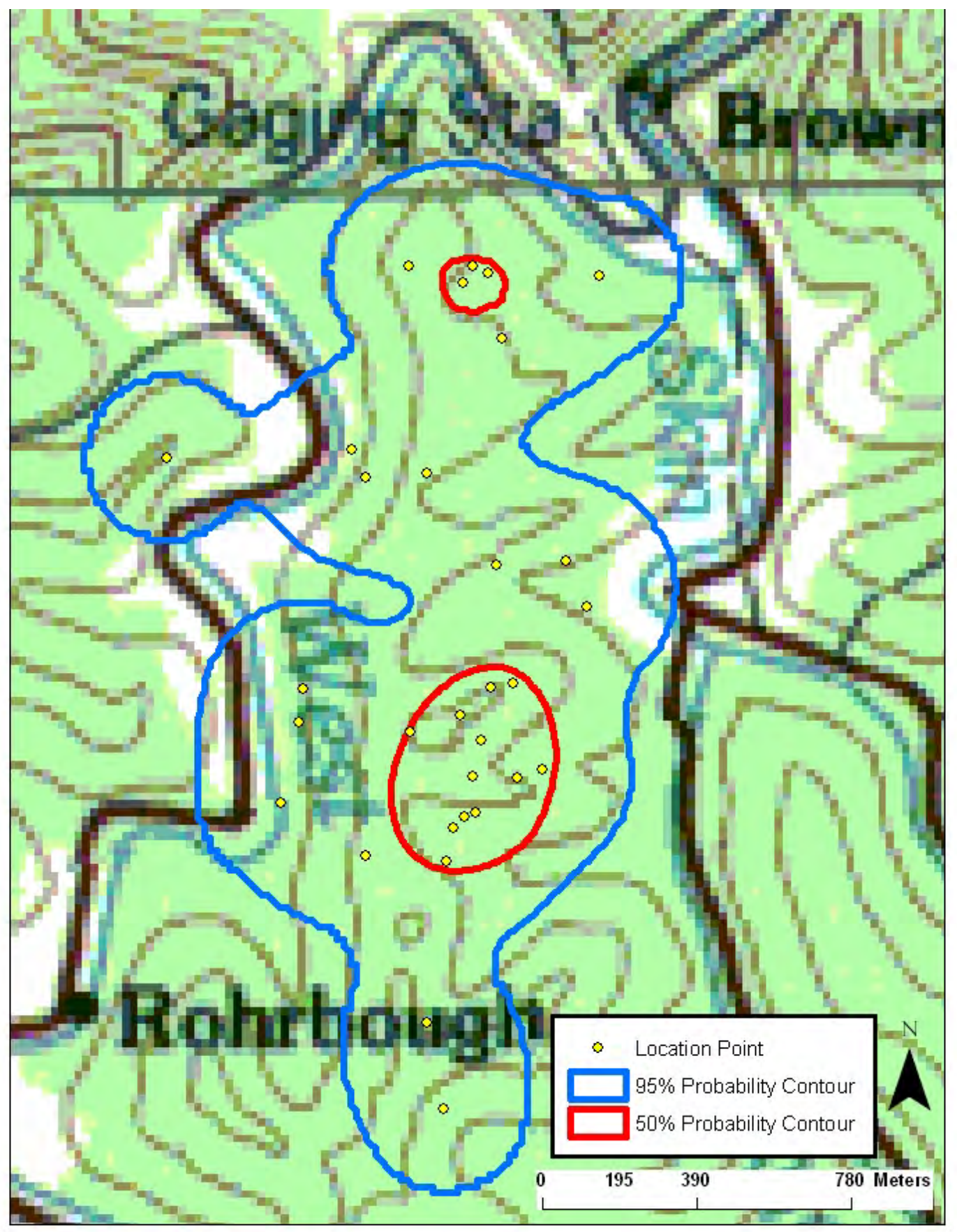


Appendix CIVa. RG5305 (adult) - 50\% and 95\% probability contours of the annual fixed kernel home range utilization distribution. Smoothing parameter (h) determined by least squares cross validation, Lewis County, West Virginia, 2004-2005 (2003 SAMB imagery).

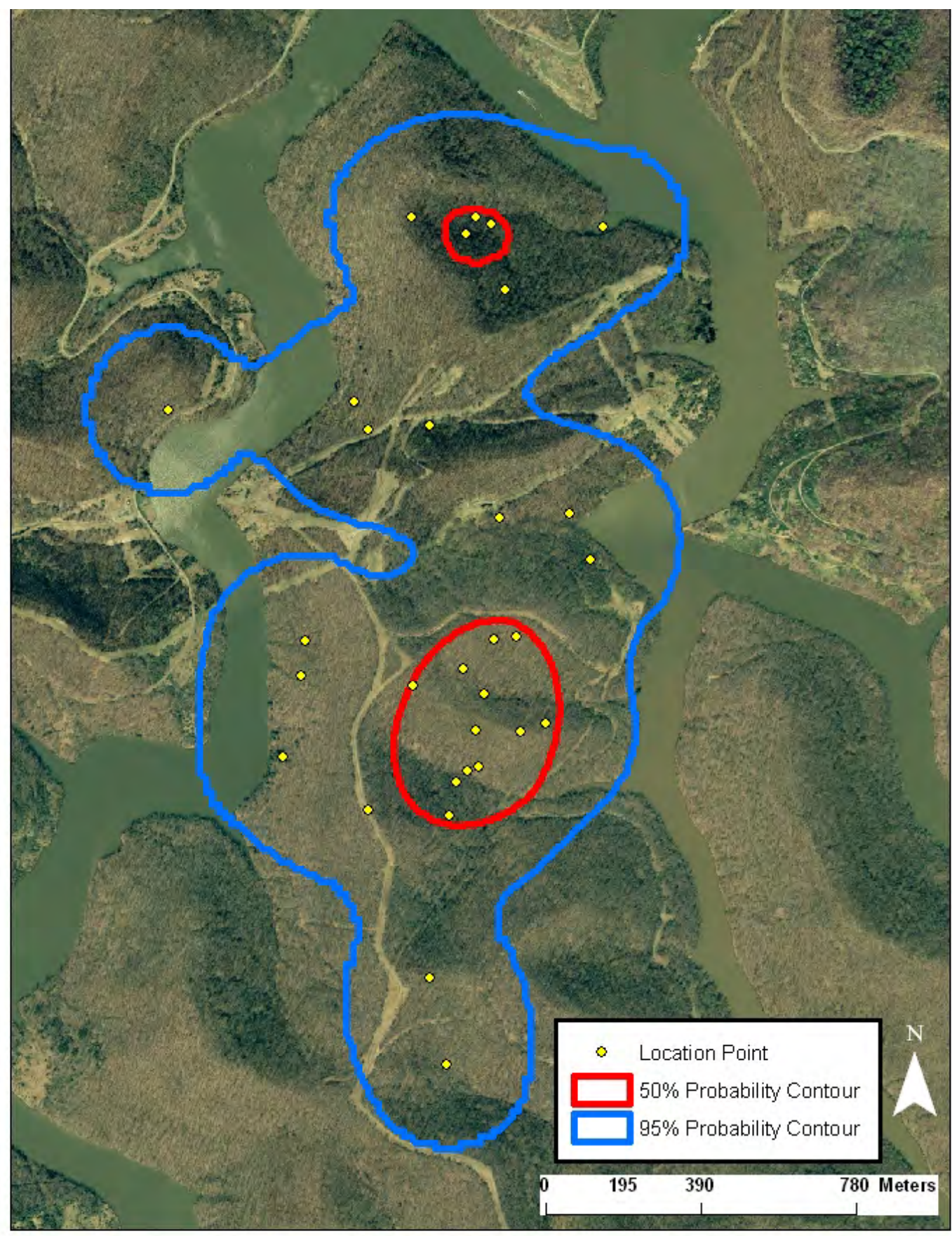


Appendix CVa. RG5310 (adult) - 50\% and 95\% probability contours of the annual fixed kernel home range utilization distribution. Smoothing parameter (h) determined by least squares cross validation, Lewis County, West Virginia, 2005-2007 (100k topo map).

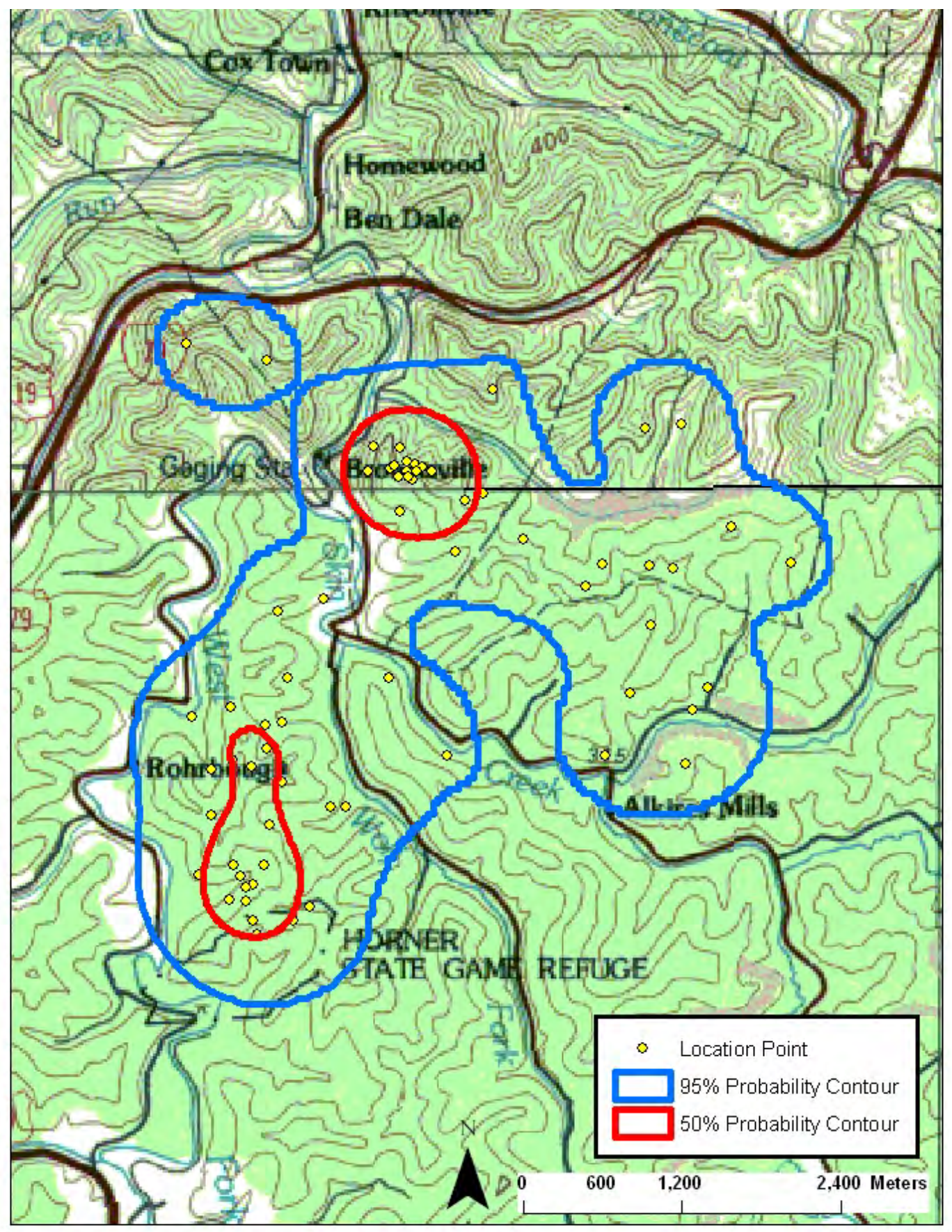


Appendix CVIa. RG5310 (adult) - 50\% and 95\% probability contours of the annual fixed kernel home range utilization distribution. Smoothing parameter (h) determined by least squares cross validation, Lewis County, West Virginia, 2005-2007 (2003 SAMB imagery).

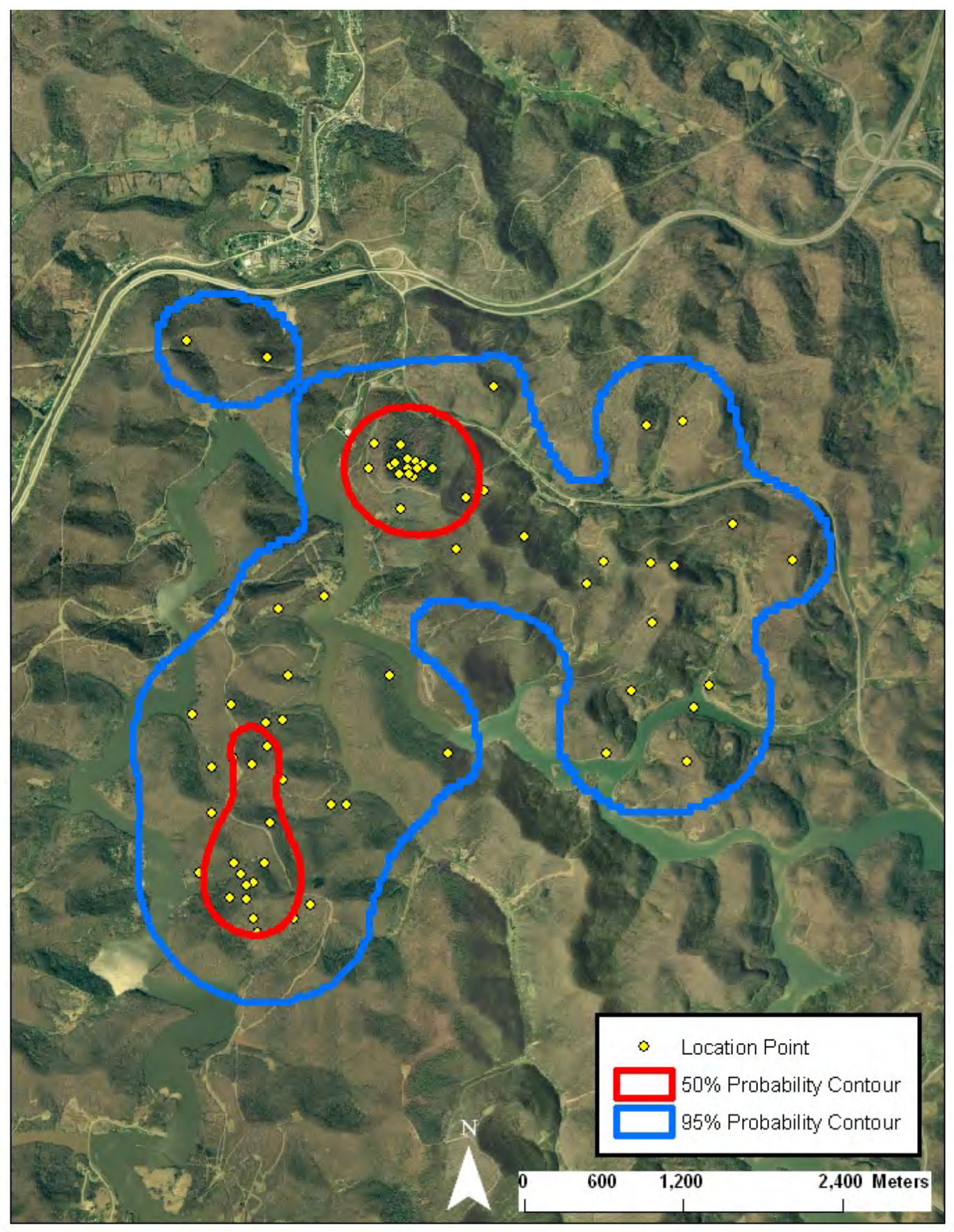


Appendix CVIIa. RG5310 (adult) - 95\% probability contours of the spring-summer and fall-winter fixed kernel home range utilization distribution. Smoothing parameter (h) determined by least squares cross validation, Lewis County, West Virginia, 2005-2007 (2003 SAMB imagery).

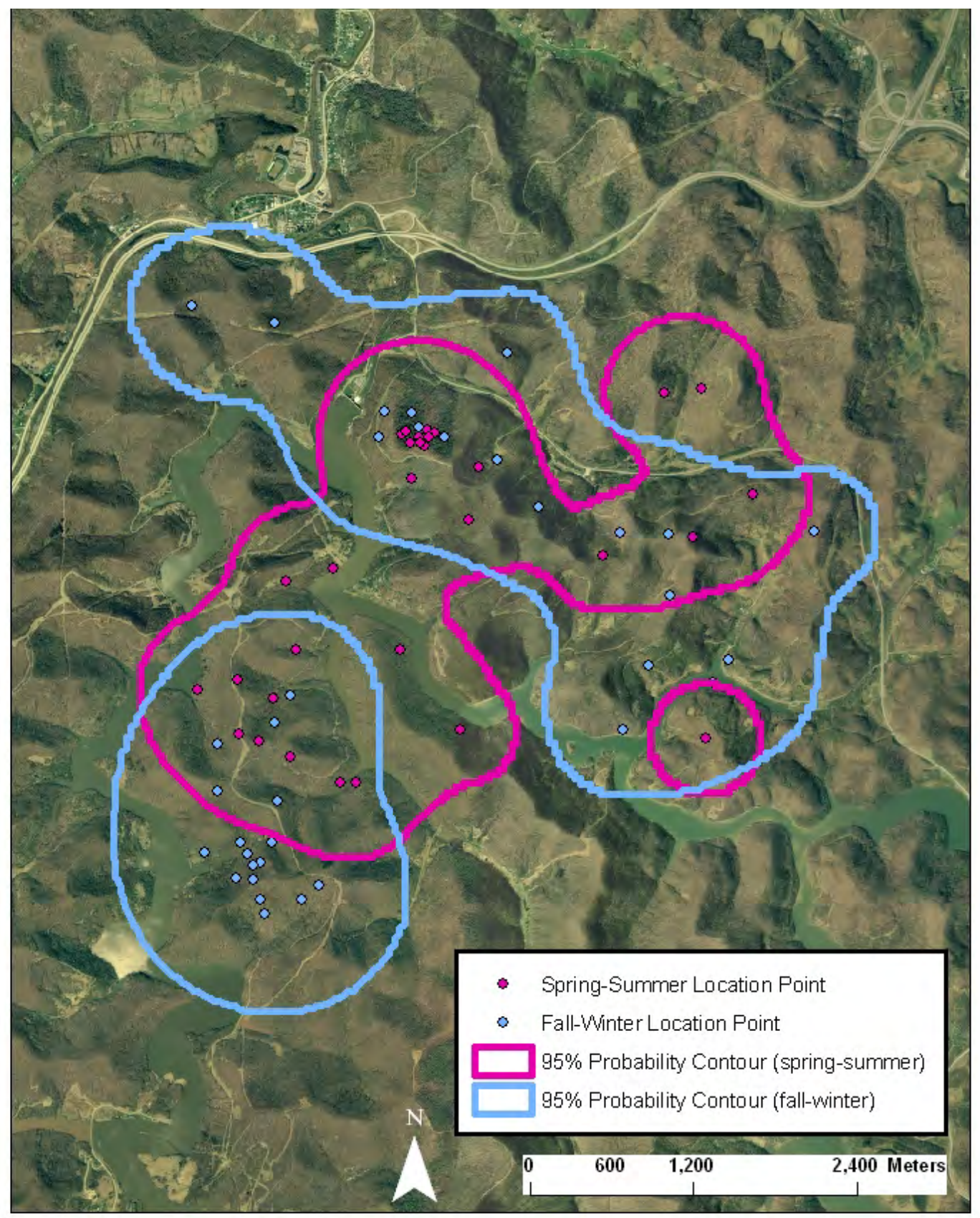


Appendix CVIII $a$. RG5315 (juvenile) - 50\% and 95\% probability contours of the annual fixed kernel home range utilization distribution. Smoothing parameter (h) determined by least squares cross validation, Lewis County, West Virginia, 2005-2006 (100k topo map).

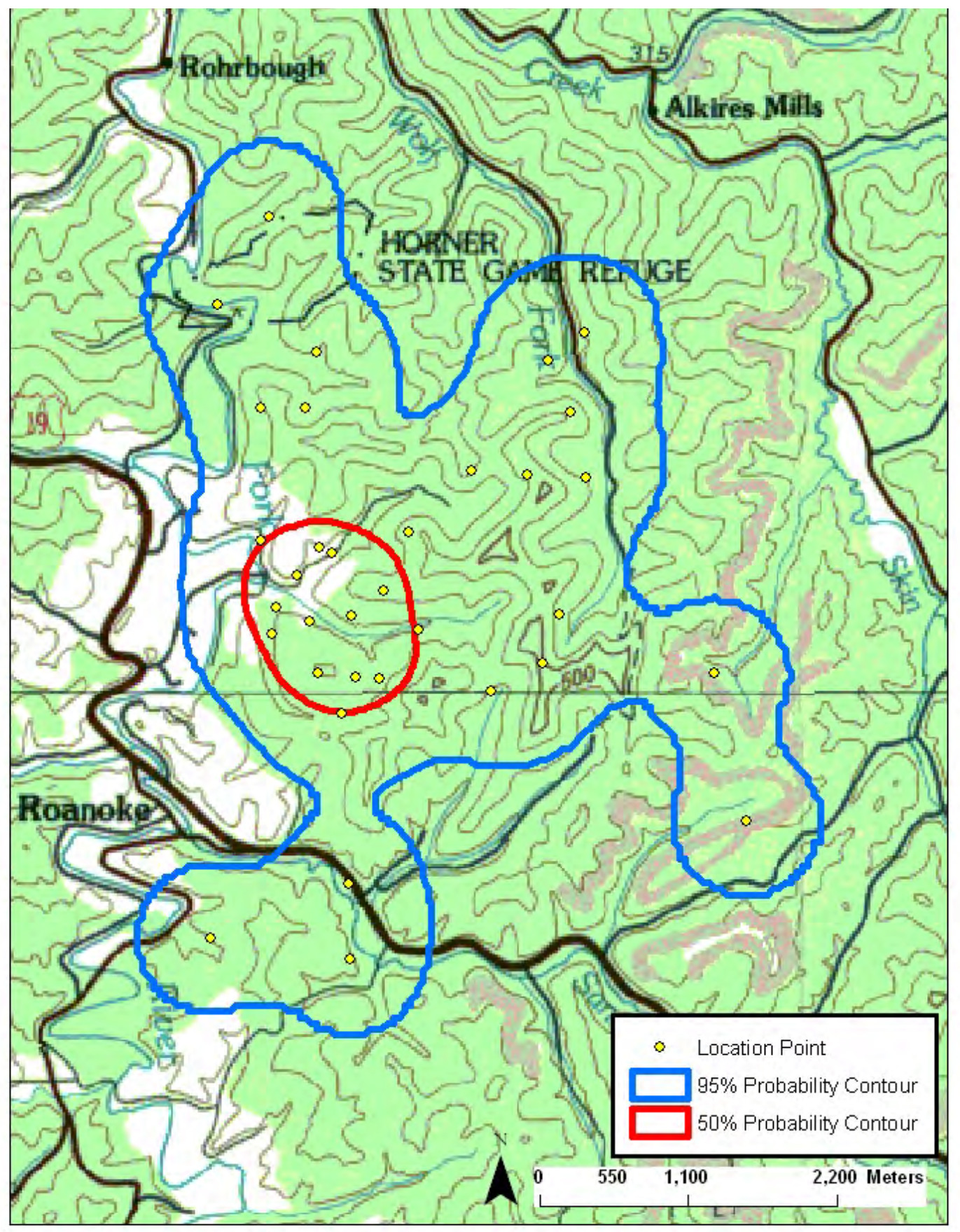


Appendix CIXa. RG5315 (juvenile) - 50\% and 95\% probability contours of the annual fixed kernel home range utilization distribution. Smoothing parameter (h) determined by least squares cross validation, Lewis County, West Virginia, 2005-2006 (2003 SAMB imagery).

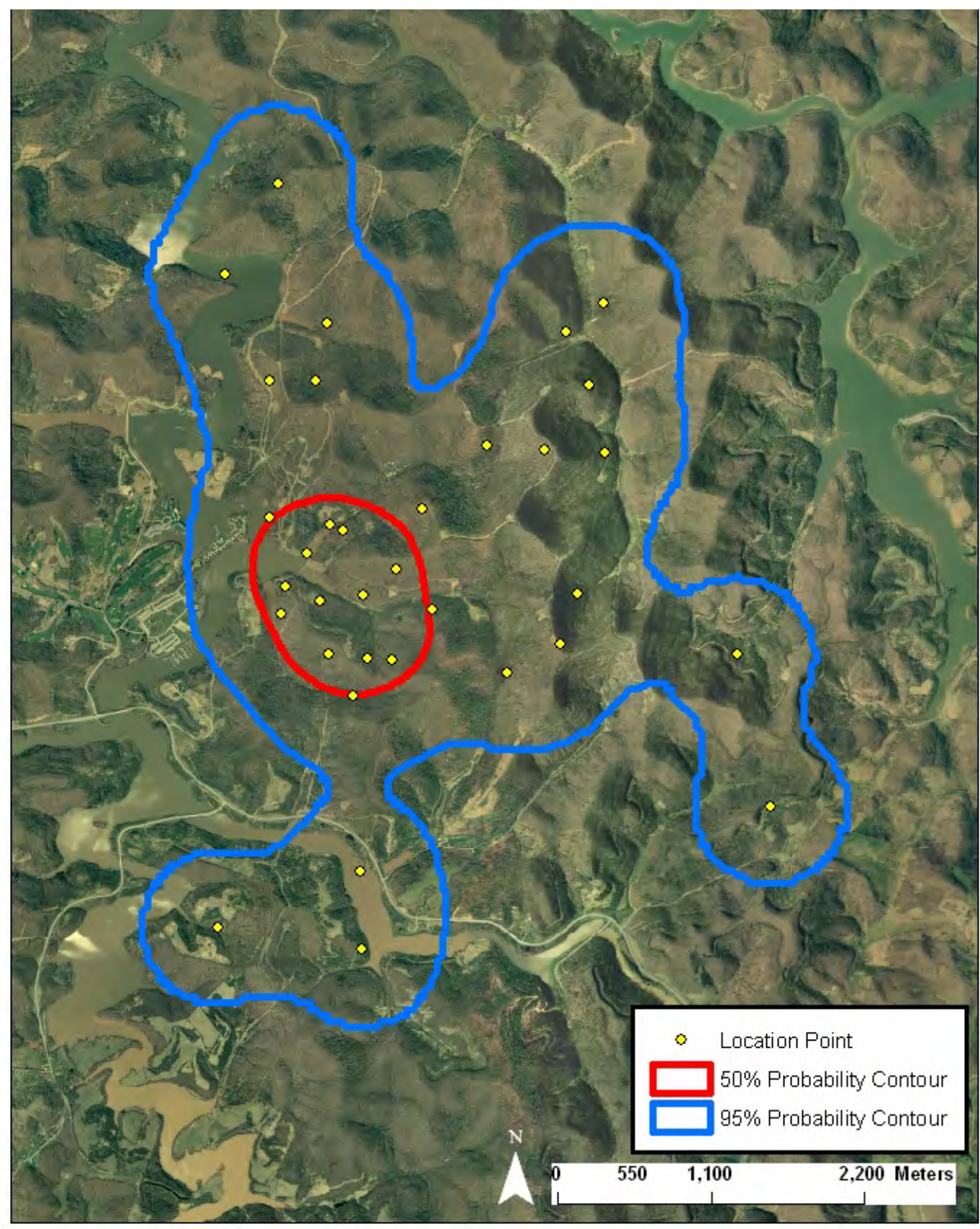


Appendix CXa. RG5315 (adult) - 50\% and 95\% probability contours of the annual fixed kernel home range utilization distribution. Smoothing parameter (h) determined by least squares cross validation, Lewis County, West Virginia, 2006-2007 (100k topo map).

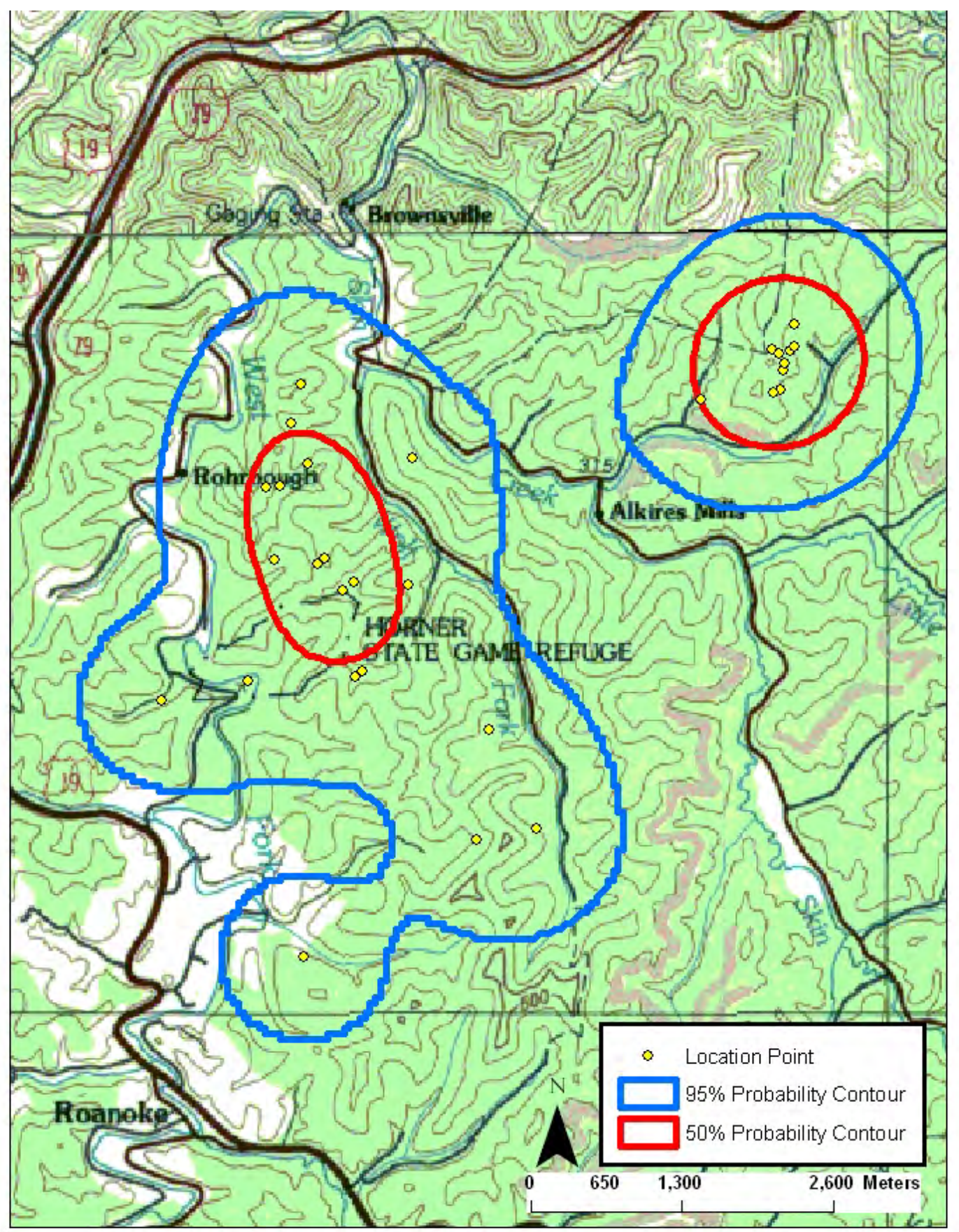


Appendix CXIa. RG5315 (adult) - 50\% and 95\% probability contours of the annual fixed kernel home range utilization distribution. Smoothing parameter (h) determined by least squares cross validation, Lewis County, West Virginia, 2006-2007 (2003 SAMB imagery).

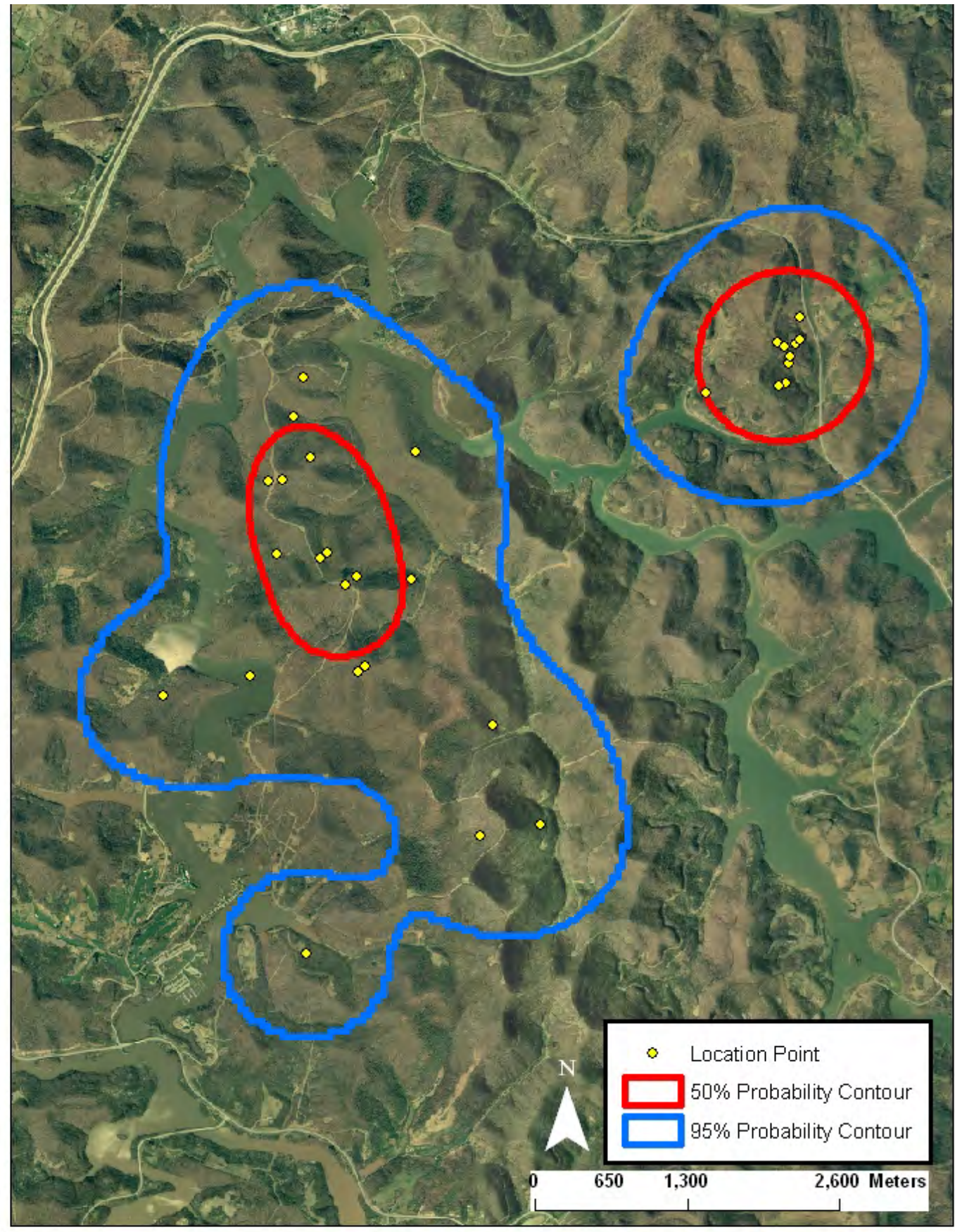


Appendix CXIIa. RG5326 (adult) - 50\% and 95\% probability contours of the annual fixed kernel home range utilization distribution. Smoothing parameter (h) determined by least squares cross validation, Lewis County, West Virginia, 2006-2007 (100k topo map).

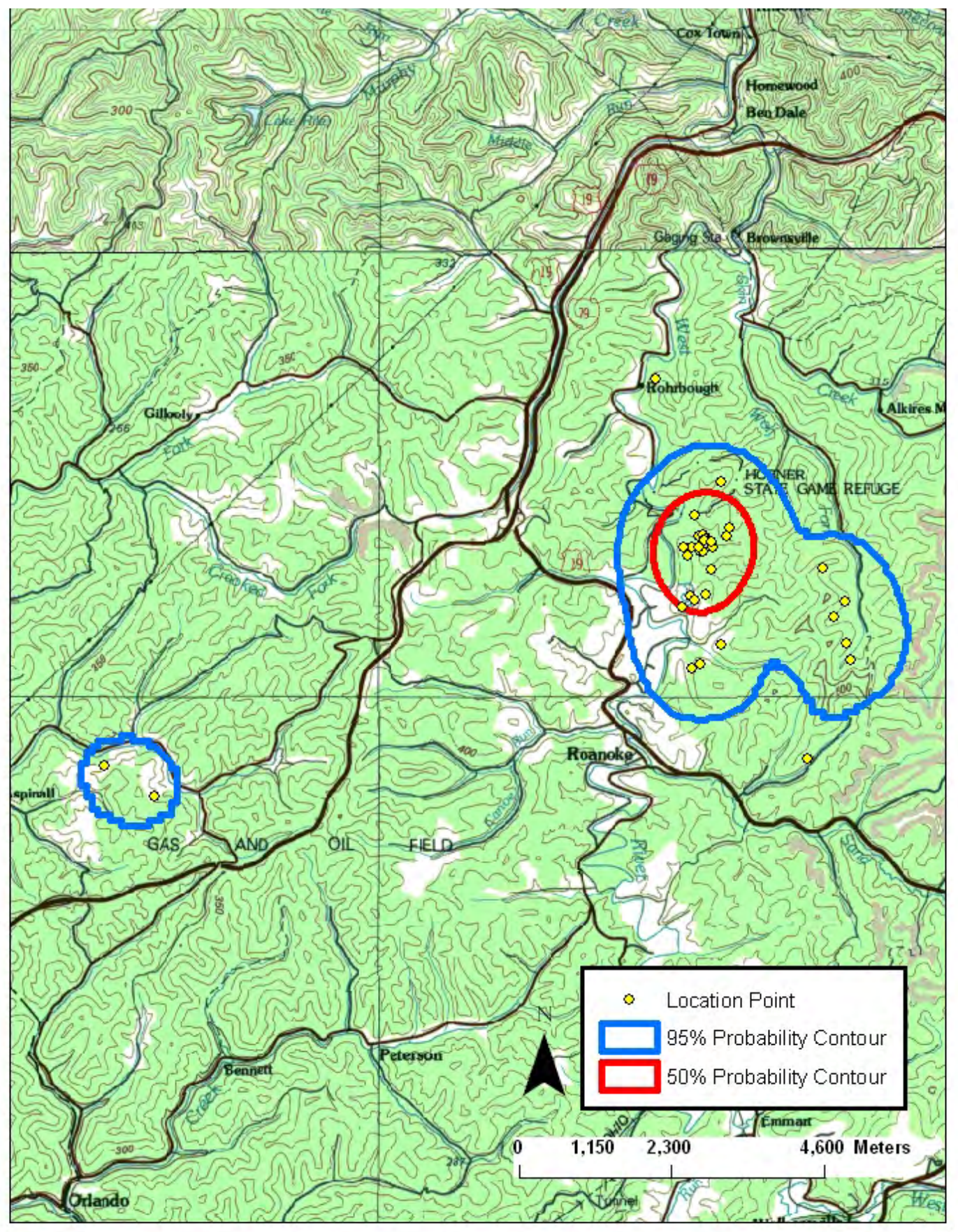


Appendix CXIIIa. RG5326 (adult) - 50\% and 95\% probability contours of the annual fixed kernel home range utilization distribution. Smoothing parameter (h) determined by least squares cross validation, Lewis County, West Virginia, 2006-2007 (2003 SAMB imagery).

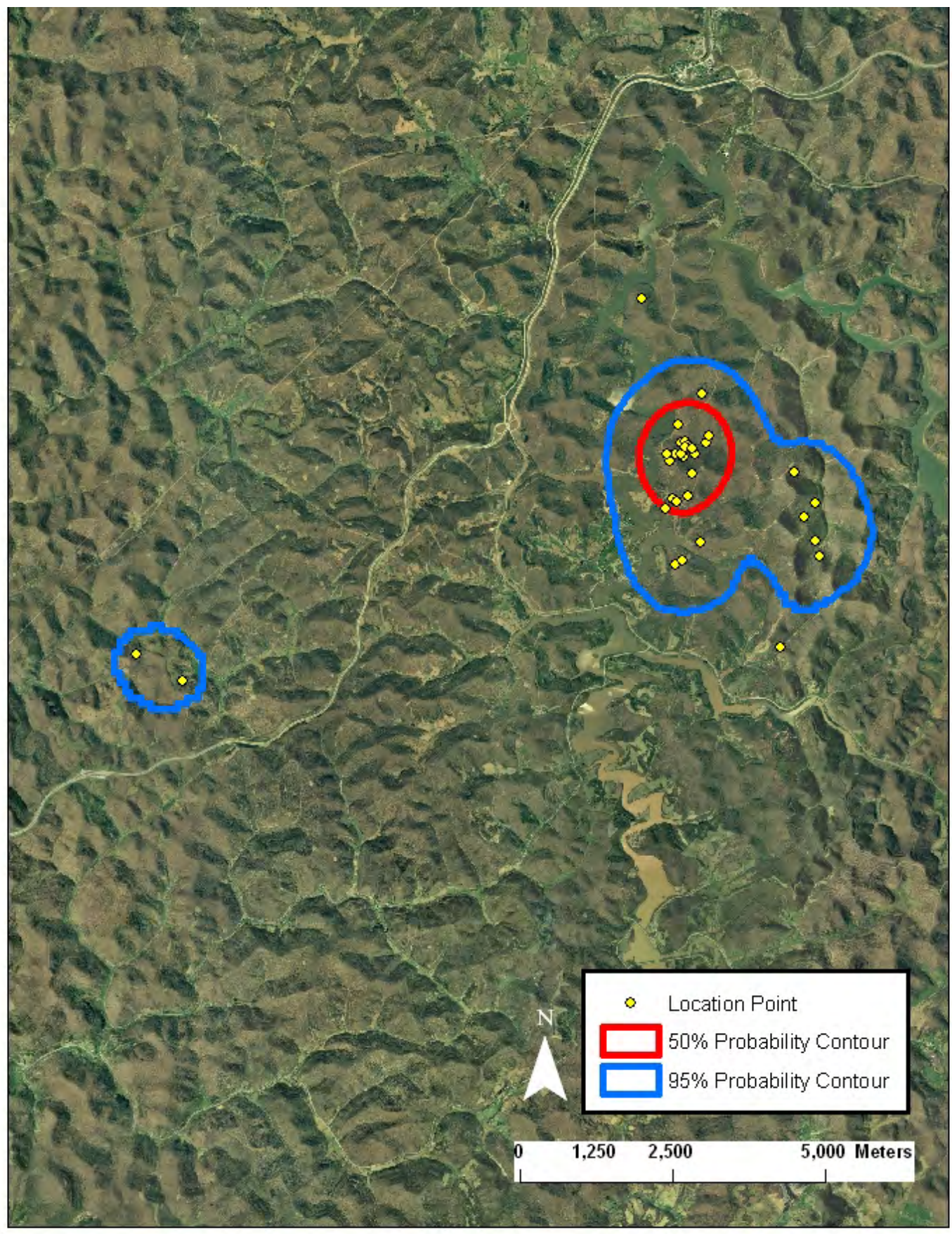


Appendix CXIVa. RG5401 (adult) - 50\% and 95\% probability contours of the annual fixed kernel home range utilization distribution. Smoothing parameter (h) determined by least squares cross validation, Greenbrier County, West Virginia, 2004-2007 (100k topo map).

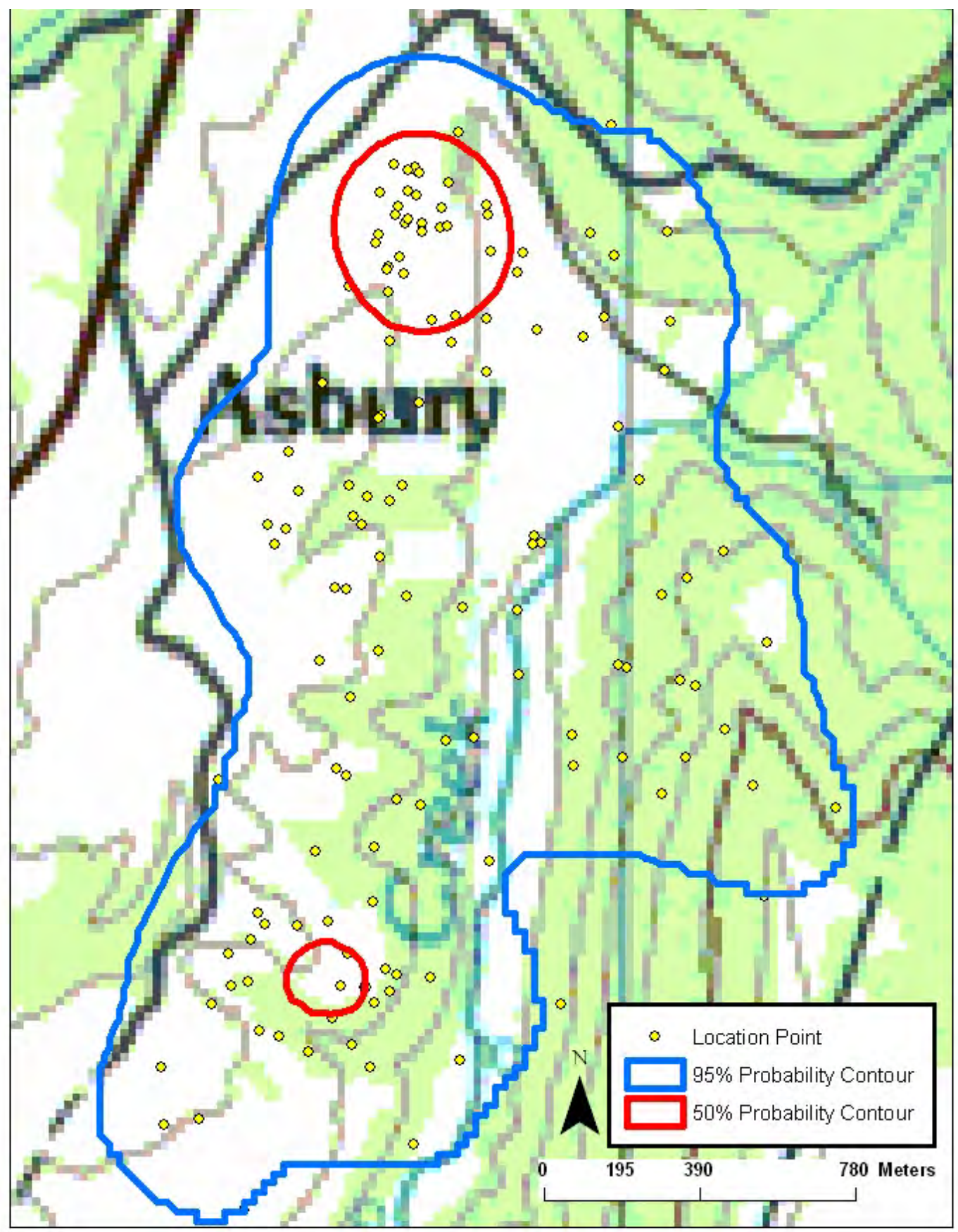


Appendix CXVa. RG5401 (adult) - 50\% and 95\% probability contours of the annual fixed kernel home range utilization distribution. Smoothing parameter (h) determined by least squares cross validation, Greenbrier County, West Virginia, 2004-2007 (2003 SAMB imagery).

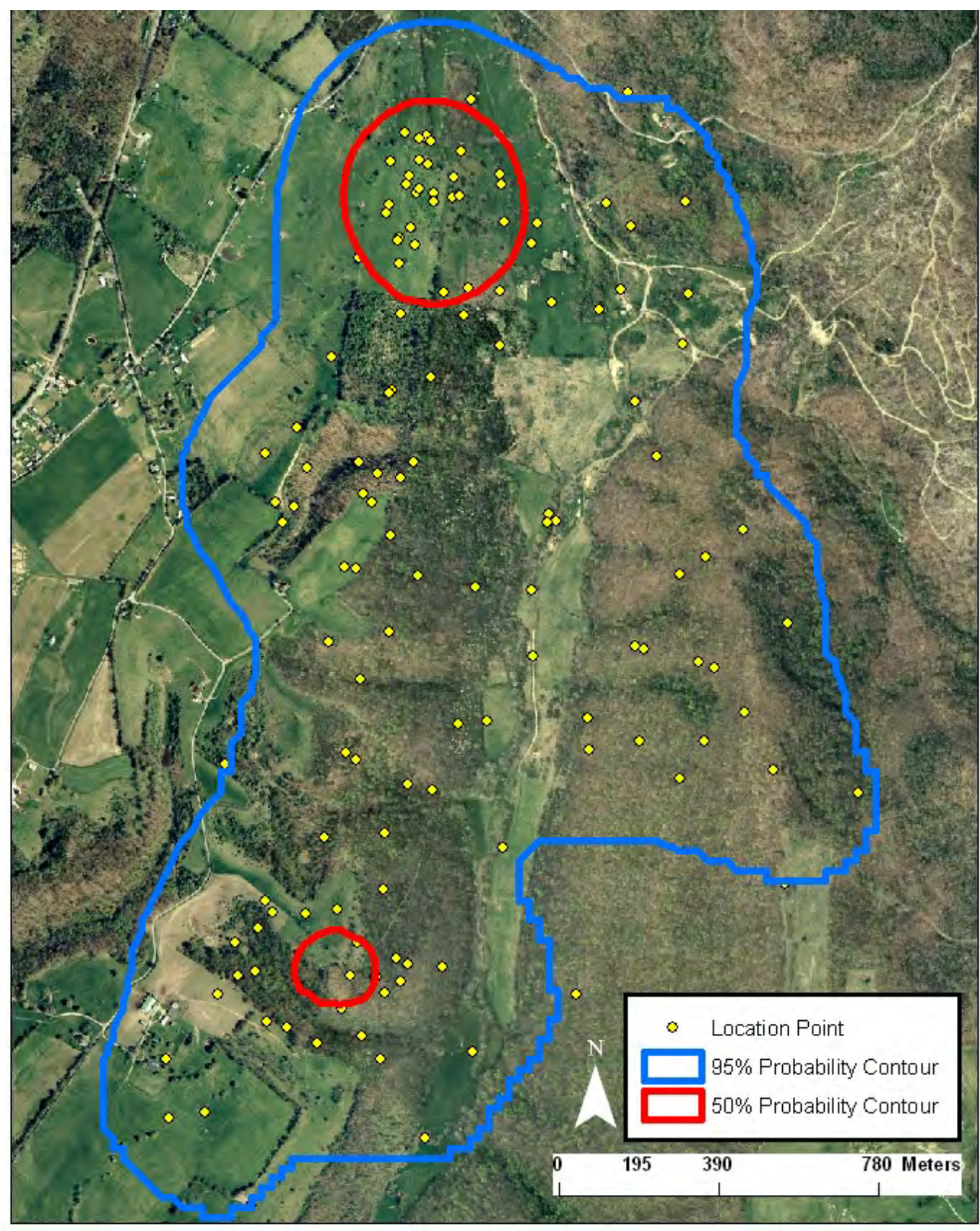


Appendix CXVIa. RG5401 (adult) - 95\% probability contours of the spring, fall, and winter fixed kernel home range utilization distribution. Smoothing parameter (h) determined by least squares cross validation, Greenbrier County, West Virginia, 2004-2007 (2003 SAMB imagery).

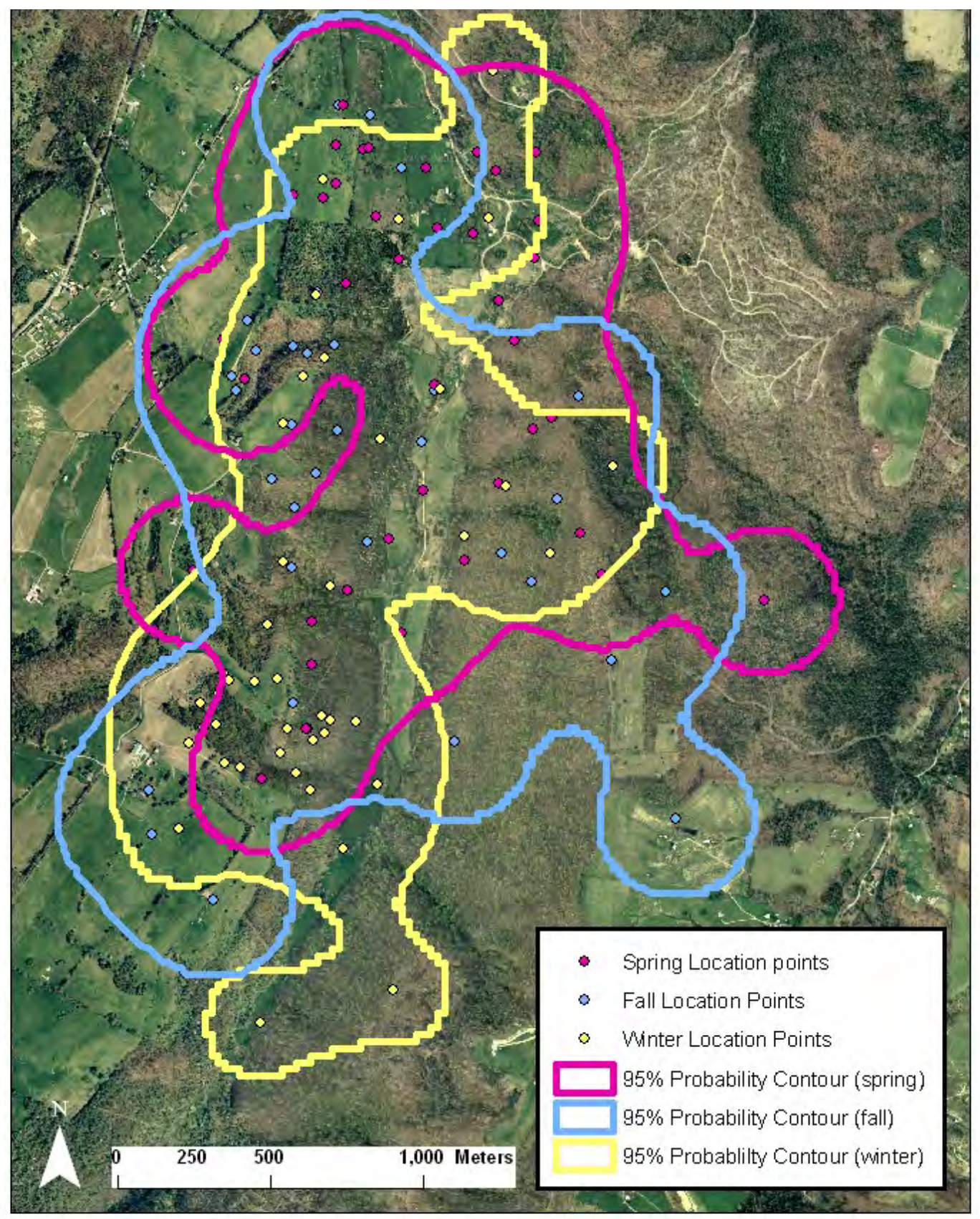


Appendix CXVIIa. RG5401 (adult) - 95\% probability contours of the spring-summer and fall-winter fixed kernel home range utilization distribution. Smoothing parameter (h) determined by least squares cross validation, Greenbrier County, West Virginia, 2004-2007 (2003 SAMB imagery).

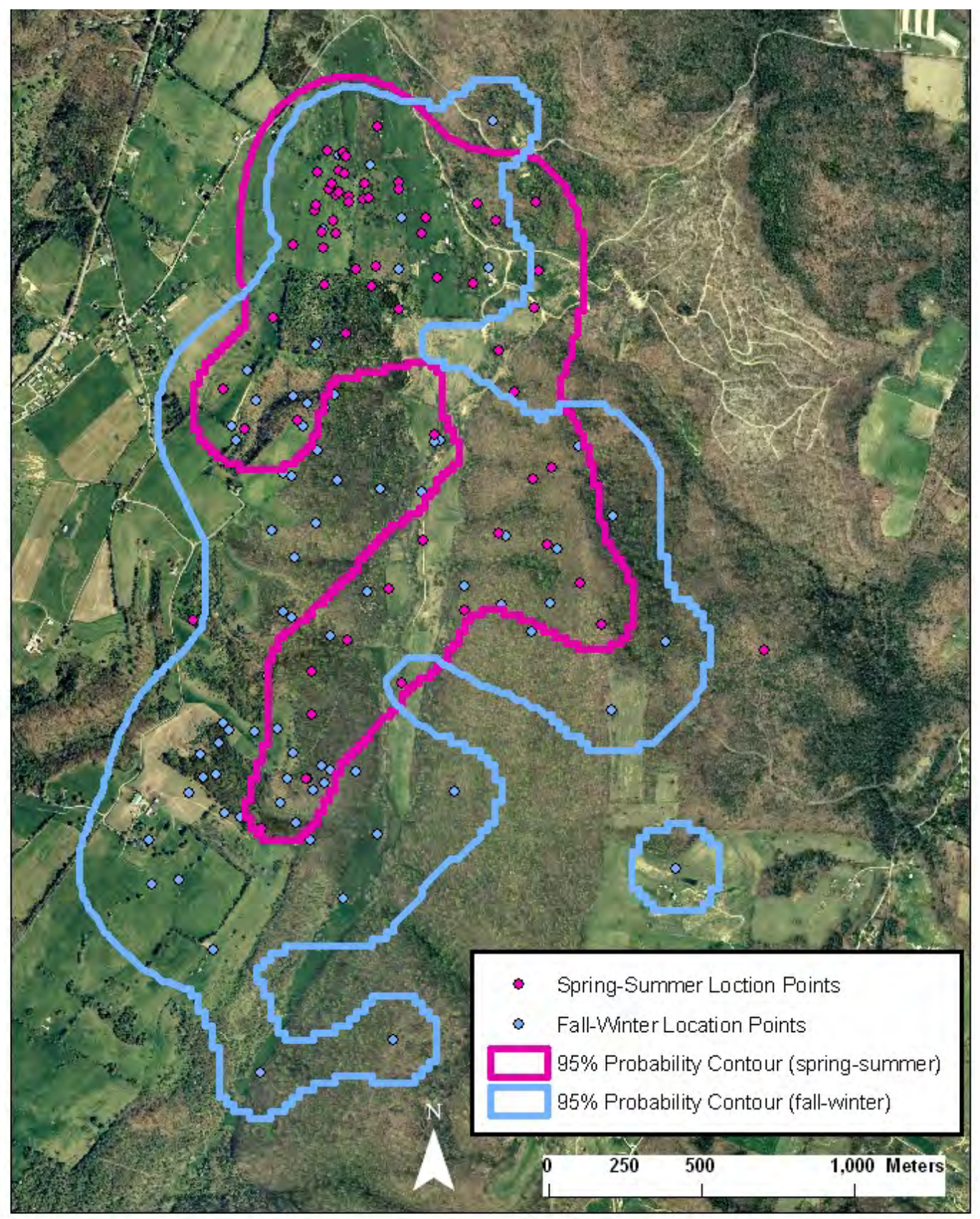


Appendix CXVIII $a$. RG5402 (adult) - 50\% and 95\% probability contours of the annual fixed kernel home range utilization distribution. Smoothing parameter (h) determined by least squares cross validation, Greenbrier County, West Virginia, 2004-2006 (100k topo map).

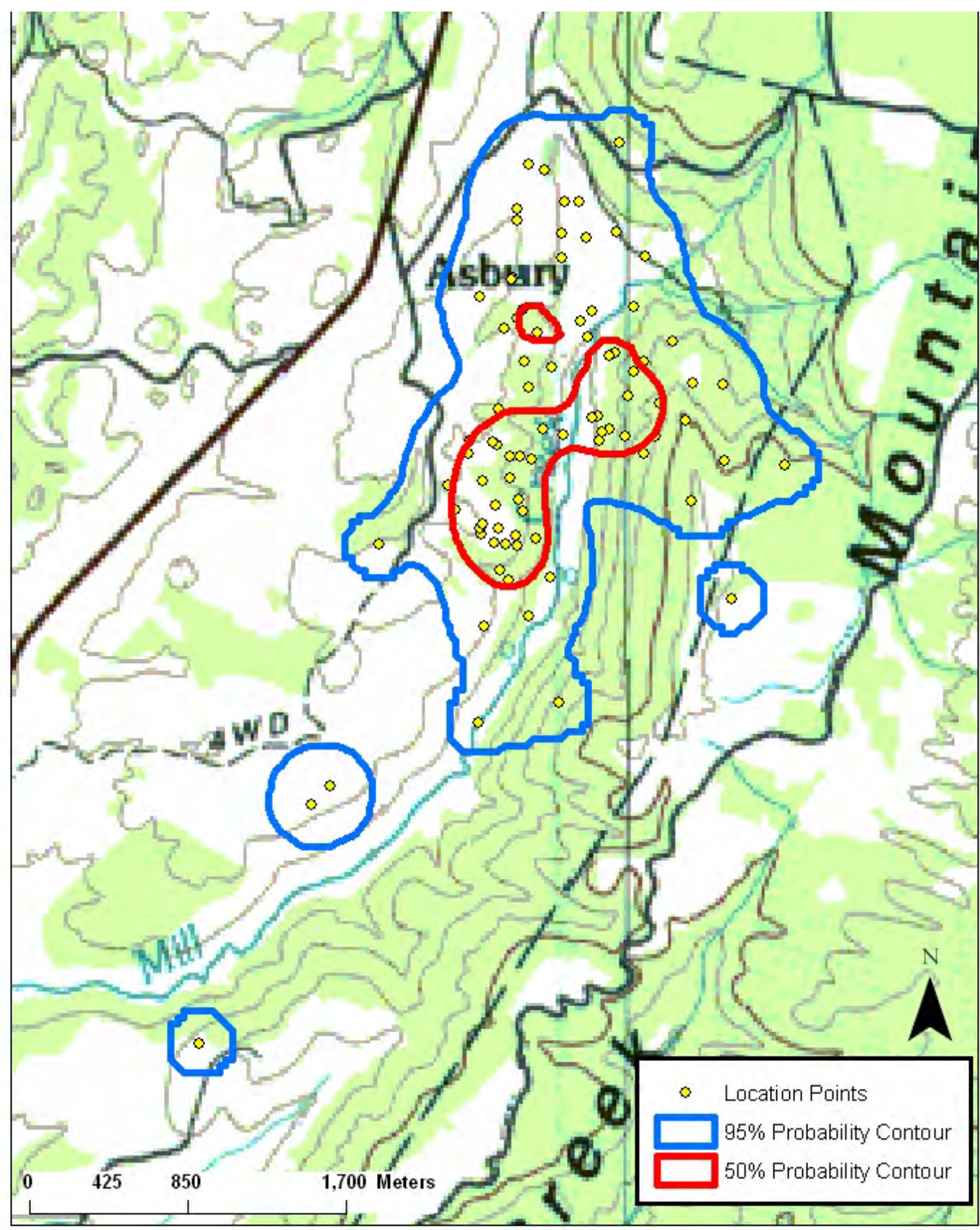


Appendix CXIXa. RG5402 (adult) - 50\% and 95\% probability contours of the annual fixed kernel home range utilization distribution. Smoothing parameter (h) determined by least squares cross validation, Greenbrier County, West Virginia, 2004-2006 (2003 SAMB imagery).

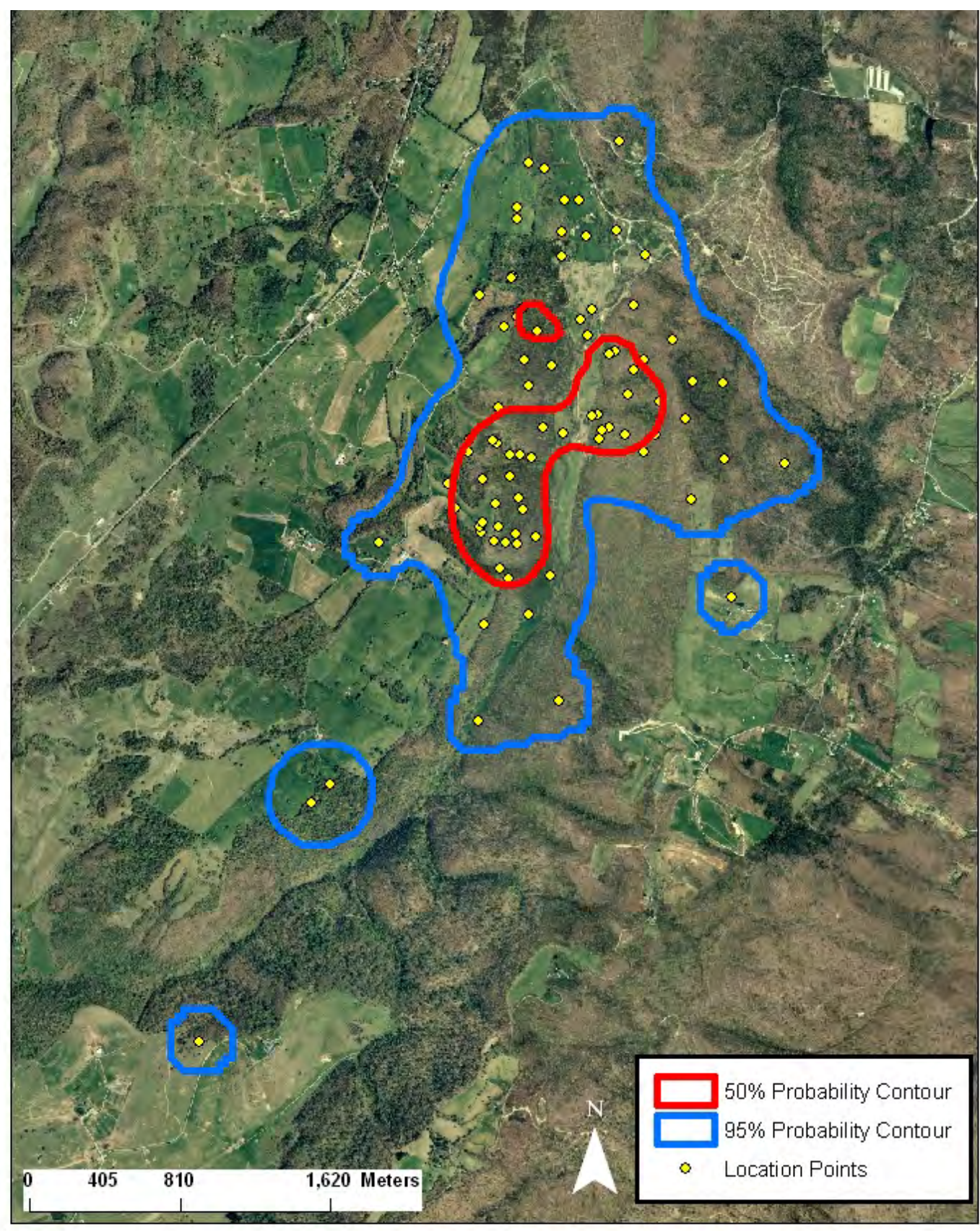


Appendix CXXa. RG5402 (adult) - 95\% probability contours of the spring-summer and fall-winter fixed kernel home range utilization distribution. Smoothing parameter (h) determined by least squares cross validation, Greenbrier County, West Virginia, 2004-2006 (2003 SAMB imagery).

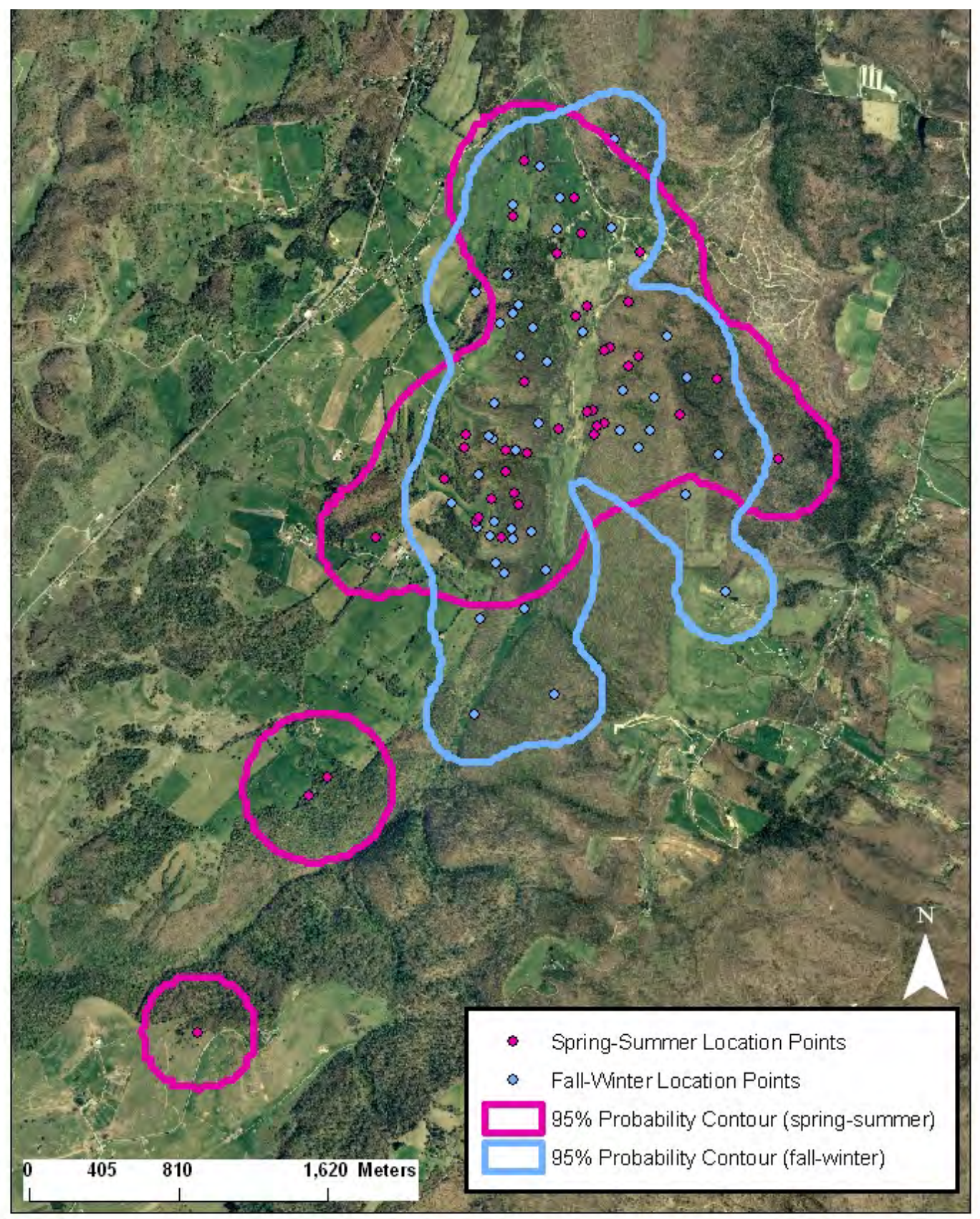


Appendix CXXIa. RG5403 (adult) - 50\% and 95\% probability contours of the annual fixed kernel home range utilization distribution. Smoothing parameter (h) determined by least squares cross validation, Greenbrier County, West Virginia, 2004-2005 (100k topo map).

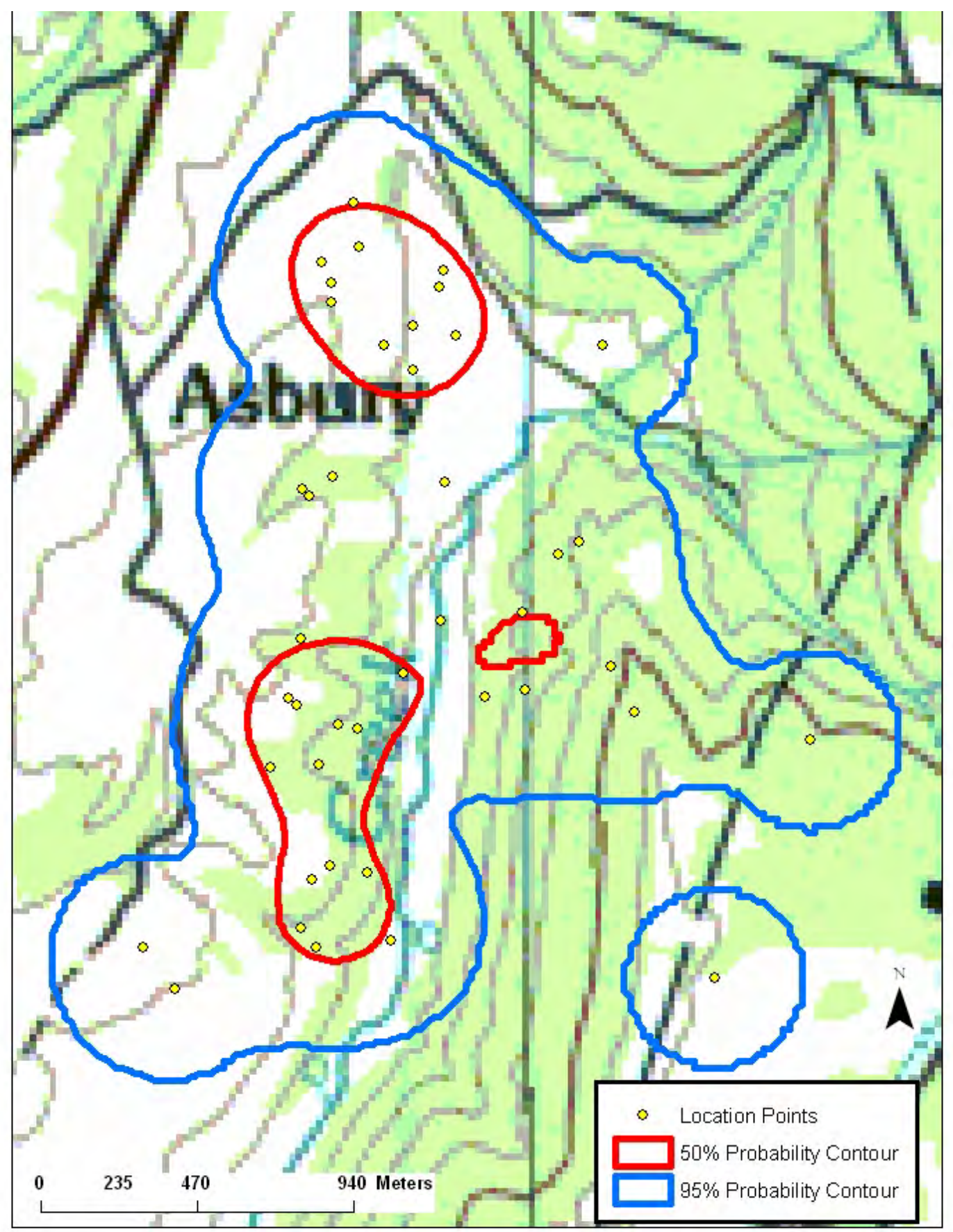


Appendix CXXIIa. RG5403 (adult) - 50\% and 95\% probability contours of the annual fixed kernel home range utilization distribution. Smoothing parameter (h) determined by least squares cross validation, Greenbrier County, West Virginia, 2004-2005 (2003 SAMB imagery).

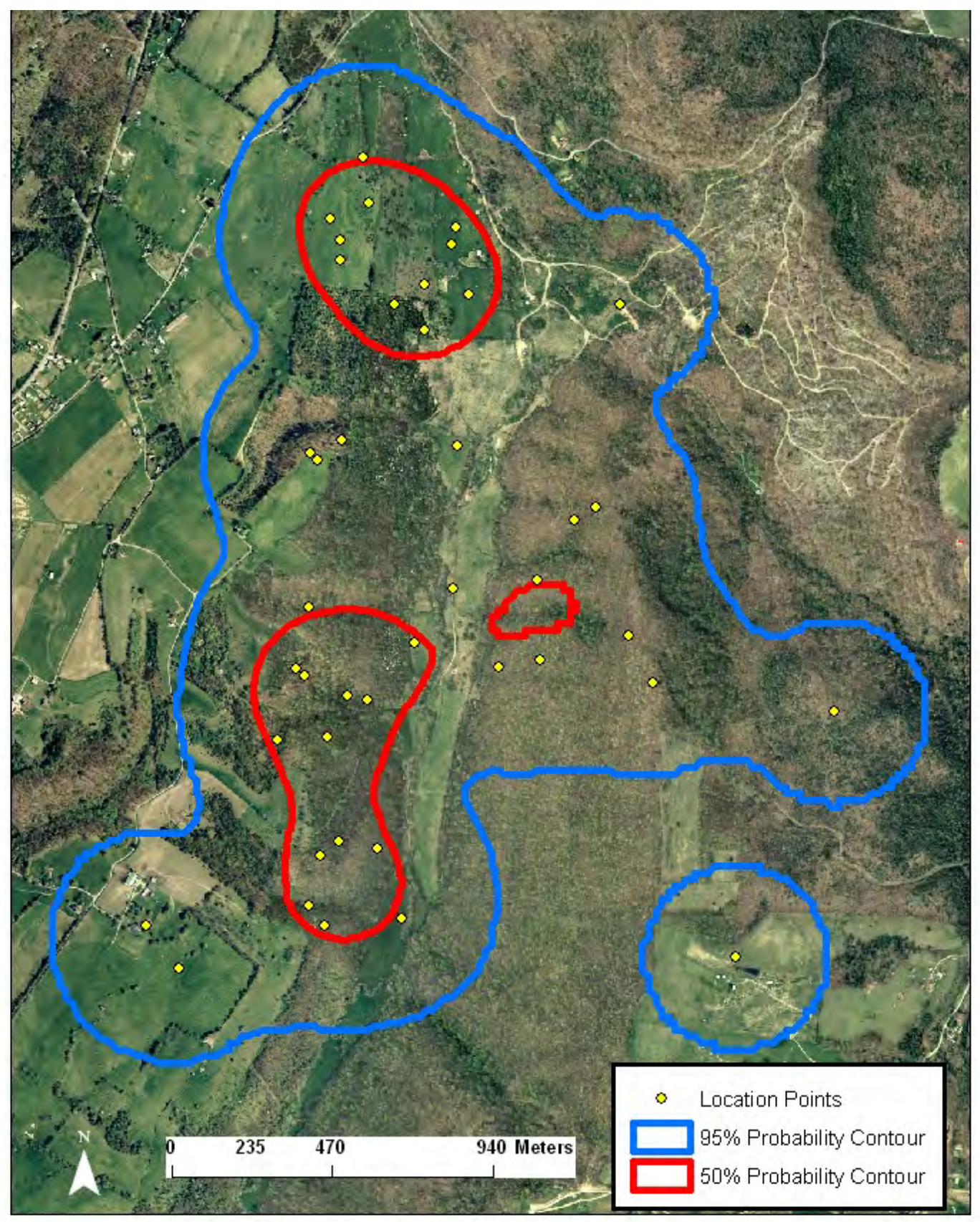


Appendix CXXIII $a$. RG5407 (adult) - 50\% and 95\% probability contours of the annual fixed kernel home range utilization distribution. Smoothing parameter (h) determined by least squares cross validation, Summers County, West Virginia, 2005-2006 (100k topo map).

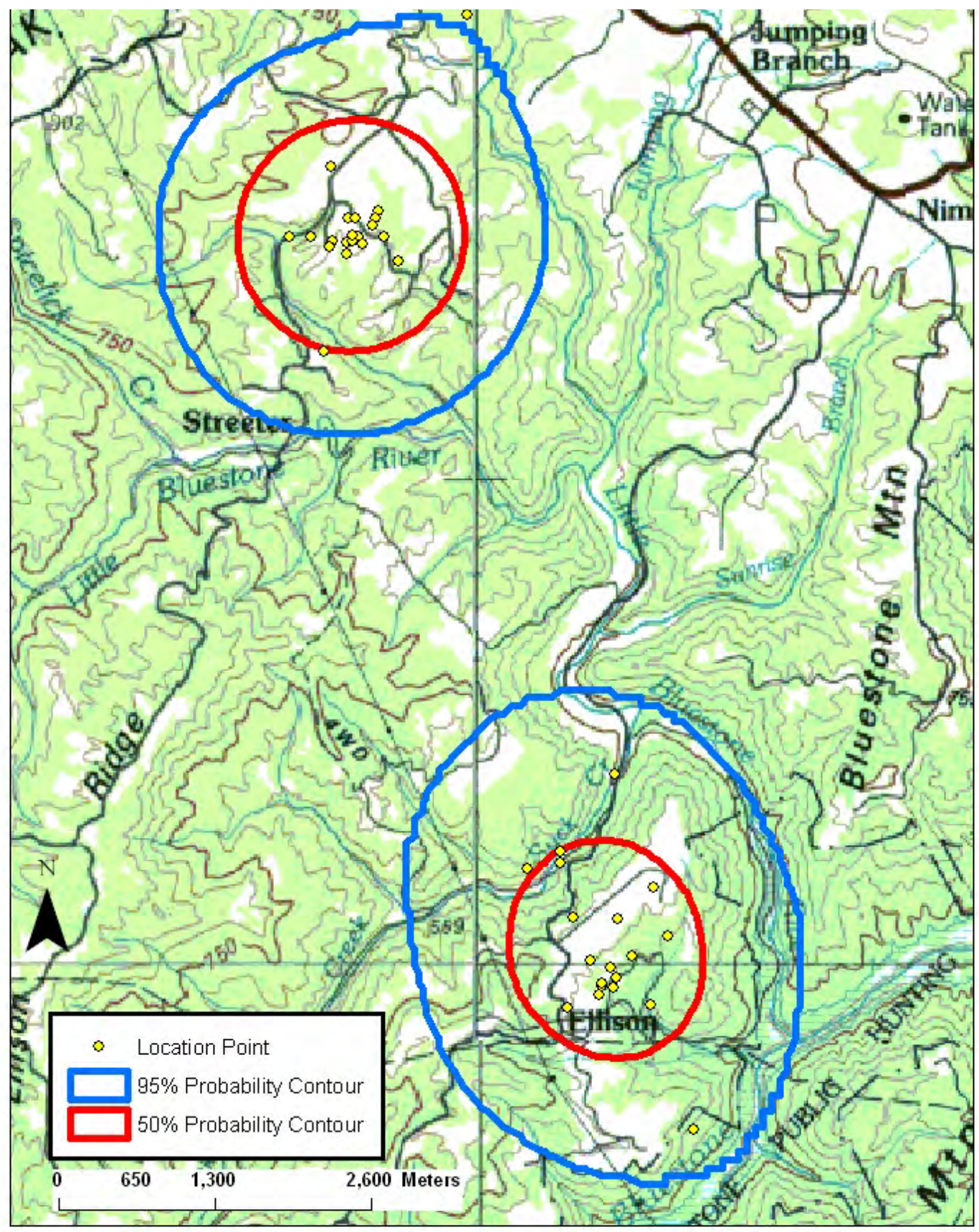


Appendix CXXIVa. RG5407 (adult) - 50\% and 95\% probability contours of the annual fixed kernel home range utilization distribution. Smoothing parameter (h) determined by least squares cross validation, Summers County, West Virginia, 2005-2006 (2003 SAMB imagery).

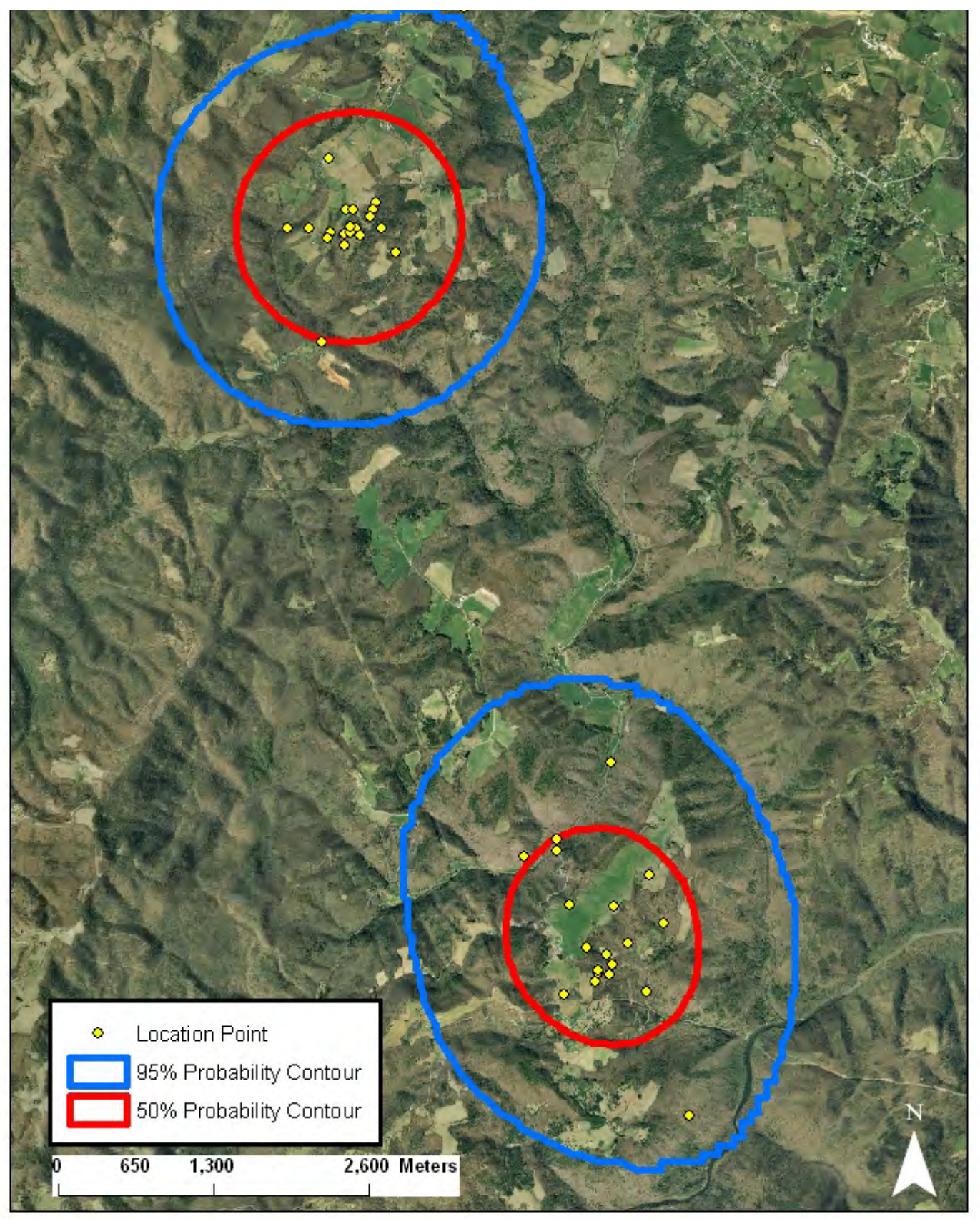


Appendix CXXVa. RG5409 (adult) - 50\% and 95\% probability contours of the annual fixed kernel home range utilization distribution. Smoothing parameter (h) determined by least squares cross validation, Summers County, West Virginia, 2005-2007 (100k topo map).

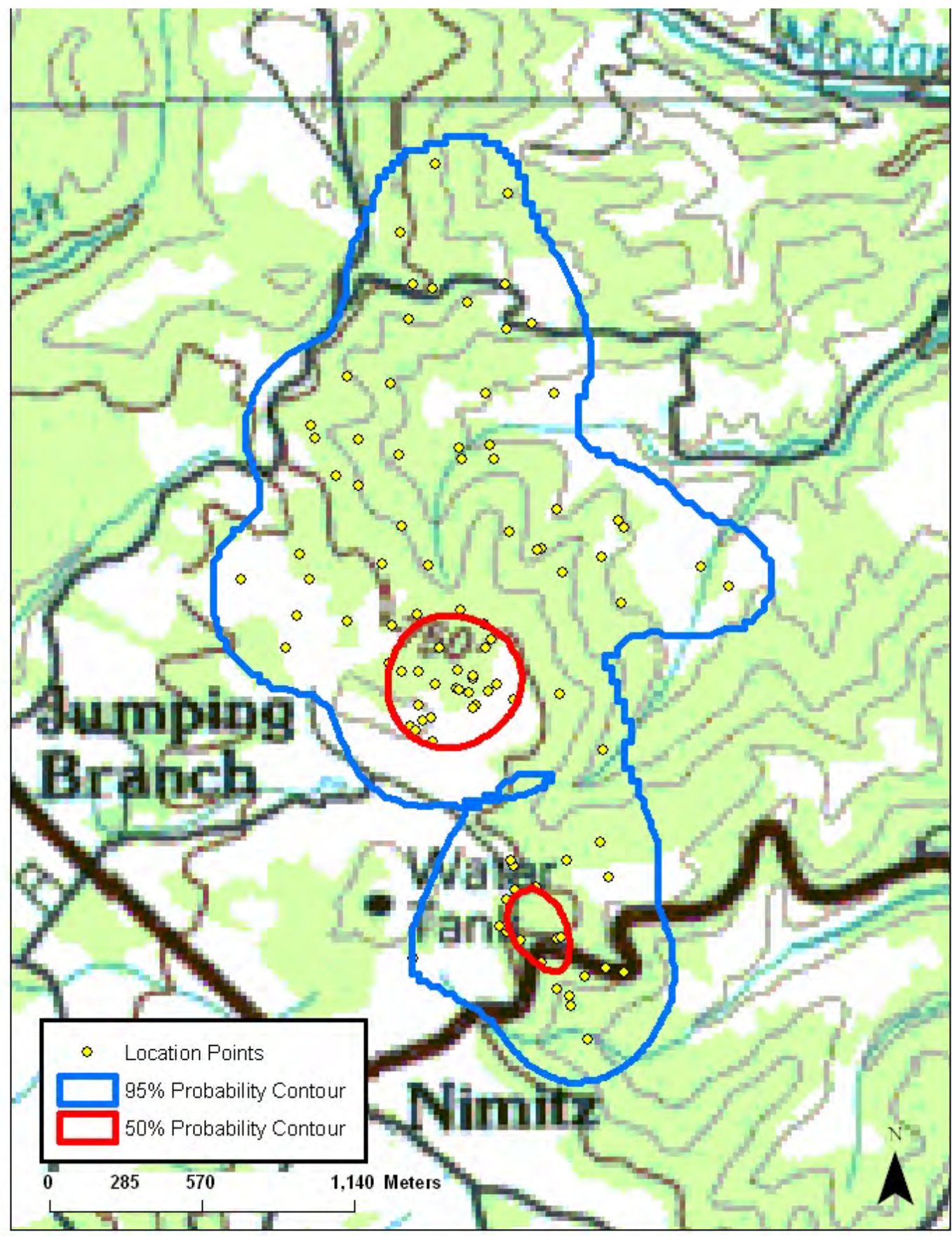


AppendixCXXVI $a$. RG5409 (adult) - 50\% and 95\% probability contours of the annual fixed kernel home range utilization distribution. Smoothing parameter (h) determined by least squares cross validation, Summers County, West Virginia, 2005-2007 (2003 SAMB imagery).

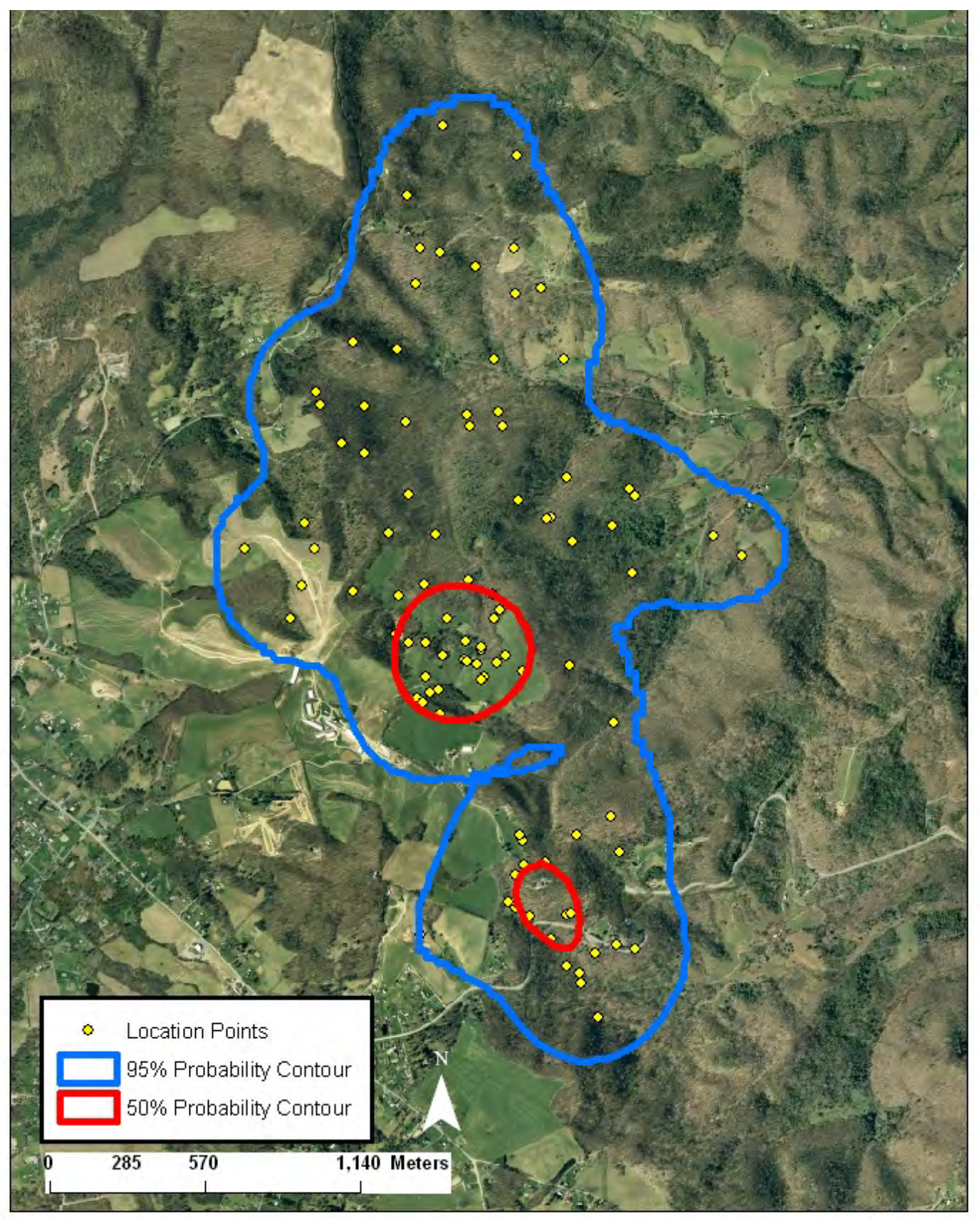


Appendix CXXVIIa. RG5409 (adult) - 95\% probability contours of the spring-summer and fall-winter fixed kernel home range utilization distribution. Smoothing parameter (h) determined by least squares cross validation, Summers County, West Virginia, 2005-2007 (2003 SAMB imagery).

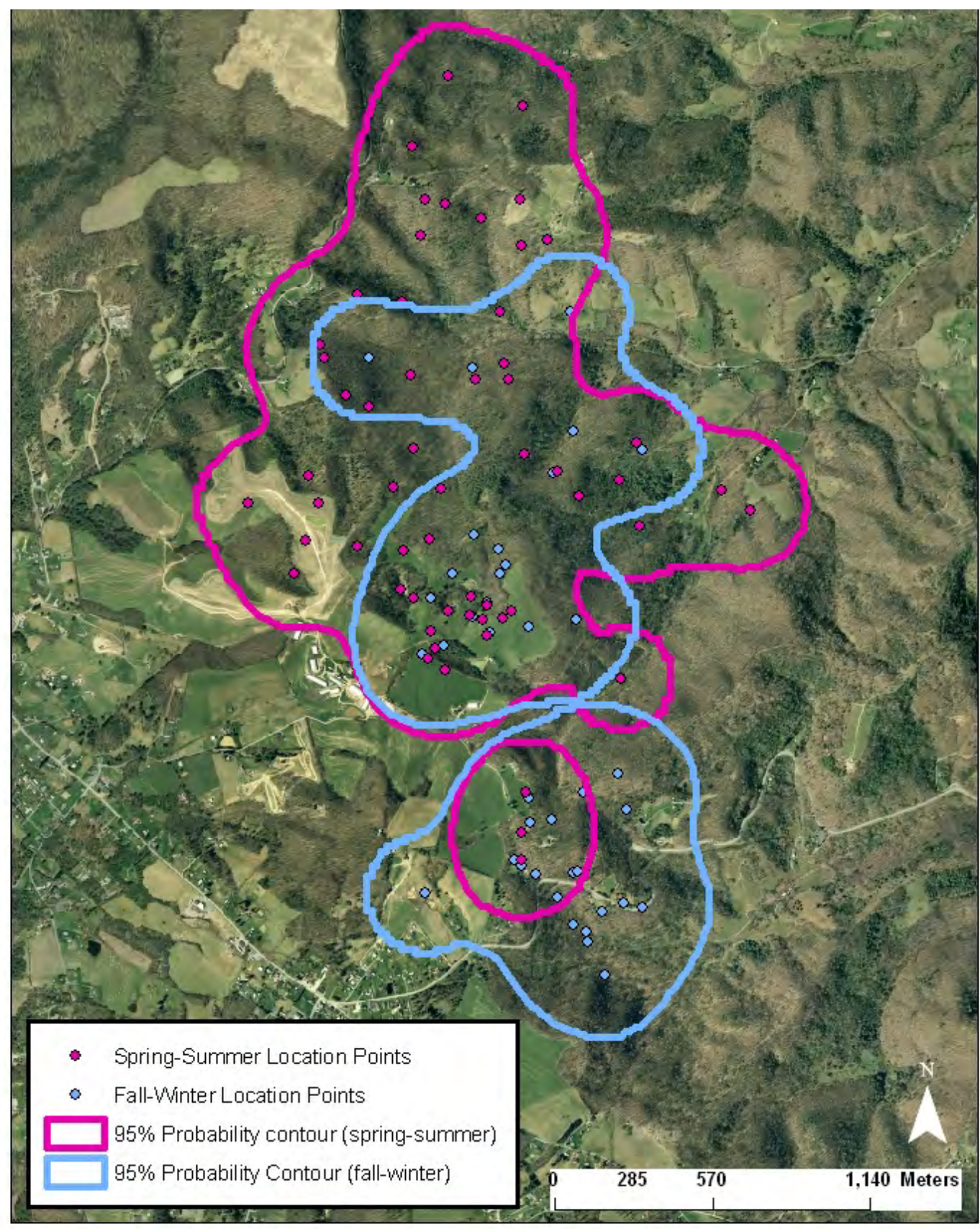


Appendix CXXVIIIa. RG5410 (adult) - 50\% and 95\% probability contours of the annual fixed kernel home range utilization distribution. Smoothing parameter (h) determined by least squares cross validation, Summers County, West Virginia, 2005-2006 (100k topo map).

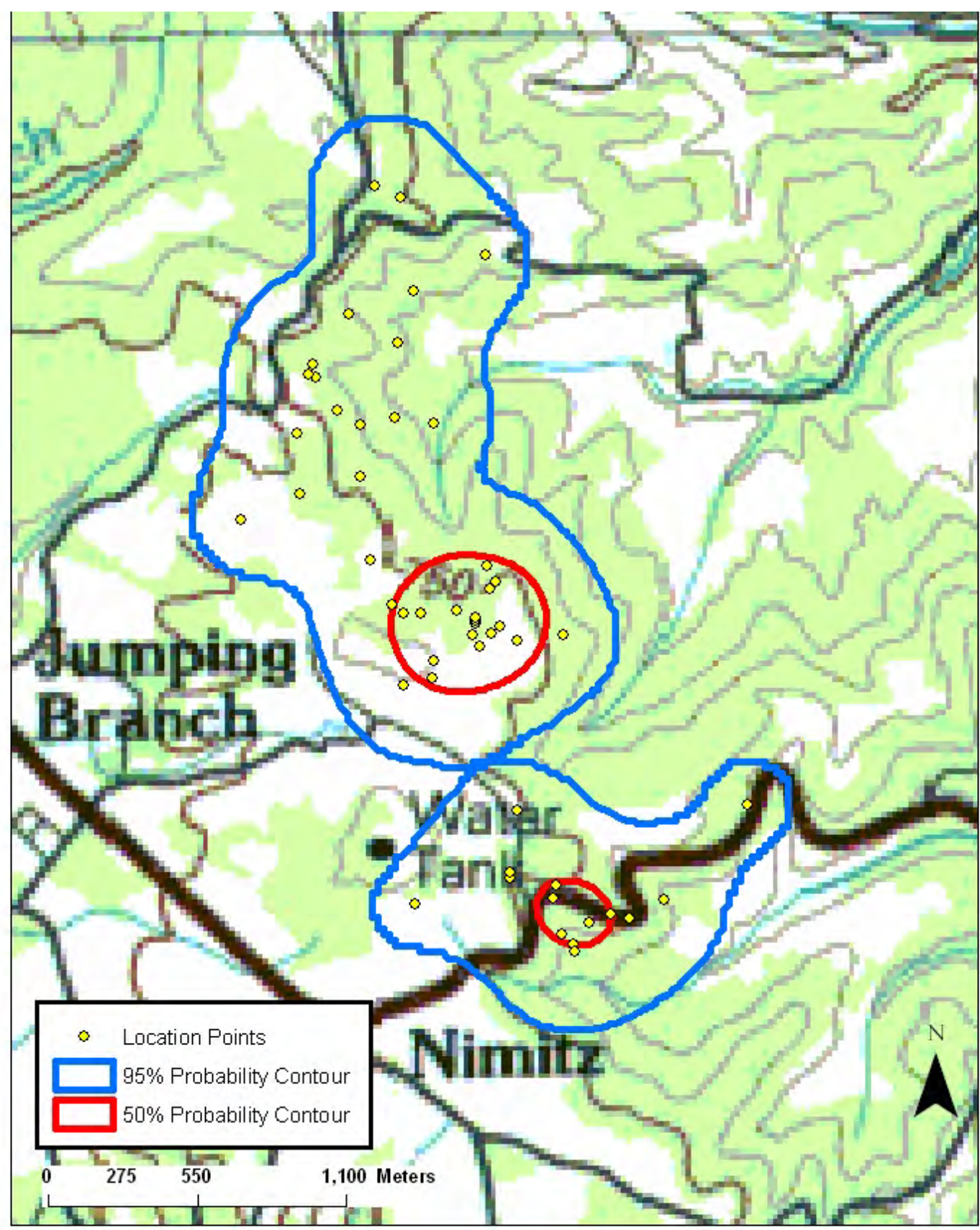


Appendix CXXIXa. RG5410 (adult) - 50\% and 95\% probability contours of the annual fixed kernel home range utilization distribution. Smoothing parameter (h) determined by least squares cross validation, Summers County, West Virginia, 2005-2006 (2003 SAMB imagery).

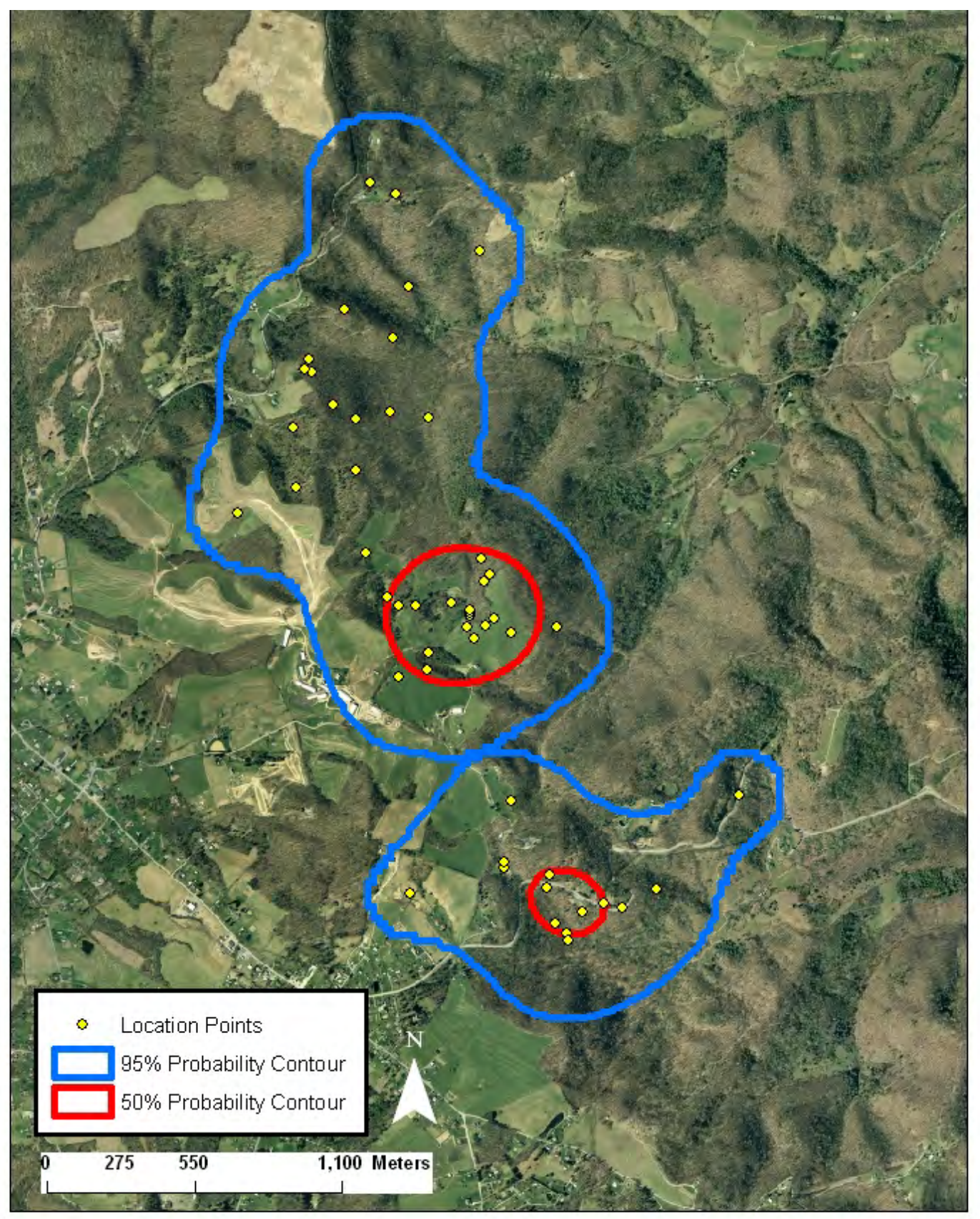


Appendix CXXXa. RG5414 (adult) - 50\% and 95\% probability contours of the annual fixed kernel home range utilization distribution. Smoothing parameter (h) determined by least squares cross validation, Summers County, West Virginia, 2006-2007 (100k topo map).

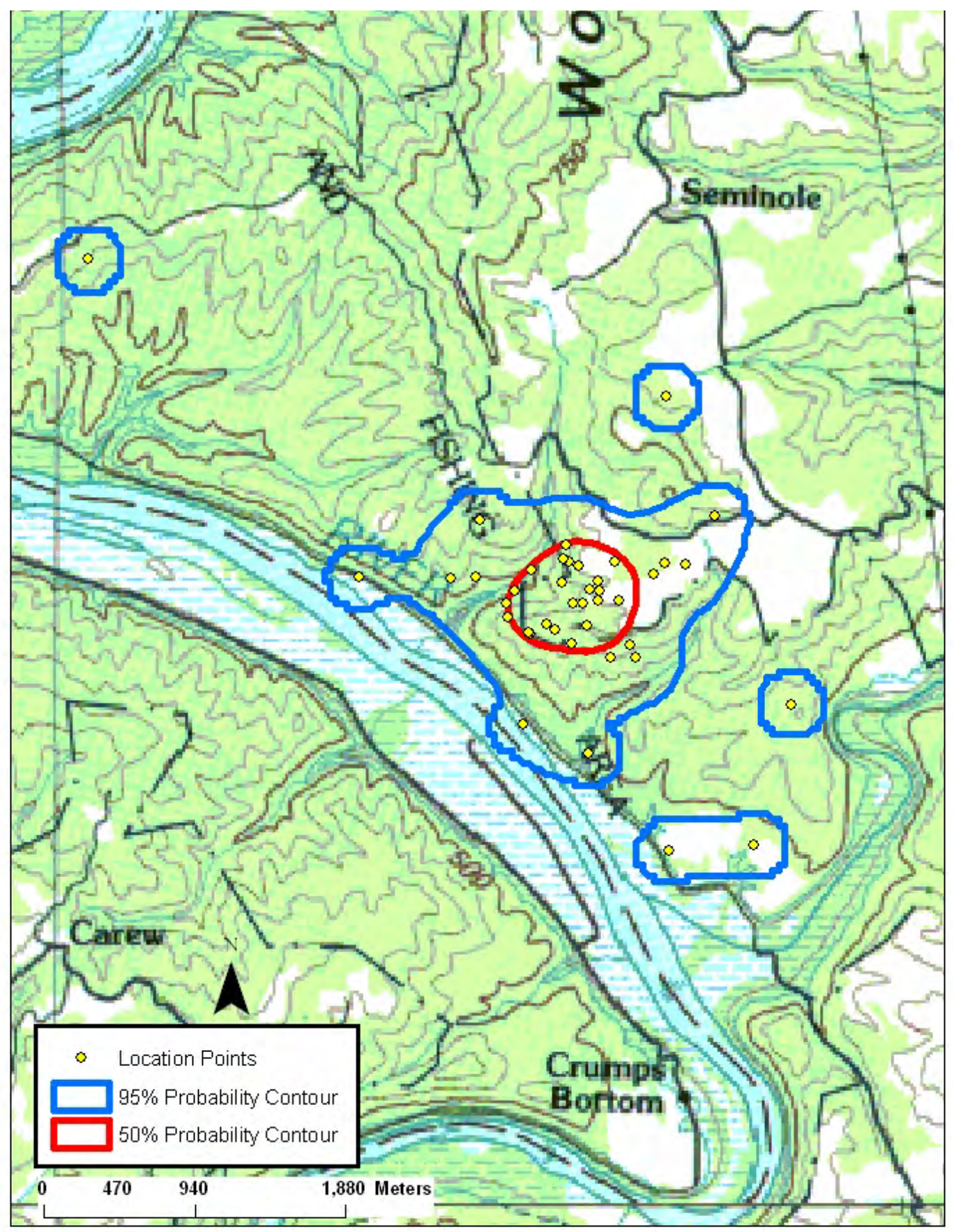


Appendix CXXXIa. RG5414 (adult) - 50\% and 95\% probability contours of the annual fixed kernel home range utilization distribution. Smoothing parameter (h) determined by least squares cross validation, Summers County, West Virginia, 2006-2007 (2003 SAMB imagery).

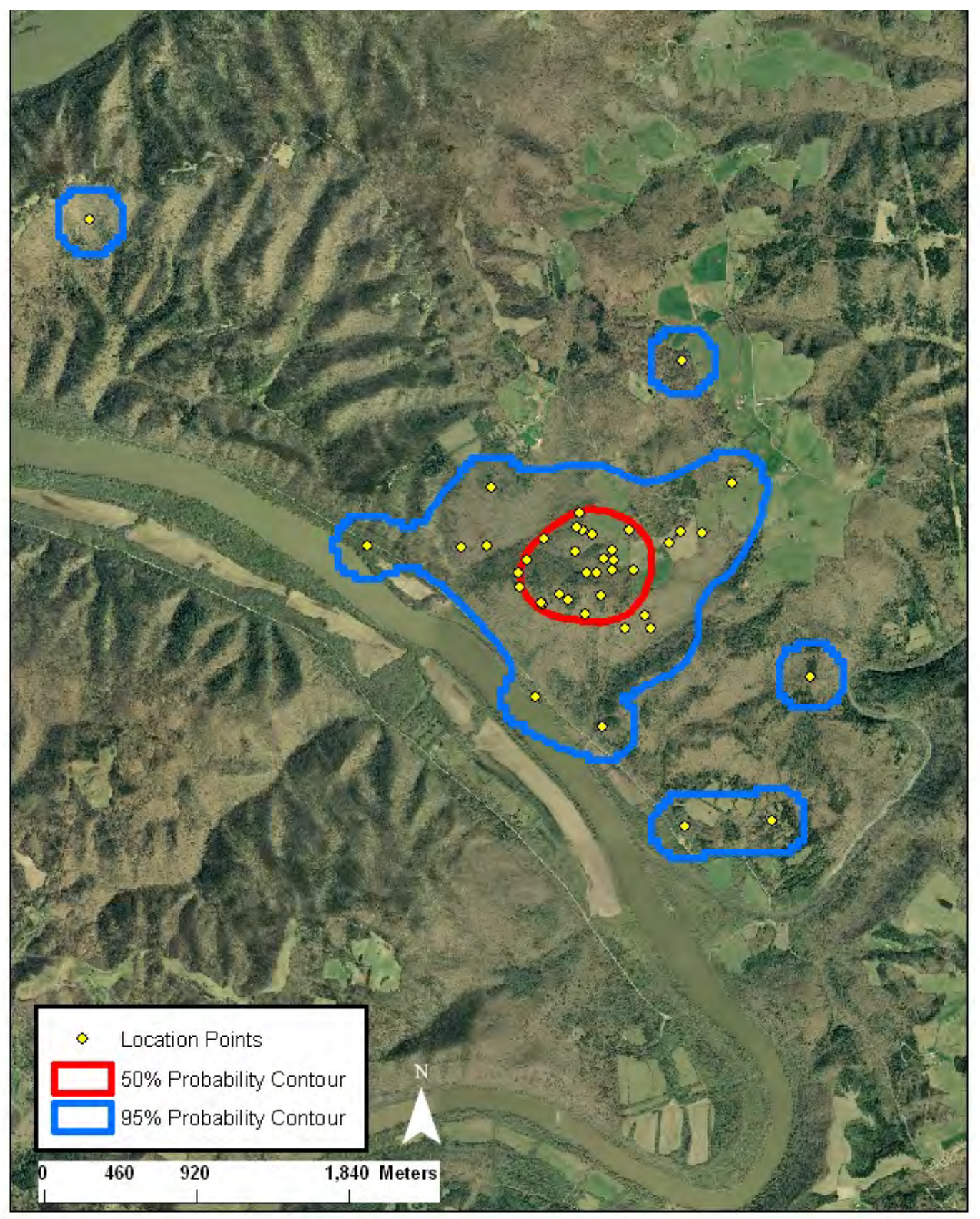


Appendix CXXXIIa. RG5415 (adult) - 50\% and 95\% probability contours of the annual fixed kernel home range utilization distribution. Smoothing parameter (h) determined by least squares cross validation, Summers County, West Virginia, 2006-2007 (100k topo map).

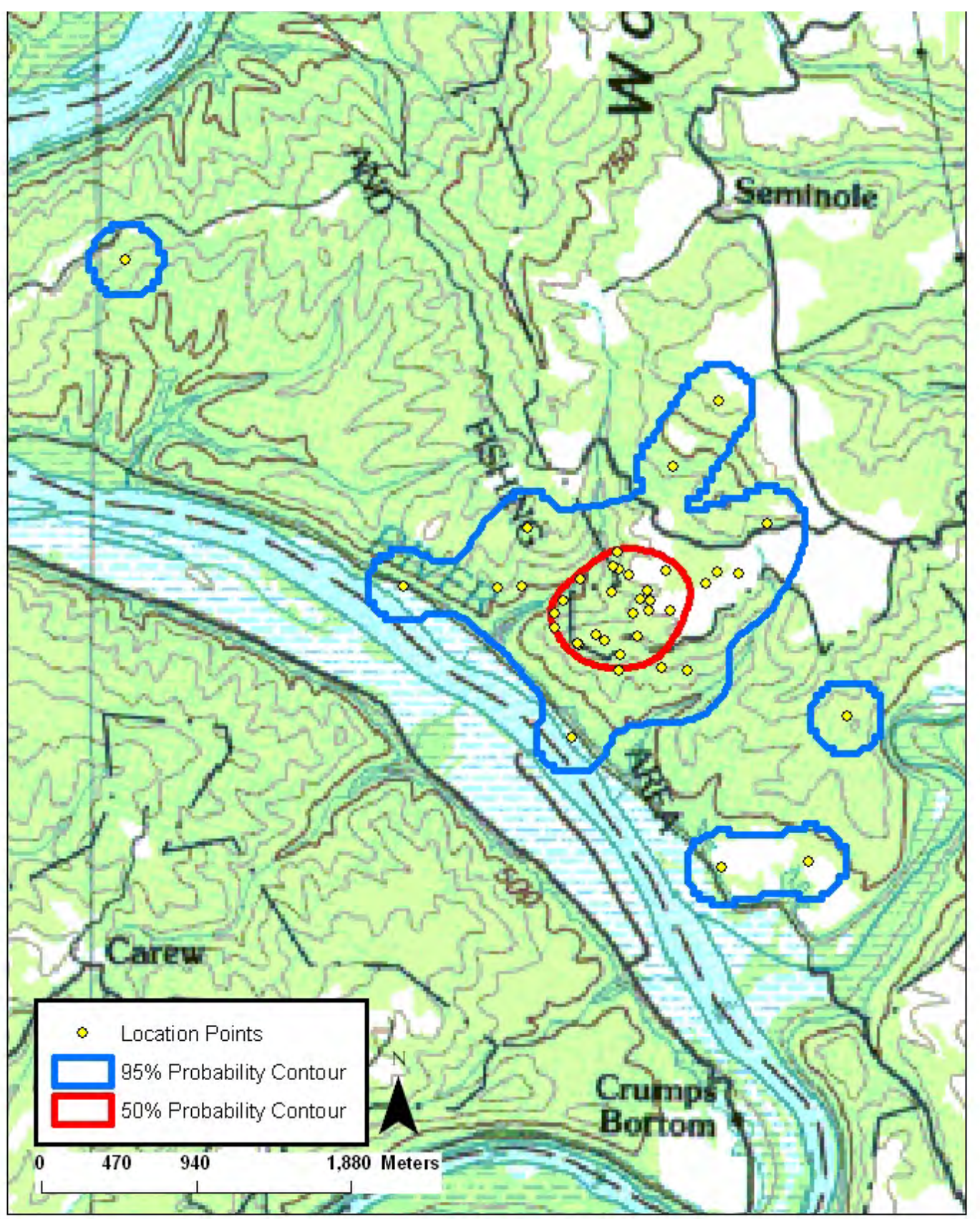


Appendix CXXXIIIa. RG5415 (adult) - 50\% and 95\% probability contours of the annual fixed kernel home range utilization distribution. Smoothing parameter (h) determined by least squares cross validation, Summers County, West Virginia, 2006-2007 (2003 SAMB imagery).

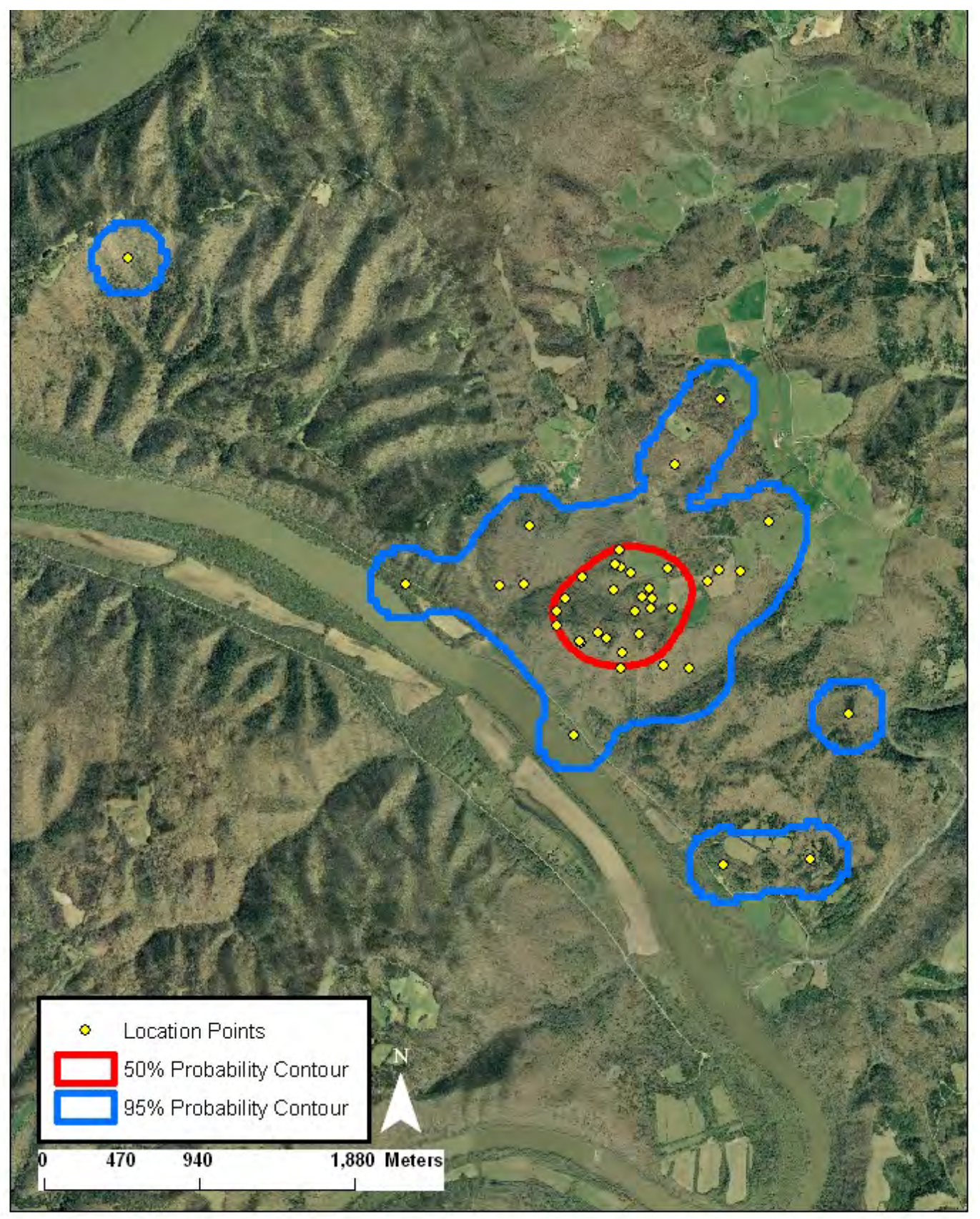


Appendix CXXXIVa. RG5416 (adult) - 50\% and 95\% probability contours of the annual fixed kernel home range utilization distribution. Smoothing parameter (h) determined by least squares cross validation, Summers County, West Virginia, 2006-2007 (100k topo map).

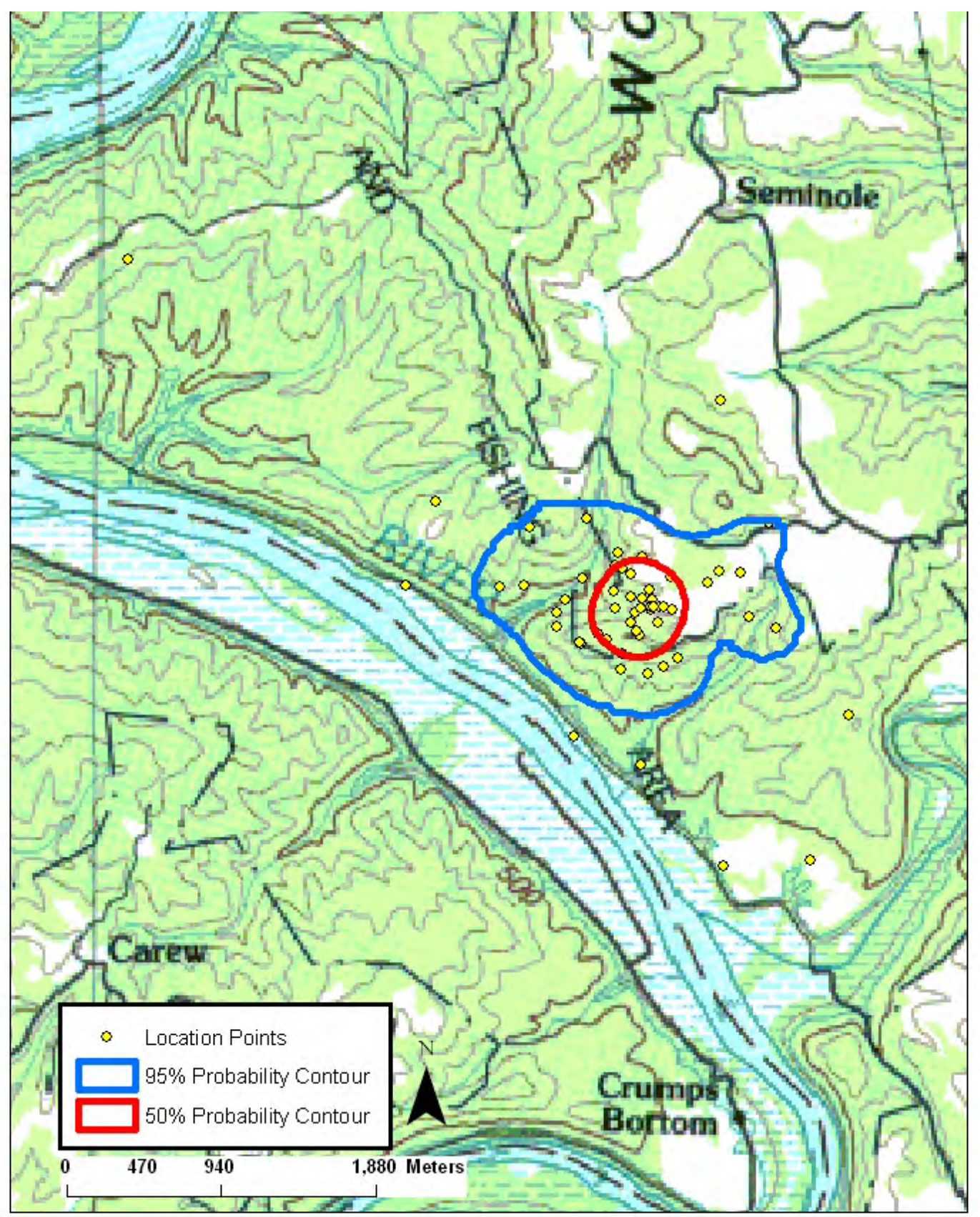


Appendix CXXXVa. RG5416 (adult) - 50\% and 95\% probability contours of the annual fixed kernel home range utilization distribution. Smoothing parameter (h) determined by least squares cross validation, Summers County, West Virginia, 2006-2007 (2003 SAMB imagery).

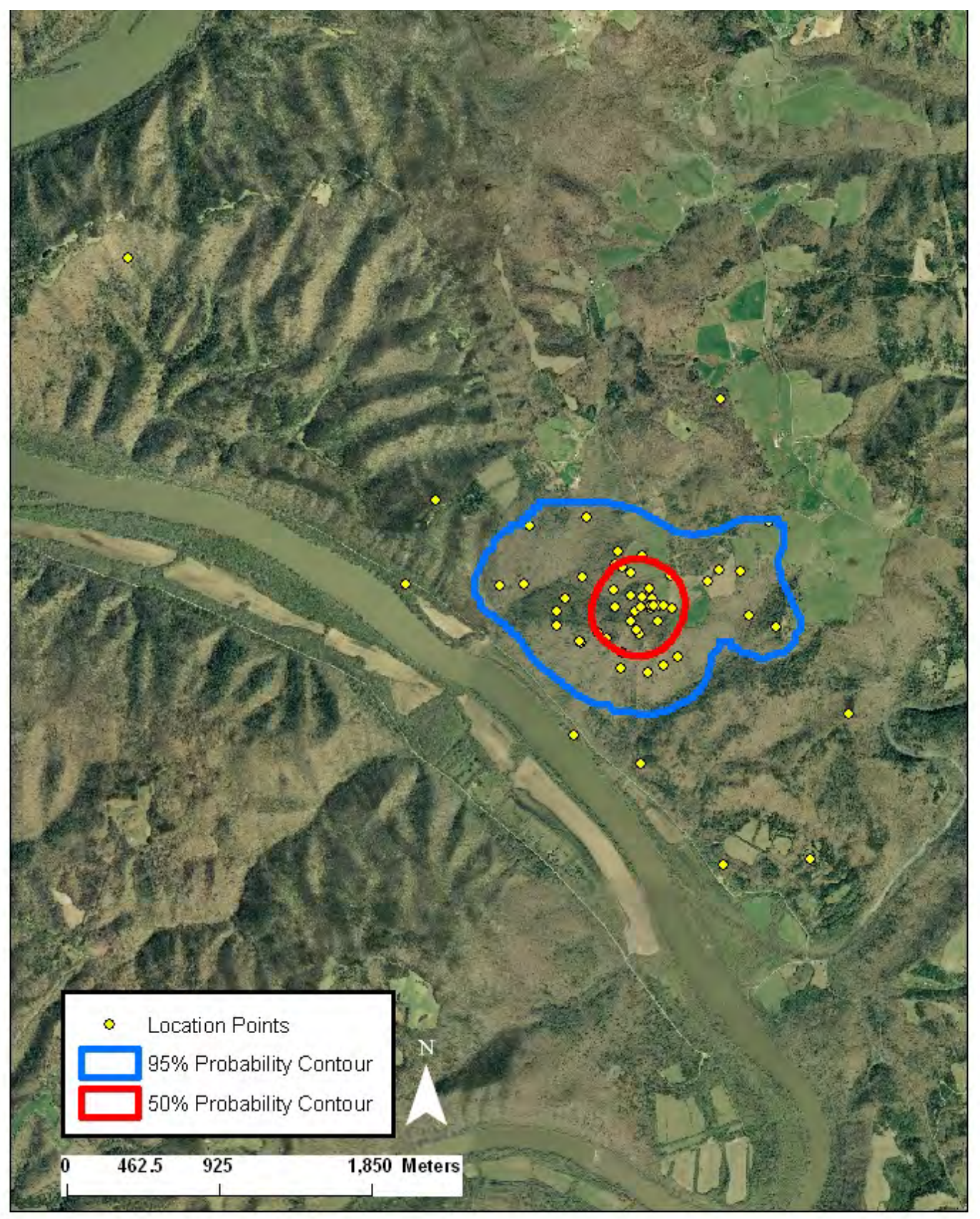


Appendix CXXXVIa. RG5416 (adult) - 95\% probability contour of the spring-summer fixed kernel home range utilization distribution. Smoothing parameter (h) determined by least squares cross validation, Summers County, West Virginia, 2006-2007 (2003 SAMB imagery).

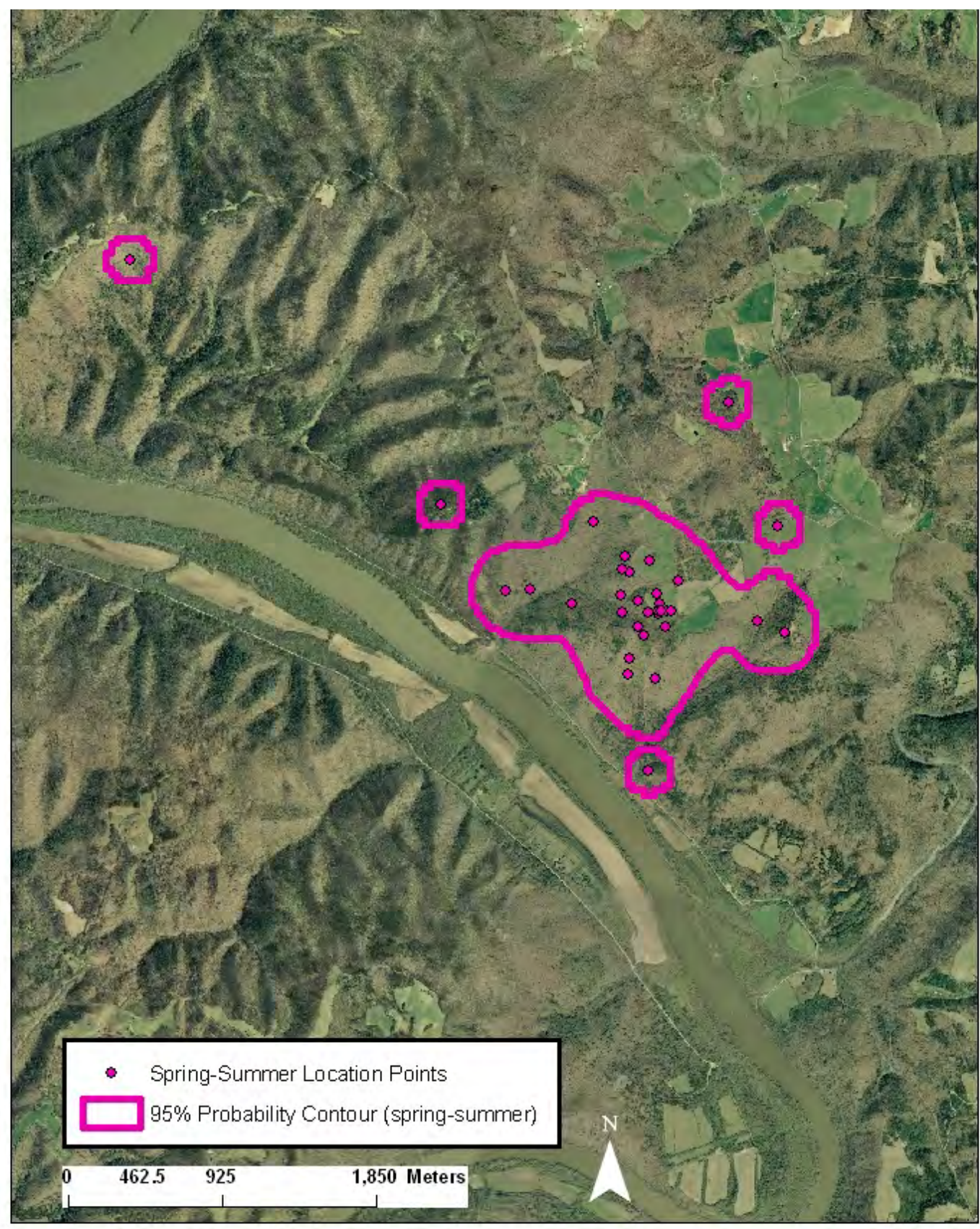


Appendix CXXXVIIa. RG5501 (adult) - 50\% and 95\% probability contours of the annual fixed kernel home range utilization distribution. Smoothing parameter (h) determined by least squares cross validation, Lincoln County, West Virginia, 2004-2006 (100k topo map).

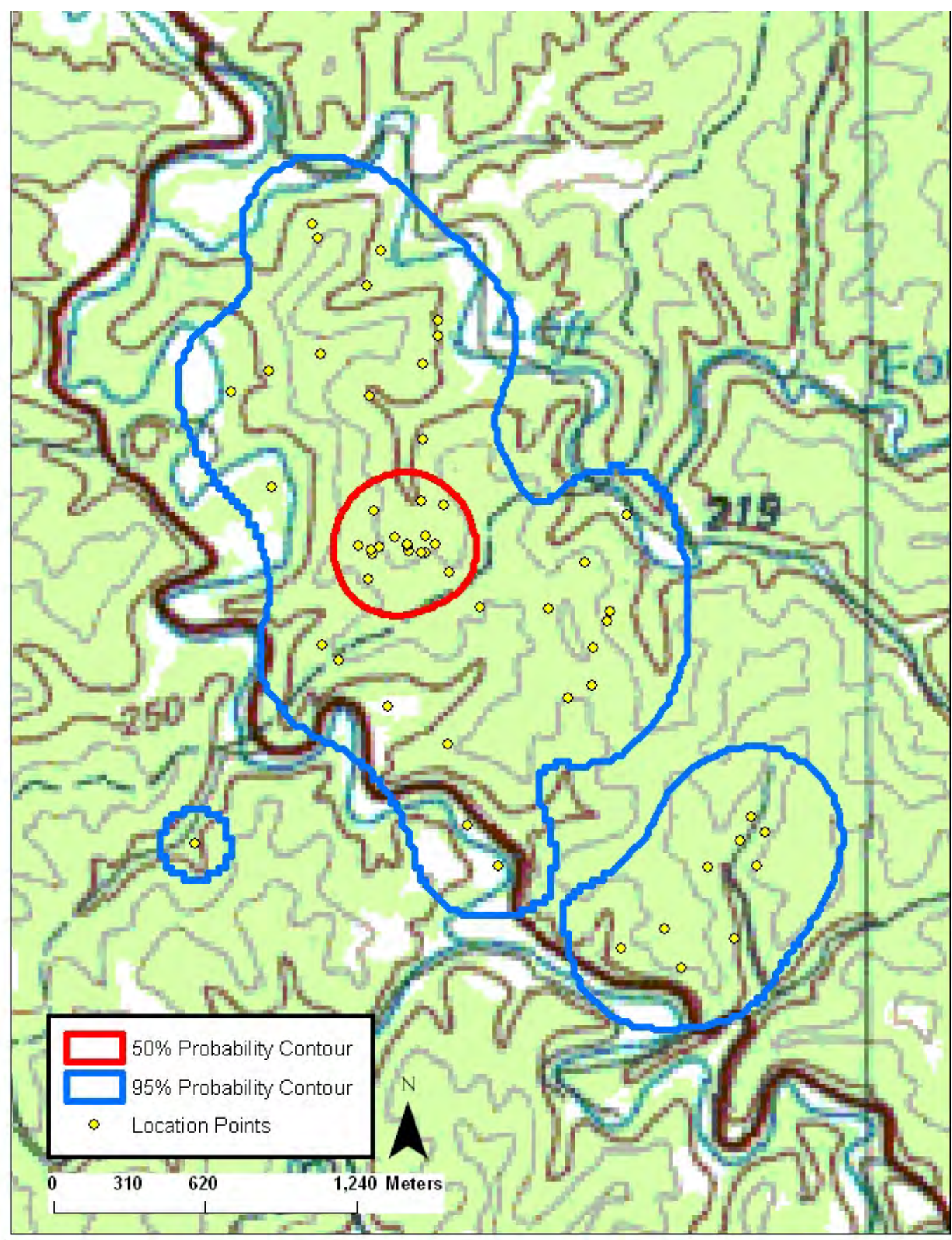


Appendix CXXXVIIIa. RG5501 (adult) - 50\% and 95\% probability contours of the annual fixed kernel home range utilization distribution. Smoothing parameter (h) determined by least squares cross validation, Lincoln County, West Virginia, 2004-2006 (2003 SAMB imagery).

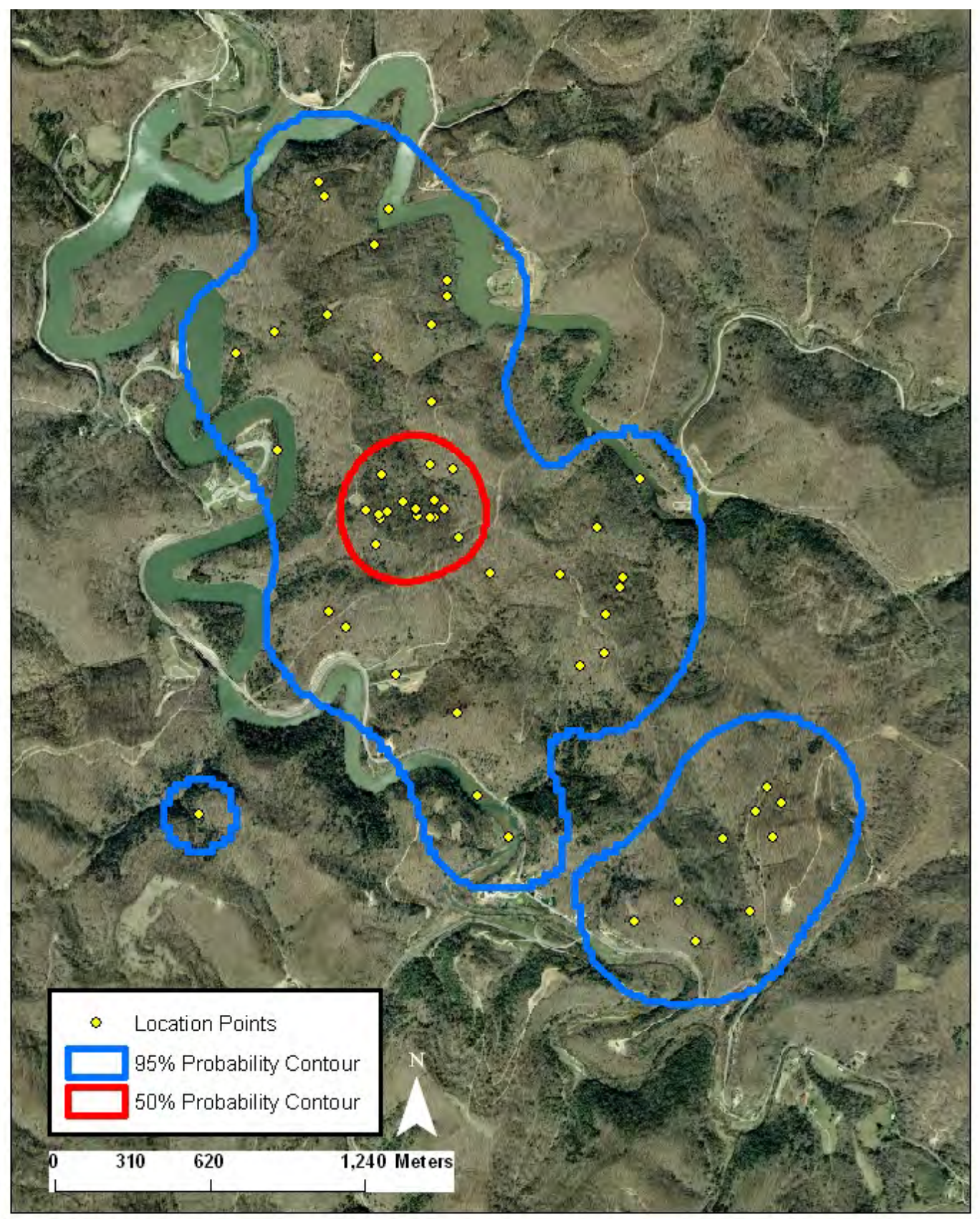


Appendix CXXXIXa. RG5501 (adult) - 95\% probability contour of the fall-winter fixed kernel home range utilization distribution. Smoothing parameter (h) determined by least squares cross validation, Lincoln County, West Virginia, 2004-2006 (2003 SAMB imagery).

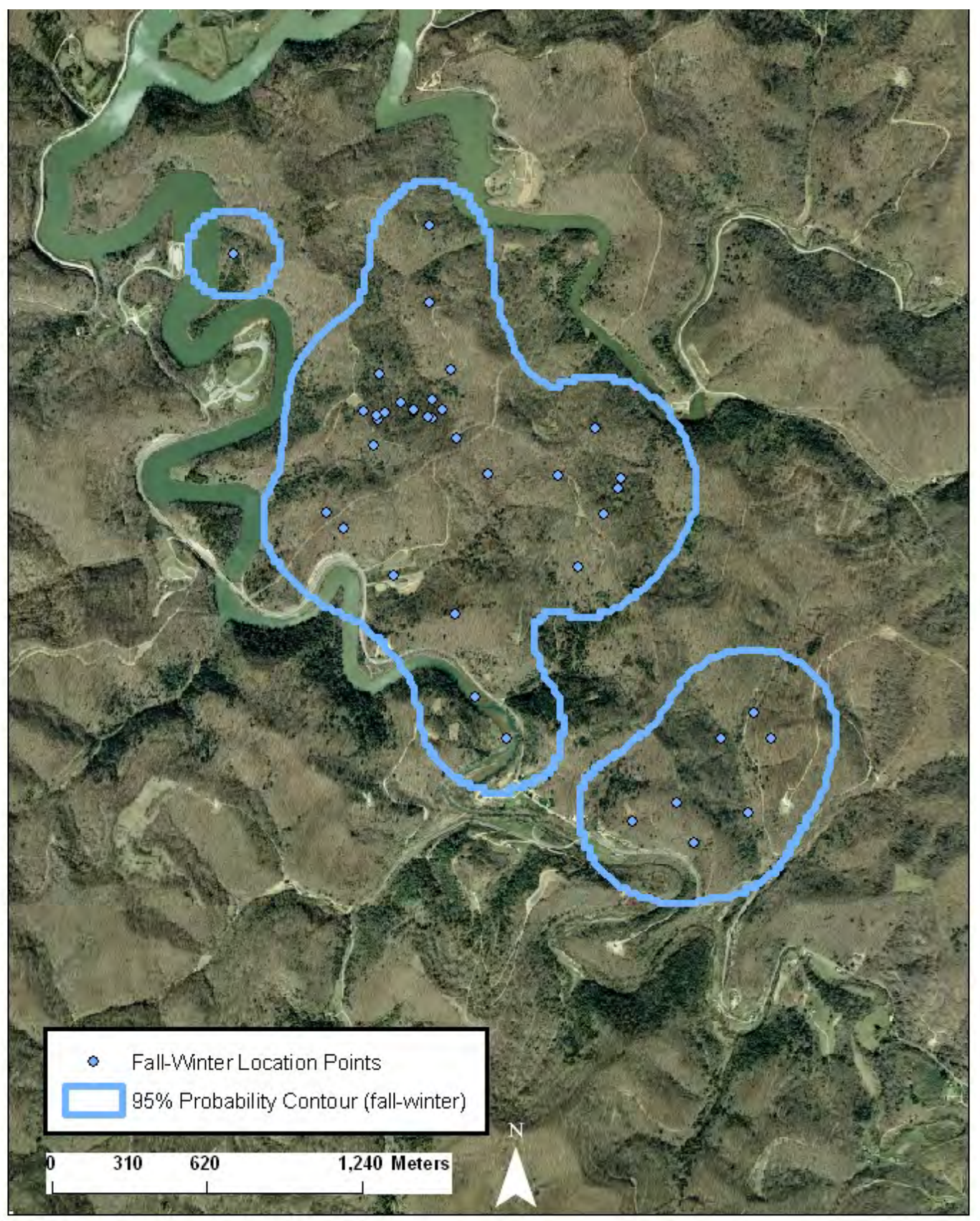


Appendix CXLa. RG5510 (juvenile) - 50\% and 95\% probability contours of the annual fixed kernel home range utilization distribution. Smoothing parameter (h) determined by least squares cross validation, Mason County, West Virginia, 2004-2005 (100k topo map).

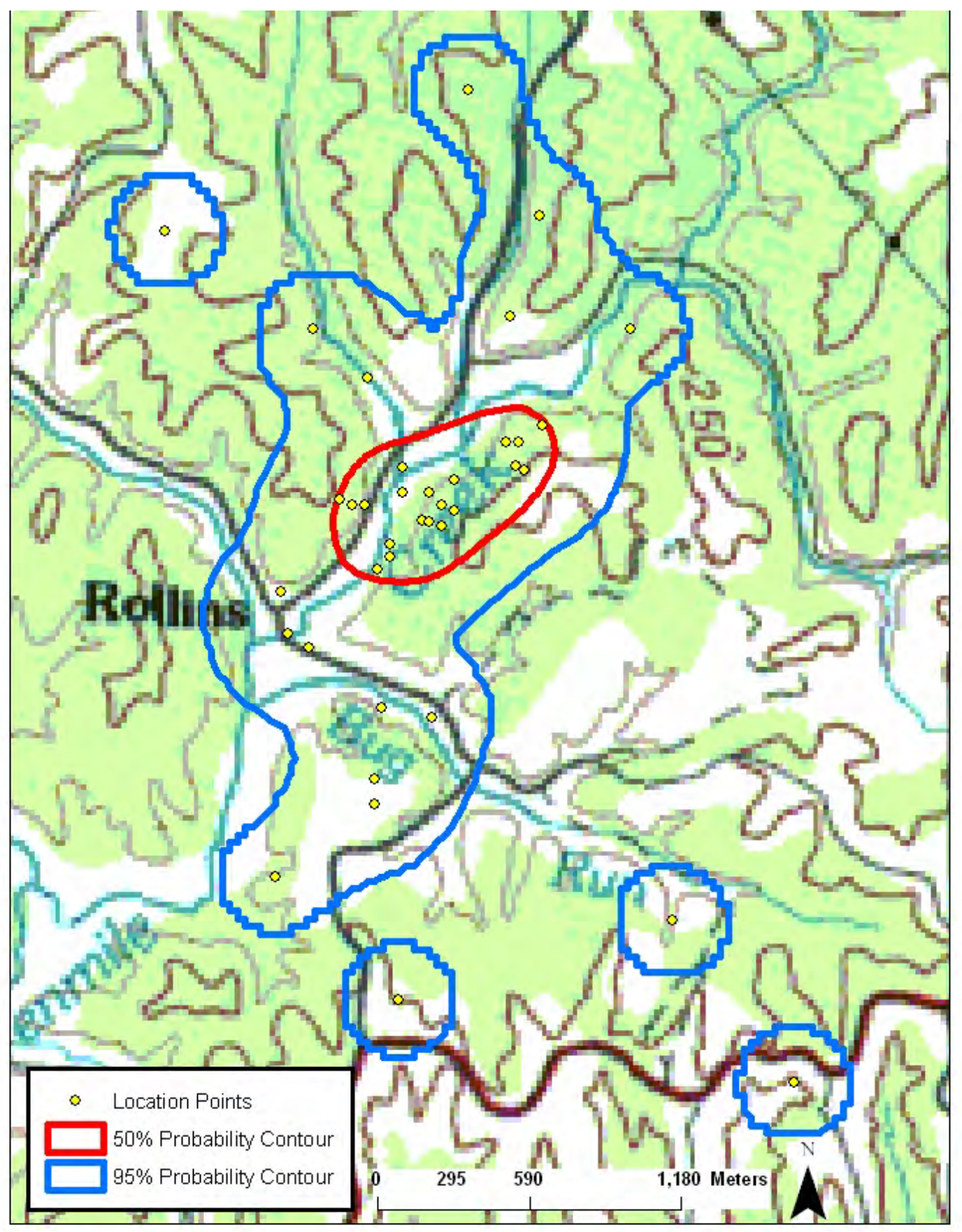


Appendix CXLIa. RG5510 (juvenile) - 50\% and 95\% probability contours of the annual fixed kernel home range utilization distribution. Smoothing parameter (h) determined by least squares cross validation, Mason County, West Virginia, 2004-2005 (2003 SAMB imagery).

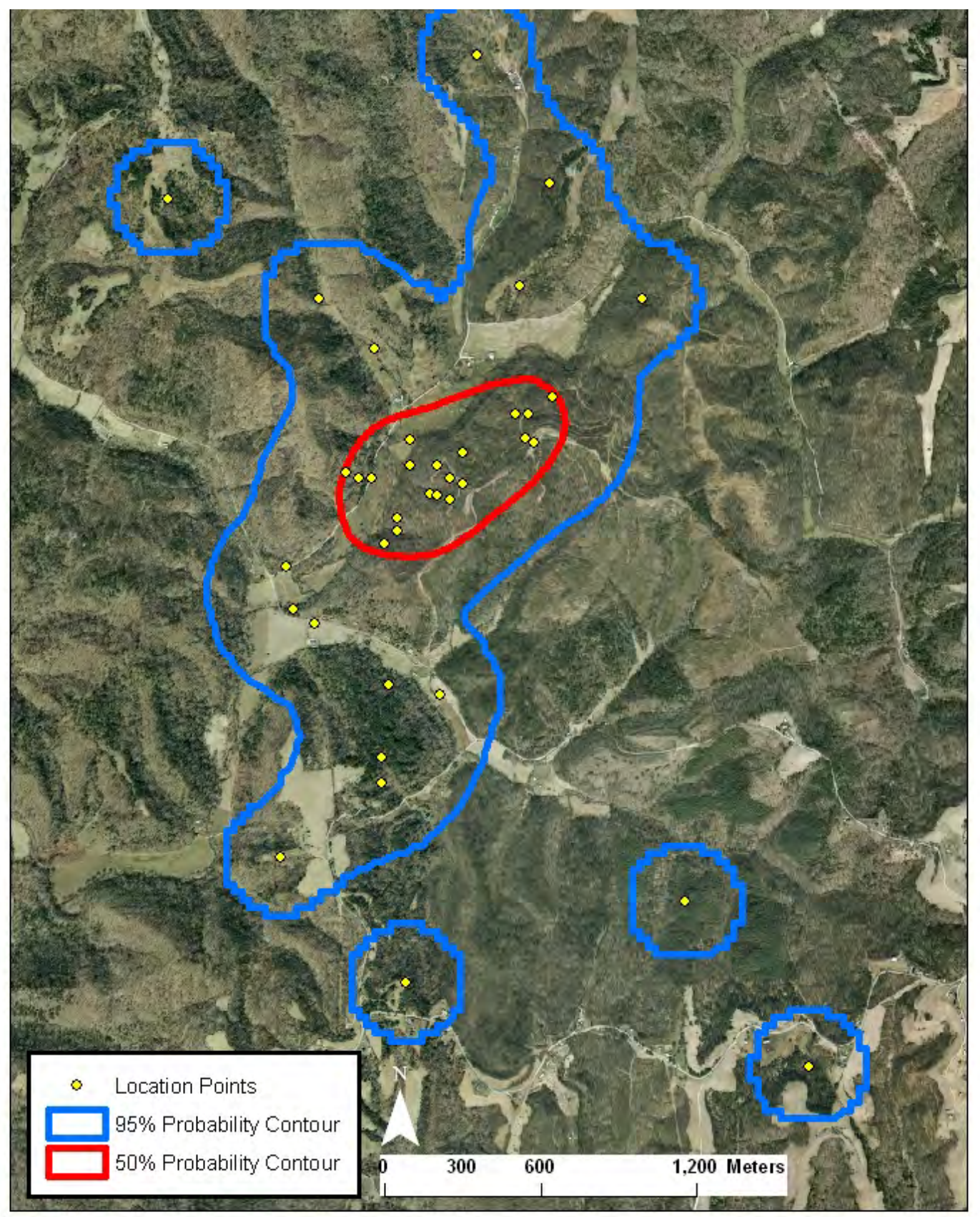


Appendix CXLIIa. RG5510 (adult) - 50\% and 95\% probability contours of the annual fixed kernel home range utilization distribution. Smoothing parameter (h) determined by least squares cross validation, Mason County, West Virginia, 2005-2007 (100k topo map).

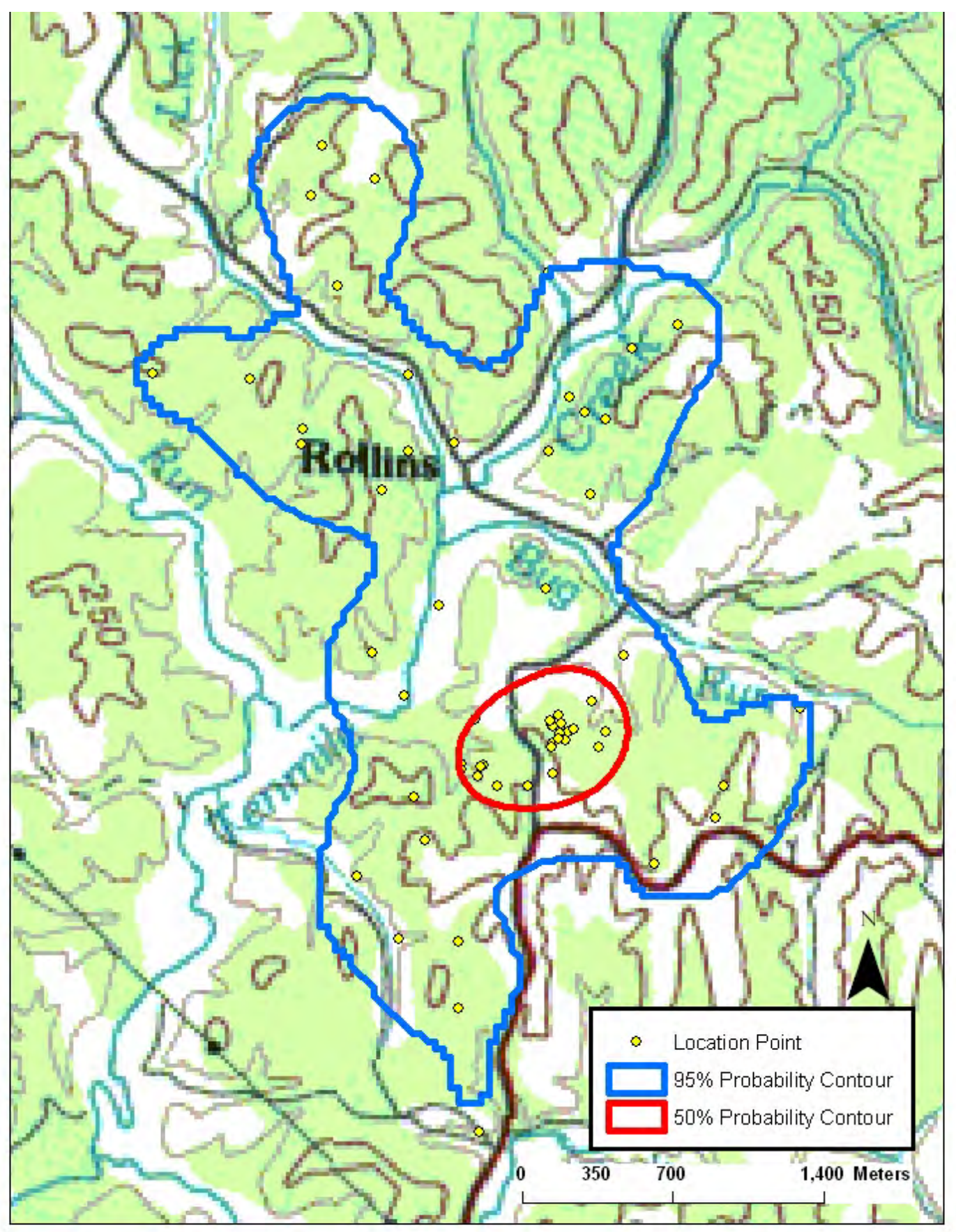


Appendix CXLIIIa. RG5510 (adult) - 50\% and 95\% probability contours of the annual fixed kernel home range utilization distribution. Smoothing parameter (h) determined by least squares cross validation, Mason County, West Virginia, 2005-2007 (2003 SAMB imagery).

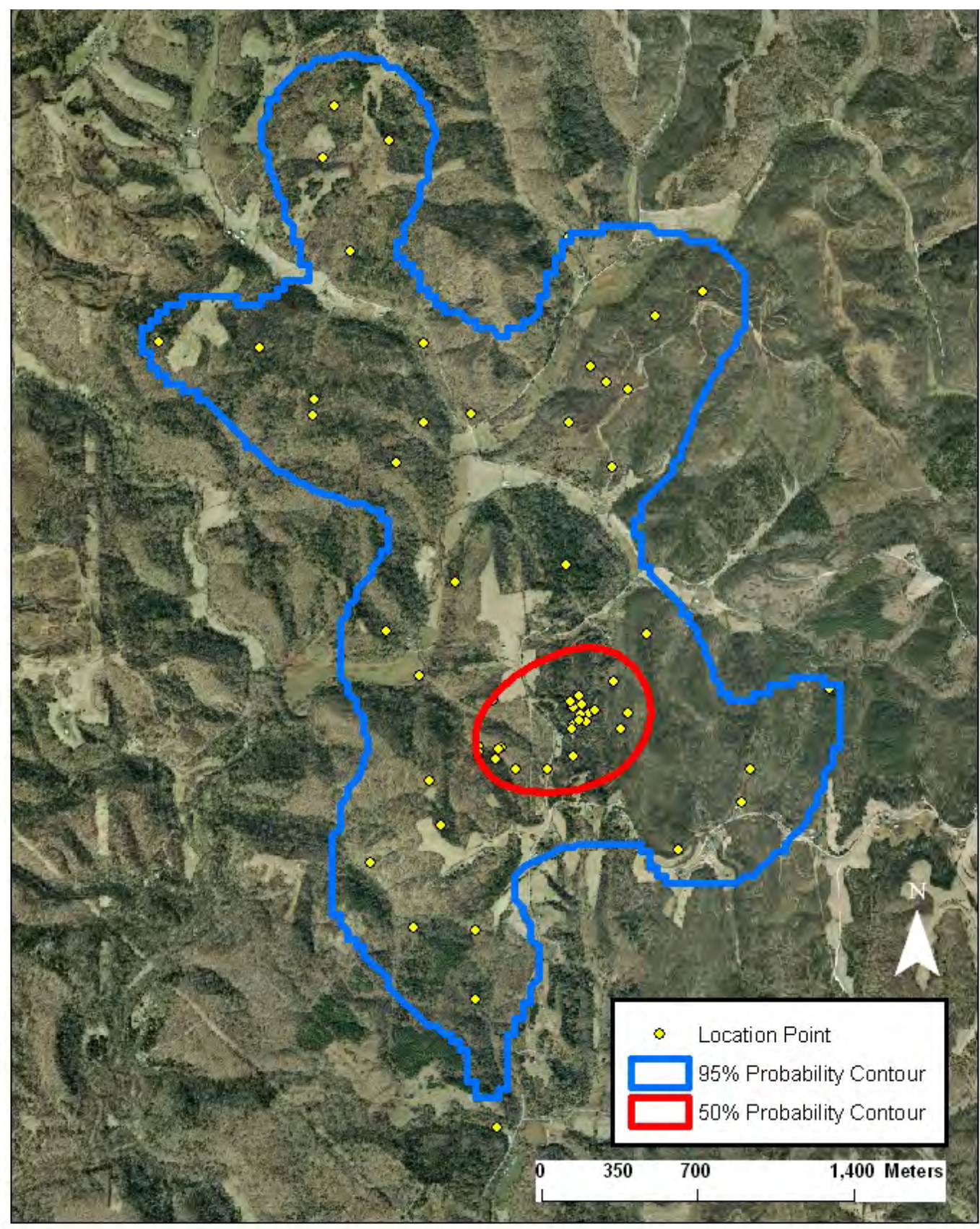


Appendix CXLIVa. RG5510 (adult) - 95\% probability contour of the fall-winter fixed kernel home range utilization distribution. Smoothing parameter (h) determined by least squares cross validation, Mason County, West Virginia, 2005-2007 (2003 SAMB imagery).

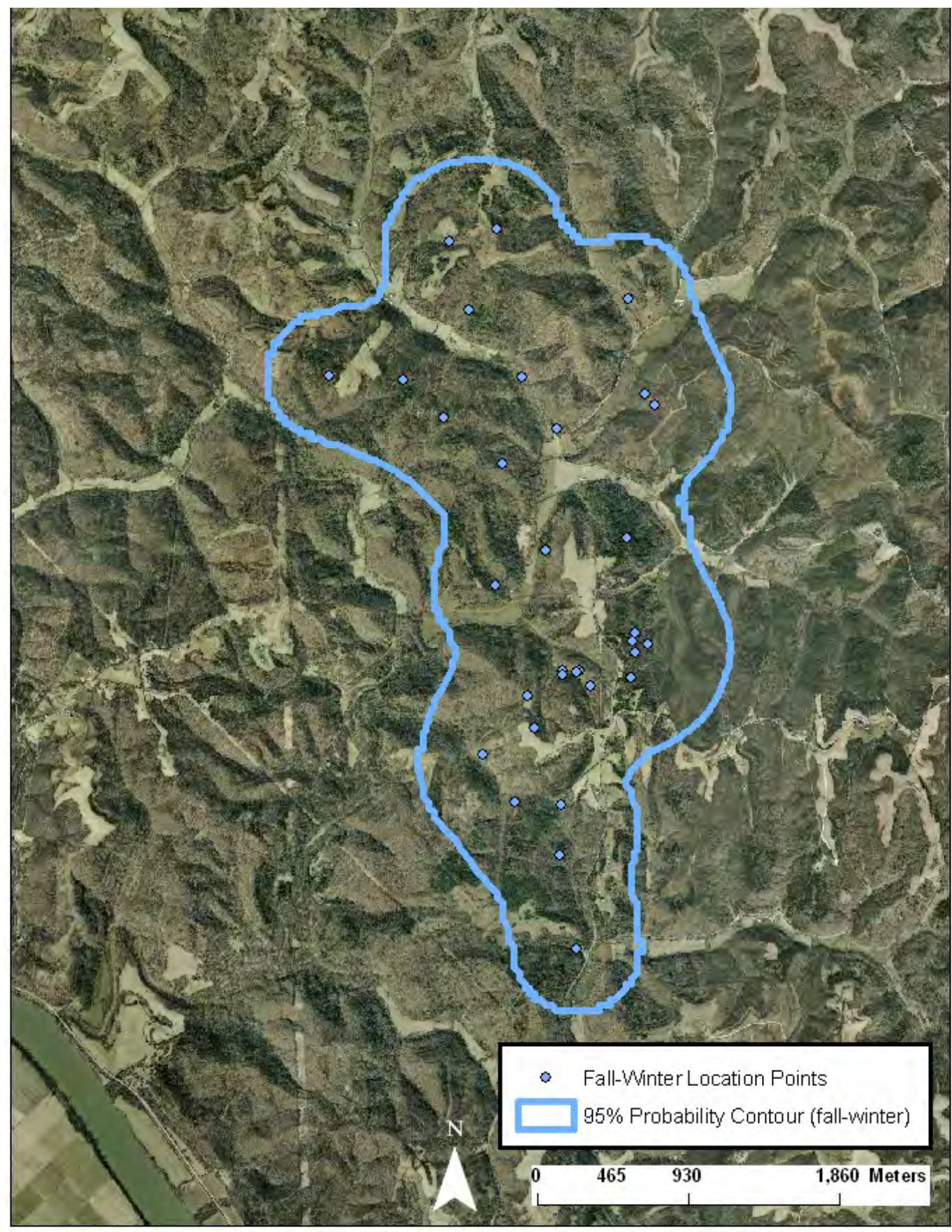


Appendix CXLVa. RG5518 (adult) - 50\% and 95\% probability contours of the annual fixed kernel home range utilization distribution. Smoothing parameter (h) determined by least squares cross validation, Mason County, West Virginia, 2005-2006 (100k topo map).

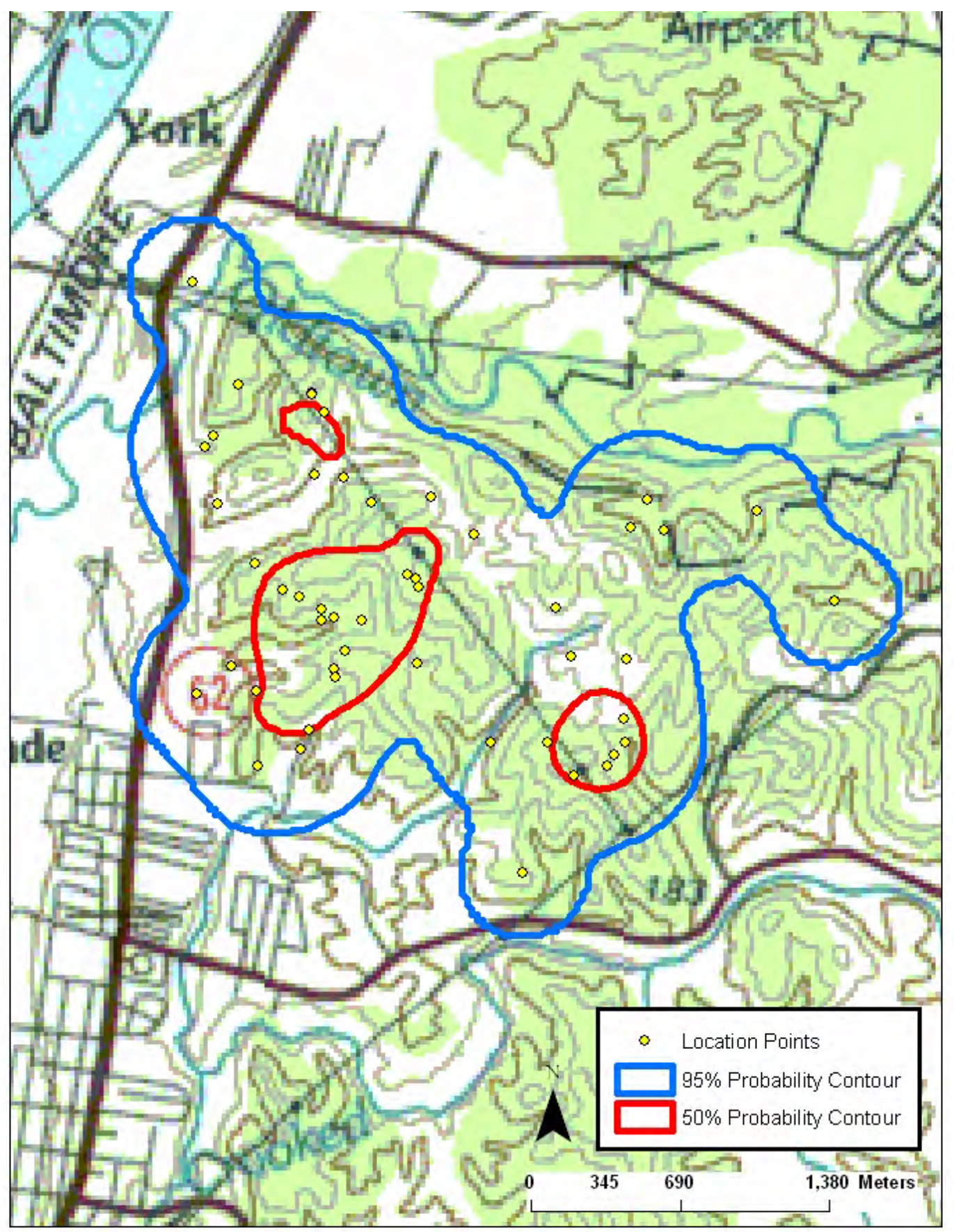


Appendix CXLVIa. RG5518 (adult) - 50\% and 95\% probability contours of the annual fixed kernel home range utilization distribution. Smoothing parameter (h) determined by least squares cross validation, Mason County, West Virginia, 2005-2006 (2003 SAMB imagery).

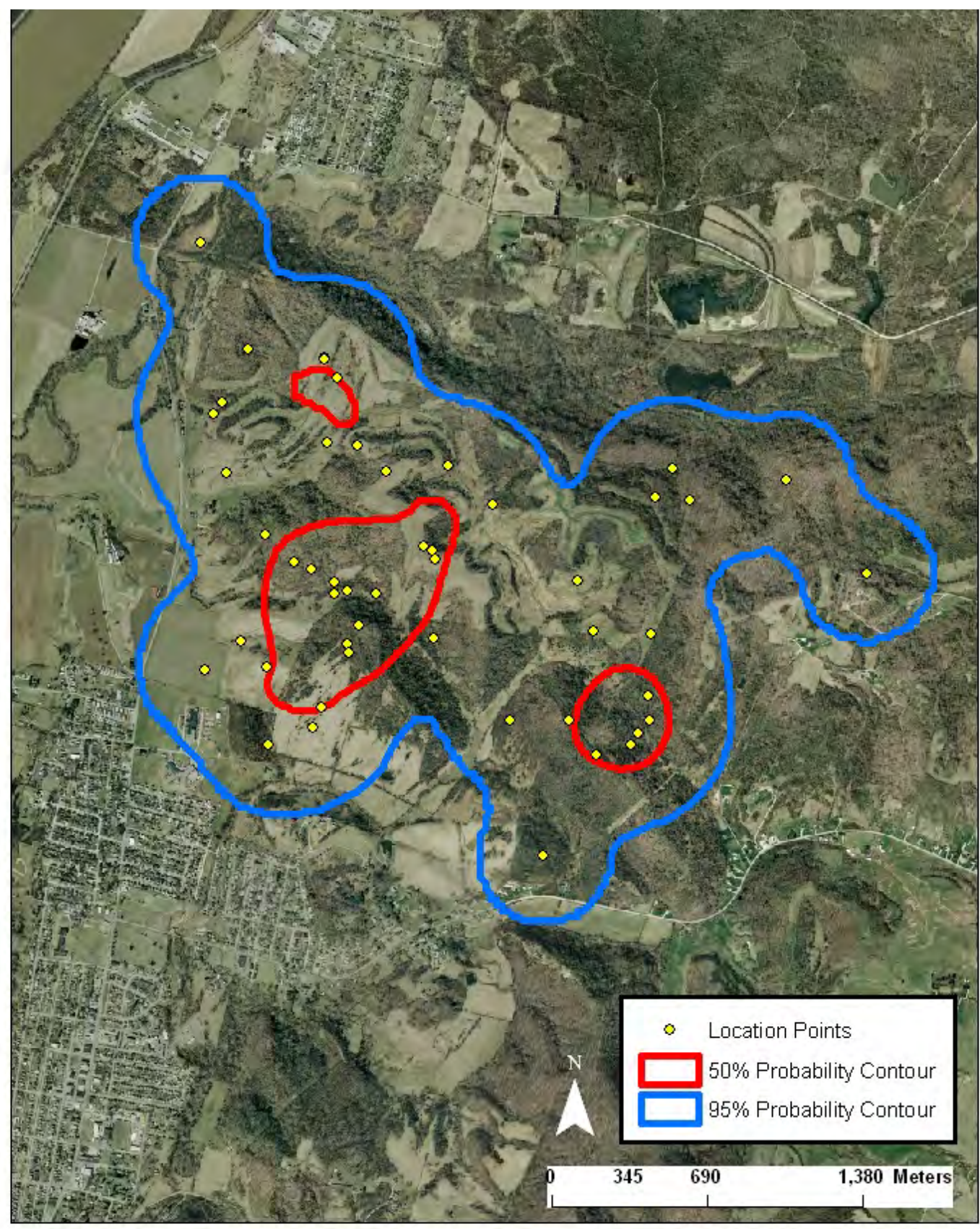


Appendix CXLVIIa. RG5519 (adult) - 50\% and 95\% probability contours of the annual fixed kernel home range utilization distribution. Smoothing parameter (h) determined by least squares cross validation, Mason County, West Virginia, 2005-2006 (100k topo map).

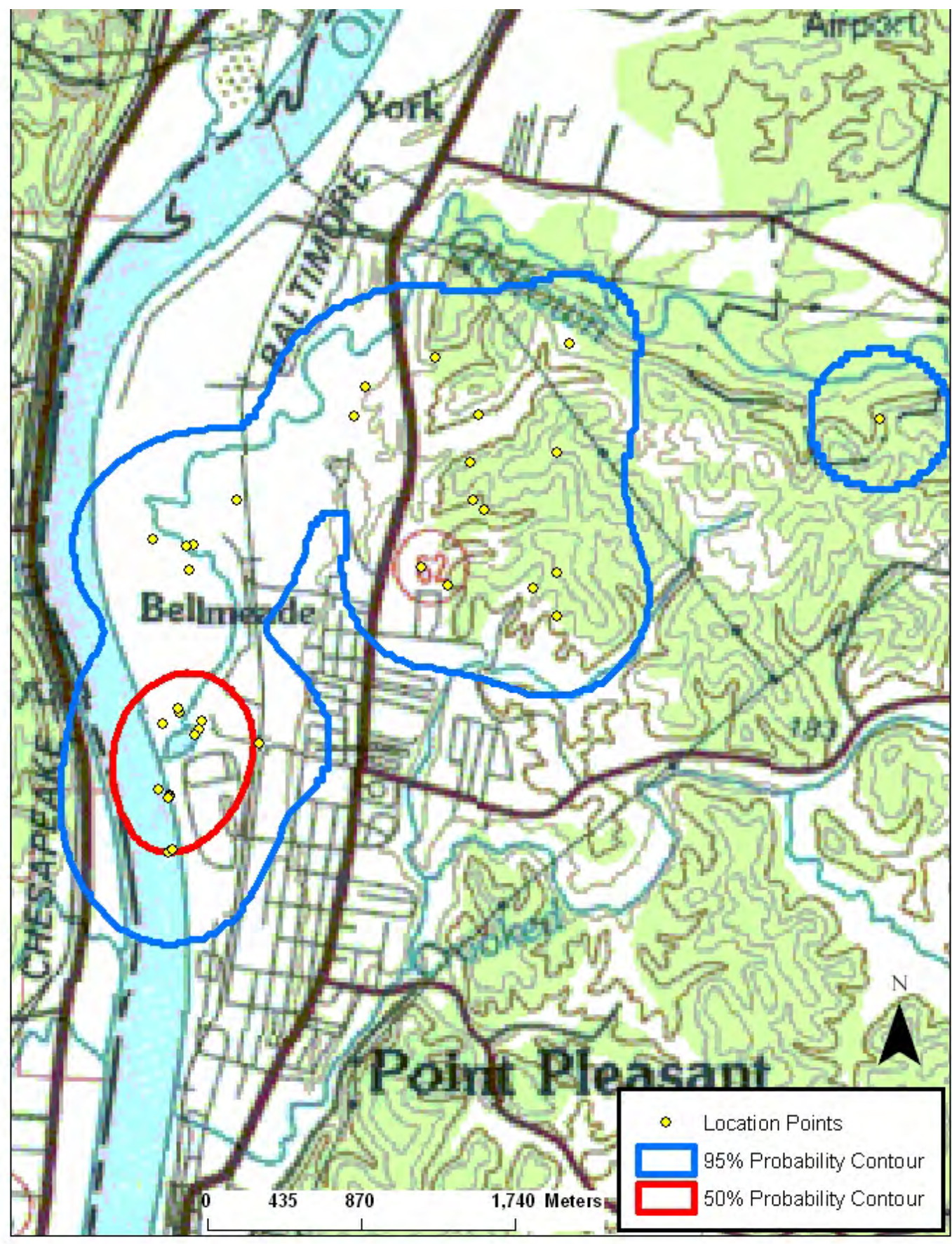


Appendix CXLVIIIa. RG5519 (adult) - 50\% and 95\% probability contours of the annual fixed kernel home range utilization distribution. Smoothing parameter (h) determined by least squares cross validation, Mason County, West Virginia, 2005-2006 (2003 SAMB imagery).

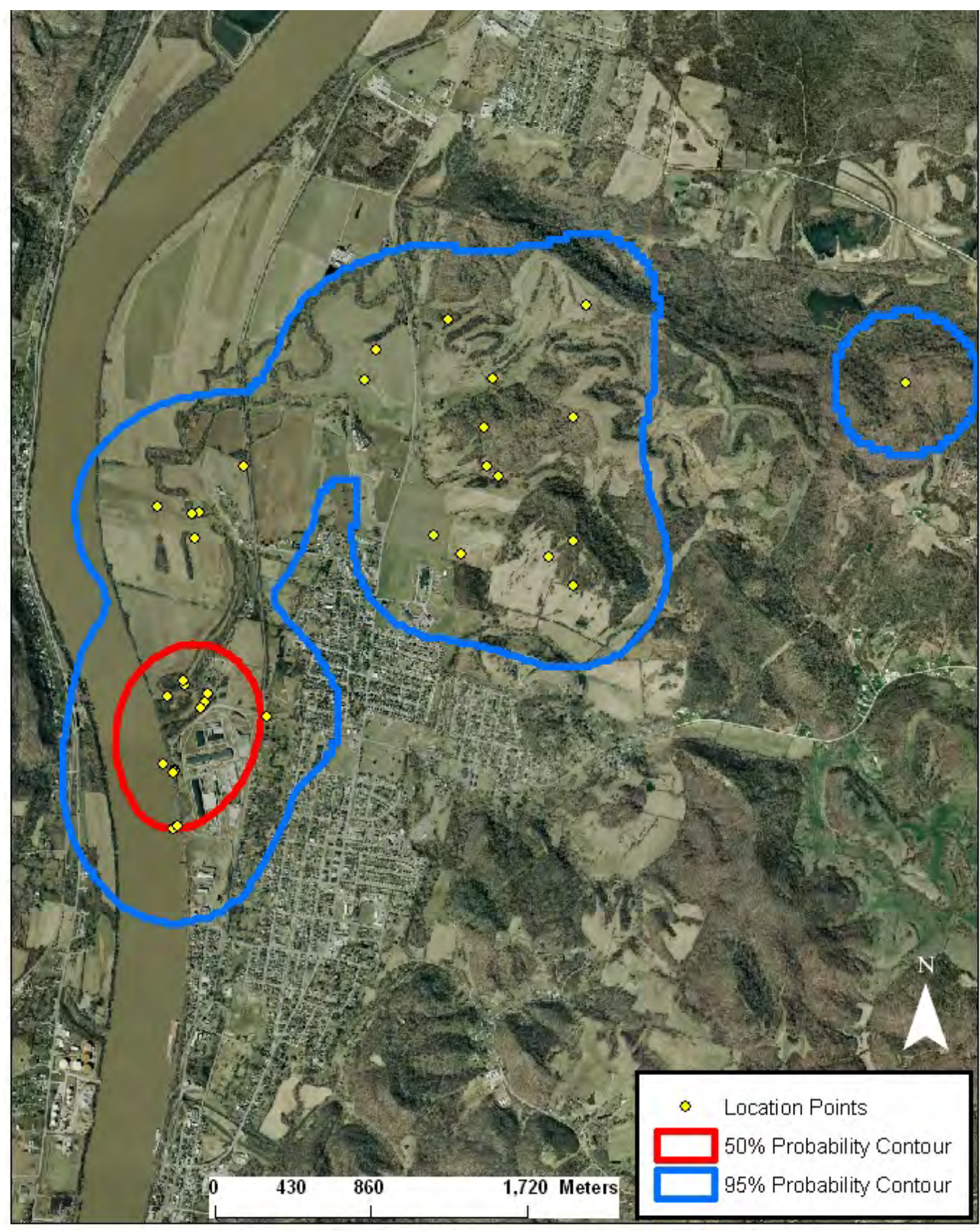


Appendix CXLIXa. RG5524 (adult) - 50\% and 95\% probability contours of the annual fixed kernel home range utilization distribution. Smoothing parameter (h) determined by least squares cross validation, Mason County, West Virginia, 2005-2007 (100k topo map).

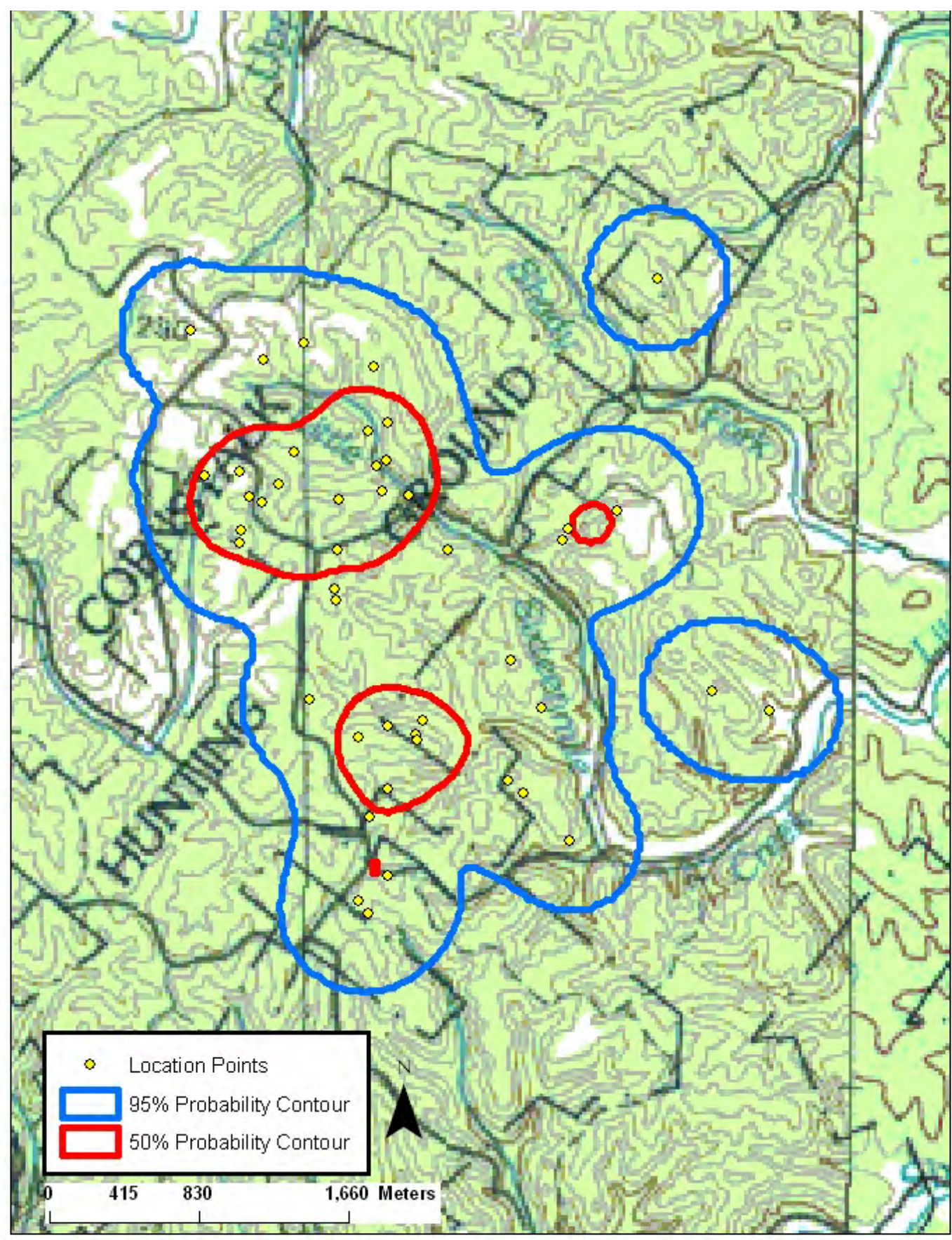


Appendix CLa. RG5524 (adult) - 50\% and 95\% probability contours of the annual fixed kernel home range utilization distribution. Smoothing parameter (h) determined by least squares cross validation, Mason County, West Virginia, 2005-2007 (2003 SAMB imagery).

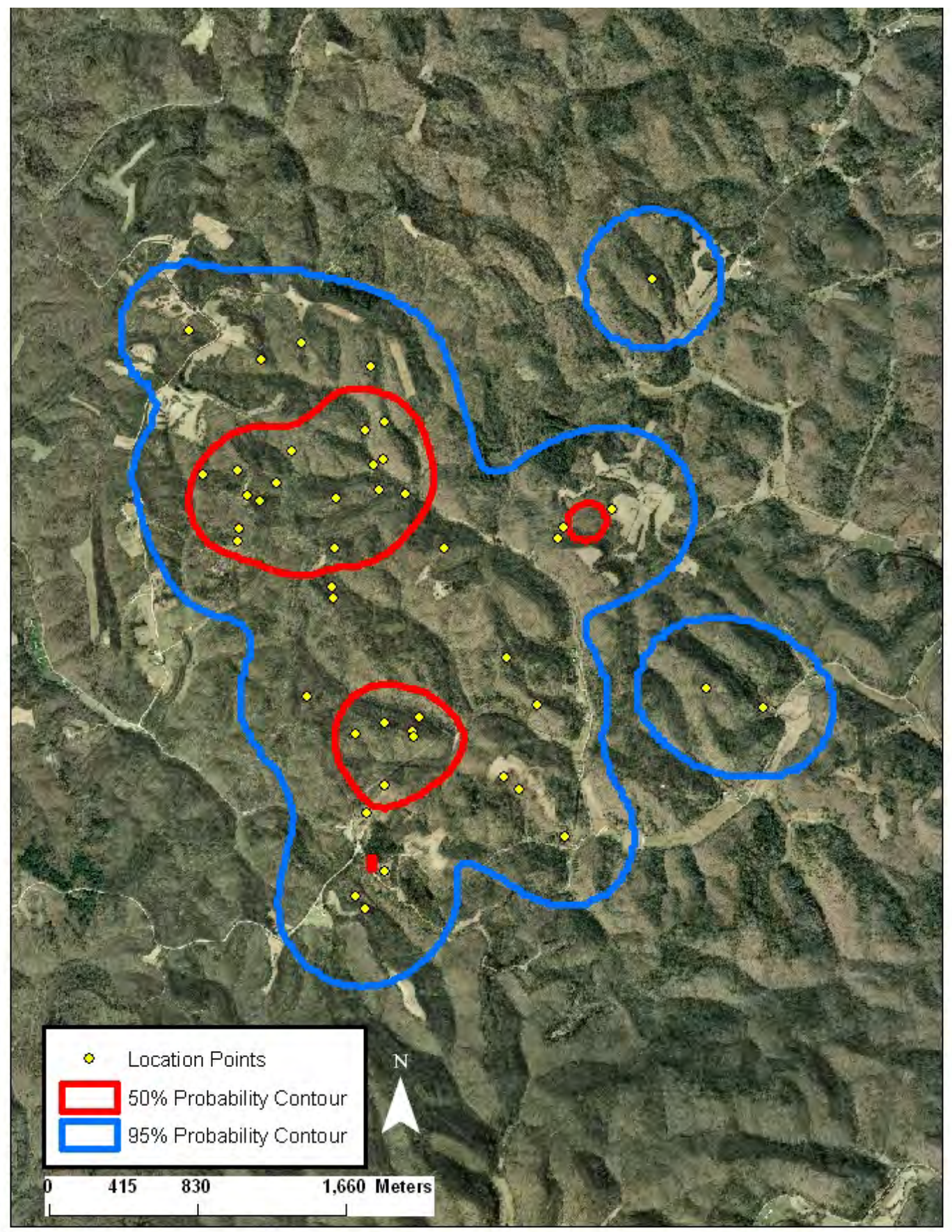


Appendix CLIa. RG5701 (adult) - 50\% and 95\% probability contours of the annual fixed kernel home range utilization distribution. Smoothing parameter (h) determined by least squares cross validation, Randolph County, West Virginia, 2005-2007 (100k topo map).

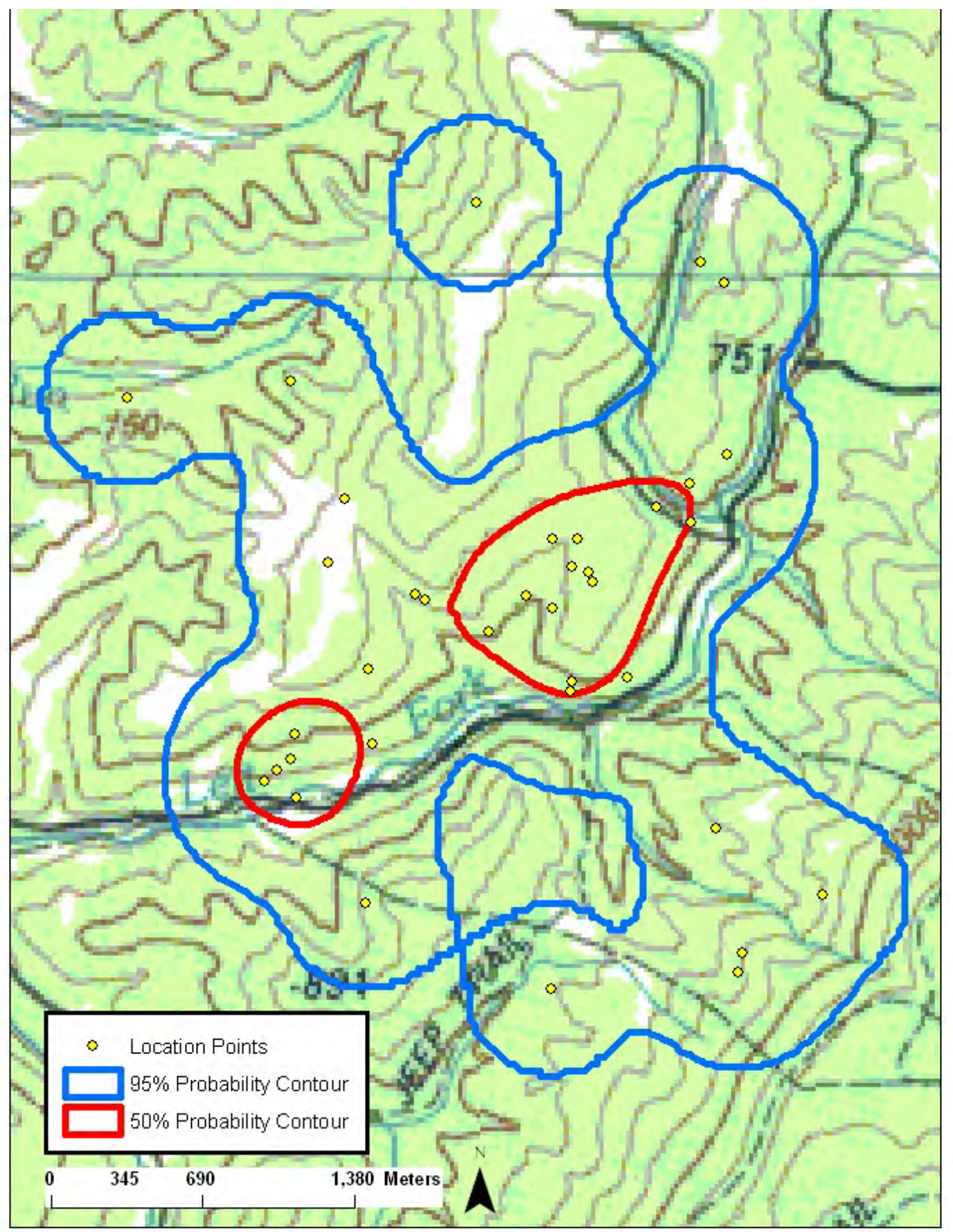


Appendix CLIIa. RG5701 (adult) - 50\% and 95\% probability contours of the annual fixed kernel home range utilization distribution. Smoothing parameter (h) determined by least squares cross validation, Randolph County, West Virginia, 2005-2007 (2003 SAMB imagery).

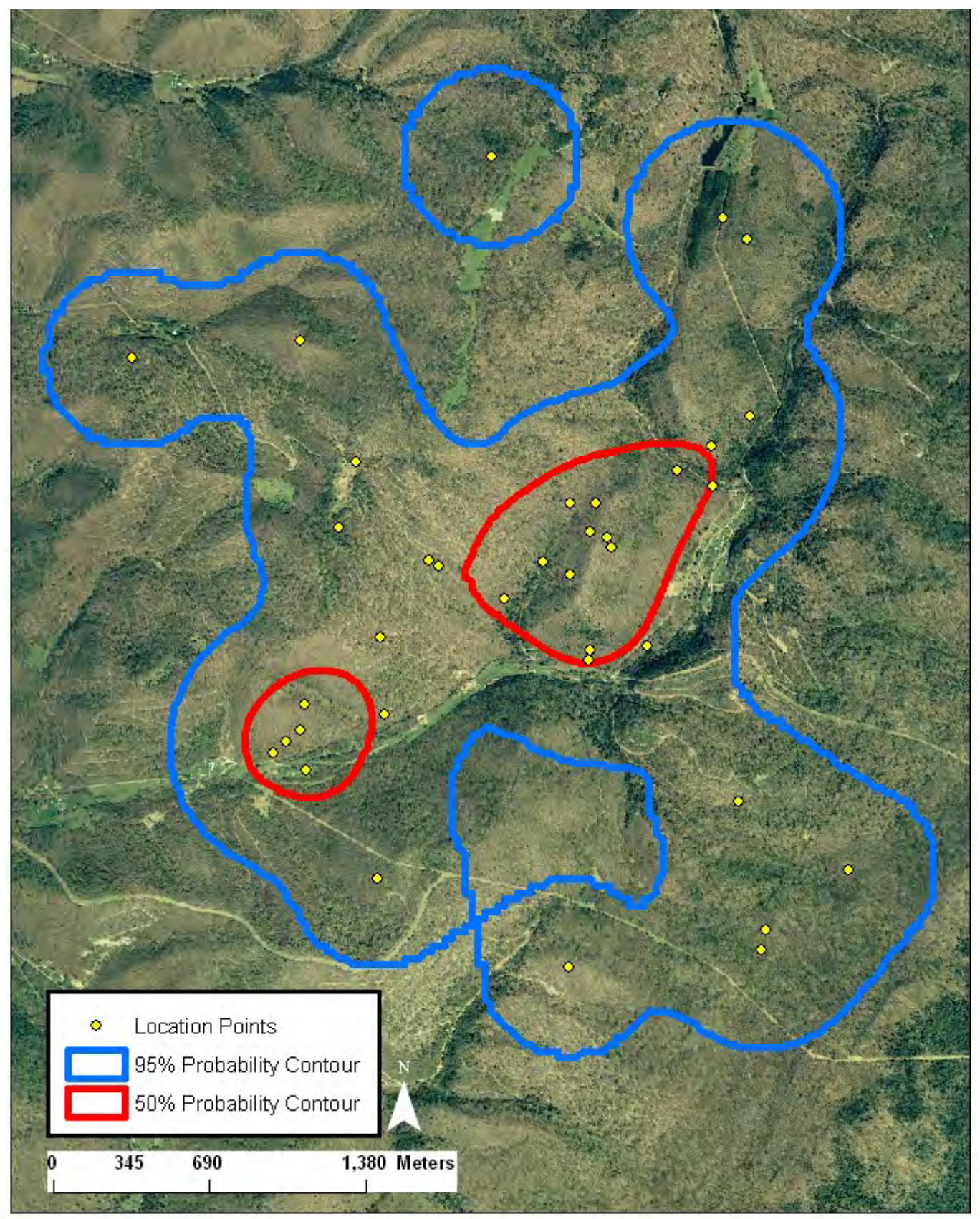


Appendix CLIIIa. RG5702 (juvenile) - 50\% and 95\% probability contours of the annual fixed kernel home range utilization distribution. Smoothing parameter (h) determined by least squares cross validation, Randolph County, West Virginia, 2004-2005 (100k topo map).

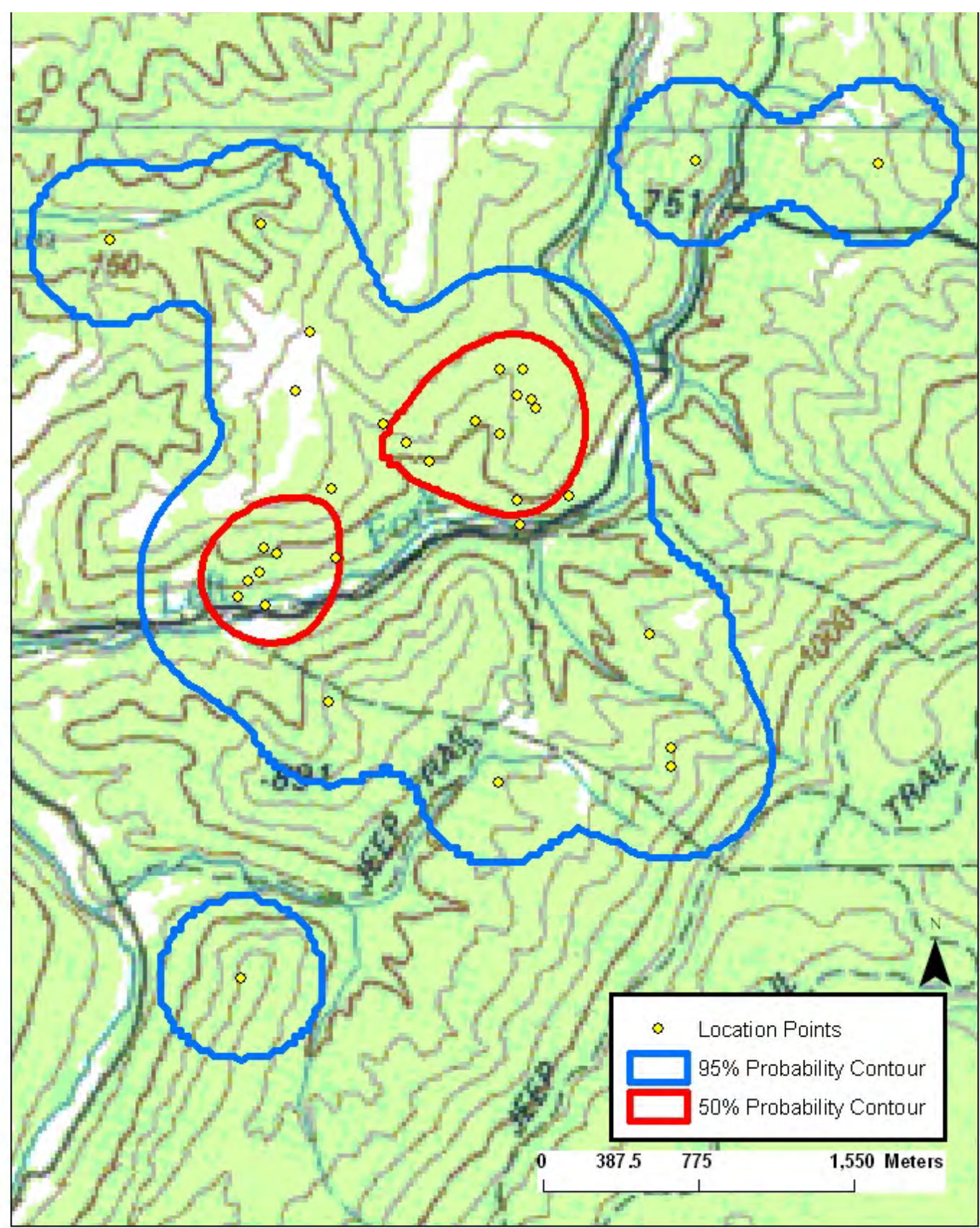


Appendix CLIVa. RG5702 (juvenile) - 50\% and 95\% probability contours of the annual fixed kernel home range utilization distribution. Smoothing parameter (h) determined by least squares cross validation, Randolph County, West Virginia, 2004-2005 (2003 SAMB imagery).

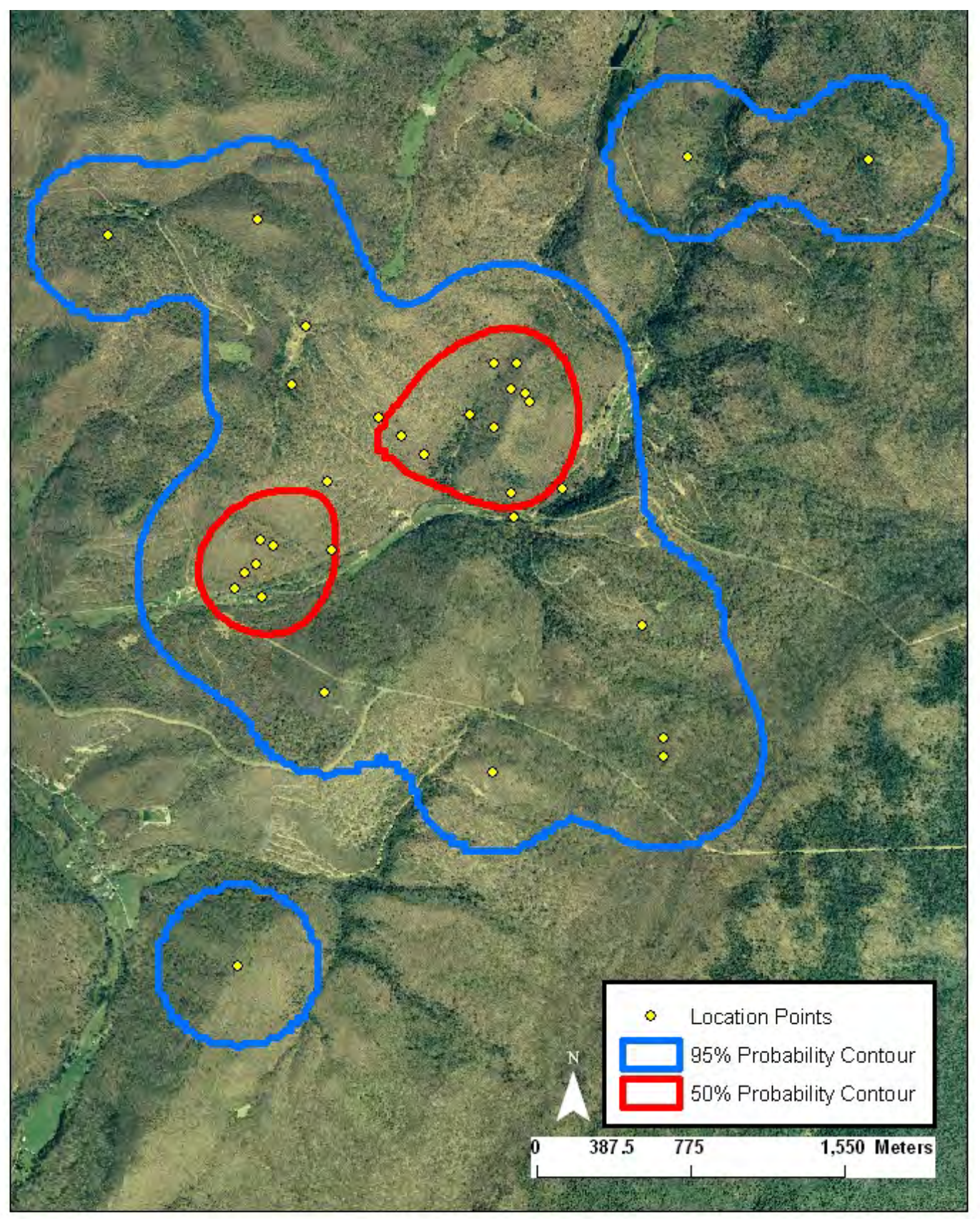


Appendix CLVa. RG5703 (juvenile) - 50\% and 95\% probability contours of the annual fixed kernel home range utilization distribution. Smoothing parameter (h) determined by least squares cross validation, Randolph County, West Virginia, 2004-2005 (100k topo map).

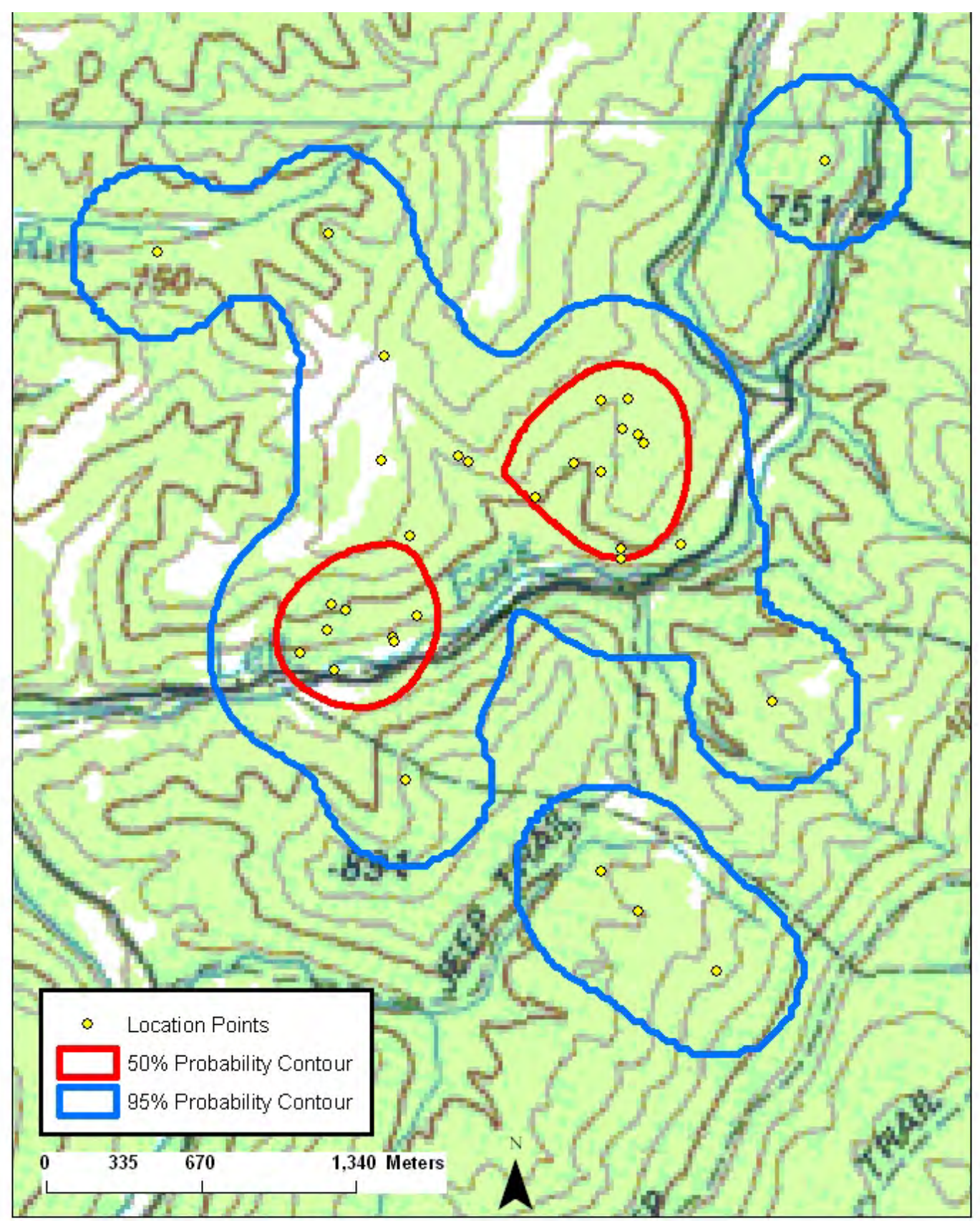


Appendix CLVIa. RG5703 (juvenile) - 50\% and 95\% probability contours of the annual fixed kernel home range utilization distribution. Smoothing parameter (h) determined by least squares cross validation, Randolph County, West Virginia, 2004-2005 (2003 SAMB imagery).

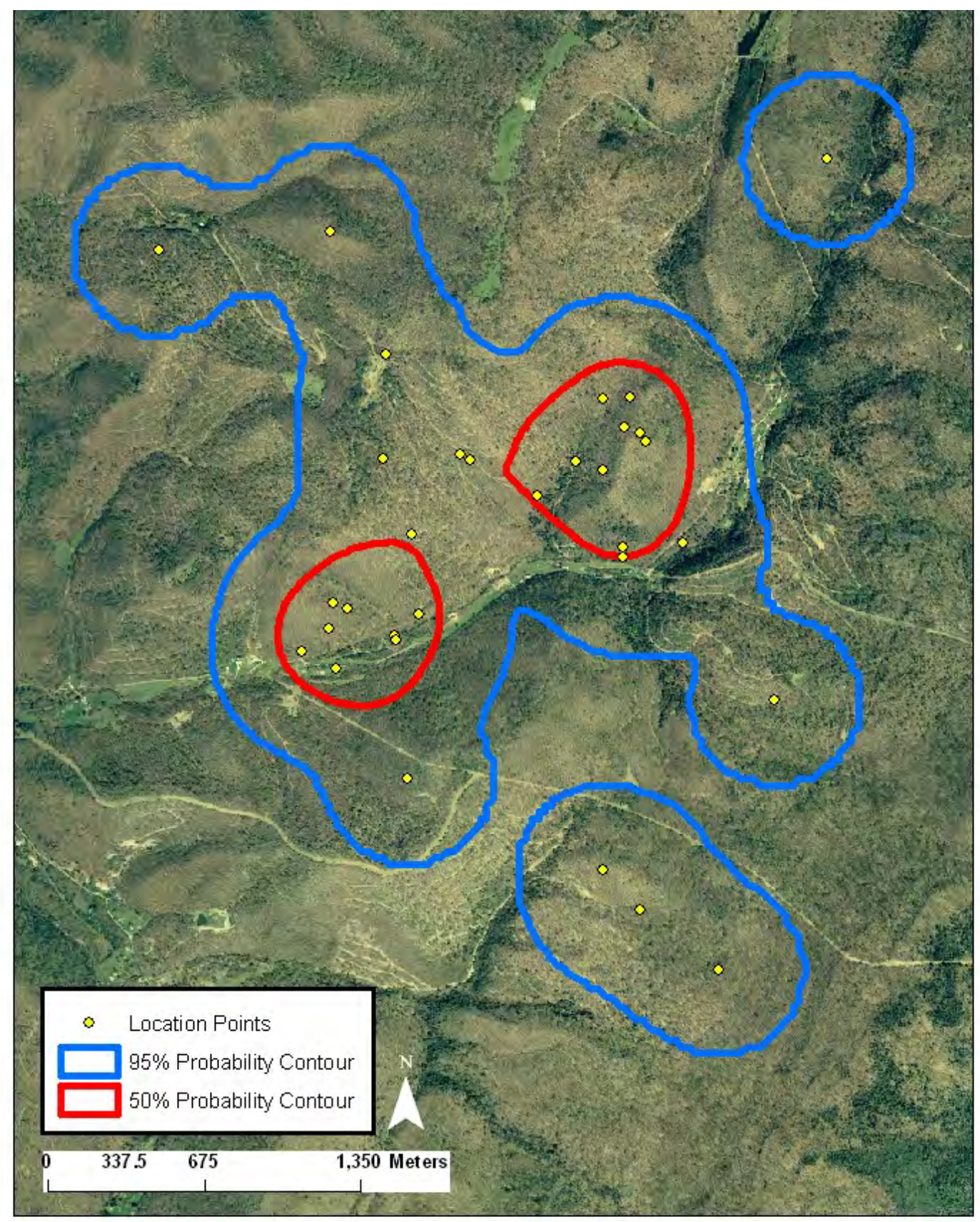


Appendix CLVIIa. RG5703 (adult) - 50\% and 95\% probability contours of the annual fixed kernel home range utilization distribution. Smoothing parameter (h) determined by least squares cross validation, Randolph County, West Virginia, 2005-2007 (100k topo map).

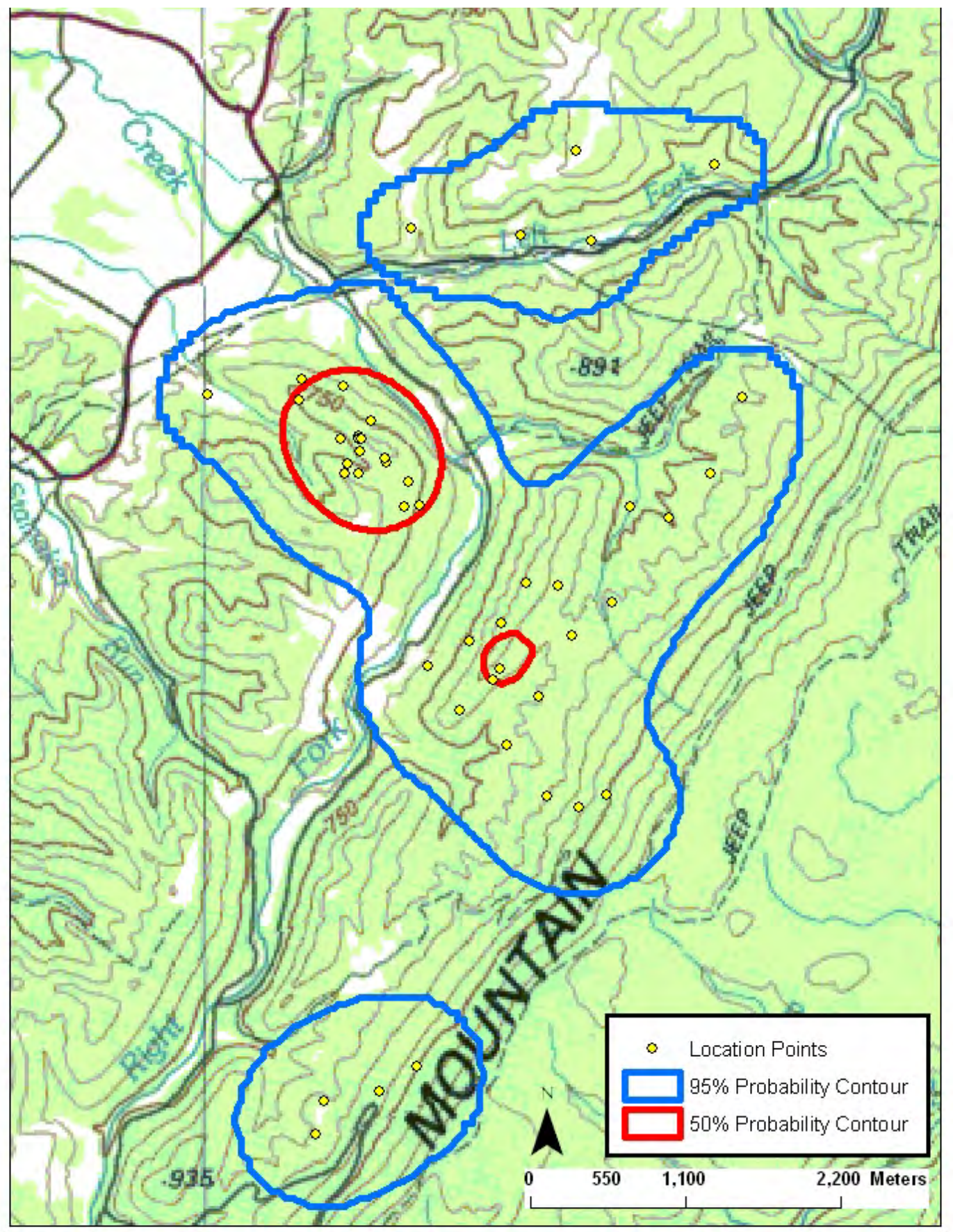


Appendix CLVIIIa. RG5703 (adult) - 50\% and 95\% probability contours of the annual fixed kernel home range utilization distribution. Smoothing parameter (h) determined by least squares cross validation, Randolph County, West Virginia, 2005-2007 (2003 SAMB imagery).

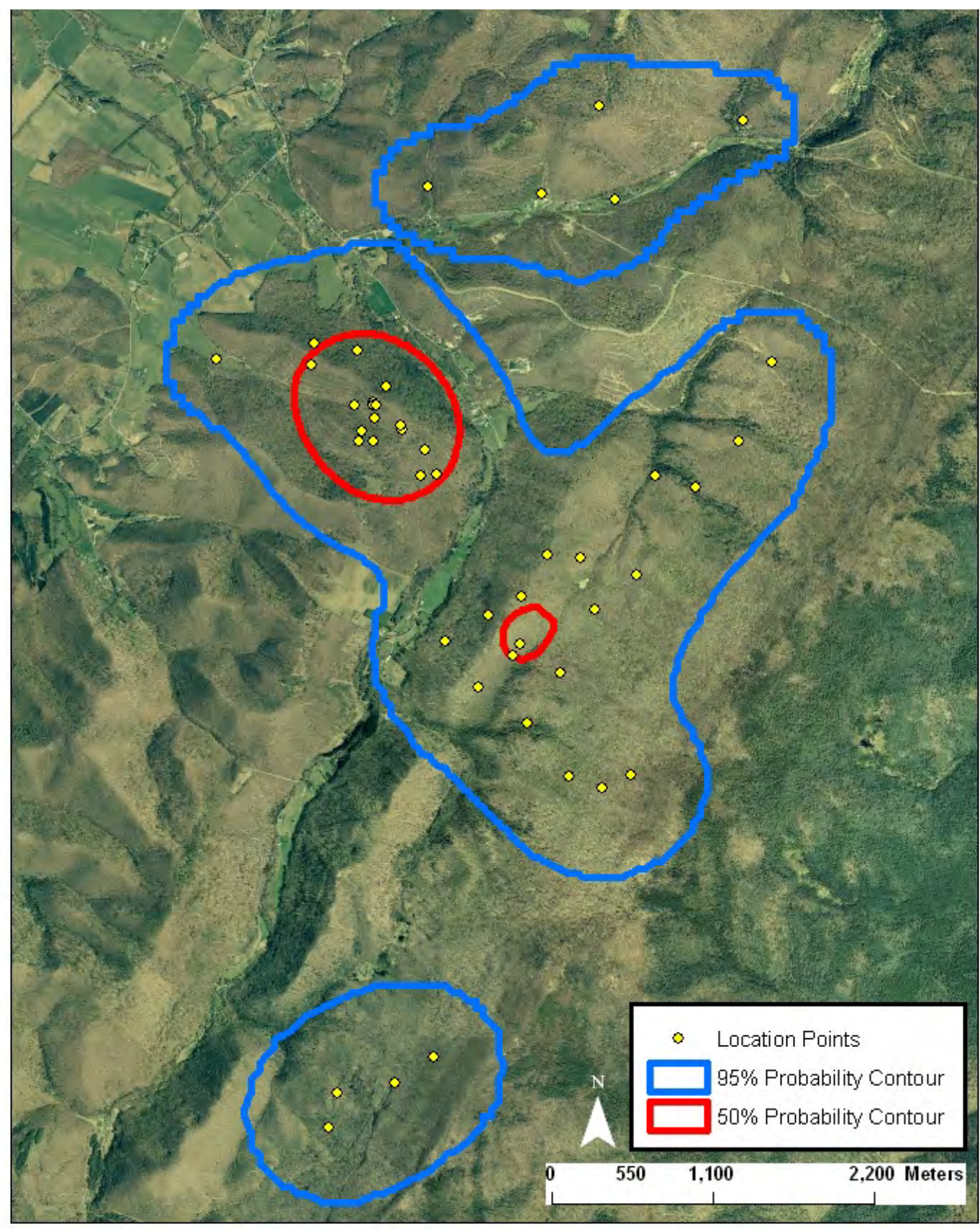


Appendix CLIXa. RG5704 (juvenile) - 50\% and 95\% probability contours of the annual fixed kernel home range utilization distribution. Smoothing parameter (h) determined by least squares cross validation, Randolph County, West Virginia, 2004-2005 (100k topo map).

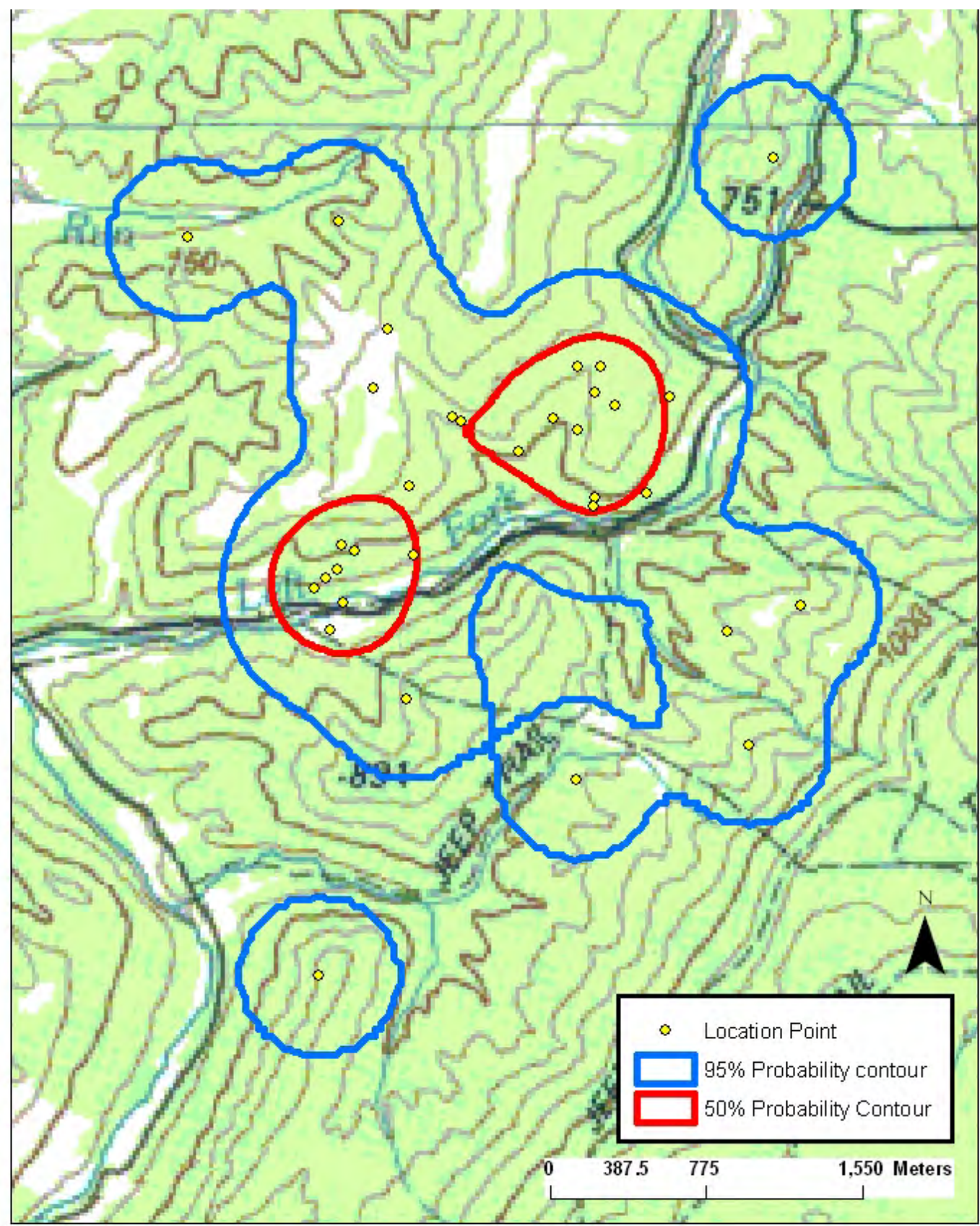


Appendix CLXa. RG5704 (juvenile) - 50\% and 95\% probability contours of the annual fixed kernel home range utilization distribution. Smoothing parameter (h) determined by least squares cross validation, Randolph County, West Virginia, 2004-2005 (2003 SAMB imagery).

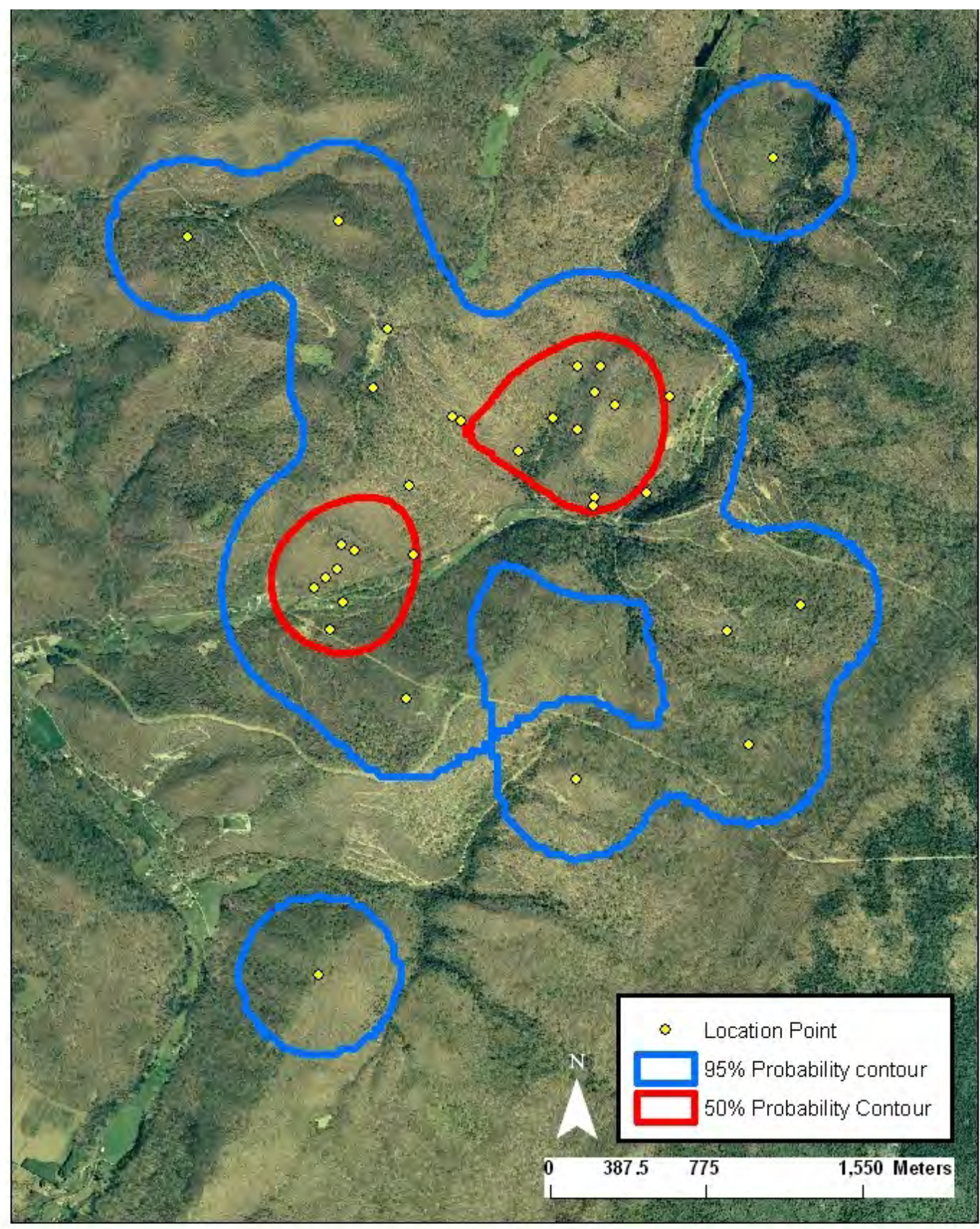


Appendix CLXIa. RG5801 (adult) - 50\% and 95\% probability contours of the annual fixed kernel home range utilization distribution. Smoothing parameter (h) determined by least squares cross validation, Greenbrier County, West Virginia, 2004-2007 (100k topo map).

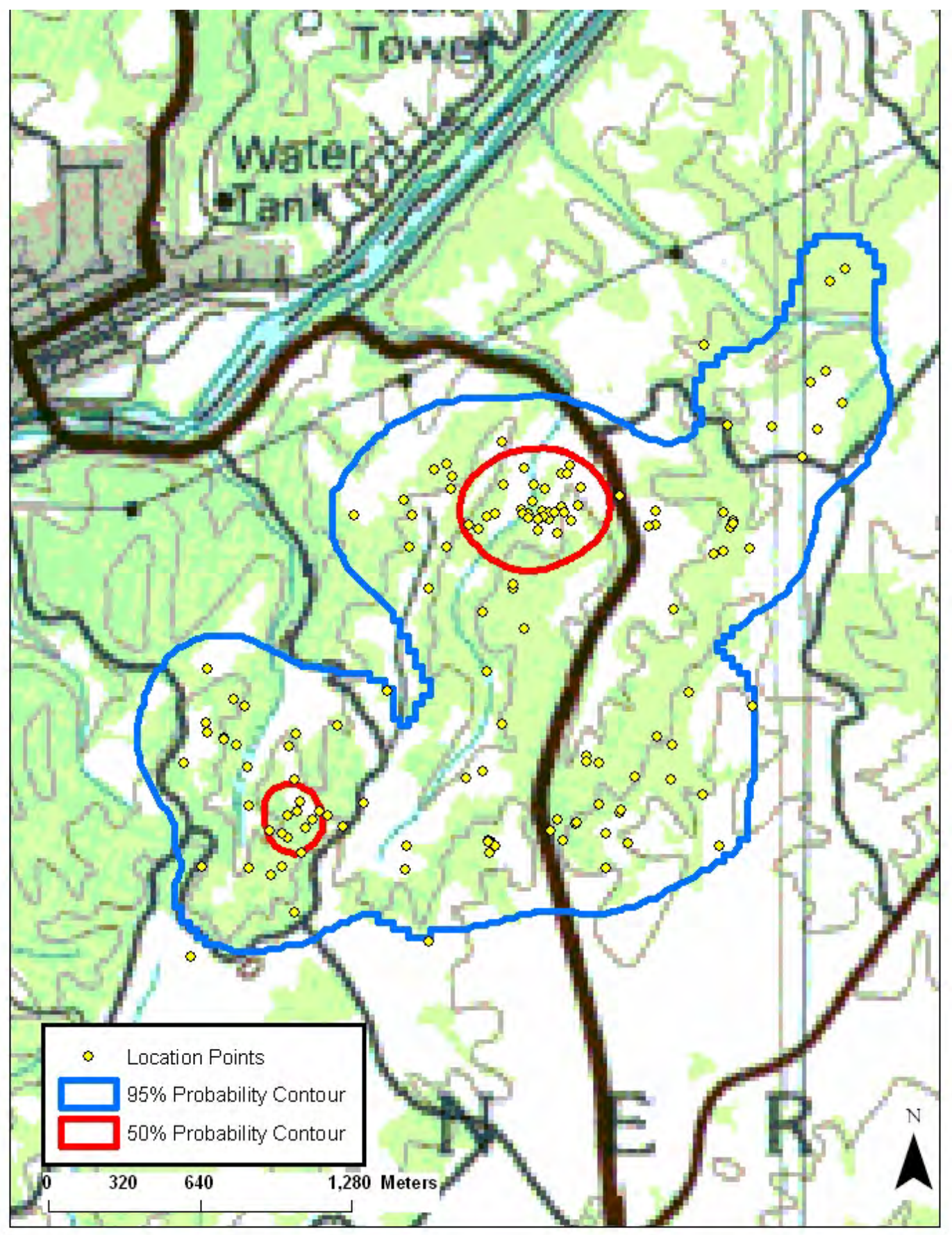


Appendix CLXIIa. RG5801 (adult) - 50\% and 95\% probability contours of the annual fixed kernel home range utilization distribution. Smoothing parameter (h) determined by least squares cross validation, Greenbrier County, West Virginia, 2004-2007 (2003 SAMB imagery).

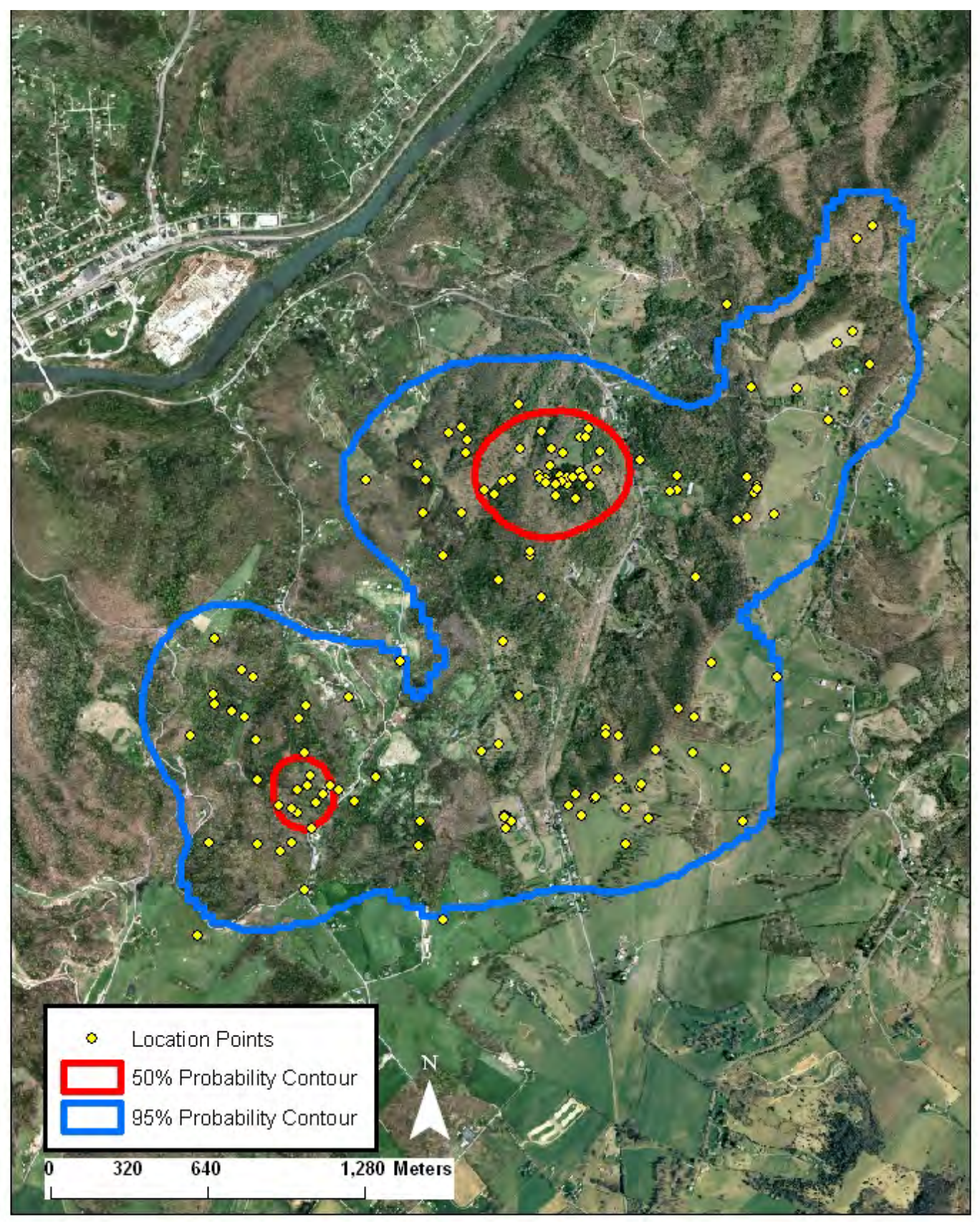


Appendix CLXIIIa. RG5801 (adult) - 95\% probability contours of the spring, fall, and winter fixed kernel home range utilization distribution. Smoothing parameter (h) determined by least squares cross validation, Greenbrier County, West Virginia, 2004-2007 (2003 SAMB imagery).

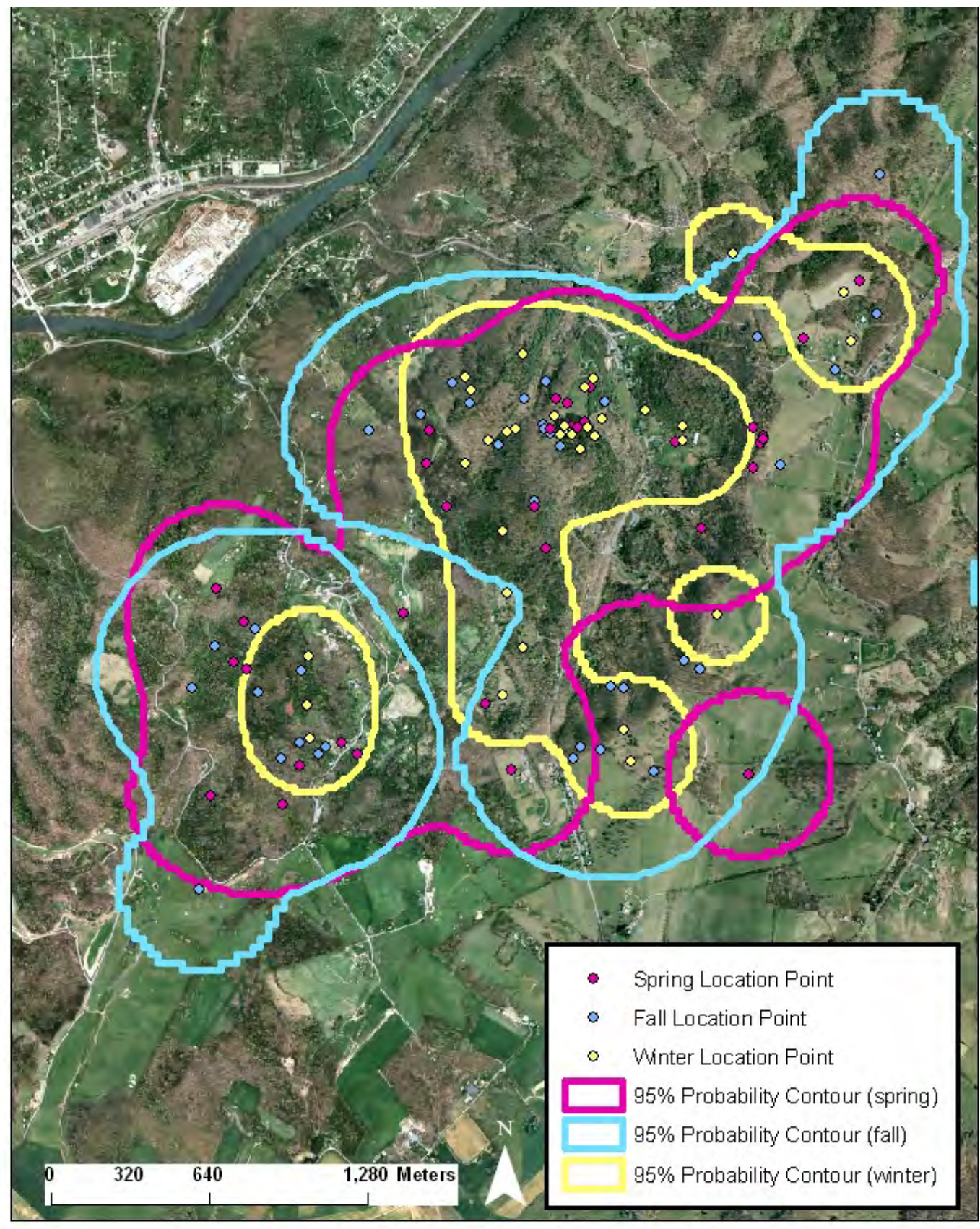


Appendix CLXIVa. RG5801 (adult) - 95\% probability contours of the spring-summer and fall-winter fixed kernel home range utilization distribution. Smoothing parameter (h) determined by least squares cross validation, Greenbrier County, West Virginia, 2004-2007 (2003 SAMB imagery).

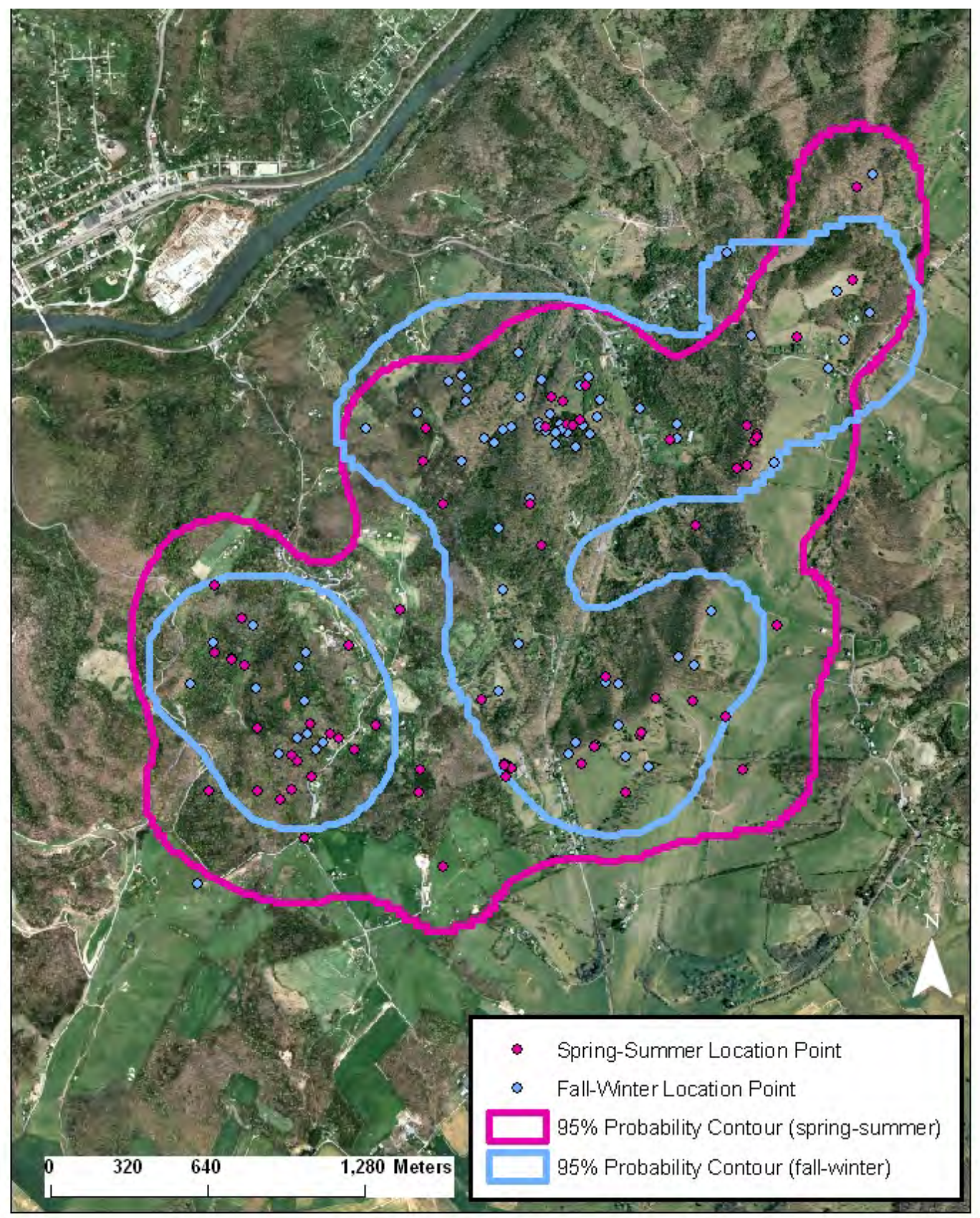


Appendix CLXVa. RG5802 (adult) - 50\% and 95\% probability contours of the annual fixed kernel home range utilization distribution. Smoothing parameter (h) determined by least squares cross validation, Greenbrier County, West Virginia, 2004-2007 (100k topo map).

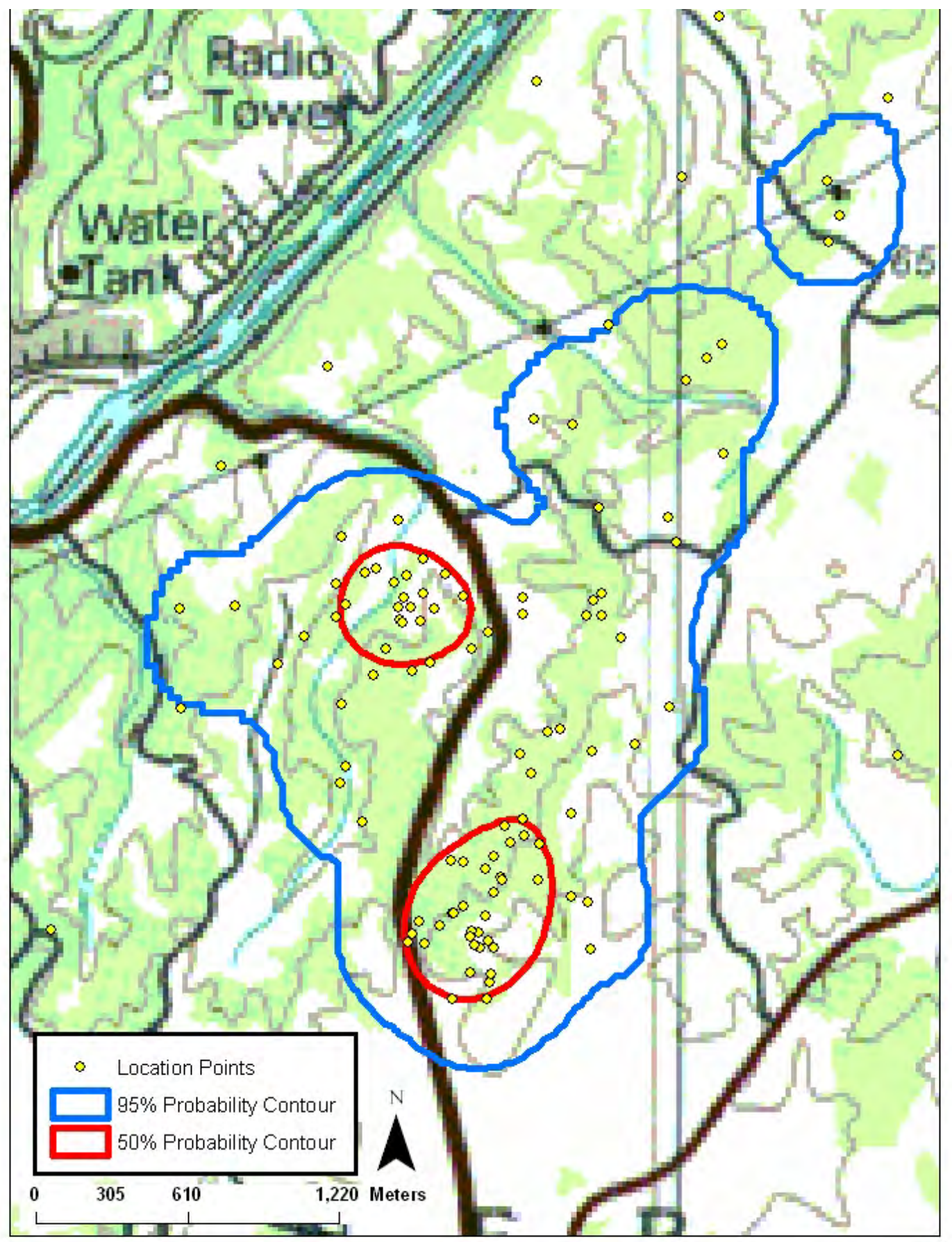


Appendix CLXVIa. RG5802 (adult) - 50\% and 95\% probability contours of the annual fixed kernel home range utilization distribution. Smoothing parameter (h) determined by least squares cross validation, Greenbrier County, West Virginia, 2004-2007 (2003 SAMB imagery).

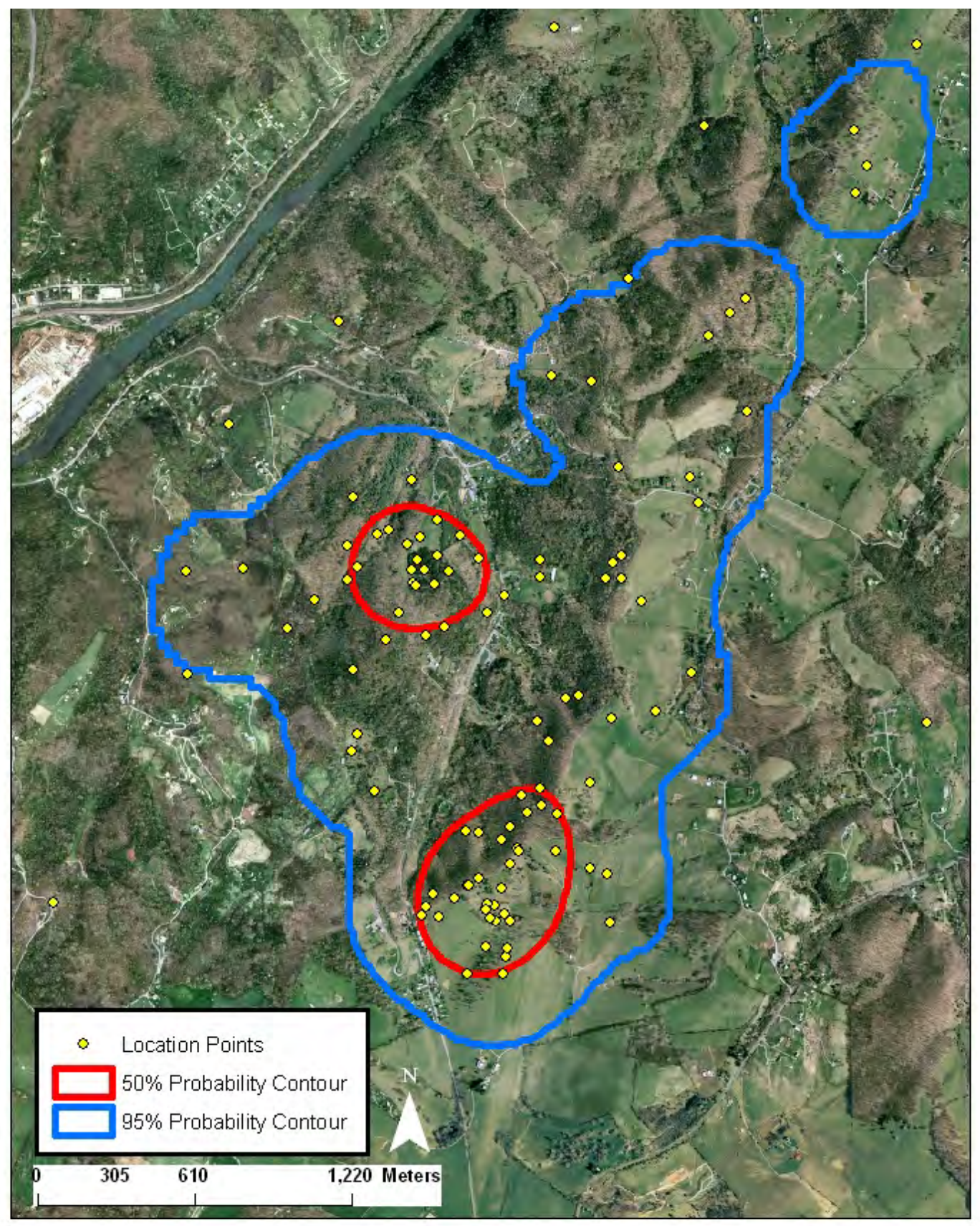


Appendix CLXVIIa. RG5802 (adult) - 95\% probability contours of the fall and winter fixed kernel home range utilization distribution. Smoothing parameter (h) determined by least squares cross validation, Greenbrier County, West Virginia, 2004-2007 (2003 SAMB imagery).

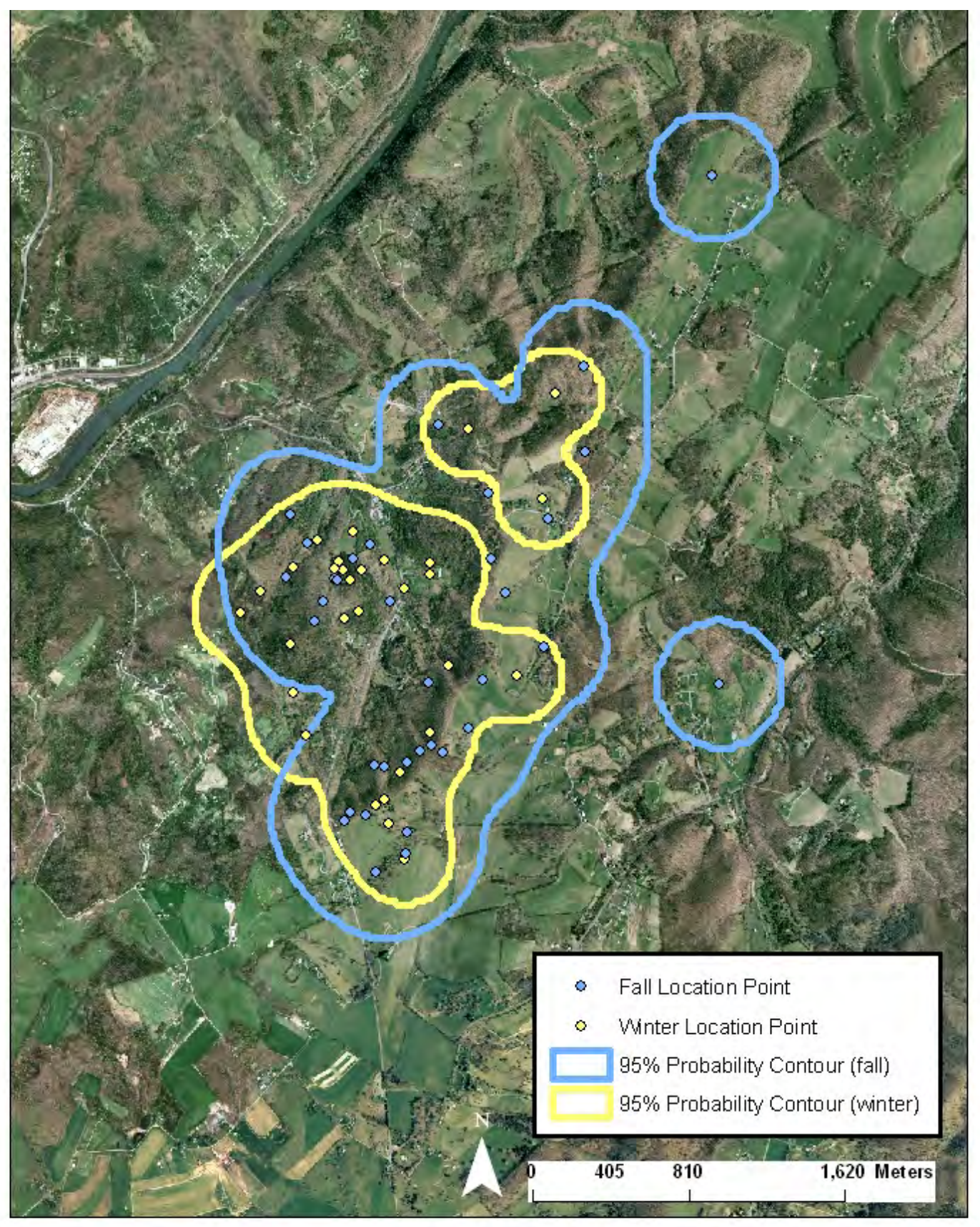


Appendix CLXVIIIa. RG5802 (adult) - 95\% probability contours of the spring-summer and fall-winter fixed kernel home range utilization distribution. Smoothing parameter (h) determined by least squares cross validation, Greenbrier County, West Virginia, 2004-2007 (2003 SAMB imagery).

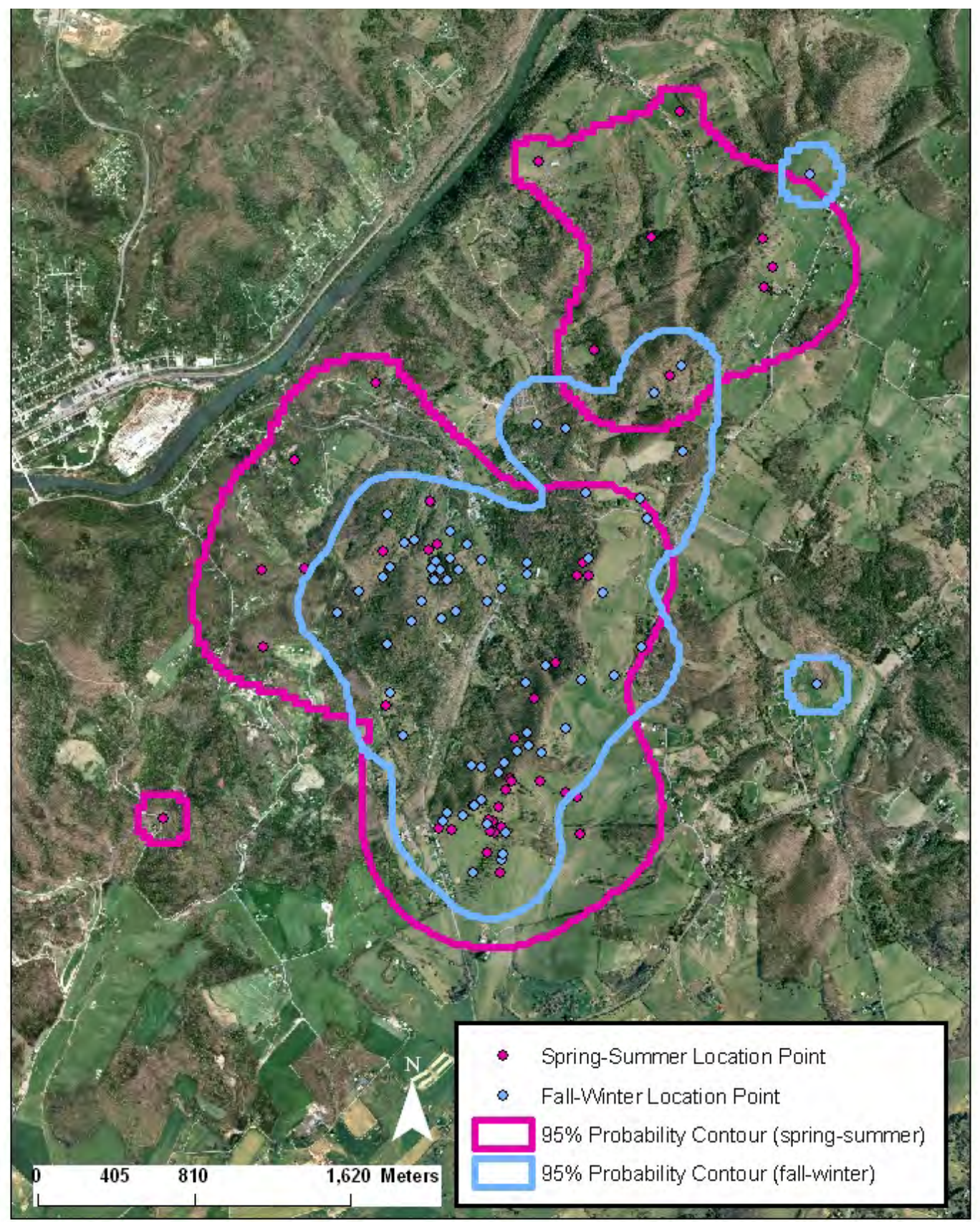


Appendix CLXIXa. RG5803 (adult) - 50\% and 95\% probability contours of the annual fixed kernel home range utilization distribution. Smoothing parameter (h) determined by least squares cross validation, Greenbrier County, West Virginia, 2004-2006 (100k topo map).

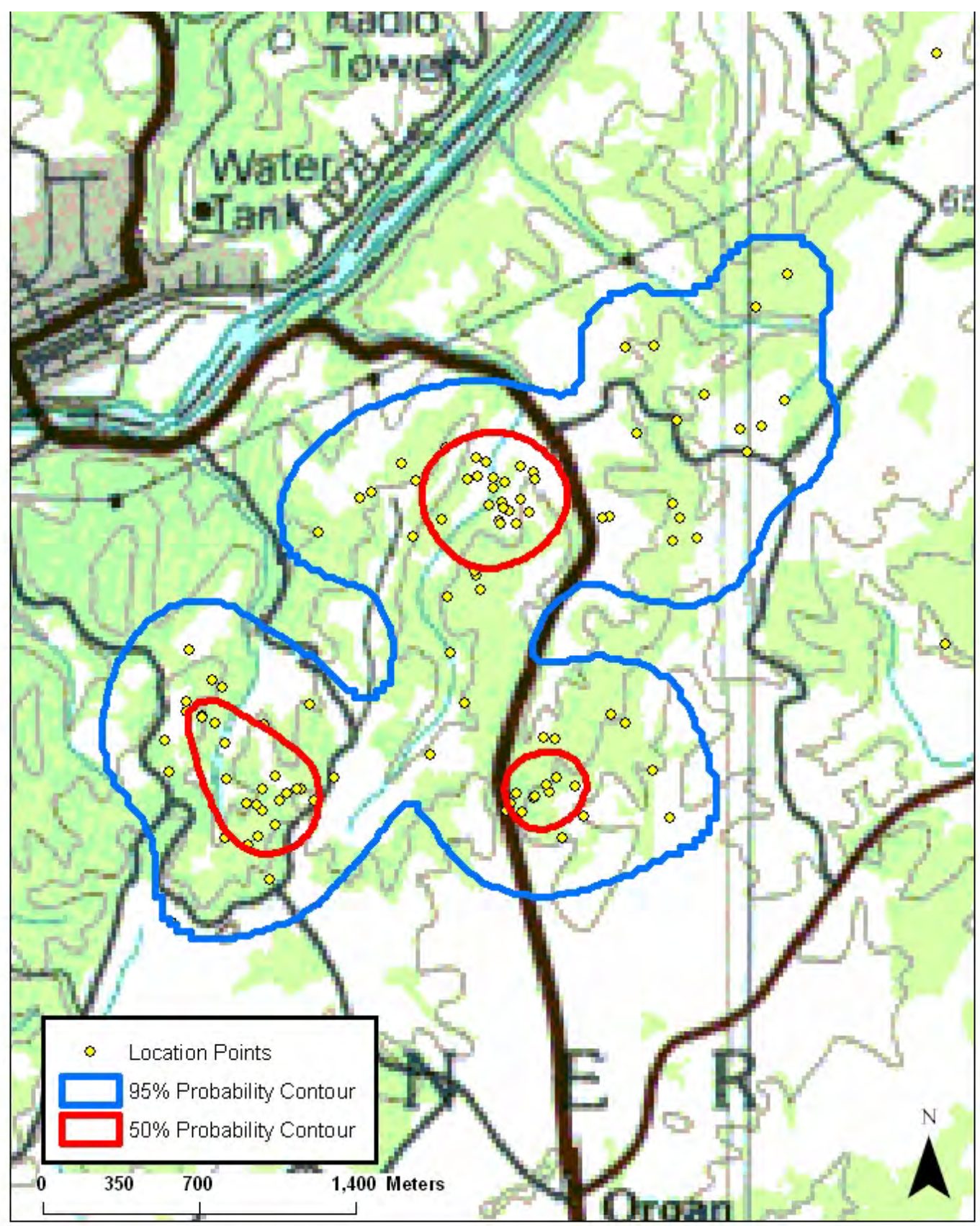


Appendix CLXXa. RG5803 (adult) - 50\% and 95\% probability contours of the annual fixed kernel home range utilization distribution. Smoothing parameter (h) determined by least squares cross validation, Greenbrier County, West Virginia, 2004-2006 (2003 SAMB imagery).

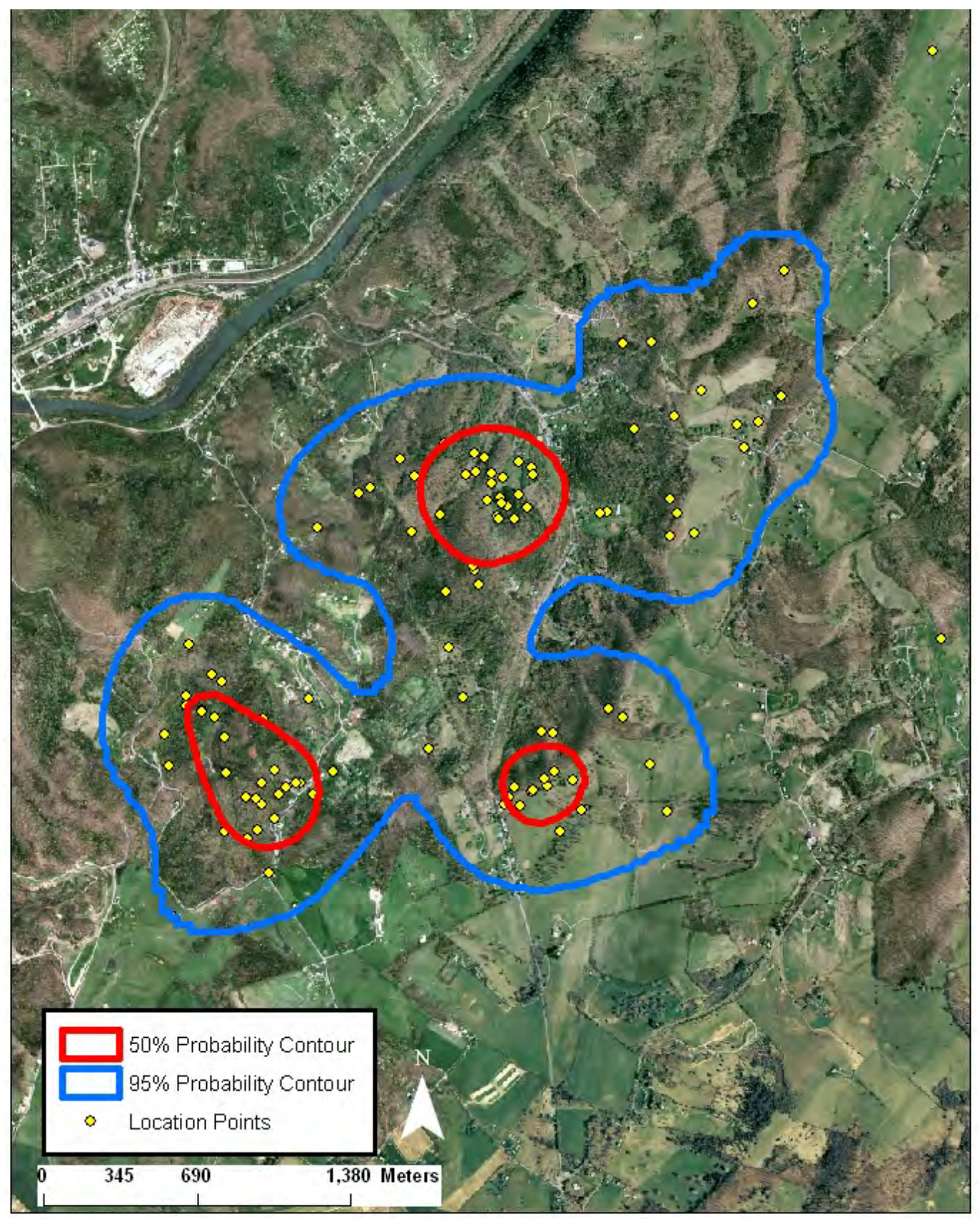


Appendix CLXXIa. RG5803 (adult) - 95\% probability contour of the fall fixed kernel home range utilization distribution. Smoothing parameter (h) determined by least squares cross validation, Greenbrier County, West Virginia, 2004-2006 (2003 SAMB imagery).

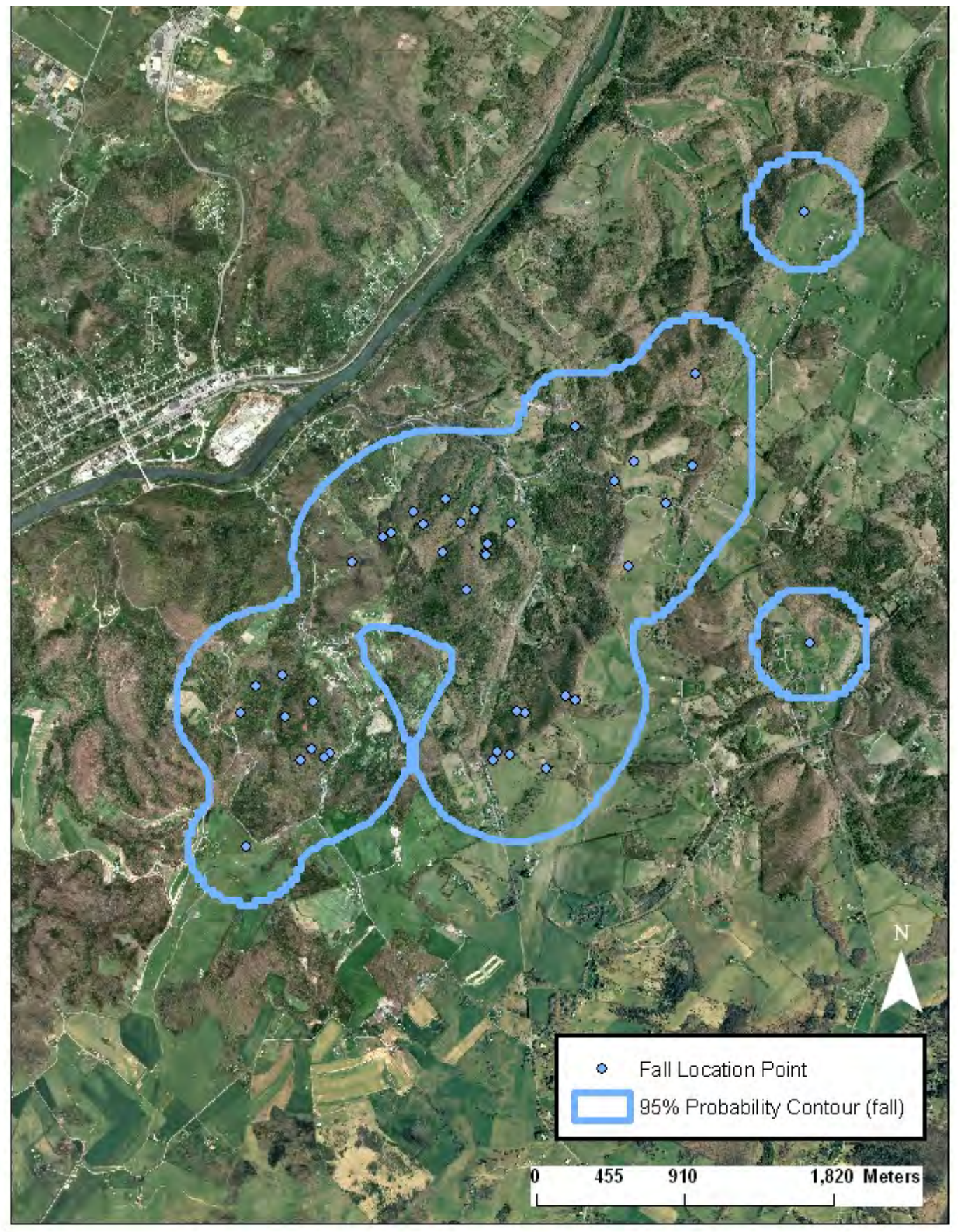


Appendix CLXXIIa. RG5803 (adult) - 95\% probability contours of the spring-summer and fall-winter fixed kernel home range utilization distribution. Smoothing parameter (h) determined by least squares cross validation, Greenbrier County, West Virginia, 2004-2006 (2003 SAMB imagery).

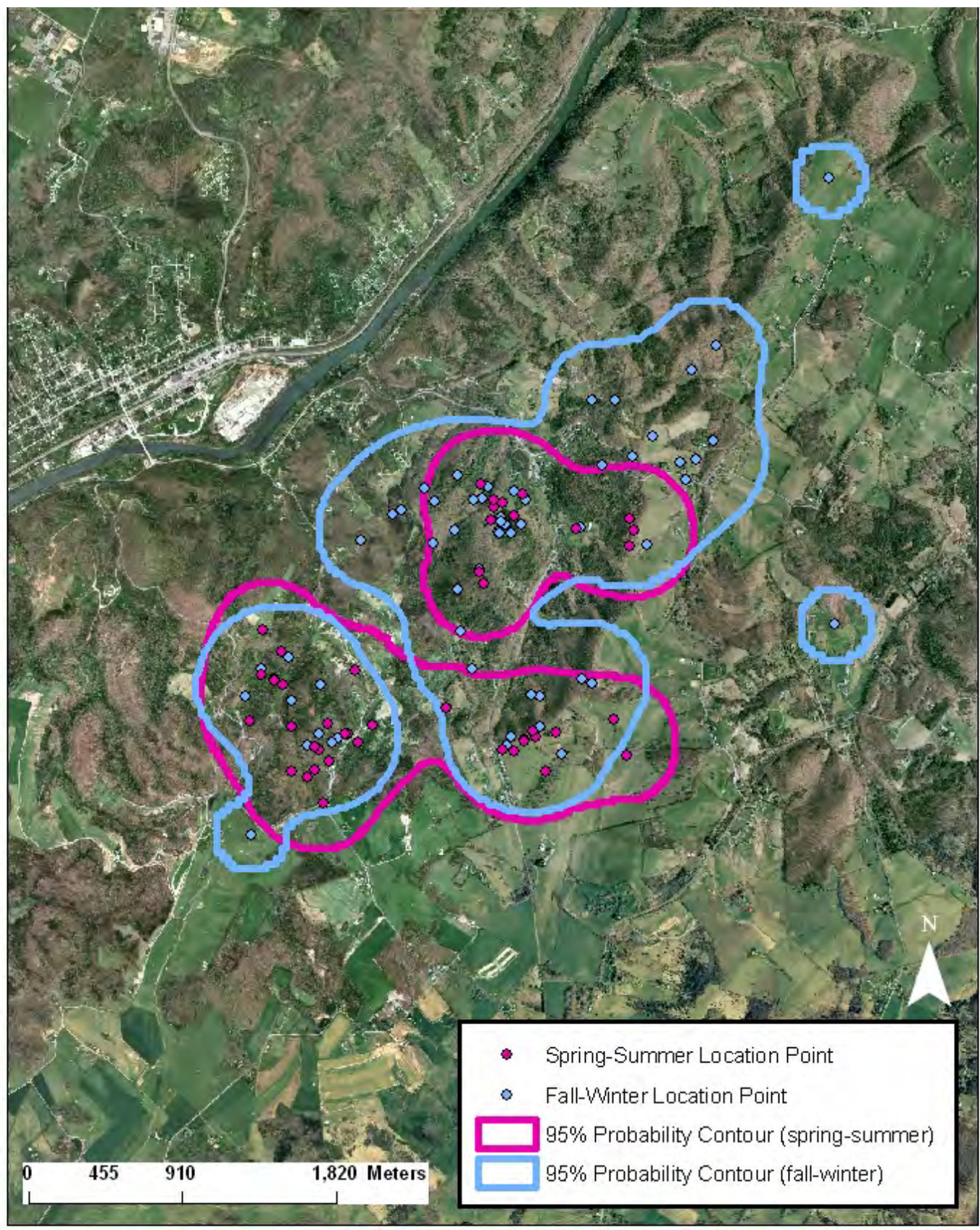


Appendix CLXXIIIa. RG5808 (adult) - 50\% and 95\% probability contours of the annual fixed kernel home range utilization distribution. Smoothing parameter (h) determined by least squares cross validation, Greenbrier County, West Virginia, 2004-2005 (100k topo map).

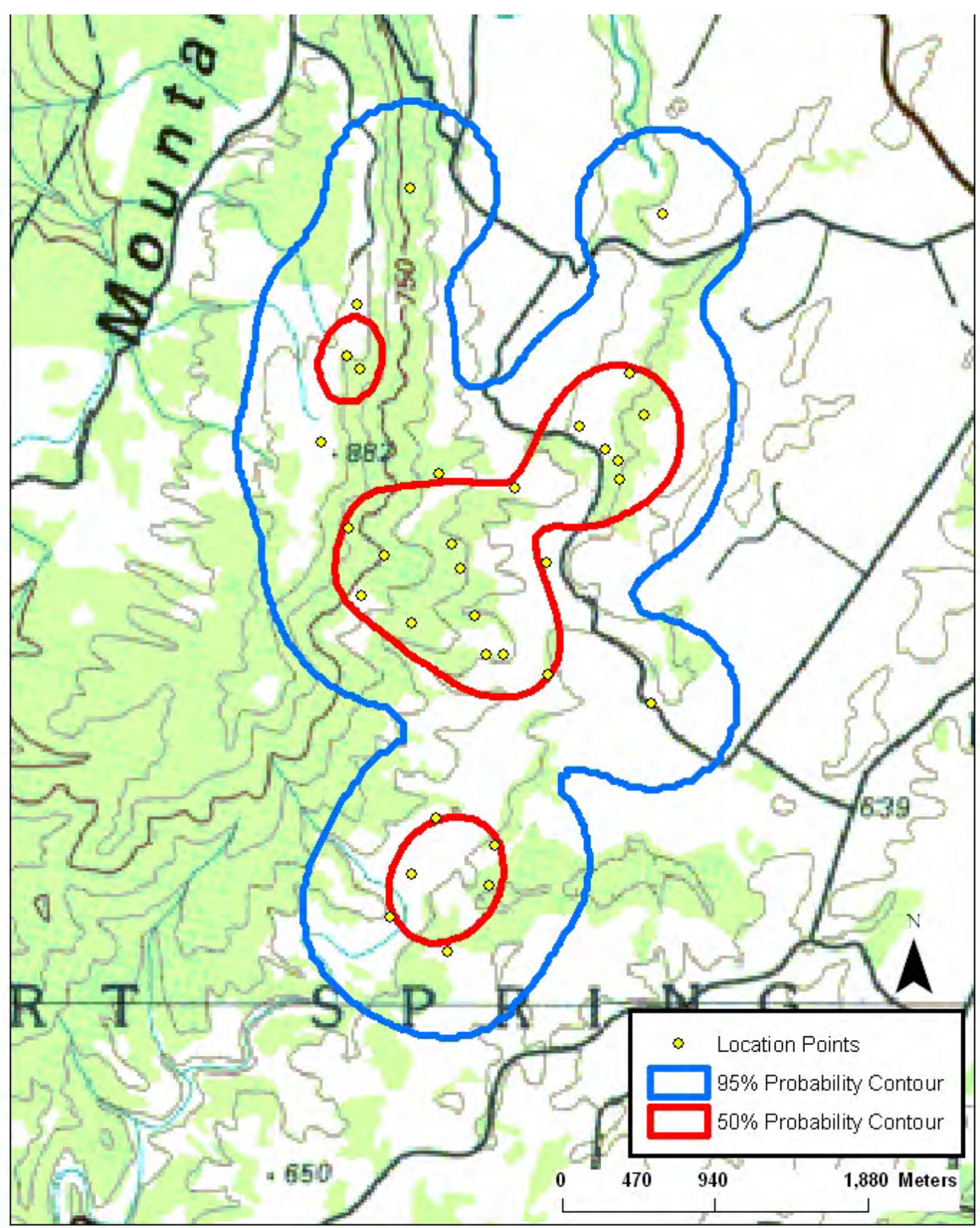


Appendix CLXXIVa. RG5808 (adult) - 50\% and 95\% probability contours of the annual fixed kernel home range utilization distribution. Smoothing parameter (h) determined by least squares cross validation, Greenbrier County, West Virginia, 2004-2005 (2003 SAMB imagery).

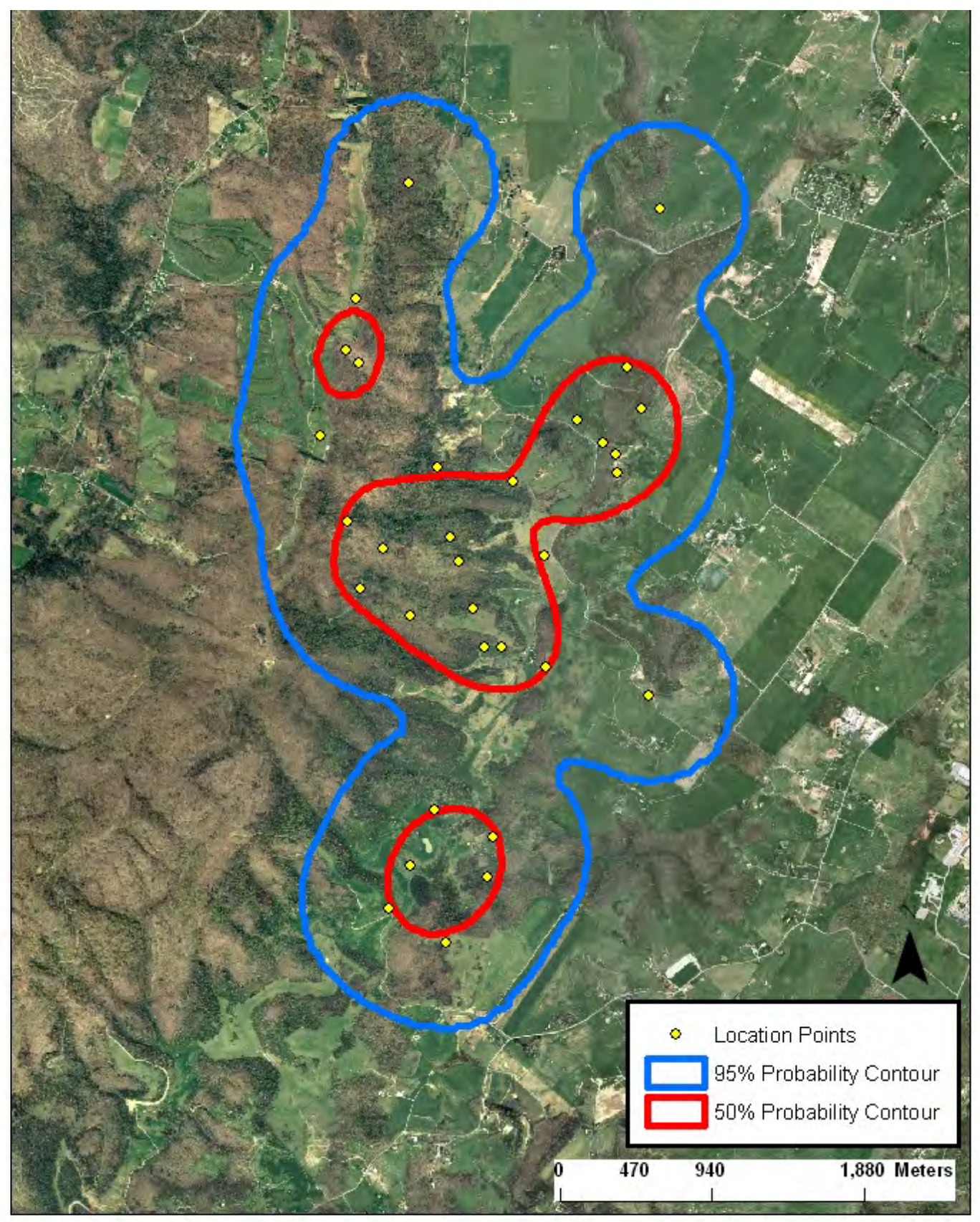


Appendix CLXXVa. RG5810 (juvenile) - 50\% and 95\% probability contours of the annual fixed kernel home range utilization distribution. Smoothing parameter (h) determined by least squares cross validation, Greenbrier County, West Virginia, 2004-2005 (100k topo map).

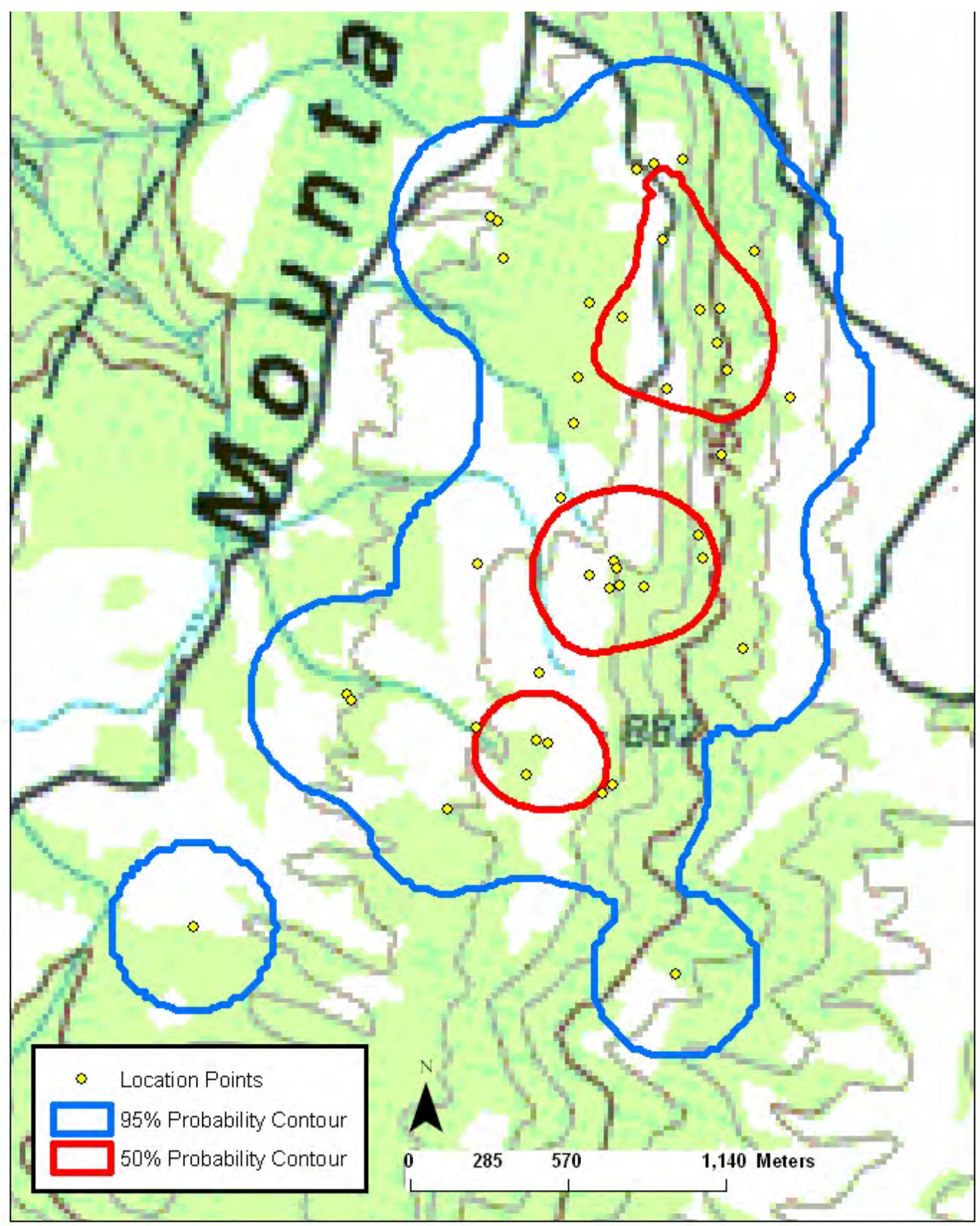


Appendix CLXXVIa. RG5810 (juvenile) - 50\% and 95\% probability contours of the annual fixed kernel home range utilization distribution. Smoothing parameter (h) determined by least squares cross validation, Greenbrier County, West Virginia, 2004-2005 (2003 SAMB imagery).

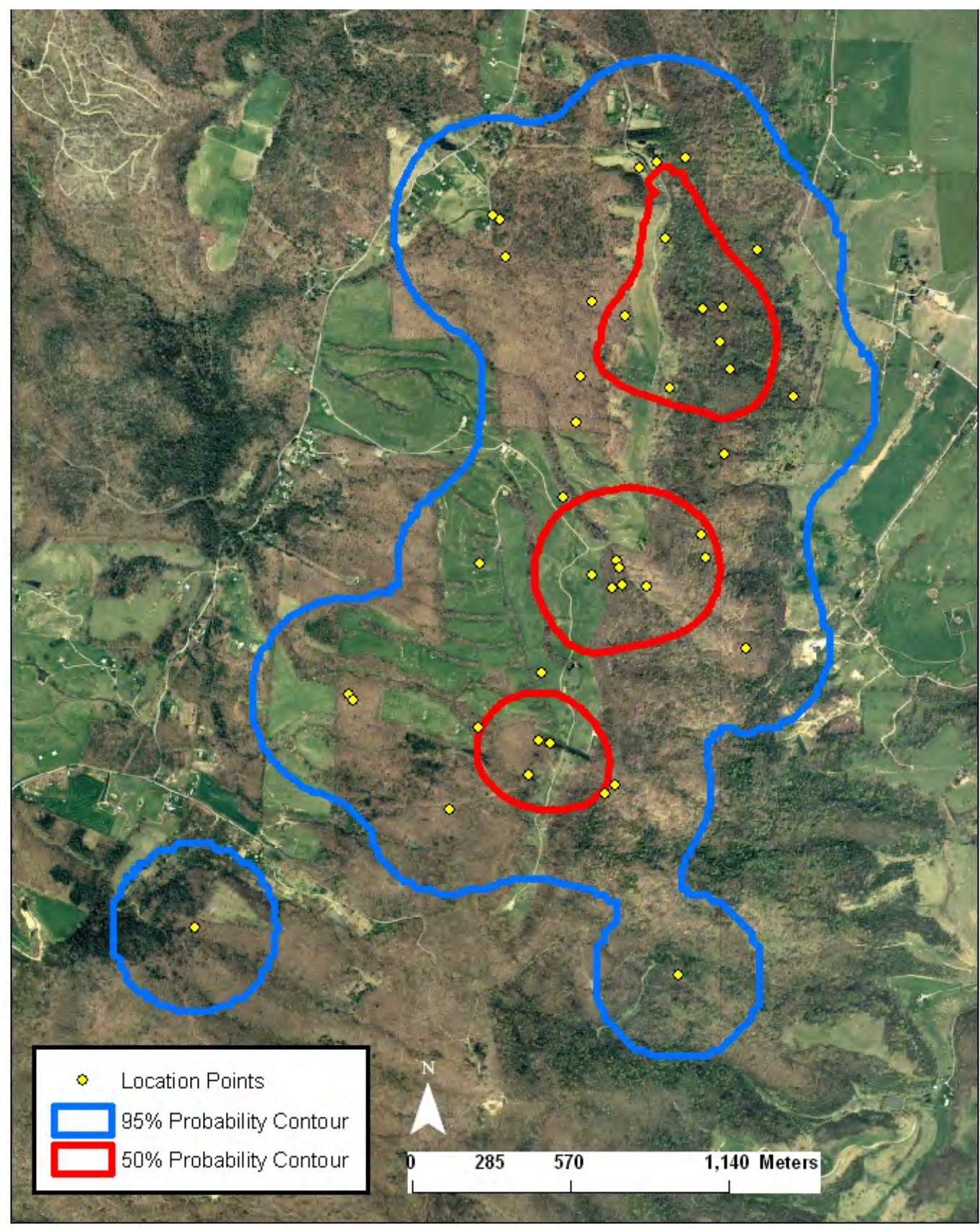


Appendix CLXXVIIa. RG5810 (adult) - 50\% and 95\% probability contours of the annual fixed kernel home range utilization distribution. Smoothing parameter (h) determined by least squares cross validation, Greenbrier County, West Virginia, 2005-2006 (100k topo map).

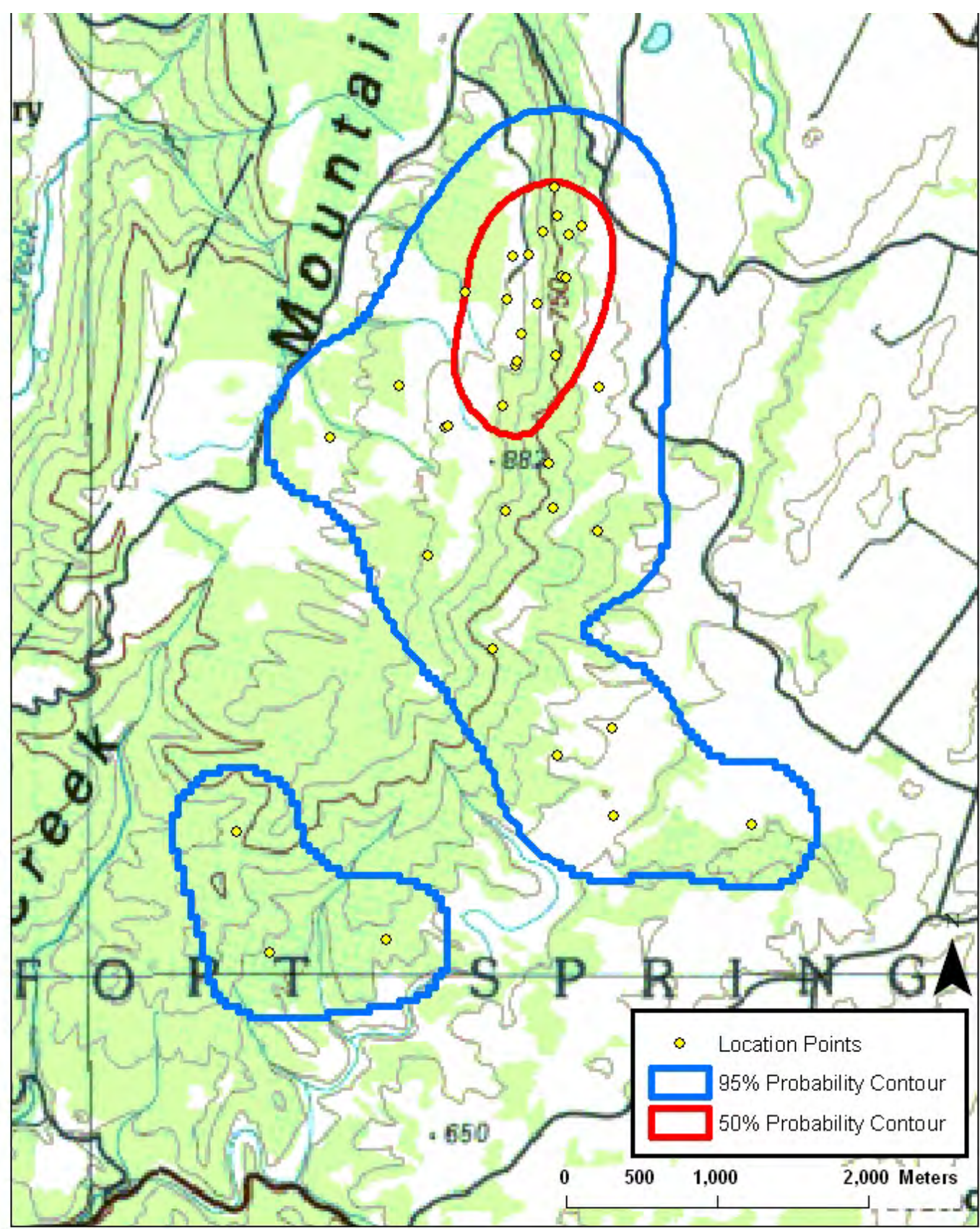


Appendix CLXXVIIIa. RG5810 (adult) - 50\% and 95\% probability contours of the annual fixed kernel home range utilization distribution. Smoothing parameter (h) determined by least squares cross validation, Greenbrier County, West Virginia, 2005-2006 (2003 SAMB imagery).

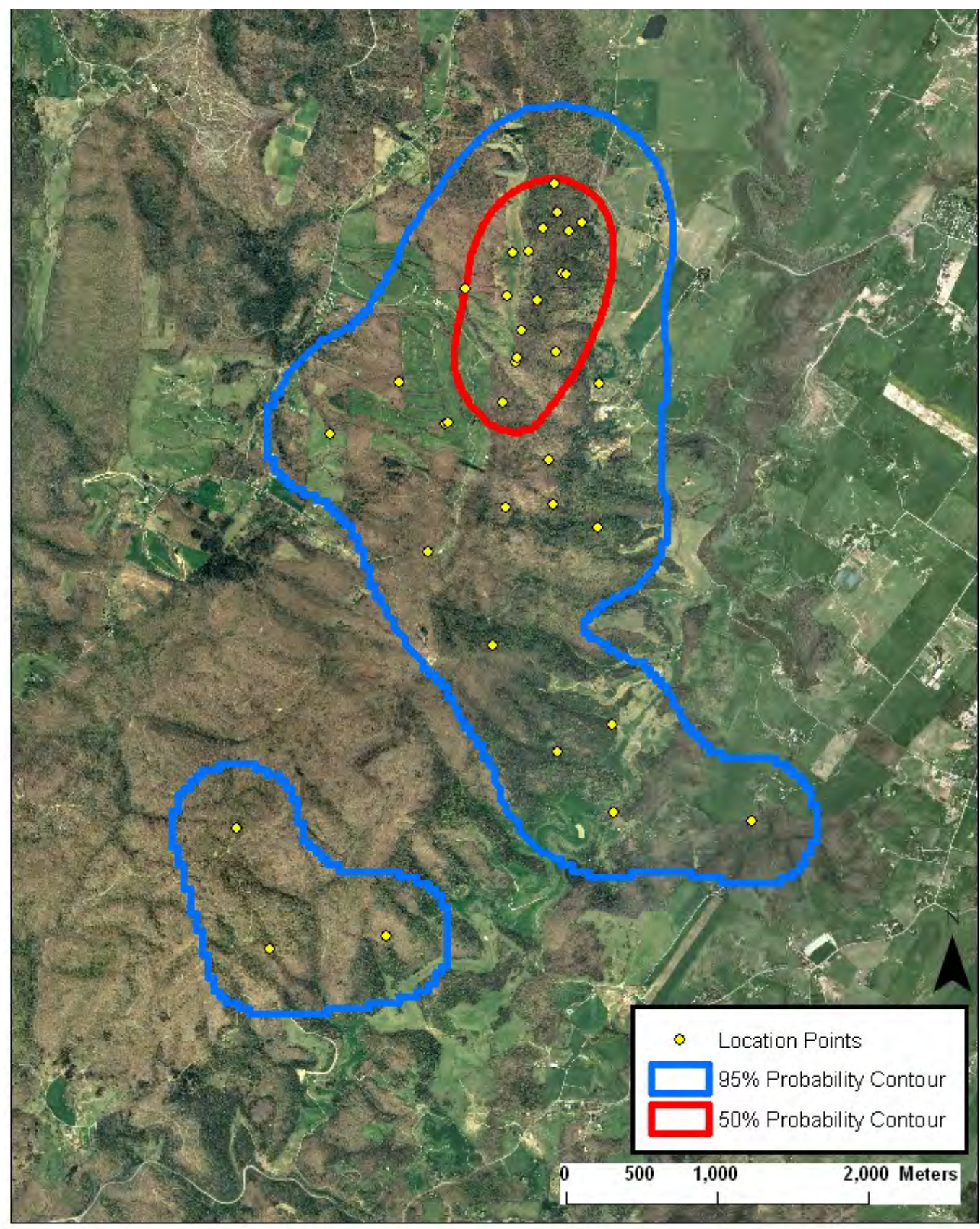


Appendix CLXXIXa. RG5811 (juvenile) - 50\% and 95\% probability contours of the annual fixed kernel home range utilization distribution. Smoothing parameter (h) determined by least squares cross validation, Greenbrier County, West Virginia, 2004-2005 (100k topo map).

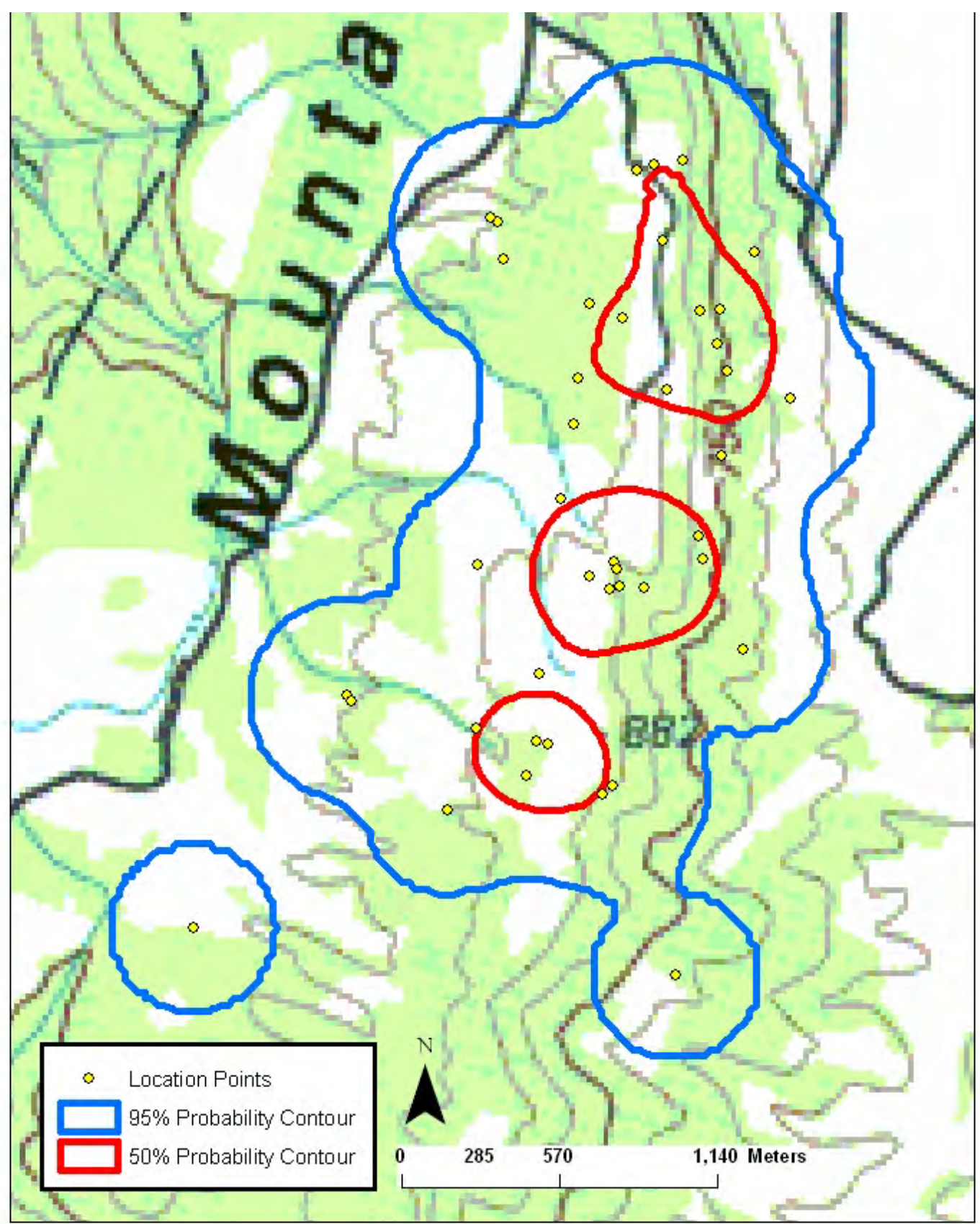


Appendix CLXXXa. RG5811 (juvenile) - 50\% and 95\% probability contours of the annual fixed kernel home range utilization distribution. Smoothing parameter (h) determined by least squares cross validation, Greenbrier County, West Virginia, 2004-2005 (2003 SAMB imagery).

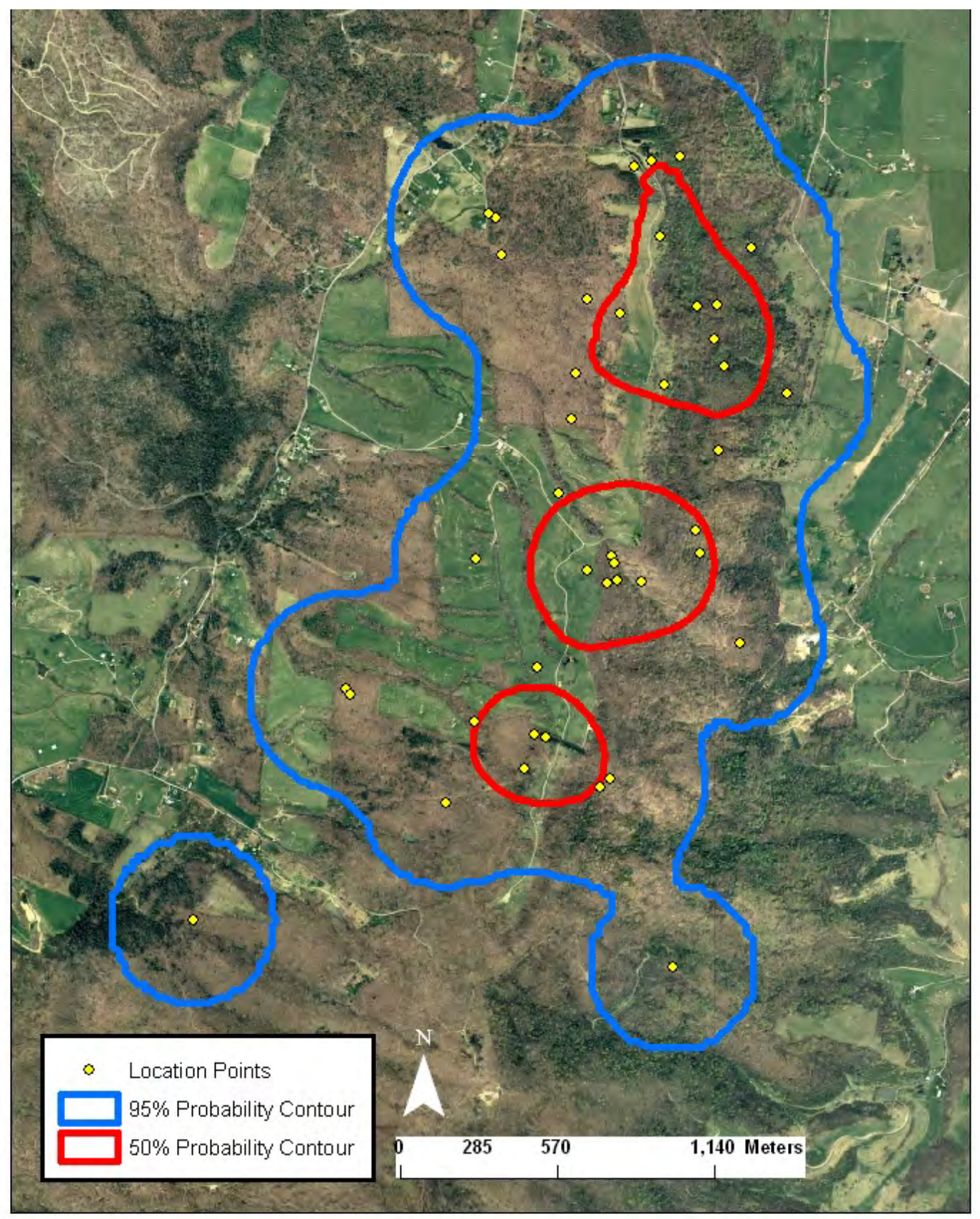


Appendix CLXXXIa. RG5811 (adult) - 50\% and 95\% probability contours of the annual fixed kernel home range utilization distribution. Smoothing parameter (h) determined by least squares cross validation, Greenbrier County, West Virginia, 2005-2007 (100k topo map).

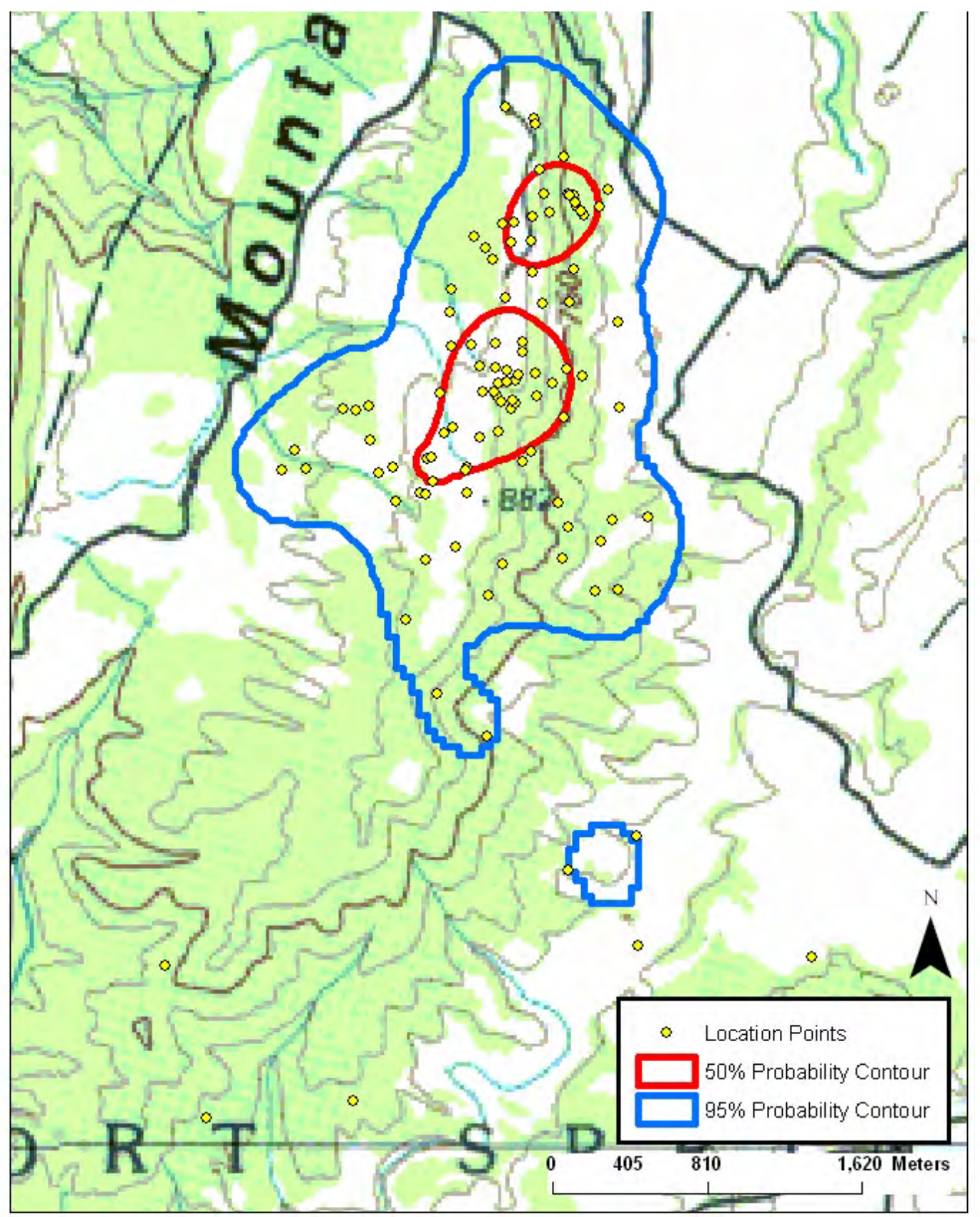


Appendix CLXXXIIa. RG5811 (adult) - 50\% and 95\% probability contours of the annual fixed kernel home range utilization distribution. Smoothing parameter (h) determined by least squares cross validation, Greenbrier County, West Virginia, 2005-2007 (2003 SAMB imagery).

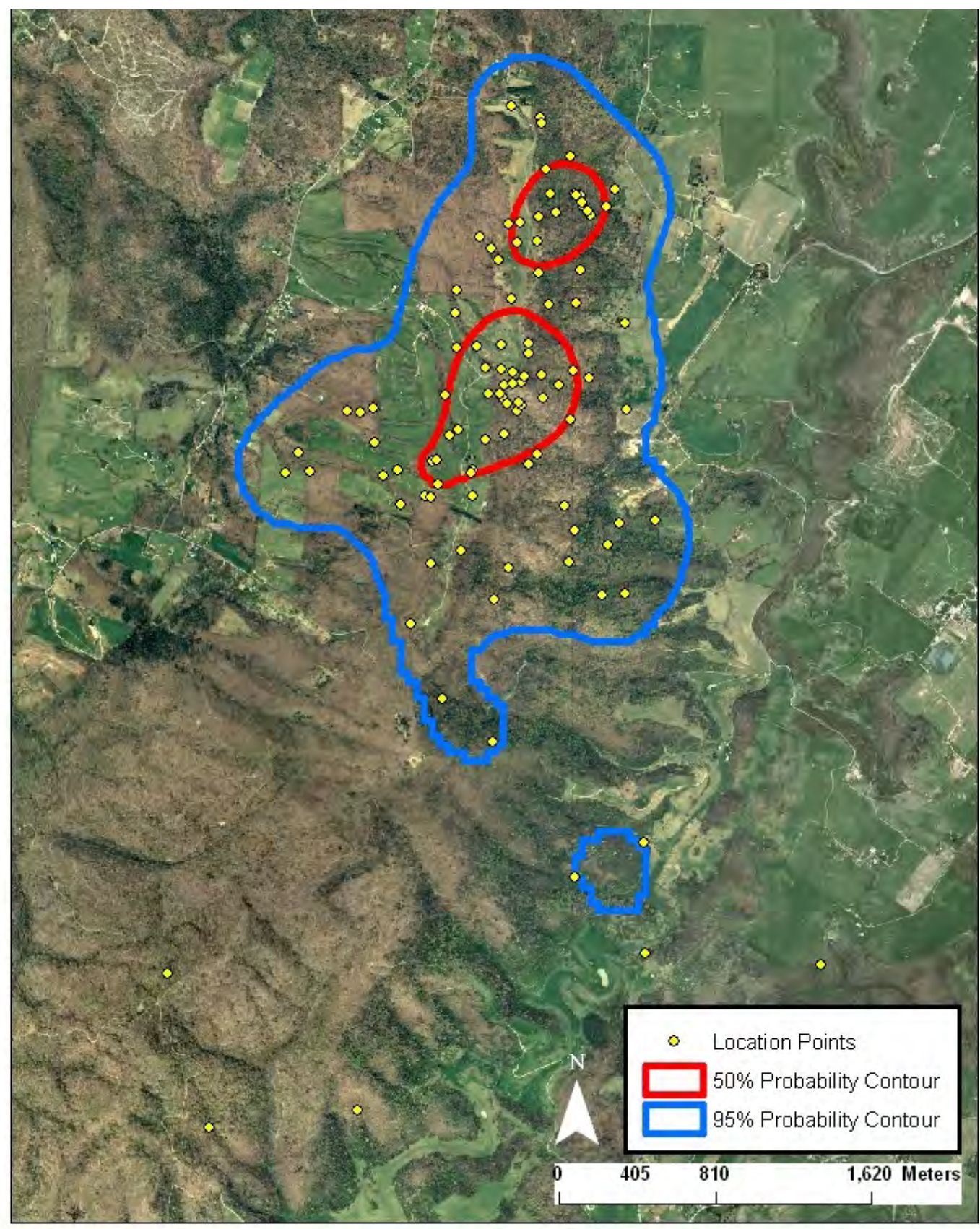


Appendix CLXXXIIIa. RG5811 (adult) - 95\% probability contour of the winter fixed kernel home range utilization distribution. Smoothing parameter (h) determined by least squares cross validation, Greenbrier County, West Virginia, 2005-2007 (2003 SAMB imagery).

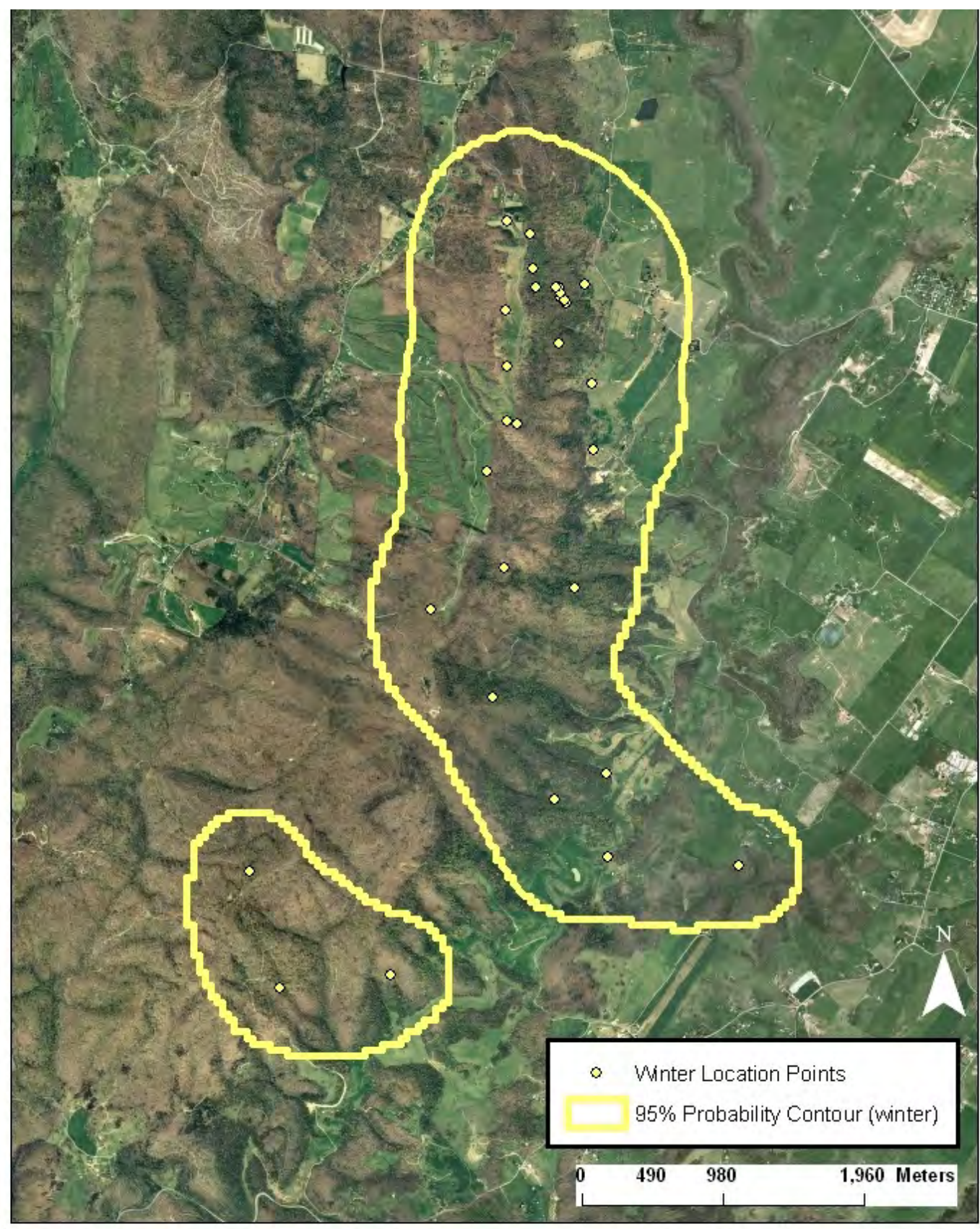


Appendix CLXXXIVa. RG5811 (adult) - 95\% probability contours of the spring-summer and fall-winter fixed kernel home range utilization distribution. Smoothing parameter (h) determined by least squares cross validation, Greenbrier County, West Virginia, 2005-2007 (2003 SAMB imagery).

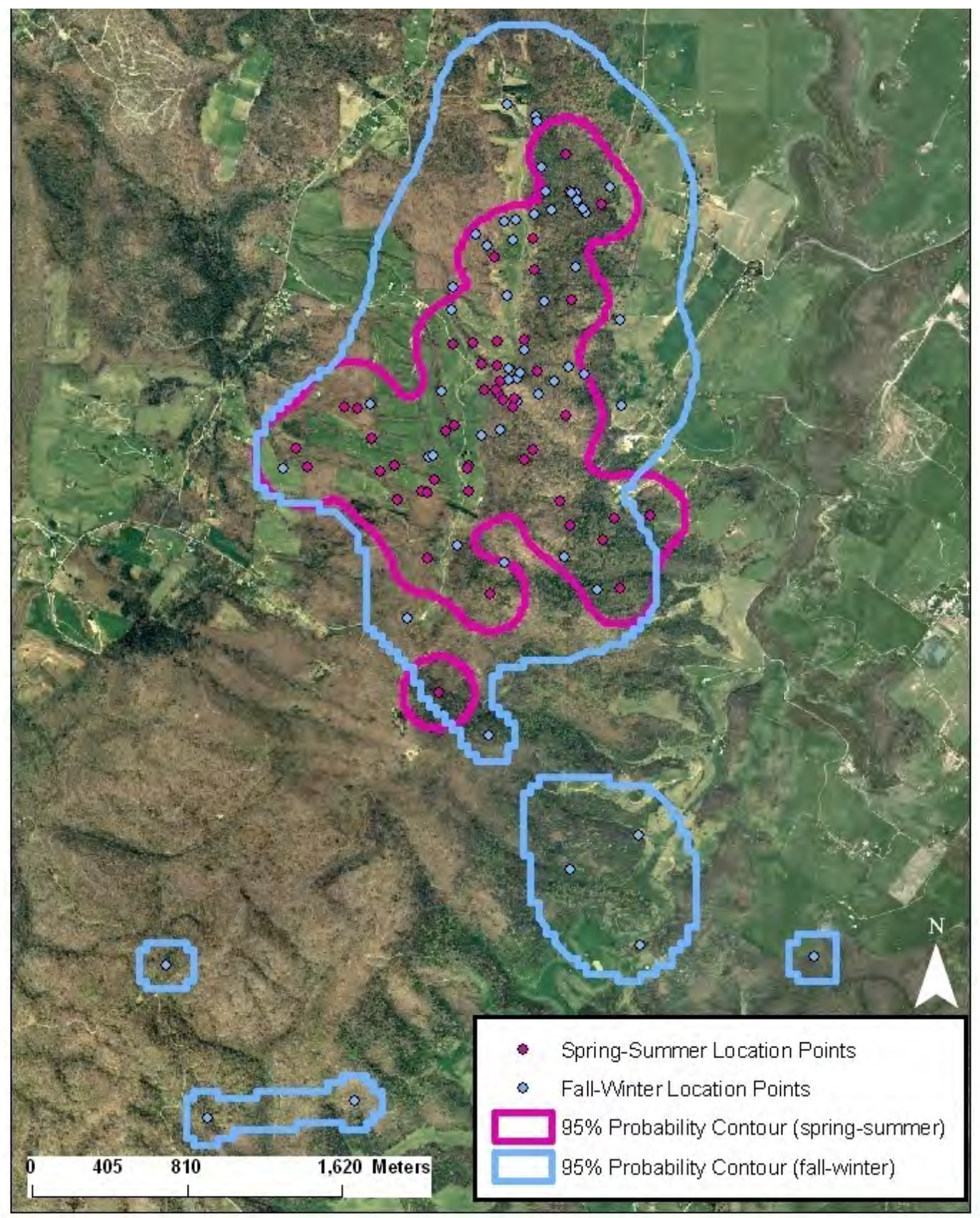


Appendix B. Annual and seasonal 95\% utilization distributions (UD’s) of the fixed kernel home range estimate (ha) of juvenile and adult male wild turkey in West Virginia, 2004-2007.

\begin{tabular}{|c|c|c|c|c|c|c|c|c|c|}
\hline \multirow[b]{2}{*}{ I.D. } & \multirow[b]{2}{*}{ Age } & \multirow[b]{2}{*}{ County Trapped } & \multirow[b]{2}{*}{ Period Monitored } & \multicolumn{6}{|c|}{ Home Range (ha) (\# of telemetry locations) } \\
\hline & & & & Annual & Spring & Fall & Winter & Spring-Summer & Fall-Winter \\
\hline \multirow{2}{*}{ RG5101 } & $\mathrm{J}$ & Taylor & $9 / 04-8 / 05$ & $1,128.3(42)$ & & & & & \\
\hline & A & & $9 / 05-4 / 06$ & 2,895.2 (41) & & & & & \\
\hline \multirow{2}{*}{ RG5102 } & $\mathrm{J}$ & Taylor & $9 / 04-8 / 05$ & $1,158.7(43)$ & & & & & \\
\hline & A & & $9 / 05-8 / 07$ & $918.8(155)$ & $679.6(69)$ & & & $674.1(94)$ & $1,190.1(61)$ \\
\hline \multirow{2}{*}{ RG5103 } & $\mathrm{J}$ & Taylor & $9 / 04-8 / 05$ & $1,088.4(42)$ & & & & & \\
\hline & A & & $9 / 05-5 / 06$ & $2,697.3(45)$ & & & & & \\
\hline RG5104 & $\mathrm{J}$ & Taylor & $9 / 04-7 / 05$ & $1,363.5(40)$ & & & & & \\
\hline \multirow{2}{*}{ RG5106 } & $\mathrm{J}$ & Taylor & $9 / 04-8 / 05$ & $530.8(49)$ & & & & & \\
\hline & A & & $9 / 05-12 / 06$ & $537.8(100)$ & 371.9 (35) & $665.9(30)$ & & $385.2(48)$ & $652.0(52)$ \\
\hline \multirow{2}{*}{ RG5109 } & $\mathrm{J}$ & Marion & $9 / 04-8 / 05$ & $537.0(49)$ & & & & & \\
\hline & A & & $9 / 05-8 / 07$ & $572.6(155)$ & 416.3 (69) & $667.6(31)$ & $248.0(30)$ & 410.9 (94) & $634.3(61)$ \\
\hline RG5110 & A & Marion & $9 / 04-4 / 07$ & $289.9(162)$ & 338.7 (55) & 741.7 (40) & $167.6(42)$ & $262.7(80)$ & 348.8 (82) \\
\hline RG5111 & A & Taylor & $1 / 05-8 / 07$ & 587.1(189) & $460.7(81)$ & 246.7 (33) & 883.9 (38) & $458.3(118)$ & $680.5(71)$ \\
\hline RG5114 & A & Taylor & $1 / 05-5 / 07$ & $680.4(163)$ & $614.5(69)$ & $241.1(32)$ & 977.1 (39) & $615.1(92)$ & $777.8(71)$ \\
\hline \multirow{2}{*}{ RG5122 } & $\mathrm{J}$ & Taylor & $10 / 05-8 / 06$ & $415.1(70)$ & 373.1 (35) & & & $274.1(48)$ & \\
\hline & A & & $9 / 06-8 / 07$ & $816.6(85)$ & $551.0(34)$ & & & 453.1 (48) & 379.3 (37) \\
\hline RG5126 & $\mathrm{J}$ & Marion & $3 / 06-1 / 07$ & & & & & $62.0(50)$ & \\
\hline RG5128 & $\mathrm{J}$ & Taylor & $9 / 06-8 / 07$ & $527.9(84)$ & $207.3(34)$ & & & 315.8 (47) & \\
\hline RG5129 & $\mathrm{J}$ & Taylor & $9 / 06-8 / 07$ & $530.4(84)$ & 205.7 (34) & & & 317.3 (47) & \\
\hline RG5130 & $\mathrm{J}$ & Taylor & $10 / 06-4 / 07$ & $153.4(41)$ & & & & & \\
\hline RG5131 & $\mathrm{J}$ & Taylor & $10 / 06-6 / 07$ & $1,345.3(61)$ & $479.2(34)$ & & & & \\
\hline RG5132 & $\mathrm{J}$ & Taylor & $10 / 06-8 / 07$ & $1,212.6(72)$ & $479.2(34)$ & & & 302.8 (47) & \\
\hline
\end{tabular}


Appendix B cont.

\begin{tabular}{|c|c|c|c|c|c|c|c|c|c|}
\hline \multirow[b]{2}{*}{ I.D. } & \multirow[b]{2}{*}{ Age } & \multirow[b]{2}{*}{ Date Trapped } & \multirow[b]{2}{*}{ \# days monitored } & \multicolumn{6}{|c|}{ Home Range (ha) (\# of telemetry locations) } \\
\hline & & & & Annual & Spring & Fall & Winter & Spring-Summer & Fall-Winter \\
\hline RG5133 & $\mathrm{J}$ & Taylor & $10 / 06-8 / 07$ & $210.0(71)$ & $290.2(34)$ & & & $228.2(47)$ & \\
\hline RG5135 & $\mathrm{J}$ & Taylor & $10 / 06-8 / 07$ & $1,191.4(70)$ & $478.8(34)$ & & & $307.0(46)$ & \\
\hline RG5136 & $\mathrm{J}$ & Taylor & $10 / 06-8 / 07$ & $1,195.5(70)$ & $479.2(34)$ & & & $307.7(46)$ & \\
\hline RG5137 & $\mathrm{J}$ & Taylor & $10 / 06-5 / 07$ & $1,416.7(58)$ & $450.3(34)$ & & & & \\
\hline RG5138 & $\mathrm{J}$ & Taylor & $10 / 06-8 / 07$ & $1,193.4(70)$ & $476.1(34)$ & & & $305.6(46)$ & \\
\hline RG5139 & $\mathrm{J}$ & Taylor & $10 / 06-8 / 07$ & $185.4(71)$ & 229.6 (34) & & & 185.4 (47) & \\
\hline RG5207 & A & Pendleton & $1 / 05-4 / 07$ & 1,179.7 (36) & & & & & \\
\hline RG5212 & A & Hardy & $3 / 05-4 / 07$ & $1,188.5(74)$ & & & & 1,232.3 (51) & \\
\hline RG5218 & $\mathrm{J}$ & Hardy & $3 / 05-10 / 06$ & $1,490.8(35)$ & & & & & \\
\hline RG5303 & A & Lewis & $9 / 04-4 / 06$ & $673.4(45)$ & & & & & \\
\hline RG5304 & A & Lewis & $9 / 04-4 / 06$ & 499.4 (51) & & & & & \\
\hline RG5305 & A & Lewis & $9 / 04-4 / 05$ & $205.0(31)$ & & & & & \\
\hline RG5310 & A & Lewis & $1 / 05-4 / 07$ & $1,502.2(66)$ & & & & 1,025.6 (31) & $1,495.9(35)$ \\
\hline \multirow{2}{*}{ RG5315 } & $\mathrm{J}$ & Lewis & $9 / 05-8 / 06$ & 1,736.9 (34) & & & & & \\
\hline & A & & $9 / 06-8 / 07$ & 2,212.3 (30) & & & & & \\
\hline RG5326 & A & Lewis & $3 / 06-8 / 07$ & 1,408.3 (34) & & & & & \\
\hline RG5401 & A & Greenbrier & $10 / 04-4 / 07$ & 329.1 (142) & 326.7 (40) & 386.6 (35) & 293.6 (41) & $181.6(66)$ & $366.0(76)$ \\
\hline RG5402 & A & Greenbrier & $10 / 04-4 / 06$ & 470.3 (85) & & & & 483.8 (39) & $447.2(46)$ \\
\hline RG5403 & $\mathrm{A}$ & Greenbrier & $10 / 04-6 / 05$ & 397.5 (42) & & & & & \\
\hline RG5407 & $\mathrm{J}$ & Summers & $11 / 04-8 / 05$ & 1,904.8 (39) & & & & & \\
\hline RG5409 & A & Summers & $1 / 05-8 / 07$ & 377.7 (98) & & & & 335.5 (59) & 249.6 (39) \\
\hline RG5410 & $\mathrm{A}$ & Summers & $1 / 05-4 / 06$ & 316.4 (51) & & & & & \\
\hline RG5414 & A & Summers & $4 / 06-4 / 07$ & 330.7 (41) & & & & & \\
\hline RG5415 & A & Summers & $4 / 06-4 / 07$ & 355.2 (40) & & & & & \\
\hline
\end{tabular}


Appendix B cont.

\begin{tabular}{|c|c|c|c|c|c|c|c|c|c|}
\hline \multirow[b]{2}{*}{ I.D. } & \multirow[b]{2}{*}{ Age } & \multirow[b]{2}{*}{ Date Trapped } & \multirow[b]{2}{*}{ \# days monitored } & \multicolumn{6}{|c|}{ Home Range (ha) (\# of telemetry locations) } \\
\hline & & & & Annual & Spring & Fall & Winter & Spring-Summer & Fall-Winter \\
\hline RG5416 & A & Summers & $4 / 06-8 / 07$ & $175.8(56)$ & & & & $188.4(33)$ & \\
\hline RG5501 & A & Lincoln & $9 / 04-4 / 06$ & $460.0(55)$ & & & & & $312.9(38)$ \\
\hline \multirow{2}{*}{ RG5510 } & $\mathrm{J}$ & Mason & $10 / 04-8 / 05$ & $378.1(40)$ & & & & & \\
\hline & A & & $9 / 05-4 / 07$ & $624.1(60)$ & & & & & $814.7(32)$ \\
\hline RG5518 & A & Mason & $2 / 05-11 / 06$ & $593.8(49)$ & & & & & \\
\hline RG5519 & A & Mason & $2 / 05-2 / 06$ & $781.2(33)$ & & & & & \\
\hline RG5524 & A & Mason & $4 / 05-6 / 07$ & $909.0(46)$ & & & & & \\
\hline RG5701 & $\mathrm{J}$ & Randolph & $9 / 04-8 / 05$ & 880.5 (37) & & & & & \\
\hline RG5702 & $\mathrm{J}$ & Randolph & $10 / 04-8 / 05$ & 921.2 (33) & & & & & \\
\hline \multirow{2}{*}{ RG5703 } & $\mathrm{J}$ & Randolph & $10 / 94-8 / 05$ & $651.0(32)$ & & & & & \\
\hline & A & & $8 / 05-8 / 07$ & $1,490.7(46)$ & & & & & \\
\hline RG5704 & $\mathrm{J}$ & Randolph & $10 / 04-8 / 05$ & 800.9 (33) & & & & & \\
\hline RG5801 & A & Greenbrier & $10 / 04-7 / 07$ & 501.0 (139) & 521.6 (35) & $698.1(31)$ & 250.3 (39) & $591.6(66)$ & 383.9 (73) \\
\hline RG5802 & A & Greenbrier & $10 / 04-4 / 07$ & 461.6 (109) & & 517.5 (35) & $295.9(30)$ & $682.9(65)$ & 389.8 (44) \\
\hline RG5803 & A & Greenbrier & $10 / 04-11 / 06$ & $543.0(102)$ & & 774.5 (41) & & 398.3 (44) & $584.4(58)$ \\
\hline RG5808 & A & Greenbrier & $10 / 04-5 / 05$ & 1,185.3 (32) & & & & & \\
\hline \multirow{2}{*}{ RG5810 } & $\mathrm{J}$ & Greenbrier & $11 / 04-8 / 05$ & $485.1(35)$ & & & & & \\
\hline & A & & $9 / 05-4 / 06$ & 1,126.3 (42) & & & & & \\
\hline \multirow{2}{*}{ RG5811 } & $\mathrm{J}$ & Greenbrier & $11 / 04-8 / 05$ & 485.1 (35) & & & & & \\
\hline & A & & $9 / 05-7 / 07$ & 470.9 (105) & & & 1,173.0 (30) & $293.3(48)$ & $644.4(57)$ \\
\hline
\end{tabular}


Appendix C. Descriptive statistics for the 95\% and 50\% utilization distributions (UD’s) of the fixed kernel and the minimum convex polygon (MCP) annual home range size estimates (ha) of juvenile and adult male wild turkey in 2 study areas in West Virginia, 20042007.

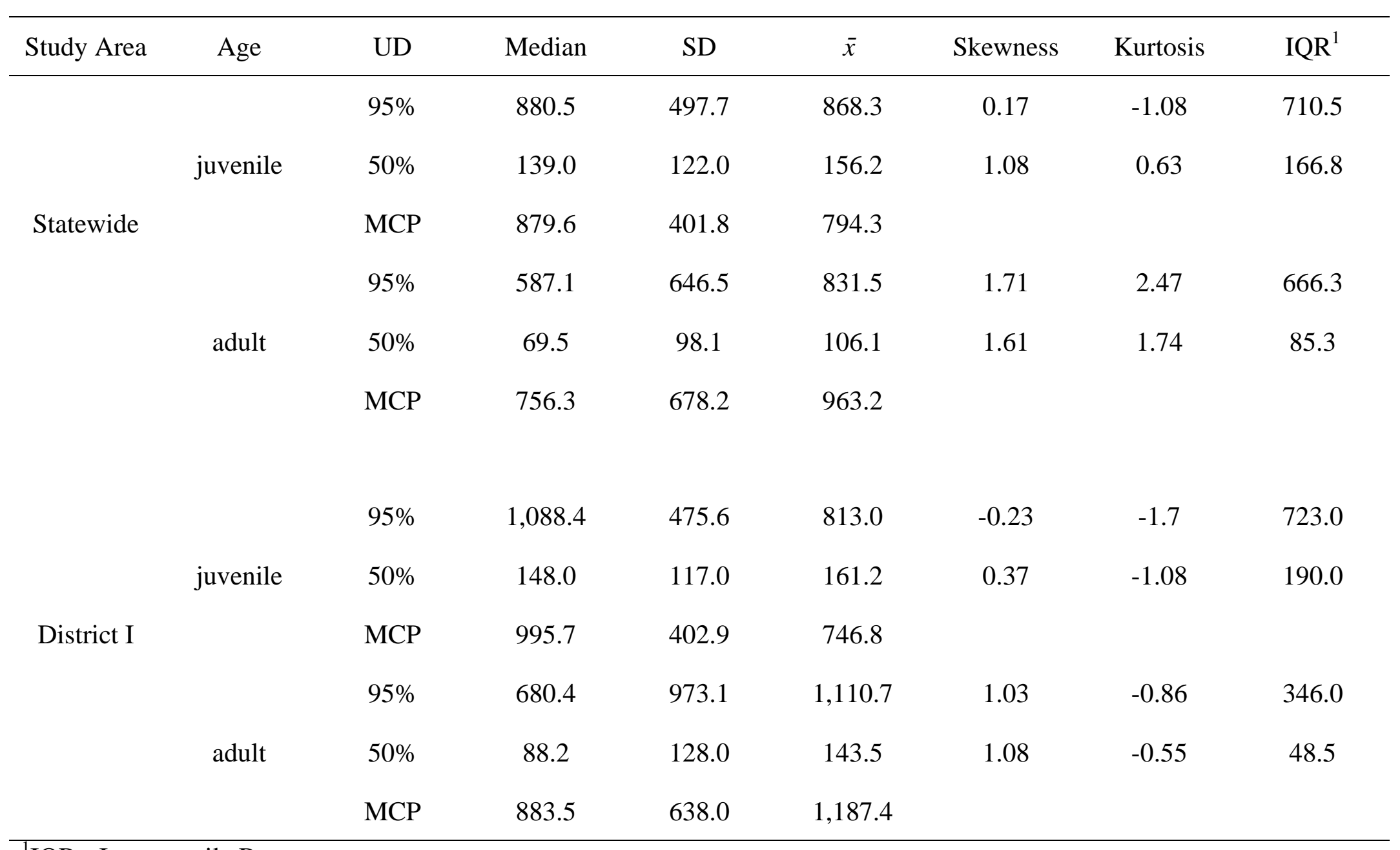

${ }^{1}$ IQR - Interquartile Range 
Appendix D. Id - XXIIId: The April-May 95\% probability contour fixed kernel home range utilization distribution of male wild turkeys in north-central West Virginia, 2006-2007. Least squares cross validation was used to determine the smoothing parameter (h) (2003 SAMB imagery used for map background). 
Appendix Id. RG5102(adult) - 95\% probability contour for the April-May fixed kernel home range utilization distribution. Smoothing parameter (h) determined by least squares cross validation, Taylor County, West Virginia, 2006-2007 (2003 SAMB imagery).

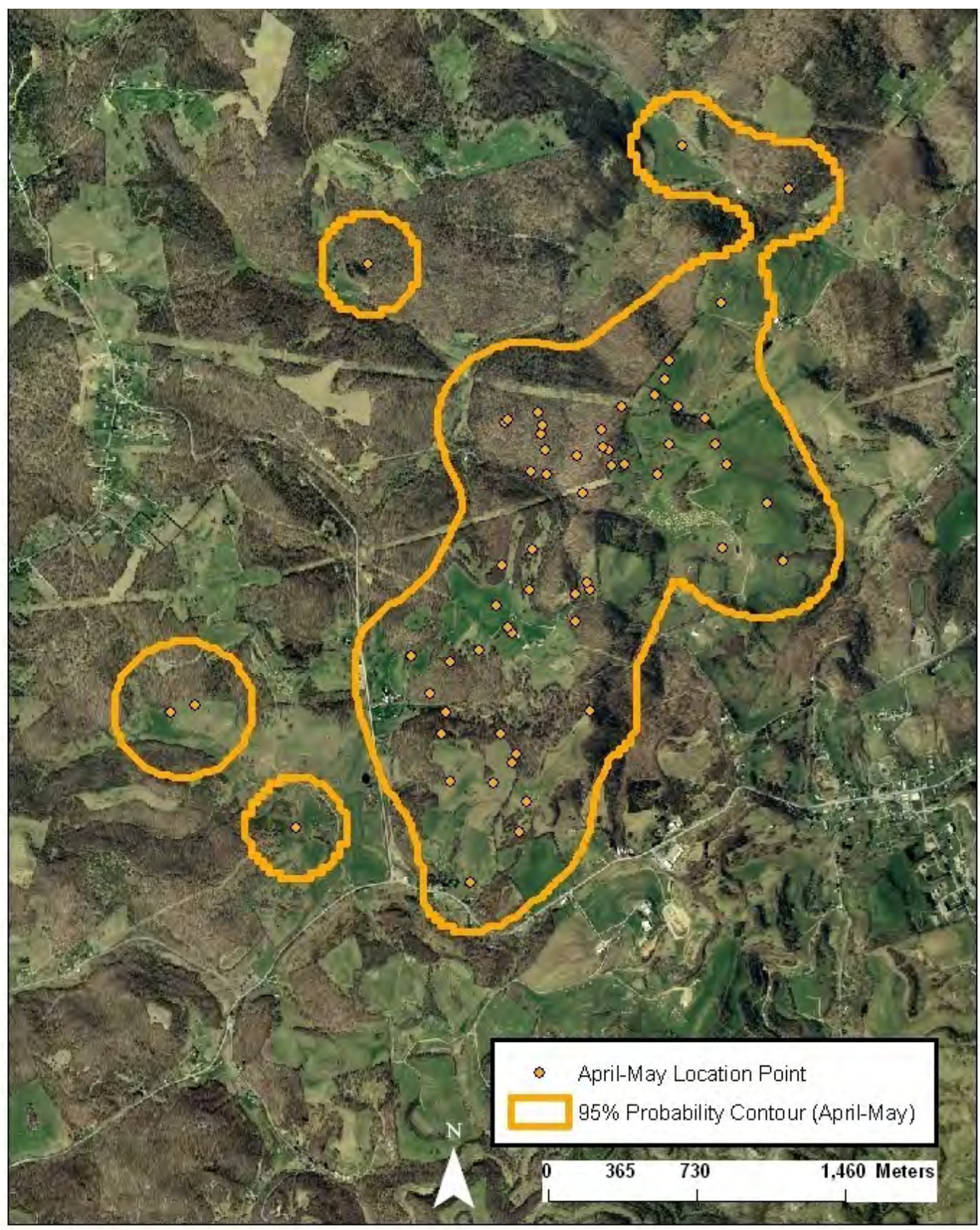


Appendix IId. RG5102 (adult) - 2yr age class (2006) and 3+yr age class (2007)

95\% probability contour for the April-May fixed kernel home range utilization

distribution. Smoothing parameter (h) determined by least squares cross validation, Taylor County, West Virginia, 2006-2007 (2003 SAMB imagery).

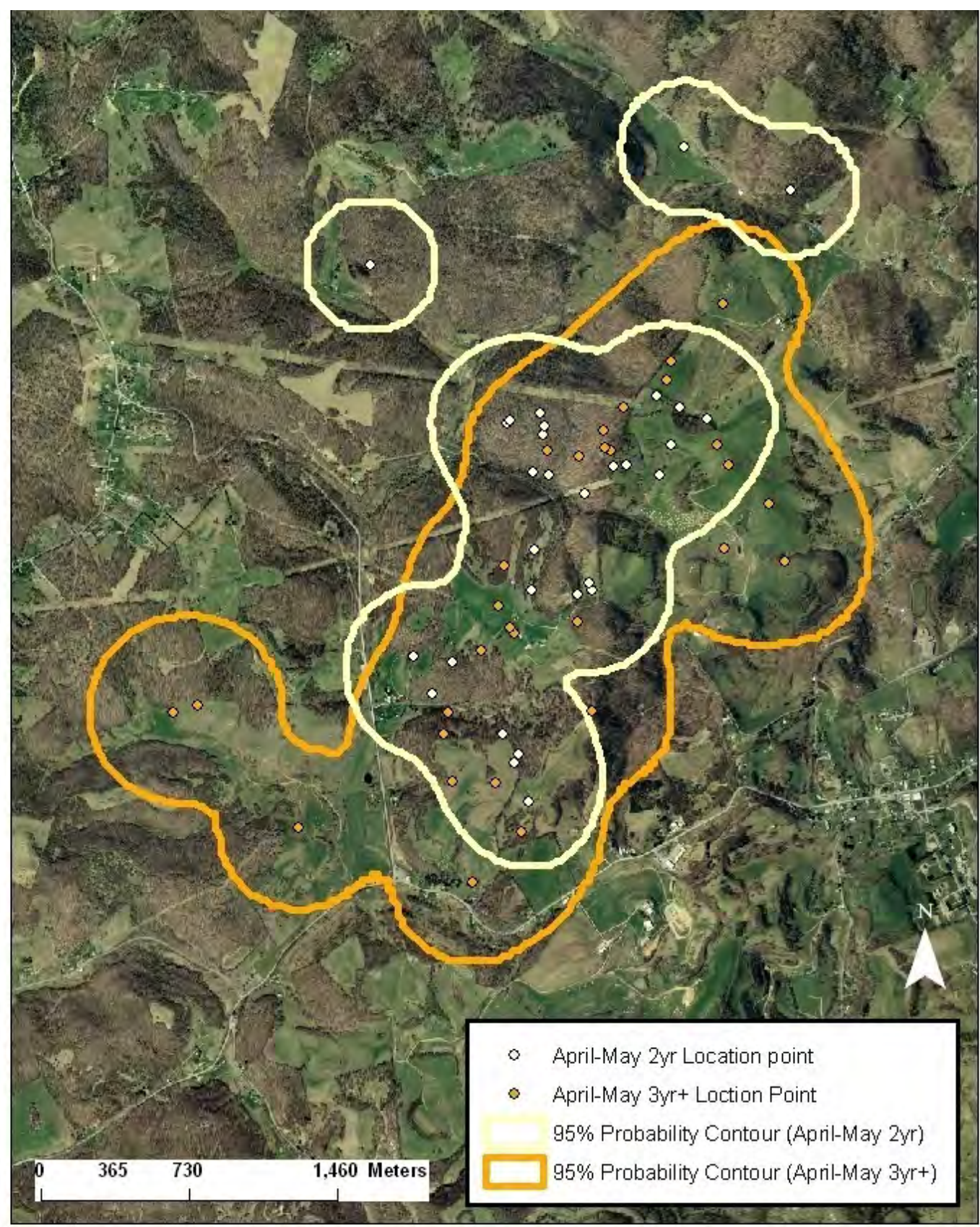


Appendix IIId. RG5106 (adult) - 2yr age class 95\% probability contour for the AprilMay fixed kernel home range utilization distribution. Smoothing parameter (h) determined by least squares cross validation, Marion County, West Virginia, 2006 (2003 SAMB imagery).

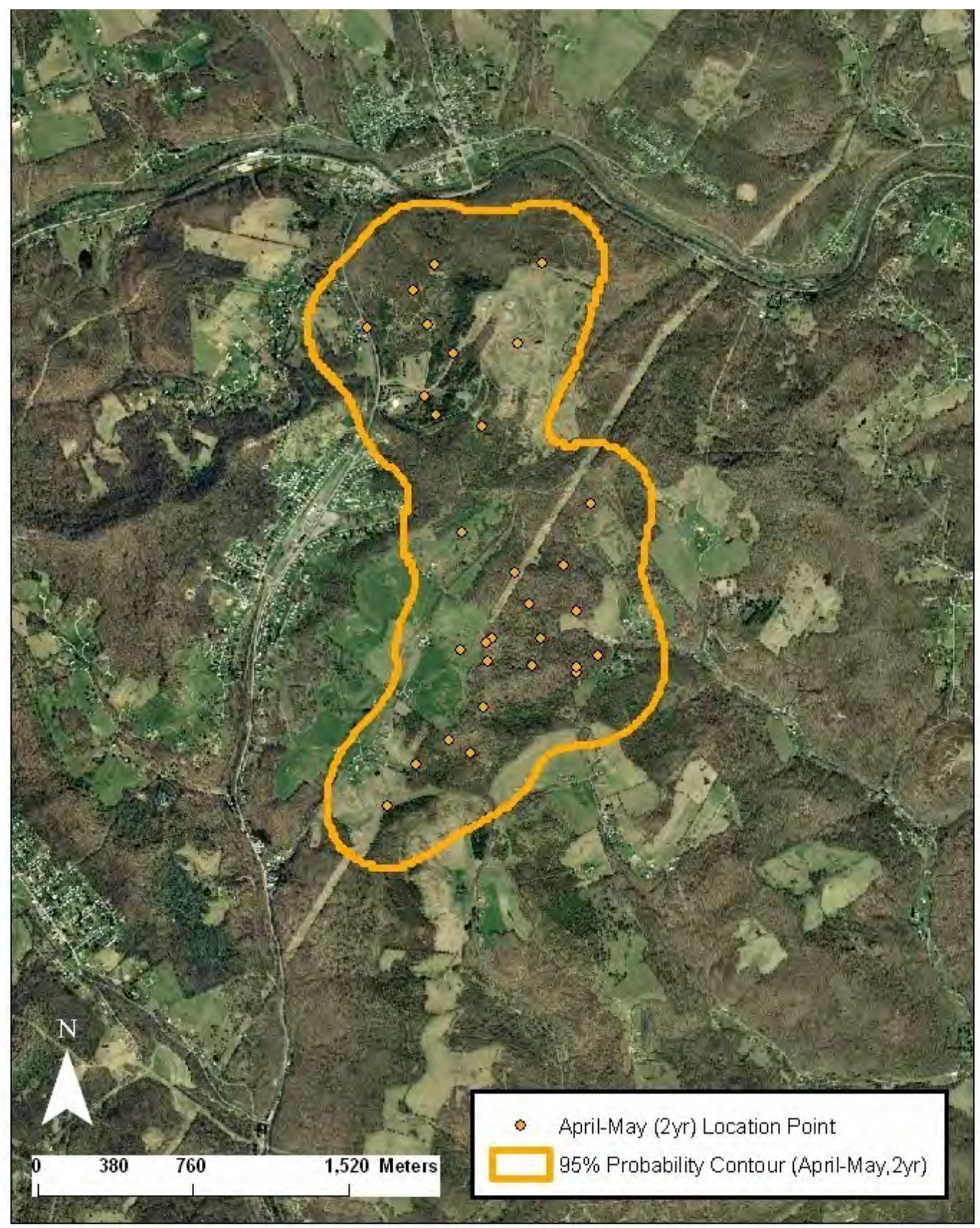


Appendix IVd. RG5109 (adult) - 95\% probability contour for the April-May fixed kernel home range utilization distribution. Smoothing parameter (h) determined by least squares cross validation, Marion County, West Virginia, 2006-2007 (2003 SAMB imagery).

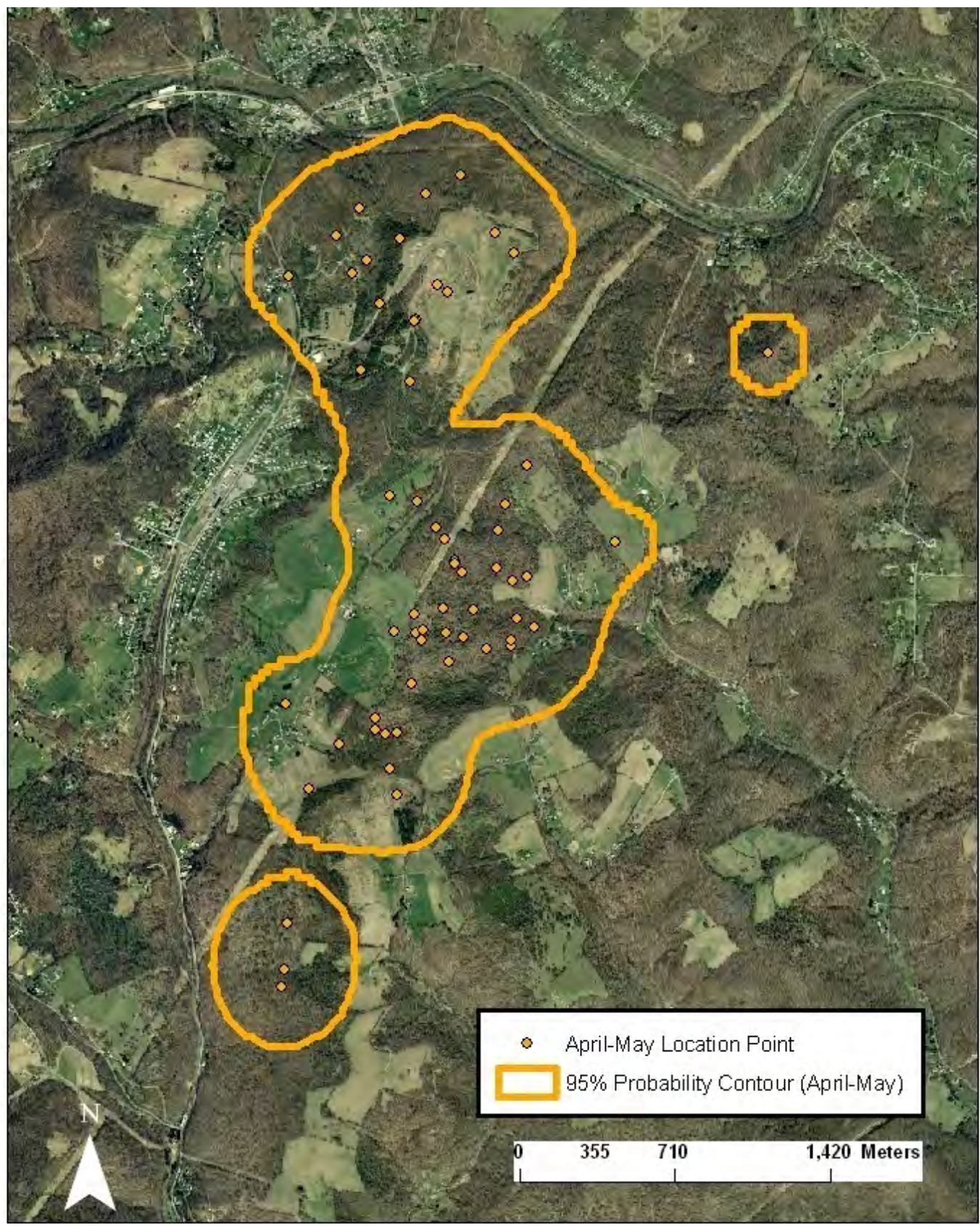


Appendix Vd. RG5109 (adult) - 2yr age class (2006) and 3+yr age class (2007)

95\% probability contour for the April-May fixed kernel home range utilization

distribution. Smoothing parameter (h) determined by least squares cross validation, Marion County, West Virginia, 2006-2007 (2003 SAMB imagery).

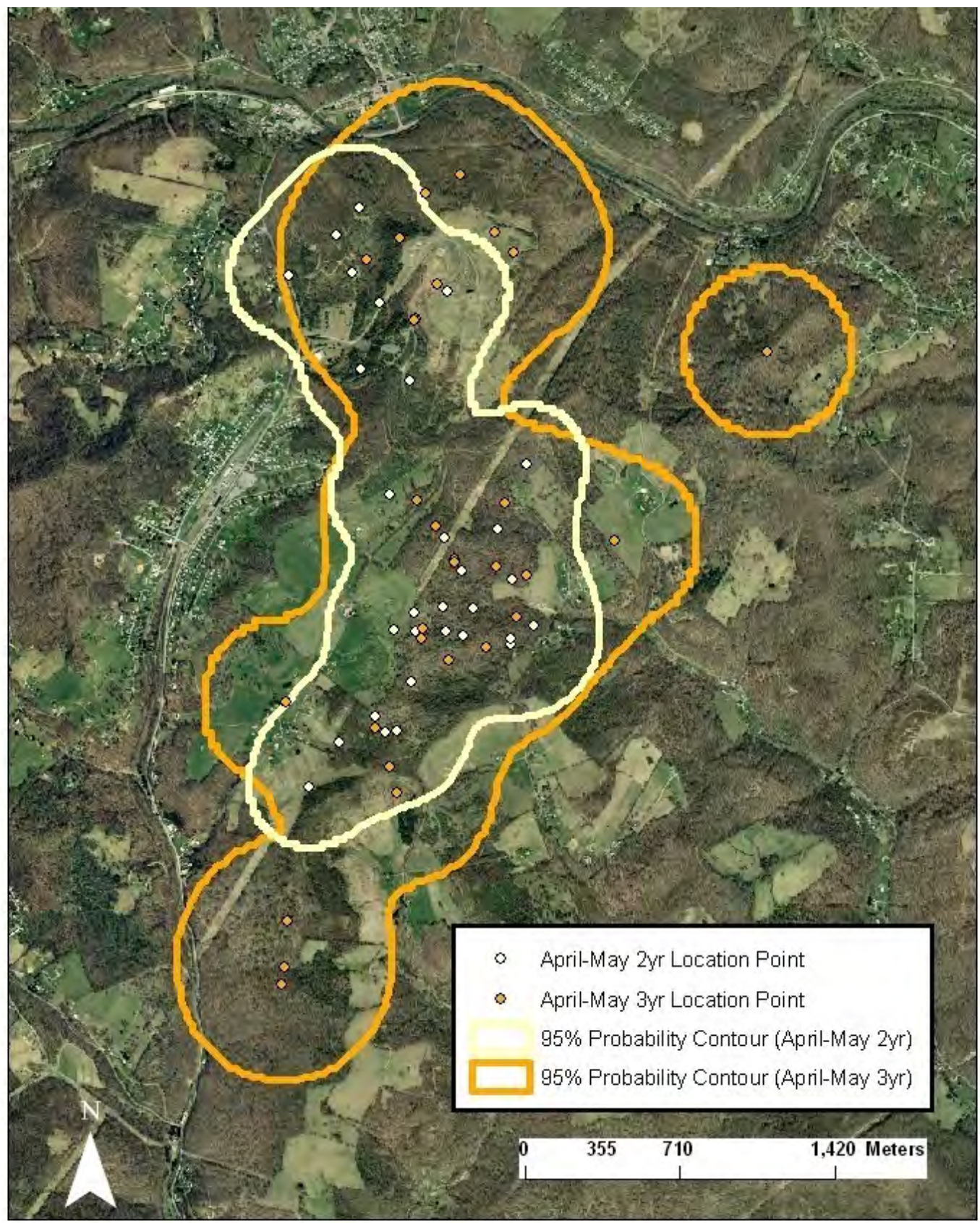


Appendix VId. - RG5110 (adult) - 95\% probability contour for the April-May fixed kernel home range utilization distribution. Smoothing parameter (h) determined by least squares cross validation, Marion County, West Virginia, 2006-2007 (2003 SAMB imagery).

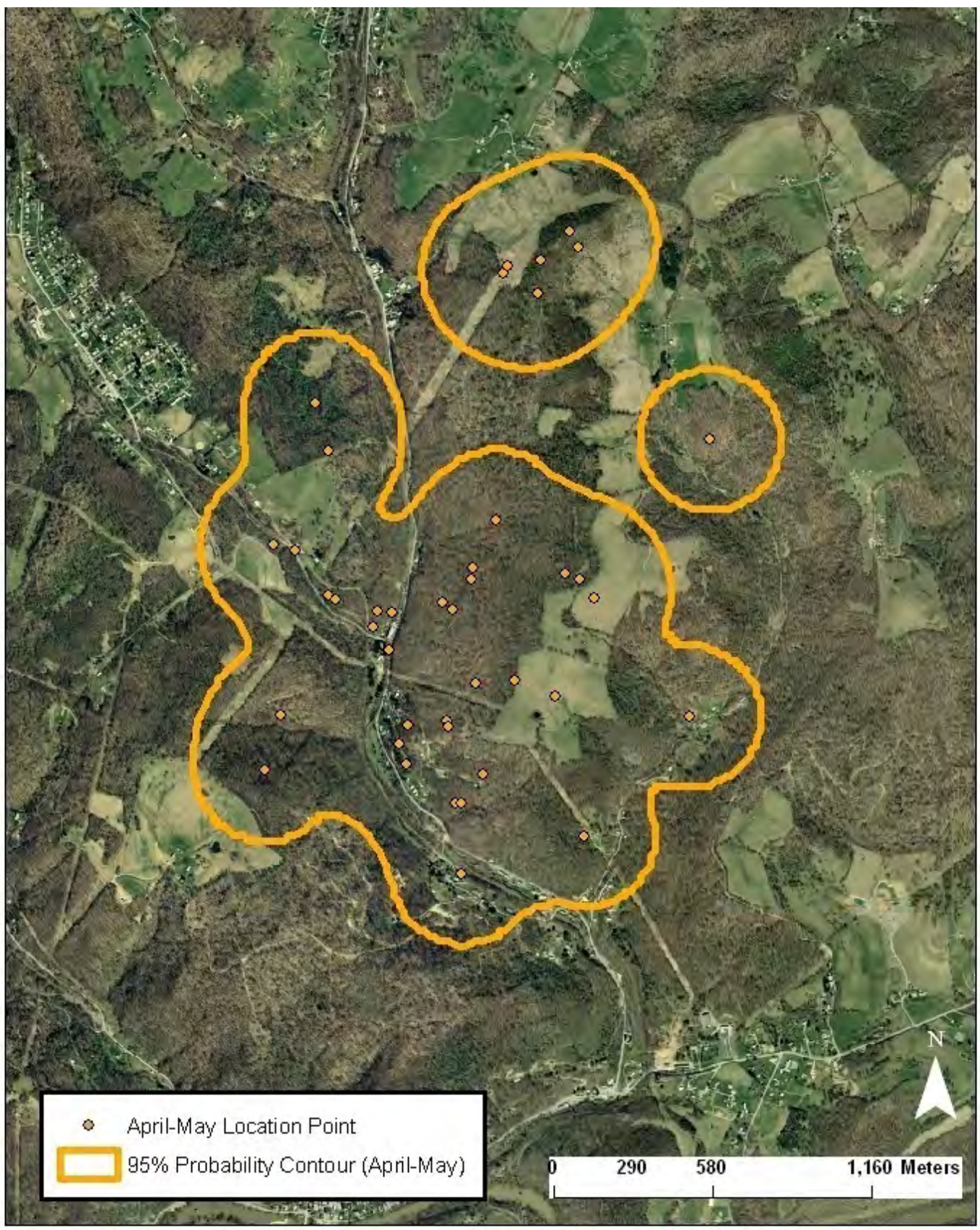


Appendix VIId. RG5110 (adult) - 3+yr age class 95\% probability contour for the April-May fixed kernel home range utilization distribution. Smoothing parameter (h) determined by least squares cross validation, Marion County, West Virginia, 2006 (2003 SAMB imagery).

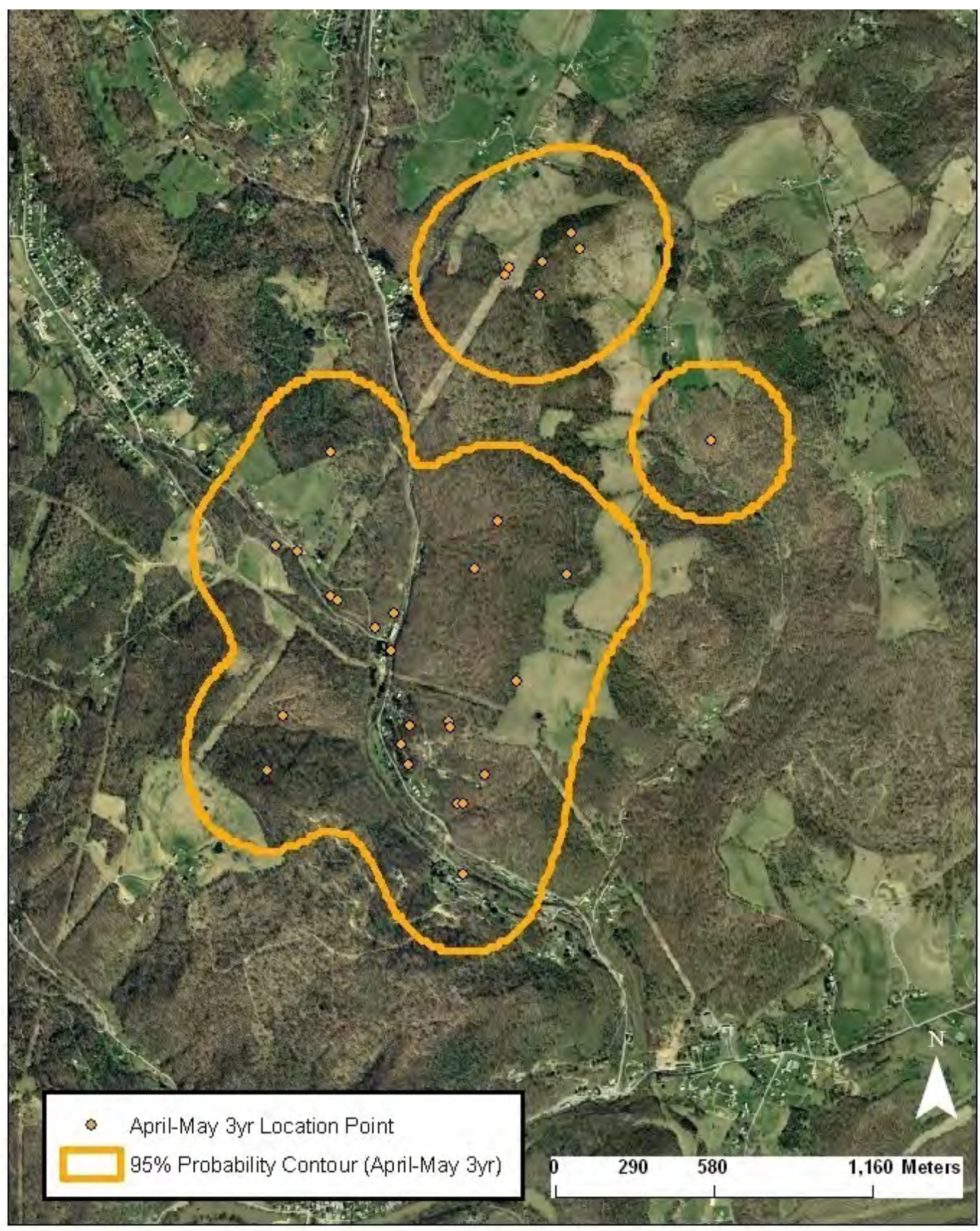


Appendix VIIId. RG5111 (adult) - 95\% probability contour for the April-May fixed kernel home range utilization distribution. Smoothing parameter (h) determined by least squares cross validation, Taylor County, West Virginia, 2006-2007 (2003 SAMB imagery).

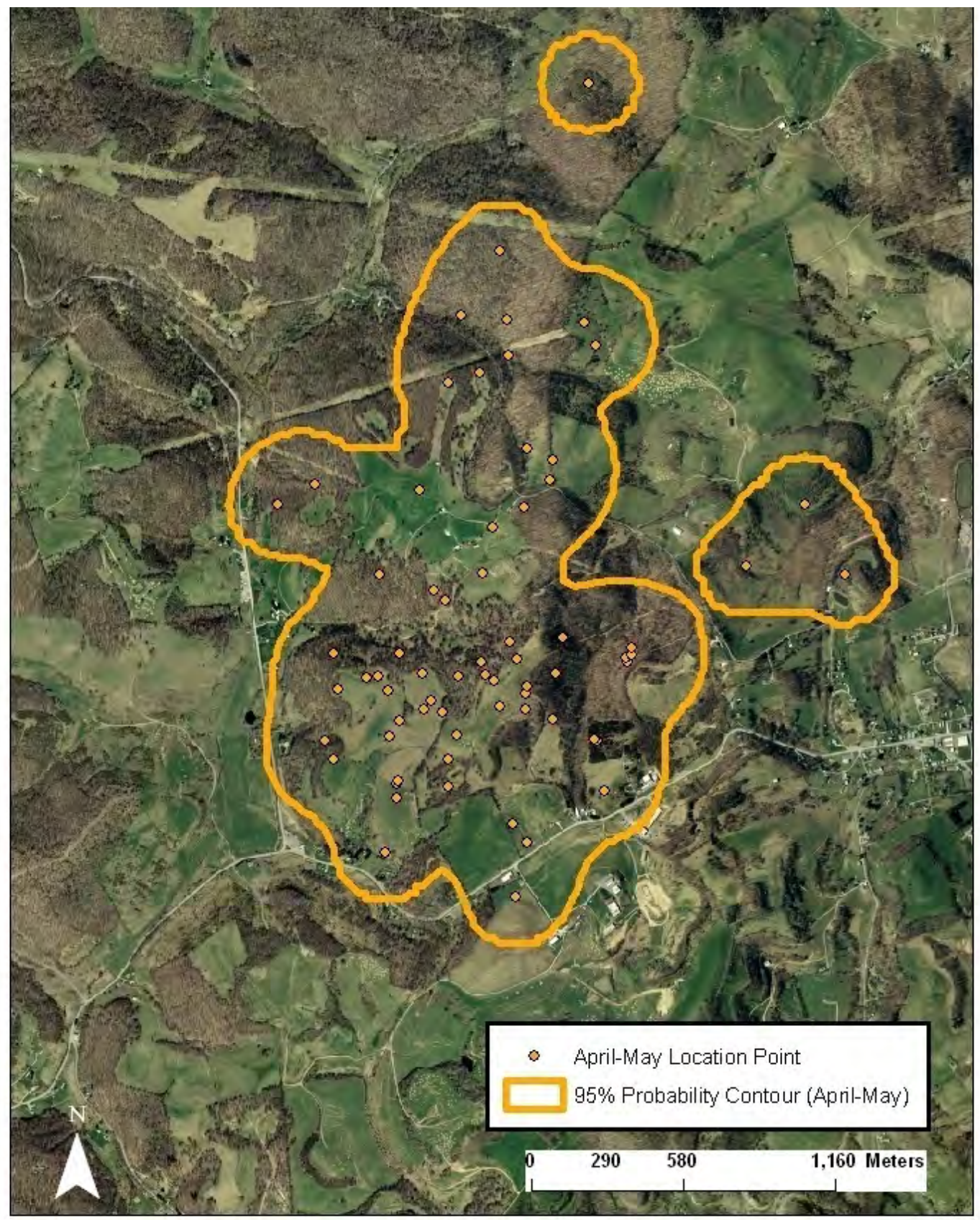


Appendix VIIId. RG5111 (adult) - 3+yr age class 95\% probability contour for the April-May fixed kernel home range utilization distribution. Smoothing parameter (h) determined by least squares cross validation, Taylor County, West Virginia, 20062007 (2003 SAMB imagery).

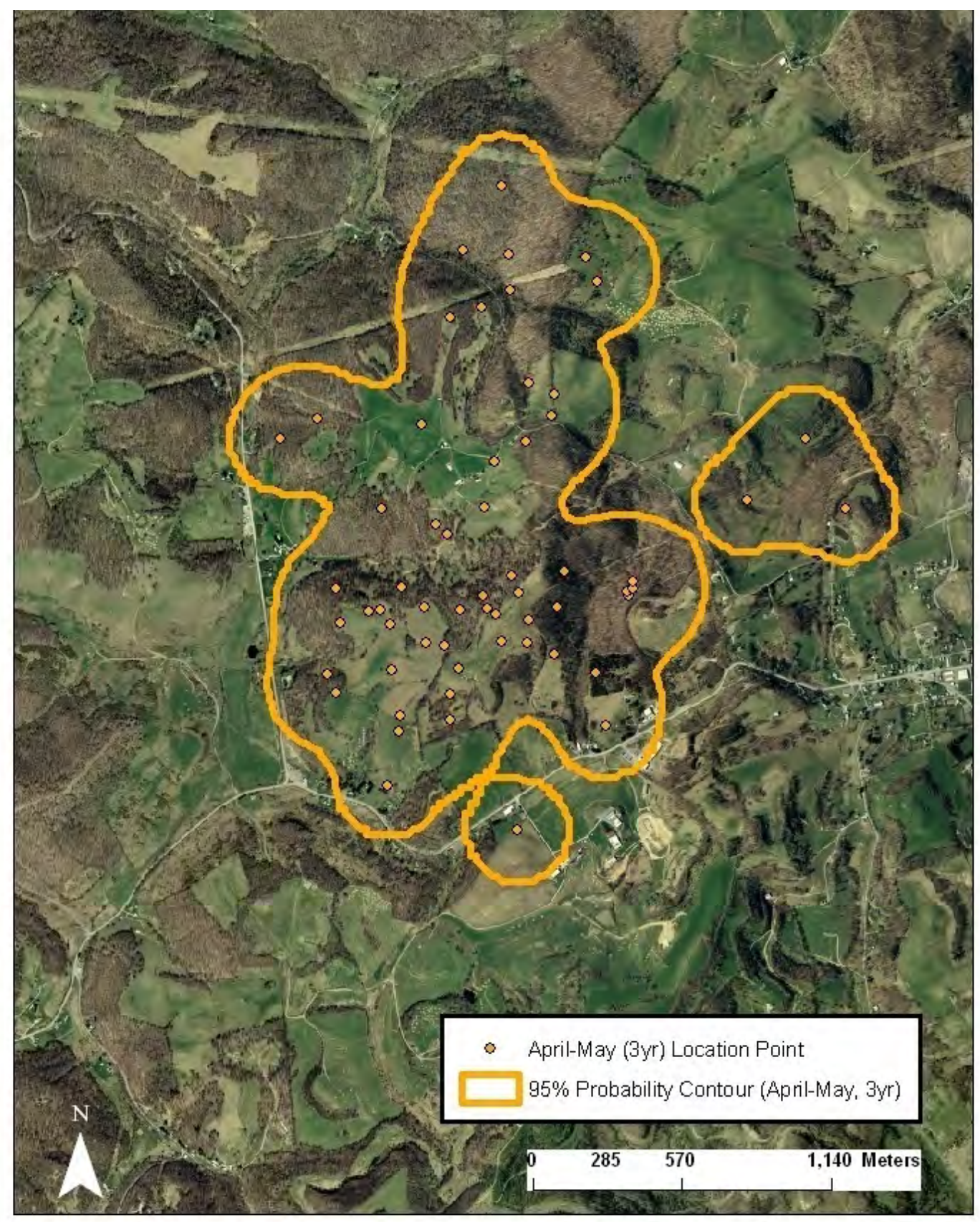


Appendix IXd. RG5114 (adult) - 95\% probability contour for the April-May fixed kernel home range utilization distribution. Smoothing parameter (h) determined by least squares cross validation, Taylor County, West Virginia, 2006-2007 (2003 SAMB imagery).

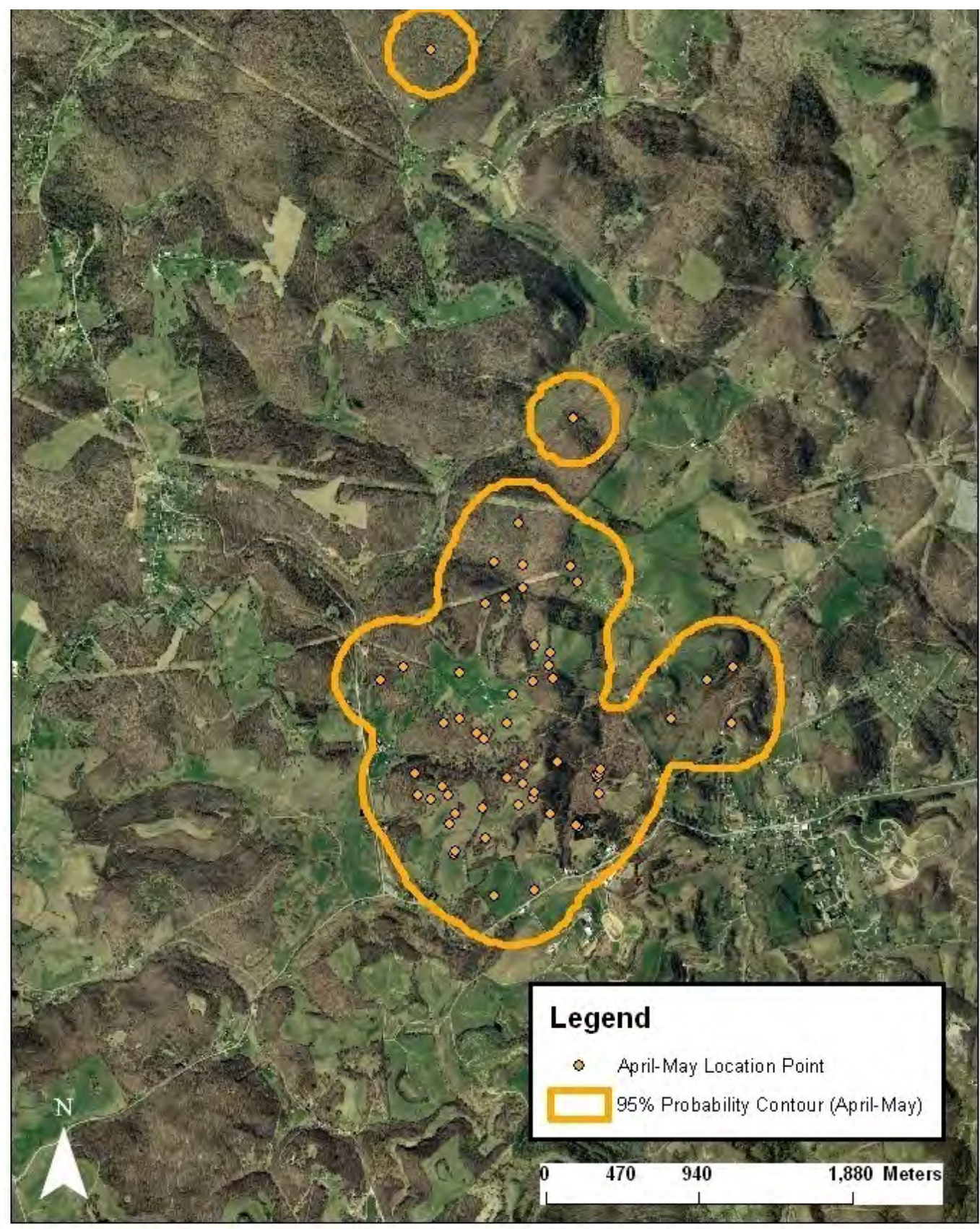


Appendix Xd. RG5114 (adult) -3+yr age class 95\% probability contour for the AprilMay fixed kernel home range utilization distribution. Smoothing parameter (h) determined by least squares cross validation, Taylor County, West Virginia, 20062007 (2003 SAMB imagery).

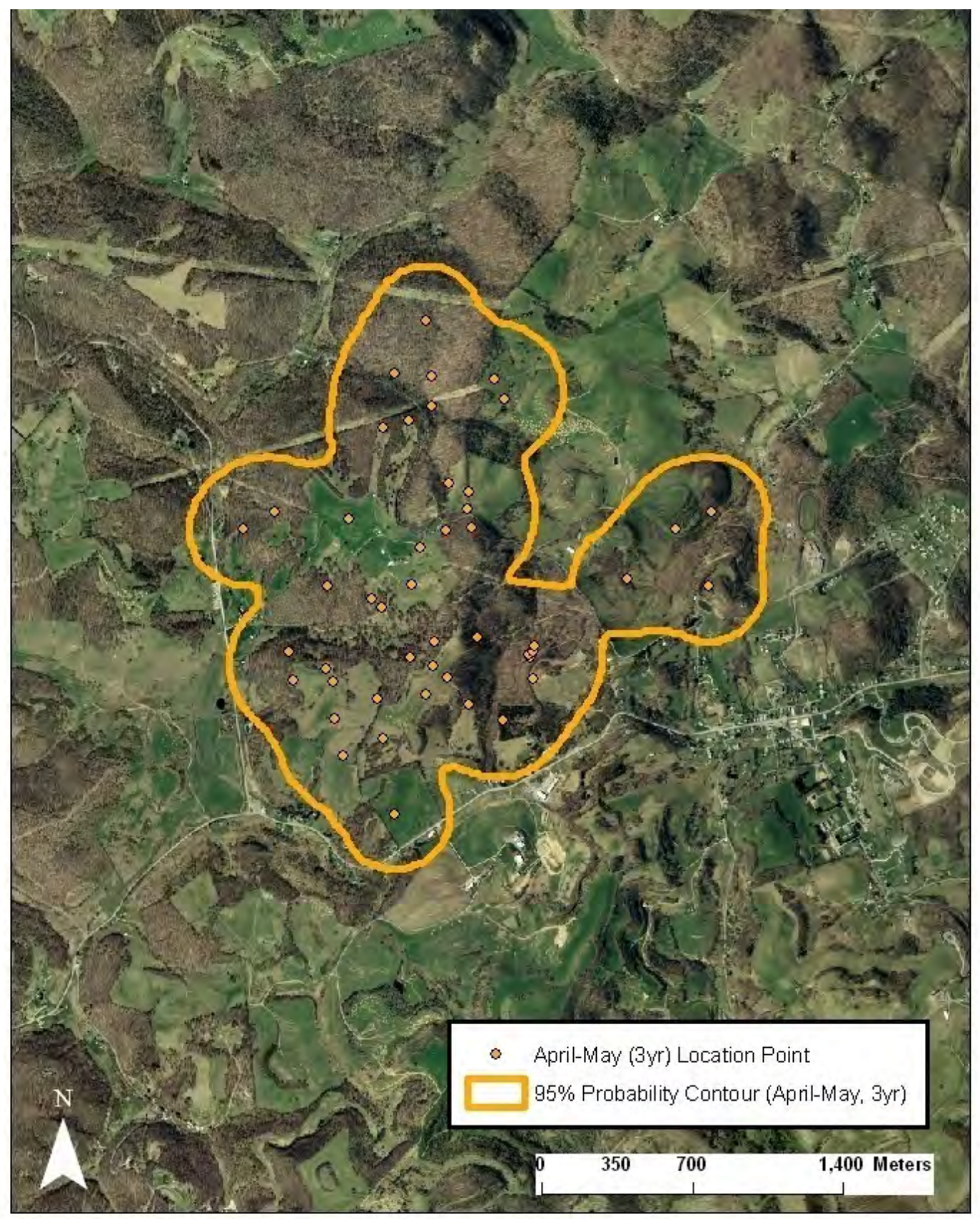


Appendix XId. RG5122 (juvenile) - 95\% probability contour for the April-May fixed kernel home range utilization distribution. Smoothing parameter (h) determined by least squares cross validation, Taylor County, West Virginia, 2006 (2003 SAMB imagery).

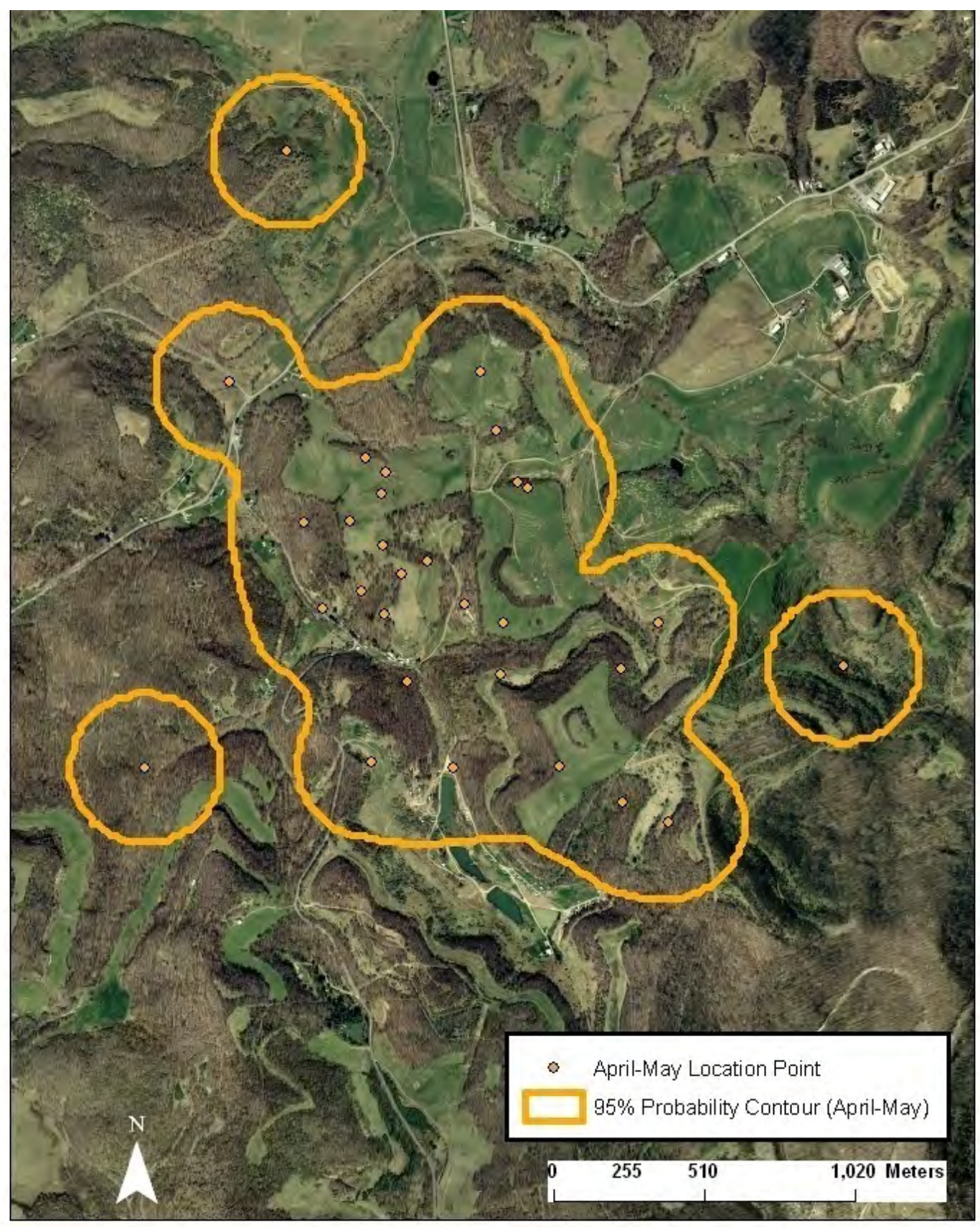


Appendix XIId. RG5122 (adult) - 2-yr age class 95\% probability contour for the April-May fixed kernel home range utilization distribution. Smoothing parameter (h) determined by least squares cross validation, Taylor County, West Virginia, 2007 (2003 SAMB imagery).

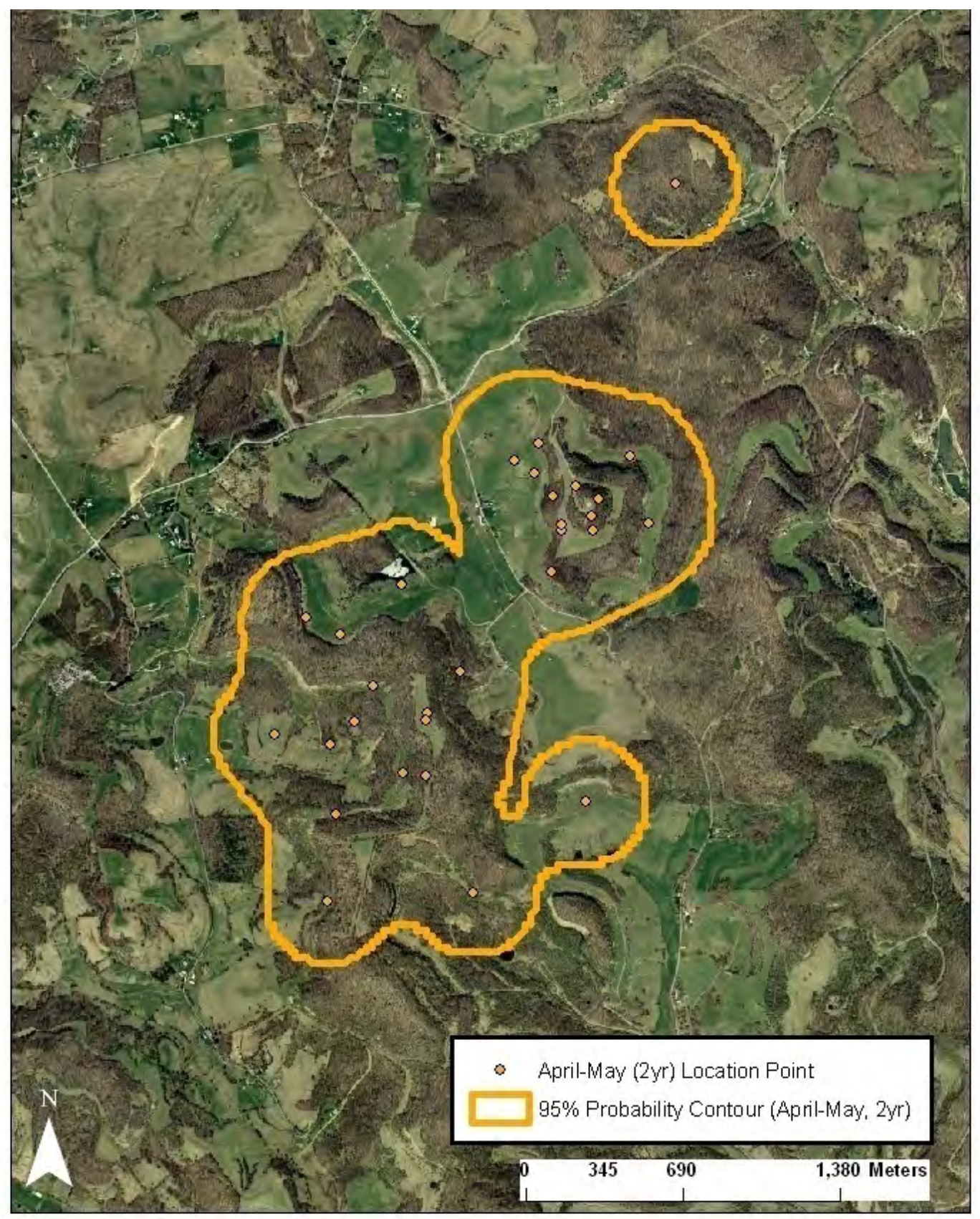


Appendix XIIId. RG5126 (juvenile) -95\% probability contour for the April-May fixed kernel home range utilization distribution. Smoothing parameter (h) determined by least squares cross validation, Marion County, West Virginia, 2006 (2003 SAMB imagery).

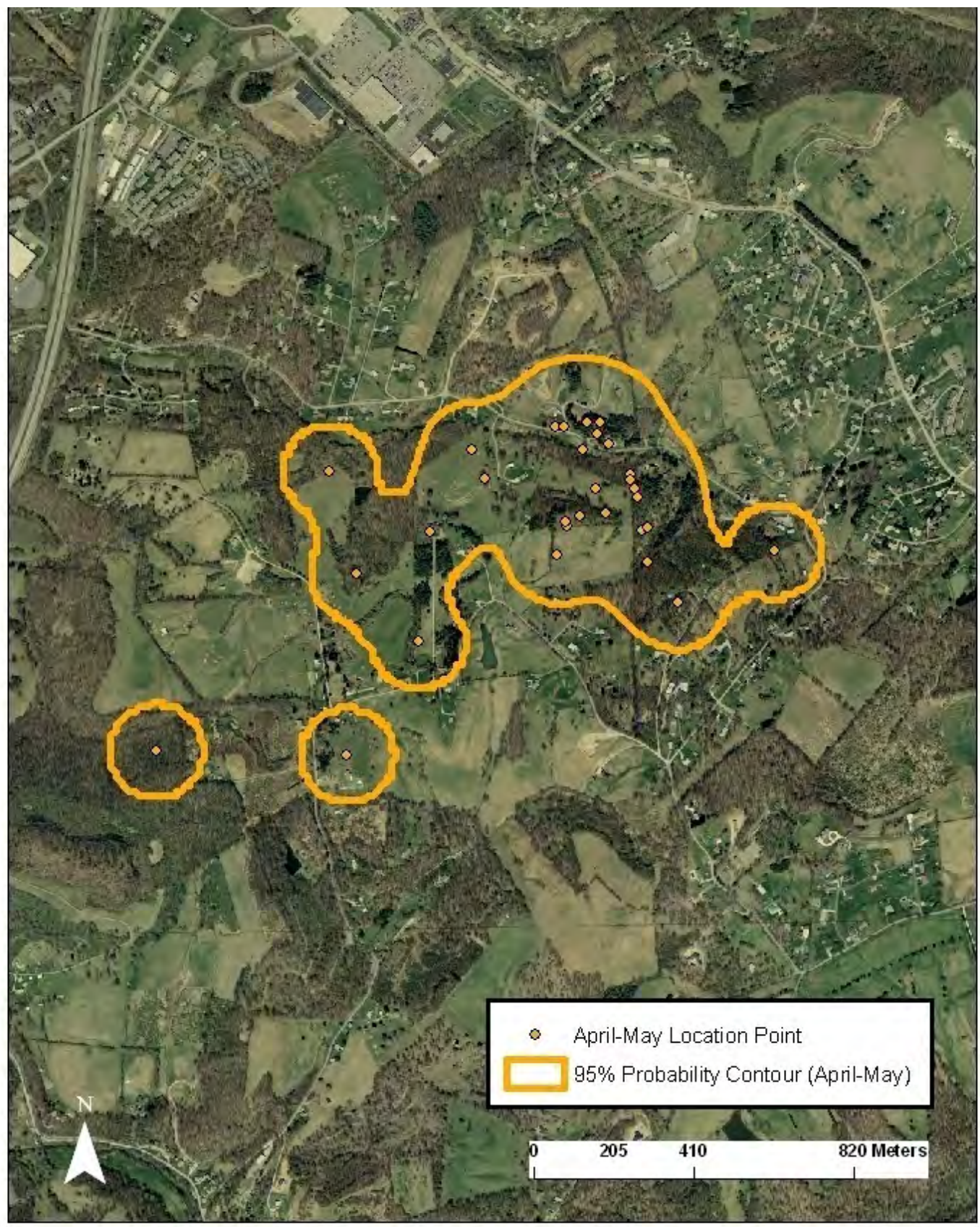


Appendix XIVd. RG5128 (juvenile) - 95\% probability contour for the April-May fixed kernel home range utilization distribution. Smoothing parameter $(h)$ determined by least squares cross validation, Taylor County, West Virginia, 2007 (2003 SAMB imagery).

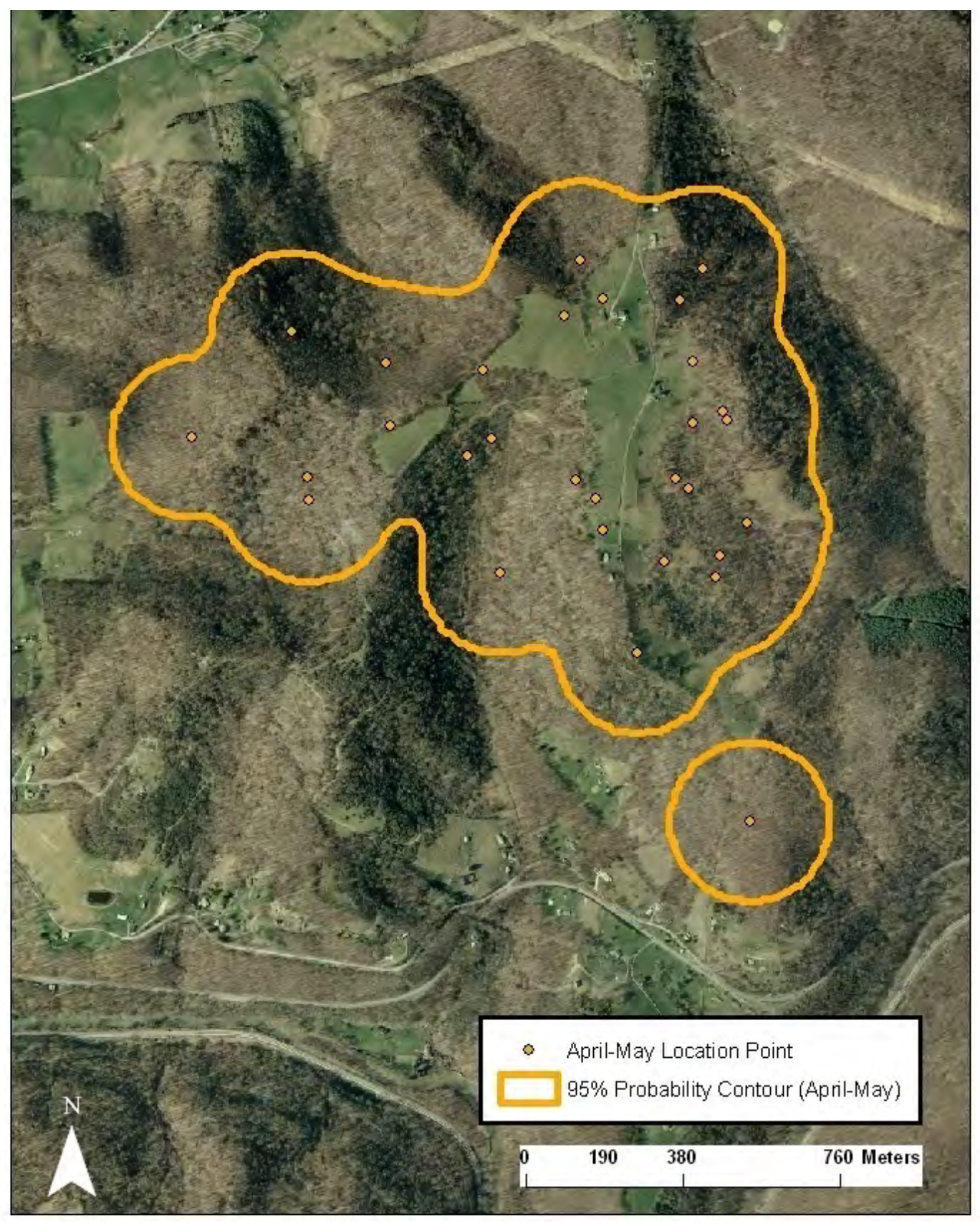


Appendix XVd. RG5129 (juvenile) - 95\% probability contour for the April-May fixed kernel home range utilization distribution. Smoothing parameter (h) determined by least squares cross validation, Taylor County, West Virginia, 2007 (2003 SAMB imagery).

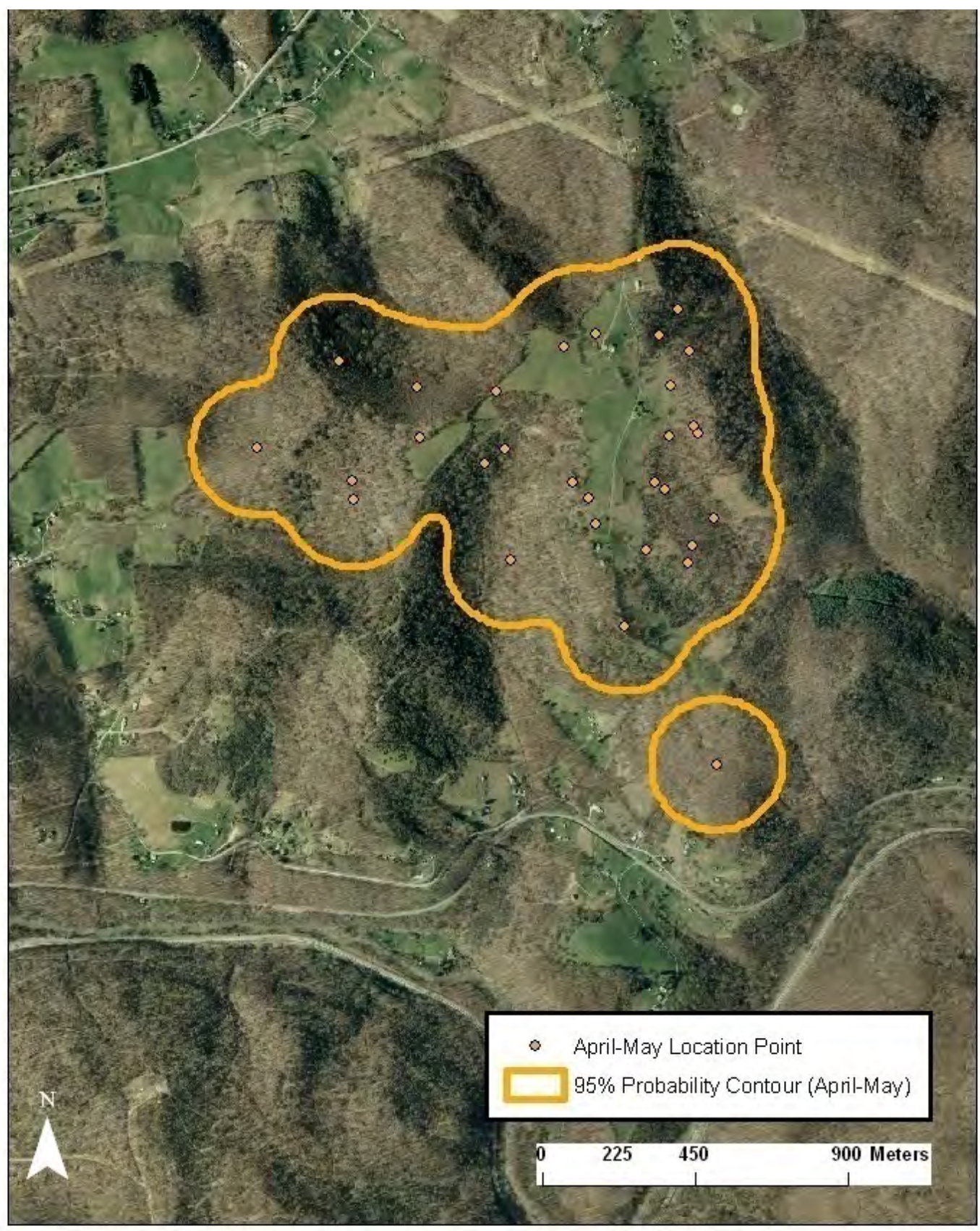


Appendix XVId. RG5131 (juvenile) - 95\% probability contour for the April-May fixed kernel home range utilization distribution. Smoothing parameter $(h)$ determined by least squares cross validation, Harrison County, West Virginia, 2007 (2003 SAMB imagery).

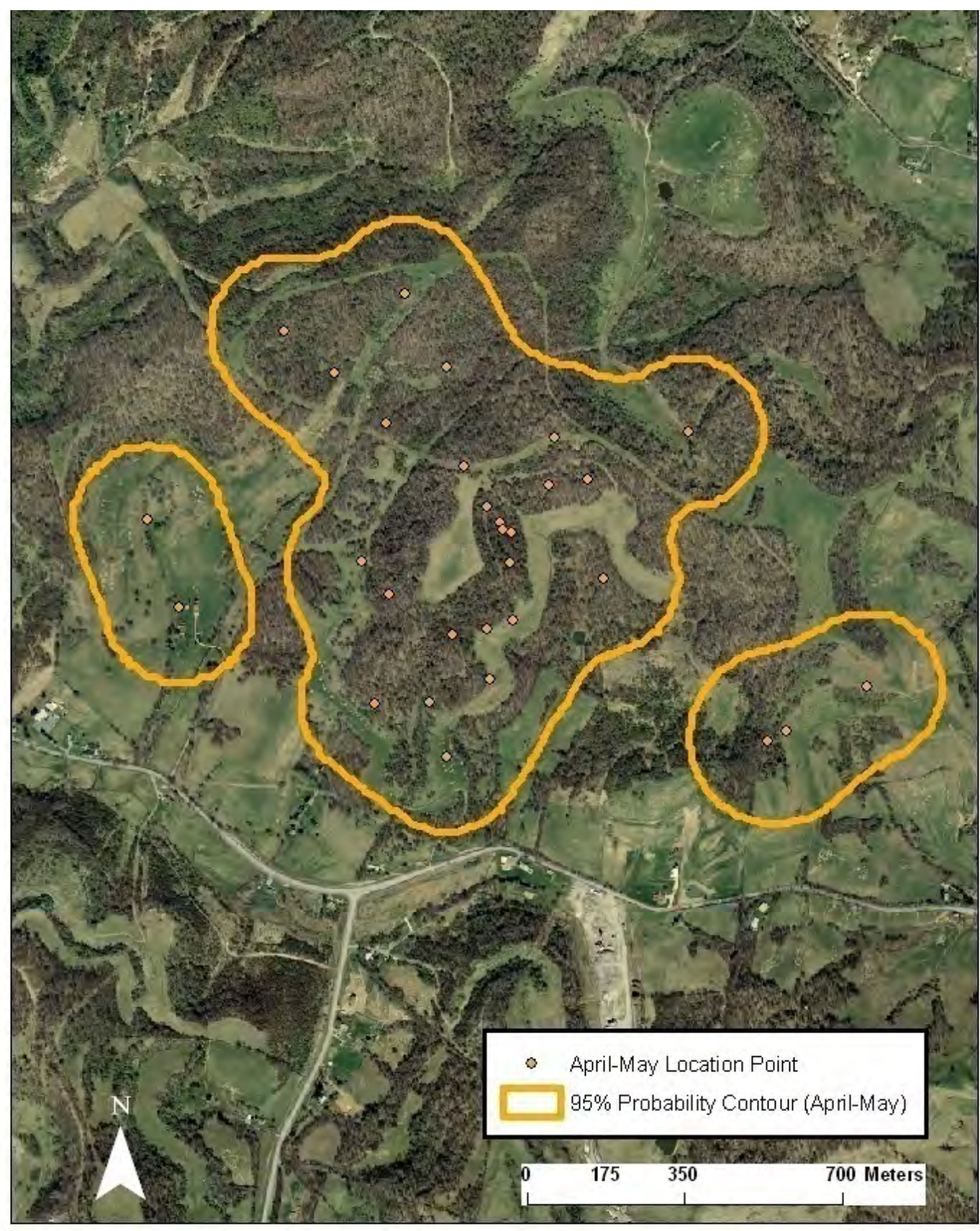


Appendix XVIId. RG5132 (juvenile) -95\% probability contour for the April-May fixed kernel home range utilization distribution. Smoothing parameter (h) determined by least squares cross validation, Harrison County, West Virginia, 2007 (2003 SAMB imagery).

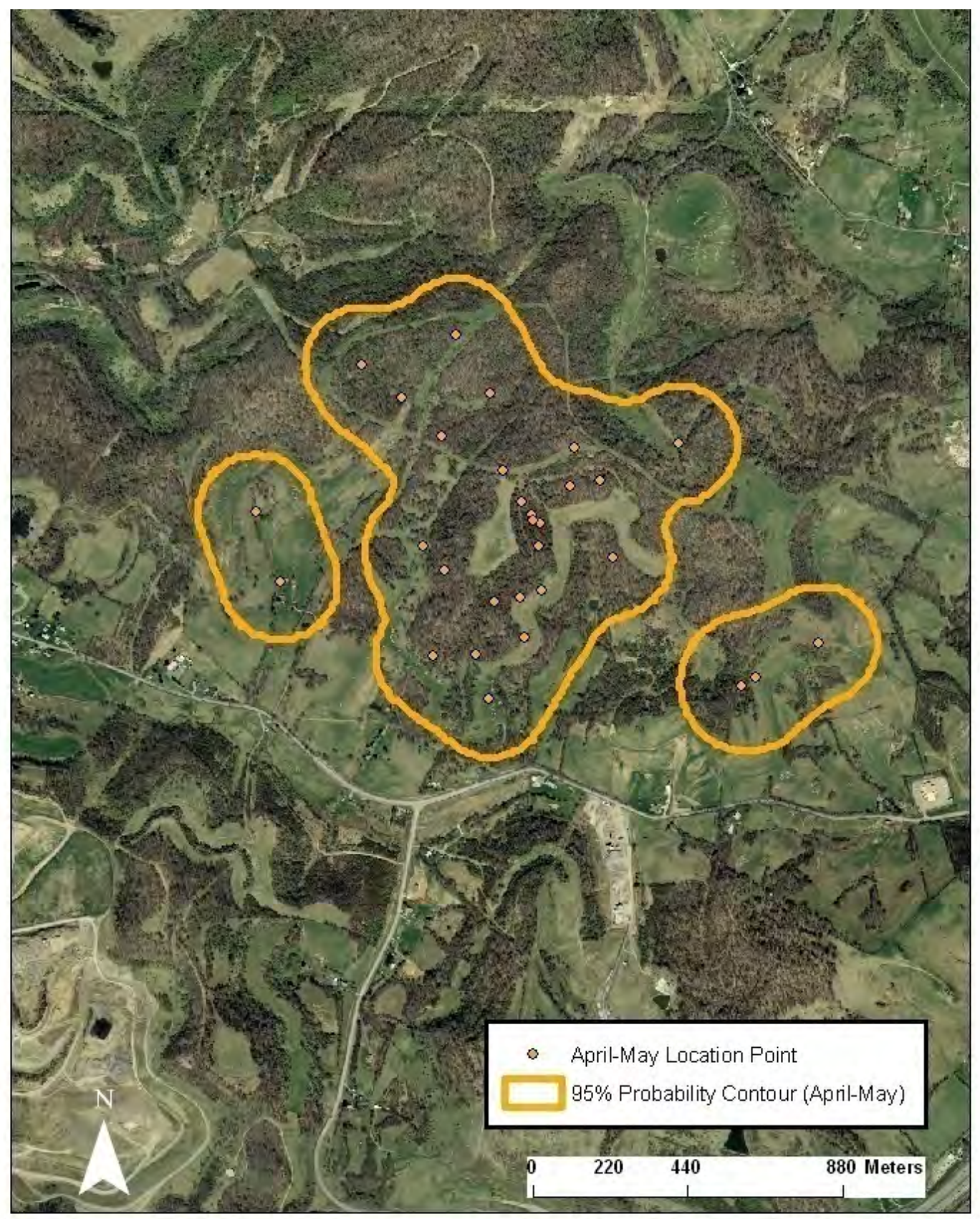


Appendix XVIIId. RG5133 (juvenile) - 95\% probability contour for the April-May fixed kernel home range utilization distribution. Smoothing parameter (h) determined by least squares cross validation, Marion/Taylor County, West Virginia, 2007 (2003 SAMB imagery).

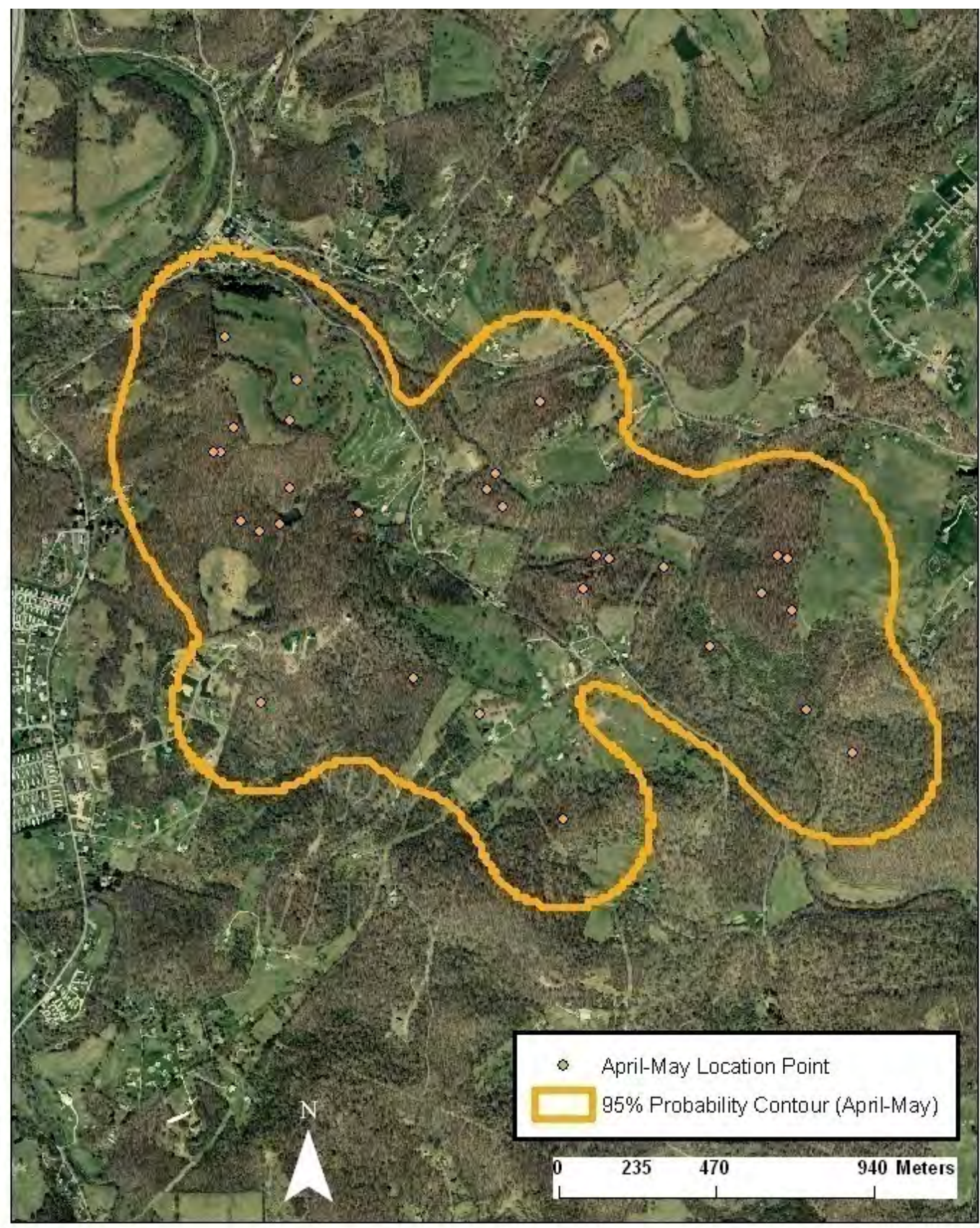


Appendix XIXd. RG5135 (juvenile) - 95\% probability contour for the April-May fixed kernel home range utilization distribution. Smoothing parameter (h) determined by least squares cross validation, Harrison County, West Virginia, 2007 (2003 SAMB imagery).

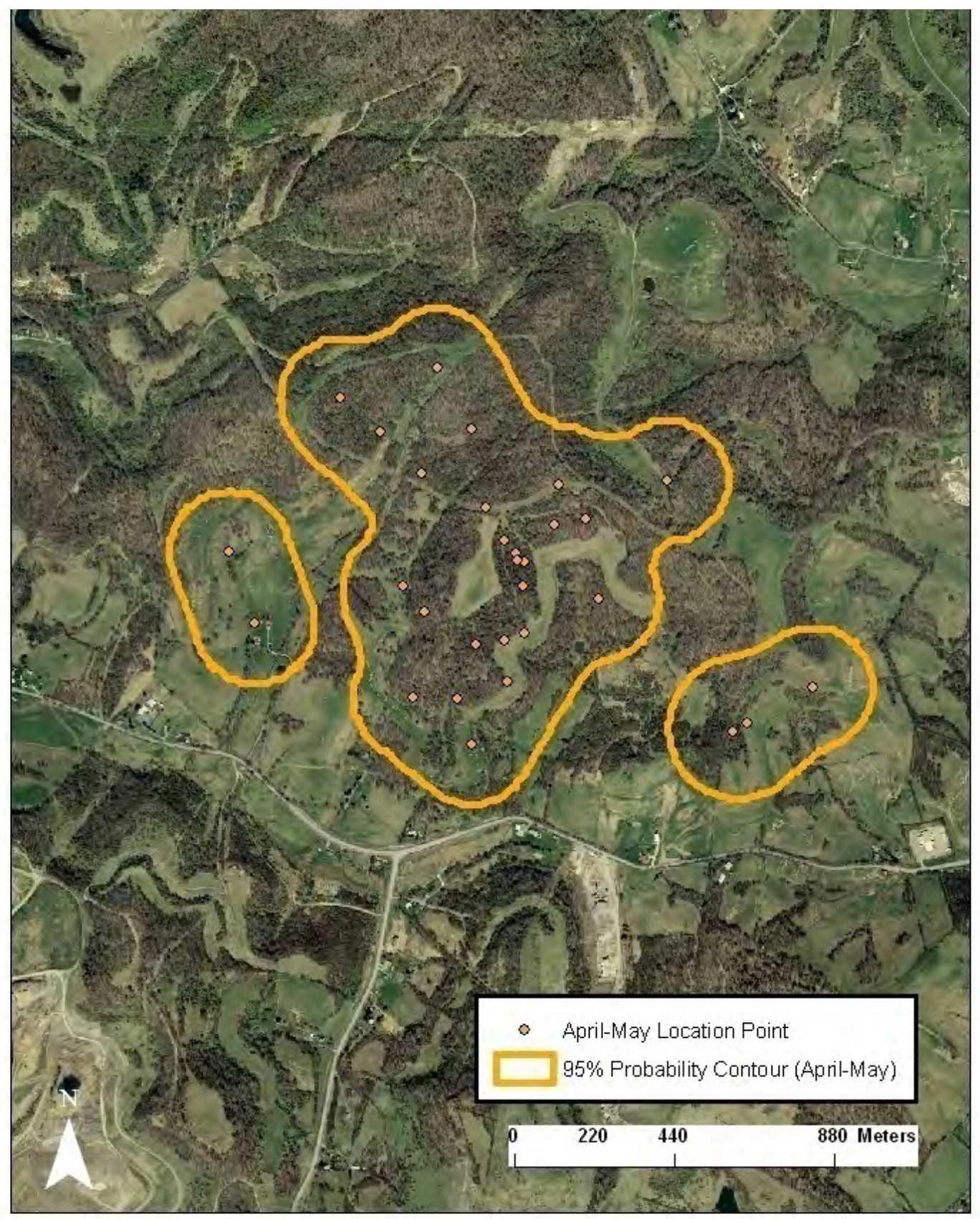


Appendix XXd. RG5136 (juvenile) -95\% probability contour for the April-May fixed kernel home range utilization distribution. Smoothing parameter (h) determined by least squares cross validation, Harrison County, West Virginia, 2007 (2003 SAMB imagery).

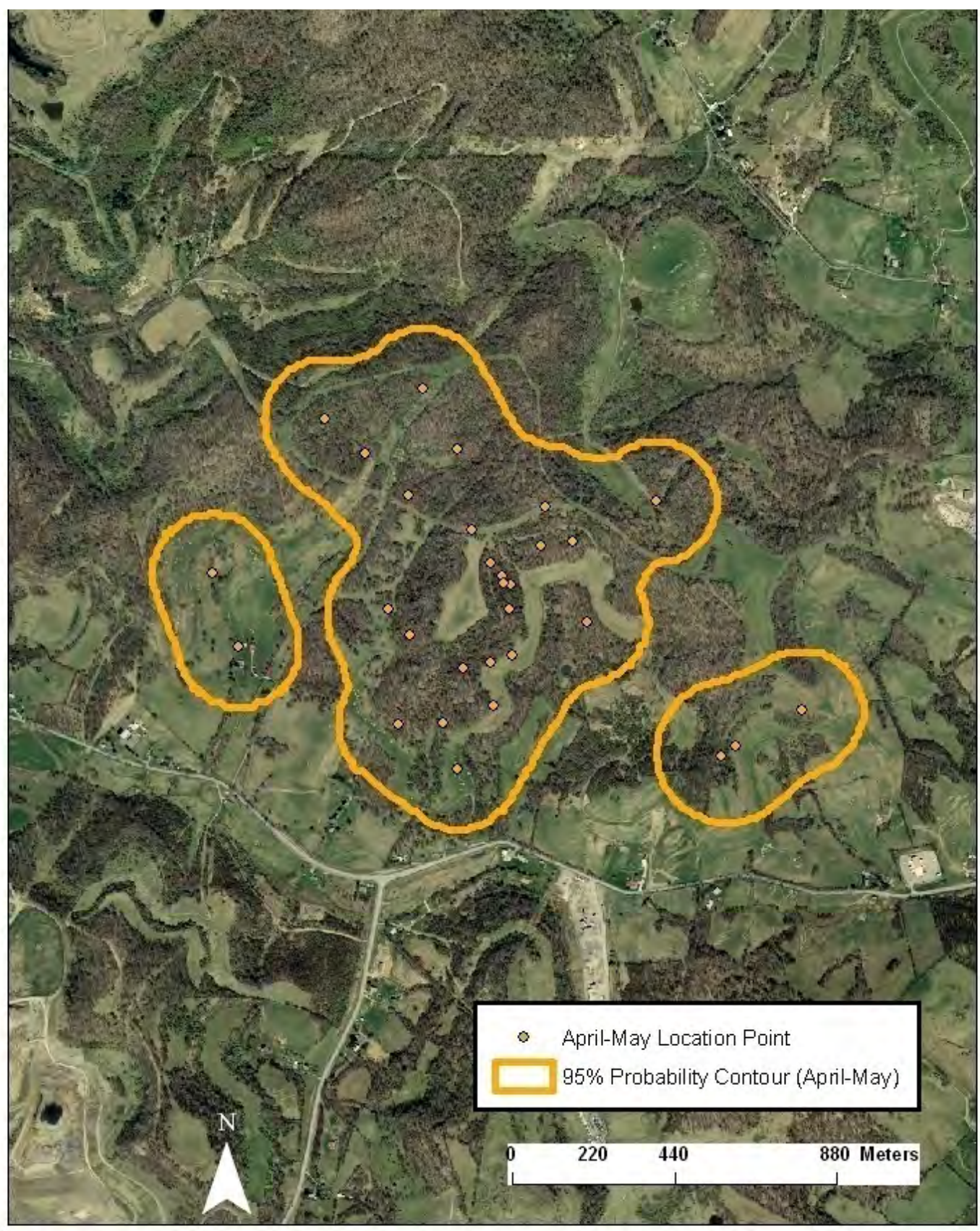


Appendix XXId. RG5137 (juvenile) - 95\% probability contour for the April-May fixed kernel home range utilization distribution. Smoothing parameter $(h)$ determined by least squares cross validation, Harrison County, West Virginia, 2007 (2003 SAMB imagery).

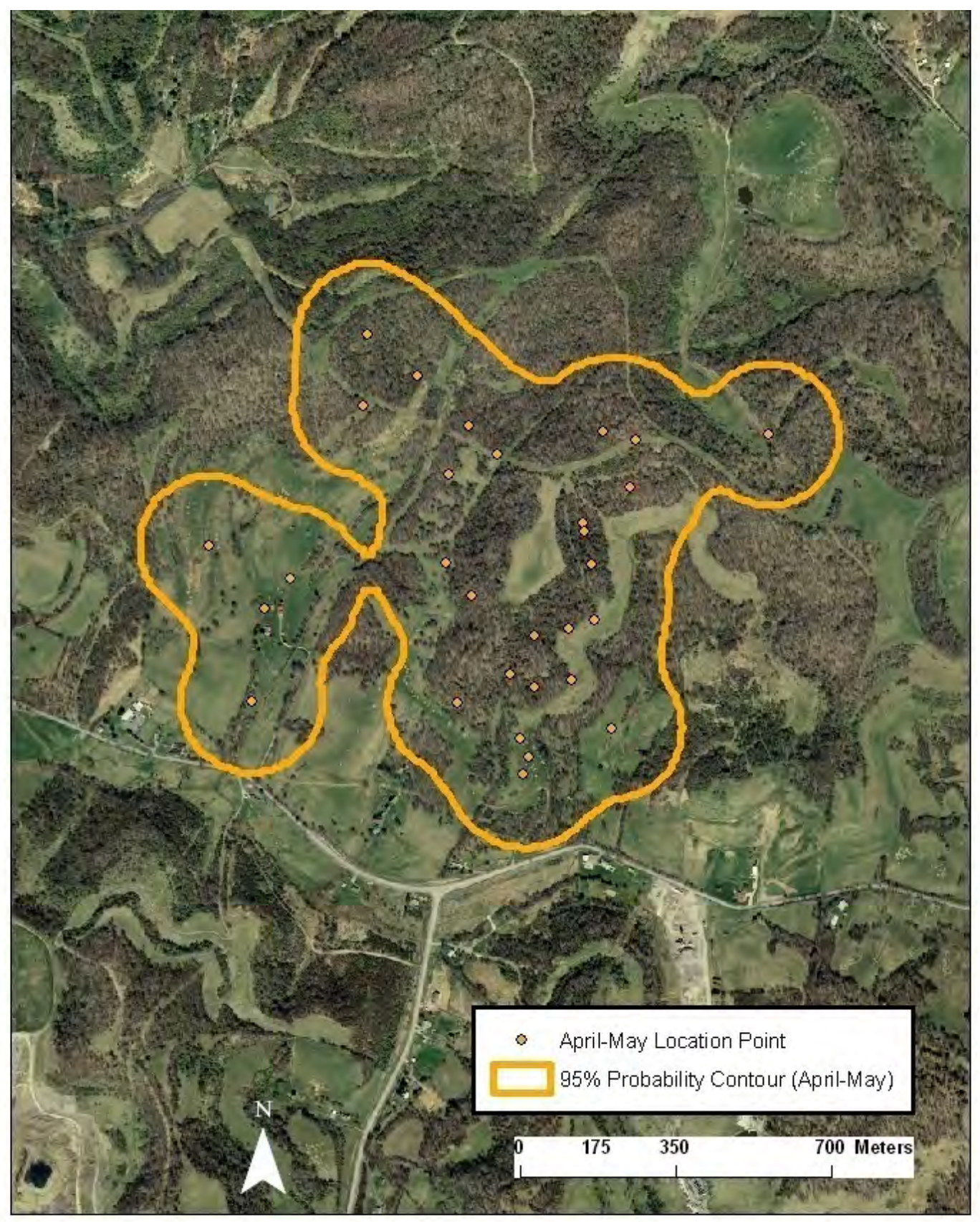


Appendix XXIId. RG5138 (juvenile) -95\% probability contour for the April-May fixed kernel home range utilization distribution. Smoothing parameter (h) determined by least squares cross validation, Harrison County, West Virginia, 2007 (2003 SAMB imagery).

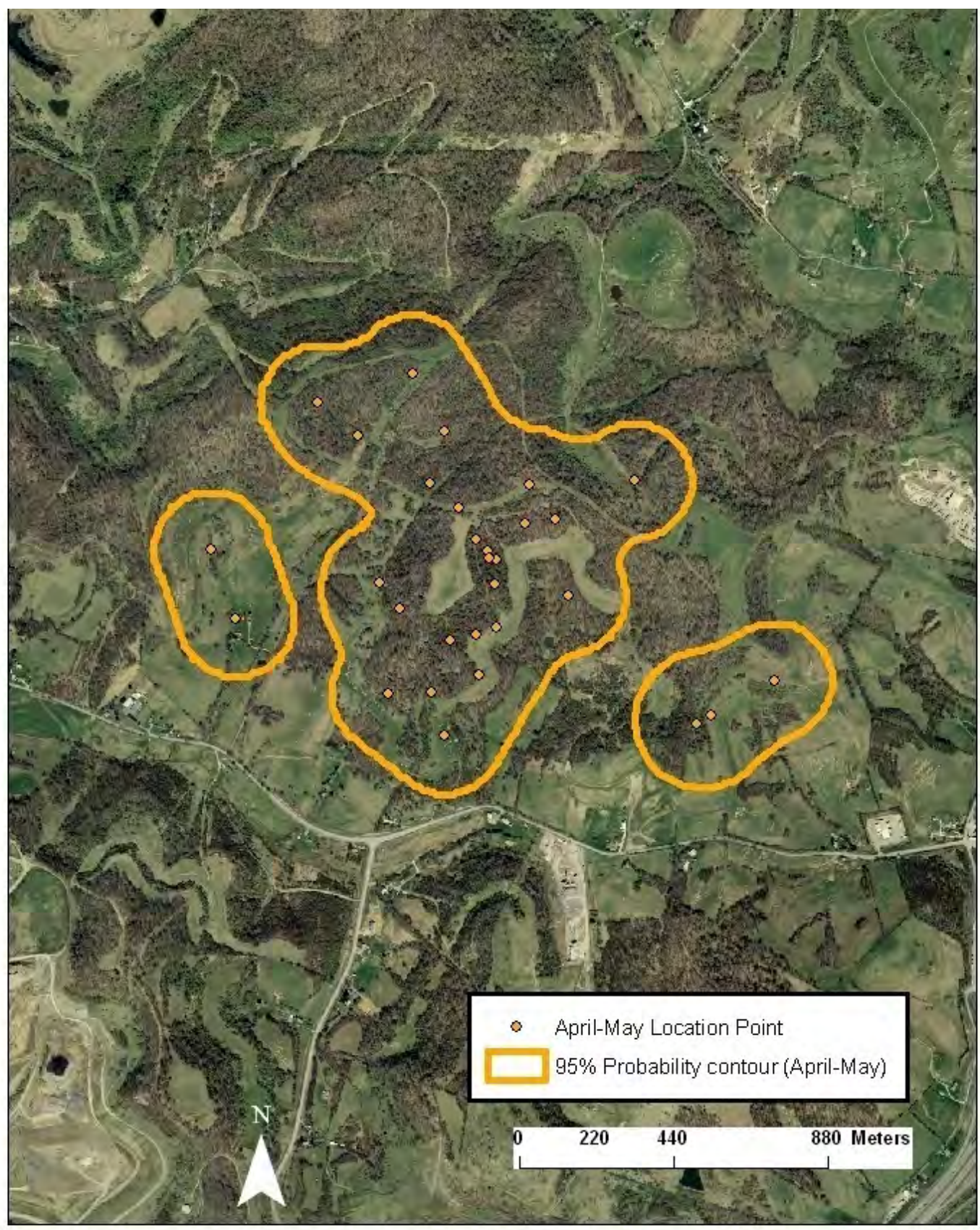


Appendix XXIIId. RG5139 (juvenile) - 95\% probability contour for the April-May fixed kernel home range utilization distribution. Smoothing parameter (h) determined by least squares cross validation, Marion/Taylor County, West Virginia, 2007 (2003 SAMB imagery).

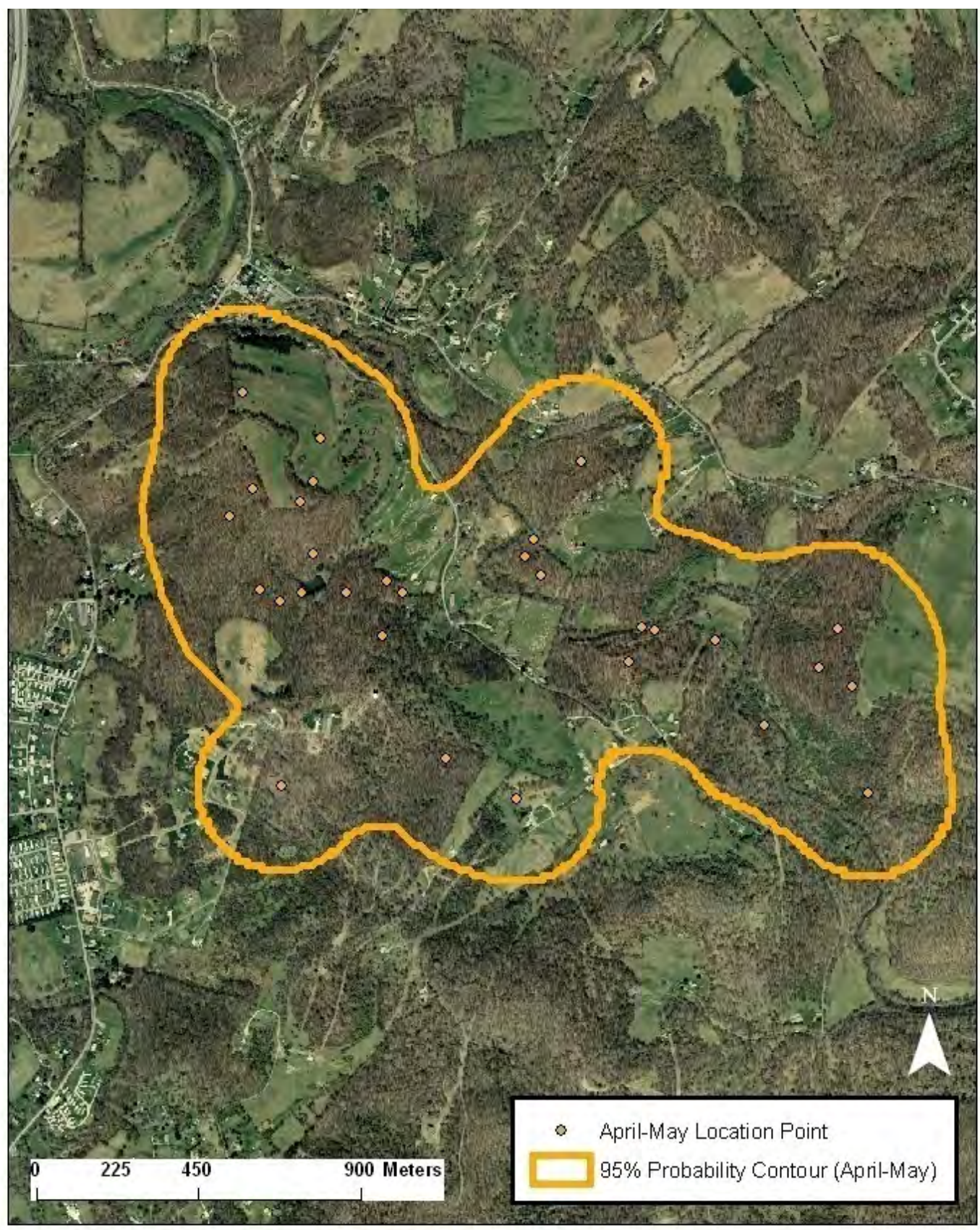

John H H

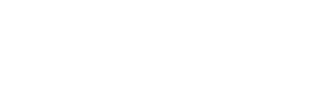

